\title{
Molten-Salt
}

Reactor Proǵram

MSGTR

Semiannual Progress Report for Period Ending February 29, 1976 


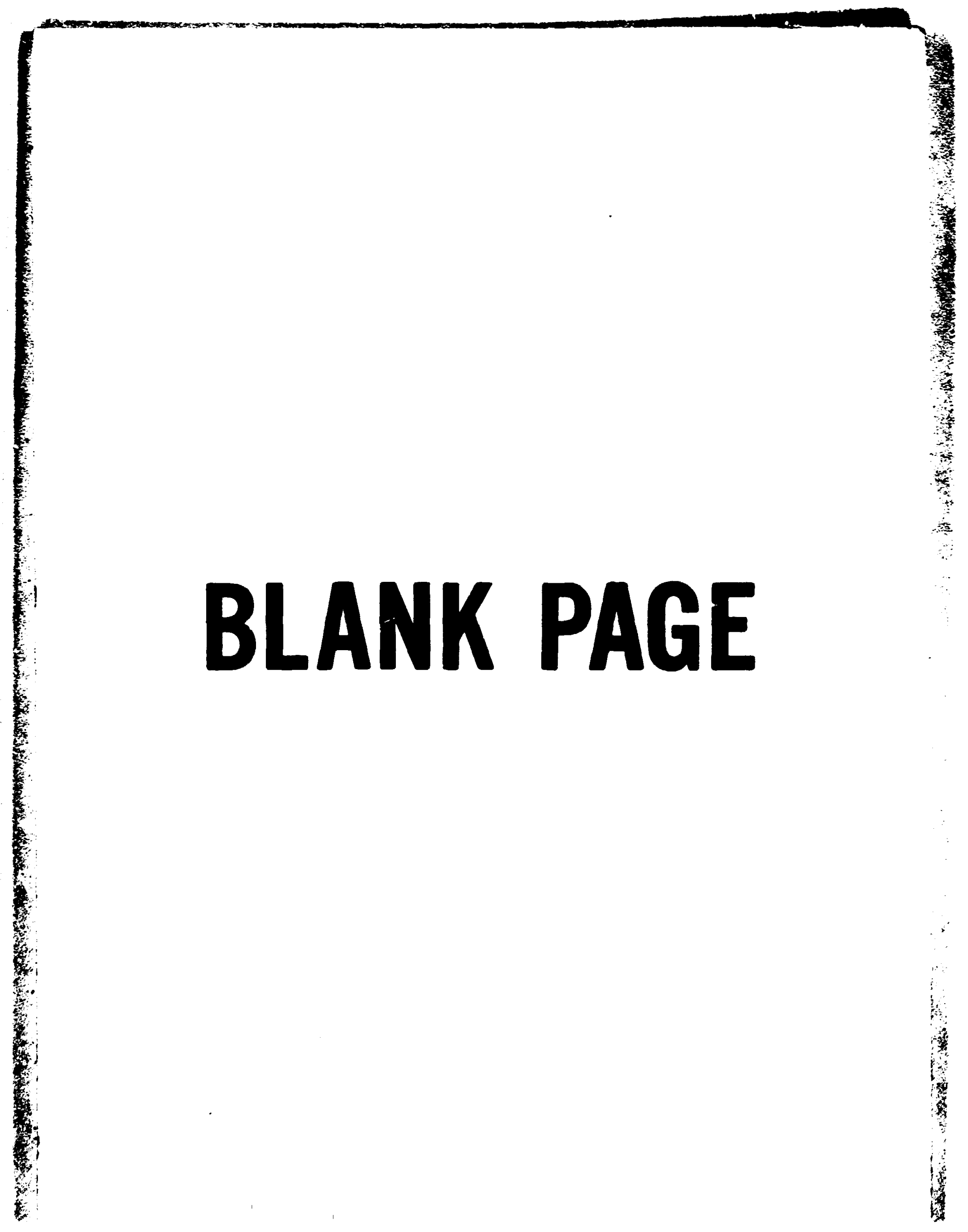


Printed in the United States of America. Available from National Technical Iniormation Service

U.S. Depertment of Commerce

5285 Port Royal Road, Springfield. Virgino 22161

Price: Printed Copy 57.75; Microfucte 52.25

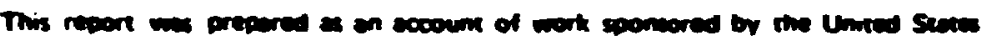

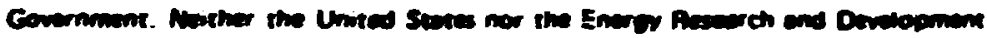

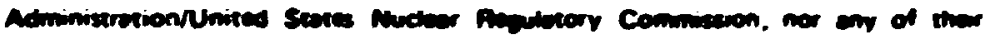

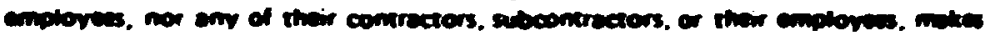

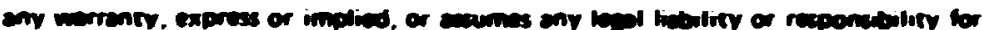

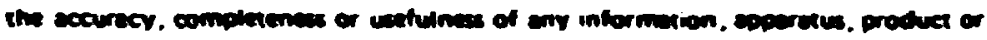

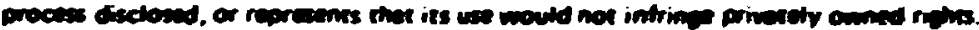


Comingis

Dinc Comer ven

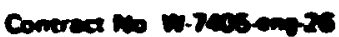

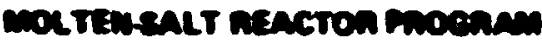

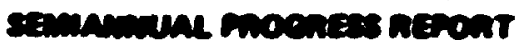 \\ Fon rencod Enome feamunr 2. nos
}

L. E. Mncherse

Proprem Dinceser $-\infty=0$

$0-2-1+-2=$ $-10-2=-1$ $-2-2-2=$ $2-2-2-2=$ $20-5=-2=0$ $-\infty \operatorname{mon}^{2}=0$

\section{AUGUST 1976}

OAK ADeE MATronuL LADOAATOAY

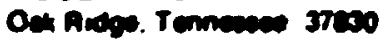
operind oy

union canene comironatron lor mo

EAZAOY RESEARCH ANO DOVELOPMEAT AONMUSTRATION

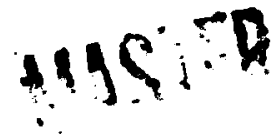

$$
i \dot{s}
$$




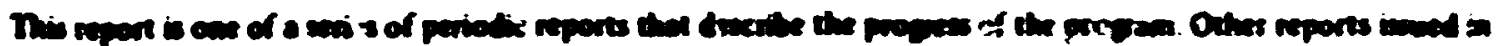

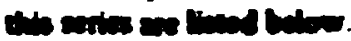

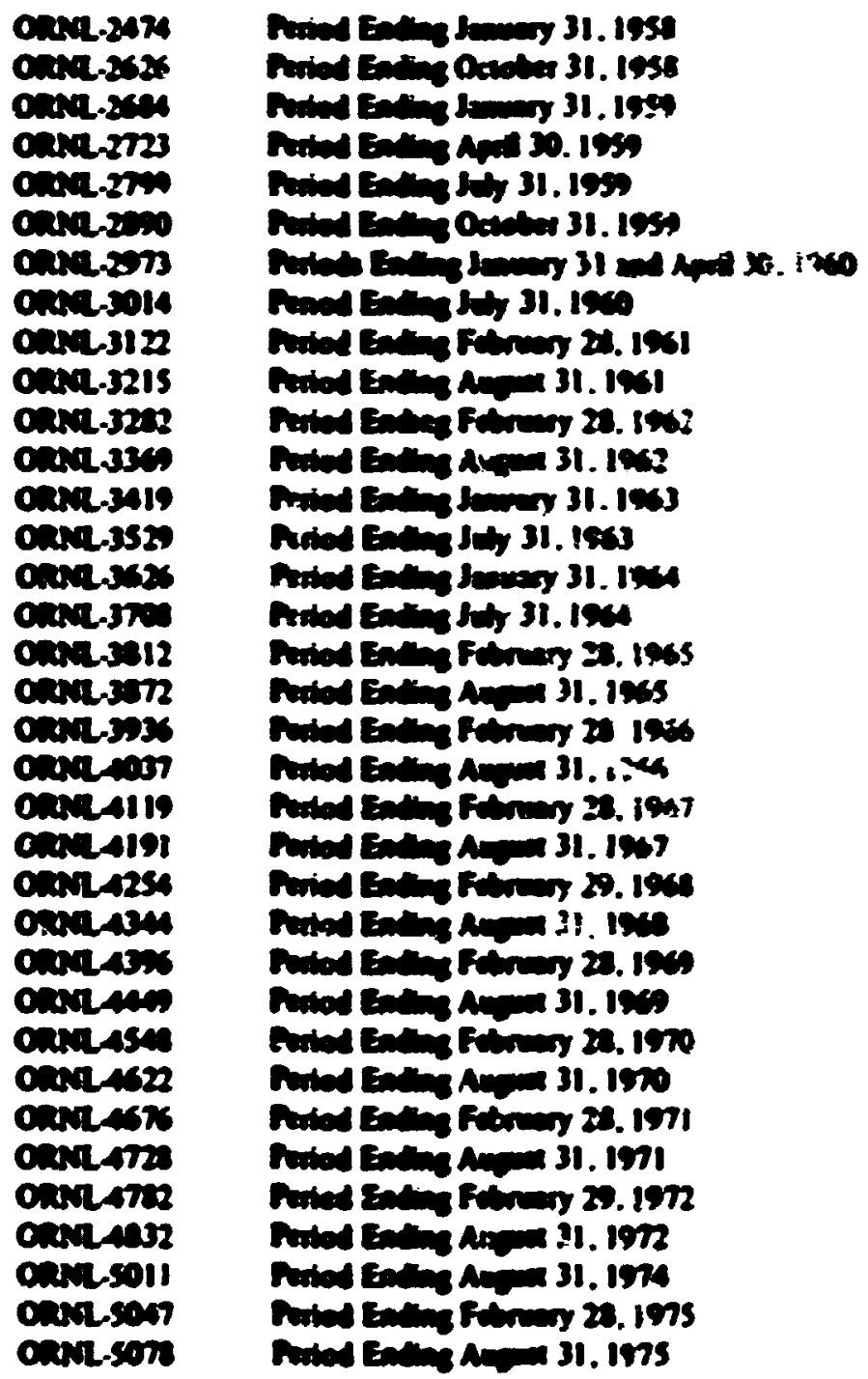




\section{Contents}

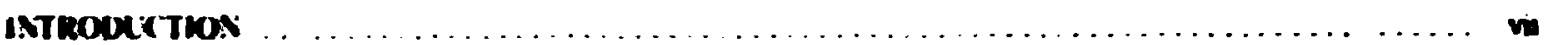

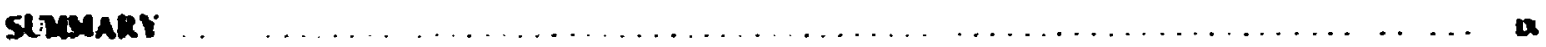

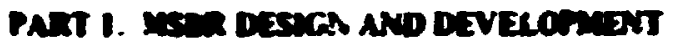

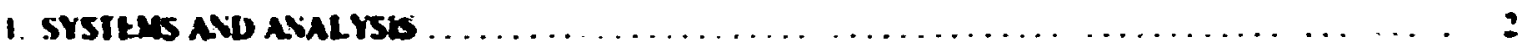

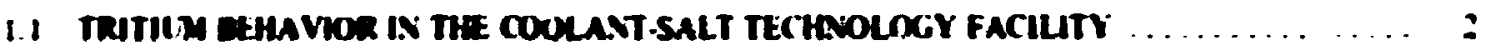

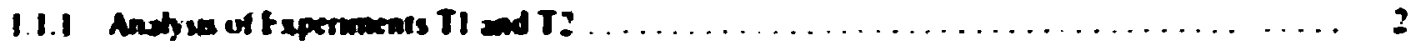

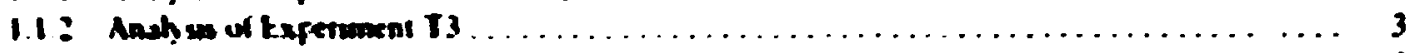

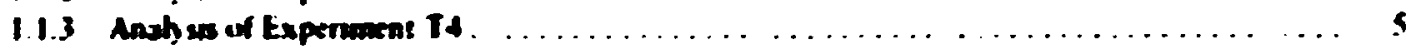

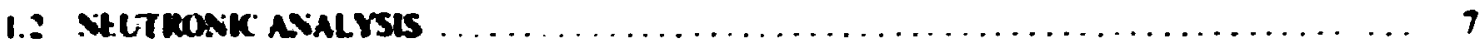

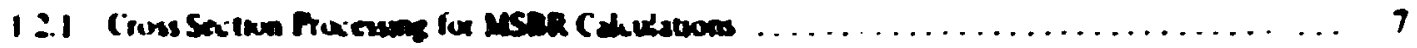

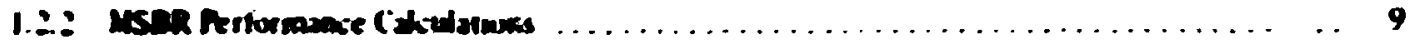

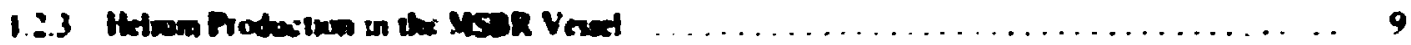

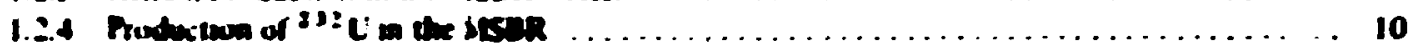

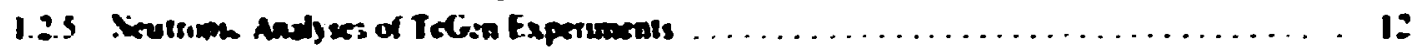

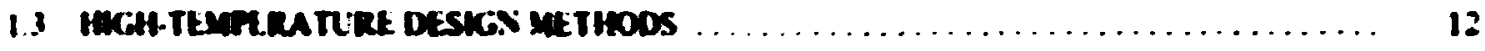

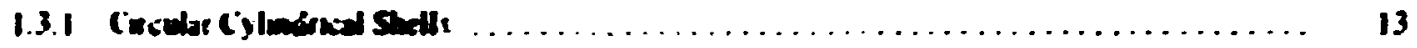

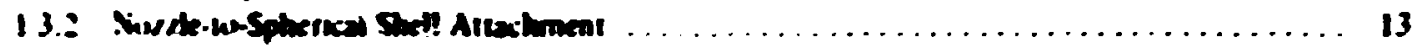

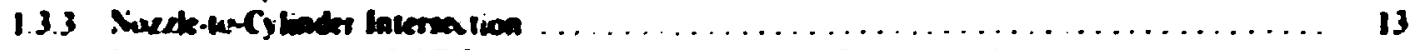

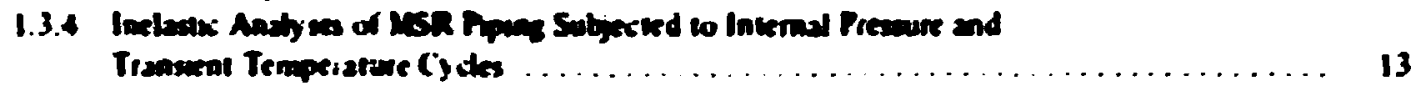

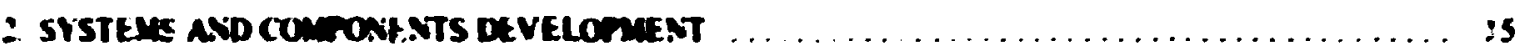

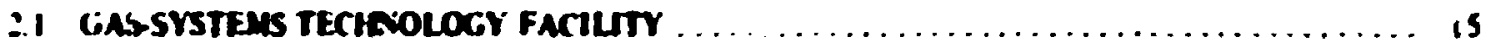

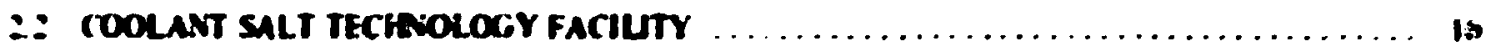

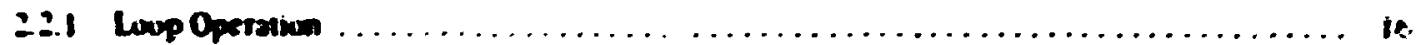

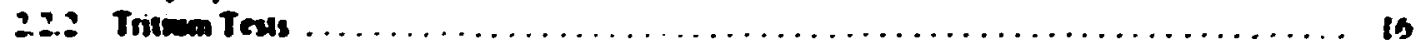

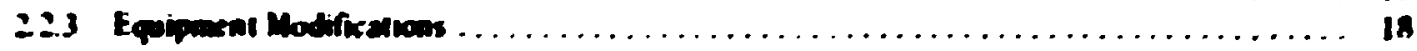

23 Foncen convectron woors $\ldots \ldots \ldots \ldots \ldots \ldots \ldots \ldots \ldots \ldots \ldots \ldots \ldots \ldots \ldots \ldots$

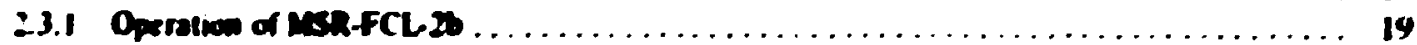

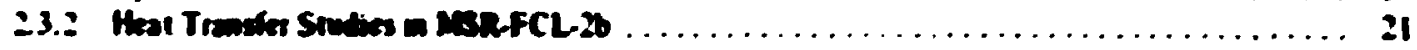

23.3 Derip ad Constnuction of FCL 3 and FCL $\ldots \ldots \ldots \ldots \ldots \ldots \ldots \ldots \ldots \ldots \ldots$

\section{PanT 2. Chimerray}

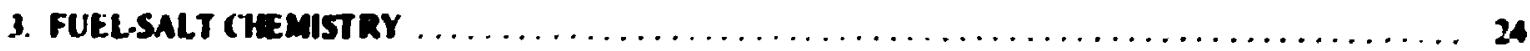

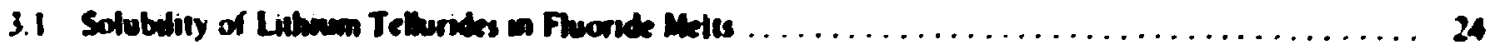

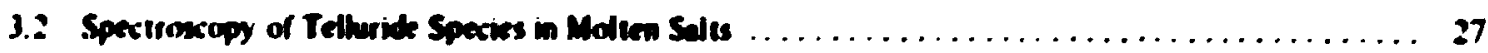




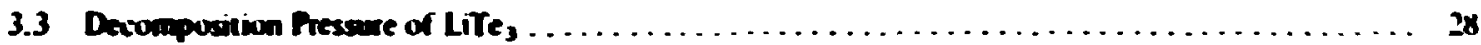

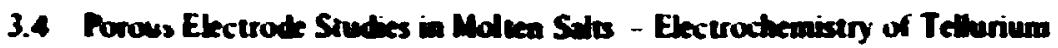

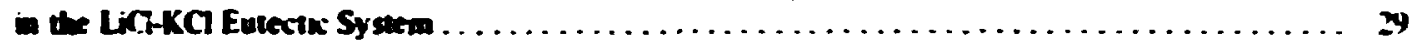

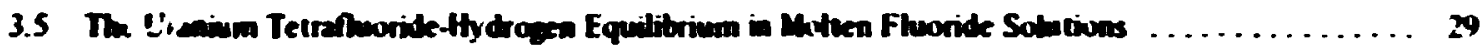

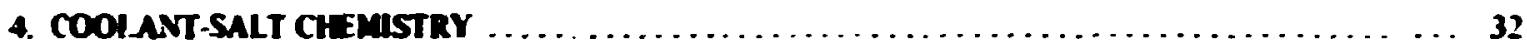

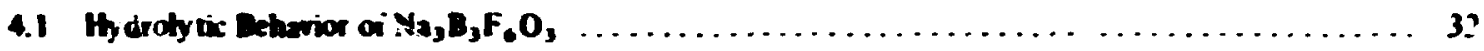

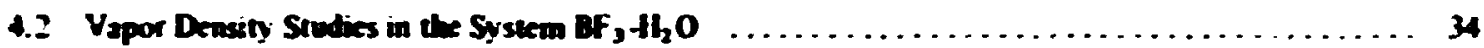

5. DEVELOMENT AND EVALCATION OF ANALYTKAL METHODS . . . . . . . . . . . 36

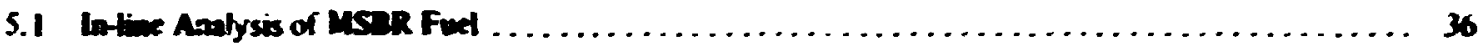

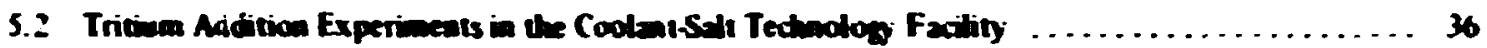

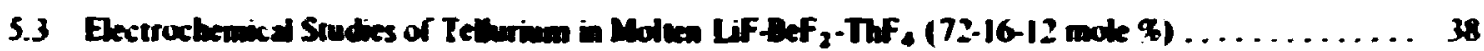

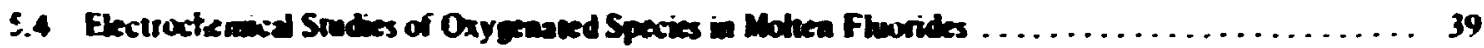

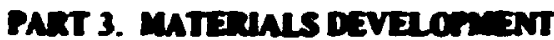

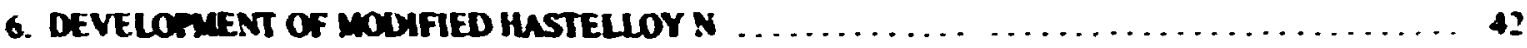

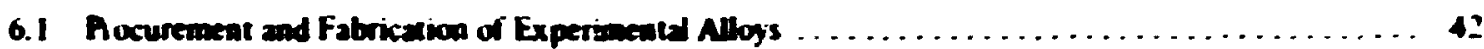

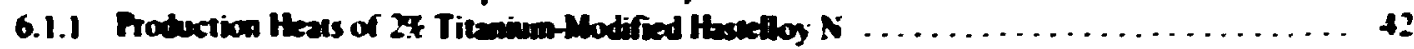

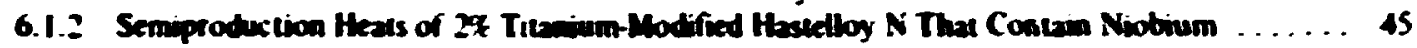

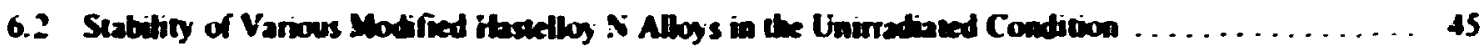

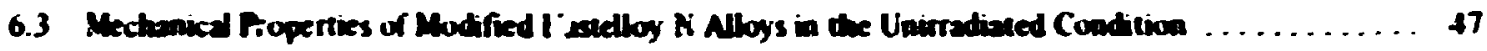

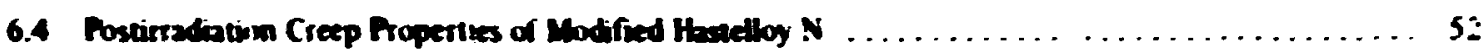

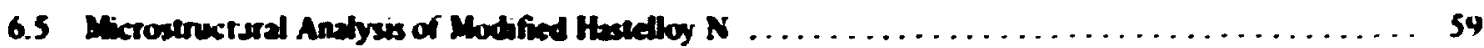

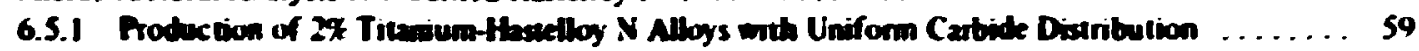

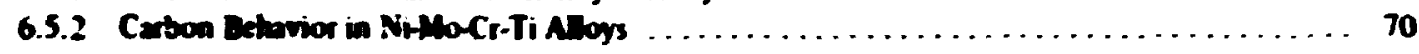

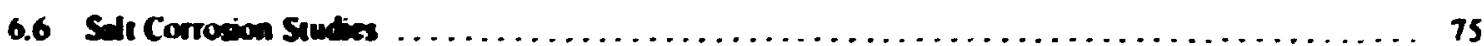

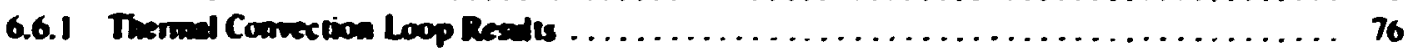

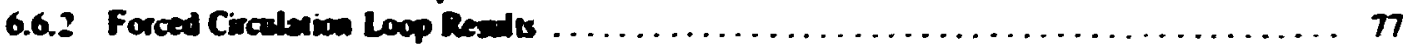

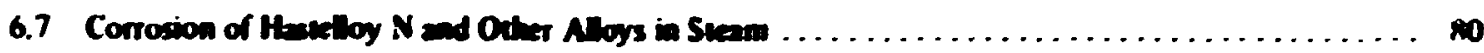

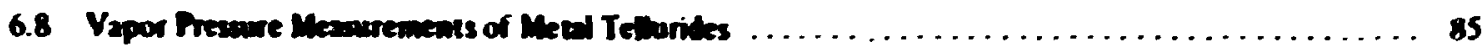

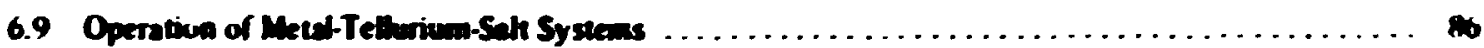

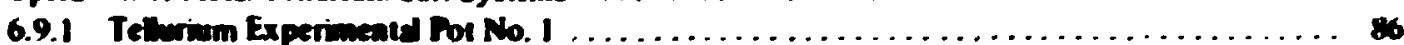

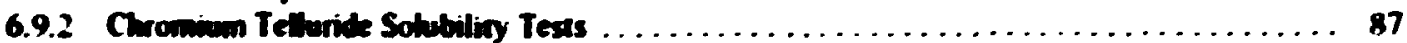

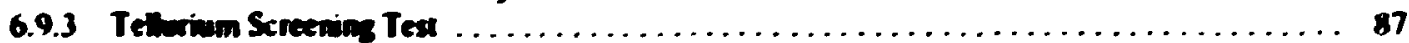

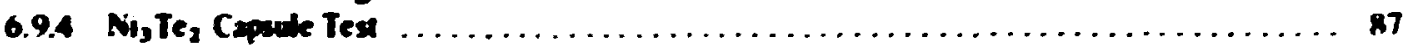

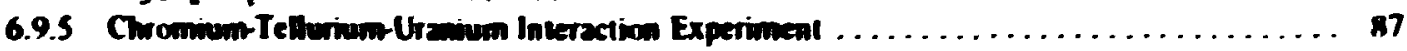

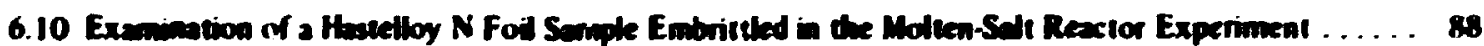

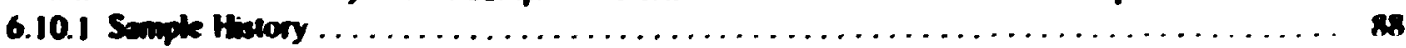

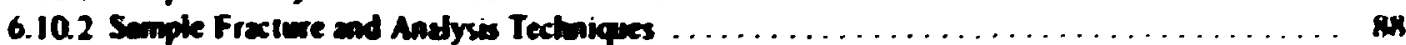

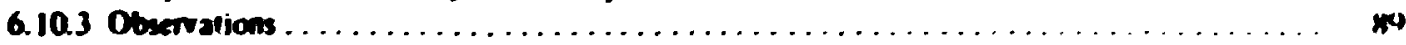

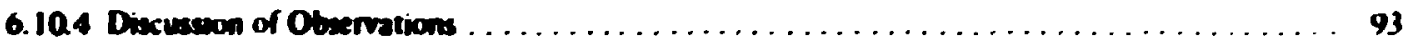

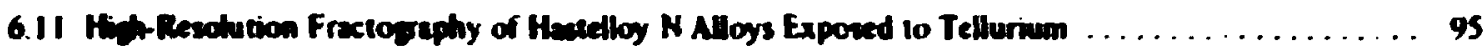

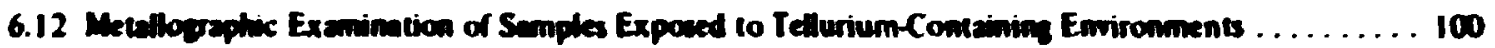

6.13 Selt-Telhurium Creap Studie $\ldots \ldots \ldots \ldots \ldots \ldots \ldots \ldots \ldots \ldots \ldots \ldots \ldots \ldots \ldots \ldots \ldots \ldots$ 


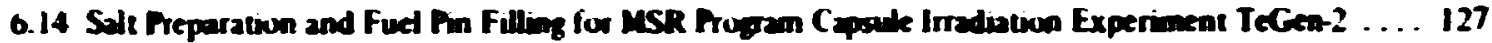

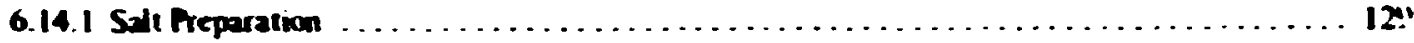

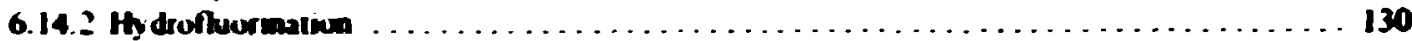

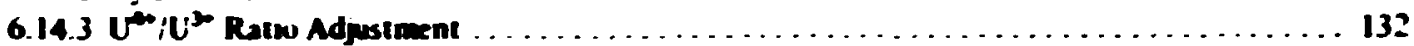

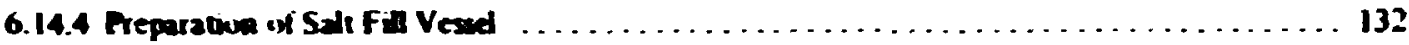

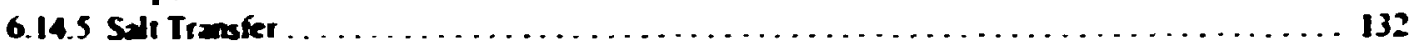

6.15 Salt Preparativa and Filliag of TeCern and $4 \ldots \ldots \ldots \ldots \ldots \ldots \ldots \ldots \ldots \ldots$

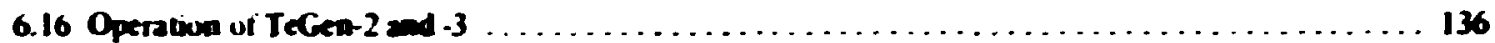

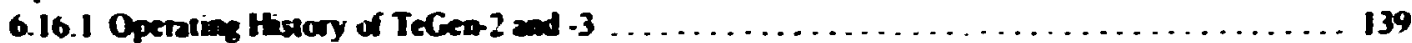

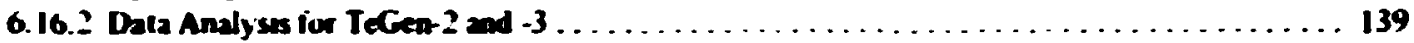

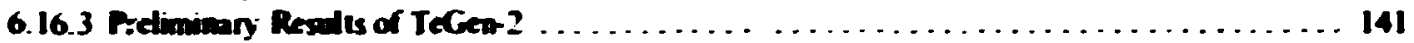

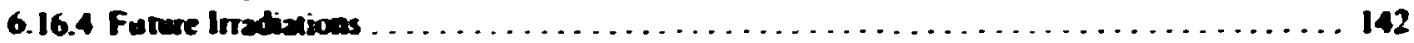

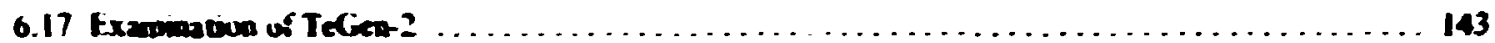

7. FUEL FoCESSING MATERIALS DEVELOMENT $\ldots \ldots \ldots \ldots \ldots \ldots \ldots \ldots \ldots \ldots$

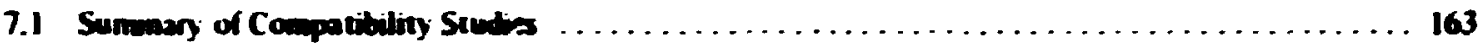

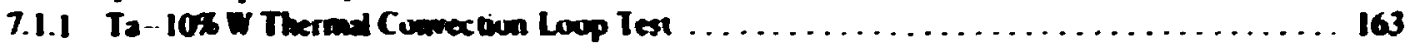

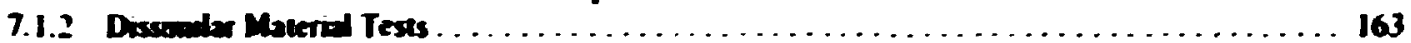

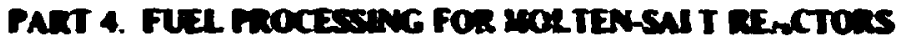

8. CHEMISTRY OF FLUORINATIOA A.VD FUEL RECONSTITLTION $\ldots \ldots \ldots \ldots \ldots \ldots \ldots \ldots$ I70

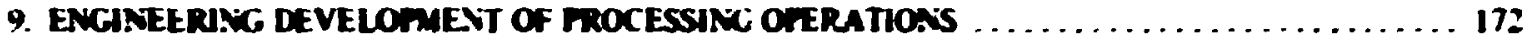

9.1 Mecil Trzaster Prucess Dendopmeat $\ldots \ldots \ldots \ldots \ldots \ldots \ldots \ldots \ldots \ldots \ldots \ldots \ldots \ldots \ldots \ldots \ldots \ldots$

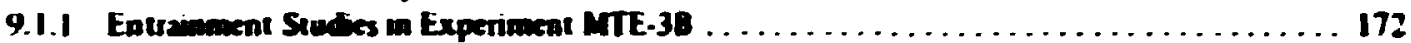

9.1 .2 Removed of LCT and Dili fheses and Adition of Rurified Solutions . . . . . . . . . 173

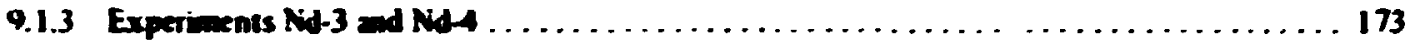

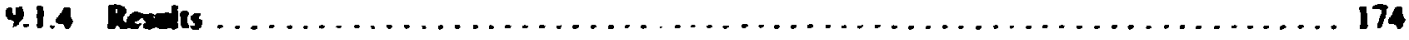

9.2 Mbe-Trander Studies Using Waler-Htercury Coatactors $\ldots \ldots \ldots \ldots \ldots \ldots \ldots \ldots \ldots \ldots \ldots \ldots$.

9.21 Experimened Equpineal and Procedure $\ldots \ldots \ldots \ldots \ldots \ldots \ldots \ldots \ldots \ldots$

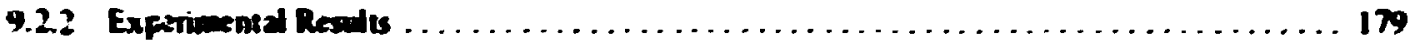

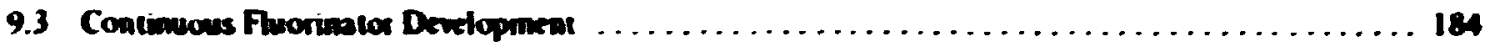

9.3.1 Autoresistance theation Test AHT $4 \ldots \ldots \ldots \ldots \ldots \ldots \ldots \ldots \ldots \ldots \ldots \ldots$

9.3.2 Frozen-Sall Corrosion Protection Demonstration (FSCFD) . . . . . . . . . . . . . 186

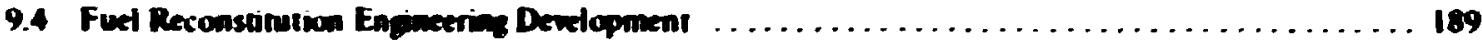

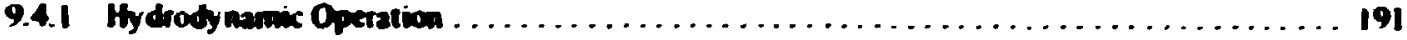

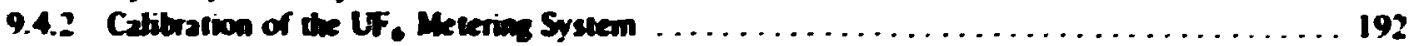

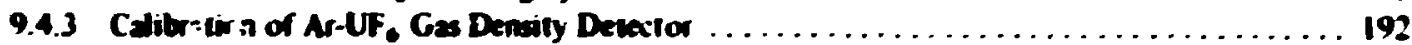

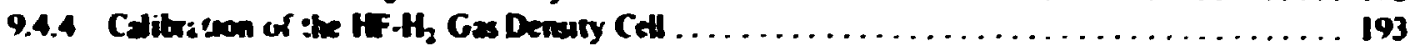

PAIT 5. SALt movuction

10. FODUCTION OF FLUORDE SALT MIXTURFS FOR RESEARCH AND DEVELONMENT 


\section{Introduction}

The objoctive of the Moluea-Sian Recter (MSR)

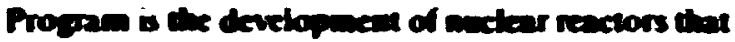

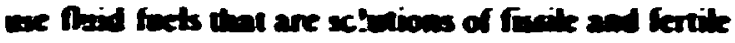

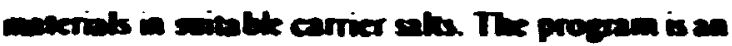
ancrowth of the effort bey over 20 rearsapo in the

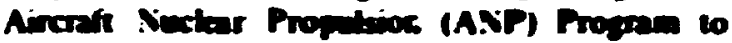

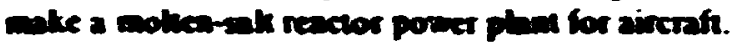
A molwewrah reactor. the Aincrafi Reactor Experi-

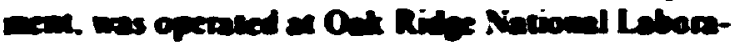
wry in ISs as part of the ANP Progan

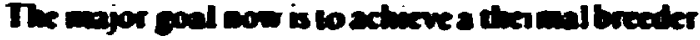

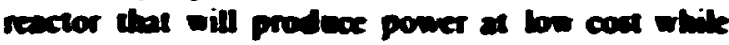

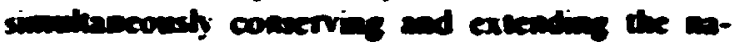
rion's guet resources. Feet for this oype of reactor wonly be :"iF. divodved in a mixture of Lif and Af:. the :"it or pheromina could be wad for

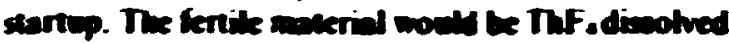

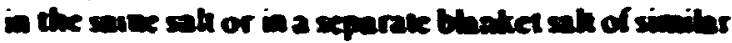

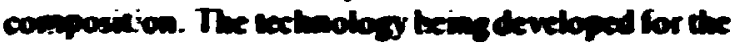

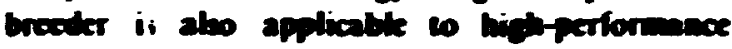
comverter resclors.

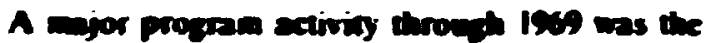
operetion of the Molnen-Sal Reacior Experimeat (MSAE). This reactor was build to ven the types of

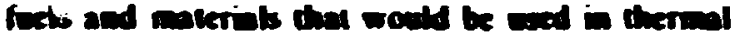
breeder and converter reactors: it abo provided operation and minimemance experience. The MSRE operated at 650 C and produced $7.3 \mathrm{MW}$ of heat.

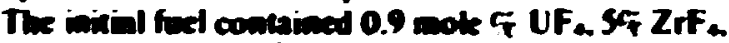

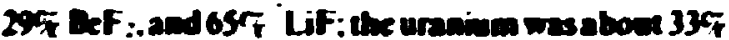
"U. The fuet circulated throngh a ronctor vead and an exiernal puinp and beat exchare system. Heat produced in the reactor wis tranderred to a coobant

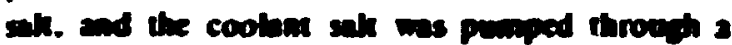

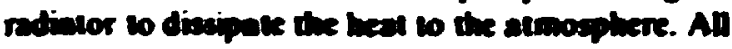
this equiponeat was comatrected of Hastetioy N. a nicket-moblybedum-iron-chromina alloy. The reaccor contaived an aceenbly of prophise moderntor bars in direct conbeet with the felel.

Derips of the MSRE was started in 190. fobrication of equipmen bepa in 1962. and the reactor becume critical on June 1. 19s5. Operntion at

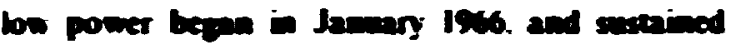

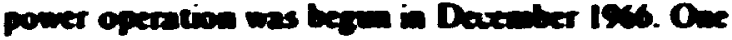
no contined for six monthe extil slopped on xchedule a Mard ises.

Completion of this six-mometh ron ended the firs phere of MSRE cperntion. in widh the objoctive wiss to strow. on a sinll scale. the auractive fentures and vectroical feasibiling of these systems for cominercial poner resctors. The condesion was then this objecine bad been actieved and that the MSRE had

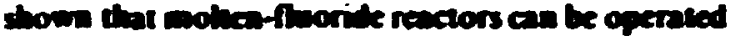

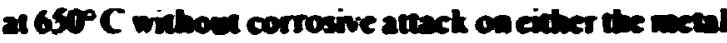
or erephice parts of the system: abo the "nel is

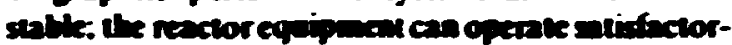
ity al these condicions: rescon can be renoved rapidly from nolven salus: and when meceseary. the redionetive equipuem ane be ropined or nepheced.

The secowd phase of MSRE operation bepen in

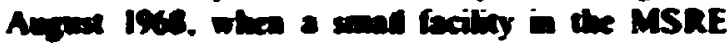

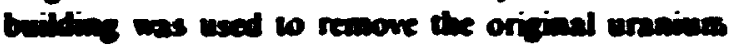
chare from the finct salk by treatuent with gaseons

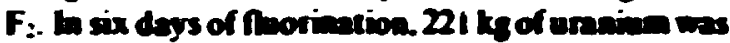
removed from the molven sall and bonded into absorters frlled with sodien froride pellets. The decombanimation and recovery of the uranians were very pood.

Aher the fuel was procesud. a chane of "U'U was aded to the orieian arrier saht. and in Oetober isces the MSRE becane the wortris first reactor to opernete on " "U. The auclear chancterivios of the MSRE with the "U were dose to the predietions and the resctor was quite stable. In Sepuenber 1969. suall

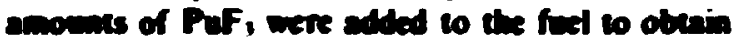

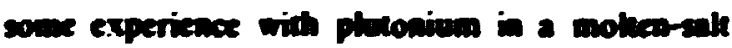
renctor. The MSRE was shet down pentanesedty Decesciber 12, 1969, so that the fends supporting its operntion cond be used elentrere in the reseanch and developuent propram.

Decanes of biampations on the chemionl-procking mothods aveibule in the pad, mode of our work on breeder rectors was aimed at two-fluid sysurms ir. which onphike tubes would be und to sepannite 
uranium-bearing for salts from thoriam-beanag fertile salus. Howener, in bet $1 \% 7$ a one-dund breeder became feasible with the detelopmeat of processes

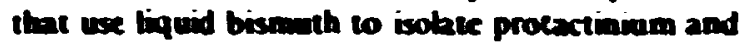
resuove rare arths from a salh that abo contains thoriun. Oor studies strowed that a soce-fluid breeder besed on thexe processes can bave fertutiluntion charecteristics approaction those of our two-fluid devon concepts. Since the eraphite serves only as modentor. the one-fluid reactor is more nearty a scale-up of the MSRE. The advanuases caused a ctange in the cuplexis of the progenan from the two find to the ome-fhid breeder. mose of the design and developonest effor is bow directed to the one-fluid system.

In the congressional anthorimation report on the AEC's progenes for FY 1973. the Joint Commintee on Alomic Energy recommended that the molven-sah reactor be appraised so that a decision could be wade abour its cominative and the kevel of fundine appropriate for in. Consequenty. a thorough review. of molken-sale rechnolosy was undertakten to provide information for an appraisal. A significant resulh of the review was the preparation of ORNL 4812. The

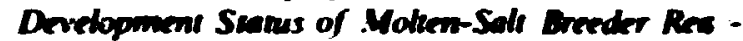
10rs. A subsequent decision was mode by the AEC to terminare wort on mothen-salt reactors for budgetary reacons: in hamany 1973 ORNL was divected to conctude MSR development work.

In lanuany 1974. the AEC program for mohen-salt reator development was reinselated. A considerabte effon during 1974 was concerned with ascembling a program staff. making operational a number of development fecilities used previoushy. and replacing a number of ke denetopmental tacilures that had been reassiened to cher reactor propram. I segaificam undertakene was the lermulatum of detraiked pleas for the recelopenem of mollen-salt breeder reacturs and the preparation on OR VI -SUIX.

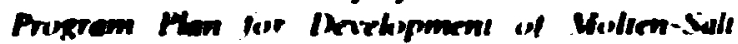
Breecter Reuciurs.

Duriag 1974 and 1975. work in the Molecn-Silh Reactor Program was devoled to the recthnobus needed for molien-sal reactors. The wort included conceptual desien studies and work on materints, the chemiatry of fuet and cootont saks. fiscios-produt betarior. prucessine methods. and the derehipment of systems aed consponcats. The most importam siagle aspect of the program was work on the developonest and demonsuration of an allog that is suitable for the prition circuit of an MSBR and has adequnte resis'sace to telburium-induced shallow intergramutar cractiog which was first observed in MSRF suneillance specimens. A second inportant area consisted of studies of the chemical meeraction of Iritium with the MSBR secondary coolant. both in laboratory chemistry studies and in a brex enginerer. ine facilivy (Coobm-Sah Technologe racility). These studies cutminated in the demonstration of an adequate basis for mapagement of trisinom in a loweMute) MSBR.

Ir February 1976. OR.VI was directed by ERDA 10 apain terminate the Moken-Sah Reactor Prigram for budgetary reasons. Wort during the remainder of FY 1976 was directed toward completion of shortterm wort in the Propram. reporting of associated information. and the assignmeme of the MSRP staff and experimental facilitus to other OR.VI. proerams. 


\section{Summary}

PART I. MSBR DESIGN AND DEVELOPMENT

$$
\text { J. R. Engel }
$$

\section{Sysceas and Analysis}

I he ipicotypatmo c.: Intium hrow nor in the MSAR reterenc combint alt. Dabt, wat cutectic. Is continuing in the cimlarst-Satt lechnokge facilut ic SIt: Rewits have heen co aluated for three shorticrm intiurn-additur tots. and preimanan results have been obvained for a seody-state test that is sill in progress.

I he buidup rate of tritium in the salt durure the shonterm (10-hr) additions undrated that SO-ta; of the added tritium was being irapped in the sali in a chemeally combed lom. However. subscyuent cialuatuiss of the loval intum fow through the csit olf at Iritium was being accumulated somenhere in the bstem 7 is released to the sal: afic: the additions were stopped. I he cutr materisl may have heen temporarit: accumulated in the hop walls a. elemental iritium. The concentratons of etemental Iritium in the salt immediateh after each of the shortterm additions were extimated from the concentraimns of elemental tritium in the off-es samples and an a sumed value lor stripping efficiency in the pump howl. The results. in conjunction with the masured concentrations of combined tritium in the sale. indicated that the ratio of combined-to-etemenis tritium in the salt was ahout $\mathbf{1 0 0}$ to 500 .

Before the fourth (seady-state) tritiun addition test. equipment was added to the CSTF to permit direct measurement of the paria! pressure of hydroyen in the salt and to provide data on the rate oi hydropen permeation through the loop walls. These additions were designed to provide all data necessany for an overall hydrogen (and intium) material halance.

The attainment of steady-state conditions required considerably mor: lime than had been proiected from the short-term tests. (Accumulation of elemen-
Lil hydrogen in the bop walls of thought to be the rate-imiting process. I Afrer about lour weets of Iritium addition. the ample resuhs undicated tha: 96 10 99; of the tritim boving the CSTF was beng remoied in the bonp off-eas. and only I to $4 r^{\prime}$ was permeating through the loop walts The overall material babnce on intium tow rate appeared to be hetwern 0.89 and 0.9 ?. Measurements of the partial pressure of hydrogen in the salt $1043 \mathrm{Pal}$ were reasomabl comistent onth the apparent porial pressure of etemer.tal hydrogen in ibe pump-boul ges spoce. as undicated by the observed concentration of elemental imum in oft-ps samples. Ise of the mosured paral pressure with the measured intiam concentration in the salt gives a value of $\$ 700$ for the ratio of combined-to-etemental tritura in the salt. If this concentration ratw were altamed in the reference-desygn MSBR. only - 3.5 Ci d of irtiun would be released to the stam system and. hence. to the environment.

The developmint of a 123 -energy-zroup neutron cross-section librar, hased on L NDF B. Version IV. was completed. The libran ineludes cross sections at four temperatires f $\mathrm{mm} 300 \mathrm{~K}$ to $1200 \mathrm{~K}$ for everal fuel-moderator ratio; that are approprate to the refersnce-desygn BSBR. Funther procassing to produce fen-zoup cross sections for mulidimen. shomal diffusion-theory calcubtions of tix ractor performance were detayed by difixultive with the relevant computer codes. However. estumates were obained for the flux spectrum and the Mux density in buth the reactor and the reactor vessel of the reference-design MSBR. White the work 'equirat :" complete the cross-section processing and the performance calculations has been idestified. it will not be done because the MSR program will be terminated at the end of FY 1976.

The estimated helium concentration in the Hastelloy $\mathrm{X}$ presure vessel of an MSBR afier 30 full-power years. due principally to (wo-step " $\mathrm{Vi}(n . y)$ "Virn.a) reactions. is $38 \mathrm{ppm}$ at the inner aurface. The concentration would decrease by about soof for 
each centimeter of pene!ration into the vessel wall. which is expected to have a thickness of abmut $5 \mathrm{im}$.

The calculated steady-state concentration of : in the uranium in an MSBR is $20 \mathrm{ppm}$ if protactinium is removed from the salt on a 10 -day cycle and if no

:"Th is present. (About 15 years would be reyuired to approach equilibrium.) Approximately $27 \tau_{c}$ of the $\because \mathrm{U}$ results from $(n, 2 n)$ and $(\gamma, n)$ reactions in : $U$. and the remainder is due to similar reactions in ":Th. A concentration of 23 ppm " Th in thorium would double the steady-state conentration of $: \mathrm{U}$.

Neutron-flux monitors were provided for two additional in-pile irradiation ca. iules. TeGen-2 and TeGen-3. The irradiated wires were recovered from TeGen-2 and are beitig analyzed. and TeGen-3 is still being irradiaied.

The development of simplieied high-temperature structural design methods. which could be applicable to MSBR design. is cont inuing. principally for other reactor programs. Sume cases have been identified i: which the simplified. elastic-analysis rules are nonconservative in comparison with more accurate (and more expenive) inelastic analyses. Potential sources of the lack of consenatism are being investigated. Some of the data (thermal transients and material properties) have been obtained to estirnate the magnitude of thermal ratchetting and creep-fatigue damage that might occur in an MSBR. inese estimates will indicite the applicability of the simplitiod design prosidures to Hastelloy $\mathbf{N}$.

\section{Systems and Components Development}

A larger diameter impeller was installed in the salt pump of the Cias-Systems Technology Facility, and additional water tests were made. The amplitude of the pump shaft oscillations was acceptable; however. the hydraulic imbalance between the volute and impeller. causeo by operation far from the pump design point. resuited in unacceptable deflections of the shaft. Extensive pump modifications would b: required to meet the $l$. : design requirements. It appears that the back vanes installed on the larger impeller overcompensated for the shaft seal leakage and reversed the direction of the flow. Because of the termination of the MSR Program at the end of FY 1976. the loop has been drained and put in standby condition.

Another transient trilium addition test was completed on the Coolant-Salt Technolugy Facility. and a lon-term steady-state iest is in progress. Several changes wsre made in the sampling systems jol the loop off-gas and for the enclosure ventilation air to improve tike reliability of the data and to permit the colketion of data that will allow the evaluation of tritium material balances for the system. Operation of the facility has been highly reliable.

The forced-convection loop. MSR-F Cl-2b. has accumulated $\mathbf{4 0 0 0} \mathrm{hr}$ of operation with MSBF. reference fuel salt ai design conditions ( $56 \%$, $C$ minimum. $704^{\circ} \mathrm{C}$ maximum: 2.5 and $5.0 \mathrm{~m}$ s salt velocities). with the expected low cerrosion rates in standard Hastelloy $\mathbf{N}$. Additions of NiF: were made in preparation for determining the currosion rates for this alloy at higher $\mathrm{U}^{\text {t* }} \mathrm{U}^{\text {:- }}$ ratios. Increases in pump power. which previously had accompanied increases in the oxidation potential of the salt. were again observed at each addition. These tests were int $r$ rupted by two successive loop piping ruptures that resulted from sait freezing in the loop during offnormal conditions. Modifications were made in conjunction uith the loop repairs to reduce the possioility of future similar failures. Because of the decision to terminate the MSR Program at the end of FY 1976, the corrosion studies with standard Hastelloy $X$ were discontinued; tests are now in progress to examine the corrosion of Hastelloy $\mathbf{N}$ modified by the addition of $19 ;$ niohium.

Construction of two additional forced-convection loops. MSR-FCL-3 and 4 , is being stopped because of cancellation of the MSR Program.

\section{PART 2. CHEMISTRY}

\section{Fuel-Salt Chemistry}

Measuremsnts were made of the solubility of $\mathrm{Li}_{2} \mathrm{Te}$ in molten $\mathrm{Li}$ :BeF's ove? the range from 500 to $700^{\circ} \mathrm{C}$. Li:Te was prepared using a mixture of stable tellurium and ${ }^{1: \mathrm{m}}$ Te tracer. Salt that had been equilibrated with the solid Li:Te was sampled. and the tracer was counted using a lithium-drifted germanium detec:or. The most recent data indicate a solubility below $10^{\circ}$ mole fracticn at $700^{\circ} \mathrm{C}$.

Spectrophotometric studies of lithium tellurides in molten Lif-BeF: mixtures were continued. This work has progressed to the point where three tentative conclusions can be made: (1) Li: Te is quite insoluble in Lif-BeF: melts: (2) the light-absorbing species in Lif-BeF: melts apparently can be represented as $\operatorname{Te}_{n}{ }^{7}:(3)$ although the results are not conclusive, it is reasonable to expect the Tei ion to exist in molten-salt solutions.

In other spectral studies, the pressures of tellurium due to the equilibrium $2 \mathrm{Lill} \mathrm{e}_{1}=\mathrm{Li}, \mathrm{Te}_{\mathrm{i}}, \mathrm{T} \mathrm{Te}_{\mathrm{i}}(\mathrm{g})$ were determined over the range from 500 to $750^{\circ} \mathrm{C}$. Previously determined vapor pressures for pure 
tellurium were used to calibrate the system. The mesured equilibrium presiures of Te: over LiTe: were only about a factor of 1.5 lower than the vapor pressures of $\mathrm{Te}$ : and can be represented by the equation in $\left.P\left(\mathrm{~mm} H_{g}\right)=15.938 \cdots 1 ? .720 \mathrm{nK}\right)$. Evidence for a slightly volatile lithium teliurie was found at temperatures , iround $1000^{\circ} \mathrm{C}$.

Electrochemical studies were initiated on the lithium tellurides $\mathrm{Li}_{2} \mathrm{Te}_{\mathrm{T}}$ and LiTe, in LiCl-KCl cutectic at $400^{\circ} \mathrm{C}$. Both of these tellurides were insoluble in the melt at this temperature. Cathodization of a tellurium electrode did show that a oneelectron process was occurring. It was also observed that the prexence of meisture in these systems led to the formation of colored soluble species.

Studies of the equilibrium UFs(d) $+!: H_{-}(g)=$ UF;(d) + HF(g) in molten LiF-BeF: mixtures were continued using a spectroscopic methed. Initially. the molar extinction coefficient fur LF: was determined in I.iF-BeF: $(66-34$ and $48-52$ mole $(\%)$. Values of the quotient for the above equi'ibrium were then determined in the two solvents over the range from 500 to $800 \times C$. The quotients in the $66-34$ mole?; solvent were essentially the same as those measured previously by Long and Blankenship: however, those in the $48-52$ moles ${ }^{\prime} ;$ solvent were atout 10 times greater than those determined by Long and Blankenship. The change in the present values with change in solvent cumposition is consistent with expectations based on prior studies of similar equilibria.

\section{Coolant-Salt Chemistry}

Raman and "L NMR spectroscopy were used to s:udy the hydrolyt ce behavior of $\mathrm{Na}_{2} \mathrm{~B}_{3} \mathrm{~F}_{\mathrm{A}} \mathrm{O}_{3}$ since this compound apnears to be the stable oxygencontaining species in Na!-NaBF, (8-92 mole ; $)$ when the total oxygen crincentration is low. The results showed that $\mathrm{Na}_{3} \mathrm{~B}, \mathrm{~F}_{3} \mathrm{O}_{1}$ and $\mathrm{NaBF}, \mathrm{OH}$ reversibly interconvert in the presence of water. Assuming that this is also true in molten NaF- $\mathrm{NaBF}$. a possible mechanism for trapping of tritium in the melt is postulated.

Studies of the vapor density in the system $\mathrm{BF},-\mathrm{H}: \mathrm{O}$ were continued. At temperatures above $200^{\circ} \mathrm{C}$. BF $\cdot 2 \mathrm{H}_{2} \mathrm{O}$ is completely dissociated. Below $200^{\circ} \mathrm{C}$. association in the vapor phase hecomes pronounced. and, with sufficient $B F_{1} \cdot 2 H_{2} O$ in the system, a stable liquid phase is formed. The vapor pressure of the liquid reaches $1 \mathrm{~atm}$ at about $200^{\circ} \mathrm{C}$. Attempts to determine equilibrium constants for the vapor-phase reactions are in progress.

\section{Development and Evahation of Analytical Methods}

The monitoring of $\mathrm{U}^{-3 \cdot} \mathrm{U}^{3 \cdot}$ ratios, which reflect the oxidation potential of the fuel sait. was continued during this period for one forced-convection loop. four thermal-convection bops. and eight creep-test machines. Forced-cenvection loop FCL-2b. after a shutdown period, ws recharged with new sit ani: back in operation. The $\mathrm{U}^{+*} \mathrm{U}^{\text {:- }}$ ratio at startup was about $5.3 \times 10^{-:}$. Thermal-convection loops $\mathrm{NCL}$ $21 \mathrm{~A}$ and -23 continue to operate at stabilized redox conditions. Thermal convertion loops 1SC and 24 have shown a gradual decline in the $\mathrm{U}^{4-} \mathrm{U}^{\text {;- }}$ ratio. which is presently about $1.7 \times 10^{\circ}$ and 80 respectively. The $\mathbf{U}^{\text {t* }} \mathbf{U}^{\text {i- }}$ ratios for the eight creep-test machines are presented in tabslar form. Generally. the melts have tended to become more reducing with time.

The results from the third tritum injection experiment at the Coolant-Salt Technology Facility are similar to those from the first two experiments. Most of the tritium occurs in a water-soluble or combinzd form. Very little tritium in the off-gas was in the elcmental form. A fourth tritium injection experiment is now under way.

Voltammetric measurements were made in molten LiF-BkF:-ThF, following additions of LiTe: and $\mathrm{Cr}_{\mathrm{i}} \mathrm{Te}_{\mathrm{e}}$ compounds in an effort to identify soluble electroactive tellurium species. No voltammetric evidence of such compounds was obtained. Electrochemica! studies were carried out on the tellurium species generated in situ in molten Lif-BeF:-ThF when a tellurium electrode is cathodized. The results indicated that the species generated is of the type $T_{i},(M \geqslant 1)$ and appears to be unstable under the existing experimental conditions.

Voltammetric studies were initiated on two anodic waves that are observed at a gold electrode in molten LiF-Ber:- ThF ${ }_{4}$ and also in molten LiF-BeF ${ }_{2}$. $\mathrm{ZrF}$. Although the results are tentative, it is believed that these waves are associated witi oxygenated species in the melts. The first wave possibly conforms to the oxide - peroxide electrode reaction. and the second wave represents the continued oxidation of peroxide species ultimately to oxygen gas. Noise on the diffusion current plateau indicates gas-bubble formation at the electrode surface.

\section{PART 3. MATERIALS DEVELOPMENT}

\section{Development of Modified Hastelloy $N$}

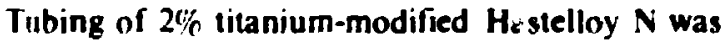
produced in a pilot run using the fabrication schedule 
for dustenitic stuinkess steels. One commercial 2500 Ib melt of Hastelloy $I$ modified with $2{ }^{2}$ c itanium and IT; niobuum was fabricated suc.esstuliy into several bar configurations. Eight small commercial alloys containing $2 ;$ titanium and various amounts of niobium were melted and fabriczied into ':-in.-thick plate laboratory alloys containing up to $4 c^{\prime}$ niobium were prepared and converted to ${ }^{t}$-in.-diam rod for evaluation.

Various types of tests were run in which specimens were exposed to tellurium-containing environments. The source of tellurium that is most representative of tellurium in an MSBR appars to be a mixture of Cr'Tes plus CriTer. Examination of specimens exposed in these various screening tests indinated that alloys containing from 0.5 to $2 \gamma_{c}$ niobium are most resistant to intergranular cracking by tellurium. Mechanical property tests showed that these alloys have slightly lover creep strength than $2 r_{i}$ titaniumnoodified Hastelloy $X$. but higher strength than standard Hastelloy $\mathbf{X}$. Postirradiation creep tests showed that the niobium-mudified alloys have excellent properties after irradiation at $650^{\circ} \mathrm{C}$. acceptable properties after irradiation at $704^{\circ} \mathrm{C}$. and poor properties after irradiation at $760^{\circ} \mathrm{C}$.

$A$ fueled capsule containing pins of $2 \tau_{\mathrm{c}}$ titaniummodified Hastelloy $\mathrm{N} .2 \%$, titanium plus rare-earthelement-modified Hastelloy $\mathbf{X}$. and Inconel 6CD revealed that all three materials were embrittled intergranularly by exposure to tive fission-product containing salt. Two other fuel capsules (six materials) aie in various stages of assembly and irradiation.

\section{Fuel Processing Materials Development}

A theimal-convection kop constructed of Ta-10r; $W$ is being nperated to evaluate the compatibility of this alloy with fuel salt. Several graphite capsules containing various bismuth-lithium solutions and either molybdenum or $\mathrm{Ta}-10 \% \mathrm{~W}$ specimens were heated for $1000 \mathrm{hr}$ at 600 or $700^{\circ} \mathrm{C}$. All capsules demonstrated excellent compatibility although some important differences were noted beiween the various capsules.

\section{Chemistry of Fluorination and Fuel Reconatitution}

Studies of th: cisemistry of fuel reconstitution were resumed. A test of the effectiveness of smonth platinum for satalyzing the hydrogen reduction of $\mathrm{U}^{\prime *}$ to $\mathrm{U}^{\mathrm{s}}$ in small gold equipment has shown that smooth platinum sheet of limited surface area would provide appreciable cata!ytic activity in the hyarogen reduction column of the Fuel Reconstitution Enginerering Experiment. Niobium is an important fission product with volatike fluorides and would be carried from the fuorinator to the fuel reconstitution step. Studies of the hydrogen reduction of NbF. showed that in the absence of granular platinum. the $\mathrm{NbF}_{+}$was raluced slowly to $\mathrm{Nb}^{\prime}$. In the presence of granular platinum. the rate of $\mathrm{NbF}_{4}$ was rapid for the first $2 \mathrm{hr}$ and decreased to a value similar to that experienced in the uncatalyzed reaction. The reason for this behavior is bei. : sought, since. if it is duc to poisoning of the platinu.s, it has significant implications for the us. of platinum catalysts in a reactor processing plant.

\section{Enqireering Development of Processing Operations}

Two additional runs werc made in Metal Transfer Experiment MTE-3B. These runs were made using agitator speeds of 4.17 and 1.67 ps to determine the effect of agitation on the transfer rate of neodymix:m from the fluoride fuel salt to the bismuth-lithium stripper solution. Prior to these runs, it was determuned that the previously observed entrainment of the fluoride salt into the $\mathrm{LiCl}$ resulted from operation of the agitators at 5 rps. This was unexpected since no entrainment was seen in experiment MTE-3 under similar conditions. Tests showed that mo entrainmeni occurred at agitator speeds up to 4.58 ps. Before the two additional (and final) runs were made. the I.iCl and bismuth-lithium solutions. contaminated with fluoride salt. were removed from the process vessels and replaced with fresh I.iCl and bismuth-lithium. Results of the two runs show that the rate of transfer of neodymium was increased by 300 to 400 \% when the agitator speed increased from 1.67 to 4.17 ps. However. overall mass-transfer coefficients for neodymium were lower than predicted by literature correlations. particularly at the LiCl-bismuth interfaces.

Students from the MIT Schnol of Chemical Engineering Practice have completed measuring water-side mass-transfer coefficients in three stirred, nondispersing, water-mercury contactors. A wide range of agitator diameters and speeds was covered in these measuremeilts. These measurements have provided a great deal of data covering a wide range of physical parameters which will be useful in developing currelations to be used for estimating massIransfer rates in large-scale nondispersing stirred 
contactors reyuired in the MSBR reductive extra: tion processes.

A lith run was made with autoresistance heating test $\mathrm{AHT}^{-4}$ using a different cooling procedure. This an demonstrated that the main problem is the plugeing in the unheated end of the salt inlet tube (electrode). A new electrode has been designed to alleviate this problem. Eight cooling tests were made with the Frozen Salt Corrosion Protection Demonstration eyuipment prior to the introdtetion of tluorine. The purpose was to define the conditions under which a satisfactory frozen salt film could be formed. The fluorine inlet (inner) tube plugged beiore the outer vall of the tube was cold enough to form a satisfactory film. During the sixth test. air oxidation resulted in a leak in the cooled tube. A second smaller tube was fabricated with a separate fluorine inlet tube. but a satisfactory film was not formed in the first two tests using argon coolant.

During this report period a preliminary hydrodynamic test of the experimental equipment for the fuel reconstitution engineering experiment (FREE) was successfully completed in which salt flow through the system was maintained under simukted experimertal conditions. A calibration of the $U F$. metering system uas completed: a gas density cell used for measuring concentrations of $L F F_{*}$ in argon was calibrated: and apparatus for producing known concentrations of HF in hydrogen was developed and was used to calibrate the gas density cell for measuring concentrations of HF in hydrogen.

\section{PART S. SALT PRODUCTION}

\section{Production of Fuoride Salt Mixtures for Research and Derelopment}

Three $150-\mathrm{kg}$ batches of fuel-carrier salt were produced in a new copper-lined treatment vessel and iessel head. The first two of these batches were of significantiy improved purity because the copper linings reduced vessel crisiosion prociucts.

A total of $1975 \mathrm{~kg}$ of salts (of various composiions) were produced since activation of the facility in 1974. Of this. $678 \mathrm{~kg}$ are stored for possible future use.

Since the program has now been ended, all production areas are decommissioned and decontaminated. All materials and equipment are appropriately disposed of. 


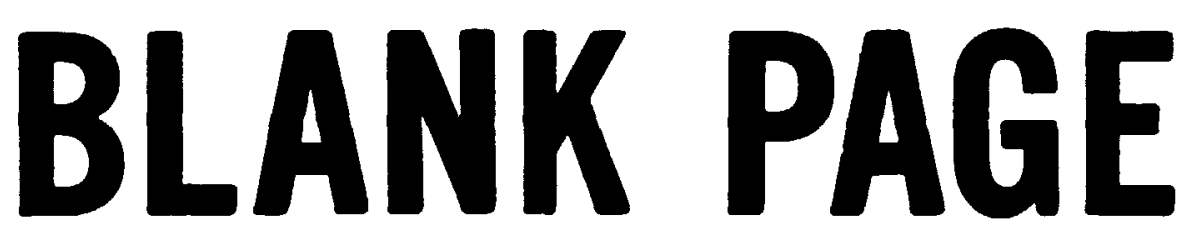




\title{
Part I. MSBR Design and Development
}

\author{
J. R. Engel
}

The overall objective of MSBR desizn and development activities is to evolve a conceptuai design for an MSBR with adequately demonstrated performance. safety. and economic characteristics that will make it attractive for commercial power eeneration and to develop the associated reactor and safety technobogy required for the detaiked design. consinuction. and operation of such a system. Since it is likely that commercial systems will be preceded by one or mone intermediate scale test and demonstration reactors. these activities include the conceptual design and technobogy development assuxciated with the intermediake systems.

Although no system design work is currenth in progress. the ORNI. reference conceptual design' is bring used as a basis to further evaluate the kectinical charackeristics and performance of tarex molicen-salt systems. A major eflort in this repard is the evaluation of tritium betavior in the Coobnt-Saln Technotong Facility and the extrapolation of those results to the MSBR. Earty results indicale that the reference coobme silt. VaBf,-Vaf eutectic. Will permit limitation of the tritium retr e to a lew curices per day.

Additional core meutronics akcutations are heing made for the reference MSBR. usine nuclear data from E.XIF B. Version IV. These calculations will proside uphated extiviales of the mackear performance. as well as aditional information on core charncteriates. Analopous methods and dats are employed to provide suppon for inpile irrediation work.

Analytic sucdies are in propress to seness the potential sienificance of thermal ravithetions and creep-fatione considerations in the desion of Hasket loy I componeats for operation at hiph temperatures.
Ihe Gas-Systems Technology Facility is an engineering-scale loop huilt for use in the detelopment of gas-injection and gas-stripping lectunologe for molien-sah systems and for the study of xenon and tritium behavior and heat transter in MSBR fuel sh. The facility was operated briefh with water to measure hoop and pump characteristics that would he reyuired for the performance and anatysis of developmental tests with fuel salt. This facility is now shut down and in a standby condition.

The Coobnt-Salt Technology faciling is being operated routinely to study processes involving the MSBR reference-design cootant sah. XaBf,-NaF eutectic. Tests are currenth in progre is to evalunte the distribution and hehavior of tritium in this system.

Candidate MSBR structural makerials are exposed to fuel sah at reference desiqn vemperatures and cemperature differences $1794 \mathrm{C}$ maximum and $1.90 \mathrm{C} \perp \mathrm{n}$ and at represemtative sah vebcities in forced-comection bops to ev aluate corrosion effects under iarwous chemical conditions. There operations. whuch are primcipalty in suppon of the materels detelopment eflort. also provide expenence in the operation of moken-ah systems and data on the physical and chemical characteristics of the sah. At presem cose boop. MSR FCL-2b. which is made of seandand Hastellon N. is in routine operation as part of a subly of the corrocion of Hastetion $\mathrm{X}$ contaiainas If niobuum. Consuruction of a major fraction of two oflher loops was completed before work on them was diecontianed because of the decision to kerminate the MSR Program at the end of FY 1976. 


\title{
I. Systems and Analysis
}

\author{
J. R. Finel
}

\section{I.I TRITUM REHAVIOM \\ IN THE COOLANT-SALT TECHNOLOGY FACHITY}

$$
\text { J. R. Engat G. T. Mays }
$$

Experiunears to etacidace de betas ior of hydrogen (tritum) in MSBR coolant salh are contianing in the Coobat-Sah Techeology Facila (CSTF). To date. three retativety shon transicat lests bave been performed. and a boger stedy-sele cest is currently in progress. In all these tests a substantial fraction of the iritialed hydrogea that was added to the salh has been retained in the oh in a chemically combined form that was slowly rewored from the system by transfer to the bop coner pas. This retention significanty reduced the amount of clemental hydrogen that was avaibble for traspon throyght che bop walls.

Preliminany resules of the first wo transient tests nere presented $n$ the previous seminnaul report. Additional results for these tests and for the third transient test are presented in the next two sections II.I.1 1.1.2). Prelininary results are ako presented for the steady-stak test that is in progness. Exirapolation of these results to the reference-design 1000 . MWi(e) MSBR indicates that tritium migration to the steam system (and hence to the envirmment) would be less than $10 \mathrm{Ci}$ day $(370$ GBq d).

\section{I.I Analysis of Exparianeats $T 1$ and $T 2$}

In experiment it: " was previously reported that the appareat half-life for removal of water-soluble (combined) iritium from the salt was $9.2 \mathrm{hr}$. This value. when incorporated into the buildup of combined tritium in the salt during the addition phase of the experiment. impiies a trapping efficiency of 85F,. After the results from experiments T2 and T3 were analyzed and after the apparent trapping efficiencies of sor; and 5scie. respectively. were akulated. the trapping efficiency of experiment TI was reexamined. Depending on the inventory at the end of the addition period and on how the data for the subsequent salt samples are extrapolated back to the end of the addition period. a half-life of $12 \mathrm{hr}$ for removal of tritium from the salt could be determined. This would lead to a trapping efficiency of $60 \%$.
- bich is more nearty consisien oith the trapping efficuencies for experimients II and I?.

In lest I2. becanse of a greater number of sample measurements ar.I less scather in bes sah data durnce ine removal portiox of tice experinent immedalek afker the addition pe: iod. a nore relable csimate of the balf-life for ren.: al of irituin from the sall could he made. For experiment I2. a 12 hr half-ife abo eas determined. Even thurgt. the data from the second experineat sugested the presence of one or more odher mexhanisms for removal of tritium frosn the salt with significanty longer time constants. the extraction of these tirac constants was not attempled because of the soller in the dala at bonger times. Conseyuenth. a singte firstonder process with a 12 hr half-life was used to describe both the remonal of tritium from the salt and the initial huildup. If the buger time constant or constants could be extracted. the half-life for the short-term process would he less than $12 \mathrm{hr}$. However. neglecting the longer lime constant and using only the 12-hr half-iife provide a reasonable besis for calculating the expected rate of tritium buidup in the salt. The comparison of cakulated and observed inventorics (fig. I. I) as functions of time during the addition period illustrate reasonable agreement. Improved agreement would the expected if additional time constants were factored into the calcubtion.

Based on the off-zas fow rate and the measured concentrations of water-solubk tritium in the off-eas during experiment 12. approximately 65 mCi !2.4 GBy) of water-soluble tritium had fowed through the off-zas system during the first $240 \mathrm{hr}$ after the start of the experiment. However, only about $\mathrm{SO} \mathrm{mCi}$ $(1.8 \mathrm{GBy})$ could be accounted for in terms of watersoluble tritium released from the salt during the addition and the inventory in thr salt at the end of the addition. Part of this discrepancy can be explained by a few apparently high off-eas sample results that were used in evaluating the integrated tritium off-pas fhow. However. the magnitude of the discrepancy and the Inng time constant for tritium removal from the salt suggest that the water-soluble form of tritium continued to appear in the salt (and to be stripped out in the off-zas) after the deliberate tritium addition was stopped. It is suggested that some of the aclded tritium temporarily accumulated in a reservoir other than the salt (possibly as elemental ritium in the pipe 


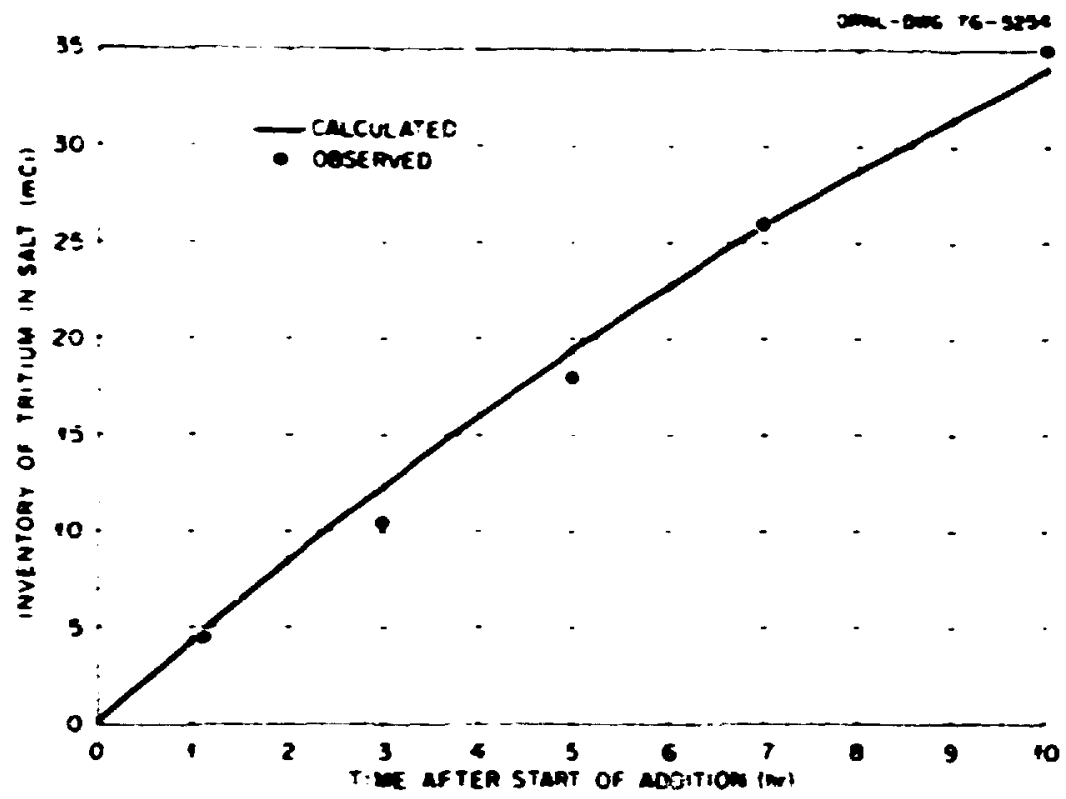

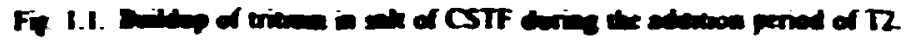

wallst and then transierred back into the st when the sit concentraivon had decayed to a suffikanthy kow kiel.

\subsubsection{Aadysis of Experinest $\mathrm{T} 3$}

In cxperiment I.3 approximately $49 \mathrm{mC}$ ill.8 (GBy) if tritium were added in $30.5 \mathrm{~cm}$ of gas during the $9 . x 7$ thr addituon period. Immediately prior to the wan of the third test. single somples of the salt and iff-pas indicated the following tritium concentrations:

$$
\begin{aligned}
& \text { In soli } \\
& 16 \text { whit is9 klagikg) } \\
& \text { In off-ex.ekmental } \quad 042 \text { pricm }^{3} 1155 \mathrm{kbata}^{3} \text {, }
\end{aligned}
$$

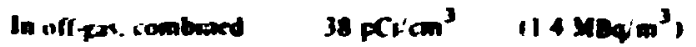

These concentrations are comparable to those ohtained at the end of both the first and second experiments. The sample results for experiment T? (fig. 1.2) are presented withoui corrections for any haseline concentrations.

The tritium concentration in the salt peaked at 40 nCi $\mathrm{g}$ ( I.5 MBY $\mathrm{kg}$ ) at the end of the addition period and decreased in a manner similar to that observed in experiments $T I$ and T2. If two first-order processes for removal of tritium from the salt are assumed. as suggested hy the data. the apparent half-lives for the processes are 8.7 and $\sim 108 \mathrm{hr}$. These processes lead to an apparent trapping efficiency of 55ti for the salt. Recalling that the apparent efficiencies in experiments $\mathrm{Tl}$ and $\mathrm{T} 2$ were $6 \mathrm{CO}_{i}$ and $\mathrm{SO}_{\mathrm{r}}$. respectively. the trapping efficiencies for the three experiments are reasonably consistent.

C sing the 8.7 and IOS hr values for the half-lives.a comparison was mode between the cakculated and observed inventories as functions of time during the tritium addition (fig. I.3). The two proceses associaled with these half-lives provide a reasonable description of both the buildep and decay of tritiem concentration in the gh.

Elemental iritium in the off-eas reached a maximum concentration of 40 PCi $\mathrm{cm} 11.5$ MEy $\mathrm{m}$ ). which was significanth higher in rebation to the tritium concentration in the solt than in test T2 The concentration of elemental tritium in the sah. inferred from the elemental tritum concentration in the off gas. was $0.1 \mathrm{nCi}$ g $13.9 \mathrm{kBq} \mathrm{kg})$. which led to a ratio of 300 for the combined-to-ekmental hyd. sen in the salt.

The concentration of water-soluble tritium in the bop off-gas at the end of the addition period was $10.200 \mathrm{pCi} \mathrm{cm}$ ( $\left.\sim 380 \mathrm{MBq} \mathrm{m}^{3}\right)$. This resule was atso significantly higher than the tritium concentration in the salt at the comparable tirse during experiment 12. Two firstorder time constants were extracted from the time variation of the concentration of watersoluble tritium in the off-ps. The half-life of the more rapid process ranged from 7 to is hr. whike the half-life for the longer process was about $70 \mathrm{hr}$.

About $150 \mathrm{hr}$ after the stan of the third addition. $37 \mathrm{mC}$ i $(1.3 \mathrm{GBq})$ of :ritium in th. water-soluble form 
hod passed throwh the off-pos sysiem while only 25 mCi conld be accoened for from sall-sample resalls. Apria. the indication is the of a tritim innemery that is not revaled by salt somples.

Measurements of the triting concentration in the exhaust air from the bopenctosure of ete CSTF nere mode shorth afer the cad of the addiaica period in an atermpt to deterticies the rake of tricicm permea-

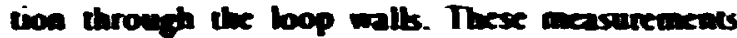
were invalidated by simbancous operations to dispose of excess trition from the addition station by ventios to the bop enclosure at the end of the third addition. When the bop ganple results had rocthed previons beretice valos. Ite bop sampling fre-

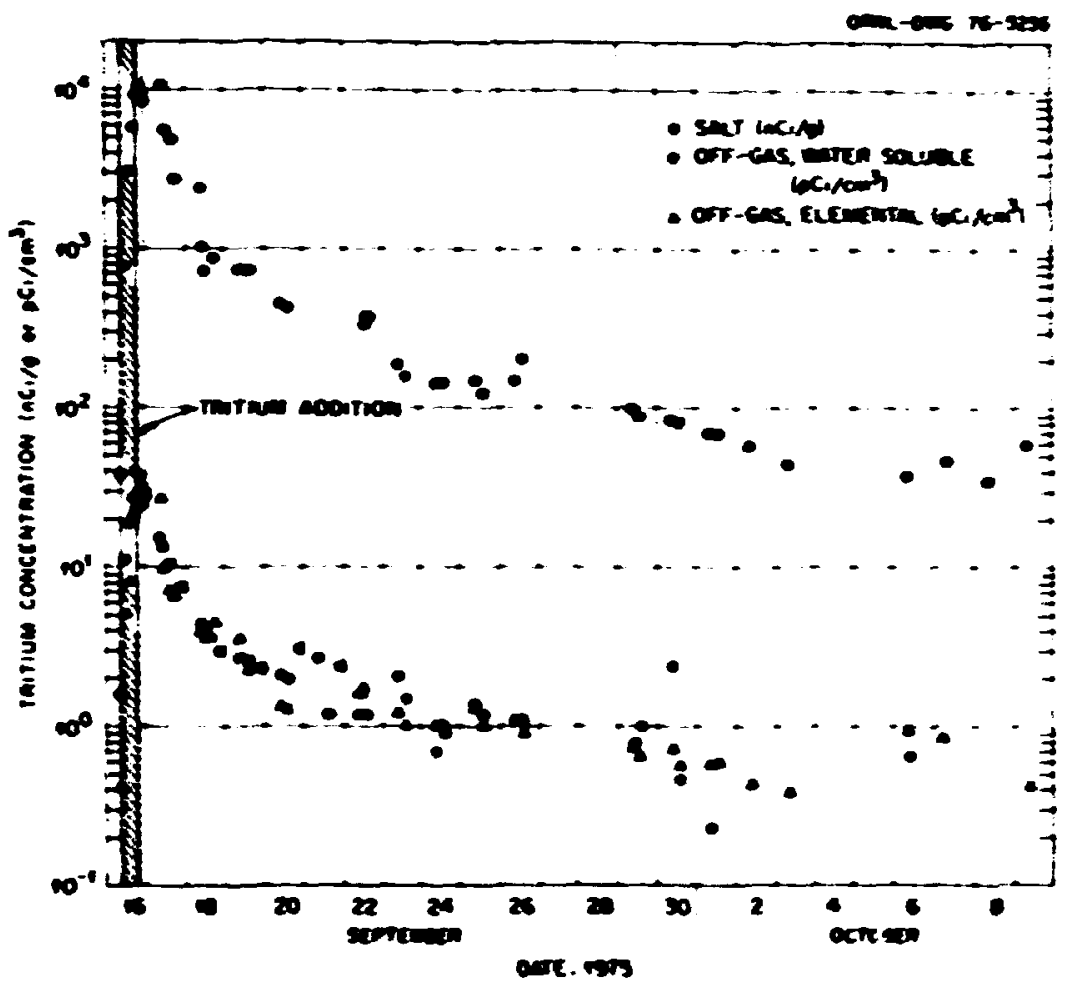

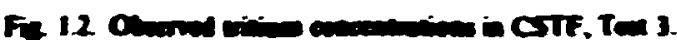

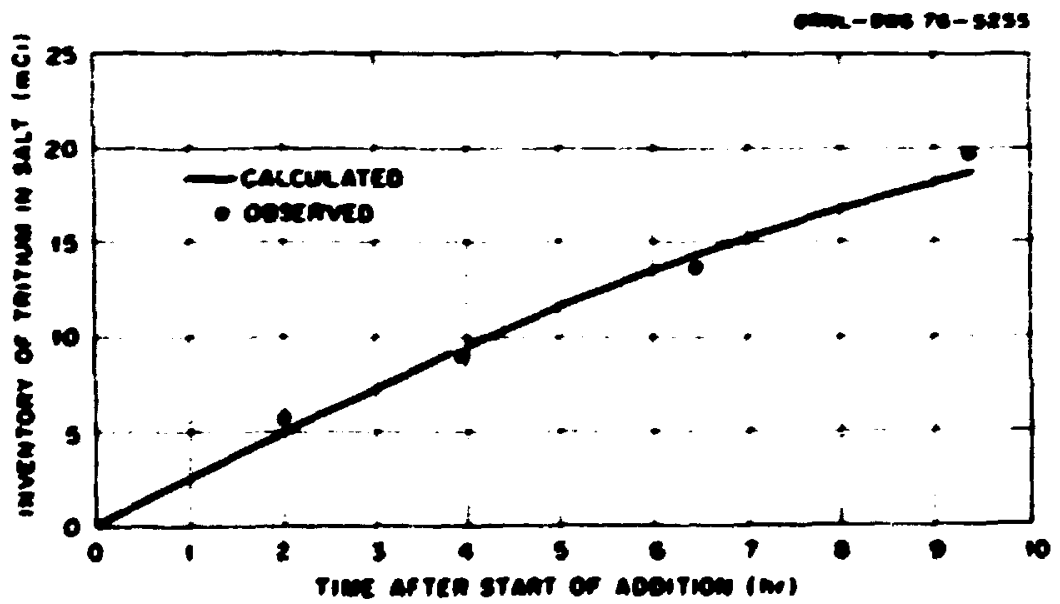

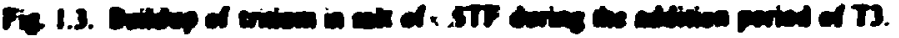


quency uas reduced and several costs were mode to develop a method for determining the rale of permation of intium through the loop wilb. Tritium was adted to the bop enctosure and to one of the coolung shrouds on the loop piping whik samples of the ventibtion air were anahyed for tritium conlent. Thexe kests bed to the uxe of an airsample tap in the disctarge line from one of the cookers and to modification of the cooker inkets to suppty fresh air linstead of air from within the enctosure) to that conoter. The results undicaled thet the tritium concentration in the air kaving the coolet would be readity and accuratety measurable if anticupated loop-wall permeation pies were experienced.

Immedacty afler the end ef the eritivam addition phase of rest T3. somse pretimionny date were abtained to determine if the addition tube lot a simibr device immersed in the main slt siream) could be used to masure the partial pressure of etemental hydrogen in the circulating git. The addinom tube was evacuated several times and then -isobled: it was expected that any pressure rise within the soblated tube would be due to hydrogen partial pressure in time salh. but the pressure did not reach a steady value. It was sobsequemty determianed that stray inicalape (presumbity of av) was occurring and that the rake of inkakape was not sefficienth consistent to permit the exipction of meaningful data about the hydrogen parial pressure. However. it appeared that a sufficiemth batight device could be used to measure hydrogen parial pressure. Iherefore. a partial-pressure prote was conseructed and installed in the CSTF for experimeat 74

\section{1 .3 Andsis of Experingex T4}

The fourth irition experimem a steady-stak experiunent in the CSTF is $m$ progress. This experiment was started on Februan 3. 197\%. Dat are still being accumalated. and resalts obcained thus for are prelimionon. The operational and experinenbl conditions for this kest are dexcrited in Seet. 2.2 .

An attempt was made to stan this experimemt on January 27. 1976. with tritinked hydrowen beines added to the koop at $6 \mathrm{~cm}$ '(STP) hr. This attempt was discontinued when the bypass rate of tritivied hydrogen into the vacuum gund chamber surrownding the addition probe was found to be significantly greater than had been obsuerved during previous tritium kests. This bypase rake was about 14 times the rate at which tritium was reaching the circulating sah.
Flow tests to measure the kakare as a function of addiniontube pressure indicated ibat. for an addition-tube pressure of $35 \mathrm{kPa}$ i 5 pia). the bypass rate wruld be I.5cm (STP) hr.approximalety eqal to the addition rate to the solt. which was comsidered tolerabte.

Prior to the alcempled addition on Jamean 27. samples from the CSTF showed the following tritium concentrations:

Iritium in the sait: $<$ to $8 \mathrm{mCi} \& 1<40$ to 300 KBy kg)

Water-solubte (combined) tritum in off-pes: 201050 pCi $\mathrm{cm} 10 . ? 102 \mathrm{MBq} \mathrm{m})$

Ekmental tritium in off-ens: 5 to $17 \mathrm{pCi}$ cm 10.2 10 0.6 MBy mi)

Elemental tritiom in cooliagdact air. Bactgrowed"

Those prevest smples aken on Februar: 3. prior to th axtwal stari of the test. were binsed by the tritivem added on the Januan 27 attemp:

The tritium concentration in the soli (Fig. 1.4) rose in a manner simibr to that observed in previoes lesess to $500 \mathrm{nCi}$ g ( - $20 \mathrm{MBy}$ Kg) abour 2.5 dens afket txe stan of the addition. The trition concenturation subsequenth rose to a value of 700 mCi g 1245 MBq kg) $(\leq 10 \mathrm{~F}$ ().

The concentration of sakct-soleble intium in the ofl-eas incrased to a value of 150000 pii $\mathrm{cm}$ "(5.S GBq mi) about fout deys aflet the stant of the addition. It then gradualk increased to 1200000 to 1900000 p(i cm 16.7 to $7.0 \mathrm{GDq} \mathrm{m})$. This corresponds 10 a flow rake of $221023 \mathrm{mCi}$ hr 10.22100 .23 GBy s) of iritum or $1.5101 .6 \mathrm{~cm}$ ' he of wal modropen (at 5600 ppon trition in hydropen) in the off-pas in the naker-soluble lorm.

The etemental tritivem concentration in the off-pis showed irregubr bethavior and seaner for abour one day following the stan of the adiaion before increasing in an orderty fashion to a value of 22000 pCi $\mathrm{cm}^{2}$ ( 0.8 GDq $\mathrm{m}$ ). Ths irregular betuvior was not emirety unexpected and may hove been due to conditioning of new piping in the off-ens grveen dat had been inetalted priot to this experionem. A somewhat similar phenomenon occurred dering the first tritium addition experiment. The concentration of elemental iritium in the off-as sebrequembs decreased in a value between 10.000 and 11.030 pCi cm' (0.37 GBq m' and 0.41 GBq m'). There-

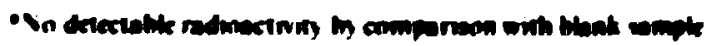




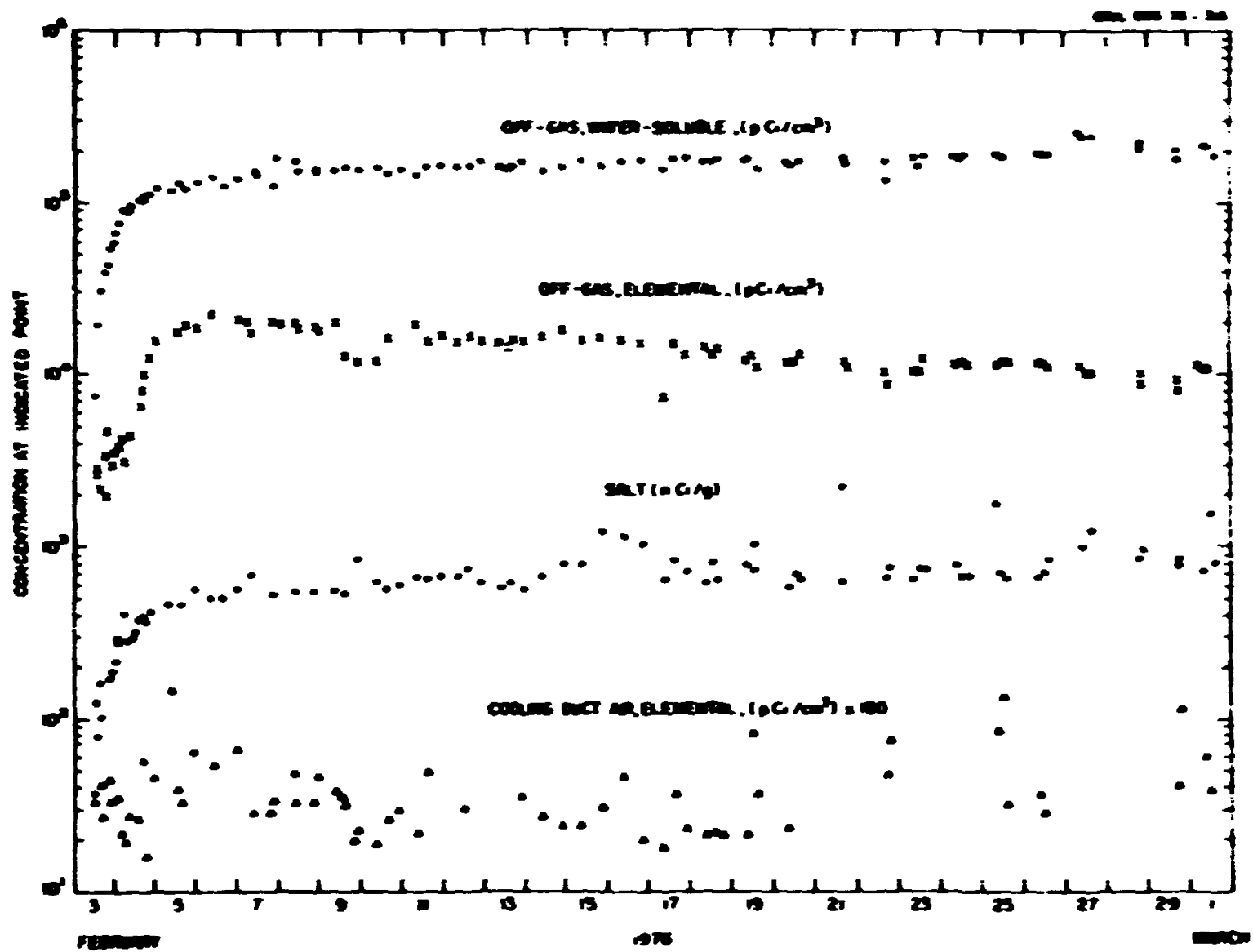

F. 1.4 Trite

fore. chemental irivisu is appeariag in the offors sysem at a sale of 1.2 to $1.32 \mathrm{mCi}$ hr $1 \sim 12.5$ to 13.6 MPa s) $\times 0.08$ to $0.09 \mathrm{~cm}$ hr tool hydrogem.

Measurable comoentsations of triturn were observed in the furst sample of air takea frow the bop cooliag duct 2 hr affer the sean of the experisient. Since then. the concentration has saried between 0.2 and 0.8 pi cm 17 lo $30 \mathrm{kBq}$ m ). These concentretions correspond to a net flow of 0.2 to $0.8 \mathrm{anCi}$ hr 12.1 co $2.2 \mathrm{MDA}$ s) of iritium or $0.013100 .084 \mathrm{~cm}^{\prime}$ br of eall hydroxen through the walts of the loop piping and powp bowt. Thes the lotal how mice of iriained mydreyen out of the CSTF is from 1.6 to 1.75 cmi (STP) hr vie the off-ens system and permention of the metal walts. with is to cert of the total being renioved through the off-as syatem.

Measurement of the bypass me of bydmen around the addition probe indicaled as averese rale of $\sim 1.2 \mathrm{~cm}$ ' hr. Tritioted hydrosen is beine consumed (addition rete to loop plus by pase race) at $\sim 3.0$ can hr. Thas wib $1.6 \mathrm{kn} 1.75 \mathrm{~cm}$ (STP) br being retwoved from the CSTF. 19 lo 97\%; of the introm that is led to the addition prubecan be accousaled for.

The mensured conceatration of elewental trition in the off-tas corraponds to a partial prevence of 0.2

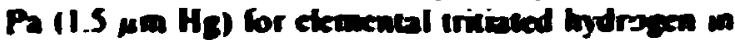
the pusp bowl as spoce. This value companes

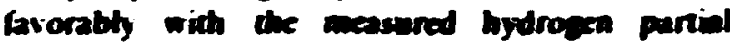
preseare in the main circubtion salt strean. $0.43 \mathrm{~Pa}$

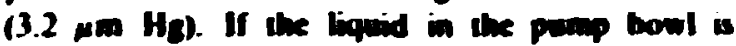
asunad to be in equilitriom with the pas phase. the chance in the hydroeen partial poeseure between the salt in the bop and that in the panp bowl nayj be used to extinume the solel wity of elemental hydrayen in the NinPF,-Naf mixture. For the nominal thow

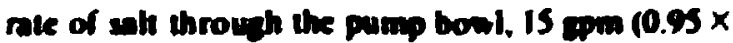

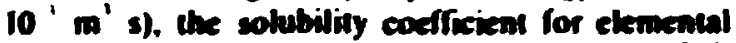
bydroen would be $1.7 \times 10^{\prime \prime}$ atm (atom cm')! compered to an eartier evivinate of $4 \times 10^{\prime \prime}$. Conversety, if the entiver eatimate of solubiliny is 
used. the sah thow rate through the pusp bowl is 36 Epm $\left(2.3 \times 10^{\circ} \mathrm{m}^{\prime} \mathrm{s}\right)$. Since both values are withia

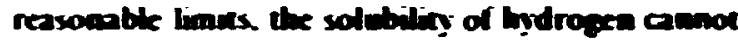
be defind more precisecty from dhese data.

A simbr aanhsos of the daca for conbined trition (lydrogen) in the of tes indicales a lydrogen pertial pressure of $8.3 \mathrm{~Pa}(62 \mathrm{mb} \mathrm{Hg}$ in the ges plonse. assumang weal pas betwavior and one atom of tritinam or hidrogea pet molocule of componed. It diss value represents ay ilibrian between the lipid and ens

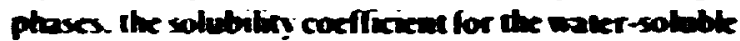
hydrogen form is $1 . ? \times 10^{2}$ atm fonolecte cm" ahl. This is chose to the value of $1.1 \times 10^{\mathrm{m}}$ estumated for the solubility of HF. which is ons possuble form of the waker-soluble componend.

Ibe apparent rate of hydrogen pernmeation through the bop walls besod on the obsened initing concentration in the bopeodingduct, is between 0.7

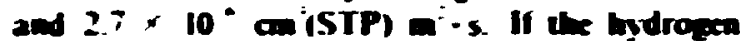
ponal pressure in the salh is 0.43 Pa, this rate requires the effectine pernuestiting of the loop piping to be between 10 and 50 ines bover one thet of bere metal. A reduction of lisis mogicte would be comsiofeat with the presence of an oxide folm on the everixe metal surtoces.

Based an the mesured concentration of watersoluthe irition in the sal (700 aCi g) and the

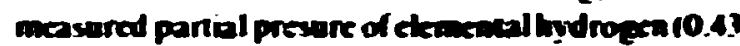
Pal. the ratm of the concentration of toelal bydropen

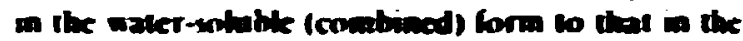

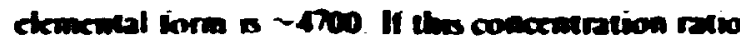
oese colablished in the conotom sin of an MSRR and for the following conditions:

1. rewomal of conbund trition from a tor sah

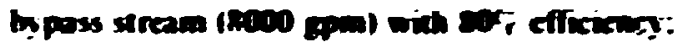

2. no soppion of HT or It on the cone graphice.

3. referrence vale of $10^{\circ}$ lor the $\mathrm{C}^{-0} \mathrm{C}^{-3}$ patio in the primang sh:

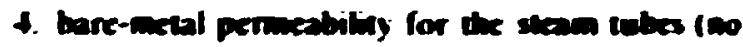
oxude finm):

abou 3.5 ( the skeam system and the released to the ewvironment.

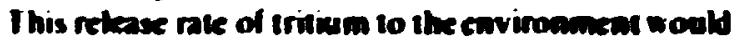
be within the ragare of release rates from presurivedwater reactoms (PWRs) curnenty operatios. The release rate of iritium for the MSAR incledes the entire fuel cycle. white that for PWRs wanld be about nOCi day if reteress ascociated with fuel reprocessing were included.

\section{NEUTRONC ANALSS}
H. T. Ken
E. J. Am
D. L. Red

The newroaic analysis efforts daring this reporting period bave locesed primanty on the procesing of cross section dac for MSEA perfor ance evalotions and bor ivestiption of precife rebad

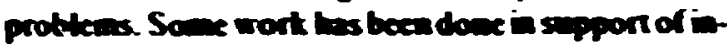
reactor inrediation experimants.

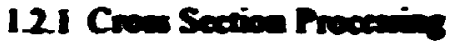 for Msen Clation}

Vemron cross sections from the ENDF DHV be files lave been procesed to form a 123 -enerygromp livery with thernal seanerime matrices for

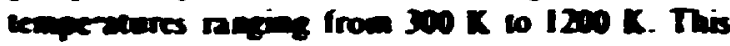

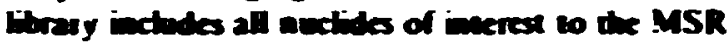
program and wil serve as a dack bese for all subsequen newromics andyses in addion to the ENDF B-N dan. graphise cross sactions obnined from Gemeral Alomies Compeny bove bee in

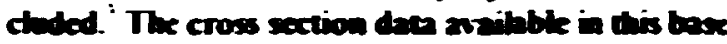

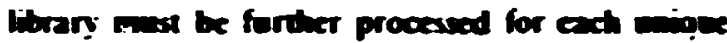
appicaion Sigrifan changes in the fect on

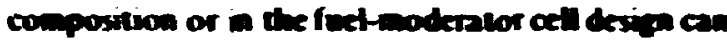
strondy infence the difative cross sections paricularty for strong absorters sech as :"Th.

The core of the reference desip MSPR is divided who two major anes. Zowe I is charecterived by approximety 1? vol $\%$ fad ole and Zone II is

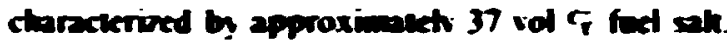

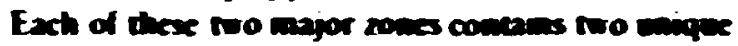

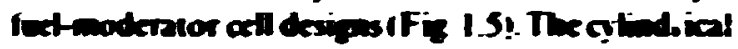
cquivalem of ecth at deigen is abo shown.

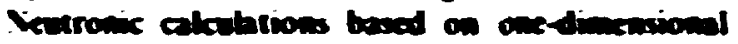
netirom tramipon theory were dowe for each

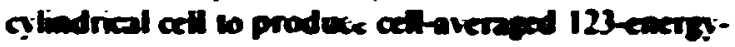

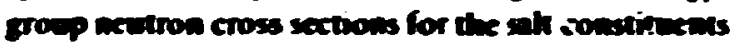

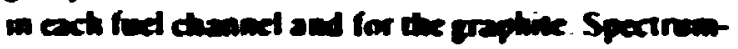

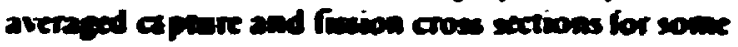

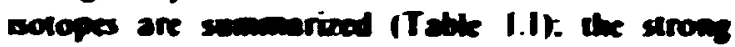

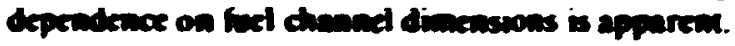
However. volume avenging the crose sections for

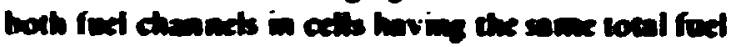

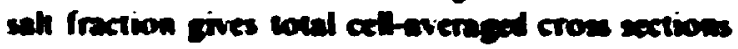
that are not very seasinive to foct chanet dinchicions. Therefore. cell-avernat cros sections for a nominal foct ah composition are prisurity dependent upon the volume fruction of fuet all in the cell.

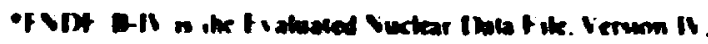

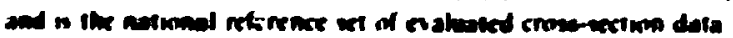



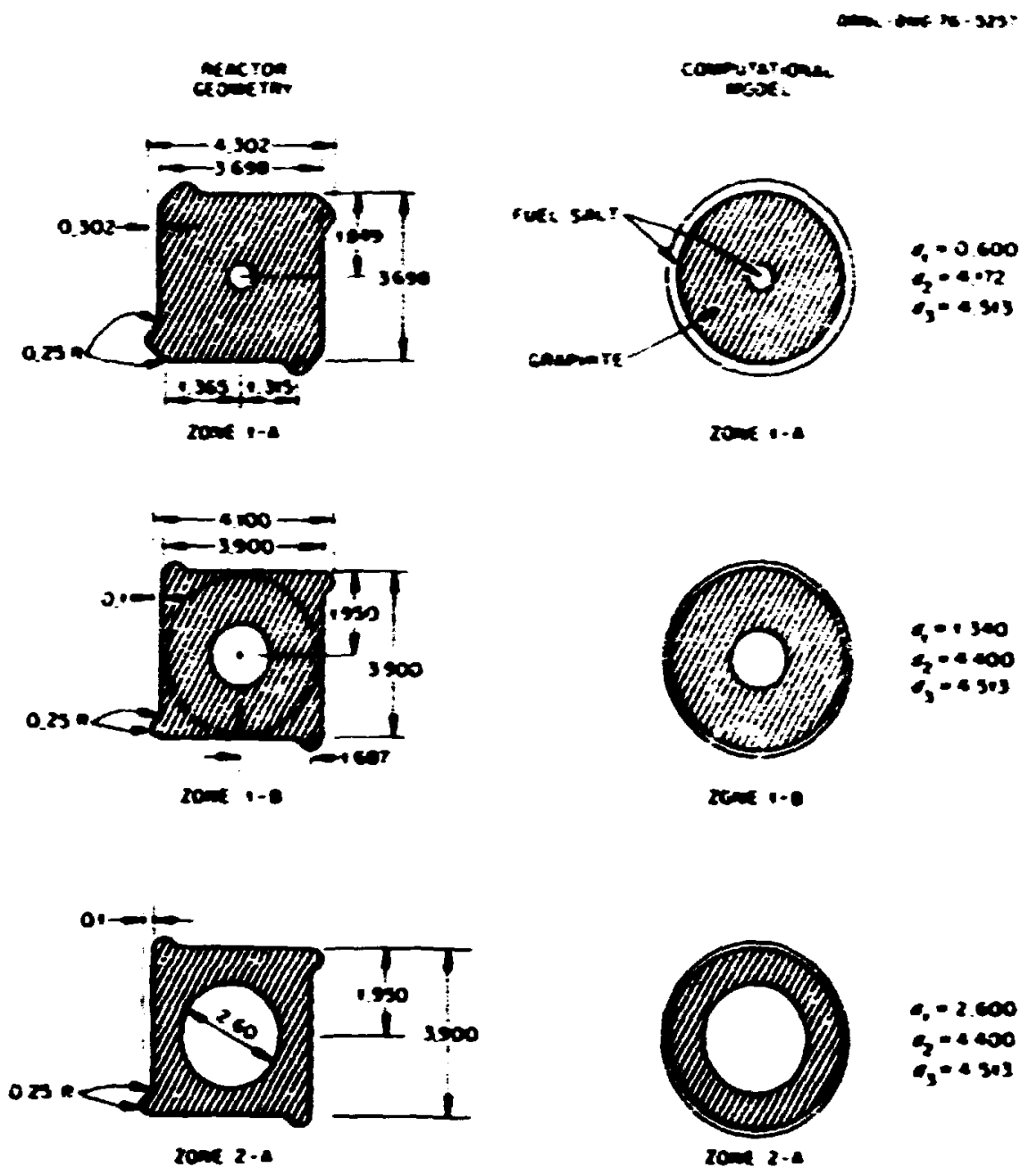

$0 .-2.000$ $a_{2}=400$ 4,4301
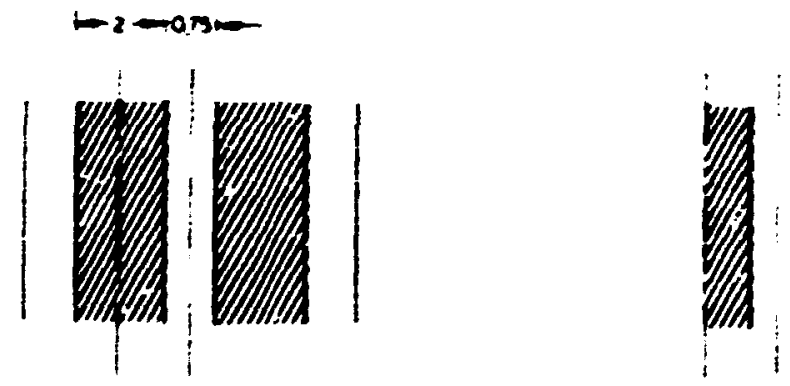

6.000

$200 \times 2-0$

rone $2 \cdot$

comenssons in menes

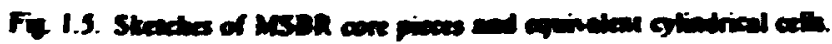


Tive I.I. Col.

\begin{tabular}{|c|c|c|c|c|c|c|c|}
\hline \multirow{3}{*}{ nearen } & \multicolumn{7}{|c|}{ 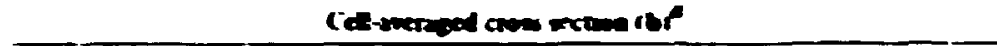 } \\
\hline & \multicolumn{2}{|c|}{ Cox mane ita } & \multicolumn{2}{|c|}{ Cortane ID } & \multicolumn{2}{|c|}{ 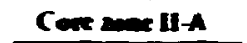 } & \multirow{2}{*}{$\frac{\cos }{a}$} \\
\hline & Comed & ملفئ & Cemal & sare & Cenerd & cand & \\
\hline 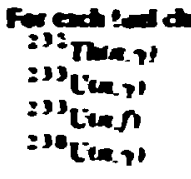 & $\begin{array}{c}2418 \\
1303 \\
1.05 \\
9711\end{array}$ & $\begin{array}{c}2202 \\
1210 \\
1021 \\
9101\end{array}$ & $\begin{array}{c}244 \\
1256 \\
1022 \\
545\end{array}$ & $\begin{array}{c}2402 \\
1425 \\
1233 \\
9220\end{array}$ & $\begin{array}{l}1490 \\
6075 \\
50 \times 5 \\
1063\end{array}$ & $\begin{array}{c}2751 \\
8342 \\
6230 \\
1154\end{array}$ & $\begin{array}{c}145 \\
005 \\
640 \\
174\end{array}$ \\
\hline 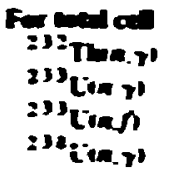 & $\begin{array}{r}12 \\
103 \\
5\end{array}$ & & $\begin{array}{r}2 \\
13 \\
113 \\
8\end{array}$ & & $\begin{array}{l}1 \\
? \\
5 ? \\
10\end{array}$ & & $\begin{array}{l}1 \operatorname{ses} \\
\text { seos } \\
640 \\
174\end{array}$ \\
\hline
\end{tabular}

$f 1 b=10^{-20} \mathrm{~m}^{2}$

As organdly conceived the cell-wedined cross sections prevousty described vece to be und in a

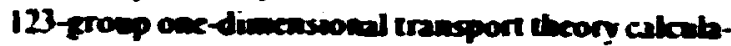

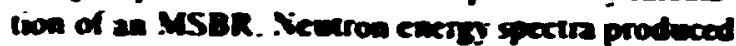
in this calchbtion were to be wat to collopse the isotopic cross sections in exch core zone into a ke

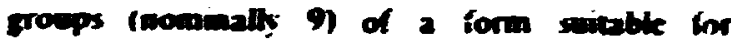
madinensional pertormence alculbtions However. considerbble delays bue beca cucouresed with the tranpon alculation an the AMPX code." First. several propan enors were decovered of widh

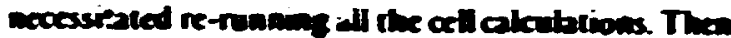
the observation was ande chat the clabed radol

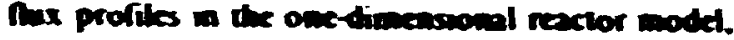
pertucubrty in the reflector and rector-vent repows. were strongly depandest on the matol thex guas used to sant the ictative procedure. This

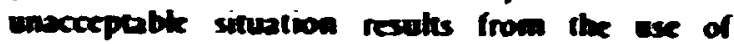
comveryence criterio in AMPX which are not surbble for onedinensional rector Max calchtions in repions haveg very low acutron source deasitics. Proyram modifications are being nade to incorporate suitakic convergence criterio. and alkemate computational schemes are being considered.

\subsubsection{MSDR Performane Calenlations}

Multidimensional perinrrance calculations for the reference design MSBR rquuire collapsed. fewgroup cross-section data for each zone of the reactor. However. for the reasons previously given (Seet. 1.2.1). the appropriate cross sections are not avalbule. The bect and the phaned serinimation of die MSR Progran a the end of FY 1976 will prectade conepletion of the performance alcokrons.

\section{Iteton Portion in te MST Vead}

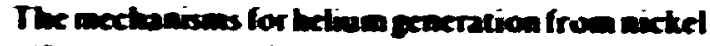

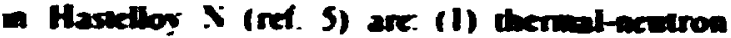
Copture in " vilollowed by trennal(n,e) rections in

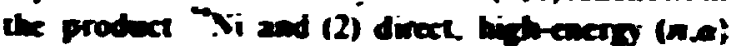

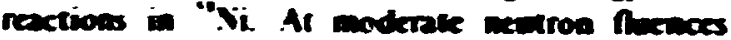

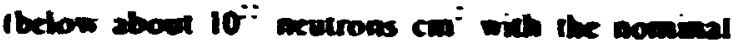
nexron enert spextrim expected in the MSDR

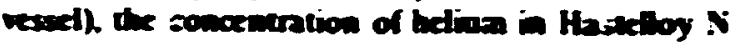
de to the two-sip. therinal prodes is adequaty rprosulad by

$$
H_{1}(t)=\frac{N \sigma_{1} \theta_{2}}{2}(\omega)^{2}
$$

Where $N$ is the alom fraction of "Ni in the alloy. o, is the effective. spectrum-averafed crms section for "Nif(n.y)" Vi rection. $\sigma$ : is the effective spectrum. averaged cross section lor "Ni(n,a) "Fe rection. is the total neutron mux. and $t$ is time.

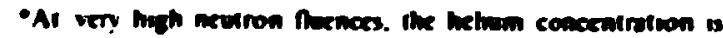

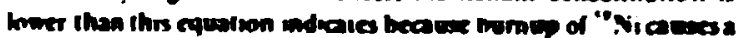
reduction in the rete of prodection of "Wi and the "Wi conceniralion appraselies an equilibrium valee. 
The dependence on the square of the fluence results from the fact that the intermediate nuclide. "Ni. must be generated by neutron capturs. The comparable approximation for heliur- uncentration due to the high-energy, (n.a) process is

$$
\mathrm{He}_{2}(t)=\mathrm{No}_{3} \bowtie t,
$$

where $\sigma_{1}$ is the effective, spectrum-averaged cross section "Nitn,a)" Fe reaction.

The ratio of these two concentrations is a linear function or fluence. Thus the high-energy process is the dominant source of helium at low fluences. and the two-step thermal process becomes dominant at higher fluences. These relations also indicite that changing the neutron flux spectnum (e.g.. reduction of the therm. 4 ccmponent) would change the relative importance of the two processes, as well as the total helium concentration that would be generated in a given time period.

Cross sections for the "Ni(n.y) reaction are fairly well known, and available information for the " $\mathrm{Ni}(\boldsymbol{n}, \mathbf{0})$ cross sections indicates that a value of $13 \mathrm{~b}$ $\left(13 \times 10^{\circ *} \mathrm{~m}\right)$ at $2200 \mathrm{~m}$ sec is reasonable. The neutron fluxes in ar: MSBR have been calculated with several differeri: computational models and are generally in good agreement for the fueled regions of the reactor. However. calculating neutron fluxes in the reactor vessel is a particularly difficult problem because the codes available for the source-type problems are not designed for newiron flux convergence in zones of low nuclear importance. A 20-group $S_{r}$ transport calculation with special convergence criteria was done.

By combining the available cross-section data for nickel with neutron fluxes from this calculation estimates were made for the amount of helium generated in the reactor vessel during the reactor lifetime. The spectrum-weighted cross sections and flix information used to estimate the helium concentration at the inside wall are summarized (Table 1.2). Using these values, calculated maximum helium concentration in the vessel is $38 \mathrm{ppm}$. About 90\% of the higher concentration is associated with the two-step thermal process discussed above.

Although some uncertainty exists in the helium concentration calculated at the inner surface of the vessel. the calculated nux has a steep radial gradient

\footnotetext{
- Neutron captures in boron. which may he present at low ppm levels as a trace contaminant in the alloy, would add a small amount to these concentrations.
}

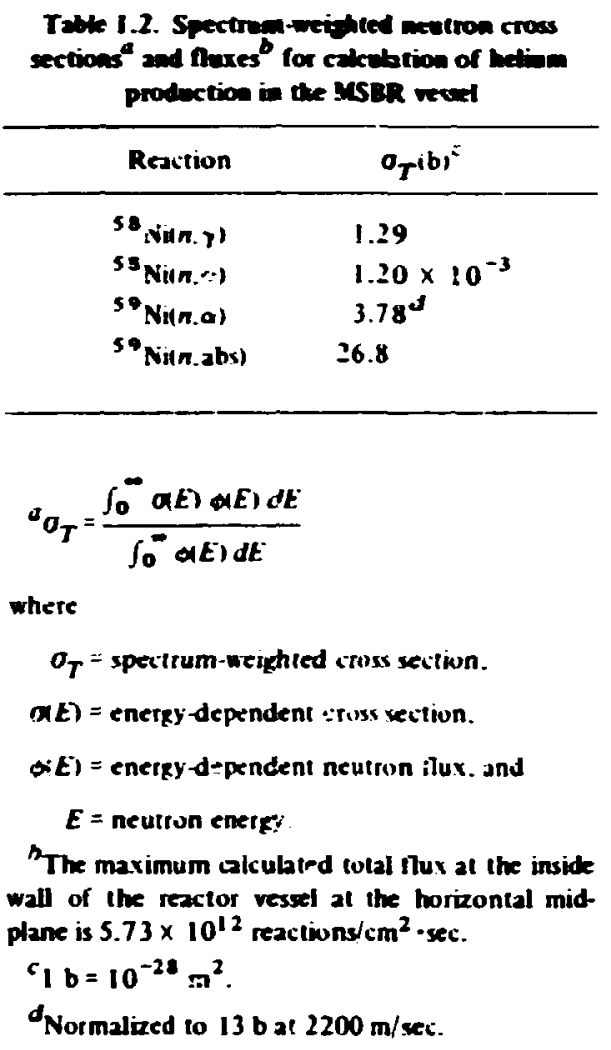

in the vessel. This gradient causes a reduction in helium concentration by a factor of about five for each centimeter of penetration into the vesset wall. Thus the concentration of helium in the Hastelloy $\mathbf{N}$ vessel wall appears to be acceptably low.

\subsubsection{Production of ${ }^{232} \mathrm{U}$ in the MSBR}

Uranium-232 has a decay chain that arproaches equilibrium over a several-year period: the nuclides in this chain emit high-energy alpha particles and gamma rays. The alpha particles, in tum, may react with otner nuclides to produce neutrons. As a result. shielding and handling costs of reactor fuels increase as the $U$ content increases. Increasing the content of "U in fuels of conventional reactors for which reprocessing and refabrication are required raises the cost by which the $x$ processes are performed and lowers the value of tice discharged fuel. In the absence of light nuclides which can undergo $(\alpha, n)$ reactions. the principal radiations from the standpoint of shielding are the 2.6-MeV gamma from ${ }^{\text {inx }} \mathrm{Tl}$ and the 
2.2-Mel gamma from ":Bi. However. in the presence of light nuclides (c.g.. F. Be. and $I . i)$. as may be the case tor MSBR fuel. a significant neutron source nould also be present.

The "I production in the reference design MSBR was examined to deteimine the concentration of " $\mathbf{U}$ that would be present in the MSBR. Decay of "' $L$ ' is not a direct problem for fuel used in the MSBR (because no fabrication is required). but the content of this isotope in excess bred fuel could affect handling and shipping costs. The five procesurs by which $\mathrm{Can} b$ : $p$ roduced are

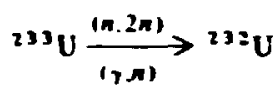

$230 \mathrm{Th} \stackrel{n .7}{\longrightarrow} 231 \mathrm{Th} \stackrel{0^{-}}{\rightarrow}{ }^{231} \mathrm{Pz} \stackrel{\mathrm{n}_{.7}}{\longrightarrow}{ }^{23}{ }^{2} \mathrm{Pz} \stackrel{0^{-}}{\longrightarrow} 232 \mathrm{U}$

${ }^{232} \mathrm{Th} \underset{r . n}{\stackrel{n .2 n}{\longrightarrow}}{ }^{231} \mathrm{Th} \stackrel{B^{-}}{\longrightarrow}{ }^{231} \mathrm{Pz} \stackrel{n .1}{\longrightarrow}{ }^{232} \mathrm{Pz} \stackrel{A^{-}}{\longrightarrow}{ }^{232} \mathrm{U}$

For the :"Th: "U ratio: $(\sim 56)$ expected in the MSBR. the $(n, 2 n)$ reaction in "Th is more important than the $(n .2 n)$ reaction in : : $U$. However. removal of the protactinium isotopes by fuel processing on a 10day cycle greatly reduces the production of "U from $\because$ Th reactions. As a conseyuence, the net production rates of $U$ from the two $(n .2 n)$ processes may be comparable in an MSBR.

The equilibrium concentration* of " $U$ in the MSBP. is given by the equation:

$\left.N_{22}=\frac{1}{\sigma_{5} \phi+\lambda_{5}} \mid \frac{\lambda_{2} \sigma_{3} \phi\left(\phi \sigma_{i} N_{00}+R_{2} N_{02}\right)}{\left(\lambda_{2}+\lambda_{R}\right)\left(0_{3} \phi+\lambda_{R}\right)}+R_{4} N_{23}\right]$.

where

$$
\begin{aligned}
& N_{22}=232 U \text { concentration, } \\
& N_{\text {oo }}=230 \text { Th concentration. } \\
& N_{n 2}=2.32 \text { Th concentration. } \\
& N_{23}={ }^{33} U \text { concentration. } \\
& \phi=\text { neutron flux (average in core). } \\
& \lambda_{2}=\text { decay constant of } 232 \mathrm{~Pa} \text {. } \\
& \lambda_{s}=\text { decay constant of }{ }^{232} \mathrm{U} \text {. } \\
& \lambda_{R}=\text { removal constant of } \mathrm{Pa} \text {. } \\
& \sigma_{1}=(n . \gamma) \text { cross section of } 230 \mathrm{Th} \text {, } \\
& R_{2}=\phi_{\sigma_{2}}+\phi_{1} \sigma_{2} \text {. } \\
& o_{2}=(n .2, n) \text { cross section of }{ }^{232} \mathrm{Th} \text {. }
\end{aligned}
$$

- Ahout $95 \%$ of cquilihrium is altained in 15 full-power years

$$
\begin{aligned}
\sigma_{2 \gamma} & =(\gamma n) \text { cross section of }{ }^{232} \mathrm{Th} . \\
\phi_{7} & =g \text { amma flux. } \\
\sigma_{3} & =(n . \gamma) \text { cross section of }{ }^{23} \mathrm{P} . \\
R_{4} & =\phi_{4}+\phi_{7} \sigma_{4} . \\
\sigma_{4} & =(\gamma n) \text { cross section of }{ }^{23} \mathrm{U} . \\
\sigma_{4} & =(n .2 n) \text { cross section of }{ }^{23} \mathrm{U} . \text { and } \\
\sigma_{5} & =(n .2 b s) \text { cross section of }{ }^{232} \mathrm{U} .
\end{aligned}
$$

The equation assumes that the consentrations of $\because C$."Th, and "Th are constant and that other isotopic concentrations are in equiuibrium.

Based on neutron fluxes obtained from the diffusion theory model of the MSBR. values were obtained for the various reaction rates. The reaction rate values, in reactions per atom per second. are summarized below.

$$
\begin{aligned}
\sigma_{1} \phi & =1.25 \times 10^{-8}, \\
\sigma_{2} \psi & =1.92 \times 10^{-13}, \\
\sigma_{2 \gamma} \phi_{\gamma} & =1.96 \times 10^{-14}, \\
\sigma_{3 \psi} & =4.30 \times 10^{-1}, \\
\sigma_{4} \varphi & =1.11 \times 10^{-13}, \\
\sigma_{4,} \phi_{7} & =1.96 \times 10^{-14}, \\
\sigma_{5} \phi & =157 \times 10^{-8}, \\
\lambda_{2} & =6.08 \times 10^{-6}, \\
\lambda_{5} & =3.05 \times 10^{-10}, \\
\lambda_{R} & =1.16 \times 10^{-6} \text { (ten-day cycle). }
\end{aligned}
$$

The :" $\Gamma h(n . \gamma)$ cross section was based on a 2200 $m$ sec value of $22.7 \mathrm{~b}\left(22.7 \times 10^{: \mathrm{m}} \mathrm{m}^{\mathrm{i}}\right)$ and a resonance integral of $996 \mathrm{~b}\left(966 \times 10^{-2 x} \mathrm{~m}^{2}\right)$. The $(\gamma n)$ cross sections for both " $U$ and "Th were taken as 0.05 b $\left(0.05 \times 10^{2 "} \mathrm{~m}^{2}\right)$ for gamma energies above 6.0 $\mathrm{MeV}$ and zero for gamma energies below $6 \mathrm{n} \mathrm{MeV}$. These very conservative $(\gamma, n)$ cross sections are based on the limited information availatle for these reactions." The gamma flux was approximated by assuming a volumetric fissicın source of gammas in an infinite medium of pure gra phite with a density equal to that of pure graphite in the MSBR. The remaining cross sections are better known. and the corresponding reaction rates should be more reliable.

Substituting the reaction-rate values into the equation for the equilibrium concentration of : $\mathrm{U}$ gives

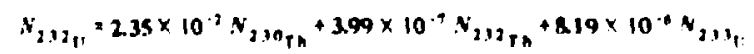


Solution of this expression for the reference design $1000 \mathrm{MW}(\mathrm{c}) \mathrm{MSBR}$ with a ten-day processing cycle for protactinium removal and no "Th keads to an equilibrium concen!ration of $20 \mathrm{ppm}$ for "U $U$ in total uranium. Of this amount. $27 c_{c}^{\circ}$ is produced by reactions in " $\mathrm{U}$. The ${ }^{: 3 \mathrm{U}} \mathrm{U}$ sitrce from ${ }^{\text {"Th }} \mathrm{Th}$ would about equal the combined source from ${ }^{33}$ Th and ${ }^{33} U$ at a concentration of $23 \mathrm{ppm}{ }^{-10} \mathrm{Th}$ in thorium. Thorium-230. which is a decay product of ${ }^{i d} \mathrm{i}$. is present to about $17 \mathrm{ppm}$ in natural uranium. Thus. if the thorium to be used in a reactor is obtained from mineral deposits that also contail, uranium. such thorium could contain a significant amount of ${ }^{2 h} \mathrm{Th}$. The Th: $l$ ratio in Monazite sands. a major thorium resource. is typically about 20 . Hence. thorium from such deposits could be expected to contain only about 1 ppm " th Th--an insignificant concentration from the standpoint of ${ }^{3} \mathrm{U}$ production. However, in the absence of a large thorium industry, initial demands for ihorium conceivably could be met by material recovered from uranium mill tailings. where the $T \mathrm{~h}: \mathrm{l}$ ratio in the raw ore :ould have been 0.2 or less. ( The ura nium ores at Blind River in Canada. for example. have Th: $\mathrm{U}$ ratios of about 0.2 .) Hence the

:" Th content could exceed $100 \mathrm{ppm}$, which wouid rasse the equilibrium "U concentration to about 107 ppm in total uranium in an MSBR.

\subsubsection{Neutronic Analyses of TeGen Experiments}

The seutronic analysis for the TeGen experiments. as described in the previous semiannual progress report," was based primarily on a flux mapping experiment in the ORR poolside and on flux monitors included in the TeGen-l experiment. Flux monitors have now been loaded into the TeGen-2 and TeGen-3 capsules and will provide additional data for characterizing the TeGen experiments.

The flux monitors in both TeGen-2 and TeGen-3 are identical and consist of two natural iron wires and two vanadium-cobalt $(0.215 \mathrm{w} 1 \%)$ wires. One wire of each type is placed on the side of the fuel specimen toward the reactor core, and the other wire of each type is placed on the side a way from the reactor core. The iron wires are $3+3 \mathrm{~mm}$ long and extend along the entire length of the fuel pin region. The vanadium cobalt wires are $76 \mathrm{inm}$ long and are located only along the middle íuel pin.

The flux monitors have been recovered from the TeCien-2 capsule and are being a nalyzed to determine the induced activities. The irradiation of the TeGen-3 capsule has not been completed.

\section{I.3 HIGH-TEMPERATURE DESIGN METHODS}

\author{
G. T. Yahr
}

Simplified analysis methods in ASME Code Case IS92 (ref. 7) and RDT Standard F9-4T (ref. 8) permit the assessment of ratchetting and creep-fatigue damage on the basis of elastic-analysis results. provided a number of restrictive conditions are met. Ctherwise, detaiked inclastic analyses, which are usual'y quite expensive for the conditions where they are currently necessary. are required to show that code requirements are met. Analytical investigations to extend the range over which simplified ratchetting and creep-fatigue rules may be used to show compliance with code requirements are being made under the ORNL. High-Temperature Structural Design Program. which is supported in part by the MSR Program. Modeling procedures for applying the simplified ratchetting rules to geometries and loadings prototypic of those encountered in L.MFBR component designs are to be identified. Then the conservative applicability of these ratchetting rules and procedures and of elastic creep-latigue rules will be demonstrated and placed on a reasonably sound engineering basis. Finally, an assessment will be made of the applicability of the simplified design methods to Hastelloy $\mathbf{N}$ under MSBR design conditions. and the importance of thermal ratchetting in an MSBR will be determined.

The detailed plans for achieving the stated objectives were given in a previous progress report." The basic approach is to perform a relatively small number of carefully planned and coordinated rigorous elastic-plastic-creep ratchetting-type analyses of several geometries. Each geometry is subjected to the axial, bending. thermal-transient. and pressure loadings described in Table 1.7 of ref. 9. Several two-dimensional cylindrical shell problems are being analyzed at ORNL. using the PLACRE computer program," while three-dimensional nozrle-to-shell problems are being analyzed by Atomics International and Combustion Engineering using the MARC computer program." Each inelast ic analysis will include a complete code evaluation for accuinulated strains and creep-fatigue damage. Also associated with each inelastic analysis are a number of elastic analyses to provide the input parameters required to apply the various simplified ratchetting rules and procedures and elastic creep-fatigue rules.

\footnotetext{
-MARC-CIX: developed by MARC Analysis Research Corporation. Providence. RI.
} 
The inclastic analysis results for the nine axisymmetrical shell cases have been tabubted and compared with the results of the Code Case 1592-3 elastic creep-fatigue rules. The elastic rules were found to be consenvative in all cases for combined creep-fatigue. but the creep damage components were not conservative for the notched cylinder and the stepped cylinder. compared to the predictions of the inclastic rules. One-dimensional inelastic analyses simulating various locations in the shells are now being performed.

Both of the three-dimensional inclastic analyses of nozzk-to-shell configurations are under way again after various problems. including cost overnuns. temporarily stopped the work. Combustion Engineering has completed an analysis of three of the five thermal downshocks to be applied to the nozzleto-cylinder configuration, and A tomics International is approximately halfway through the analysis of the one thermal downshock to be applied to the nozzkto-spherical shell configuration.

\subsubsection{Circular Cylindrical Shells"}

Results for the nine circular cylindrical shell cases of this study have now been tabulated, and the results of Code Case 1592-3 elastic rules have been enmpared with the inelastic results. The elastic fatigue damage rules have been found to be conservative in all cases studied. Both the elastic ratchelting rules and the elastic creep-damage rules have been found to be nonconservative in some cases. There are two types of geomitries in which nonconsenvatisra has arisen-at a notch in a pipe wall and in the thick-walled portion of a shell involving a stepped-wall thickness.

Wori is now under way to carry out onedimensional inelastic analyses simulating various locations in the nine circuiar cylind rical shell cases. It is expected that these simulations will throw further light on the nonconservatism found.

\subsubsection{Nozzk-to-Spherical Shell Attuchment ${ }^{\dagger}$}

The project on three-dimensional inelastic analysis of a nozzle-to-spherical shell attachment was discontinued for approximately five months because of funding problems associated with computer costs. It was reactivated early in November, but the scope has been reduced from a five-cycle to a one-cycle

\footnotetext{
- Work done al OR Ni. hy W. K. Sartony.

tWork dnne al Atomics International by Y.S. Pan.
}

inelastic analysis. The elastic thermal stress analysis and the full-scale inelastic amalysis are now being continued.

At this time. 26 thermal load increments and I zero load increment have been completed. The temperature in the entire thin-walled nozxie section of the attachment reached $427^{\circ} \mathrm{C}\left(800^{\circ} \mathrm{F}\right)$ at the twenty-first increment. The maximum temperature in the structur= at the twenty-sixth increment is $576^{\circ} \mathrm{C}$ $\left(1036^{\circ} \mathrm{F}\right)$. There are approximately six more increments to complete the thermal down-transient. Problems associated with the number of increments which could be submitted at one time. computer hardware and system problems. and problems associated with the error messages in the MARC program have slowed the rate of analysis. but these problems have been resolved.

\subsubsection{Nozzle-10-Cylinder Intersection"}

This investigation involves a detuiled inelastic analysis (elastic-plastic and creep analysis) of a nozzle-to-cylinder intersection. The geometry of the intersection is that of the primary inlet nozke of the intermediate heat exchanger (IHX) for the fast-flux test Gacility (FFTF).

Cyclic thermal and mechanical loading will be repeated until the strain-stress history shows a repetitive pattern or steady-state response. A maximum of five cycles will be done. The inelastic analysis has been performed for the first three cycles.

\subsubsection{Inelastic Analyes of MSR Piping Subjected to Internal Prescure and Trancient Temperature Cycles}

The temperature histograms for two of the most severe thermal transients that might occur in an MSBR have been obtained to serve as a basis for evaluating the magnitude of thermal ratchetting and creep-fatigue damage that might be expected. One of the transients results from a $60 \%$ decrease in load demand from full power operation in just $3 \mathrm{sec}$. The maximum thermal downshock rate during this event is only $3.3^{\circ} \mathrm{C} \sec \left(5.9^{\circ} \mathrm{F}\right.$ sec), and 120 such events might occur over a 30-year life. The other event considered is a control-rod scram. which results in a maximum thermal downshock rate of $19.3^{\circ} \mathrm{C}$ sec $\left(34.7^{\circ} \mathrm{F}\right.$ sec). This rather severe transient is expected to occur no more often than once each year.

\footnotetext{
\$ Work done at Combustion F.ngineering my R.S. Barsoum.
} 
Creep-rupture data and creep curves for Hastelloy $N$ at 593,704 , and $816^{\circ} \mathrm{C}$ (1100. 1300, and $\left.1500^{\circ} \mathrm{F}\right)$ have also been obtained. When cyclic stress-strain data are obtained for Hastelloy $\mathbf{X}$. solution of the sample problems will proceed. Results from the sample pioblems will be examined to determine whether thermal ratchetting and or creep-atigue inage will be significant problems in an MSBR.

\section{REFERENCES}

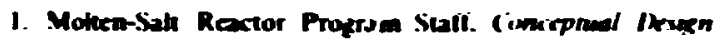

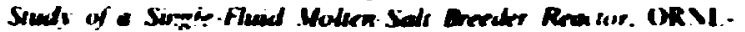
4541 (June 19711.

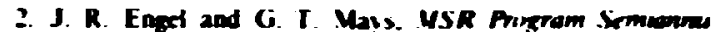

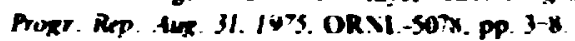

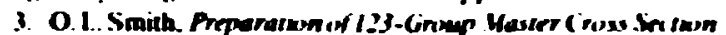

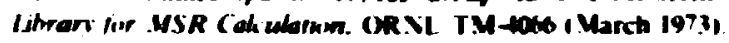

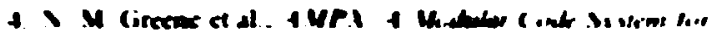

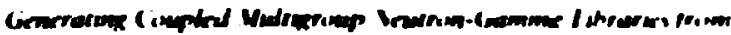

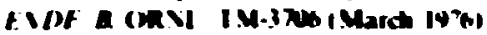

5 H. I. Ketr. I) I Reed. and I J Allew. WSR Wrmmonom

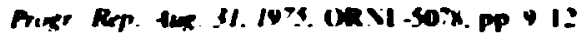

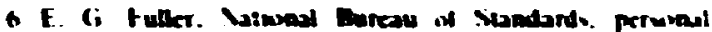
cromenamative. Fetrean 1976

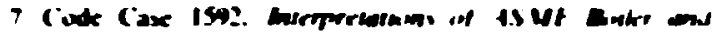

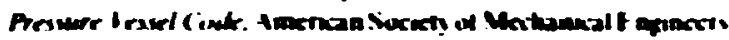
Dew Iont. 14:4

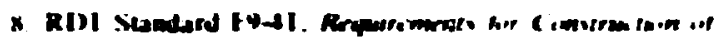

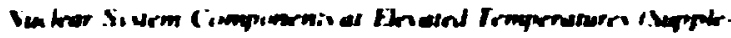

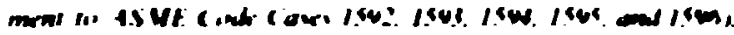
Seprember 1974

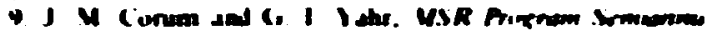

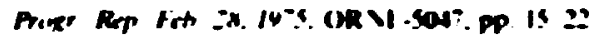

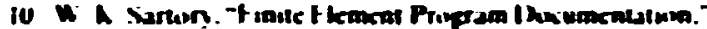

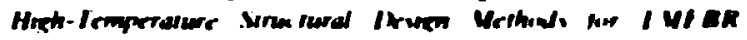

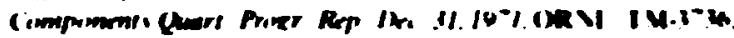
pos 


\subsection{GAS-SYSTEMS TECHNOLOGY FACIITY}

\section{R I Cousmon}

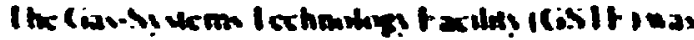

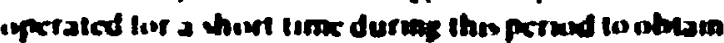
munc inloormation in thr wh mup poblem

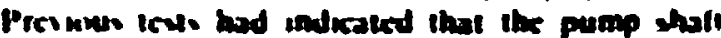
incillatione muthe be seduced af the operation sped

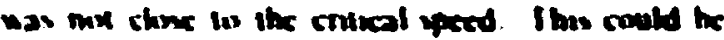

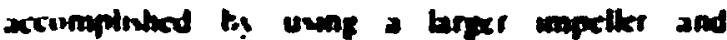

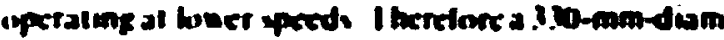

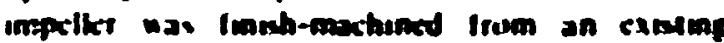
catiaf li scplace the old 3m-mon-dam impelles

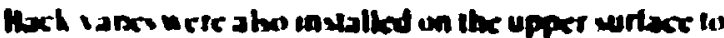

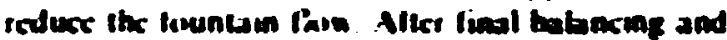
molallatuon of the pump rothan ckencat. the bop was retilled with water and tching sav rewomed in (ktubet 2. 1975. I hos umpellet develaped the desured

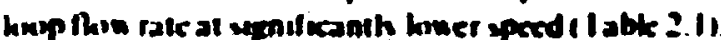

Itre amplotudes of the shalt incollatwons aere

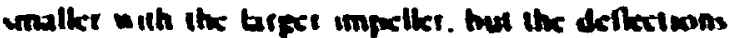

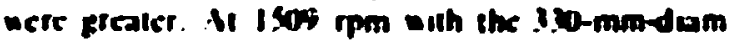
inpelkt. Ihe deflextmus sarned between 1.5 and :.: $\mathrm{mm}$ irom run lis run and at lomes showed definoke wens thit the folan ckment eas rubung apans

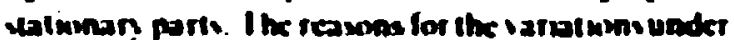
apparenth dentiol conduluans are not known. I he delketwas are high becousc of the pettommance mismotch between the ampellet and the volute. I his mismolch roulted trom pump desyn modufiations made in an ctlon to use an existing pump.

Ihe operating characterivice et an MSRf coolant pump would be sotiafactory for the present reyurements of this loop. and the shatl excillotions and deflections should be low. Therefore. consideration wat eiven in comening the Mart II pump into a contant pump. This could he accomplished in installing an araibhte coolani-purap volute in the Mark II howl and usions a contant-pamp impellet. The buril could also be shortened so that an existing short-shafl rotan element could be ured. I he cost of these modifications was catimated at 5104.000.

The effectiveness of the impeller teck vanes in reducine the fountain flow was determined. With an gas how to the bubble enemator. the rave of off tens Row from the bubble separator was about I liker min when the water level was below the cencertione of the pump volute and a few tenths of a liter min at levels

\begin{tabular}{|c|c|c|c|}
\hline & Parenorter & & \\
\hline \multirow{8}{*}{ ind } & mant. & Ise & 330 \\
\hline & $n$ onte. $m^{2}$ & 1.53 & 15 \\
\hline & $.00 m$ & 1770 & $\begin{array}{l}1500 \\
75\end{array}$ \\
\hline & ses & 0.10 & 0.10 \\
\hline & was & 0.41 & 0.41 \\
\hline &, 10 & $x$ & 32 \\
\hline & & 2.6 & 0.5 \\
\hline & m. & as & .15 \\
\hline
\end{tabular}

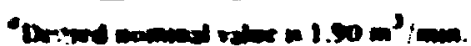

abou $100 \mathrm{~mm}$ abone the cencertine of the volute. This as though to be due to a reterse fountain fow mexting pes from the purep bow l into the bop.and in could indicole that the unpeller bect vanes are 100 kine. The uaket thow rake in the lountain area was $0.38 \mathrm{~m}$ min at a punp speed of $1503 \mathrm{rpm}$. besed on po-flow makrial balances in the punp lank. However. Anese kets do not provide information to dukerentale between fountain how and reverse lountaun now. Operation at lower pump speeds gave a lower fountain tow rate. This woold be expected for normal fountian fon because of the lower head developed. However. changine the spoed could atso allect the reverse fountain fow by changing the ratio of the punping efficiency of the beck vanes to that of the main inpeller lanes. : might be posstble to determine whether the tow is normal founain now

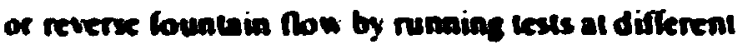
heads but at the same salf-punp specd or at duterent liquid levels in the pump tank.

Work restarked on lahrication of components required for solt operation wa: sopped hecause of the planned cermination of the MSR Program at the end of $f Y$ 1976. The kop has heen drained and put in slandly condition. and all records and parts have heen slored.

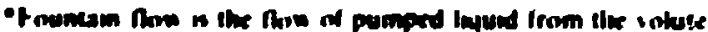

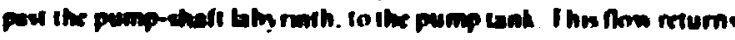

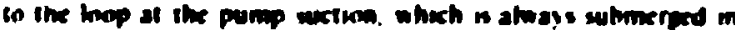

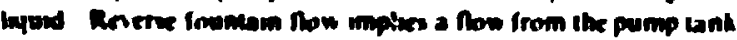

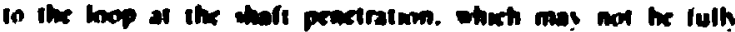

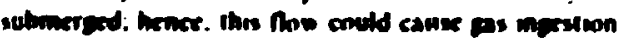




\subsection{COOLANT SALT TECHNOLOGY FACIITY}

\section{I. Smith}

I third transiem tritium addition test was completed th the end of Otoher 1975. The foup was then shut down w $1 /$ install a probe to miasure the parial pressure of hy drogen in the circilating salt. (2) rev ixe the ofi-gas sample system. and (3) install $a$ cinling-air somple system to measure pipe-wall permeatum. Operation of the bop was resumed in Janunn Ih. 1976. and a sleady-state tritum acdition test was started in tehruary 3. 1976. At the end of the report period. the steady-state test was still under way. and work on the tabrication of a second hydrogen addituon tube had heen started. Ihe firs tuhe. now in sen ice. developed a keak. which makes it unsuitable for use in subsequent ptanned tests. The data accumulated thus fat indicate that improvement is still needed in both the salt and air sampling procedures: efforts are being directed toward this end.

\subsubsection{Loop Operation}

The bop was in operation at the beginning of the report period, and operation cominued unt i lovemher 4. 1975. when the system was shut dow $n$ to make eyuipment changes related to the tritium tesis (Sect. 2.2.3). Operation was resumed on January 16. 1976. and continued throughout the remainder of the report period at sutc with other hasic hop operating conditions described previously. The operating experience with the off-zas cold trap continues to agree with the previous experience. "The off-zas system has operated without any sign of pluging indicating that the salt mist filter" is effective. As of 0000 on February 29. 1976. the loop had accumulated $\$ 67.3 \mathrm{hr}$ of salt circulating time since heing reactivated in Iecember 1974.

\subsection{Trition Tess}

A third transient tritium addition test (Test No. T3). similar to those described previously:" was started on September 16. 1975. Data for calculation of the amount of added gas are shown (Table 2.2). The tritium concentration in the salt declined to about backgruund ketels approximately $300 \mathrm{hr}$ after the addition was stopped. and the concentrations in the lwop off-gas continued to decline for several more days. A few additional salt and off gas samples were obtained during the next four weeks while experiments were performed to determixe the nature of the planned system modifications. The analyses of these samples showed no significant changes from earlier results. The CSTF was then : nit down on November 4. 1975. to make the modifications.

On january 27. 1976. an attempt was made to start a steady-state tritium addition test by pressuriving the tritium addition tube to an absolute pressure of $550 \mathrm{k}$ Pa. The test was discontinued when it was noted that the bypass into the vacuum annulus surrounding the tritium addition tube was about 1400 times higher than the rate which had heen observed during the previous tritium tests. Inder these conditions. the hydrogen by pass rate was about 14 times higher than the planned rate of input into the salt $144 \mathrm{~cm}$ : $\mathrm{hr} \mathrm{cs} 6$ $\mathrm{cm}$ hr). Tests indicated that the brpass rate decreased rapidly with addition tube pressuti. and at an absolutc pressure of $35 \mathrm{kPa}$. the kak rate was about the same magnitude as the permeation rate into the sale. A bypass rate of this sire would be toterable: so the steady-state test was started on February. 3. 1976. with a nominal absolute pressure in the tritium addition tuhe of $35 \mathrm{kPa}$.

The basic plan for the steady-state test is to add tritiated hydrogen to the circulating salt at d rciatively constant rate Inng ennugh for the tritium concentration in the salt and the rate of transfer of tritium to the two sinks folf-gas and permeation

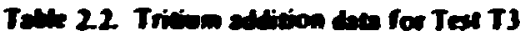

\begin{tabular}{|c|c|}
\hline 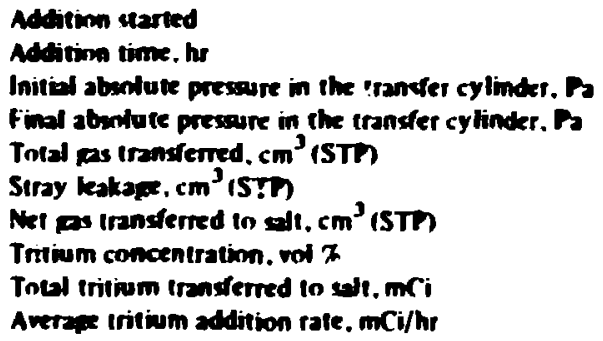 & $\begin{array}{l}0924.9 .16-75 \\
9.87 \\
1.37 \times 10^{5} \\
1.08 \times 10^{5} \\
30.8 \\
0.3 \\
30.5 \\
n .0615 \\
48 \\
4.9\end{array}$ \\
\hline
\end{tabular}


(hrough the salt pipe walls) to approach steady state. The absolute pressure in the addition tube is contrelled at an average value of about $35 \mathrm{kPa}$ by pressurizing to $42 \mathrm{kPa}$ and then repressurizing when the pressure has dropped to about $32 \mathrm{kPa}$. A $500-\mathrm{cm}^{\text {; }}$ volume was added to the addition-tube piping (Fig. 2. I) to reduce the absolute rate of prescure drop and thus permit operation for at least $24 \mathrm{hr}$ before having to repressurize the addition tube. The rate of pressure drop in the addition tube is coninually monitored. and these readings are used to evaluate the rate at which tritiated hydrogen is being supplied to the system. The rate at which tritinted hydrogen is being bypassed into the vacuum annulus is evahuated by periodically isolating an appended $1000-\mathrm{em}^{\prime}$ volume and noting the rate of pressure increase. The net rate at which tritiated hydrogen is being added to the circubting salt is then the difference between the total addition rate and the rate of bypass into the vacuum annulus (in the absence of other leaks). The net input of tritium into the system is determined from the input gas rate and the tritium concentration of the in; out gas. which is determined by collecting periodic samples of the input gas for analysis by mass spectrometry.

The outhow of tritium in the off-gas stream is determined. as in the previous transient tests. by sampling the off-pas stream. To estimate the rate at which tritium permeates through the salt pipe walls. samples of the ait from the lower loop cooling duct are baken. and the air flow from the duct is measured. The atio of the total permeation rate to the permeation rate into the cooker is assumed to equal the ratio of the respective pipe surface areas. The inventory of chemically combined tritium in the sate is determined by sampliag the salk. wite the concentation of elemental tritium in the salt is inferred from readings taken on the bydrogen pressure probe (Sect. 2.2.3). Independent estimates of the elemental tritum in the salt are also inferred from the concentration of elemental tritium in the off-zas stream and from the rate at which tritium is permeating the salt pipe walls.

The status of the steady-state test at the end of the report period. at which time the test was still in progress. is summaried as follows:

1. As of 0300 on Februar: 29. 1976. the steady-state test had been in progress ior $622 \mathrm{hr}$.

2. The concentration of the addition gas was about 5700 ppm tritum. the net rate of gas input to the salt was about $1.8 \mathrm{~cm}$ (STP) hr, and the rate of tritium input was atuut $26 \mathrm{mCi}$ hr.

3. During the initial phase of the test. samples were taken at about 2-hr intervals. After the tritium concentrations started to kvel off. the sample freyuency was reduced to three pet day.

4. The salt sample results showed considerable scatter. and biork is in progress to determine if this is caused by the sampling procedure.

5. The tritium kevel in the air samples from the loop cooling dust varied randomb between about 0.3 and $0.8 \mathrm{pCi} \mathrm{cm}^{\circ}$. This concentration is near the limit of sensitivity of the analytical method being

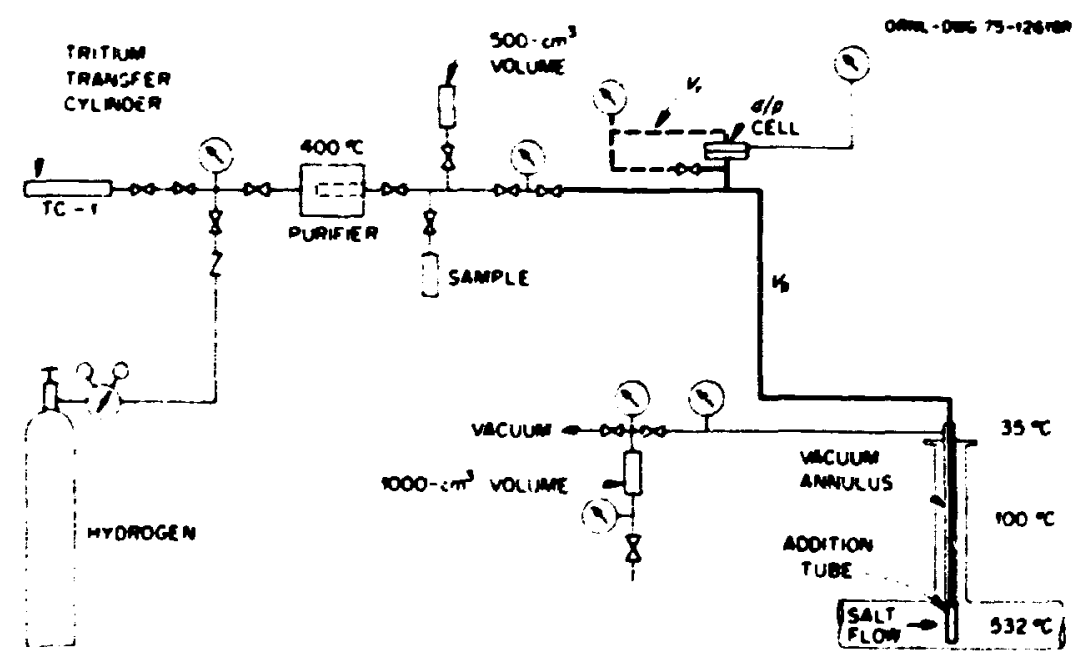

Pie 2.1. Trithom adition syatem In CSTP. 
und. and varwous schenes are beine consinkred for increasing the trivinan concemetion. sech as roducing the cooling-aic thow ans raving the concentration of trition in the addition gas.

6. The dala from the hydrogen partial-presenre probe indicate that the pantal pressure of eteraceneal hydrogen in the salk is yuite bow thess than $10 \mathrm{ma}$ Hgl. which is generally in agrecencent with the bow concentration of tritium found in the cooline -air amples and abo with the concentrations of elenental tritium found in the off $p$ anples. Phas are being made to verify the hydrogen pressure probe readiats by using a mestespectromener leak detector macthibe.

Test resules are discussed in Seet. 1.1.3.

At the end of the report period. the irivion levets in the sat. off-as and cooling air appeared to be at stendy state. The pha is to cominue the test bone enou h to examine varions scticanes for improving or verifying the data for tritivan concentration in the cooling air and in the salt and to provide better estimates of the tritium material balance. Irapping efficiency. and mass-transfer processes. In the mantiane. a new tritium addition lube is being Gbriated for sulsequem tests. These will be decigned to show variations in inpping efficiency as a function of the pas addicion rate and the presence of chemical additines in the salt.

\section{Eqpipated Modifentions}

During the loop shutdown beginning November 4. 1975. the test equipment was changed to improve the yuality of the data and to provide additional data. The following is a summary of the changes:

1. Hydrugen Prexurure Prohe. A probe was inserted in the main salt stream at a point about 1.25 m downstream from the salt pump discharge to measure the parial pressure of elemental hydrogen in the salt. The probe consisted of a sealed Hasielloy $N$ tube. $12.7 \mathrm{~mm}$ OD $\times 1.1 \mathrm{~mm}$ wall. connected to the necessary valving and instrumentation to permit pressure readings inside the probe in the range of 0.01 to $100 \mathrm{~Pa}(0.1$ to $1000 \mu \mathrm{m} \mathrm{Hg}$ ). Since this probe is completely submerged in salt, its response should depend only on conditions in the salt.

2. Off-Gas Sample Sristem. Several changes were made for the purpose of improving the reliability of the sample system and the quality of the sample data: (a) A salt mist filter was fabricated from porous copper sheet (made from pressed and sintered copper puoderl with a porosedy of 0.23 and a pore hydraulw radus of $6.0 \mu \mathrm{m}$. I he fihet. hurued in a Hascelkn I bud. oas installed at the inlet to the ges sample link with a heafet and monlation to permit cperatum ist SM $C$ and as oriented weth that trapped alt coukd drain back to the off-eas line (h) A 3-wa! Monel value ons insealled in phoce of lhe 3-way glass stoproct isendiatety upstram of the firse tritum pretrap. The glas wait had wome kakage and condensation of mid and ato was mot suited lor operation at the higher temperature non heing used. (c) The tewiperature of the eas coaple line Irom the salt mist filier to the inlet to the first urstum pretrap was increased from 150 to 200 C. This change was 10 mianinive the condensation of funds in the gas sample bine. Such nuids. collected in the sample lines. were probaby parth rexponsible for sotuc earliet erratix saiple resules.

3. Erhoust-Air Sompte Sistem. Eyupment was installed for collecting samples that can be used to eximale the rate at which tritium is being bos duc (I) permeation through the bop pipe walts a sample up eas installed in the air line coming from the bover bop cooline duct (fig. 2.2); this lap was connected to a diaphragm pump that circulates sample gas at a rate of about $1700 \mathrm{~cm}$ min and vents the pas into the loop enclosure. At the pump discharge. where the pressure is controlled at an absolute pressure of 140 KPa. a $100 \mathrm{~cm}$ min side seream is Laken off for tritium trapping. The sample stream is mixed with 20 $\mathrm{cm}$ " min of humidified helium. and the combined streams are passed through a CuOfumace to convert the tritium to tritiated water and then through a water trap and a cold trap to collect the tritiated water. The tritium content is determined by scintillation counting in a manner similar to that used for the off-gas samples. The air intakes to the lower cooling duct were extended so that the air is drawn from outside the loop enclosure. thus avoiding contamination of the air samples by extraneous tritium which might be in the enclosure. The flow of air through the cooling duct is determined by sampling the air stream whike adding a known flow of tritium to the air inket

In the original design of the tritium addition system. a vacuum pump maintained a low pressure (less than $75 \mathrm{~Pa}$ ) in the vacuum annulus surrounding the addition tube. The discharge gas from the vacuum pump was vented into the lonp enclosure and was eventually discharged to the stack along with the loop ventilation air. Thus the air exhausted from the loop enclosure nomaliy contained a small amount of tritium from the vacuum annulus in addition to the tritium that permeated thrnugh the loop pipe walls. 


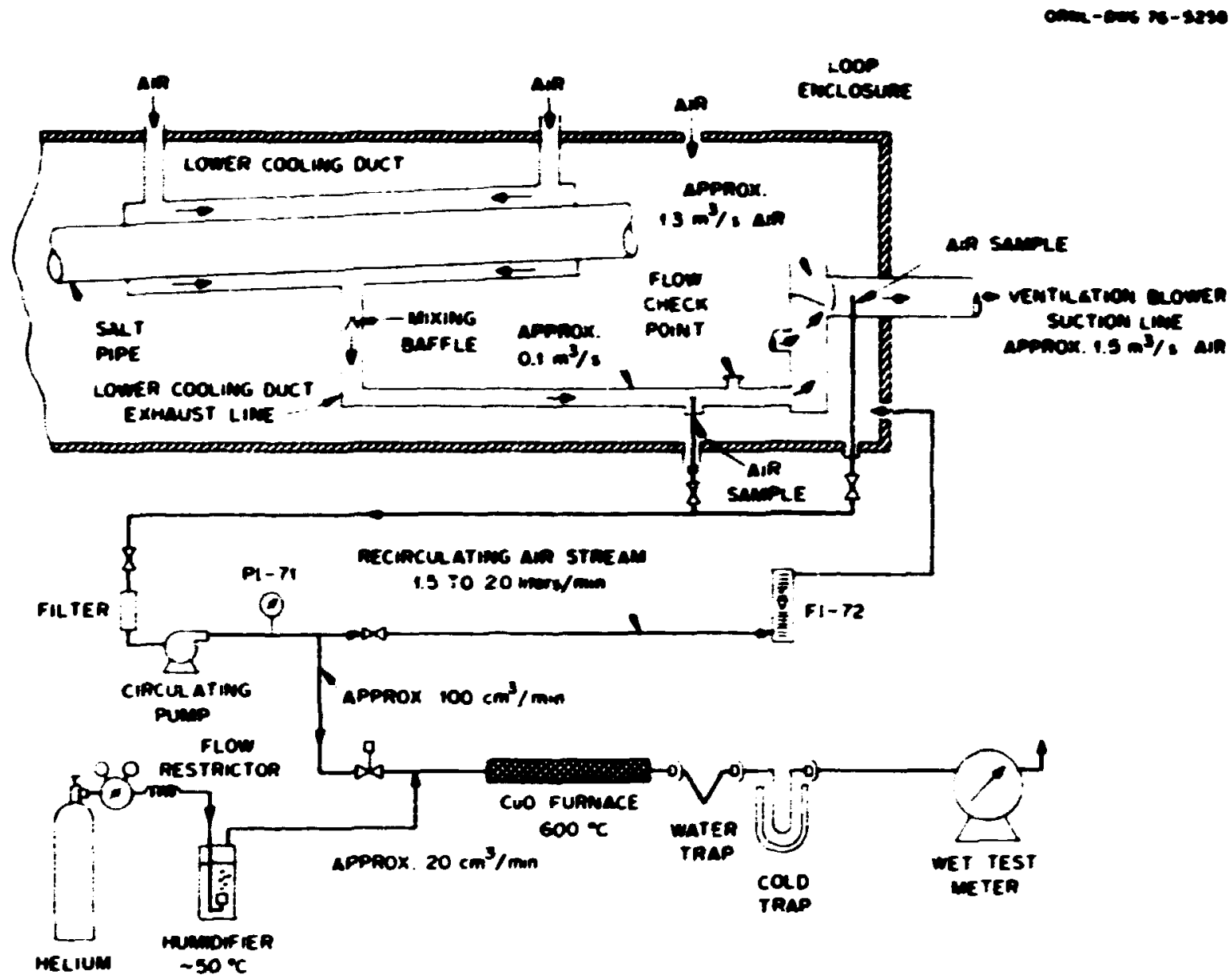

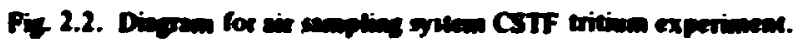

During the steady-state test. (Sect 2.2.2). the amount of addition gas which is bypassed into the vacuum annulus is about 10 ' higher than was the case curing the earlier transient tests. This extra tritium must be kept out of the loop enclosure because extra tritium there would interfere with the evaluation of pipe-wall permeation from the tritium content of the loop exhaust air. Therefore. shortly after ine steady-state test was started. a new line was instalked to route the vacuum pump exhaust around the loop enclosure and directly to the suction of the stack fan.

\subsection{FORCED CONVECTION LOOPS}

\section{W. R. Huntley R. H. Guymon} M. D. Silverman

Operation of forced-convection lnops is part of the effort to develop a satisfactory structural alloy for molten-salt reactors. Corrosion Inop MSR-FCI.-2h is presently operating with reference fuel salt at typical MSBR velocities and temperature gradients to evaluate the corrosion and mass transfer in Hastelloy $X$ albys. At this tume. the loop has operated approximately $\mathbf{4 0 0} \mathrm{hr}$ with fuel salt at MSBR reference design conditions with the expected low corrosion rates in the standard alloy. A test has heen started to obeain corrosion daca on specimens of Hastelloy $\mathbf{I}$ containing Ir; niobium.

Construction of two additional corrosion loop facilities. designated MSR-FCL-3 and MSR-FCL-4. continued for most of this reporting period. but this effort has been discontinued because of the decision to terminate the MSR Program at the end of FY 1976.

\subsubsection{Operntion of MSR-FCL-26}

A 4000-hr corrosion test was completed on Ocinber 2. 1975. in which standard Hastelloy $X$ 
specioncus were exposed to fuel sah at typical MSBR operatiag temperatures. Dariag the kest. 18 corrosion specianens were exposed to salh at velocities up to $\mathrm{S}$ in sec at throe different exipperature levets S6S. 635. and 705.C. As expected. corrosion rales were bo throughout the lest period and <3 um year 10.1 mil year) duriag the fral 1000-hr increment of the les. A detailed diverusion of the corrosion results is presened wader Salh Corrosion Siudies (Sect. 6.6).

On October 6. a series of . Vif: addinions to the loop salh was begen to increase the $U^{40} U^{10}$ matio. It was

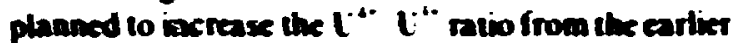
equmibrium salue of abour 100 to a new bevel of aboux INOS and then to evaluate corrosion mites at the higher ket. which reflects a more axidizing condition in the salt. The Nif: was added by dropping small pellets of Vif:-fuel carrier salt (50-50 "I Ti from a sealed aur lock. via a ball value and riser pipe. to the fucl-salt surface within the auxitian: puusp tank. During the additions. the loop was operated isothermally at $\sim 695^{\circ} \mathrm{C}$ with a pump specd of $4000 \mathrm{rpm}$ to provide a sah flow rate of ahour 12 liters min. Four separate additions of 0.8 \& of Vif: were made between October 6 and October 21. followed by a final addition of $1.6 \mathrm{~g}$ on . Vovember 3 . 1975 (4.8 \& toval addition to the 14tkg salt inventory). The work was inkernupted at this time by operational problems. but the limited obsenvations made are described below.

The effects of Nif: additions were simitar to those observed in September and Oetober 1974. "when fine Nif: powder was added to the salt inventory of $\mathrm{FCL}$. 2b. Immediate pump-power increases of 8 to 10\%, were apain noted with each $0.8-2$ addition. The salt ketel in the auxiliary tank decreased with each Nif: addition. which surpests that Nif: affected the salt surface tension and may have thers:by reduced helium ingassing in the pump bowl. During the first four NiF: additions of 0.8 s each, the sall kevel dropped about $\mathbf{l}^{\prime}$ : $\mathrm{mm}$ immediately after ach addition. A $I^{\prime},-m m$ kvel change represents an apporemt salt density increase of about 1\%: therefore. density change of the pumped salt should account for onty about one-tenth of the pump power increases noted. and the remaining power increase is believed to be due to increased dras forces on the pump impeller. The final addition of $1.6 \mathrm{~s}$ of NiF; resulved in a $14 \%$ increase in pump power and a barger-than-expected level drop of $12 \mathrm{~mm}$ at the auxiliary tank.

Each Nif: addition to the salt resultec in an immediate increase in the $U^{\circ}, U^{\prime *}$ matio. which reached a maximum in a few hours. followed by asymptotic decay; c.g. the first addition increased the ratio from $\sim 100$ to $>1000$. bat afker three dajs of inotivermal operation at cos C. the ratio had decreased to 130. Similarty. the fourth addition increased the patio from $\sim 250$ so 10.000 . bue in had dropped to 200 afier eigted days. Juas prior to the fral

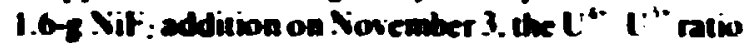
was 150. T wo hours aflet the 1.0-g addition. the ratio was $2.6 \times 10^{4}$. and a day beer the ratio had iallew to $4.8 \times 10^{\circ}$. No further readians were obuained because of a elt berk in the pipiag system which orcurred on tovember 5. 1975. The phan to rua a corrosion test at a high $\mathrm{C}^{\mathrm{A}} \mathrm{L}^{\text {'t }}$ ratio was abaadoned at this tiene.

The loop did not accumalace any significam operating time between November S. 1975. and Fetruary 18. 1976. because of sall leaks that occurred on November 5 and December 10. 1975. Both leaks resulted from tube rupures durine reheating operaicons immodiateh afier transfier from $I T$ wo isothermal operation of the bop.

Sall freezing had atways occurred in ithe coolers of $\mathrm{FCl}-2 \mathrm{~b}$ after a bop scram" because of the laree mass of air-cooled metal within the cooker housing and the rebtivehy small mass of hot solh within the cooker coils. This had not caused significant probkems during the past $20000 \mathrm{hr}$ of operation. other than delaying resumption of sah circulation for a few hours whike gradual remething oceurred. However. in each of the two recent shuldowns where lakage occurred. salt froze in ancther portion of the loop not monitored by a thermocoupte. in addition to the known freezing in the coolers. Since the second frozen area was not apparent to the operators during either incident. nomal operating and remelting procedures were followed which resulted in salt liquid expansion and pipe rupture bet ween the froren cookers and the unsuspected salt plus.

The salt leak of November 5. 1975. occurred in a resistance-heated section of the loop piping ( $r R$ heater No. 2). The location and cause of the frozen area which precipitated this faijure are not definitely known. but the cold spot was probably at metallurgical station Yo. 2. The sall leak of December 10. 1975. occurred at metallurpical station No. 3. where an adapter (for line SO8) is saddk-welded to 19-mm-OD $\times 1.8-\mathrm{mm}$-wall tubing. The cause of the frozen area retated to this keak was a $10-\mathrm{cm}-\mathrm{tons}$ uninsulated portion of a salt drain line (S-112). Insulating this portion of line had been overlocted during prior

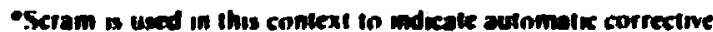

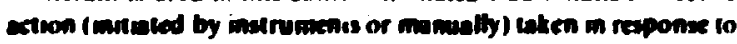

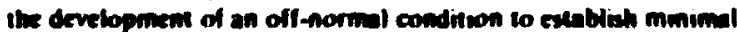
sable oprratien conditions.
} 
repair uperatioms because of pipare complexity and inaccessibilin!.

Sicieral desizan modifico.ions nere made to the hxop to reduce the likelihosin if further uncudents of this Iype. Ithe scram circuits were revised to provide continuous salt-pump operation at a reduced speed of $2000 \mathrm{rpm}$ atter each xram instead of the previcus procedure. which sippped the pump. This provides more heat enere! to the cooled metal within the coubler hursing in the thw ing salt. Also. the cooker housing was modified by adding internal thermal insulation and electric heaters to reduce the mass of cold metal in which the valt-coataining cocker coil can transter heat. Thirdls. an automatic solenoid valie was added to turn off auxilian cooling air to the resistance-heating lugs on the main heaters atter a wram or whenever the main heaters are deactivated.

Pipine replacement and modification were necesa.y after each of the $($ wo incidents of salt kakage. The entire kngth of the seandard Hastelloy resistance-heated section ( $f R$ heater $N$. 2) was replaced. as well as metallurgical station Vo. 3. Drain lines nere replaced because of damage from salt running down the exterior tube surfaces from the kakage areas above. All three 6.3-mm-OD drain lines were replaced with 9.5-mm-OD lines because the original lines were too small and had hampered operation and repair functions. A new. larger standard Hastelloy I filt-and-irain tank was also instalked because the original tank had a marginal capacily.

The loop repairs and modifications were completed in Februany 1976. and $20.25 \mathrm{~kg}$ of new fuel salt mixture was transferred to the new Hastelloy $V$ idrain tank. The oit was sampled after transfer into the drain tank. and impurity levels were found to be low. which indicsted that the new salt was in good condition.

The loop piping was filled with salt on February 18. After the salt circulated isothermally for $3 \mathrm{hr}$. the oxidation potential of the salt was measured electrochemically and found to correspond to a $\mathrm{U}^{4 \cdot} \mathrm{U}^{\text {1* }}$ ratio of about 4600 . The $\mathrm{U}^{4 *} \mathrm{U}^{70}$ ratio dropped rapidly, as had been the previous experience. and decreased to a value of about 500 after 1 wo days' operation at design conditions and full $\Delta T$.

A scram lest from $\perp T$ operation was made to verify that the recent design modifications would prevent salt from freeting in the cookers. The test was successful and showed tha: the original scram circuits functioned and that the newly added automatic feature worked as planned: that is. the pump speed reduced from $\mathbf{4 0 0 0}$ to $\mathbf{2 0 0 0} \mathrm{rpm}$. the guard heaters on the coulers were deenergared. and the cooling air on the resustance-tieater lues was cut off. Because of the new desiga modifications, the salt continued to flow at a reduced rate aftet the sctam and the isothermal circulating satt temperature fell to only $565^{\circ} \mathrm{C}$. which is comidered a sefe kvel above the sale liquidus temperature of $500 \mathrm{C}$.

At the completion of the scram tests. 18 new corrosion specimens were installed in the three metallungioal sample stations. The corrosion specimens are falericated from modified Hastelloy $Y$ containing Ir; niobium. instead of the standard Hastelloy. $I$ specimens tested previoush in FCL-2b. After the specimens were inserted. the hop was uperated isothermally at about $700 \mathrm{C}$ over the weekend and was brought to design $\triangle 7$ conditions on February 23. Operation is continuing. and removal of the currosion specimens for their first examination is planned after $\mathbf{5 0 0} \mathrm{hr}$ of $\perp T$ operation.

\subsubsection{Heat Tonefer Sondies in MSR-FCL-20}

The heat transfer performance of the fuel salt proposed for an MSBR (LjF-BeF-ThF -LF : 7I.710-120.3 mole $r_{\text {) }}$ ) was measured in one of the resistance-heated sections of MSR-FCL-2b. Heat transfer data were obtained over the following range of variables: Reynolds moduli, IS40 to 14. 200: Prandil moduli, 6.6 to 14.2: heat fluxes. 142 to 630 $k W \mathrm{~m}$ : salt velocities. 0.5 to $2.5 \mathrm{~m}$ sec: and fuid temperatures, 549 to $765^{\circ} \mathrm{C}$.

Film coefficients ranged from 1.32 to 11.8 $\mathrm{kW} \mathrm{m}^{-}-\mathrm{K}$ at Nuscelt moduli of $1 /$ to 102 . There was satisfactory agreement with the empirical SiederTate correlation in the turbulent region at Reynolds moduli from $\sim 8000$ to 14.200 (Fig. 2.3). Between Reynolds moduli of $\sim 2100$ and 8000 , the experimental data follow a modified Hausen equation." which is normally applicable to the trnsition region between laminar and turhulent now. The extended transition region is probably due to the high viscosity and large negative temperature coefficient of viscosity of the fuel salt. Hydrodynamic stability theory predicts the possibility of such an extension when heat is transferred from a solid interface to a fuid whose viscosity decreases with temperature. Insufficient data were obtained in the laminar flow region to allow any conclusions to be draw. The results of these experiments are similar to those obtained in FCl.-2 with coolant salt" (NaBF-Na F: $92-8$ mole $\%$ ) and indicate that the proposed fuel salt behaves as a norimal heat imanser nuid. 


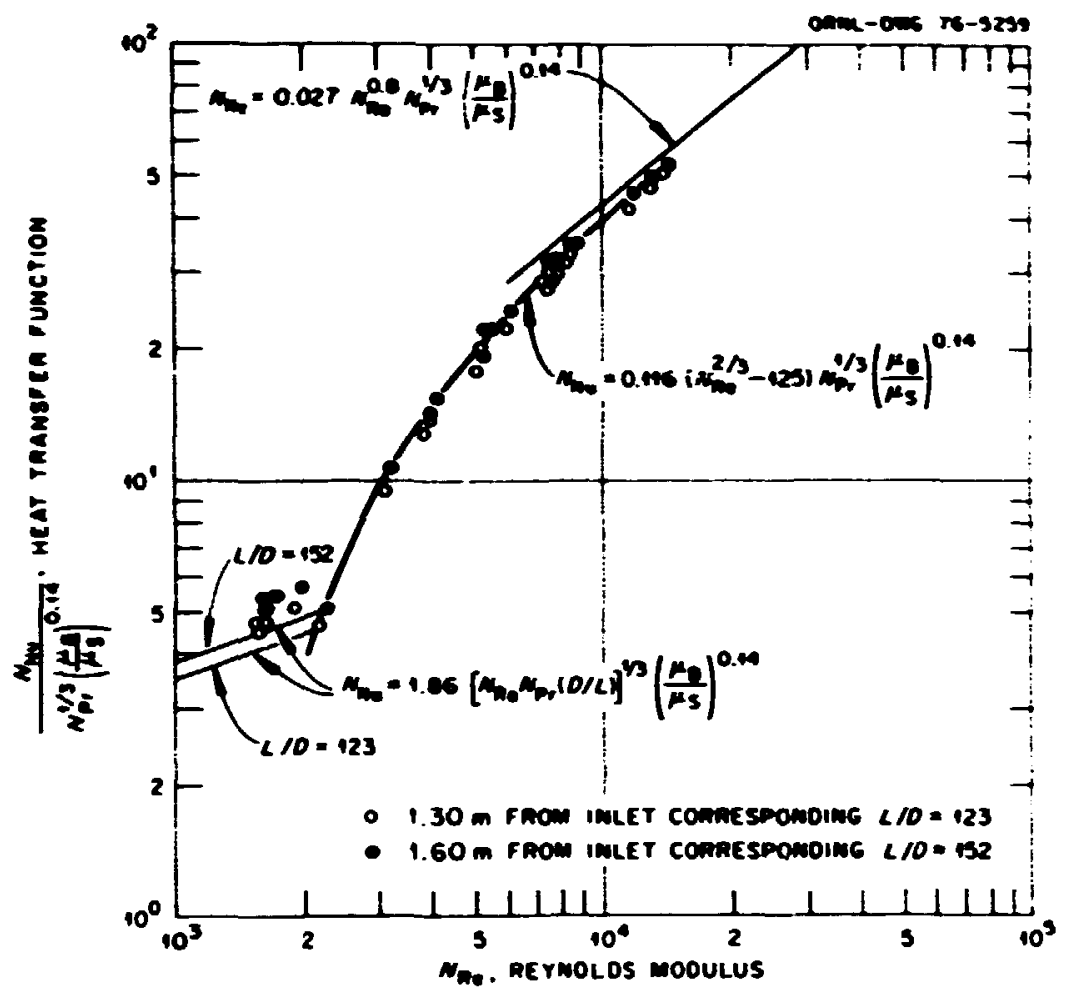

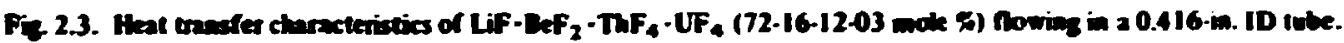

\subsubsection{Design and Construction of FCL-3 and $\mathrm{FCL}-4$}

All components for FCL-3 and FCL-4 are on hand except the finned-cooler sections. which were to be fabricated of titanium-modified Hastelloy $\mathbf{V}$ tubing. Components received during this report period inclusie the resistance-heater lugs. koop shielding. two ALPHA-pump bowis. FCL-4 control paneis. and parts for four ALPHA-pump rotary assemblies. Assembly of the electrical power supply and auxiliary piping for FCL-3 progressed as far as practical in the absence of tubing for the solt loop. Assembly work on FCL-4 electrical power supplies and auxiliary piping was continued for most of this reporting period. However. the $\mathrm{FCl}-4$ assembly work has . ow been stopped because of the decision to terminate the MSR Program at the end of FY 1976.

\section{REFERENCES}

I. R. H. Guy mon and G. I Mạ̦s. USR Prongrum Srmwnnu. Prong. Rep. Auge. 31. 19:5. OR.XI.-S07x. pp $16-22$

2. A. G. Girindell et al.. MSk Progerem .Semeormu. Proger. Ror 4ux. 31. 19\%1. OR.VI.472x. p. 35 .

3. A. S. Smith. MSR Program Semuannu. Proger. Rep terg JI. 197. 6RNI-S07\%. pp. 22-23.

4. Ret. 3. p. 23.

5. A. X Smith. HSR Program Semuennu. Pringr. Rep. Fro. 2x. 1975. OR.XI.-S047. p. 27.

6. A. X. Smilh. GSR Program Semionnu Progr RTP Aug. Il. 1975. OR.VI.-507\%. pp. 24-25.

7. F. X. Sieder and (i. F. Iatc. Heat Iransler and Pressure

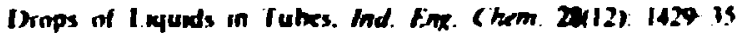
(10.4).

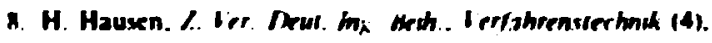
pp. 91 9\% (1943).

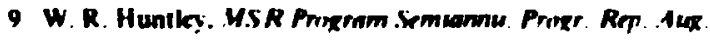
J1. 1071. OR.VI. $472 \pi$. P. 152. 


\section{Part 2. Chemistry}

\section{M. Ferris}

Chemical research and development related to the design of MSBRs have concentrated on fuel- and coolant-salt systems chemistry and the development of ana!ytical methods for use in these systems. This work is presently being phased out along with the rest of the MSR Program.

I he chemistry of tellurium in fuel salt has been emphasired because this ekment is responsible for the shailow intergranubr cracking of Hastelloy $\mathbf{X}$. Preliminary measurements of the solubility of Li:Te in molten Li:BeF, confirmed the expected low solubility. High-temperature spectroscopy was used to study the hehavior of tellurium species in molte. Lif-Bet: mixtures. The results of these studies are in agreement with the masured low solubility of Li:Te. and they show that the soluoke species can probably the represented as $\mathrm{Te}_{n}$ ". Spectroscopy was also used to determine the equilibrium tellurium pressures for the reaction 2L.iTe: = Li:Te + ":Te., but the method could not be used for similar studies with nickel and chromium iellurides because of their ven low dissociation pressures in other spectroscopic work. eyuilibrium quotients for the reaction (IF, (d) + $': H:(g)=U F_{1}(d)+H F(g)$ were determined in I.jFBeF: mixtures and in MSBR fuel salt. Lif-BeF:ThF, (72-16-12 mole $\left.r_{i}\right)$. The values obtained generally are in agreement with those obtained previously by other workers using a different method.

Electrochemical studies of lithium tellurides confirmed the low solubility of both 1.i:Te and l.iTe: in $\mathrm{l} . \mathrm{iCl}-\mathrm{KCl}$ eutectic at $400^{\circ} \mathrm{C}$. iut they did indicate that an oxidant such as water rapor could generate more soluble and celored species.

Work on several aspects of coolant-salt chernistry was continued. It was shown that $\mathrm{Na}_{3} \mathrm{~B}_{3} \mathrm{~F}_{4} \mathrm{O}_{\text {; }}$ is the stabk oxygen-containing species in the system Naf$\mathrm{YaBF}_{4}-\mathrm{B}_{2} \mathrm{O}_{1}$ at low ciygen concentrations. This compound reversibly intercomerts with $\mathrm{NaBF}_{3} \mathrm{OH}$ in aqueous systems. a situation which is probably also the case in the coolant sait. Based on this assumption. a plausible mectanism for trapping tritium from an MSBR in NaF-NaBF, coolant solt has been postulated. Vapor density studies of the system BF $-H_{2} O$ were also continued. It was shown that $\mathrm{BF} ; \cdot 2 \mathrm{H}_{2} \mathrm{O}$ is completely dissociated in the vapor phase at temperatures above about $200^{\circ} \mathrm{C}$. Below $200^{\circ} \mathrm{C}$. association occurs. and a stable liquid phase can be formed.

Monitoring of $\mathrm{l}^{\text {s. }} \mathrm{C}^{\circ}$ ratios in several forcedconvection loops. thermal-convection loops. and creep-test machines was continued. Data were obtained during the third tritium injection experiment at the CSTF The results were similar to those from the first two experiments in that most of the tritium was found in a water-soluble or combined form. Electroanalytical studies indicated that LiTe: and $\mathrm{Cr}_{\mathrm{T}} \mathrm{Te}_{\mathrm{e}}$ are insoluble in MSBR fuel salt. Cathodization of a tellurium electrode in the presence of fuel sals appareritly produced a species of the Ispe $\mathrm{Te}_{\mathrm{e}}(n \geqslant 1)$. which was unstable under the experimental conditions. Some evidence for oxide and or peroxide species was obtained in other electrochemical studies. 


\title{
3. Fuel-Salt Chemistry
}

\author{
A. D. Kelmers
}

\section{I SOLUBILTYY OF LITHIUM TELLURIDES IN FLUORIDE MELTS}

\section{Y. Vakntine A. D. Kelmers}

It has been demonstrated that fission-product tellurium is the agent responsible for the shallow intcrgranular cracking of Hastelloy $\mathbf{X}$ surfaces which was sbserved in the MSRE: However. the state or states in which tellurium is actually present in the LiF-BeF:-ThF + - CF + (71.7-16-12-0.3 mole $C_{\text {i }}$ ) fuel sai: under reactor operating conditions remains to be determined. The lithium-iellurium system was the first to be investigated. The two species that are known to exist in the Li-Te system. Li:Te and LiTe. have been prepared. ' Li Te: undergoes disproportionation to Li:Te and Te quite casily ${ }^{3}$ and thus does not kend itself to dynamic so'ubility measurements. On the other hand. Li:Te is quite stable and was used here to make the first tellurium solubility estimates. Molten Li:Bef, was used instead of the thoriumcontaining fuel salt since the density of Li:Te (3.4 $\left.\mathrm{g} \mathrm{cm}^{\prime}\right)$ is similar to the density of the fuel salt 13.75 $\mathrm{g} \mathrm{cm}$ ). However. Li:BeF, has a density of $2.2 \mathrm{~g} \mathrm{~cm}$. which is probably sufficienth different from $\mathrm{L}$ : Te to prevent the suspension of Li:Te particulates in the melt.

The solubility study was carried out in a closed nickel vessel completely lined with POCO-AXF-SQ graphite. The various parts are shown before assembly (Fig. 3.1). Openings in the graphite liner lid accommodate a thermocouple (TC) well and a sparge tube, both ' SQ graphite. The TC well and sparge tube were joined to the top of the nickel pot ty brazing a tantalum ring hetwea the graphiteand the nickel pot. Design of the graphite pirts and the graphite-Ta-Ni joint was contributed by H. C. Cook of the Metals and Ceramics Division. The brazing techniques werc developed by J. F. King of the Welding and Brazing Laboraiory. Metals and Cernmics Division. This type of joint is reported to withstand temperatures up to IISOC $\mathrm{C}^{+}$It has been in continuous use in this experiment for many weeks over a temperature range of $500^{\circ} \mathrm{C}$ to $800^{\circ} \mathrm{C}$ without showing signs of failure.

Two stainless steel ball values wel "ad to the lop of the pot allow samples to be laken with filter sticks. The filter sticks were also made of POCO-AXF-SQ graphite. A screw cap on the end of each filter stick bolds a graphite frit disk in place. The pore size of the frit is about $150 \mu$. The filier stick. frit. and serew cap are shown in the foreground of Fig. 3. $i$. The filter stick :" it.-OD. '(n-in-ID) was found to be extr.mely strong. An enlarged chamber behind the frit holds the sample. The filter stick is admitted to the melt through a Tefon sleeve above the ball vahes on the pot top. A Swagelok fitting is used around the filter stick. allowing it to pass imto the pot ttrough a closely fitting Teflon slecve. In addition, an overpressure of argon is maintained while the filter stick is being lowered into the melt, assuring that contamination of the melt from ingress of air does not occur.

Enrictied $\left(95.07 C_{C}\right)$ ':Te was purchased from Isotope Sales Division. ORNL. Irmdiation of this isotope in the Bulk Shiciding Reactor for $48 \mathrm{hr}$ produced ": Te haviny a half-life of 117 days. This isotope emits a 159-keV gamma ray suitable for counting with a lithium-drifted gemanium detector. The ":imTe was melted with natural tellurium (purity 99.999+ we (from Alpha Ventron Products Co.) in a tungs:en erucible. The tracer-bbeled tellurium (Te*) was then used to prepare Li: Te* in the same tungsten crucible by meting the lithium on the surface of the Te and slowly raising the temperature until reaction occurred. The Li.Te product was then ground and sintered to evaporate any excess reactants and bottled for removal to the sunn. "I facility. The dilutic.n and subsequent preparation $f L_{i}, T^{*}$ were carried out in an argon atmosphere vacuum box equipped with a heater designed especially for use in vacuum boxes.

After the vessel top was welded into place. the empty vessel was installed in the vacuum-argon system and heated under vacuum to $800^{\circ} \mathrm{C}$ to test the weld joints. The graphite parts had previously been outgassed at $1000^{\prime} \mathrm{C}$ for $24 \mathrm{hr}$ under vacuum. The evacuated vessel was then tmanferred to the argon atmosphere box, where it was loaded through the ball valves with Li,Te followed by Li, BeF s. The vessel was then replaced in the argon-vacuum system and heated while maintaining a $50 \mathrm{~cm}^{3}$. min argon sparge flow. The fumace temperature was controlled by an Electromax $\|$ controller to $\pm 1^{\circ} \mathrm{C}$. The entire assembly is shown in Fig. 3.2.

*I he frit was supplied by S. M. Robhins. Metals and Ceramics Division 


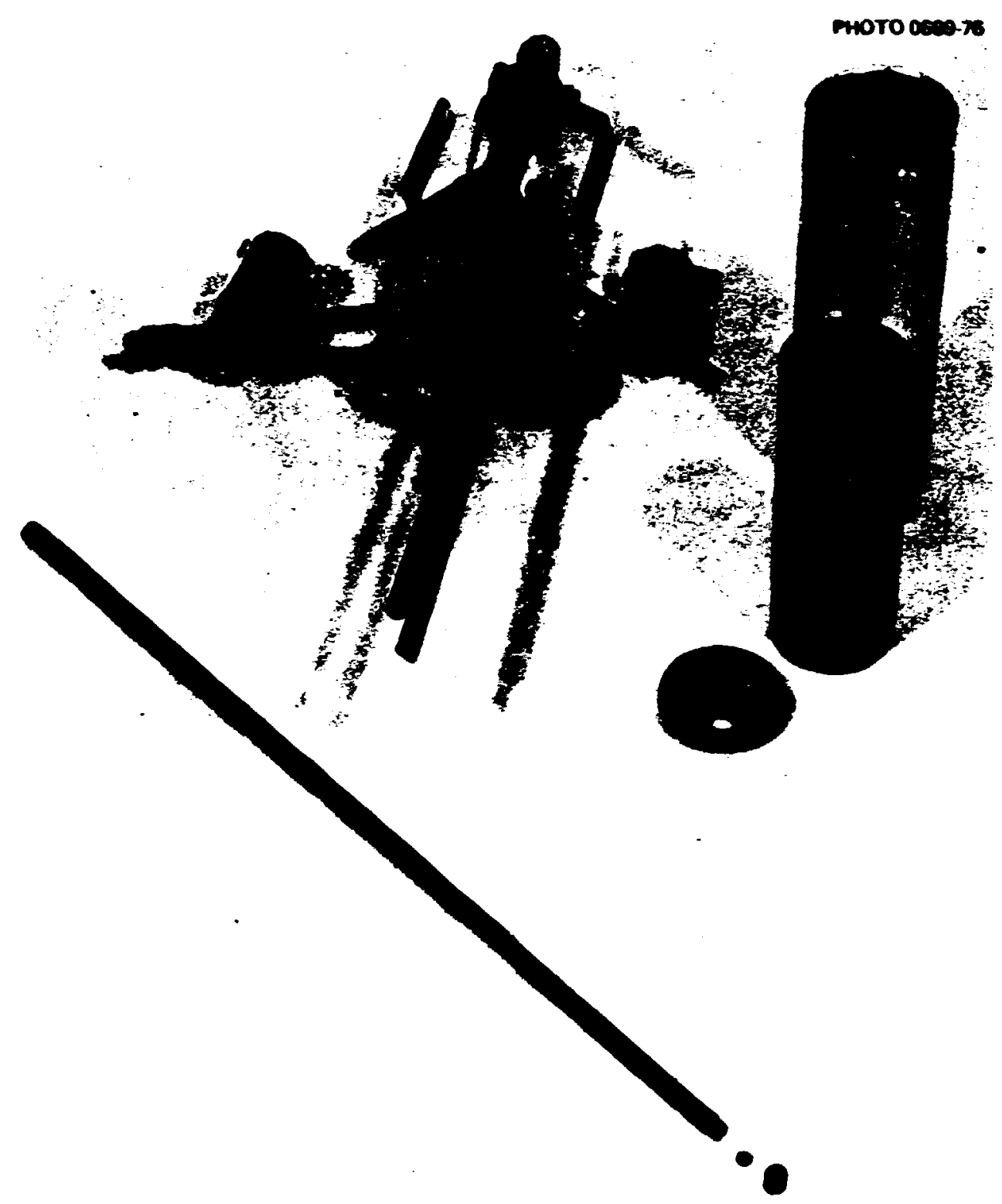

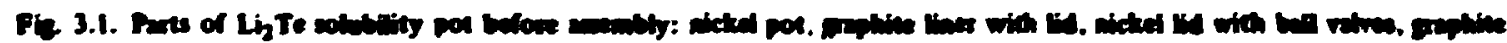

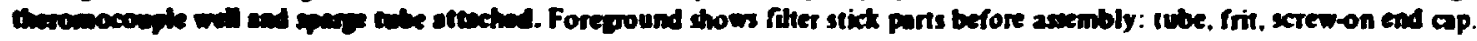

Samples were taken at temperatures between $500^{\circ} \mathrm{C}$ and $700^{\circ} \mathrm{C}$. No wetting of the graphite by the salt occurred. and ihe filter sticks could be withdrawn smoothly. After a sample had been taken. the filter stick end cap was unscrewed, the frit removed, and the body of the filter stick encapsulated under vacuum in a quartz tube. The tube was then heated in a furnace to about $750^{\circ} \mathrm{C}$. allowing the sample to flow by gravity into a quartz. cup in the bottom of the tube. The sample did not adhere to the quartz; 30 uniformly shaped sample buttons were produced which were then weighed and counted.

The 159-keV gamma mys from the ${ }^{123 m}$ Te tracer were detected with a high-resolution lithium-drifted germanium detector (10\% relative efficiency). A DDP-11/05-based pulse-height-analysis system was used to acquire the energy spectra and subsequently 


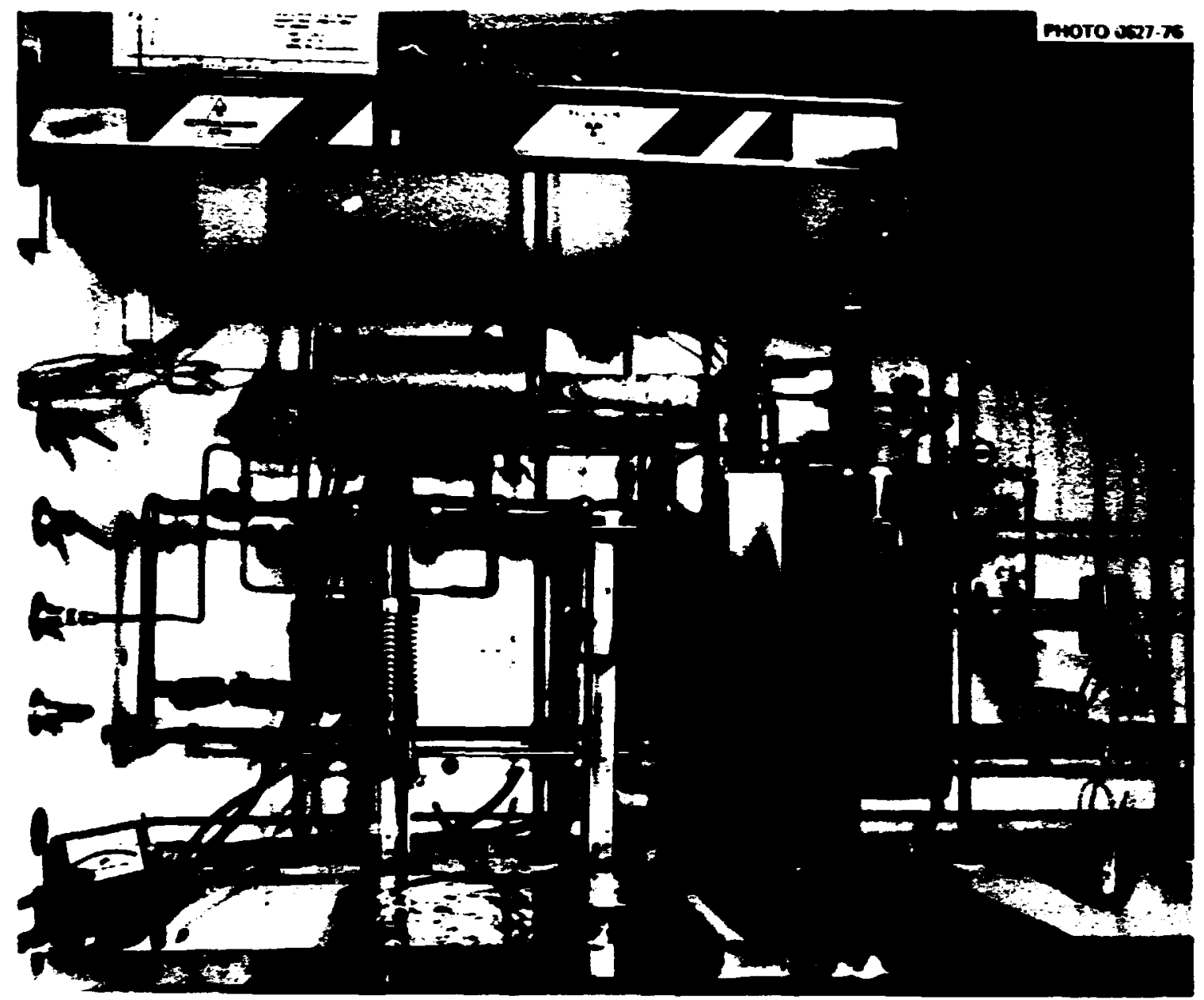

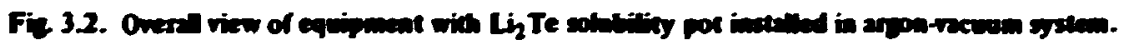

In perform yuantitative isotopic analyses." The first few samples were counted at two source-to-detector distances $10 \mathrm{~cm}$. directly on the detector endcap, and $30.5 \mathrm{~cm}$, a distance at which the photon detection efficiency was accurately known from previous calibrations) to establish the efficiency at closer geometries. Subsequent samples were counted at 0 cm only.

To perform the quantitative analysis. the computer estimates the baseline under the full energy peak and

\footnotetext{
-I wn wentical systems were used for these analyses. The first samples were counted on the low-hackground system of $F$. F. Iner. Analyfical Chemising IBvision. Subseyuent amples were counted on the sustem of $X$. H. Valentinc. Instrumentation and Controis Drvison. One of the samples counted on I yer's system was used in nhtain a yuantilative calibration of Vakntine ssystem. thus using I her's careful efficiency calibration work.
}

then integrates the peak. Data such as half-life and branching ratio are supplied to the computer in the form of an isotope table and are used in the activity calculation (corrected to any arbitrary reference date and time). The only correction not automatically applied by the program is that resulting from selfabsorption in the sample. However. the ganma-ray attenuation length' for $L_{.} i_{2} B_{e} F_{+}$is about $3.6 \mathrm{~cm}$ at 159 keV, and since the samples are small (less than 0.5 $\mathrm{cm})$. this correction does not exceed $10 \%$. In addition. the production of sample buttons of consistent size and shape facilitated this correction.

The first samples taken indicated a solubility of

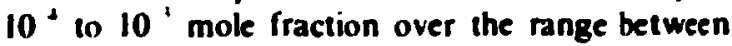

\footnotetext{
Attenuation length is that length by which the intensily is reduced by a factor of I $e$.
} 
475 C to $700 \mathrm{C}$. More recent data indicate a solubility betow $10^{\circ}$ moke fraction at $700^{\circ} \mathrm{C}$. It is suspected that particulates of Li:Te may have contaminated the tirst measurements. The melt has been examined for possible oxidation. and no evidence of an oxidized tellurium species was seen. Samples will continue to be taken until reproducibiiity can be achieted. which presumably will indicate that any particulate settling process has been compketed. The melt will atso be examined for suspended colloids.

\subsection{SPECTROSCOPY OF TELIURIDE SPECIES IN MOLTEN SALTS}
B. F. Hitch
L. M. Toth

Spectrophotometric studies of lithium tellurides in molten salts have continued. Several experiments involving the addition of tellurium compounds to l.iF-BeF: (66-34 mok $r_{\text {i) }}$ mixtures have been conducted using a diamond-windowed graphite cell. The primany objective of these experiments is to identify the anionic tellurium species present in fluoride melts at $500-700^{\circ} \mathrm{C}$ which absorb in the 200 to 2500-nm range.

When Li:Te was equilibrated with LiF-BeF: melts. the diamond-windowed cell was used in the conventional manner with the atmosphere above the melt in contact with the atmosphere inside the fumace. Howevet. when l.iTe, was used as a solute, the entire cell was encapsulated in quartz and the cell-capsule assembly was positioned in the furnace such that the entire unit was isothermal to prevent mass transpor of Te: to the cell walls by the decomposition reaction:

$$
\text { 2L.iTe: - Li:Te + ":Te:(g). }
$$

In LiF-BeF: melts. Li:Te did not show any absorbance except in one case where a small 10.1 absorbance unit) broad band appeared at approximately 470-480 $\mathrm{nm}$. This band disappeared when the cell was evacuated. indicating that the absorbing species was probably not due to $\mathrm{L}_{2}$ Te but instead to a species of greater tellurium activity which was present in $L_{i}$ Te: that is, the $L_{i}$ Te was not stoichiometric and may have contained a slight excess of tellurium.

Additions of LiTer to LiF-BeF: mixtures gave a small hand ( 0.2 absorbance unit) at $450 \mathrm{~nm}$ which remained stable. Previous work in chlorides indicated that maximum absorbance was obtained with so:utions in which the lithium-tellurium s'oichiomeIny was approximately one. Thus a Li:Te addition was made to the LiF-BeF: mix ture containing LiTe: which shifted the lithium-ellurium stoichiometry to 45-55 at. C $\mathrm{i}$. After the Li:Te additioc. a very brge band $(2$ to 3 abserbance units) at $465 \mathrm{~nm}$ was observed (Fig. 3.3) which remained stable during two weets of measurements. The color of the solution was deep orange. Following these measurements. enough iellurium metal was added to retum the lithium-tellurium stoichionetry to 25-75 at. (LiTe,. The absorbance decreased slizhtly. but not to the original 0.2 absorbance unit seen for the meh in contact with LiTer. The anomalous betavior of LiTe. may arixe from slow kinetics involved in its equilibration with meits.

These results sugeese that the most soluble tellurium species in Lif-Bef: (C6-34 mole $\left.r_{r}\right)$ meths under isothermal conditions is an ion such as $\mathrm{T} e:$ " or Te. Our wort in chloride meths." the work of Bamberger et al.." and recent electrochemical studies suppon the imerpretation.

Currently. preparations are being made to carefully titrate a nuoride melt containing Li:Te with tellurium metal and to bocate the lithium-telhurium

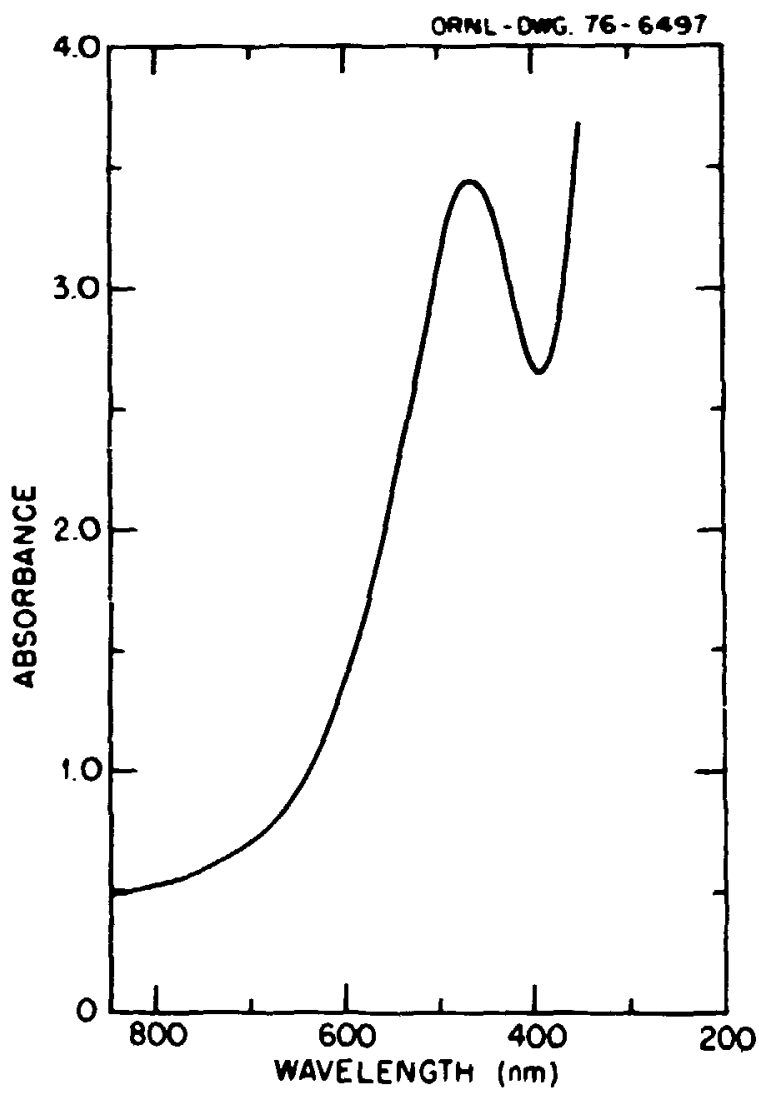

Fiz 3.3. Aberoranace spectrum of Te ${ }_{n}^{n-}$. 
ratio which gives the maximum absorbance. This information will establish the stointiometny of the solubte lithium-tellurium species. and oect this stoichiometry is known. addicion of this compunad (or mixture) to Lif Bef: metes would establish its solubility and absorption coefficient.

The following tentative conctusions are drawn (1) Li:Te does nor appear to be solubte in Lif-Bef: metis, or, if it is solubte. the $T_{c}{ }^{\circ}$ ion does not absort in the region investignted. (2) The light-absorbing species present in Lif-Bef: solution (as well as in molien chlorides) appears to be one represenved by Te" (e.g. Te or Te:" ). besed on our titration measurements. Although solid compounds suct as LiTe or Li:Te have not been observed in phase diagram studiex, the stability of a Te." ion in metts could easily be explained by sohation effects. (3) The experimental results have not been sufficienth consistent to establish that the $\mathrm{Te}_{\mathrm{i}}$ con exists in molten-salt solutions as a light-absorbing species. It is. nevertheless. reasonable that it should occur as one of a series of colored ions derived from the Te ion in the following manner.

$$
T_{e}+T_{e:}=T_{e} \text {. }
$$

or. in eneral.

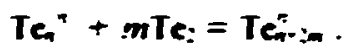

\subsection{DECOMPOSITION PRESSURE OF LITE}

\section{$\begin{array}{ll}\text { B. F. Hitcin } & \text { L. M. Toth }\end{array}$}

In spite of frequent reference to LiT i $_{\text {as a source of }}$ tellurium in MSR experimental work, no equilibrium data are avaibable for its decomposition reaction:

$$
\text { 2LiTe }-\mathrm{Li}_{i} \mathrm{Te}_{\mathrm{T}}+\mathrm{ATe} \text { (g) } \text {. }
$$

As a result. Te: pressures over LiTer (either solid or liquid) have been a matter of considerable conjecture. The relatively high $\mathrm{Te}_{\text {: }}$ pressures (as indicated by the characteristic yellow color over LiTe, at temperatures greater than $600^{\circ} \mathrm{C}$ ) could be determined for an isothermal LiTe, system by means of absorption spectroscopy; a Cary 14-H spectrophotometer measured the Te: pressure over LiTe, by monitoring the 4130-A band of Te: vapor.

Approximately $155 \mathrm{mg}$ of LiTe, was loaded (under an inert atmosphere) into a shallow tungsten crucible, which was, in turn, placed in a I-cm silica cell. which was evacuated before being sealed off. The crucible was necessary to prevem atlact of the silio bn Li:Te formed during the decompusition. The absorbence of Te: vapor ovet moleca lellurien metal wos simiburly measurd, and the absorbances were retaled to known vapor pressure dento This calibration emabled the comersion of the absorbance data for Te over molvea LiTe: to pressures and atso perminted determination of the mobr extinction coeffrcieal fo = 3232 132 a mole ' $\mathrm{cm}$ ') for Te: (Fig. 3.41. The upper cunve gives the vaius for the vapor pressure of pure tellarivam. The equilibrium pressares of Te: over molen LiTer are given by the lower curie

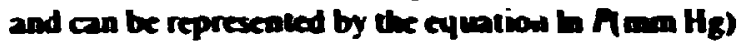
$=15.938-12.720 \pi^{\circ} \mathrm{K}$ ). As seen. the pressures of Te: over moken LiTer are quite bigh being oahy about a factor of 1.5 bower than the vapor pressures for pure tethrium. This uechaique is applicable onty to tellurides with simitarty high Tc: decomposition pressures: therefore. decomposition pressures of chromium and nicket tellurides canoor be measured spectrophotemetricalty.

Earlier measurements by this techaique indicated somewhat lower pressures of Te: over LiTe. The observed pressures decreased continuously with

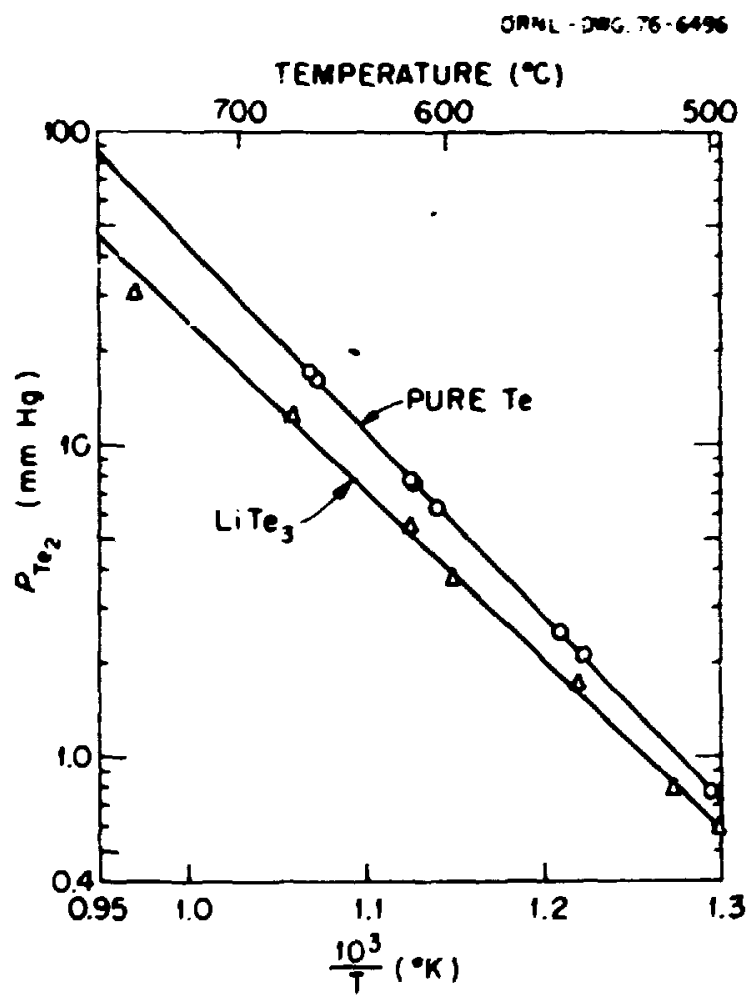

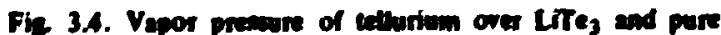
celinertum as a function of tempentuse. 
probunged exposure at 700 -C with ithe simulancous appearance of sitica altact in the lapor space above the crucible. Since 1 e: does not atton lis silica. even at $1050 \mathrm{C}$. probabth one of the liativim telturides has

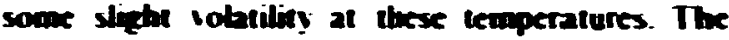
experiments reported above were performed at bower temperatures to avoid this attack.

This study will be conctuded with a determimation of the Ie: pressure over a solid mixture of Li:Te and lite: which will provide an equilibrium comsam for E4. (I). With this constan and the above data for moken LiTe. the activity coefficients for Li:Te dissolved in the molken LiTer phase an be determined.

\subsection{POROUS ELECTRODE STUDIES IN MOLTEN SALTS-ELECTROCHEMBTRY OF TELLURIUM IN THE LiCHEA EUTECTK SYSTEM}

\section{H. R. Bronstein F. A. Posey}

Out previous studies have established the capability of the packed bed etectrode of ghssy carbon spheres for monitoring etectroactive species in mohen salts by use of voltage-scaming coulometry techniques." It has been generally established that intergranular attack and subsequent embrittiement of the structural materivi of the MSRE was caused by fission-produced tellurium. It would therefore be highly desirable to estublish the solubility and the valence state of tellurium species present in the MSBR fuel salt. The complex behavior of tellurium species derived from the apparent dissolution of Li:Te and LiTe, in various molten salts has been amply demonstrated by spectrophotometric studies. ${ }^{2}$ ::

An electrochemical study of these tellurides in the $\mathrm{LiCl}-\mathrm{KCl}$ eutectic was initiated to provide additional information which would help in the elucidation and interpretation of the results obtained spectrophotometrically. Of almost immediate impact was the observation that the addition of Li: Te to the highly purified and dehydrated $\mathrm{LiCl}-\mathrm{KCl}$ eutectic melt $\left(400^{\circ} \mathrm{C}\right)$ produced no color, as was observed in previous spectrophotometric studies. ${ }^{\text {ml: }}$ A voltammetric scan showed no species attributabk to the dissolution of $\mathrm{Li}_{2} \mathrm{Te}$. This means that $\mathrm{L}_{i}$ Te is not soluble in this solvent at $400^{\circ} \mathrm{C}$.

Next, LiTe, was added to the melt. No color was observed and no trace of soluble tellurium species was detected by volt-a mmetry. Again, the conclusion must be that $L$.iTe; also is not soluble in this solvent at
400. C. Remoral of the carboa addition cup revealed that the Lite: had decomposed and had deposited metallix cellunium on the ouser surtace surrounding the holes is the cap. In loght of the abone resulks. the decomposinion of LTter reteasiog metallic eetharium can probabty be oriuken as

$$
\text { Te: }- \text { Te + Te: : }
$$

Cathodization of an accteratety seighed telluriwm electrode produced no color formation around the etectrode. From the coutionb accuspention and weight loss of the electrode. a sone-electron process was derived. in agreement with the finding of D. L. Manning in fleoride meths." The bet of color on cathodiration is also in agreement with that of Plambeck:

Our experiments, along with those of Plambect: have shown that. not only are the lithium tellurides insolubte in the LiC1-KCl eurectic at $400^{\circ} \mathrm{C}$. but also in highty purrified metes the reaction products are not present which lead to colored solutions.

These colored solutions may be due to interaction of the sellurides and trace amounts of moisture present as a contaminant in the mett. To test this premise. LiCl-KCl eutectic-Li:Te mixtures were contaminated with varying quaminies of moisture and melted in seaked quartz tubes. As anticipated. the tube with the largest contamination of moisture developed the darkest color. whereas the least contaminated meth had the lightest color. However. if true solubility of tellurides should oceur in other melts. colored solutions could arise due to the presence of polytelluride ions such as those observed for the polysulfides. ${ }^{\text {: }}$

\section{S THE URANIUM TETRAFLUORIDE- HYDROGEN EQUILIBRIUM IN MOLTEN FLUORIDE SOLUTIONS*}
L. O. Gilpatrick
L. M. Toth

A continuing study" of the redox equilibrium

$$
U F_{d}(d)+{ }^{\prime}: H_{2}(g)=U F_{3}(d)+H F(g)
$$

has produced values for the equilibrium quotient.

$$
Q=\left[\left(U F_{1}\right)\left(P_{M H}\right)\right] \div\left[\left(U F_{4}\right)\left(P_{H}\right)^{\prime}\right] \text {. }
$$

-This research in support of the MSR Program was funded by the F.R DA Division of Physical Research. 
at a ranee of lemperatures for the solvexts Lif-ReF: (66-34 mole $C_{2}$ ) and (40-52 mote $C_{i}$ ). Decaits of the procedure the bece given previoush:"

Since the spectroscopicalts measured LF: and LF, concentrations are directh dependewe on their mobr extinction cuefficients" (e). it was mecesong thet eccurake values be known for boch the uraniam ions

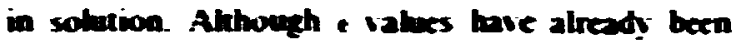
reported" for CF ; no corresponding values exist for LF: at $360 \mathrm{~mm}$ (which is the wie kength used to monitor the (F):. Therefore. the equilibrium study was ietestrped to obrain these data.

The refuction of a dilute IF, solution with airconium metal was found to be the most satisfacson procedure for obtaining CF : excitation coefficients. By preparing LF $_{\text {s }}$ solutions of known composition and reducing all the $\mathrm{CF}_{\text {a }}$ to UF ; with excess rirconium, an accurate determination of $\mathrm{e}_{1}$, at $360 \mathrm{~nm}$ was possible. At the same time. the presence of trace $\mathrm{Zr}^{4+}$ ion $1<0.1$. Min solution. either as a result of the reduction or intentionalh added. served to getter any trace oxide ion which would Otherwise precipizate UO: and upset the accuracy of the analysis.

Surprisinghy. solutions of pure UF a were stable up to $700^{\circ} \mathrm{C}$ with respect to arbide formation in the graphite spectropho:ometric cell: therefore. it was possibte to perform the calibration on pure $\mathrm{UF}_{\mathrm{z}}$ solutions. Above $700^{\circ} \mathrm{C}$. loss of UF, was observed (with the presumed formation of $U C_{:}$). and it was then necessary to extrapolate back to the time where the instability occurred in order to obrain an estimate of the absorption coefficients at higher temperatures. Consequently. the high-temperature calibration data are not as good as those at the lower temperatures.

Values of two apparently decrease somewhat with increasing temperature. but the magnitude is within the present experimental error. The average values for the two solvents Lif-BeF, $(66.34$ mole $\%)$ and (48-52 mole $i i)$ were found to be 1030 (for $500-7505 \mathrm{C}$ ) and $11552 \mathrm{~mole}^{-1} \mathrm{~cm}^{-1}$ ( for $400-750^{\circ} \mathrm{C}$ ) respectively. A discrepancy in the calibration experiments for the latter solvent led to a rather high $\left( \pm 10{ }^{\prime}\right)$ error. These experiments will be repeated if time permits at the end of the $H$ : reduction studies.

Equilibrium quotients at a given temperature were determined by sparging the system with a fixed HF $H_{\text {. gas ratio for a day or more until the UF }} / \mathrm{UF}_{\text {, }}$

\footnotetext{
- Defined hy Reer's I.aw. $A=\ldots$. where $A$ is the measured absorbance. is the molat extinction coefficient (in y mole 'cm '). $r$ is the concentralion (in moke ), and $Q$ is the path length (in $\mathrm{cm}$ ).
}

ratio becanc constan This kngth of time was abo mecessary to obtain consistent MF amalyses from the furance inkt and oetlet pas streams because of ine vern low HF H: ratios $\left(10^{*}\right.$ to $\left.10^{\circ}\right)$ shich eyuilibrated very slowh with the furmace and pas bises as well as with the meth.

The values measured for $Q$ are shown in Fig. 3.5 along wiah standard derivation (o) bars. Inchuded atso are the $Q$ values cakubied from the Loog and Banteaship (L\& B) equation.

$$
\begin{aligned}
& \text { log:- } Q=+.0-9.33\left(10^{\circ} n\right. \\
& +3.77 x_{18} \div 2.09\left(x_{a+1}-0.30\right) \text {. }
\end{aligned}
$$

in which $I$ denotes mole fraction. The heat of reaction. $\mathrm{JH}$. for LiF-BeF: $166-34$ mole $\left.r_{1}\right)$ determined from our data is $\$ 2 \mathrm{kcal}$ and compares favorabiy with the $L$ \& B value of $42.7 \mathrm{kcal}$. However. our individual $Q$ values all fall slightly higher than the previous I. B values except for those at $1000^{\circ} \mathrm{C}$.

The equilibrium quoticnts for the 48-52 moke', solvent are approximately ten times greater than those cakulated from the 1.\& B equation. These cannof be due to the 10; uncertainty in the $t$ : an (UF,) values beause the error in the $Q$ values is equivalent to the error in the absorption coefficient. The 48-52 moke 'i solvent composition falls outside the range of

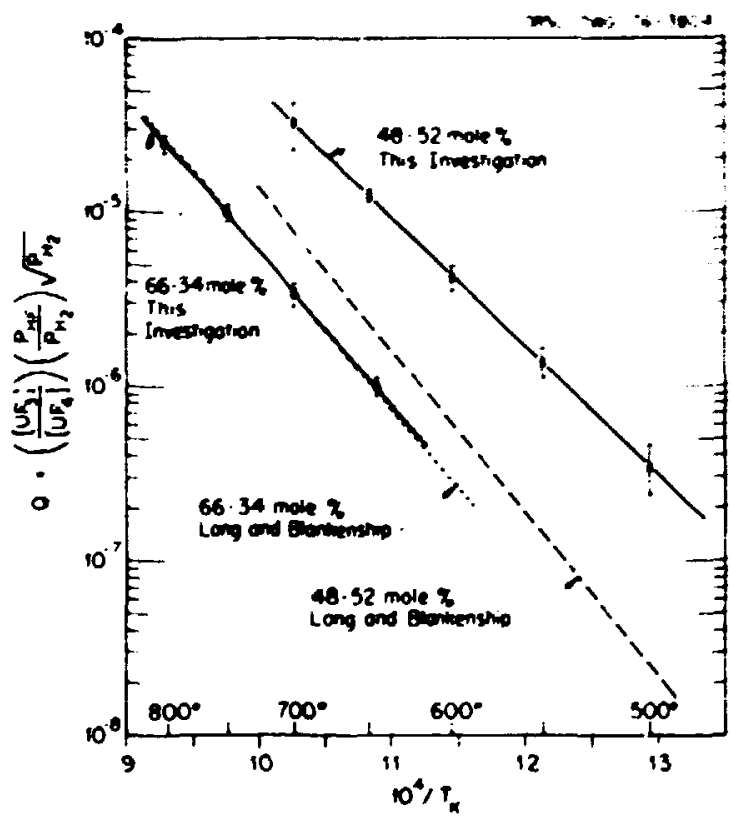

Fiz 3.5. $Q$ rahes measared in Lif teef, solvents (66-34 mole * and 46-52 mole $\%$ ) at severd lemperatures for the reaction $U P_{4}(d)+1 / 2 H_{2}()^{2}=U P_{j}(d)+H F(c)$. 
Ite I. 28 data. and there is somx indication in their dela that the $Q$ ialues are not lunearty rebted to the Bef: concentratuna. as sugpestad by the above eywaiman iser Fig. 9 of ref. 17). Therefore. such deviations due to gross solient changes do not necesarily conflict with the I. A B date.

Ithe hal of reaction in the 4-52 mole?

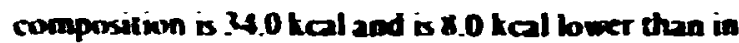
the 66-14 moke'; meth. This is what one would expect for a change in solution in going from a fivoride-rich to a fluoride-deficient soheat and is in ageement with our previous ambsis. for the :F-lC: cyuilibrium with CF : and graphite.

This study will be conctuded by measuring $Q$ with I.it-Bet:- IhF , 1?2-16-12 moke $r_{1}$ ) as the selvent.

\section{REFERENCES}

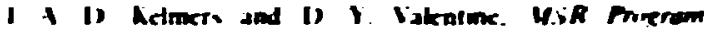

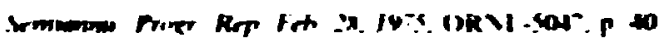

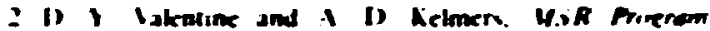

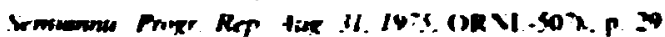

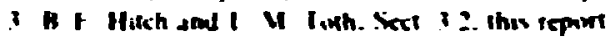

4 I Kinf. perwwal cosmmunxatuon

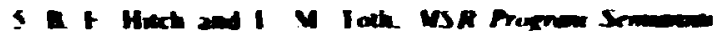
mar Ar tor $11.10 \mathrm{~s}$ onv-som. o

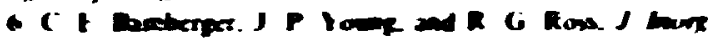

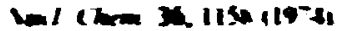

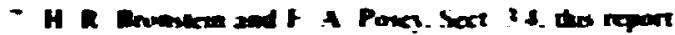

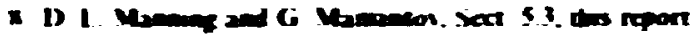

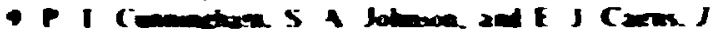

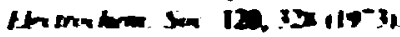

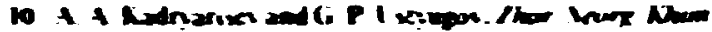
a. 120,19011

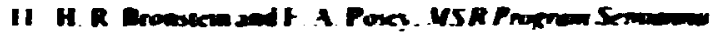

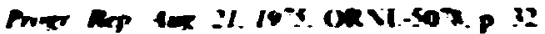

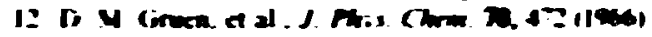

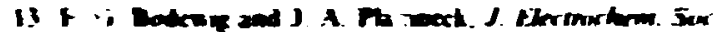

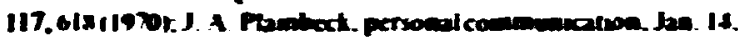
1976.

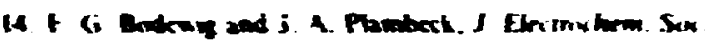
117. 2011070$)$

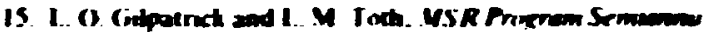

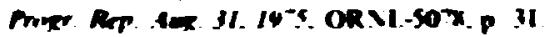

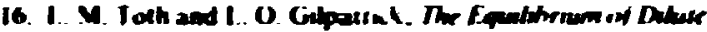

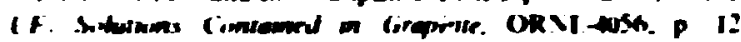
IINecmber 19:21

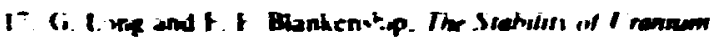

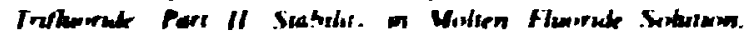

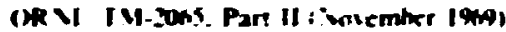

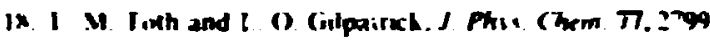
$\left(19^{-3} 3\right)$ 


\section{Coohnt-Sah Chemistry}

\section{A. D. Nelowers}

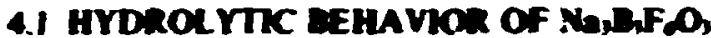 1. Mụa}

I he hydruhta hehas ine of Wa:B F.O nas stodied in means of it autear magantic resuance (MMR I and Raman spectroscupn to chrit! the posoble

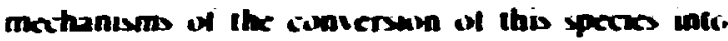
hydroxude. I he compound Va:B.F.O. appears to be

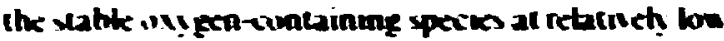
oxde conneratrations $13-15$ moxe "; B.0:1 in the Iner: lat-labt.-B:O.. I hoxe comperstivis approvech that of the conlant melt. alshewgh the bitier contatns a hower oxide concentratum. I his finding a of ugnificance stoue intuum trapping in coolant melt probolit miohes an cypulbrium betecen oxide and

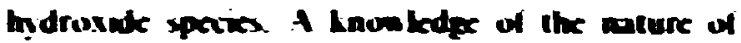
these specis and their chemixtry sould pronide lurtber understanding of the trappine process.

The Raman spectram of a $0.66-1$ solutiva of W.B.F.O. D grien (Fu- 4.I) It eas coactuded that the lines at 875 and $760 \mathrm{~cm}$ were due to $H:$ :OO: and Bf .OH resuling from the depohmesivatum of the B.F.O. ion as described by the folluning seyuential reactums:

Na:B.F. -3 H.O = I MBF $(O H):$

2. MaBF $($ (OH): $=$

VaBF:OH + H:BO: - NaF. III

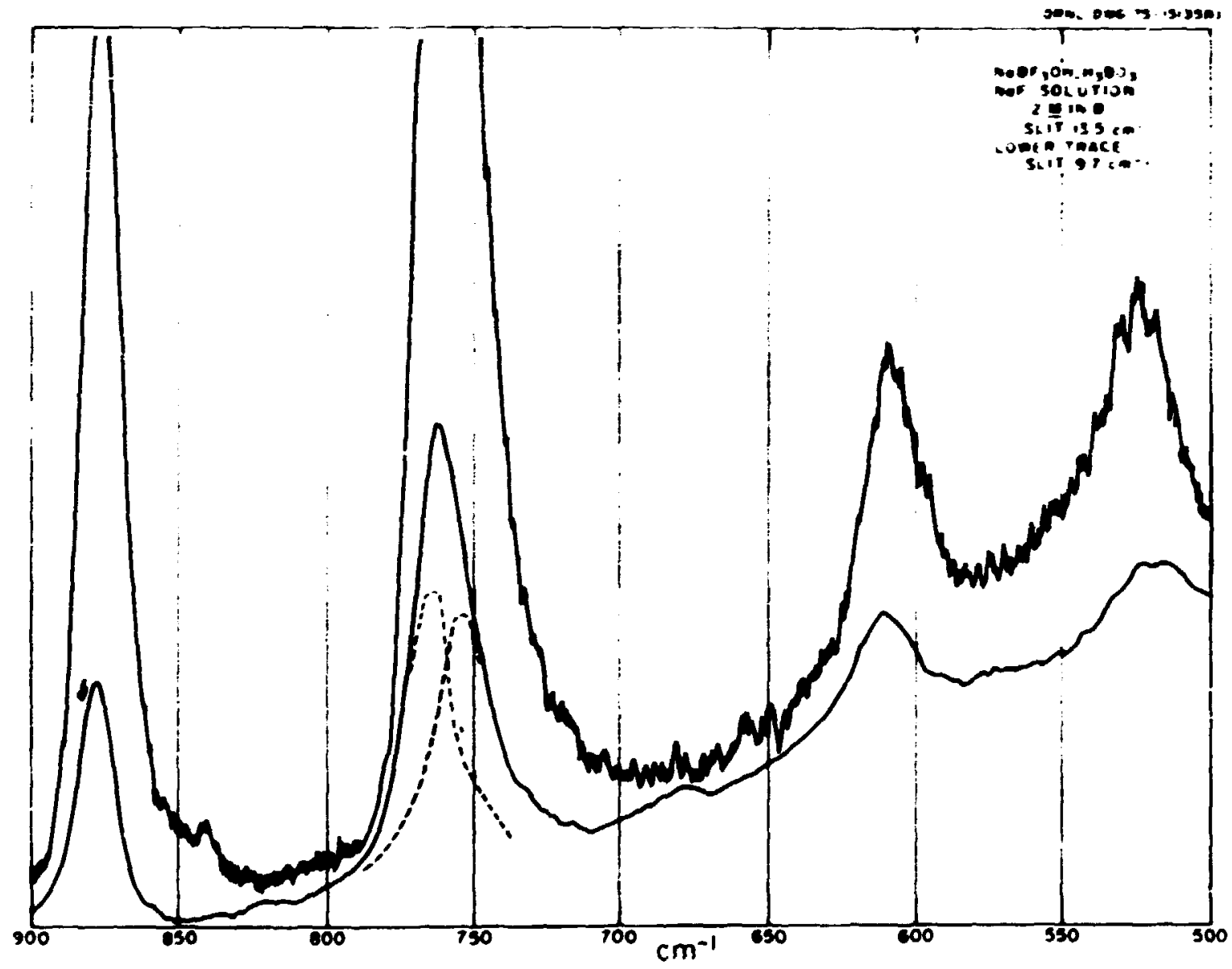

Fic. 4.1. Raman spectrum of a soletion $2 M$ in boron with an F/B ratio of 2. 
This situation is not supprising since tetraborate is depolymeried in water into H.BO: and BOHts. Mibben obseried such betwaior on the basis of Rarza spectra.

The sloichionetry of the depolymerivation reyuired that sodium lluoride. which was not obsened in the Raman spectrum. would be formed. This surpested inat borix axid. sodium thoride. and wdium hydroxylluoroborate that were dissohed in cyuiziknt proportwors should exorate the same spectrum as ayuevers $\mathrm{C}: \mathrm{B}: \mathrm{F}, \mathrm{O}$. This was found to be the case: furthermore. ex aporation of the solution sielded pure Na:B.F,O:, as espblished by elemealal analysis. infrared spectroscops. allialimetric titration and the r-ray powder diffraction pattern. This experiment proved the reversibility of the equations dexcribed above and gave an altermate and sumpler method of șmthesinine the compiex salt. In spice of the apparenty straphtormard chemistn described above. Closer strution of the Raman spectrum reveated some inconsistencies. Pure MaBt:OH absorts at $753 \mathrm{~cm}$, and the $760 \mathrm{~cm}$ band actualty observed appeared to be asymetric. A band at 610 $\mathrm{cm}$ was also detected. The incensity of this hand proved to be temperature dependent. increasing at boer temperatures. This sugeested the presence ot more species than originally assumed. ? he "I MMR spectrum (fiz. 4.2) revealed a considerable proportion of species containung an $F \mathbf{B}$ ratio of 2.0. The spectral evidence indicates that the equilibria

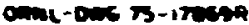

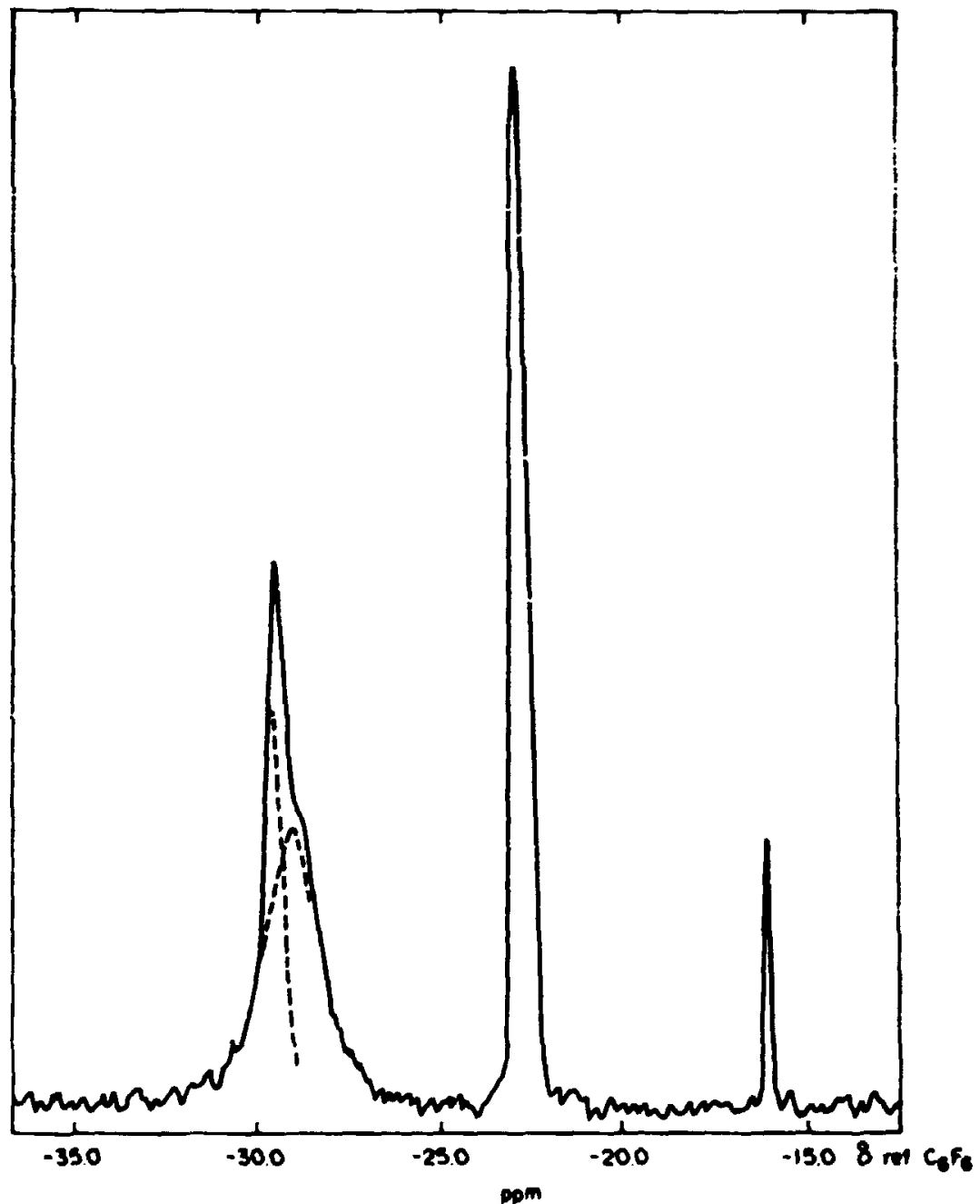

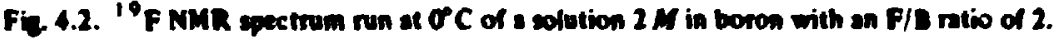


described in Fys. (1) and (2) are mo shilled completety to the reght and that there are consulerabte amounts of BF.(OH): and B:F.O." nns present. Anatysis of the $760 \mathrm{~cm}$ band with a curve resolec rencaled ino compunents at 763 and 753 in . The first beus due to BF :OH . as asseraed on the hasis of pure $\mathrm{M}_{2} \mathrm{BH}$ OH. and the secund due to BF.OH): - This gives an additional poim to the corretation of the $y$ hand frequency of parially substituted fluoroburates with the deznee of substilution. Thes. BF: abuorts at $70 \mathrm{~cm}$. Br: OH at $7 \mathrm{~b}, 3$ $\mathrm{cm}$. Bf $(\mathrm{OH})$ at $753 \mathrm{~cm}$. and B(OH) at 75 in . Simibrh. analysis of the If NMR sienal at - $29.6 \mathrm{ppon}$ is referenced to (.F.) resealed two segals. one due to BFyOH) and the other apporently due to the B:F.O: The presence of B:t.O. Is confirmed in the hand at $610 \mathrm{~cm}$ in the Raman ypectrum. I his line corresponds to the line at 545 cm cthered in the spectrum of the wold.

I vempuantitatise malicral habane. haxed on the intencises on the if WNR and a calibratum ot the BuH' and laBt OH lines in the Raman yecirum. gises the tolksw ing approvemal: divirimution lor a wolution 2 I/ in horen prepared b! diswols ing eyuimolar amiunts of VaBt (OH. Vat. ond H. BOS.

\begin{tabular}{|c|c|c|c|c|c|}
\hline & $\mathrm{OF}, \mathrm{OH}^{-}$ & of : $10 H_{2}^{-}$ & $\mathrm{B}_{3} \mathrm{~F}_{4} \mathrm{O}_{3}{ }^{3-}$ & $1^{-}$ & $R_{3} \infty_{3}$ \\
\hline $\begin{array}{l}\text { Approx inoule } \\
\text { motarity }\end{array}$ & n.s & 0.5 & 0.2 & 0.5 & \\
\hline
\end{tabular}

F ree lluorde is not shoun in the spectrum given in fig. 4.2. It ahurth at about $-44 \mathrm{ppm}$ and is not rewilved from Bf(CH): : thus. among other uncertainticx. it is a polential surce of error in the material halance.

Having estahlished that $\mathrm{Ya}$.B:F.(): and $\mathrm{NaBF}, \mathrm{OH}$ interconvert reversibily in the presence of water. It ss powihle in assume that a similar mechanism operates in the melt. This led to the postulation of a number of plausihk reactions which could take place in the melt insolving these species. hydrogen (tritium). and discolved metal nuntides.

$$
\begin{aligned}
& \text { H. } \mathbf{M F}:=2 H F+\mathbf{H} \\
& 2 H F+2 \mathrm{VaHF}: \mathrm{OH}=2 \mathrm{VaBF}_{\mathrm{H}}+2 \mathrm{H}, \mathrm{O} \\
& 2 \mathrm{H} \cdot \mathrm{O}+\mathrm{Ha}_{\mathrm{B}} \mathrm{B} \mathrm{F}_{4} \mathrm{O} \cdot= \\
& \mathrm{NaBF} \text { OH + } \mathrm{VaF}+\mathrm{H}_{1} \mathrm{BO} \\
& \text { H.RO: }={ }^{:} \mathbf{B}_{2} \mathbf{O}_{1}+{ }^{\prime}: \mathbf{H}_{2} \mathbf{O} \\
& \mathrm{HOO}+\mathrm{NaF}+\mathrm{NaBH} \mathrm{H}_{3}=\mathrm{Ha}_{\mathrm{A}} \mathrm{BH}_{4} \mathrm{O}_{1}
\end{aligned}
$$

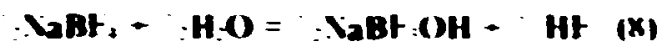

I the incrall reatwa is

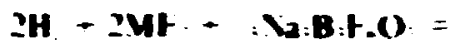

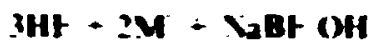

Ihe cyulitwum constant hor this reatinn is

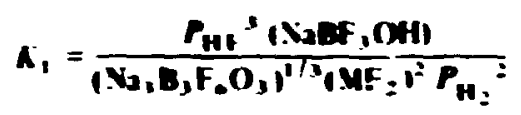

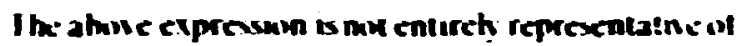
the suem vine $H F$ and WBr (H) ean react acciscline in.

$$
\text { HF - VaAt (OH - H }
$$

Ihis cyulibrium constant for the reatusn os

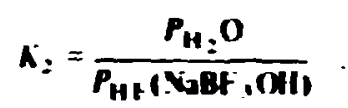

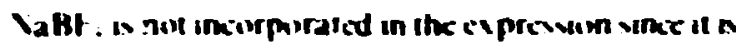
the whent I inall! the "y wem ciould he reprexned hy combinitg $A$ and $A$ into the following copres viom

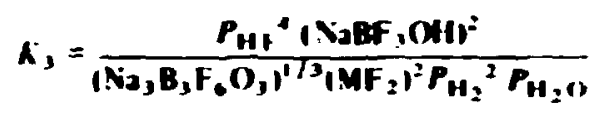

Fialuation of the comstant $K$. would kad to a yuantitative dexioiption of the system. A morte practical qualitative observation hased on this copression is that tritium trapping will he lavored hy relatively high concentrations of oxide and or metal Nusride in the salt alosg with a rebtivels high salue for the partial pressure of water.

\subsection{VAPOR DENSITY STUDIES IN THE SYSTEM BF, $-\mathrm{H}_{2} \mathrm{O}$}

\section{Maya S. M. Russell*}

In the last report. 'it was stated that dissxciation of BF: $2 H . O$ is complete at $400 \mathrm{C}$. The present sel of experiments was aimed at exeablishing the temperature threshold at which association or condensation of the vapor species takes place. These experiments showed that at about 200 C there is a departure from complete dissociation. This departure hecomes

-SiC I studeni parricipant. 
prenmunced at IS) (. and. with uncreavne amounts

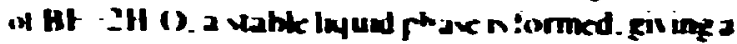
aturatum sapur pressure awh remains constant with sanging ameunts of B1- -2H $O$. I hus behavior wis uncepected. un vew ol the repurt that BF -2H.O doimpinen upm distillatiun: howerer. that vork wav derox in plass in an opra si sem. Ths fandiag led in a crses of experuments bo ohama a set of saturation ıрми prenure date al different temperatures (Table $+11$

\begin{tabular}{|c|c|c|c|c|c|c|}
\hline & $|0|$ & $1:=$ & 150 & 16 & $16:$ & 120 \\
\hline$r_{1}$ - & 4 & $\rightarrow$ & $2:=$ & 3 & 335 & 362 \\
\hline$P_{:} . \operatorname{mos}$ & 42 & 103 & $2 n$ & 324 & 333 & 361 \\
\hline
\end{tabular}

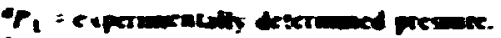

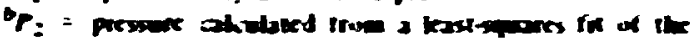

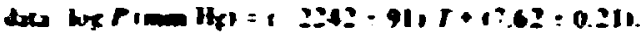

A phr of in P w $T$ lor BH . IH:O gave an exirapulated tholing point Iactualk the icmperalste at wh-h diswation presure and sapor preswure

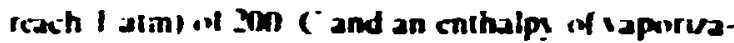

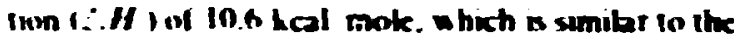
$\therefore$ If of a number of etherates of Bt.

inerher wet of experiments masconducted to study th. disuxatum hehaviur of Bt :-2H.O and Bt :-H.O in the sapir phax. I his was dowe chosing conditions such that no liyuid phace could be present. Iypical revules of these runs are presenied in Table 4.2

\begin{tabular}{|c|c|c|c|c|}
\hline \multirow{2}{*}{$\begin{array}{c}\text { Iemeraber } \\
C \mathrm{C})\end{array}$} & \multicolumn{2}{|c|}{$w_{1}-2 u_{2} 0$} & \multicolumn{2}{|c|}{$\mathrm{H}_{3} \mathrm{H}_{2} \mathrm{O}$} \\
\hline & $P_{1}$ & $P_{c}$ & $P_{1}{ }^{\circ}$ & $P_{6}$ \\
\hline $\begin{array}{l}150 \\
160 \\
170 \\
181\end{array}$ & $\begin{array}{l}54 \\
14 \\
34\end{array}$ & $\begin{array}{l}210 \\
212 \\
3=1 \\
402\end{array}$ & $\begin{array}{l}158 \\
118 \\
314\end{array}$ & $\begin{array}{l}10 \\
215 \\
330\end{array}$ \\
\hline
\end{tabular}

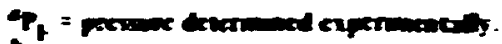

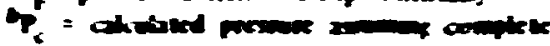
andingen
}

Consuderima mas ginen to uxing the dat in the cakubtima of cquitionam comscants and theranodymamic yountitus. bet it was ket that becouse of the

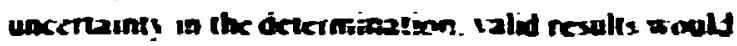
ax be chlained. Oa tbe ofhet hand. the resoles clearin show that there is associstuse herween Bf: and H.O in the iapot phase.

\section{REFERENCES}

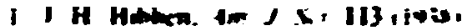

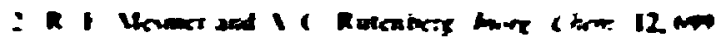

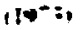

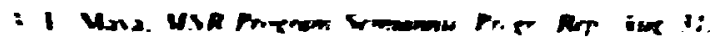

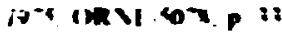

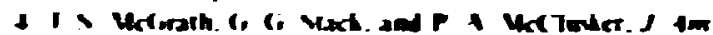

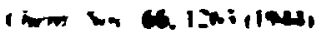

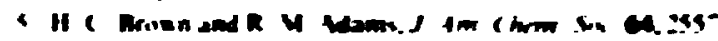
184:1 


\section{Development and Evaluation of Analytical Methods}

\subsection{IHLDTE ANALIST OF MOLTEN MSI FUEL \\ R. F. Apple D. L. Mannias}

A. S. Moger"

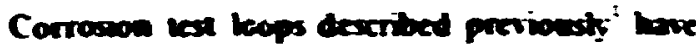

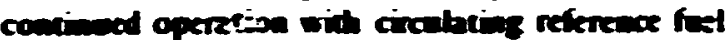

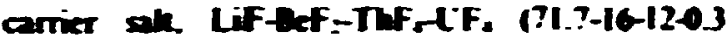

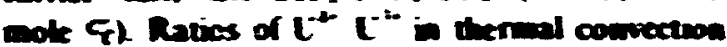

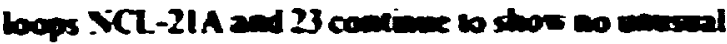

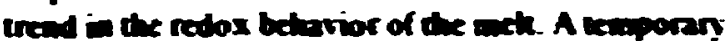
rive it the ratio in response so the adtaion of wer

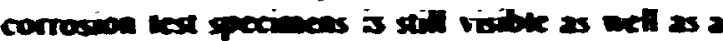
recovery to the orijul retios wition a shor tinc.

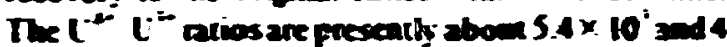

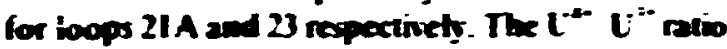

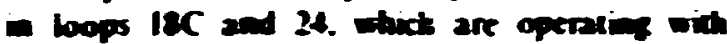
Haxtion 1 cerrosion specionems. bave thown a Groden decine and are presenty abon $1.7 \times 10^{\circ}$ and 10 respectivety.

Forced cowection loop. FCL-2b. bes beea chared with wew she and is beck in operation afker a shedown period. The $\mathrm{C}^{-t-}$ " pato is presently of the miet of $5.3 \times 10^{\circ}$. which iadicates that the raeth is oxidixime Probuly the retio will decrose repulty as

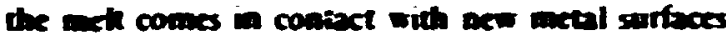
dex bave been mastived in the loop.

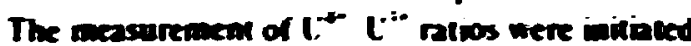
in Vovenber on cight creep-kest machines bocked in Bulding 2011. Since the ibitial measuretenents, ite metes have tended to become more resucing. For comparison. first mesuretucals and preseat

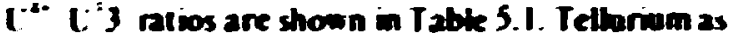

\begin{tabular}{|c|c|c|}
\hline \multirow{2}{*}{$\begin{array}{l}\text { Marine } \\
\text { ilentity }\end{array}$} & \multicolumn{2}{|c|}{$\mathbf{U}^{\circ} \mathbf{N}^{3}$ ravo } \\
\hline & Inicial & nesean \\
\hline $\begin{array}{l}15 \\
16 \\
17 \\
18 \\
19 \\
20 \\
21 \\
22\end{array}$ & $\begin{array}{c}1.6 \times 10^{3} \\
3.5 \times 10^{2} \\
2.3 \times 10^{3} \\
3.5 \times 10^{2} \\
3.5 \times 10^{2} \\
5.3 \times 10^{2} \\
65 \\
3.1 \times 10^{2}\end{array}$ & $\begin{array}{c}1.4 \times 10^{3} \\
100 \\
76 \\
90 \\
35 \\
63 \\
22 \\
61\end{array}$ \\
\hline
\end{tabular}

\section{J. M. Dak}

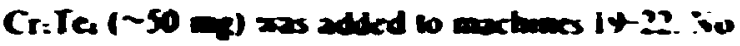
decetable clange in the redox beterior was

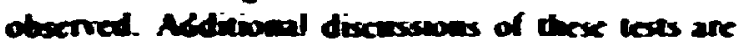
presenad etwentere:

\section{S2 TRTIUM ADDITON EXPERMETTS E THE COOLAWT-SHLT TECHSOLOGY FACUITY}

$$
\text { R. F. Apple }
$$

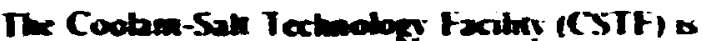

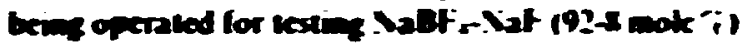
Cor its sucaldity as a possilite secosdart condan. In cooperation widh bop enginesers and uechancions. the

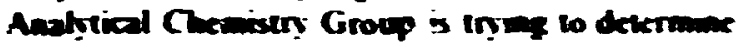

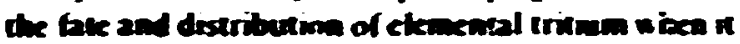

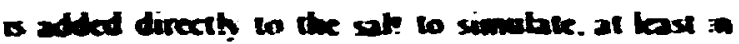

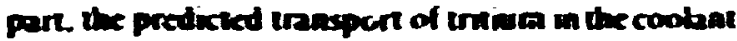
sysecm via diffusion throsth the priven hat exhaner. The ancthodology and the resenis from the fird two tritian mextion experiments were described presions:- This section presents the resolis of the thind irition ingexizen experiment.

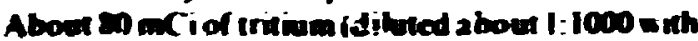
protivan) was introduced into the sabl mer a period of

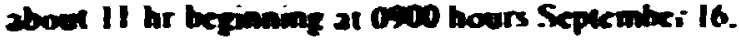
1976. Trition conceratrations wese ancasured at the cover ges and salt from the hepaning and for several days thereafket (Tabte 5.2).

Pretimuany eratuation of the daca indicales that abour hall of the injected tritium expericaced siguificant hold up in the salt but was cremtualh removed in the off-as stream. Very litik tritium in the off-ras was in the elemental form. The majority wes in a valer-soluble or conbinad form which is advantareous irom the seandpoint of trition treppiag by the salt. Atso. there appers to be evidence that at bow concent rations some of the iritiom which is capturad by the salt has a vendency to escape on sandine. A paeral discussion of the behaving of tritium in the CSTF and a more complete anabysis of the injaction experinents are given elsewhere.'

A fourth tritium injection experinent now undet way uses improved pasadition and sampling technipues. Tritium will be added in this experiment

- Deceased 


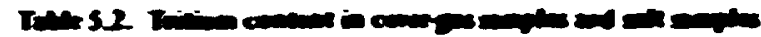

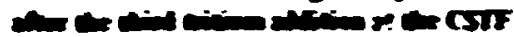

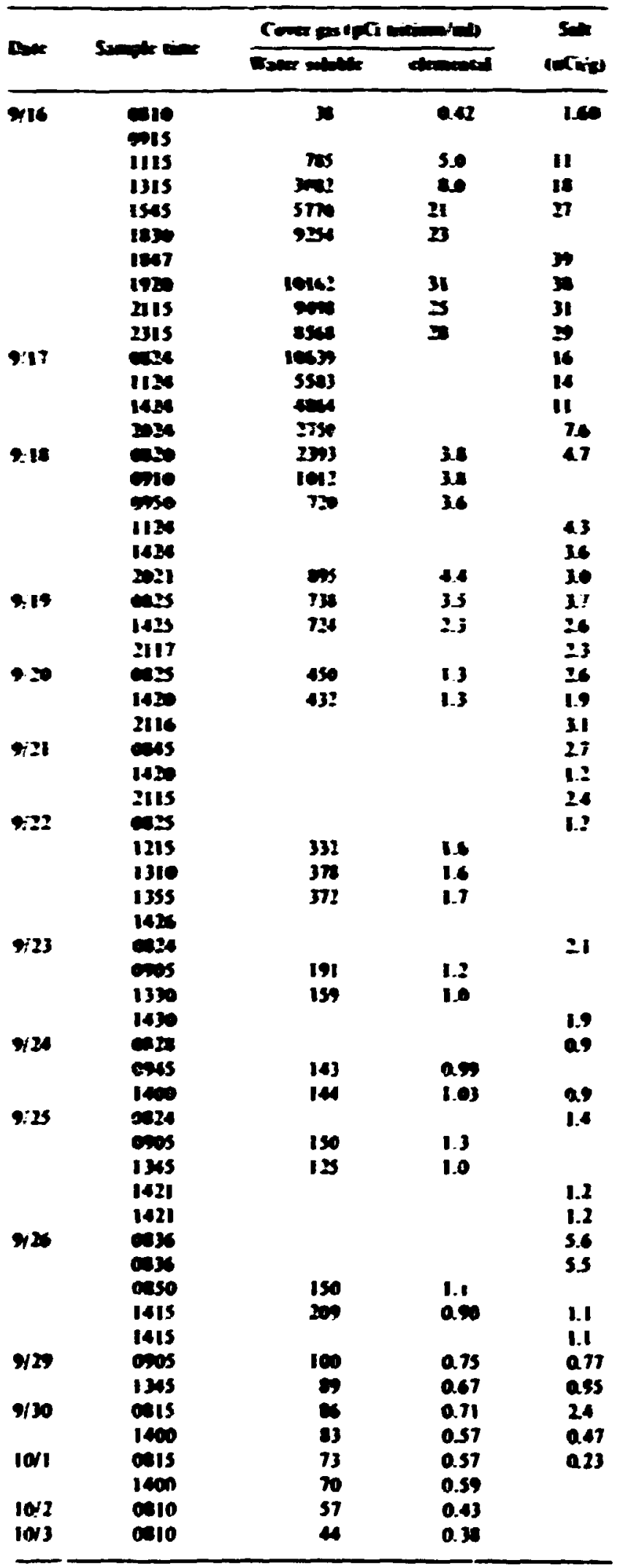


until a sieady state is reached. A preliminary evaluation of the results obtained so far is presented elsewhere.

\subsection{ELECTROCHEMICAL STUDIES OF TELLURIUM IN MOLTEN LiF-BeFr-ThF، (72-16-12 MOLE \%)}

\section{L. Manning G. Mamantor}

Tellurium occurs in nuckear reactors as a fission product and results in shallow intergranular cracking in structural metals and alloys." Erforts were continued to characterize this substrance electrochemically and to ascertain the feasibility of in situ monitoring by electroanalytical means.

Tellurium screening studies were carried out in cooperation with J. R. Keiser of the Metals and Ceramics Division. As previously reported." lithium telluride. Li:Te, was added to molten LiF-BeF:ThF ${ }_{\text {s. }}$ which was contained in a cell equipped with viewing ports in addition to the electrode ports. Subsequent voltammograms did not reveal any waves that could be attributed to soluble eleciroactive tellurium species. Chemical analysis indicated $<5 \mathrm{ppm}$ tellurium in the melt. Following cleanup of the cell and recharging with Lif-BeF $F_{2}-T_{H} F_{\text {s. }}$ standard additions of LiTe, were made in the form of pressed pel'ets. The pellets disappeared more rapidly from the meit surface tinan did the $\mathrm{Li}_{2} \mathrm{~T}$ e pelsets. A greyish film having a metailic appearance formed on the surface. Subsequent voltammograms did not show any significa nt changes over background scans. The equilibrium pot:ntial remained the same, which was different from the $\mathrm{L}:$ : Te additions where the melt became more reducing. This means that LiTe, is not stable under our operating conditions. Bamberger et al. showed that isothermal conditions were necessary to hold the characteristic color for any length of time in experiments on spectral measurenicits of what was reported to be LiTe, in LiF-BeF:. Under nonisothermal conditions the color quickly disappeared with evidence of tellurium metal formation. Since our conditions are nonisothermal, the LiTe, probably decomposed immediately after contacting the melt. The greyish film having a metallic appearance that was noted on the melt surface apparently tended to short out the electrodes after 1 lew hours besause the voltammograms became extremely noisy and nonreproducible. However. there was no change in the equilibrium potential.

Thus. we have been unable to detect stable electroactive telluride species in molten LiF-BeF ${ }^{-}$-
ThF, following standard additions of Li:Te and LiT $i$, compoundz under these conditions. It appears that these selluride.: are, for the most part. relatively insoluble and or thermally unstable under these experimental cenditions.

In the ahsence of meaningful voltammograms. experinents were initiated to determine the decomposition potential of etemental tellurium ( $m$ Te + ne - Tem ${ }^{n}$ ) retative to the half-wave potential of the U(IV) - U(III) electrode reaction. This should provide some insigh! on the reducing power [U(IV) U(III) matio] required to fator :he existence of tellurides (if stabk) over elemental tellurium in MSBR fuel salt. For these experiments. the molten LiF-BeF; - ThF was contained in is py rolytic boron nitride cup. The holder for the small tellurium pool electrode ( $z$-in.-diam) was fabricated from spectrographic-grade graphite. Cathodic polarization curves recorded on the tellurium pool electrode right after dipping into the melt at $\sim 650^{\circ} \mathrm{C}$ and for the next hour or so revealed a decomposition putential of about $+1.15 \mathrm{~V}$ vs the melt limit. It was observed that $\sim 100 \mathrm{mg}$ of tellurium volatilized from the graphite holder in approximately $1 \mathrm{hr}$. The halfwave potential for the U(IV) - U(III) electrode reaction relative to the melt limit is $\sim+0.75 \mathrm{~V}$. Thus the decomposition potential of tellurium relative to $E_{1}:$ for $U(I V)$ - U(III) reduction is of the order of t $0.40 \mathrm{~V}$. which corresponds to a U(IV). U(III) ratio of $\sim 150$ al $923 \mathrm{~K}\left(650^{\circ} \mathrm{C}\right)$. From these measurements. it appears that a relatively reducing melt is required to favor the existence of stable telluride species over elemental tellurium in molien LiF-BeF:-ThF -U(IV) at $923 \mathrm{~K}\left(650^{\circ} \mathrm{C}\right)$.

In a second experimental setup located in $J . K$. Keiser's lahoratory and with Keiser's cooperation. we are monitoring the $U(I V)$ U(III) ratio in molten LiFBeF:-ThF, following additions of tellurium as $\mathrm{Cr}_{1}$ Tes. With the U(IV): U(III) ratio at a stable value of $\sim 110$ at $978 \mathrm{~K}\left(1300^{\circ} \mathrm{F}\right)$, a standard addition of 105 $\mathrm{mg}$ of $\mathrm{Cr}_{4} \mathrm{Te}_{4}$ was made. This addition resulted in no change either in the U(IV): U(III) ratio or shape of the voltammograms over a two-day monitoring period. A second addition of $1.00 \mathrm{~g}$ of $\mathrm{Cr}_{3} \mathrm{Te}_{4}$ was then made, which resulted in an increase in the U(IV) U(III) ratio from $\sim 110$ to 220 . This effect has been observed previously and is believed to be due to slight moisture contamination during addition procedures. Within three days the $U^{\prime \prime} ; U^{\prime \prime}$ ratio had decreased to abou: 90 and appeared to stabilize at about this value. No change in the characteristics of the voltammograms (new waves, efc) was observed 
following the larger addition. although the U(IV) U(III) ratio appeared to kel out at a somewhat lower value. Metal specimens present in the cell will be removed and examined for tellurium effects.

In order to obtain additional information on the formation and stability of tellurides under nonisothermal conditions. studies were conducted on the telluride species produced in situ from cathodizing ekemental tellurium ( $m$ Te $+m e^{-}-T_{e}{ }^{*}$ ). Chronopotentiometric and doubte potential step experiments conducted at a tellurium pool electrode contained in a graphite cup revealed that the telluride species generated does not appear to be stable at $\sim 650^{\circ} \mathrm{C}$. Instability was indicated from the chroncpotentiometric exp-riments by comparing the rato of the forward and reverse transition times.' Generation of a stable but insoluble substance yields $\tau_{p}, \pi=1$; for 2 soluble and stable species. $\tau_{f} \tau_{r}=3$ is predicted. For an unstable species. on the other hand. the value of $T_{i} r$, should be greater than three. For these experiments, the current was reversed at a time $r<r_{r}$ : however, the above conclusions remain valid as long as $t \leqslant r_{r}$. Potential-time curves recorded at the tellurium pool electrode produced a value of $r_{;} r,>3$ in all the runs, indicating that the telluride species generated is not stable. at kast within the time frame of the experiment (seconds).

In the double potential step' experiments, the anodic-cathodic current ratio $\left(i_{a} i_{i}\right)$ is plotted is a function of time $[F(t)]$ during which the potential step is applied and removed. For a stable system. $i_{c} i_{r}=1$ when $F(l)$ is extrapolated to zero. For the generation of an unstable species, $i_{a} i_{\text {s }}<\mathrm{I}$; this was observed for the tellurium experiments.

Plots of $\log i$ vs $E$ from potential step experiments revealed an $n$ value close to unity. The validity of $n$ value determinations by this method is discussed by Armstrong $e t$ al. " and Bacarella and Griess. "Thus if $n=1$, the telluride generated can be represented as $m \mathrm{Te}+c-\mathrm{Te}_{m}(m \geqslant 1)$. Bronstein." using a different method, also ohtained an $n$ value of unity from polarization studies of tellurium in molten chlorides.

A stable telluride of the type $\mathrm{Tem}_{\mathrm{m}}$ should exhibit a color when dissolved in the melt.' In an effort to observe this effect. we cathodized elemental tellurium in molten I.iF-BeF, at $\sim 480^{\circ} \mathrm{C}$. The melt was held in a quartz tube to permit visual observations. When a current of $\sim 150$ to $300 \mathrm{~mA}$ was applied for several seconds or longer. a dark brown substance was observed streaming from the tellurium electrode: however. the material appeared insoluble, and a colored melt was not produced. After the material diffused a way from the electrode a shert distance ( I $\mathrm{cm})$. the color could no longer be seen. These results also indicate that wo are generating an enstable species that under nonisothermal conditions tendergoes a decomposition reaction. Reasonable reactions are as follows:

$$
\begin{aligned}
& 2 \mathrm{Te}^{\mathrm{i}} \rightarrow \mathrm{Te}^{\mathrm{i}} \\
& \text { Te: }{ }^{:}-\mathrm{Te}^{\mathrm{i}}+\operatorname{Tei}(m=1) \\
& 2 \mathrm{Te}_{m} \rightarrow \mathrm{Te}^{-i}+(2 m-1) \text { Tei }(m>1)
\end{aligned}
$$

The $T=$ does not appear to be soluble in fluoride miclss. at bast to the extent inat voltammetric ietection is feasible.

\section{S.4 ELECTROCHEMICAL STUDIES OF OXYGENATED SPECIES IN MOLTEN FLUORIDES}
D. L. Manning
G. Mamantov

Voltammetric anodic scans at a gold electrode in molten LiF-BeF :-ThF _ (MSBR fuel solvent) and also in molten LiF-BeF:-ZrF, (MSRE fuel solvent) revealed two anodic waves at peak potentials $\sim 1.05$. $1.3 \mathrm{~V}$ and $0.85,1.2 \mathrm{~V}$ vs an iridium quasi-reference electrode (Ir QRE) respectively. Noise is encountered on the diffusion current plateau of the second wave. which is indicative of gas-bubble formation at the electrode surface. The waves are irreversible at slow (0.1 V: sec) scan rates. Although the results are tentative, these waves are probably associated with the oxygenated species in the melts.

A calculation of the $n$ value for the first anodic wave from the ratio of the volt-ammetric $i_{p}: v^{\prime}$ ' to the chronopotentiometric $i \tau^{\prime:}$ and also the chronoamperometric it' "revealed a value of approximately unity in both melts. Scan rate studies of the first wave in Lif-BeF $;-T_{h} F_{4}$ revealed a decrease in the $i_{p} v^{\prime}$ : value of $\sim 30 \%$ over the range of 0.1 io $5 \mathrm{~V}$ sec. A possible mechanism that reflects this behavior involves a charge transfer follon:"ad by dimerization." If it is assumed that the wave is 1ssociated with "oxide" in the melt. a like.y reaction could be

$$
\begin{aligned}
& 0-l e \rightarrow 0 \\
& 20 \rightarrow 0:-
\end{aligned}
$$

which would account for the one-electron charge and dimerization. Efforts to carn out similar measureropts in LiF-BeF:-ZrF, were hampered by a imall 
prewave at the foot of the first anodic wave which became very large at the faster scan rates. The peak current $\left(i_{p}\right)$ of the prewave was roughly proportional to $r$ (scan rate). which is indicative of adsorption of product (probably $\mathbf{O}$ ) at the electrode surface. It is not clear why this adsorption effect is so pronounced in LiF-BeF:-ZrF.

If the first anodic wave represents the oxidation of oxide to the peroxide. the second anodic wave must represent the continued oxidation to superoxide and ultimately oxygen gas. The noise on the diffusion current phteau of the second wave is indicative of ges formation at the electrode surface. The reactions are complex: however. the overall $n$ value for the second wave should be 2 (assuming $0_{:-}-2 e-0$ ).

For chronopotentiometry, the magnitude of the Iransition time. $r_{1}$ and $r_{\text {? }}$ for the stepwise oxidation of a substance involving $n=1$ and $n=2$. tespectively. results in a ratio of transition limes $\tau_{1} \tau_{2}=8$. The experimental data from chronopotentiograms recorded on both melts were in reasonable agreement with the predicted value.

If the second anodic wave is a perioxic: oxic: $:$ tor: wave, the addition of peroxide to the melt should

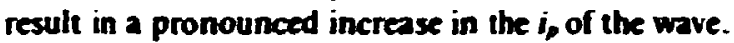
We added $600 \mathrm{mg}$ of $\mathrm{Na}: \mathrm{O}$ : to the LiF-BeF,-ZiF, melt. The first interesting observation was a 200-mV anodic shift in the equilibrium potential (more oxidizing) over a period of a few minutes and, then, a gradual refum to about the original value within a few hours. A pronounced increase was observed for the second anodic wave height. At faster scan mtes ( S-50 V sec) the second wave is split, and a small post-wave can be observed. This led us to believe that we were seeing the intermediate peroxide - superoxide step and that the small post-wave was due to the superoxide oxidation. To check this further, a standard addition of sodium apperoxide. $\mathrm{NaO}$. was made, and a pronounced increase in the peak height of the post-wave was observed, which supports our helief that the wave is due to superoxide oxidation.

It is also worth noting that a new cathodic voltammogram at $-0.5 \mathrm{~V}$ vs Ir ORE was detected following the $\mathrm{Na}_{2} \mathrm{O}$ : addition. The wave apparently involves a one-ectron step. Although it is interesting to speculate on various electrode reactions, at present it can only be said that the wave results from the reduction of peroxy and superoxy species. The value of the reduction putential [ $-400 \mathrm{mV}$ more negative than that for Nill)] for this process is suprising.

After one day the wave heights of the voltammograms had diminished. and after about four days the effect of the Na.O: was no bager detected. The reason that an increase in the first anodic wave (believed to be due to oxide $\rightarrow$ petuxide) was not seen as the peroxide decomposed $\left.120^{\circ}=-0_{:}+20^{\prime}\right)$ is that the melt may have already been seturated with ixide. The fact that the second anodic wave increased upon adding $\mathrm{Na}_{2} \mathrm{O}$ : supports our belief that this wave. although complicated. is due to peroxide oxidation.

These observations continue to be encouraging. The reproducibility of the curves for a given set of conditions is generally good. It is believed that a significant step has been taken toward the capability of in-line monitoring of the oxide level in fluoride melts under favorable conditions.

\section{REFERENCES}

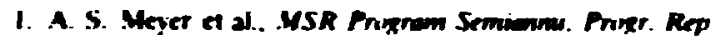
Akx. H. 1075. ORNL.507\%. p. 44.

2. This repon. Sects. 6.11 6.13.

3. This repon. Sects, I.1.1 and 1.1.2.

4. This nepon. Sect. I.I.3.

5. H. E. McCoy. Materials for Salt Concaining Vesuets and Piping-" in The Development and Siarus of Malem-Selt Reariors. ORXil-412. p. 207 (February 1975).

6. A. 5. Meget a al. MSR Program Semienmu. Protr. Rep ALs. 31. 1975. ORXL-507K. p. 48.

7. C. F. Ramberger. J. P. Young. and R. G. Ross. Th Chemisary of Tellurium in Molesen Li; Bef.- J. Inung. Vurl. Chem. 34. 1155 (1974).

B. A. Weissberger (ed.). Physical Methods of Chemisury. Parr IIA: Ekctrochmiced Methods. p. 620. Wilsy-Interscience. Vev York. 1971.

9. Ry. A. p. 602.

10. R. D. Armstrong. T. Dickinson. and K. Taylor. The Anodic Decomposition of Copper (I) S-Methylhexamethylenctetramine Bromide." $f$. Ekriromal. Chem. 6. 155 (1975)

11. A. L. Bacarelia and J. C. Griess. Jr.. The Anodic Dissolution of Copper in Flowing Sodium Chloride Solutions Between $25^{\circ}$ and $175^{\circ} \mathrm{C}$. A. Flertrorhem. Sex. 12, 459 (197.3).

12. This report. Sect. 3.4.

13. W. V. Childs. J. T. Maby. C. P. Kesrthelyi, and A. J. Rard. - Vottammetric and Coubmetric Siudies of the Mechanism of Electrodimerization of Diethyl Fumerate in Dimethylformamide Solutions," I. Electrochem. Sor. 118, 174 (1971). 


\title{
Part 3. Materials Development
}

\author{
H. E. McCoy
}

The main thrust of the materials program is the development of a structural material for the MSBR primary circuil which has adequate resistance to embrittlement by neutron irrediation and to shallow intergranubr attack by fosion product penetration. A modifred Hastelloy $\mathbf{N}$ containing $2 \%$ timaium has good resistance so inrdiation embritlement. but does not have suficient resistance to shallow intergranubr cracking by telurium. It appears necessary to modify the alloy by the addition of niobium to impart betier resistance to cracting.

Laboratory progams to study Hastelloy N-ahtelluriom interactions are being established, including the development of methods for exposing test materials under simulated reactor operating conditions. Surface-analysis capabilities have been improved so that the reaction products in the affected grain boundaries can be identified.

The procurement of products from two commercial heats $(8,000$ and 10.000 lb) of $2 \%$ titaniummodified Hastelloy $\mathbf{N}$ continued. Some of the seamless tubing was received and was of good quality. The products are being used in all phases of the materials program. One $2500-1 b$ heat of $2 \%$ tiknium plus 14 aiobiom modifed Hastelloy $\mathbf{N}$ was procured as several ber products. Small sath

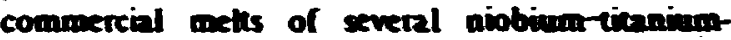
modifed alloys were obrined and were inchoded in all phases of the propram.

The wort on chemical processine materials is concentrated on evaluation of graphice for use in reductive extraction seps involving molven nalts and liquid bismuth. Capsale tests are in propress to study possible chemial inferections between erephicemetal systems and bismuth-lithiam solbiwns and to evaluate the mectanical intrusion of these solutions into the graphice.

Some of the effort durng this reporting period was expended in reesablishing test facilities. Six thermal. convection loops are in operation in the new bop facility. which will accommodate at least ten bops. The mechanical property and general tex facility is partially operational. but numerous rea fixtures remain to be assembled and tests snarted. An air lock has been added to the general text facility to make it more functional, and plans were partially developed for further expansion of the facility. 


\title{
6. Development of Modified Hastelloy $\mathbf{N}$
}

\author{
H. E. MeCoy
}

The purpose of this program is the development of metalix structural materials for an MSBR. The current emplasis is on the developuent of a material for the primery circuit. which is the most important problem at present. Material for the primary circuit will be exposed to a modest thermal-neutron fux and to fuel sale that contaiss fission products. A modifintion of standard Hastelloy $N$ will probably be a setisfactory meterial for this application. An alloy that contains $2 \%$ tianium appears to adequety resist irradiation cubrittlement. but the $2 F_{5}$ tianium does not impart adequate resistance to inter pranular embrittement by velurium. Additions of 0.5 to 25 niobium are effective in reducing tethrium-induced stallow intertanular crackinebut the eflects of neutron irrodiation on alloys containing niobium have not been characterixed fully. Obtaining this information has been a major part of our work during this report period. Increasing the chromium concentration from the present $7 C_{8}$ to between 12 and 159 may ako be beneficiai in preventing telhurium-induced shallow intergranular attack. Currently. Ectors associated with production of the $2 C_{c}$ titanium-modified alloy in commercial quantities are being studied. while smalker heats are being made of Hastelloy $\mathbf{N}$ containing additions of niobium alone as well as additions of niobium and mre earths to $2 \%$, titanium-modified Hastelloy $\boldsymbol{N}$. These materials are being evaluated.

Two large heats, one $10,000 \mathrm{lb}$ and the other 8,000 Ib. of the $2 \%$ titanium-modified alloy have been meited by a commercial vendor. Product shapes including plate, bar, and wire have been oblained for use in the alloy development program. Tubing is currently being produced by two independent routes. The various product forms from the two large heats are being used to fabricate the salt-contacting portions of two forced-circulation loops. One 2500-Ib heat of an alloy modified with $2 \%$ titanium-1\%; niobium was produced and converted to bar products.

Laboratory methods for studying Hastelloy $\boldsymbol{N}$. salt-tellurium reactions are under development. Methods must be developed for exposing candidate structural materials to simulated reactor operating conditions. Tests are being run in which specimens are exposed at $700^{\circ} \mathrm{C}$ to the low partial pressure of tellurium vapor in equilibrium with tellurium metal at $300^{\circ} \mathrm{C}$. Other tests involve metal tellurides that are either added to salt or sealed in evacuated yuant vials to provide a source of tellurium. Several experimenal alloys have been exposed to tellurium. and the extent of intergranutar crecting was evaluated metallographically. Froential to this program are adequate tectaiques for idenifying and characterixins the reaction products. Several anchods for the ambyis of surface byets are under development.

Meterials thai are found to resist shallow intertranubr cracting in btoratory tests will be exposed to fossioning silt in the Oal Ridp Reseanch Reactor TeCer fuckd-capole series. Three sets of fuet pins bave been filled with feel ah and are at warious sages of evaluation. These pins are made of alloys modified with titanium. chromium. niobium. and titanium ples niobium.

\subsection{PROCUREMENT AND FABRICATION OF EXPERIMENTAL ALLOYS}
T. K. Roche
B. Mcriabb
J. C. Feltuner

\subsubsection{Production Heats of $2 \%$ Titaninm-Modified Hanelloy $N$}

One of the activities in the materials development program has been the production scak-up of 2\% titanium-modified Hastelloy N. a candidate structural material for the primary circuit of an MSBR. As reported previously.' two large heats of the alloy. one $10,000 \mathrm{lb}$ and the other $8.000 \mathrm{lb}$, have been produced by a commercial vendor. These heats have been used to establish processing parameters for producing plate, bar, and wire; and recent emphasis has been placed on processing seamless tubing. Mill products from these heats are being used in the general experimental program. with a principal use being the construction of two forced circulation loops designed for studying the compatibility of the alloy with fue! salt.

Two routes have been taketi, one by the vendor and the other by ORNL. for the fabrication of seamless tubing. with the starting stock in both cases originating from the $8,000-1 b$ heat of the alloy (heat No. 8918-5-7421. generally designated as 75421). The vendor's route included forging and tuming six fieces of bar, each 4.5 in. in diameter by $6 \mathrm{ft}$ long: production of a tube hollow by trepanning to a 4.5-in. $\mathrm{OD} \times 0.5$-in. wall by a subcontractor: tube reducing (pilgering) in th ree steps with intermediate anneals to 
20-in. $O D \times 0.063$ and 0.095 -in. wall: and drawing to final tubing sines. 1.0. 0.75. 0.5. and 0.375-in. OD $x$ 0.035 so $0.072 \mathrm{in}$. wall by a second subcontractor.

Since the probkem of siress-induced annaling cracks or fire cracting had been encountered to some degree with heat .W. 75421 during cold drewing and annealing of 0.312-in.dinm ber and 0.125-and 0.095 in. dian wire. the three tube-reducing operatious by the vendor were initinlly coafined to one tube hollow to determine if fure cracting would reman a problem. The iniermediate ansealing keuperature was $1121^{\circ} \mathrm{C}$. followed by water quencting. Ansaling of the bolbw between each tube-reducing operation was preceded by the ananealing of a sample which was then liquid-penetrant inspected for evidence of crackine With this procedure the holbow was caken through the tube-reducing steps and ansealing treatments with no major probsems. At this stage. approximalety it ft of 2.0-in. OD $\times 0.187$ in. well strck was avaible for further processing. Onethall of this quantity. or $12 \mathrm{ft}$. was then tube reduced to 1.25 -in. OD $>0.095$-in. wall $x$ about $36 \mathrm{ft}$ at the bacilities of the subcomtactor and was then returned to the vendor fier annealing. The tute was cut into four kngths. eaci about 9 ft. and returned to the subcontractor for the pilot drawing run to fmal sizes.

The reduction sehedule by plug drawing and sinking for the four keng 'hs of 1.25 -in. OD $\times 0.095$-in. wall tubing closely follo wed that for stainkess steel (i.e. approximately $25 \%$ riduction of area per pass). The schedule was designea to cover three of the four finish sizes required. The drawing and sinking operations were performed on a $15.000 \mathrm{lb}$ draw bench. Commercial lubricants were used. The lubrication practice consisted of applying Houghton Plastic No. 467 to the outside and inside surfaces. then drying for about $30 \mathrm{~min}$. During the actual draw, a lubricant, G. Whitfield Richards EPHA. was nowed over the outside diameter before the tube entered the die. The tubing was degreased and annealed at $\left.1394 \times(112)^{\circ} \mathrm{C}\right)$ after each draw. Annealing was carried out in a continuous. hydrogen-atmosphere furnace without water quench. The overall annealing cycke was slightly under $20 \mathrm{~min}$. once the tube entered the fumace, with time in the hot zone being about $6 \mathrm{~min}$. As with earlier practice. a 12-in. sample was cut from the tube, degreased. annealed. pickled. and then visually and liquid-penetrant inspected before committing the balance of the tube to these operations. Hardness measurements were made before and after annealing.

With the procedure out lined above, the quantity of tubing indicaled in Table I was produced from the pilot run with no difficulty. So tendency for cracking was indicated by the liquid-penetrant inspections. The hardness before and after annealing was typically R, 25-35 after cold working and $R_{m}$ 78-81 after annealing-

A final annaling temperature of $1450 \mathrm{k}(1177=\mathrm{Cl}$ has been specified for mill products of the allos. including tubing. In the production of cold dnewn bar and wire. the vendor precoded the $1450 \times\left(1177^{\circ} \mathrm{C}\right)$ anvel with a $1394 \mathrm{~K}\left(1121^{\circ} \mathrm{C}\right.$ annal since it was feth that the prior bower-temperature anneal helped to minimixe fure cracting. To Jetermine if there were any difference between a direct $1450 \mathrm{~K}\left(117^{\prime} \mathrm{C}\right)$ and 2 combined $1394 \mathrm{~K}\left(1121^{\circ} \mathrm{C}\right)$ plus $1450 \mathrm{~K}\left(1177^{\circ} \mathrm{C}\right)$ final aneal ior the tubing the iwo lengats of 0.750 in. OD $\times 0.072$-in. wall tubing were anocaled both ways. . To cracting was observed in either case by. liquid-penetram inspection. These kengths were also eddy-curren inspected at the facilities of the subcontrector and were compared against an 0.005 in. deep transverse nouch filed in one of the tubes. Three iadications within a kagah of about 4 in. were found in the center of the tube given the direct $1177^{\circ} \mathrm{C}$ anneal. The -defect" section was cut from the tube and inspected rediographically apairst a pernetrameter with an 0.010-in.diam bole and an 0.010-in.-wide nouch. No flaws could be found in the section. Reinspection with liquid penetrant again showed nothing. In addition. a '-in.-long ring was cut from each of the annealed tubes and was crushed flat with no evidence of cracking.

The tubing from the pilot drawing run has been received at ORNL. Prior to delivery. the various kngths were hydrostatically tested at 1000 psi: they passed successfully. Since receipt. additional inspections have been performed. A6-in. length of each size of tubing was cut. split in half longitudinally. and liquid-penetrent (red-dye) inspected on both ODand ID, no faws were found (Fig. 6.1). Metallographic examination of samples of the 0.750 -in. OD $\times 0.072$ in. wall tubing which were given the two annealing

Table 6.1. Tobing produced of 27\% vitainion molifind Hasteloy N derime pinot ma

\begin{tabular}{lcc}
\hline Size & \multicolumn{2}{c}{ Quantity } \\
\cline { 2 - 3 } & $\begin{array}{c}\text { Number of } \\
\text { piects }\end{array}$ & $\begin{array}{c}\text { Total length } \\
\text { (ft) }\end{array}$ \\
\hline 0.750-in. OD x 0.072-in. wall & 2 & 22 \\
0.500 -in. OD $\times 0.042$-in. wall & 2 & 26 \\
0.375 -in. OD X 0.035-in. wall & 4 & 44 \\
\hline
\end{tabular}




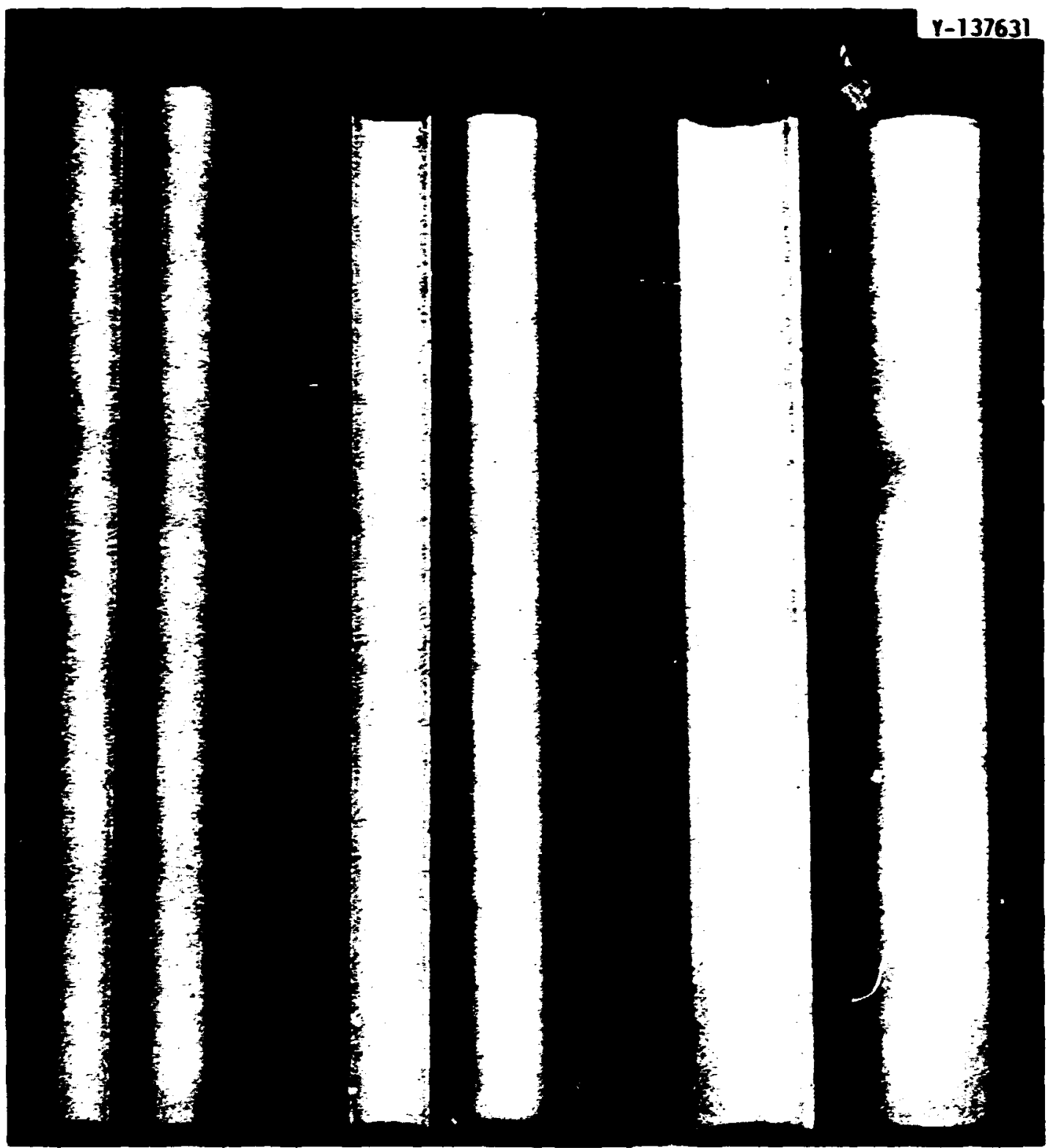

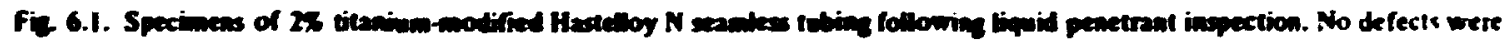
observed.

treatments showed recrystallized structures. All tubing from the pilot run was ultrasonically inspected and compared against standards of standard Hastelloy $\mathbf{N}$ with an 0.004 -in. deep notch. No indications greater than those from the notched standards were observed.

Following completion of the pilot drawing run. the remaining tube hollow stock was committed to the production run. The slock was tube reduced to 2.0-in. OI) $\times 0.187$-in. wall by the vendor, annealed, then further tube reduced by the subcontractor to the two previously mentioned sires. I.25-in. OD $\times 0.095$ and 0.083 -in. wall. (The lighter wall stock is scheduled to finish at 1.00 -in. OI) $\times 0.065-1 n$. wall by drawing.) $A t$ this stage, inspection of both cold worked (as tube reduced) and annealed specimens showed the OD. to be íree of flaws. but horescopic examination of the IDs indicated questionable:- reas. Subsequent metallographic examination of these areas revealcd the presence of cracks generally hetween 0.001 and 0.008 
in. deep with several between 0.012 and 0.018 in. decp. These craiks were oricnied paralkef to the tube

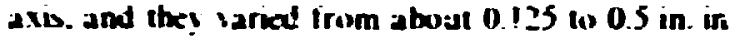
knzth. A tolal of ten kngths ol each of the 0.063-in. and 0.0\%5-in. wall slock were involved in this chaluation.

Sunce the pilise dra wing rus had been accomplished without difficulis. the incidence of ID cracking during the production run anas be satstectority explained at present. Sevcral options are open for the curnpletion of the prodection rua: ( I) hoax the IDs of the tube-raduced bollons to remove defects before proceeding with the drawing operations or (2) cummit a portion of the lot io final drawing with no ID conditioning. If the haws do not propezate and remain a constant percentaye of wall thictness. Iheir deptin at faish should be mosty within the inspection criterion of 3r; of the wall thickness or 0.004 in. whichever is greater. If the flaus to propapate. the balance of the lot will be avalable for ID conditioning prior to drawing. Option 2 is preferred.

is described in the previous progesess report. the second route to whain seamless tubing invotied hot exirusion of tube shells from billets machined from a forged har of heat Vo. 75421. Followed by cold drawing by an nutside source. The extrusions were made with maderale success but reyuired conditioning of the IDs to climinate hod tears. This pmblem was felt to be caused by inadeyuate glass lubrication. during extrusion. In test this assumption. two more extrusions were made using MoO: as the lubricant miber than glass. The billets were prepared from the same heat of the alloy with a motybdenum tube lining the IDs and a plasma-sprayed molybdenum coating on the OIS. These bilkets were exiruded at $1250^{\circ} \mathrm{C}$ to tube Manks. 1.625-in. OI) $\times 1.0$-in. 1D. or in extrusion ratio of approximately 10 to 1 . After removal of the residual molybdenum, the surfaces of the extrusions were found to be significantly improved. These tube hlanks were scheduled into the redra activities of the outside source. However. definitive results were not obtained on tine redraw characteristics of these extrusions since the altemate approach to obtain tubing was terminated at this proint. All tube processing effort was thell directed toward the routing of the first vendor and his subcontractor in view of their success with the pilot drawing run.

\subsubsection{Semiproduction Heats of $2 \%$ Titunium-Modified Hatelloy $\mathbf{N}$ That Contain Niobium}

Products of nine heats of r.obium-titaniummodified Hastelloy $\boldsymbol{N}$ have been received from a cuminercial sendor for a mure complete characteriation of alloys within this system. Chemial analyses are given in Table 6.2. Niobium additions to the 2r; titanium-modif:ed Hastelloy $\mathbf{Y}$ base are being sludied fo: enhar.cing resistance to iellurium embritthement. Eight of the alloys (heats 70025 through 76032) were $50-1 b$ vacuum induction plus vacuum arr remelied hats with niobium levels between about 0.5 and $\mathcal{M}_{i}$. Four of these alloys contain different levels of the residual elements iron. manganese. and silcon. whict. are important beause of their beneficial effects upon oxulation resiseance. The eight heats were successfully converted to ",-in. thick hot-rolled plate. approximatety 30 it per alloy. which is presently being prepared for weldability evaluation. Wire and rod are beine processed at ORNL from strips cut from the plate to provide material for weldability. salt corrosion. Iethrium compatibility. and mechanical propenty tests.

The ainch alloy (beat 76902 ) wes a $2500-1$ b vacuum induction plus electroslag remeled heat of nomisally IF; niobium-2r, tianium-modified Hastelloy $N$. Product received included $247 \mathrm{lb}$ of ${ }^{\circ}$-in.-diam bar. $538 \mathrm{lb}$ of " and $610 \mathrm{lb}$ of 4 -in.-square bar. Several bilkets have been cut from the 4-in.-square ber for hot rolling a small quantity of ' ${ }^{\text {in }}$-thick plate for weldability studies. Wire and mechanical property specimens are being prepared f-om the "is.tiam bar.

\section{STABILITY OF VARIOUS MODIFIED HASTELLOY N ALLOYS IN THE UNIRRADIATED CONDIION}
T. K. Roche
H. E. McCoy
J. C. Feltner

The sudy of the stabilits of niobium. titanium. and aluminum containing modified Hastelloy $\mathbf{N}$ with respect to intermetalic precipitation has continued. The objective of this study is to define the upper limits of these elements that can be added to Hastelloy $\mathbb{Y}$ and still maintain a reasonable degree of stability. The stabilities of a number of alloys. including bboratory. semiproduction. and production heats. containing varying amounts of the elements under consideration were determined by hardness. tensik propertics. creep-rupture properties. and microstructural evaluation. From results reported in the previous progress reperi" for titanium-aluminummodified Hastelloy $N$.' it was possible to propose gamma-prime solvus temperature boundaries at 650 and $704^{\circ} \mathrm{C}$ as a function of titanium and aluminum concentrations. During the present repon period the locations ol these boundaries have heen refined, and 


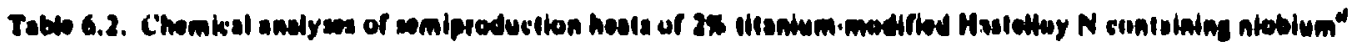

\begin{tabular}{|c|c|c|c|c|c|c|c|c|c|c|c|c|c|c|c|c|c|}
\hline \multirow{2}{*}{ Hout } & \multicolumn{17}{|c|}{ ('uncentrulluen (*x) } \\
\hline & $\mathbf{N i}$ & Mos & $C_{p}$ & $\mathbf{T i}$ & Nob & c & si & Mn & lio & A) & $\boldsymbol{\mu}$ & s & ('is & "I & $w$ & iv & Ix \\
\hline $\begin{array}{l}76023 \\
76026\end{array}$ & $\begin{array}{l}\text { Batione } \\
\text { Baliunce }\end{array}$ & $\begin{array}{l}1187 \\
12.07\end{array}$ & $\begin{array}{l}7.40 \\
7.21\end{array}$ & $\begin{array}{l}1.48 \\
1.49\end{array}$ & $\begin{array}{l}10.51 \\
0.95\end{array}$ & $\begin{array}{l}0.1862 \\
0.055\end{array}$ & $\begin{array}{l}0.05 \\
0.04\end{array}$ & $\begin{array}{l}<0.01 \\
<01.05\end{array}$ & $\begin{array}{l}0.106 \\
11.06\end{array}$ & 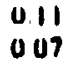 & $\begin{array}{l}0.01018 \\
0.110401\end{array}$ & $\begin{array}{l}\text { (1.01)1 } \\
\text { (1.01)2 }\end{array}$ & $\begin{array}{ll}0 & 17 \\
0 & 111\end{array}$ & $\begin{array}{r}\| 11001 \\
.11 .100 \mid\end{array}$ & $\begin{array}{l}11112 \\
0.111\end{array}$ & 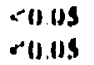 & $\begin{array}{l}\text { :11.115 } \\
\text { C(1) US }\end{array}$ \\
\hline 76027 & Bulance & 11.77 & 7.28 & 1.94 & 1.37 & o.ush & 0.0 .5 & . (1) 01 & 0.06 & D On & (1.100n & $(0 .(1) 1)$ & 0.09 & . (1) (10) & 0.01 & $\therefore 0.05$ & $\therefore$ il os \\
\hline 761) 28 & Mulunie & 11.84 & 7.1 .3 & {$[9]$} & $|8|$ & 0.060 & 0.01 & $.011 \mathrm{~s}$ & now & 1) 47 & UIMM & $\|(x) \mid$ & 0.04 & $.-\|(n) \mid$ & $(1.01$ &. HIIS & $\therefore 11.115$ \\
\hline 76029 & Balance & 12.04 & 7.22 & 19.9 & 0.94 & 0) 060 & 0.04 & $.010 \mathrm{~s}$ & 341 & 0.07 & (1.)(num & (1) (1011 & 0.114 & $\because 110411$ & $(113)$ & -13.115 & $\because 0.05$ \\
\hline 76030 & Holunco & 11.96 & 7.29 & 198 & 096 & 0.061 & 0.1 .5 & $\therefore 0.03$ & 010 & 11.10 & I) 0un & IIINUI & 1119 & J.001 & $(1,11)$ & $\because 0.05$ & .11.11S \\
\hline 76031 & Bistance & 11.98 & 7.28 & 2.01 & 0.97 & 0.037 & 0.015 & :.10.113 & 007 & 0.07 & 11) U1w & II a11) & U.111 & . (101) & $(1.01$ & $\therefore$ & $\therefore 0.115$ \\
\hline 76032 & Bulance & 12.09 & 6.98 & 198 & 0.99 & 0.062 & 0.12 & $0.1 \mathrm{x}$ & 9.10 & 007 & o out & 11.001 & 1). 64 & $\therefore(x) 1$ & 0.111 & $\therefore 4119$ & $<0<1$ \\
\hline 76902 & Balunie & 11.90 & 7.17 & 2.16 & 0.95 & 0.117 & 0.07 & $\therefore$ OI US & 0 & 01.1 & (1).001) & o.chIs & rous & . $0 .(10) 1$ & $(1) .(1) 1$ & Allos & $<(1) .(1) \mathrm{s}$ \\
\hline
\end{tabular}

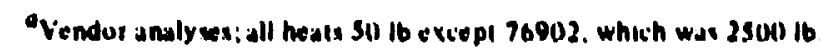


the sul ( Moumian has been proposed. Ihis has been prossible through the accumulation of edditional crecp-rupture. hiardnoss. and tensik data on earlicer alloys and tixe saluatuon of new compositions. sechanual property data for pertinent alloys are presented in lables 6.3 and 6.4 . and thexe data have been ancly/ed as a unil in arriseng at the propuxed cammaprime wis us at 650. 704. and xor ( Ifice (.).1.

The mechanical property tata in I ables 6.3 and 6.4 were grouped according to alloy stabilits at the barious temperatures. Al a given ess temperature. unstable allons show creep rates between one and three orders of mapritude less than the creep rates of stabke alloys. and the rupture lives of unsabic allons are signifanty bonget than those of stable alloys. In the case of barduess and tensile dan. instability or ape hardeaing results un an increase in bardness and strenglh and a cecrase in ductility retalive to values for anficaled malerial. This study has shom n that the M; tianium-modifed Hastellọ $N$ allow $a n$ contain up to ahuet 2.2\%; tilanium with $6.4 \%$, aluminum and still retain reasumable stability.

\subsection{MECHANICAL PROPERTIES OF MODIFIED HASTELLOY N ALLOYS IN THE UNIRRADIATED CONDITION}
I. K. Roche
J. C. Feliner
B. Mclibb

The determination of reference mectianical property data has continued for the varions heats of modified Hastelloy $\mathbf{N}$ =lloys being evaluated. These data incluck room-and elevaled-temperature uensik properties and creep-rupture properties in air al 650 . 704. and 760-C and serve as a reference for comparison with the propertics of scandard and other modified hastetlon. I alloys both in the unirradiated and irrediated conditions

Several of the heats of $F_{i}$ tiranium-modified Hastelloy $\mathbf{I}$ which bave heen factored into the program include two production heats 179001 and 75421) and sx semproduction beals (74533. 74534.

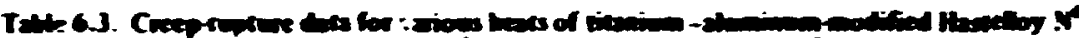

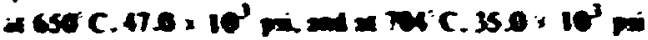

\begin{tabular}{|c|c|c|c|c|c|c|c|c|c|c|}
\hline \multirow{3}{*}{ Cafrots } & \multirow{3}{*}{ Heal } & \multirow{2}{*}{\multicolumn{3}{|c|}{ Contentration ('s) }} & \multicolumn{3}{|c|}{ Texied at $5711 \times 10^{3} \mathrm{pu}$ sad $650 \mathrm{C}$} & \multicolumn{3}{|c|}{ Texted as is $0 \times 10^{3}$ pon and $704 \mathrm{C}$} \\
\hline & & & & & \multirow{2}{*}{ 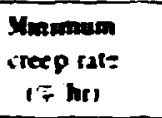 } & \multirow{2}{*}{$\begin{array}{l}\text { Ruprore } \\
\text { Inie } \\
\text { (hr) }\end{array}$} & \multirow{2}{*}{$\begin{array}{c}\text { Tolal } \\
\text { chomption } \\
\text { Tit }\end{array}$} & \multirow{2}{*}{ 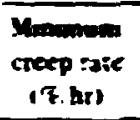 } & \multirow{2}{*}{$\begin{array}{l}\text { Repiure } \\
\text { bie } \\
\text { Itri }\end{array}$} & \multirow{2}{*}{$\begin{array}{c}\text { Total } \\
\text { Chmptom } \\
\text { if }\end{array}$} \\
\hline & & $\mathbf{T}:$ & Al & C & & & & & & \\
\hline $\mathbf{A}$ & 74901 & 18 & $n 10$ & 0 is & 0.020 & 395 ? & 26.87 & 0.0797 & 193.2 & 39.47 \\
\hline A & 75471 & 190 & 012 & 0.07 & D 0475 & 2634 & 26.6: & 0.1525 & 146.4 & 39.35 \\
\hline 4 & 74533 & 217 & 048 & cons & 00335 & 4646 & 30 55 & 0.1225 & 195.5 & 41.65 \\
\hline 4 & 74534 & 209 & $0 \leq 3$ & 0.28 & o ason & 3018 & 4281 & 0.1490 & 171.7 & 46.13 \\
\hline$A$ & 427 & 240 & 018 & $n 014$ & n.03ra & 26.6 & 21.69 & 01570 & 820 & 23.49 \\
\hline A & $42 \pi$ & 2.47 & 0.16 & 0004 & 00131 & 852.3 & $18+3$ & ก. 1470 & 2018 & 60.75 \\
\hline B & 429 & 240 & 0.35 & 0.017 & 09018 & 957.2 & $16.3 n$ & gom & 200.6 & 22.75 \\
\hline$B$ & $43 n$ & 2.50 & 0. 34 & n073 & 0.0016 & 34569 & 20.63 & 0.1380 & 2124 & s5.9 \\
\hline B & 476 & $=46$ & 041 & 0046 & 0.0012 & 25633 & 1318 & 0.1010 & 2717 & 45.15 \\
\hline $\mathbf{B}$ & 477 & 2.55 & 041 & ons2 & 0.0 .014 & $1344.1^{\circ}$ & $512^{c}$ & O.R950 & 272.2 & 42.76 \\
\hline$c$ & 44 & 3.90 & 0.13 & 0.077 & $0.00037^{d}$ & 1964.9 & $1.16^{d}$ & 0.0110 & $\ln 33 n$ & 29.98 \\
\hline D & 431 & 2.50 & 074 & 0016 & nonos & 23090 & 2.19 & 0.0002 & 2939.3 & 6.40 \\
\hline D & 432 & 2.35 & 0.69 & 0.051 & $0 \mathrm{~mm} 2$ & $4587.4^{c}$ & $1.68^{r}$ & 0.0003 & 3611.5 & 13.72 \\
\hline D & 478 & 2.50 & 0.75 & 0.055 & $0.00 \mathrm{ma}$ & $1340.2^{6}$ & $1.34^{c}$ & 0.00044 & 1341 of & $2.38^{r}$ \\
\hline D & 479 & 2.45 & 0.73 & n.058 & 0.00065 & $908.6^{\circ}$ & $0.98^{c}$ & 0.000 s & $908.0^{\circ}$ & $1.46^{c}$ \\
\hline$D$ & 443 & & 1.16 & 0.053 & 0.00057 & $908.9^{c}$ & $0.61^{c}$ & 0.0019 & $835.9^{6}$ & $6.16^{c}$ \\
\hline
\end{tabular}

Base. Ni 12\% Mo $77 \mathrm{Cr}$.

A Stabke al 650,704, and porer.

B Unstabie at 650 $C$ : slable at 704 and $800^{\circ} \mathrm{C}$

C Unsiabie a1 650 and $704^{\circ} \mathrm{C}$ : stabte al $800^{\circ} \mathrm{C}$.

D. Unstable at 650.704, and $800^{\circ} \mathrm{C}$.

'Test discontinued.

Test in progress. 


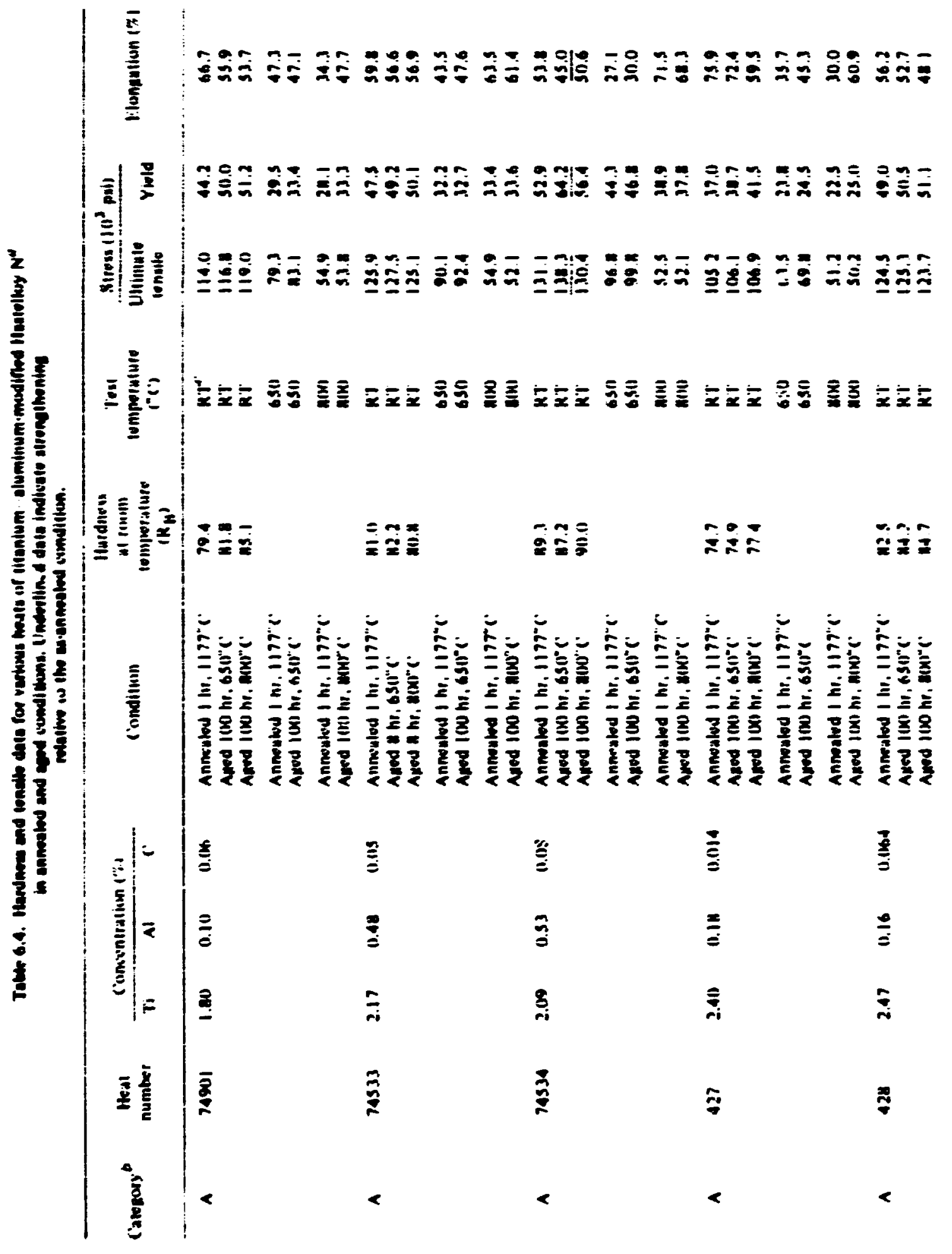




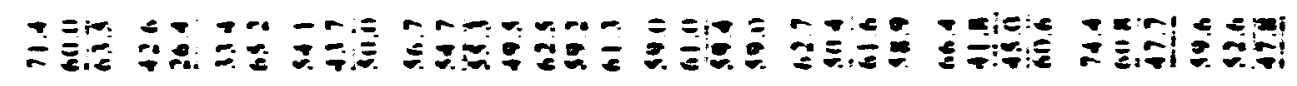

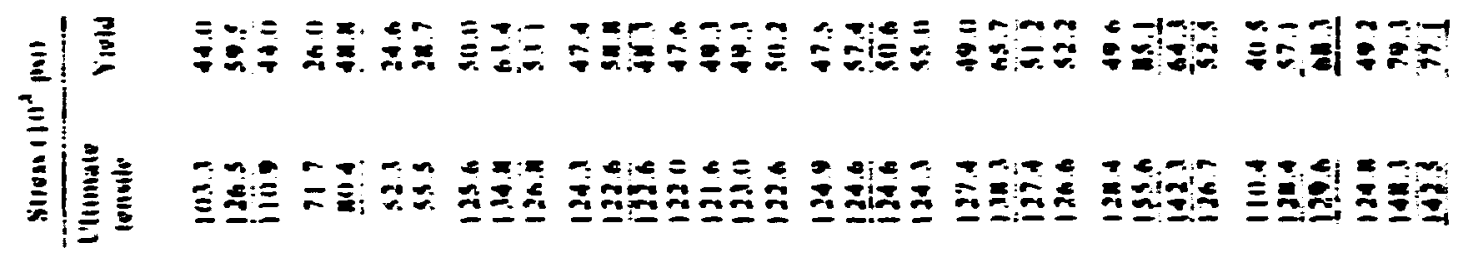

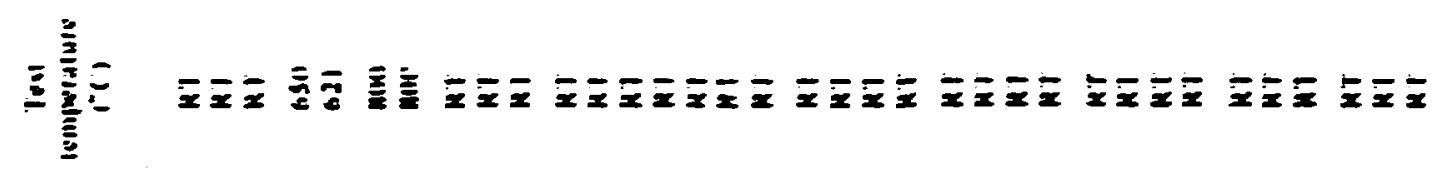

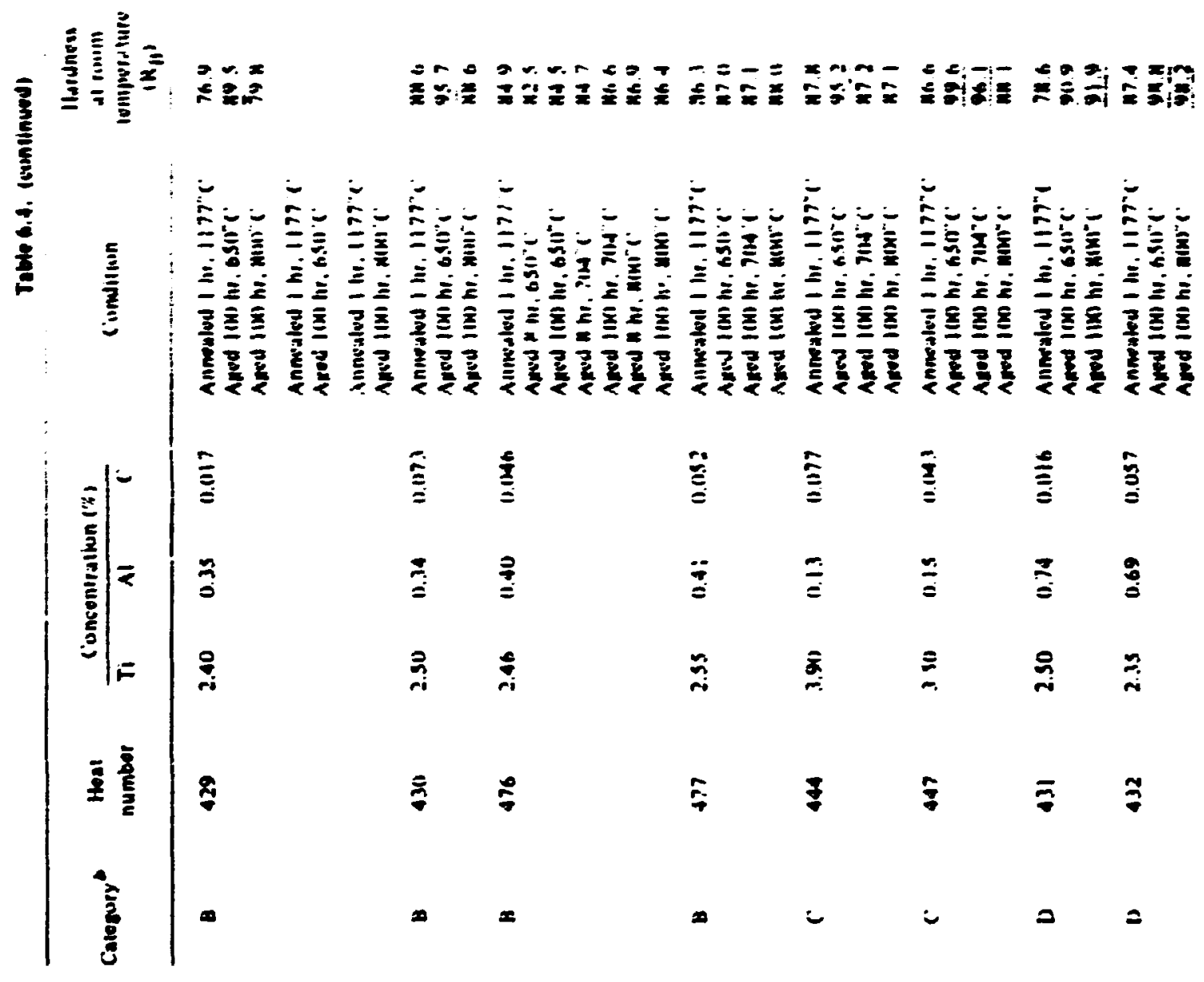




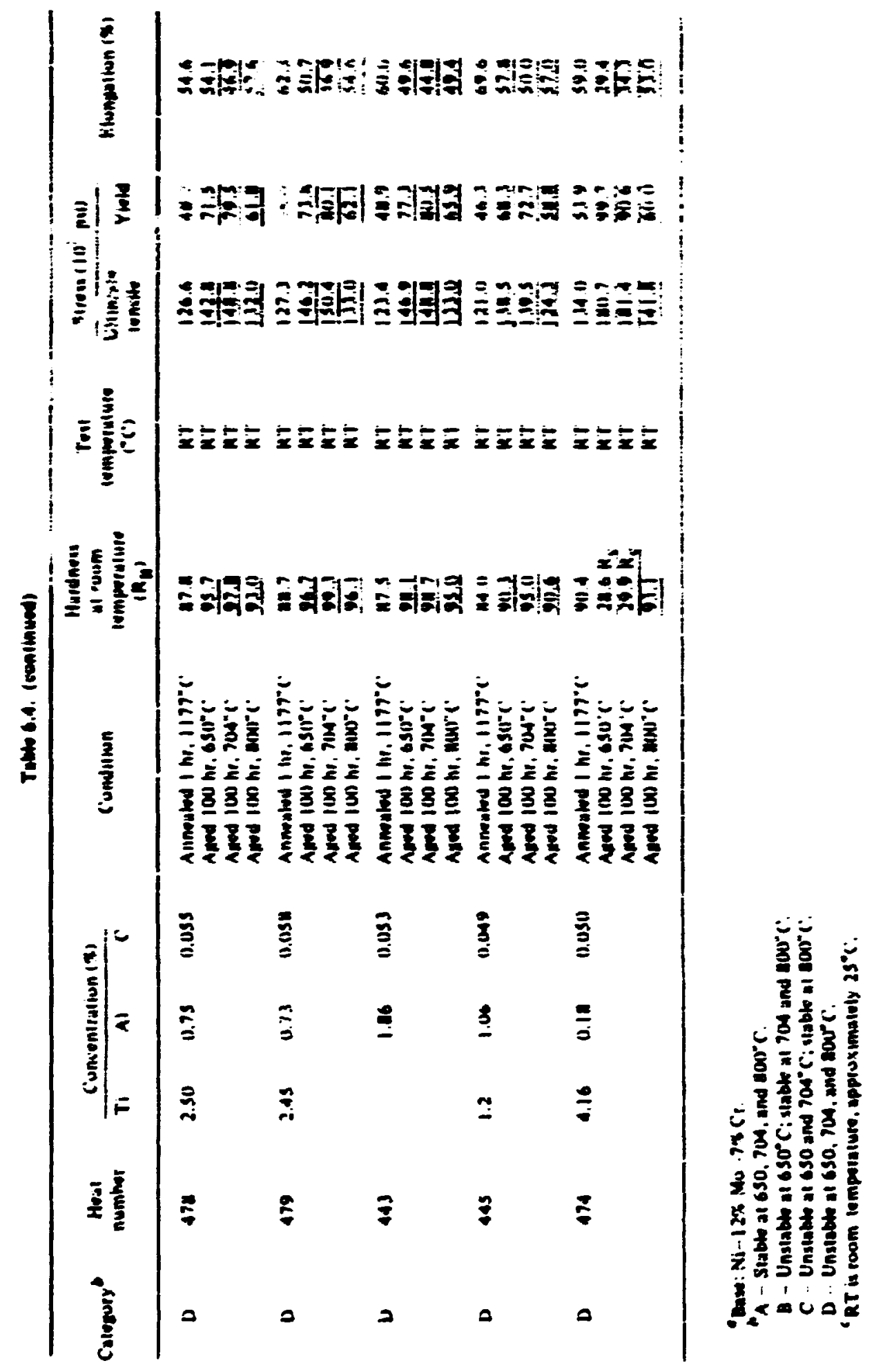




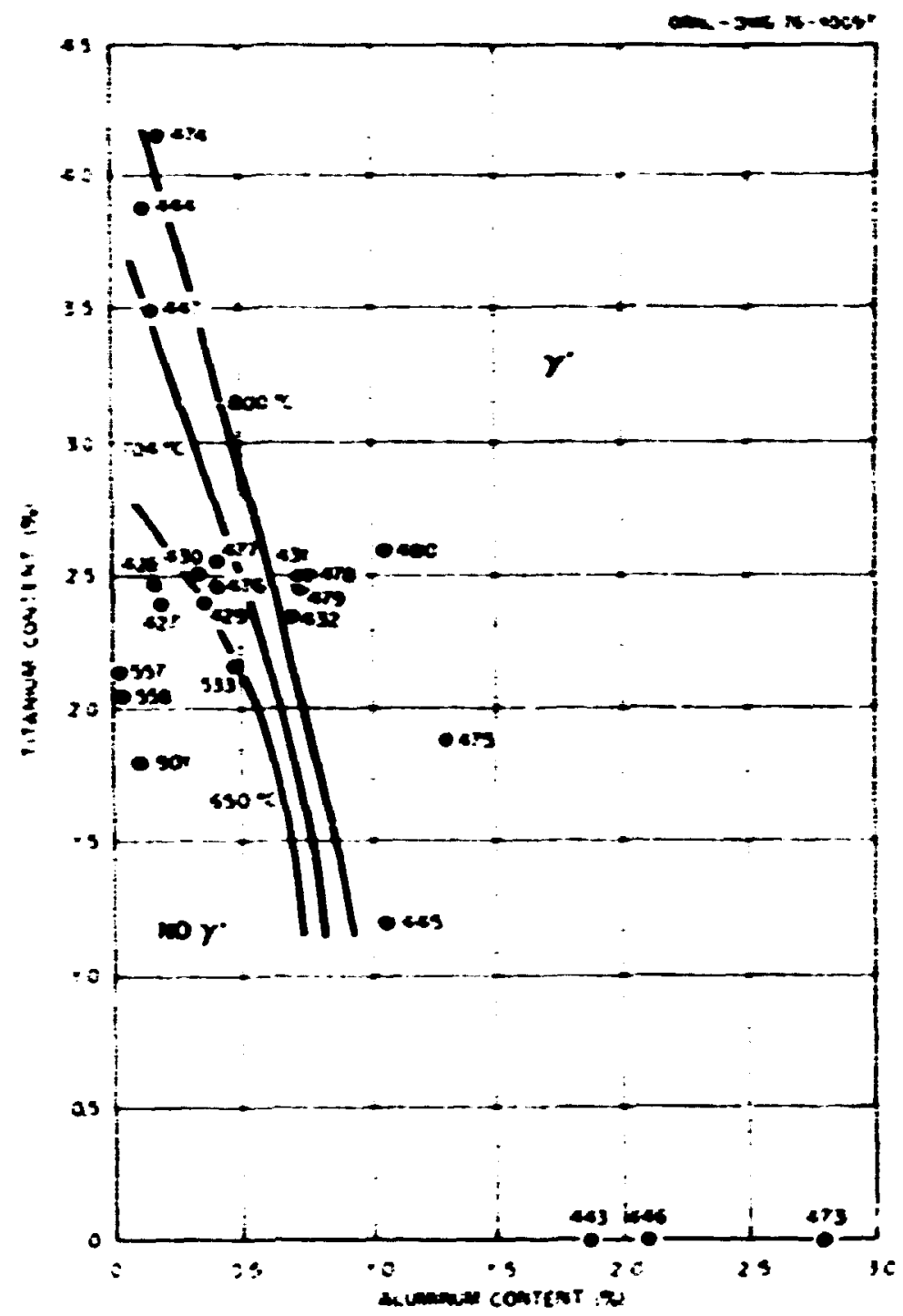

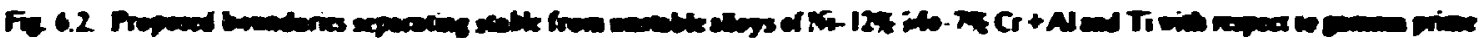

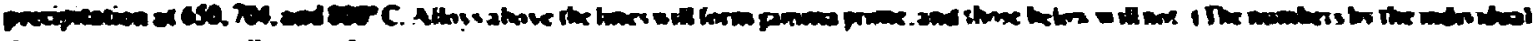

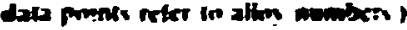

74535. 745.9. 74557, and 74554) produced by an outside vendor. Four of the six semiprnduction heats conlain small additions of rare earth elements. bnihanum. cerium. and misch metal. The componiinons of these alloys were chosen to study the effectiveness of rare-carthelement additions for minimizing the extent of shallow intergranubr cracking. The processing history and chemical analysis of these alloys have alrady been reported.'

During this repont period. creep-rupture tests were completed for heat 75421 at three stress kevels for each of three test iemperatures. The specimens were prepared from a 's-in. diam bar of the alloy and were given a pretest anmeal at 1177 C. In Table 6.5 a comparison is made between the rupture ines and elongations for this beat and the nange of these values determined for the other heats of this series. Al650 C the ruplure behavior of heat 75421 balls on the lower side of the rang. At 704 and $760 \mathrm{C}$ the rupture hehavior of this heat is more within the esablished range. In all cases the 25 tituniunmodified albys exhibit longer rupture times than standard Hastelloy $N$ tested under the same conditions.

Tensile properties at room and elevated temperature for several of the hats in the annealed condition. I he at $1177^{\circ} \mathrm{C}$. are presented in Table 6.6. Included 


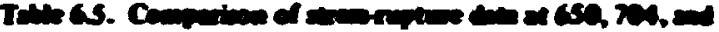

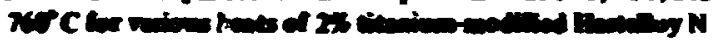

\begin{tabular}{|c|c|c|c|c|c|}
\hline \multirow[b]{2}{*}{$\begin{array}{c}\text { Ted } \\
\text { (C) }\end{array}$} & \multirow[b]{2}{*}{$\underset{\left(10^{3} \mathrm{pt}\right)}{\text { stees }}$} & \multicolumn{2}{|c|}{ Fea 75421} & \multicolumn{2}{|c|}{ Rna } \\
\hline & & $\begin{array}{l}\text { Reprove } \\
\text { Efe (tr) }\end{array}$ & $\begin{array}{c}\text { Rercese } \\
\text { (x) }\end{array}$ & $\begin{array}{l}\text { Rempere } \\
\text { Efe (lex) }\end{array}$ & $\begin{array}{l}\text { Romare } \\
\text { (x) }\end{array}$ \\
\hline 650 & $\begin{array}{l}40.0 \\
47.0 \\
550\end{array}$ & $\begin{array}{r}63 \\
265 \\
63\end{array}$ & $\begin{array}{l}32 \\
30 \\
29\end{array}$ & $\begin{array}{c}1120-1013 \\
302-591 \\
70-166\end{array}$ & $\begin{array}{l}23-42 \\
20-43 \\
18-51\end{array}$ \\
\hline 704 & $\begin{array}{l}25.0 \\
30.0 \\
35.0\end{array}$ & $\begin{array}{l}1164 \\
361 \\
146\end{array}$ & $\begin{array}{l}48 \\
48 \\
41\end{array}$ & $\begin{array}{l}073-1518 \\
301-49 \\
172-207\end{array}$ & $\begin{array}{l}36-97 \\
37-47 \\
39-63\end{array}$ \\
\hline 760 & $\begin{array}{l}15.0 \\
200 \\
250\end{array}$ & $\begin{array}{r}537 \\
301 \\
80\end{array}$ & $\begin{array}{l}32 \\
47 \\
54\end{array}$ & $\begin{array}{c}\text { sw-155s } \\
211-4: 6 \\
x-123\end{array}$ & $\begin{array}{l}25-54 \\
42-58 \\
47-57\end{array}$ \\
\hline
\end{tabular}

Arane for 74533.74534. ?4535. 74539. 74557. 74559. and 74301.

with these data are the properties for two eartier beats (beats 471-114 and 471-583) of 2\% titanium-modifed Hastelloy $\mathbf{V}$ and typiol propertics for surciand Hastelloy N. From the tabubtion. it can be seen for any one alloy that increasing teaperature within the cemperature mange of 650 to $800 \mathrm{C}$ has a greater effect in reducing the ultimate tensile strengh than the yield strength. In fact. the yield streagh of any one alloy remins retatively conetant in this teaperature renge, br: there are hatt-to-heat variations which realt in a epread from $40.01029 .0 \times 10^{3}$ pai. The data are prenented in the erenexal order of decreasing vield streath of the various bots at elevated ceraperature and there is an apperent correlation between yidd areagh and tianium content in the rance of 1.8 to $2.1 \%$. Note that the two hnthanum-contining alloys (heats 474-534and 4745s8) show the higheat yield atrengths. In making this correlation, other variables which abo influence censile propertics have not been considered.

All the alloys show a decreace in ductility (rupture elongtion) at elevated temperature relative to the value at room temperature, a characteriatic of nickefbase alloys. The magnitude of this decrease and the rate of recovery as temperature increases vary from heat to heat. As with creep-rupture propertics, the tensik properties of the $2 \%$ titanium-modified alloys are higher than those of the sandard alloy.

Niobium-modified Hastelloy $N$ seems to have good resistance to tellurium embritilement, and a new series of bbostory alloys beed upon Ni-12\% Mo-7\% Cr-0.2\% Mn-0.06\% C containins between 0 and $1 \%$ niobium in $0.2 \%$ increments was prepared for a clocer evaluation of rediation damere revistance.
Creep-rupture tests on unirmadinted specimens are under way in air at $650^{\circ} \mathrm{C}$ to establish beseline data. Limited results obtained thus far show that these alloys have shorter rupture lives at 650 ( than $2 \%$ tivenium-modified Hastelloy $N$.

\subsection{POSTIRRADIATION CREEP PROPERTIES OF MODIFIED HASTELLOY $N$}
H. E. MaCoy
T. K. Roche

Teats have been made on a number of alloys. bul the main emphas's during this report period was on alloys modified with niobium. Prior tents on these alloys measured the properties with ite material heat treated to produce a fme grain size. We bter lamed that guen anneals did not produce optimum properties in Hastelloy N, but our work had shown that the addition of about $2 \%$ titunium resulted in excellent resistance to imadiation embrittlement; so we did not continue inverivation of the niobium-modified alloys. Recent observations conceming the excellent resiutance of the niobium-modifed alloys to embritthement by tellurium offered added incentive to more fully investipte the irmdiation embrittement of the niobium-modifiad alloys.

Experiment ORR-233 was an for the explicit puppose of irredinting alloys curnenty on hand which contaned niobium." The individual tensile specimens were mounted in clusters of three inside a small heater (Figs. 6.3 and 6.4). The temperature was

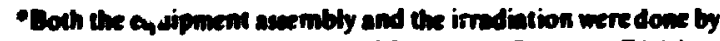
3. W. Woode and C. K. Thoma, Metale and Ceramios Division. 


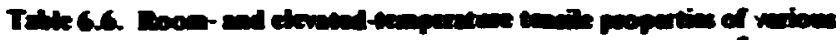

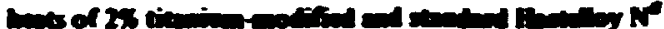

\begin{tabular}{|c|c|c|c|c|c|}
\hline Heat numbere & $\begin{array}{l}\text { Test } \\
\text { Iemperature } \\
\text { CO }\end{array}$ & 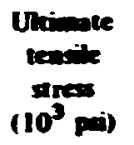 & $\begin{array}{c}\text { Yis. } \\
\text { Apes } \\
\left(10^{3} \mathrm{pil}\right)\end{array}$ & $\begin{array}{l}\text { Elompion } \\
\text { (X) }\end{array}$ & $\begin{array}{c}\text { Renection } \\
\text { ivarea } \\
\text { (ख) }\end{array}$ \\
\hline $474-534$ & $\begin{array}{r}25 \\
650 \\
704 \\
700 \\
210\end{array}$ & $\begin{array}{r}131.1 \\
958 \\
87.8 \\
688 \\
52.5\end{array}$ & $\begin{array}{l}52.9 \\
44.3 \\
45.5 \\
39.3 \\
38.9\end{array}$ & $\begin{array}{l}53.8 \\
27.1 \\
52.0 \\
77.0 \\
71.5\end{array}$ & $\begin{array}{l}59.5 \\
32.2 \\
46.2 \\
44.4 \\
67.2\end{array}$ \\
\hline $474-558$ & $\begin{array}{r}25 \\
650 \\
204 \\
700 \\
000\end{array}$ & $\begin{array}{r}126.4 \\
87.3 \\
81.5 \\
65.8 \\
53.1\end{array}$ & $\begin{array}{l}52.1 \\
38.8 \\
38.3 \\
38.7 \\
37.4\end{array}$ & $\begin{array}{l}54.3 \\
24.0 \\
25.8 \\
36.0 \\
47.8\end{array}$ & $\begin{array}{l}58.6 \\
30.5 \\
30.0 \\
32.7 \\
43.8\end{array}$ \\
\hline 474-557 & $\begin{array}{r}25 \\
650 \\
704 \\
760 \\
200\end{array}$ & $\begin{array}{r}130.4 \\
87.5 \\
83.8 \\
72.2 \\
56.9\end{array}$ & $\begin{array}{l}51.1 \\
37.3 \\
36.7 \\
37.1 \\
36.2\end{array}$ & $\begin{array}{l}57.9 \\
28.7 \\
23.5 \\
35.1 \\
46.2\end{array}$ & $\begin{array}{l}60.3 \\
28.6 \\
27.5 \\
31.6 \\
40.4\end{array}$ \\
\hline $474-533$ & $\begin{array}{r}25 \\
650 \\
704 \\
760 \\
800\end{array}$ & $\begin{array}{r}125.9 \\
90.1 \\
87.0 \\
68.6 \\
54.9\end{array}$ & $\begin{array}{l}47.5 \\
32.2 \\
32.1 \\
31.8 \\
33.4\end{array}$ & $\begin{array}{l}59.8 \\
43.5 \\
38.7 \\
54.6 \\
63.5\end{array}$ & $\begin{array}{l}61.4 \\
40.4 \\
30.8 \\
40.4 \\
53.2\end{array}$ \\
\hline 471.583 & $\begin{array}{l}25 \\
650 \\
760 \\
600\end{array}$ & $\begin{array}{r}121.8 \\
85.9 \\
64.4 \\
52.2\end{array}$ & $\begin{array}{l}45.9 \\
30.2 \\
29.4 \\
28.9\end{array}$ & $\begin{array}{l}73.3 \\
49.0 \\
45.0 \\
47.0\end{array}$ & $\begin{array}{l}60.1 \\
38.4 \\
47.1 \\
15.0\end{array}$ \\
\hline $471 \cdot 114$ & $\begin{array}{r}25 \\
650 \\
704 \\
760 \\
800\end{array}$ & $\begin{array}{r}120.7 \\
86.9 \\
82.3 \\
64.3 \\
50.6\end{array}$ & $\begin{array}{l}44.8 \\
29.1 \\
28.6 \\
28.7 \\
29.7\end{array}$ & $\begin{array}{l}72.6 \\
56.2 \\
53.4 \\
52.8 \\
51.0\end{array}$ & $\begin{array}{l}58.9 \\
39.6 \\
40.5 \\
50.4 \\
55.4\end{array}$ \\
\hline $674-901$ & $\begin{array}{r}25 \\
650 \\
704 \\
160 \\
600\end{array}$ & $\begin{array}{r}114.0 \\
79.3 \\
71.9 \\
66.9 \\
54.9\end{array}$ & $\begin{array}{l}4.2 \\
29.5 \\
27.9 \\
29.2 \\
28.1\end{array}$ & $\begin{array}{l}66.7 \\
47.3 \\
33.5 \\
31.2 \\
34.3\end{array}$ & $\begin{array}{l}35.4 \\
43.4 \\
36.8 \\
29.7 \\
29.5\end{array}$ \\
\hline $\begin{array}{l}\text { Standard } \\
\text { Hadelloy Ne }\end{array}$ & $\begin{array}{r}25 \\
650 \\
704 \\
760\end{array}$ & $\begin{array}{r}114.4 \\
82.4 \\
69.9 \\
61.8\end{array}$ & $\begin{array}{l}44.7 \\
27.5 \\
28.0 \\
26.2\end{array}$ & $\begin{array}{l}50.0 \\
37.0 \\
24.0 \\
21.0\end{array}$ & \\
\hline
\end{tabular}

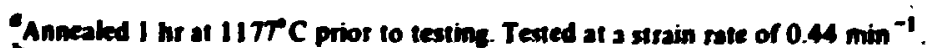

See Table 6.21 for detailed chemical compositions.

'Typical data for 0.045 in. thick sheet annealed at I1s0'C. 
measured by a themocouple attached to the center of the cluster. and the signal from this thermocouple was also used for temperature control. The assembly of 102 specimens was welded in an aluminum can for insertion into the Oak Ridge Research Reactor (ORR) for irradiation. The specimens were perpendicubr to the face of the reactor where the peak thermal fux was $1.5 \times 10^{: 4}$ neutrons $\mathrm{cm}$ " sec". After irradiation for $90 \mathrm{hr}$ to thermal tluences ranging from 2 to $5 \times 10^{\circ}$ neutrons $\mathrm{cm}^{\circ}$ and at cemperatures of 650 . 704. and $760 \mathrm{C}$. the assembly was removed from the $O R R$. The individual specimens were recovered in a hot cell and translerred to another cell for creep testing.

The partial chemical compositions of the alloys in this experiment are given in Table 6.7. The alloys contained from 0.45 in $2 \%$; niobium and various combinations of niobium and titanium. The postirr-

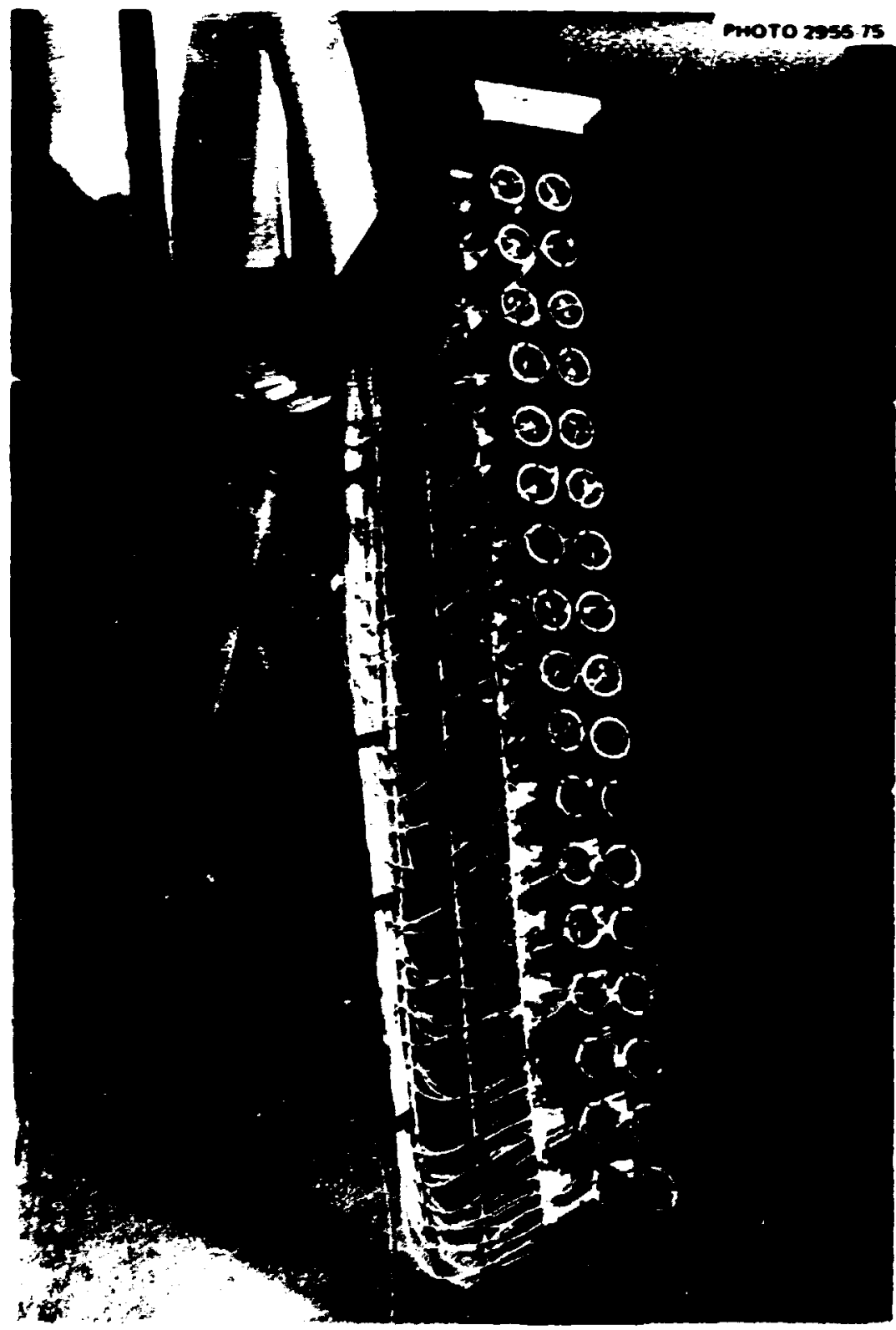

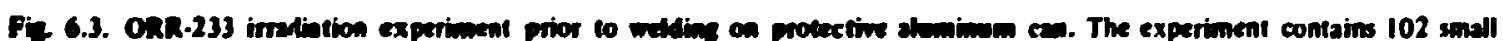
creep specimens with themocouples and heater for measuring and controlling the temperature. The rarious heater and ithermocouple lead wires are touted through ithe access fube to the control room. 


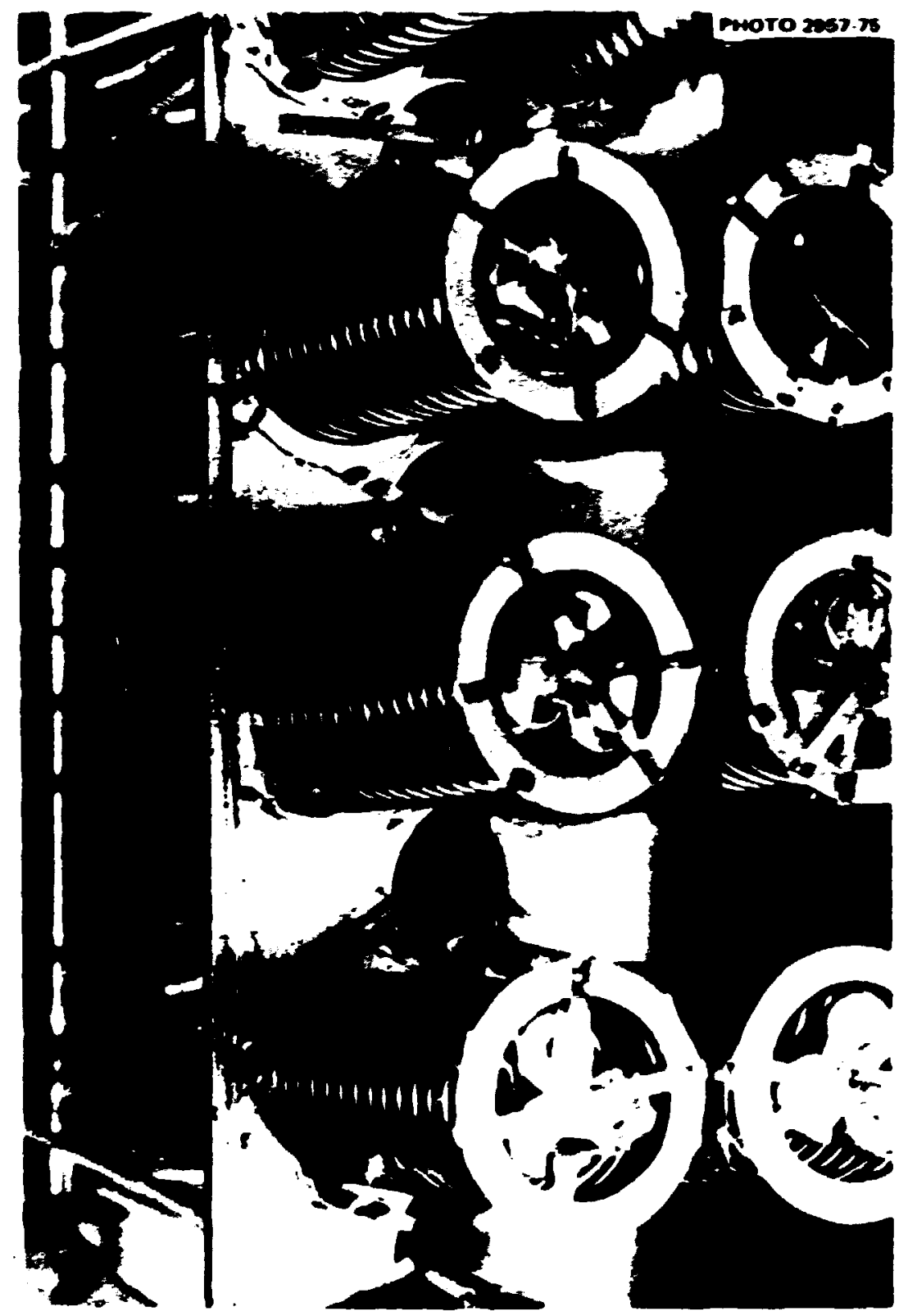

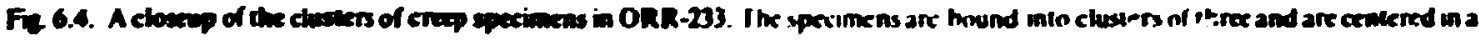
smoll furnaxe. A thermoneupte is atlached in the center of ithe cluster.

diation creep properties measured in date are summarized in Table 6.8. The stress-rupture properties at $650 \mathrm{C}$ of several of the alloys are shown graphically in Fig. 6.5. All specimens irradiated at $650^{\circ} \mathrm{C}$ had rupture lives in excess of those of standard Hastelloy $\mathbf{N}$ in the unirradiated condition. The fracture strains were quite high and gencrally fell in the 10 to $20 \%$ range. Irradiation at $704^{\circ} \mathrm{C}$ caused a pronounced deterioration of the properties of the alloys modified only with niobium. The alloys containing I to 2r; niobium were affected kess, and their propenies are still acceptable after irradiation at this condition. After irradiation at $760^{\circ} \mathrm{C}$. only the alloy containing $2 r$ iohium retained acceptable propertics.

Alloys 30.3 and 413 (fig. 6.5). which contained ninhium and itanium additions. had excellent postirmadiation properties after irradiation at 650 . 
74. and $760^{\circ} \mathrm{C}$. However. these alloys do not have good resistance to exbritulement by tethrian.

The results from three of the miobinam-modified alloys are shown ia more detail in Fia. 6.6 and 6.7 . The siress-rupture properties is Fis. 6.6 show that all three alloys had good rupore propertics afer irradiation at 650 C. thet alloys containing I and 24

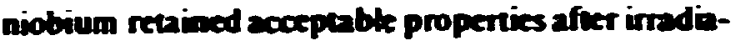

\begin{tabular}{|c|c|c|c|}
\hline \multirow{2}{*}{ Aloy } & \multicolumn{3}{|c|}{ Comprive (n) } \\
\hline & $\mathbf{m}$ & $\mathbf{T}$ & Odx \\
\hline 345 & 0.45 & & 0.225 \\
\hline 348 & 0.62 & & 0.475 \\
\hline 21543 & 0.7 & & \\
\hline 295 & 0.25 & & \\
\hline 411 & 1.0 & & \\
\hline 237 & 10 & & \\
\hline 20 & $2.0^{\circ}$ & & \\
\hline 303 & 0.24 & 0.9 & \\
\hline 304 & $10^{\circ}$ & 0.8 & \\
\hline 305 & 1.3 & ore & \\
\hline $400-725$ & 0.62 & 0.82 & \\
\hline 425 & 0.49 & 1.9 & \\
\hline 413 & 1.0 & $1.0^{3}$ & \\
\hline
\end{tabular}

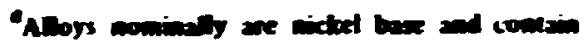
125 20. 75 Cr. $=0.05 \pi \mathrm{C}$.

Siominal vines. tion at $70 \% \mathrm{C}$. and that only the alloy coataining 24 aiobinm retained good properties after irradintion at $760^{\circ} \mathrm{C}$.

The miaiman creep ples for these three alloys are stown in Fis 6.7. One problem in this comperison is thet the specinens tested in the unirradied coodition were simply annealed I hr at 1177 - C before

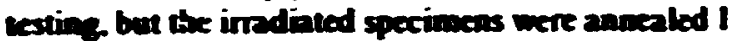
or at $1177^{\circ} \mathrm{C}$ and thes beld at the indicaled ceaperature for 94 ar daing intediation before creep lesting. The btter ineaten precipioles carbides and pewerally increases the creep rate by removing alloying etepents from sobetion. In the vairrediated condition. all three alloys have aboet equivaleat creep rates and are stronger (have bonet creep rates) than standand Hastelloy N. The linined data on alloy 21543 (0.75 niobina) show thet the creep rate wes increard by irrediation and that the increase was grater as the irradietion teuperature was increased. Alloy 237 (1\% aichina) exhibied a shigh increase in creep rate dec 10 irradiation at 650

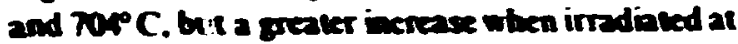
760 C. The creop rate of alloy 2\%3 (2\%; niobiusu) was not aliered detectably by irradiation at any of the three temperatenes.

Alloys 345 and 348 comaned additions of niobium and silicon and the resionace of these alloys to icllorium embritlemeat was excelient. However. these alloys had very poor postirrediation properties

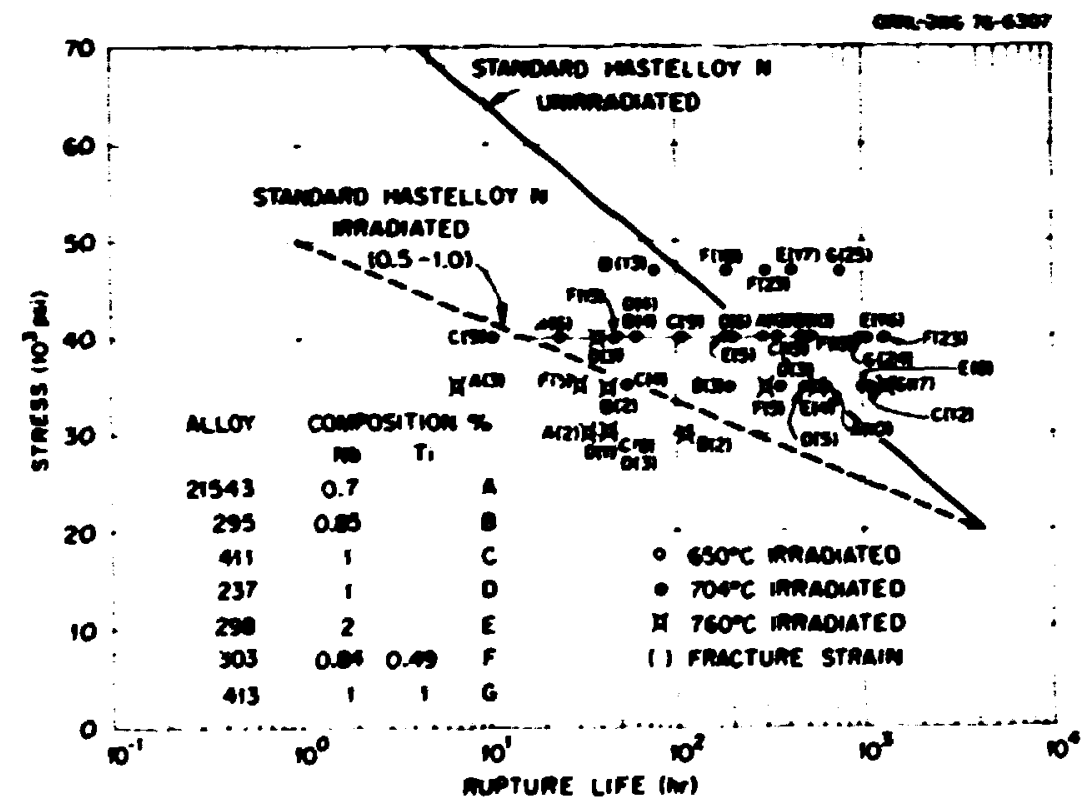

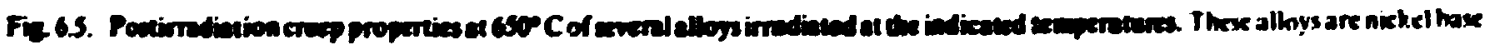

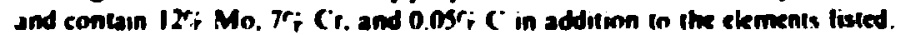




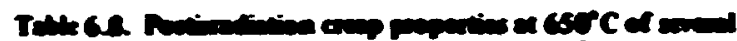

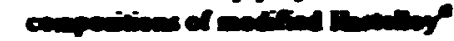

\begin{tabular}{|c|c|c|c|c|c|c|c|}
\hline Alay & Tor & 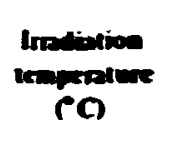 & $\begin{array}{c}\text { Streas } \\
\left(10^{3} \text { pal }\right.\end{array}$ & 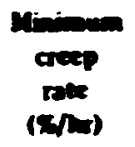 & $\begin{array}{l}\text { arese } \\
\text { (Ma) }\end{array}$ & Lisin & Totid \\
\hline 305 & $\begin{array}{r}02047 \\
020 \times 3\end{array}$ & $\begin{array}{l}650 \\
204 \\
704\end{array}$ & $\begin{array}{l}10.0 \\
10.0 \\
30.0 \\
35.0\end{array}$ & $\begin{array}{l}0030 \\
00325\end{array}$ & $\begin{array}{r}3.7 \\
10.8 \\
75.1 \\
2.0\end{array}$ & $\begin{array}{l}1.72 \\
1.45 \\
0.20 \\
3.15\end{array}$ & $\begin{array}{l}3.36 \\
2.20 \\
0.61 \\
3.97\end{array}$ \\
\hline 309 & $\begin{array}{l}02045 \\
02058\end{array}$ & $\begin{array}{l}650 \\
704 \\
704\end{array}$ & $\begin{array}{l}\mathbf{4 0 . 0} \\
\mathbf{4 0 . 0} \\
30.0 \\
35.0\end{array}$ & $\begin{array}{l}0.021 \\
0.070\end{array}$ & $\begin{array}{r}77.6 \\
8.6 \\
74.7 \\
12.4\end{array}$ & $\begin{array}{l}1.95 \\
1.85 \\
0.04 \\
3.00\end{array}$ & $\begin{array}{l}4.12 \\
4.05 \\
1.36 \\
4.13\end{array}$ \\
\hline 21543 & $\begin{array}{l}02033 \\
02014 \\
22033\end{array}$ & $\begin{array}{l}650 \\
650 \\
700 \\
704 \\
700 \\
700\end{array}$ & $\begin{array}{l}40.0 \\
35.0 \\
40.0 \\
30.0 \\
35.0 \\
30.0\end{array}$ & $\begin{array}{l}0.021 \\
0.011 \\
0.046\end{array}$ & $\begin{array}{r}232.0 \\
55.7 \\
24.8 \\
\\
7.1 \\
34.3\end{array}$ & $\begin{array}{l}4.25 \\
1.20 \\
4.05 \\
2.35 \\
1.13\end{array}$ & $\begin{array}{r}12.03 \\
10.11 \\
5.63 \\
\\
3.03 \\
1.55\end{array}$ \\
\hline IOS & $\begin{array}{l}R 2059 \\
122029 \\
R 2035 \\
R 2065 \\
R 2041 \\
R 2073\end{array}$ & $\begin{array}{l}650 \\
650 \\
704 \\
704 \\
700 \\
700\end{array}$ & $\begin{array}{l}47.0 \\
40.0 \\
40.0 \\
35.0 \\
35.0 \\
30.0\end{array}$ & $\begin{array}{l}0.059 \\
0.015 \\
0.035 \\
0.0053 \\
0.0000 \\
0.0003\end{array}$ & $\begin{array}{r}77.2 \\
48.3 \\
6.5 \\
191.9 \\
41.9 \\
110.7\end{array}$ & $\begin{array}{l}4.58 \\
2.36 \\
1.11 \\
0.29 \\
0.47 \\
0.39\end{array}$ & $\begin{array}{r}13.24 \\
9.56 \\
3.54 \\
3.36 \\
1.91 \\
2.21\end{array}$ \\
\hline 411 & $\begin{array}{l}22031 \\
\text { a } 2037 \\
\text { R } 2070 \\
\text { R } 2043\end{array}$ & $\begin{array}{l}650 \\
650 \\
704 \\
704 \\
700\end{array}$ & $\begin{array}{l}40.0 \\
35.0 \\
40.0 \\
35.0 \\
35.0\end{array}$ & $\begin{array}{l}0.018 \\
0.027 \\
0.023 \\
0.0005\end{array}$ & $\begin{array}{r}345.1 \\
1101.9 \\
105.4 \\
55.0 \\
415.2\end{array}$ & $\begin{array}{l}4.22 \\
2.99 \\
4.81 \\
2.49 \\
2.49\end{array}$ & $\begin{array}{r}15.42 \\
12.36 \\
9.15 \\
4.13 \\
7.76\end{array}$ \\
\hline 237 & $\begin{array}{l}R 2023 \\
R 2058 \\
R 2034 \\
R 2065 \\
R 2040 \\
R 2012\end{array}$ & $\begin{array}{l}650 \\
650 \\
704 \\
704 \\
700 \\
700\end{array}$ & $\begin{array}{l}40.0 \\
35.0 \\
40.0 \\
35.0 \\
35.0 \\
30.0\end{array}$ & $\begin{array}{l}0.016 \\
0.0051 \\
0.019 \\
0.0027 \\
0.014 \\
0.0055\end{array}$ & $\begin{array}{r}206.0 \\
46.1 \\
65.3 \\
365.5 \\
37.9 \\
4.0\end{array}$ & $\begin{array}{l}1.24 \\
0.35 \\
2.02 \\
1.32 \\
1.77 \\
0.26\end{array}$ & $\begin{array}{l}5.94 \\
4.82 \\
3.93 \\
3.16 \\
2.49 \\
1.32\end{array}$ \\
\hline 24 & $\begin{array}{l}R 2040 \\
R 2030 \\
R 2035 \\
R 2057 \\
R 2042\end{array}$ & $\begin{array}{l}650 \\
650 \\
704 \\
704 \\
700\end{array}$ & $\begin{array}{l}47.0 \\
40.0 \\
40.0 \\
35.0 \\
35.0\end{array}$ & $\begin{array}{l}0.028 \\
0.011 \\
0.011 \\
0.0014\end{array}$ & $\begin{array}{r}413.1 \\
1031.7 \\
106.6 \\
50.0 \\
565.6\end{array}$ & $\begin{array}{l}2.56 \\
1.17 \\
1.05 \\
0.25 \\
0.5\end{array}$ & $\begin{array}{r}16.74 \\
15.52 \\
4.44 \\
7.82 \\
3.77\end{array}$ \\
\hline 303 & $\begin{array}{l}\text { R } 2049 \\
\text { R } 2052\end{array}$ & $\begin{array}{l}700 \\
650 \\
650 \\
704 \\
704 \\
700 \\
700\end{array}$ & $\begin{array}{r}50.0 \\
47.0 \\
40.0 \\
47.0 \\
40.0 \\
40.0 \\
35.0\end{array}$ & $\begin{array}{l}0.019 \\
0.0052\end{array}$ & $\begin{array}{r}234.6 \\
1244.9 \\
184.1 \\
473.3 \\
\\
316.4\end{array}$ & $\begin{array}{l}3.22 \\
1.65 \\
2.92 \\
1.04 \\
0.30\end{array}$ & $\begin{array}{l}23.3 \\
23.3 \\
17.6 \\
15.4 \\
\\
5.15\end{array}$ \\
\hline 304 & $\begin{array}{l}R 2075 \\
\text { R 2015 }\end{array}$ & $\begin{array}{l}650 \\
650 \\
704 \\
704 \\
760 \\
760\end{array}$ & $\begin{array}{l}47.0 \\
40.0 \\
40.0 \\
35.0 \\
35.0 \\
30.0\end{array}$ & 0.12 & $\begin{array}{l}30.8 \\
67.6 \\
16.6 \\
12.8\end{array}$ & $\begin{array}{l}2.61 \\
0.70 \\
0.65 \\
0.90\end{array}$ & $\begin{array}{l}1.06 \\
3.46 \\
1.96 \\
1.44\end{array}$ \\
\hline
\end{tabular}


Trute che (continger)

\begin{tabular}{|c|c|c|c|c|c|c|c|}
\hline Anoy & Tax & 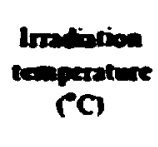 & $\begin{array}{c}\operatorname{sen} \\
\left(10^{3} \text { pais }\right.\end{array}$ & $\begin{array}{l}\text { creep } \\
\text { rate } \\
\text { (x/lar) }\end{array}$ & $\begin{array}{l}\text { Rerecte } \\
\text { life } \\
\text { (h:) }\end{array}$ & $\begin{array}{l}\text { Loadins } \\
\text { strie } \\
\text { (क) }\end{array}$ & $\begin{array}{l}\text { Toty } \\
\text { strin } \\
\text { (x) }\end{array}$ \\
\hline 305 & R 2003 & $\begin{array}{l}650 \\
650 \\
704 \\
704 \\
700\end{array}$ & $\begin{array}{l}55.0 \\
47.0 \\
55.0 \\
47.0 \\
35.0\end{array}$ & & $\begin{array}{r}82.0 \\
400.2\end{array}$ & $\begin{array}{l}4.57 \\
1.52\end{array}$ & $\begin{array}{l}19.2 \\
13.8\end{array}$ \\
\hline 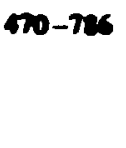 & $\begin{array}{l}12005 \\
12005 s \\
\text { R 200ss }\end{array}$ & $\begin{array}{l}650 \\
650 \\
704 \\
700\end{array}$ & $\begin{array}{l}47.0 \\
40.0 \\
35.0 \\
35.0\end{array}$ & $\begin{array}{l}0.0013 \\
0.0077\end{array}$ & $\begin{array}{l}134.3 \\
755.4 \\
345.5 \\
446.6\end{array}$ & $\begin{array}{l}3.90 \\
118 \\
1.09 \\
1.77\end{array}$ & $\begin{array}{c}20.9 \\
14.2 \\
7.19 \\
7.5\end{array}$ \\
\hline 425 & 22034 & $\begin{array}{l}650 \\
650 \\
704 \\
x 00 \\
700\end{array}$ & $\begin{array}{l}55.0 \\
47.0 \\
47.0 \\
40.0 \\
35.0\end{array}$ & & $\begin{array}{l}123.9 \\
871.3\end{array}$ & $\begin{array}{l}6.00 \\
2.95\end{array}$ & $\begin{array}{l}17.6 \\
16.7\end{array}$ \\
\hline 413 & R 2032 & $\begin{array}{l}650 \\
650 \\
760\end{array}$ & $\begin{array}{l}47.0 \\
40.0 \\
35.0\end{array}$ & 0.015 & $\begin{array}{r}725.3 \\
973.2 \\
1300.4\end{array}$ & $\begin{array}{l}3.25 \\
1.85 \\
1.28\end{array}$ & $\begin{array}{l}24.9 \\
24.1 \\
16.8\end{array}$ \\
\hline
\end{tabular}

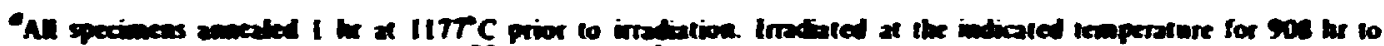

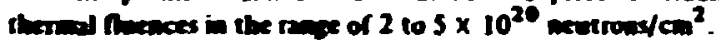

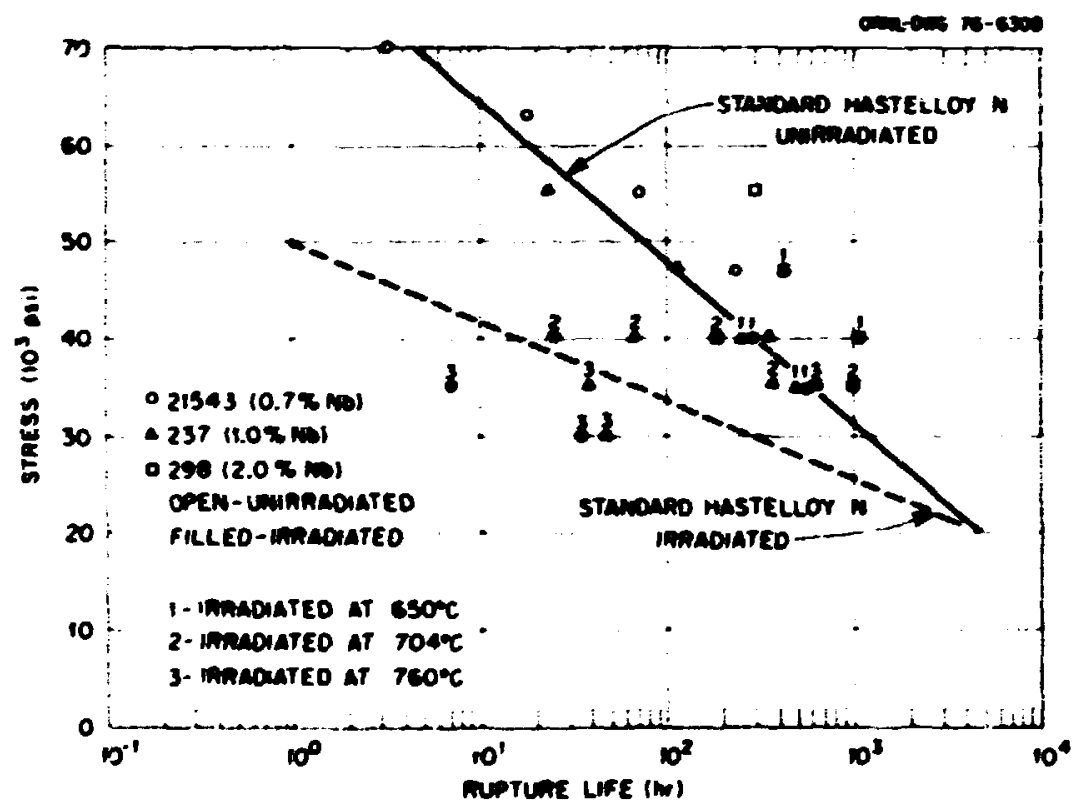

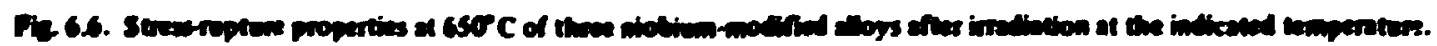




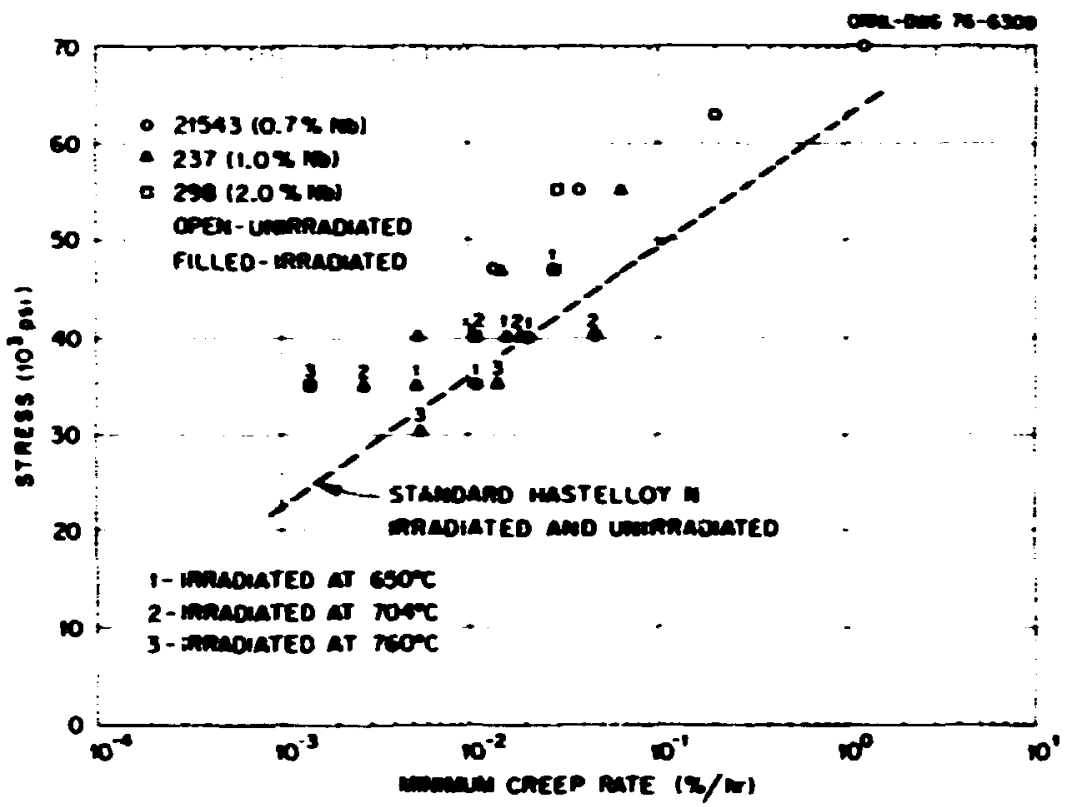

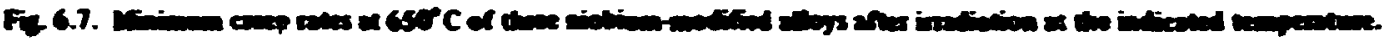

(Tabk 6.8). This result was anticipated because of the role of silicon in promoting the formation of coarse M.C-yype carbides rather than the fiacly dispersed MC-type carbides formed in the absence of silicon. It is not known whether the good resistance of these alloys to tellurium embrittement was from the presence of niobium or silicon or both. but these postirradiation results show clearty that silicon kevels in the range of 0.2 to 0.5 cannot be tolerated because of the effects on the mechanical properties.

These postirradiation creep data have shown that the niobium-modified alkuys have adequate resistance io embrittlement by neutron irrediation. Some further work is needed to optimize the niobium kevel and to definc the maximum albwable service temperature.

\subsection{MKCROSTRUCTURAL ANALYSIS OF MODIFIED HASTELLOY $N$}
D. N. Breski
D. J. Bredky
J. M. Leitnaks:r
G. A. Potter

Two largety independent studies are in progress concerning the microstructure of nickel-base alloys. One study is funded by the Molien-Salt Reactor Prozram and involves alloys of direet Prozram interest. In the other "tudy, which is being done by an OR AU student, sir, pler alloys ara being investigated to obtain more hasic data. However. both programs consribute to our understanding of nickel-base alloys. and research data fiese hoth programs are included in this report.

\subsubsection{Production of 2\% \\ Traninu-Hadelloy N Aloys with Uniform Cartide Diatrivion}

\section{N. Breski \\ J. M. Leitnaker \\ G. A. Potier}

Introdection. Improved properties. especilly those related to irrediation resistance. have been achieved by adding about 2 we 9 titanium to Hastelloy N. However. this new alloy demonstrated large. and as yet unexphined, variations in postirmdiation creep properties.' Metallographic examination showed that the microstructures of the inrediated samples were quite inhumoseneous. The purpose of this investigation was to develop metalturgical rechniques that could be used to produce a homoeneous microstructure in 2\%, titanium-Hastelloy $\mathbf{N}$. Specifically. the coal was to nemove the corbide stringers from the alloy and to redistribute the carbides uniformby throughout the microsenucture. With this accomplished. in was hoped that buth the mechanical properties and corrosion resistance of the alloy could be simuleancoushy optimized. Furthermore. it should be expected that the principles developed in reaching this goal would be generally applicable to most structural alloys. 
The tucwory effect- that is tho carbides reprecipitate into striagers afker mormal soletion annealiag and aging trotments. woll be discused firse. after whect the resules of varioes experinests aimed al producing aniform carbic destribution will be presculed and discussed.

The Memory EFfre. The microsirecture of thanium-modified Hastelloy $I$ comsists of two phases: (I) a face-cenered-cubic. aictet-rich matrix and (2) bace-centered-cubix. MCtype corbides. where $M$ is a combiration of primaris nothbdeaum. titanum. chrominam. and iron." inariably. the carbide partictes be in stringers or bues parallet to the

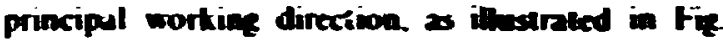
6.60. Which stoons a polished and etethed bongitudian section of swaged 0.25-in. dian rod from alloy 452 The chemical composition of alloy 452 Table 6.9) shows that this alloy contans 0.04 ent $F$ carboa - an anouse seffecicat 10 provide pood sireacth properies to Hastelloy $X$. When samples of alios 452 were sobution-anacaled for I hr at 1177 (a standard annealing ireatmeat wed for Hastetion V) most of the carbides mere dissolved into the matrix (Fig. 6.8h). Recrysalliantion and growh of the coldworked microsinecture lave ato caken plece. as evidenced by the brext. equi-axed grams. The grian boundaries were noulinear probably causad by the pining action of remaining carbides duriag the grain growth process. When the amples were aged for 160 hr at 760 C. Carbides precipitated out in the matrix (Fig- 6.86). Precipitation of arbides occurral predominateby in areas where they existed before the colution annal at II77. C and hence demonstrated what is colled a "wemory eflect."

A clarer picture of what happened in the microstructure of alby 452 during aging ix given in Fig. 6.9. This transmission etectron micrograph was bken from the same sample shown in fig. b.8r and

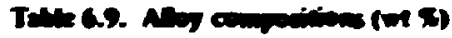

\begin{tabular}{|c|c|c|c|c|}
\hline \multirow{2}{*}{ Elowatent } & \multicolumn{4}{|c|}{ Allo menter } \\
\hline & 450 & 451 & 452 & 453 \\
\hline mo & 136 & 13.5 & 13.5 & 13.2 \\
\hline $\mathrm{Cr}$ & 8.1 & 3.2 & 7.1 & 1.2 \\
\hline $\mathrm{Ti}$ & 21 & 1.9 & 1.5 & 20 \\
\hline C & 0.052 & 0.017 & aors & 0.035 \\
\hline Mn & $<0.1$ & $<0.1$ & $<0.1$ & $<0.1$ \\
\hline No & $<0.1$ & $<0.1$ & $<0.1$ & $<a .1$ \\
\hline Fe & $\sim 0.3$ & -0.3 & -0.3 & -0.3 \\
\hline $\mathrm{Ni}$ & Delonet & Eabace & Ealuace & Nonese \\
\hline
\end{tabular}

shows that fox ivictype carbides precipitale out ina stacting lavin morpholog" alons (III) planes. Th: brex primary carbide lose that did not dixohe dariag the solution ancall bes a peouctic shape and woy have ponched on prismatic dislocations - bich initiale te growth of seationg bolk precipitale ribbows. However. it will be shown bier that primany

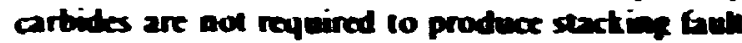

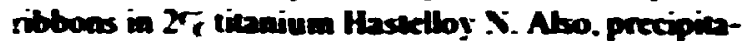
tion did not alweys ocever in ribbons. Frequenty carbides precipitated on disboctious bing along the (III) planes and formed this. separale phectets insteed of riblows (Fiz 6.10). Anabses by boh selexted-anca elextron diffrections of thim foils and $x$ rey diffection of etectroctreanicalty entrected precipitates showed that all the cartinies. nepadless of morphology. ene of the foc. MC type.

The main point in defining and tryiat to colet-

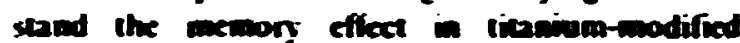
Hastelloy $X$ is that this eflect and be overcone in onder to bobricace an allon wilbout cartude striagers. As bas as the menory eflea mas occurriat. it was virtually impossible to at ind of carbide striagers. The exineral approecth to etiminatios the memory

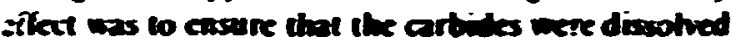
and in solution duriog the fabriction process. This could be carrial on in two wass (1) bowet the arton contian of the alloy and comine to lese the sane Lbricition sctuedule or (2) mainain a arbos conlent of $\rightarrow 0$ os we : bet adjost die fabriation paraneters so that the carbides rewain in solution dering labriation. Both of these approaches nexe investipled.

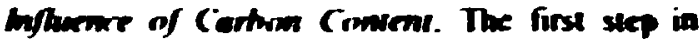
adjusting inc carbon content of elte alloy was to estimate the solubility of carbon in 2r; tikasiummodifed Hastellog 1 at $1177 \mathrm{C}$. Usiag precipitation extraction data from aged samples. the awount of corbon soluble in the allow at $1125^{\circ} \mathrm{C}\left(\sim 50^{\circ} \mathrm{C}\right.$ below the desired anneling temperature) was cakubted to he 0.045 wi $F_{\mathrm{T}}$ cathon. Thus a $2 \mathrm{~T}$ titanium-modified Hastelloy- $N$ alloy with hos than 0.045 w $r_{p}$ carboa should he free of carbide particles at IIT7 C. Alloys 451 and 453 were prepared with carbon contents of 0.017 and 0.035 w $i$ respectively. They were Gbriented into ' a-in. diam rod according to the Gbrication schedule (Table 6.10). With the lowet carbon content alloys, the solution annol conducted at IITT C after het swaying! was expacted to dissolve the carbides. With the arbides in solution. no stringers mere expected to form during the remaining cold swaging sueps. 

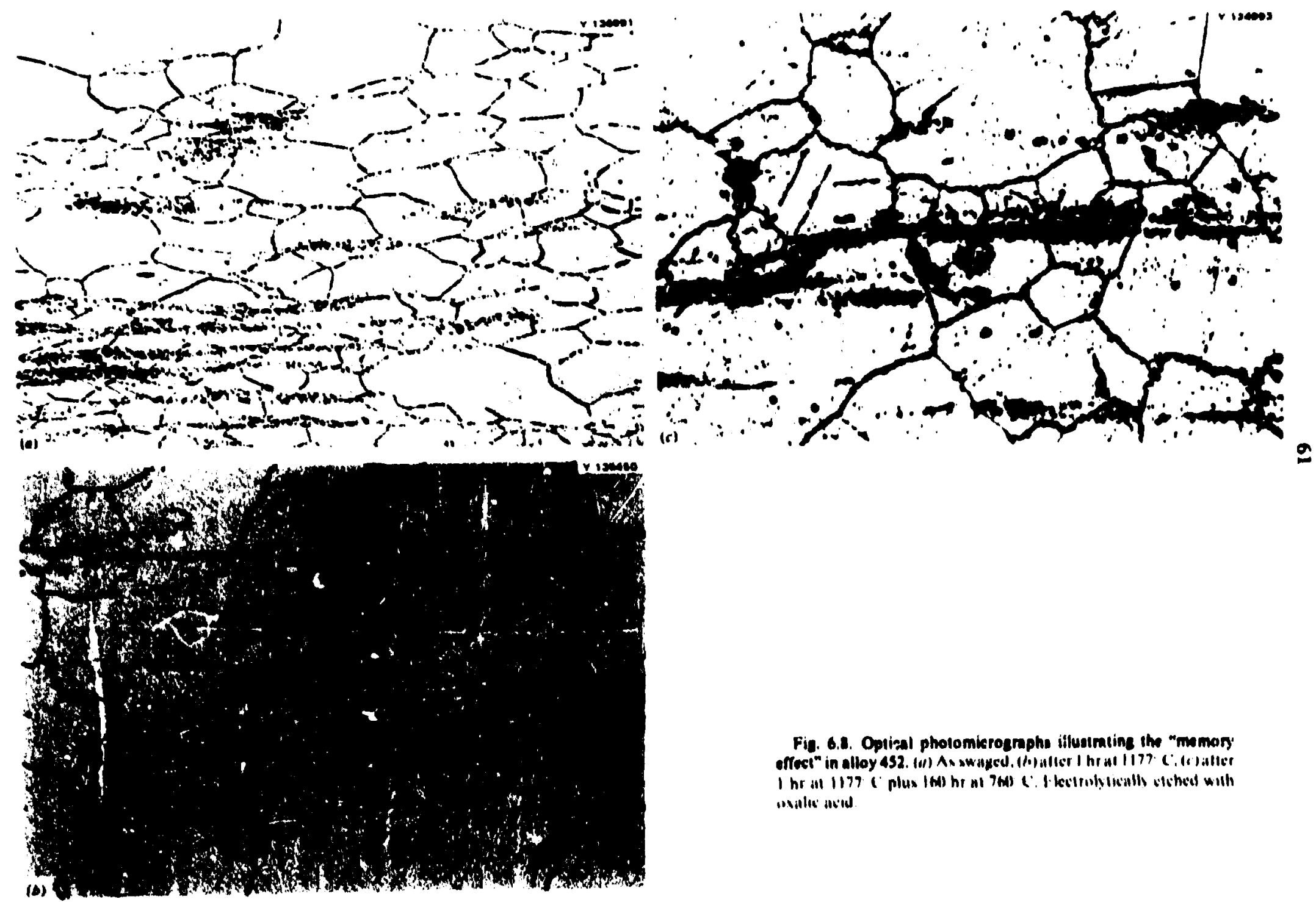

Fig. 6. Optiaal pholomikrognpho itluatmating the "momon

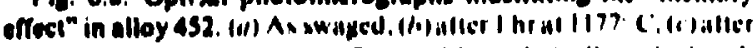

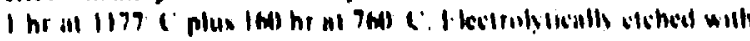
milles intid 


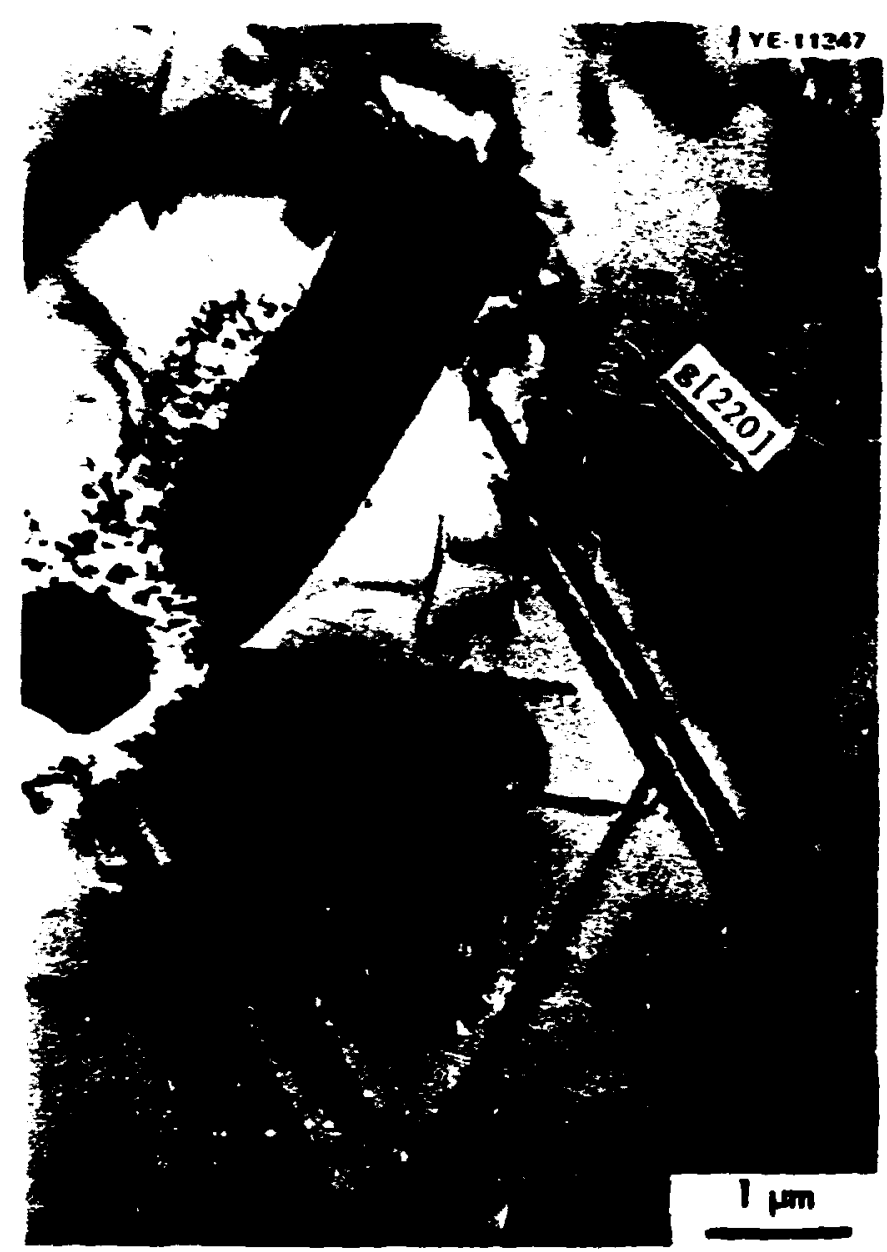

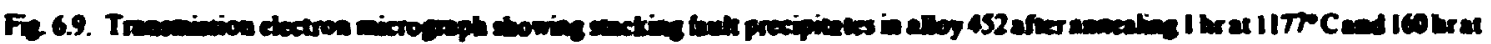
repc.

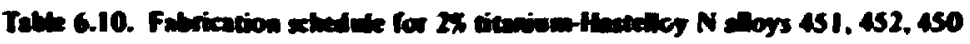

\begin{tabular}{|c|c|c|c|c|c|c|}
\hline $\begin{array}{c}\text { Siep } \\
\text { number }\end{array}$ & $\begin{array}{l}\text { Fabrication } \\
\text { process }\end{array}$ & $\begin{array}{c}\text { D':meter } \\
\text { (in.) }\end{array}$ & $\begin{array}{l}\text { Reduction } \\
\text { in ares } \\
\text { (x) }\end{array}$ & $\begin{array}{c}\text { Alloy 451 } \\
10.01750)\end{array}$ & $\begin{array}{c}\text { Nboy } 452 \\
(0.048 \pi()\end{array}$ & $\begin{array}{c}\text { Aloy } 450 \\
(0.0517()\end{array}$ \\
\hline 1 & Arc-drop cast & 1.00 & & & & \\
\hline 2 & $\begin{array}{l}\text { Hot swage at } 1177^{\circ} \mathrm{C} \\
\text { Pas 1 } \\
\text { Pass } 2 \\
\text { Pass } 3 \\
\text { Pass } 4 \\
\text { Pas } 5 \\
\text { Pase } 6\end{array}$ & $\begin{array}{l}0.87 \\
0.74 \\
0.64 \\
0.54 \\
0.49 \\
0.43\end{array}$ & $\begin{array}{l}24.7 \\
27.7 \\
25.2 \\
28.8 \\
17.7 \\
22.9\end{array}$ & $\begin{array}{l}15 \text { min reheat } \\
\text { time bet ween } \\
\text { pases }\end{array}$ & $\begin{array}{l}30 \text { min reheat } \\
\text { time between } \\
\text { passes }\end{array}$ & $\begin{array}{l}\text { Can in } 316 \text { stainless steet: } \\
\text { is mis rebeat time be. } \\
\text { tween penses }\end{array}$ \\
\hline 3 & Homopenizing anowal & & & $\begin{array}{l}\text { I h at } 1177^{\circ} \mathrm{C} . \\
\text { ais cool }\end{array}$ & $\begin{array}{l}2 \mathrm{hr} \text { at } 1177^{\circ} \mathrm{C} \text {. } \\
\text { ais cool }\end{array}$ & $\begin{array}{l}\text { I hs at } 1260^{\circ} \mathrm{C} \text {, air cool, } \\
\text { i hr at } 1300^{\circ} \mathrm{C} \text {, water } \\
\text { quench }\end{array}$ \\
\hline 4 & Cold swape of $25^{\circ} \mathrm{C}$ & 0.34 & 37.5 & & & \\
\hline 3 & Intermediate anoeal & & & It to at $1177^{\circ} \mathrm{C}$ & I th at $11777^{\circ} \mathrm{C}$ & $15 \min$ at $1177^{\circ} \mathrm{C}$ \\
\hline 6 & Cold swe at $25^{\circ} \mathrm{C}$ & 0.25 & 45.9 & & & \\
\hline
\end{tabular}




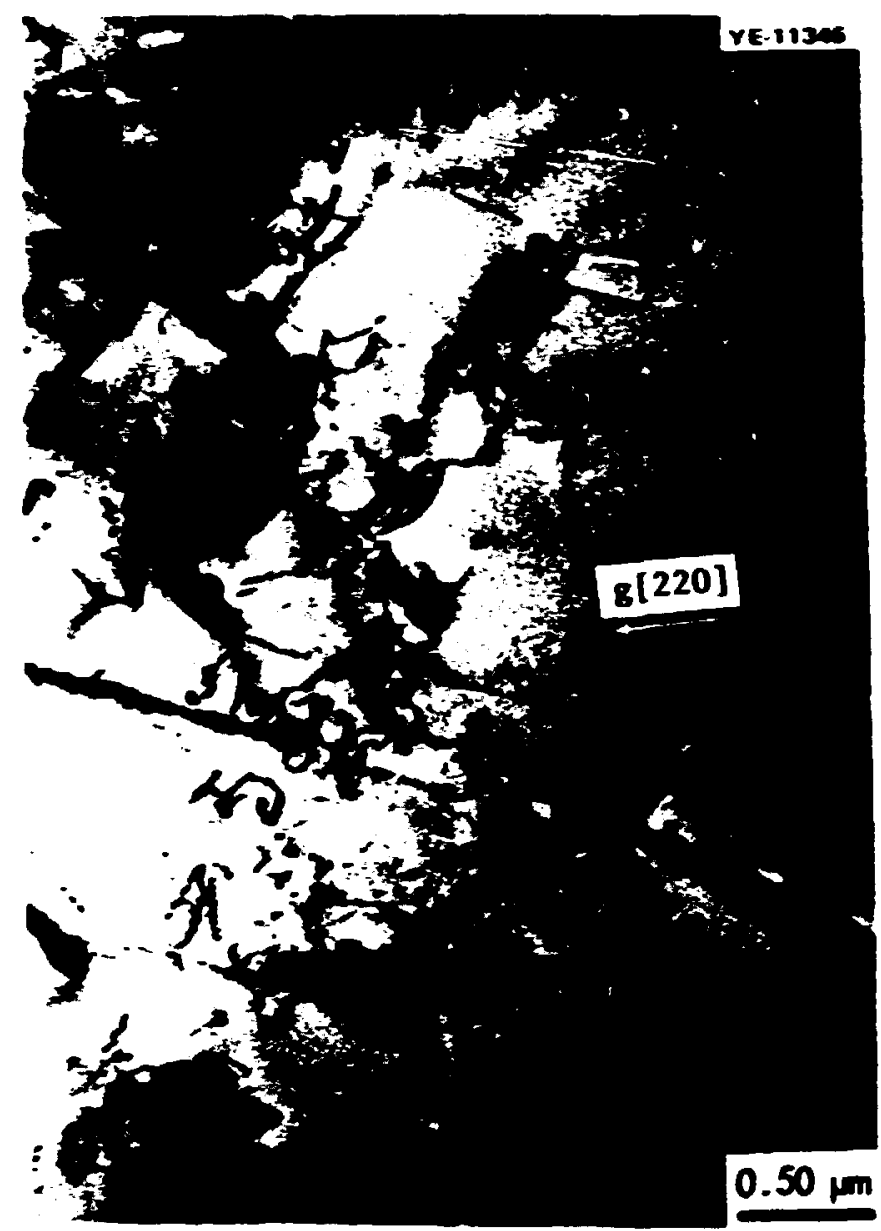

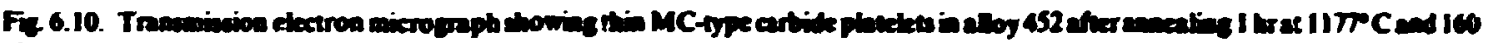
or a xioc.

Unfortunately. hoth alloys contained carbide stringers after fabrication was complete. as demonstrated by the microstructure of alloy 45$)\left(0.017\right.$ w: $r^{\prime} ;$ carton) in the as-swaged condition (Fig. 6.11a). However, when a sample of alloy 451 was given a I hr solution anneal at $1177^{\circ} \mathrm{C}$. almost all of the carbides

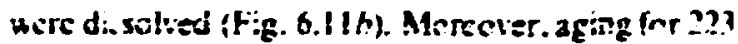
hr at $760^{2}$ produced no carbide stringers (fig. 6.Ilc). Instead. tiny carbide particks precipitated out on grain boundaries. twin houndarics, and preferentially on crystallographic planes. These details were more apparent with the electron microxcope. Figure 6.12 shows $M C$-1ype carbides in a grain boundary of the aged sample of alloy 451 . Figure 6. I 3 shows small MC platelets losated near the center of a grain in the sample. Trace analysis showed that the platelets all lic on (III) planes. Note that one of the thin MC platelets alsn lies in the (III) foil plane. Thesc results show that the memory effect must have been present during tabrication of alloy 451 but was eliminated when small samples of the same heat were solutionannealed for I hr at $1177^{\circ} \mathrm{C}$ after swaging. Assuming that the fabrication furnaces were at the correct temperatures. the solution annealing time necessany in disenlye the carhides must he sensitive to the mass of materiai being treated. Intuitively, this is reasonabke and has actually been observed repeatedly throughout the investigation. The results for alloy 453 were similar to those for alby 451 except that a final I hr at $1177^{\circ} \mathrm{C}$ did not remove the memory effect from that alloy. Higher annealing temperatures or Ionger times at $1177^{\circ} \mathrm{C}$ would be required to produce a uniform carbide distributicn in this 0.035-wi of carbon alloy.

The rate of carbide dissolution was determined quantitatively for both alloys 452 and 451 by solution 


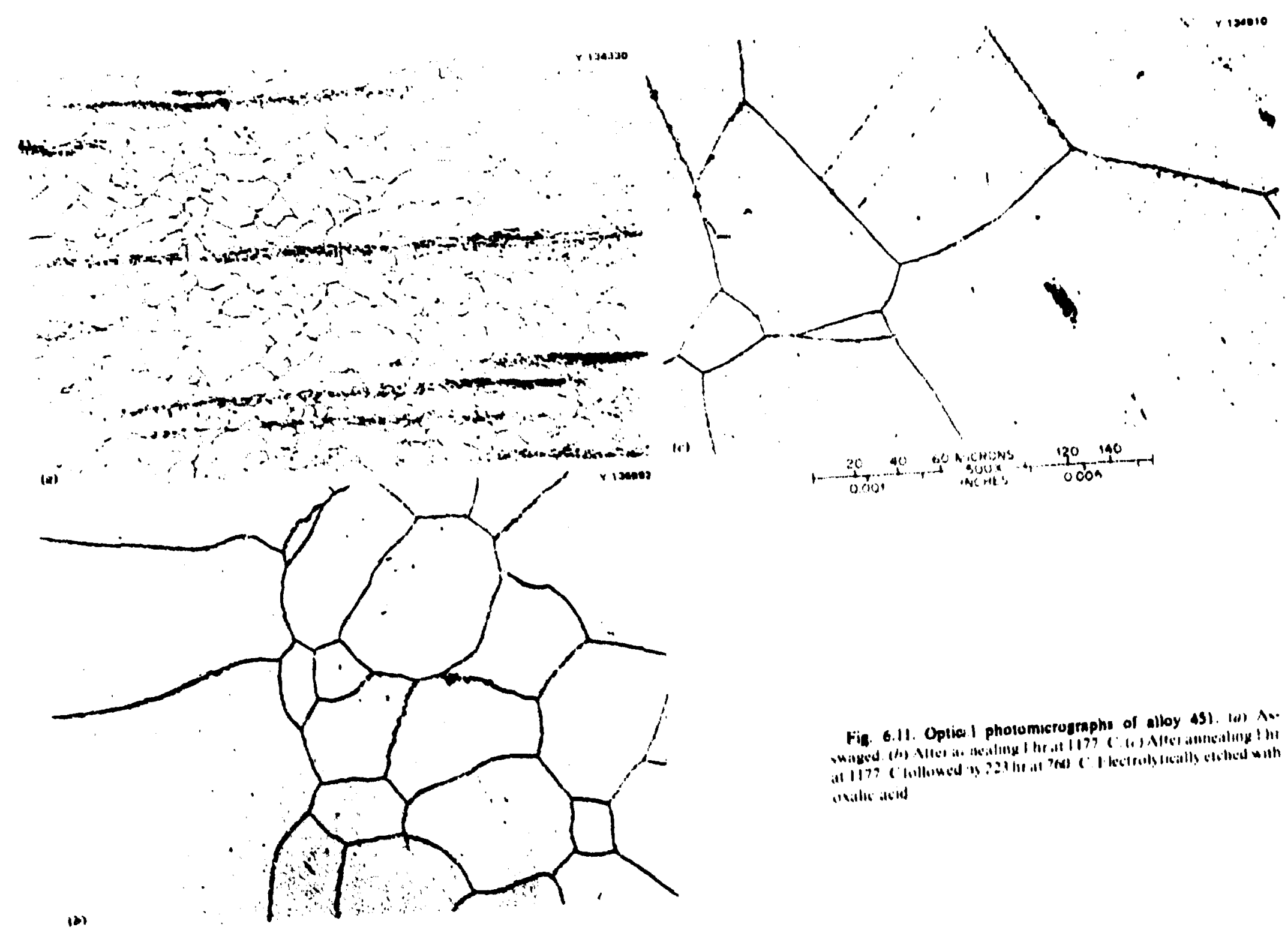




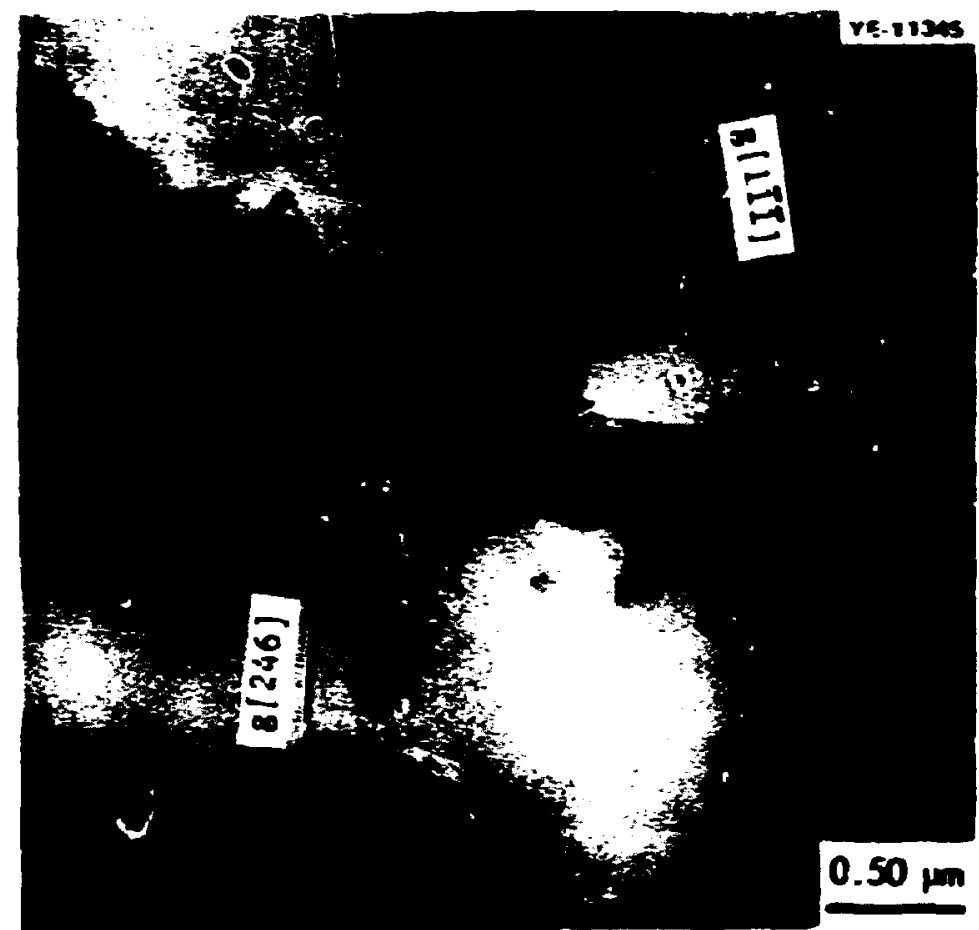

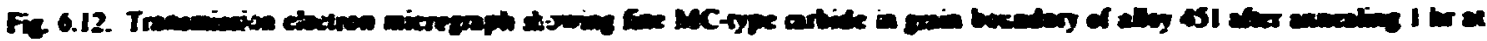
IITrC ras 203 bo a retC.

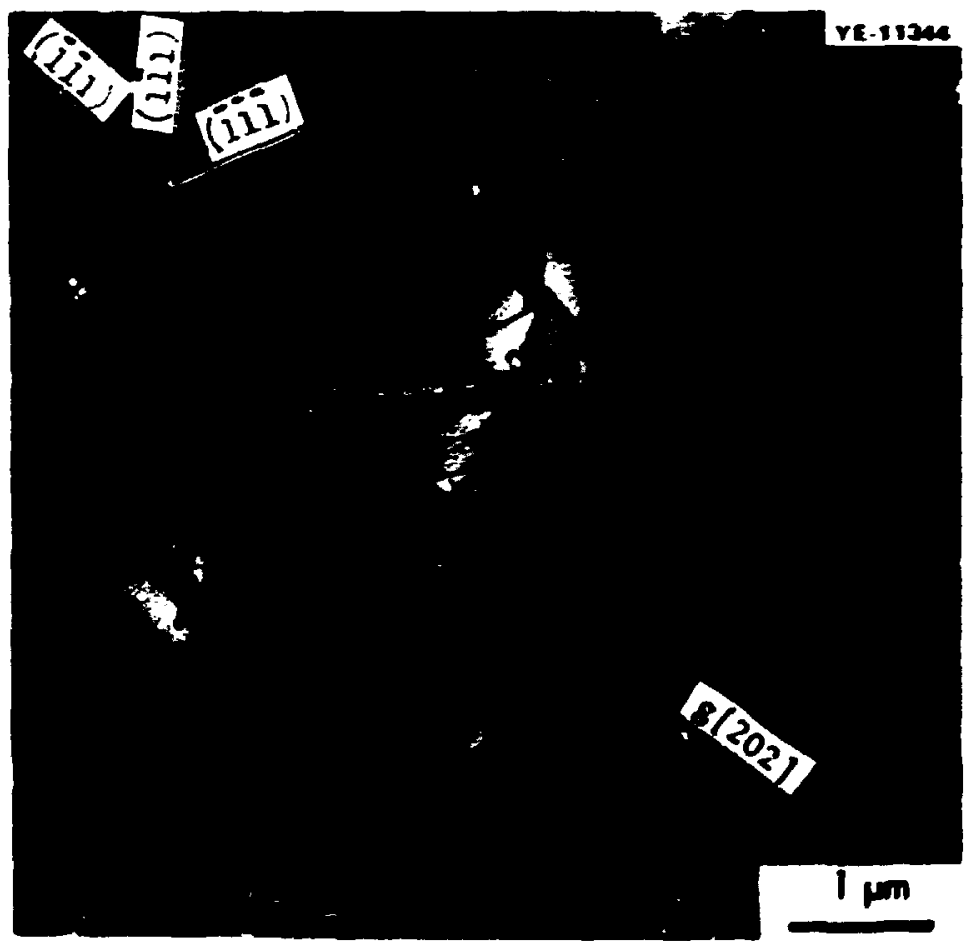

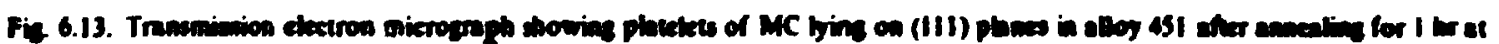
$117 r$ C plus 223 hr at 7cor C. Plane of Inil = iill) 
annealiag at $1177^{\circ} \mathrm{C}$ at different times and then using tixe electrochemial extraction techniques to measure the yuantity of undissolved carbide keft in the mixrostructure (Fig. 6.14). Small samples of both alloys were anneaked at $1177^{\circ} \mathrm{C}$ for 'imes up $108 \mathrm{hr}$ in an argon atmosphere and were then analyzed for the amounts of cabides remaining. In the case of alloy 45I. at least I hr was needed to reach what appears to be an eyuilibrium amount of precipitzte remaining in the alloy. For times greater than about I hr. essentially all of the carbides were dissolved into the mairix. However. small amounts of carbide precipilate were extracted at even the lorgest annealing time. It is possible that some precipitation $<0.1$ wt (i) can occur upon cooling the sample after solution annealing. There is also the possibility that a very small amount of other insoluble inclusions present in the allo: were being colketed.

Another important point concerning the removal of the memony effect in $2_{i}$ t titanium Hastelky $\mathbf{N}$ is that once the carbides dissolve. additional time is reyuired for the carbide-forming elements to diffuse away from stringer areas. Ii the ekments are not given sufficient time to disperse. they will reprecipitate in a stringer morphology. The relation of time and carbide dissolution is clearly illustrated by the elect rochemical extraction data on annealed samples of alloys 451 and 452 (Fig. 6.14). The data for alloy 452 show that its higher carbon content resulted in greater amounts of carbides in the miciostructure
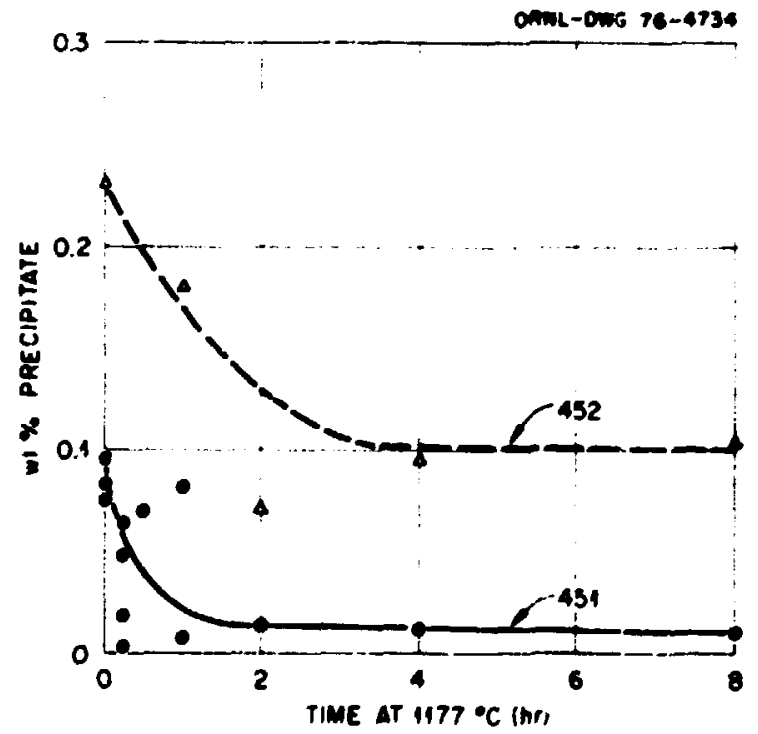

Fi2 6.14. Reauls of electrochemion extnetions cas iampies of alloys 451 and 452 ansealad for verious timas at IIT," C. than for alloy 451 for all anncaling times investigated. lis higher carbon cöntent also made carbide resolution sufficiently shuggish to enabte the memory effect to operate for annealing times up to at least 8 hr. This meant that longer times at 1177 C or higher temperatures would be needed to eliminate the memony effect from alloy $\mathbf{4 5 2}$.

Influence of Fabrication Paremeiers. The previous section incicated that $2 \%$ titanium-Hastelloy $N$ alloys with less than $\sim 0.035 \mathrm{~m} \%$ carbon could be Gabrizated by the existing shop fabrication schedule shown in Table 6.10 for alloy 451. Usually. however. carbon comtents from $0.050100 .060 \mathrm{~m}$ \% have been - wed in the alloy drvelopment program to obeain good mechanical properties. Therefore. experiments were conducted to determine how to alter the fabrication prociss so that the memory effect would be eliminated when the alloy carbon content was near $0.050 \mathrm{~m} \mathrm{c}$. In fabricating alloy 452 . doubling of hot swaging reheat times as well as the time of the homogenizing anneal (Table 6.10) was unsuccessful in removing carbide stringers from the microstructure (Fig. 6.8a). Therziore. samples of the as-swaged alloy 452 were solution-anneaked for I hr at 1177. 1204. 1'200. and 1300 C. respectively, in an attempt to dissolve the MC-type carbides. These samples were then aged at $760^{\circ} \mathrm{C}$ for $160 \mathrm{hr}$ to reprecipitate the carbides. The results of the solution annealing experiment are shown in optical metallography (Fig. 6.15). Solution annealing at $1177^{\circ} \mathrm{C}$ (Fig. 6.15a) and at $1204^{\circ} \mathrm{C}$ (Fig. 6.156) did not eliminate the memony effece. and many carbides reprecipitated in areas originally containing stringers. However. the anneals at $1260^{\circ} \mathrm{C}$ (Fig. 6. 15c) and at $1300^{\circ} \mathrm{C}$ (Fig. 6.15d) successfully remo ied the carbide stringers. Instead of stringers. the high:r solution anneals produced a fine Widmanstäten structure of MC-type carbides within the grains. The habit planes for cartide precipitation were the matrix (III) planes. The relationship hetween MC and matrix was epitaxial. that is. (III) he \|(III) mens. MC-type carbioes were aiso found in the grain boundaries. Much of the precipitates in the sample annealed at $1204^{\circ} \mathrm{C}$ (Fig. 6.15b) had the Widmanstatten morphology, but many of the caibides concentrated in prior stringer a reas. This observation strongly suggested thai whik most of the carbides were dissolved at $1204^{\circ} \mathrm{C}$. a I-hr annealing time at this temperature was not sufficient to permit adeolvate homogenization of the carbideforming elements throughout the matrix. These results confirm earlier statements on solutionannealing which stress the importance of not only dissolezng the carivides but also allowing the carbide. 

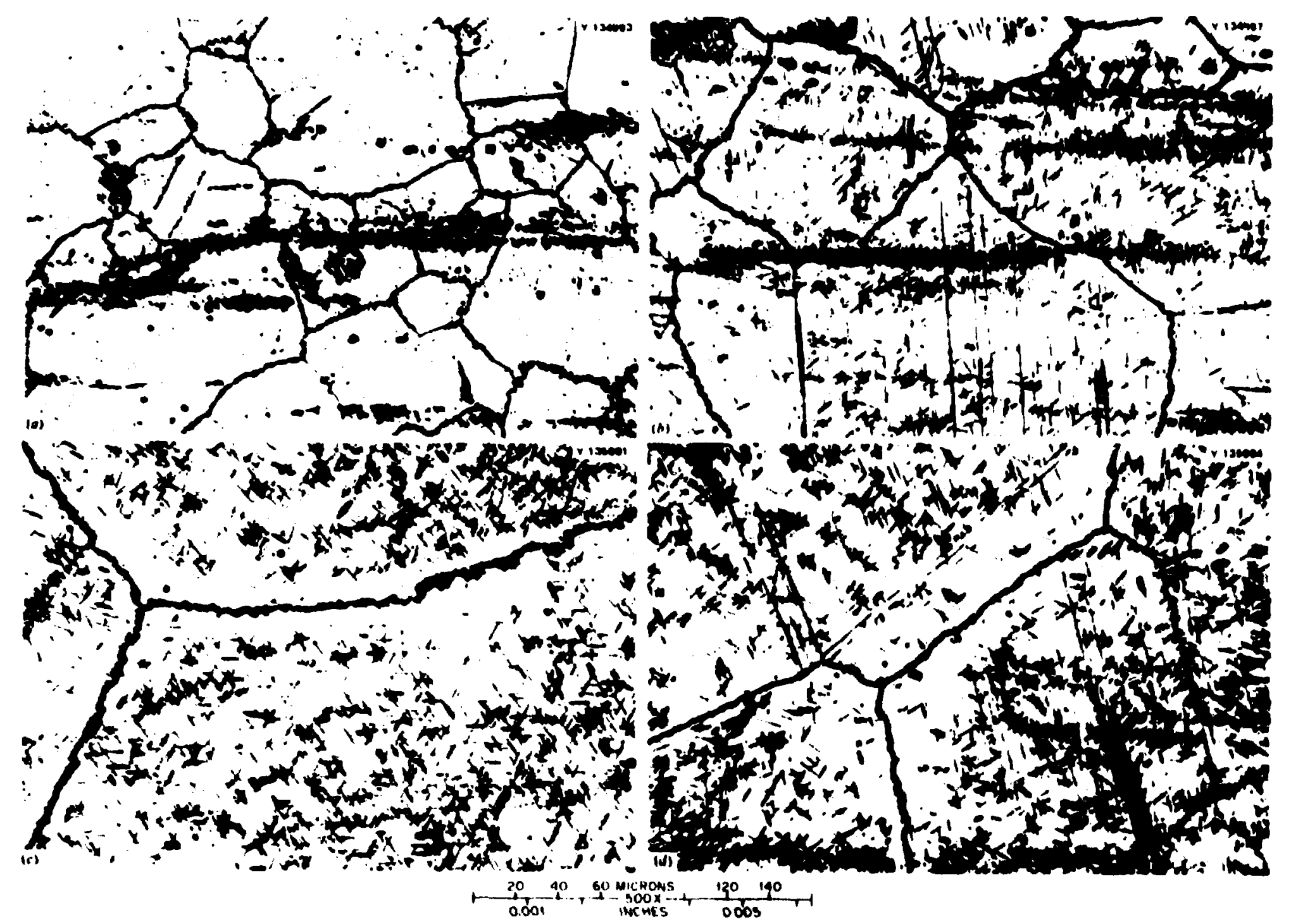

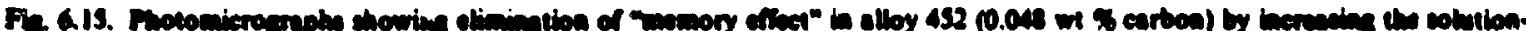

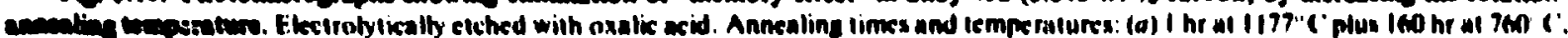

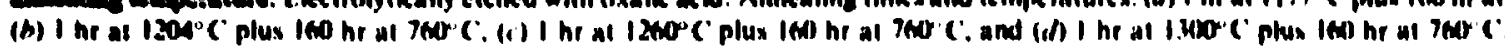


forming elements to disperse uniformh. The experiments by Bradky and Leitnaker. to be discussed in the next section of this repon (Sect. 6.5.2), indicate that molybdenum is the controlling element that must be dispersed.

From the result of the preceding experiments, it was pussible to desigm a new fabrication schedule that produced a microstructure without stringers in an alloy containing $\sim 0.050$ wt $T$ carbon. The pilot run of this new schedule is given in Table 6.10 for alloy 450 (see Table 6.9 for chemical composition). The arc cast ingot was 1.0 in. in diameter by $\rightarrow$ in. long and was consed in type 316 stainless steel having a 0.120 in. wall thickness. The purpose of cbdding the material was to minimixe decarturization during processing at high temperatures in air. The as-cast ingot contained irregular-shaped grains with numeruus patches of carbide paricicles (Fig. 6.16a). Hot s* ging was conducted at $1177^{\circ} \mathrm{C}$. as before. but the reheat times were held to $15 \mathrm{~min}$. Afier hot swaging. the microstructure contained a sine grain structure with carbides in the grain boundaries (ifig. 6.16h). Areas lacking in carbides experienced mure grain growth. and hence a duplex grain structure was produced.

The swazec' rod of alloy 450 was anncaled at I zôf C for I hi which dissolved most of the carbides and produced large recrystallized grains (Fig. 6.16c). However. enough carbides remained to justify an additional anneal of $\mathrm{I}$ hr at $1300^{\circ} \mathrm{C}$. The samples were quenched in water after the $1300^{\circ} \mathrm{C}$ anneal to prevent precipital ion of carbides during cooling. This btter anneal was ::ffective in dissolv ing essentially all of the carbides (as shown in Fig. 6.16d). The discrepancy between the results of a I-hr anneal at 1260 C tor alloys 452 and 450 again apparently lies in the difierences in amounts of material anneaked. Thus the annealing practice must be controlled closely with this alloy to obtain reproducible results.

The final three micyographs in Fig. 6.16 show the material after cold swaging (Fig. 6.16e). after a subseyuent stress relief anneal for $15 \mathrm{~min}$ at $1177^{\circ} \mathrm{C}$ (fig. 6.16/f) and after final cold swaging (fig. 6.16g). During these final steps the grain size was reduced through cild work and recrystallization processes. Some carbides were precipitated in the grain boundaries, but 1,o stringers were observed. As final preof that the memory effect had beer eliminated. an as-swaged sample was aged at $760^{\circ} \mathrm{C}$ for $168 \mathrm{hr}$. The microstructure after aging did not contain stringers but displayed a fine Widmanstatten structure of thin MC platelets lying epitaxially on the (III) matrix planes (Fig. 6.1(th).
Precipitatc extraction cata Irom semples setected during the Labrication of alloys 452 and 450 ate compeired (Fiz. 6.17). These dala show, in a different way, how the memory effect was removed from 2 ; titanium Hastelloy. Both alboys contained $\sim 0.050$ wit $r_{f}$ arbon. and the cast ingot contained a nominal amount of carbides. Some precipitation occurred during hot swaging. and the trtal for both alloys increased. Solution annealing was the critical step in eliminating the memory effect. since substantialty more carbides were dissolved in alloy 450 because of highter annealing temperatures. The extracted amounts of carbides remained essentially unchanged for both alloys after solution annealing. A highte:mperature anneal would effectively remove stringers firom both alloys after fabriation was completed. but the material wovid end up with a very larex grain sixe. By performing the hightemperature anneal early in fabrication. it is possible to produce some grain retinement during bater steps involving cold work and recrystalliation. Alloy 450 is currently being tested to determine its resistance to idciation damage and also its resistance to embrittement by tellurium.

Conclusions. The following conclusions have been reached as a result of work discussed above:

I. Carbide stringers form in $2 \%$; titaniumHastelloy $N$ alloys. as in many other structural materials. during fabrication from the original castings. A memory effect has been obsened in the solution-anneaked and asged $2 \%$ titanium-Hastelloy $Y$ alloys where carbides reprecipitate in areas that originally contained stringers.

2. The memory effect was eliminated. and a uniform distribution of carbides was produced in alloy 451 by lowering the carbor content of the alloy from $\sim 0.050$ to $0.017 \mathrm{wi} \%$. The standard $\mathrm{I} \mathrm{hl}$ at $1177^{\circ} \mathrm{C}$ solution-annealing temperature was used.

3. The memory effect was eliminated in $2 \%$ titanium-Hastelloy $N$ alloys with $\sim 0.050$ wt $\%$ carbon by increasing the solution-annealing temperature to $\sim 1300^{\circ} \mathrm{C}$. The high-temperature anneal was given early in fabrication to help maintain a reasonably small grain size in the final material.

4. To remove the memory effect (carbide stringers). a solution-annealing treatment must:

a. dissolve most of the carbides.

b. be of sufficient duration to allow the carbideforming elements (especially molybdenum) to dispersc. by diffusion. uniformly throughout the alloy, and 

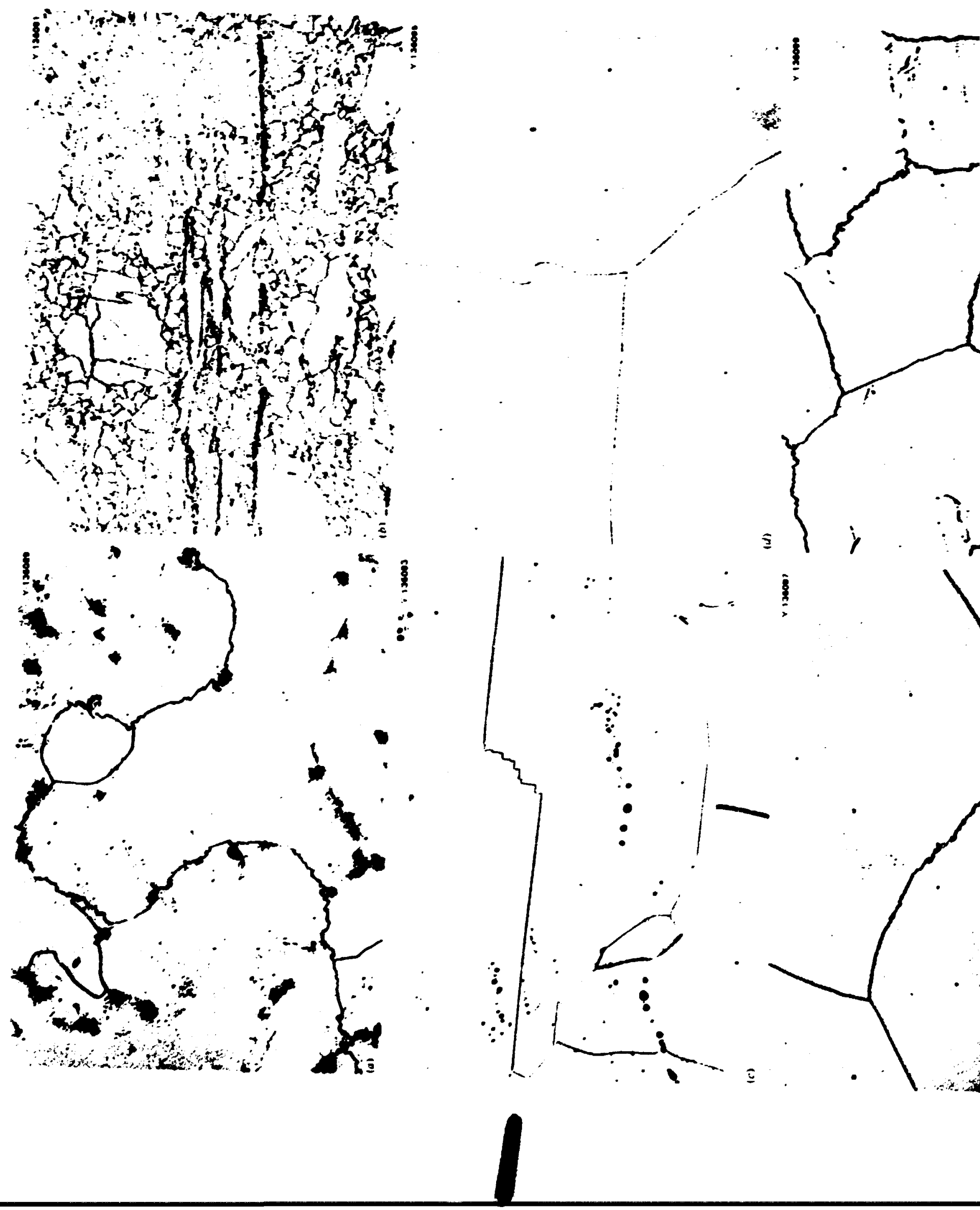


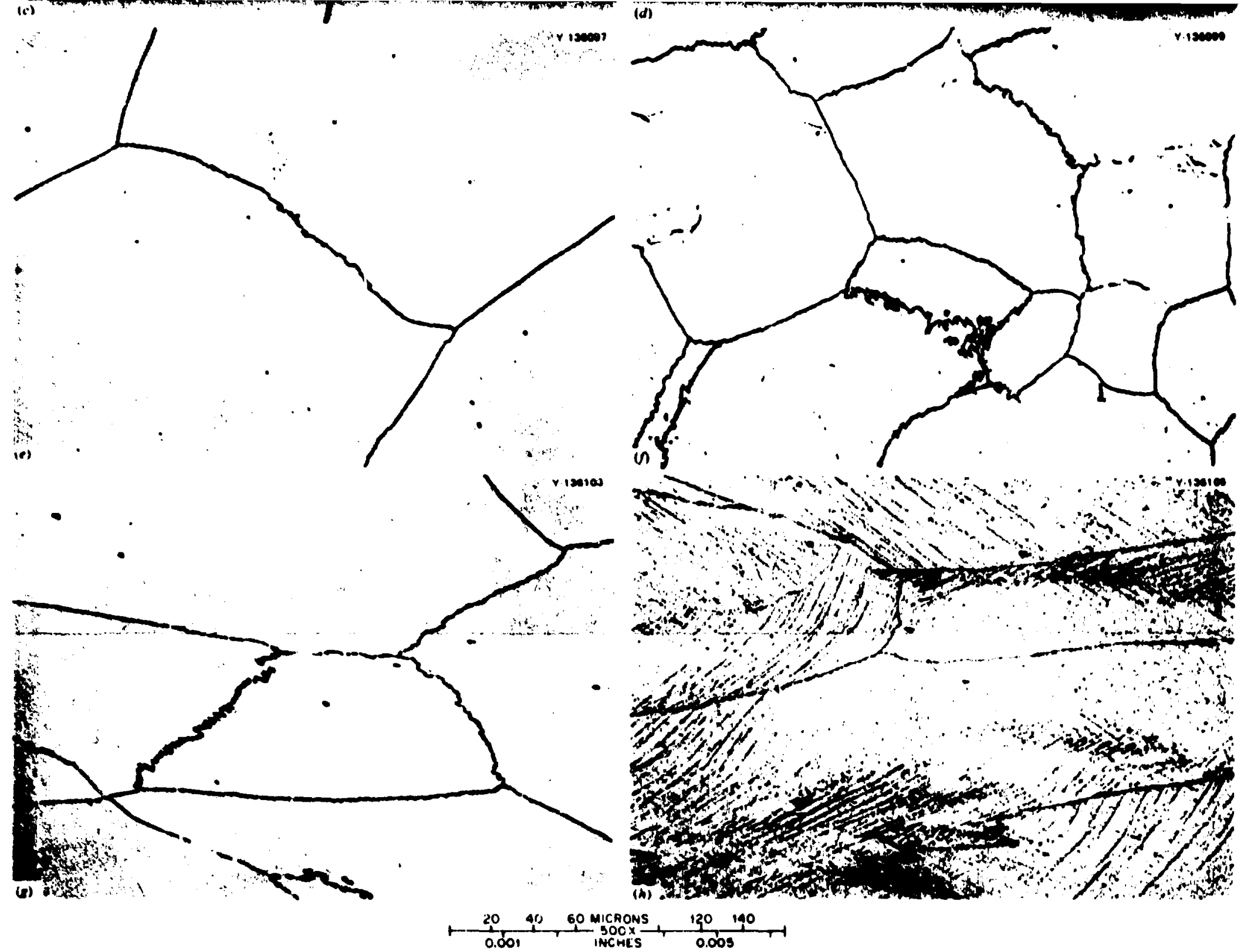

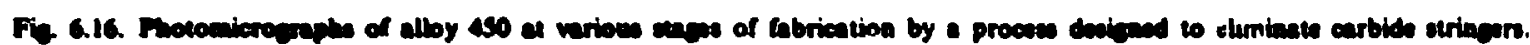
Electrolytically etched with oxalic acid. (o) As cast. (b) after hot swaging al I $177^{\circ} \mathrm{C}$. (c) solution annealed I hr al i $260^{\circ} \mathrm{C}$, (A) annealed I hr at

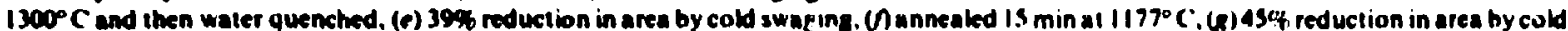
swagine (finished', s-in diam rod), and (h) aged $168 \mathrm{hr}$ at $7 \mathrm{fw}$ ) (C. 


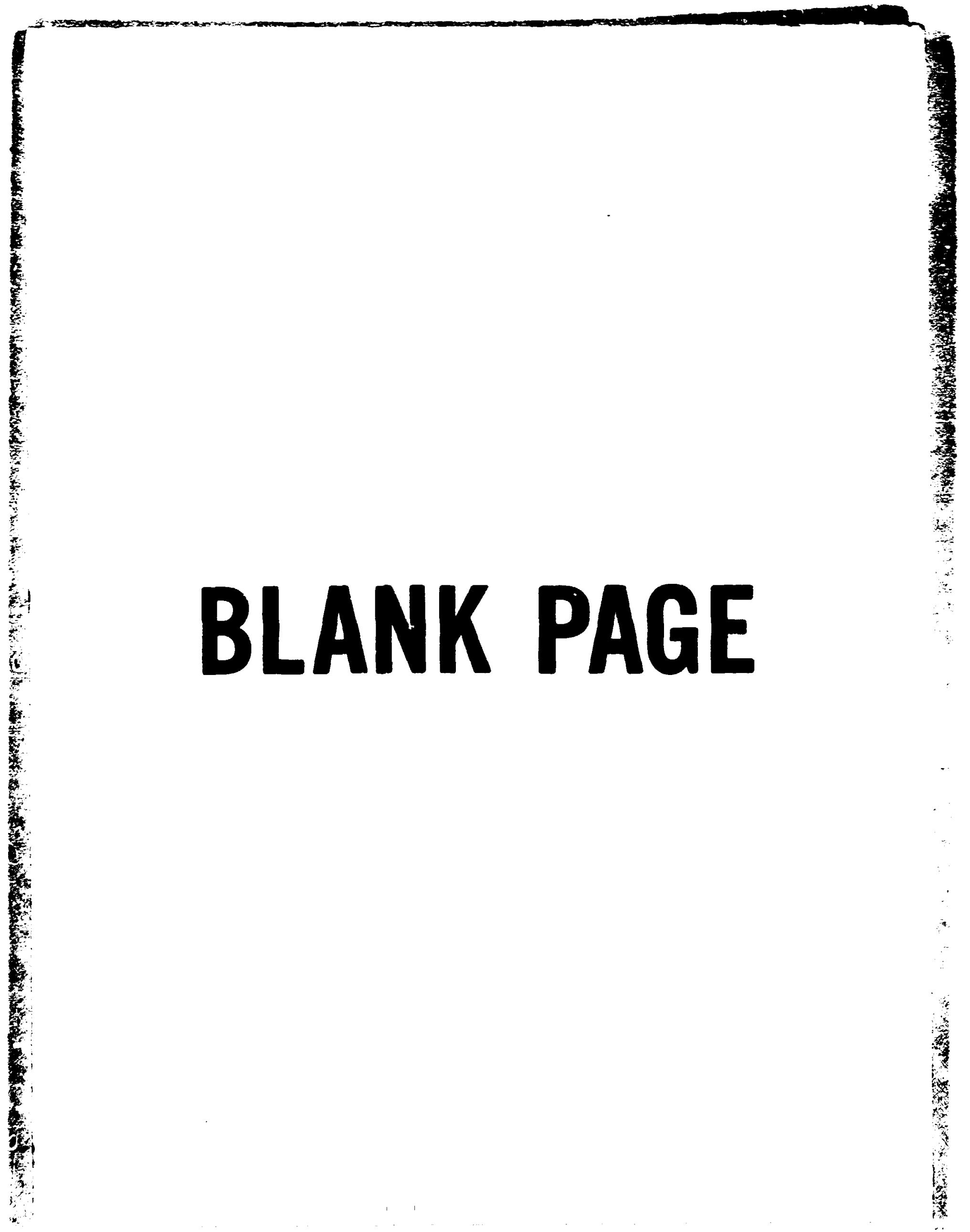




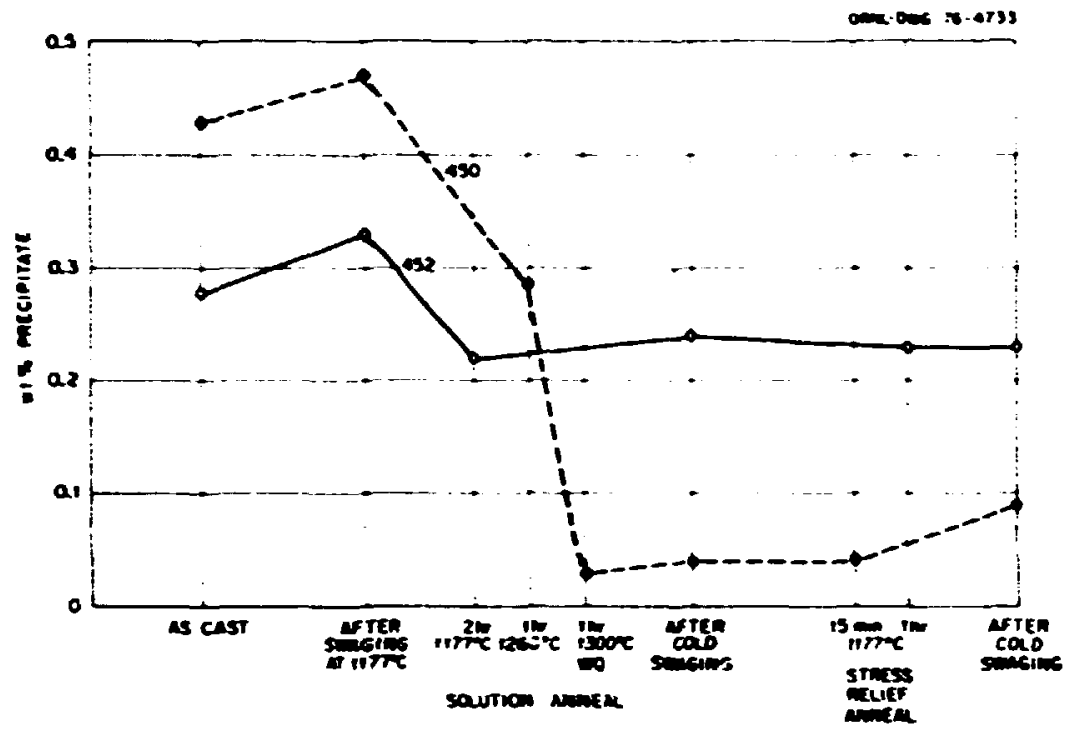

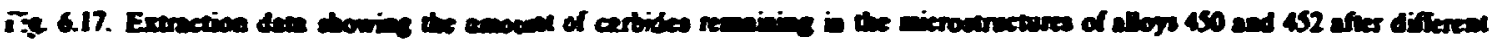
Griction sion.

c. take into account the volume of material being treated-larger quantities of material require more time.

5. In $2 C$ titanium-Hastelloy $\mathbf{X}$ alloys where the memory effect was eliminated. the MC-typecarbidcs formed a fine Widmanstätten structure with thin MC platelets lying epitaxially on the (111) matrix planes. Some small cartide paricks were also observed in the grain boundaries.

6. All the carbides observed in $2 \%$ titunium Hastelky $\mathbf{N}$. regardkss of carbon content or heat treatment, were identified by both =lectron and $x$-ray diffraction as the face-centered-cubic. MC type.

\subsubsection{Carbon Behavior in Ni-Mo-Cr-Ti Alloys}

\section{J. Bradky J. M. Leitnaker}

To understand and predict the properties of titanium-modified Hastelluy $N$, a basic study in the phase relationships has been undertaken. The primary manpower funding for this portion of the project is an ORAU Fellowship. The program is divided into two parts: (1) preparation and characterization of specimens and (2) oxtermination of the phase rele.tionships in the matrix and the precipitate. The base alloy has been divided into three stivalloys having the compositions (l) Ni-14\% Mo-2C/ $\mathrm{Ti}-0.1 \% \mathrm{C}$, (2) $\mathrm{Ni}-8 \% \mathrm{Cr}-2 \% \mathrm{Tr}-0.1 \% \mathrm{C}$, and (3) $\mathrm{Ni}-2 \% \mathrm{Ti}-0.1 \% \mathrm{C}$. A limited amount of work has also been done with alloy $472-503$. a small commercial heat of $2 \%$ titanium-modified Hastelloy $\mathbf{X}$. Three areas have been investigated as part of the sample preparation and characterization portion of this study. They are decarburization. precipitation rate. and homogeneity of the material.

Decarburization is thought to be a surface reaction of the type

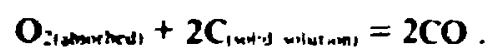

In principal, this reaction can be casily controll ad hy controlling the environment around the satple. However. experience has shuwn that this is not a simple task. Our work with decarburized samples has shown a considerable variation of the latice parameter of the MC-type precipitate as a function of bulk carbon concentration (Fig. 6.18). This can be explained in terms of a lowering of the carton activity, resulting in a carbon-deficient MC lattice. Similar tehavior can be expected from other alloys. which explains the wide range of lattice parameters of precipitate found in this system earlier. The carbondeficient MC phase identified in our samples is probably not the equilibrium phase for the given temperature and bulk composition, but a result of the carbon sink at the surface. Long-term reannealing of the decarburized material could then result in the formation of a precipitate with an equilibrium composition. which would not necessarily be $M C^{\prime}, \ldots$ furure experiments should show whether these suppositions are correct and should yield the exact relationship between the metal-to-carbon ratio and precipitate lattice parameler. 


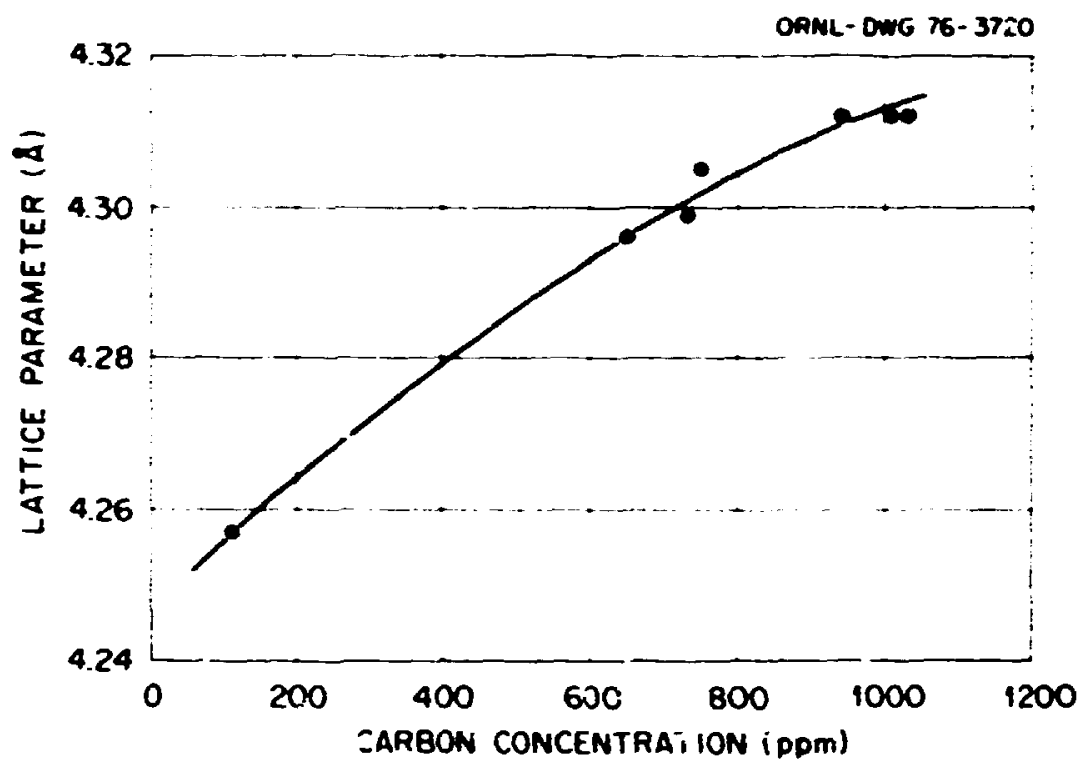

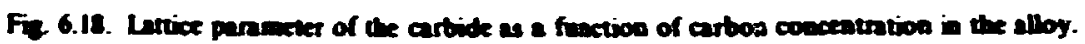

The turnace in which the decarburization tonk plice has been exiensisely modified. Decarburizatinn can be properly controlled now and possibly used to advantage. Rather than using $O$ : to decarburise. a mixture of $H_{(g)}$ and $\mathrm{CH}_{(\mathrm{g})}$ will be llowed through the turnace to prevent decarburizatiinn.

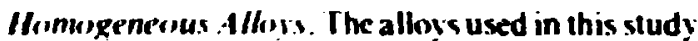
were tabricated in the usual manner with intermediate heat treatment at $1177^{\circ} \mathrm{C}$. Subsequent metallographic examination revealed MC-type precipitale stringers parallel to the working direction (Fig. 6.19). these vemgers represent a very inhomogeneous distribution ot the alloning elements: the precipilate morphology can likely the herter contsolted if the alloying elements are distribuled inore homogeneously. Io thisend. alloys nere annealed at 1260 C for in hr and then aged for $100 \mathrm{hr}$ at $760 \mathrm{C}$. Previnusly. it had heen determined that $4 \mathrm{hr}$ was sufficient to dissolve the stringers at 1200 . C. The samples azed at 760. (C) were then exa mined metallographically (Fig. 6.2(ka-c). As the photomicregraphs reveal. the stringers are now only present in alloy $I$. The matrix of alloys 2 and 3 contains small. rvenly distributed MCtype precipitates. hut in alloy 2 a high density of carhide stringers is evident. The alloy containing molybdenum appears to have a "memory effect" even after $16 \mathrm{hr}$ at $1260^{\circ} \mathrm{C}$. A high-carbon sample of alloy 472-503 has also been examined, and the memory effecl was found to be still evident after $\mathrm{SO}_{0} \mathrm{hr}$ at 1179 C (Fig. 6.21). The conclusions are that molybdenum is responsible for the memory effect and that. once formed. stringers in molybdenumcontaining alloys are extremely difficult to remove.

Precipizalion Srudies. Another part of the present characterization studies has centered on ihe rate of precipitation. Originally all the samples were cooled in the cold gone of the furnace. Nonreproducible solubility da:a and discrepancies from expected hehavior ked to the postulation that precipitation was occurring on cooling. To verify this postulation. two sets of samples were annealed at 1200 - C (Table 6.1 II). One set was cookd by being pulled into the fumace cold mene. and the other was cooled by dropping into

Table 6.11. Effect of cooling rave on precipitation at $1200^{\circ} \mathrm{C}$ in sloy $1(\mathrm{Ni}-13.9 \% \mathrm{Mo}-\mathrm{I} .94 \% \mathrm{Ti}-0.30 \% \mathrm{C})$

\begin{tabular}{|c|c|c|c|c|c|c|}
\hline \multirow{2}{*}{$\begin{array}{l}\text { Sample } \\
\text { number }\end{array}$} & \multirow{2}{*}{$\begin{array}{c}\text { Time at } \\
1200^{\circ} \mathrm{C} \\
\text { (hr) }\end{array}$} & \multirow{2}{*}{$\begin{array}{l}\text { Cooling } \\
\text { method }\end{array}$} & \multicolumn{4}{|c|}{$\begin{array}{l}\text { Carbon concentration in } \\
\text { extracted precipirases }\end{array}$} \\
\hline & & & No. 1 & No. 2 & No. 3 & Arera \\
\hline IAlHS & 1 & $C Z$ & 0.194 & 0.300 & & 0.24 \\
\hline A2HS & 2 & $C Z$ & 0.199 & 0.342 & & 0.27 \\
\hline BA4HS & 4 & $\mathrm{CZ}$ & 0.106 & 0.197 & & 0.151 \\
\hline BashS & 8 & $\mathrm{CZ}$ & 0.118 & 0.209 & & 0.164 \\
\hline BAIGHS & 16 & $c z$ & 0.130 & 0.167 & 0.148 & \\
\hline BAIH & 1 & $B Q$ & 0.097 & 0.024 & 0.142 & 0.104 \\
\hline ВА2H & 2 & BQ & 0.066 & 0.084 & 0.134 & 0.96 \\
\hline
\end{tabular}

" $\mathrm{CZ}$ indicates that the sample was cooled by pulling into the coll tone of the fumece. BQ indicates that the semple was dropped from the hot zone directly into an $\mathrm{H}_{2} \mathrm{O}-10$ t $\mathrm{NaCl}$ solution at room temperature. 


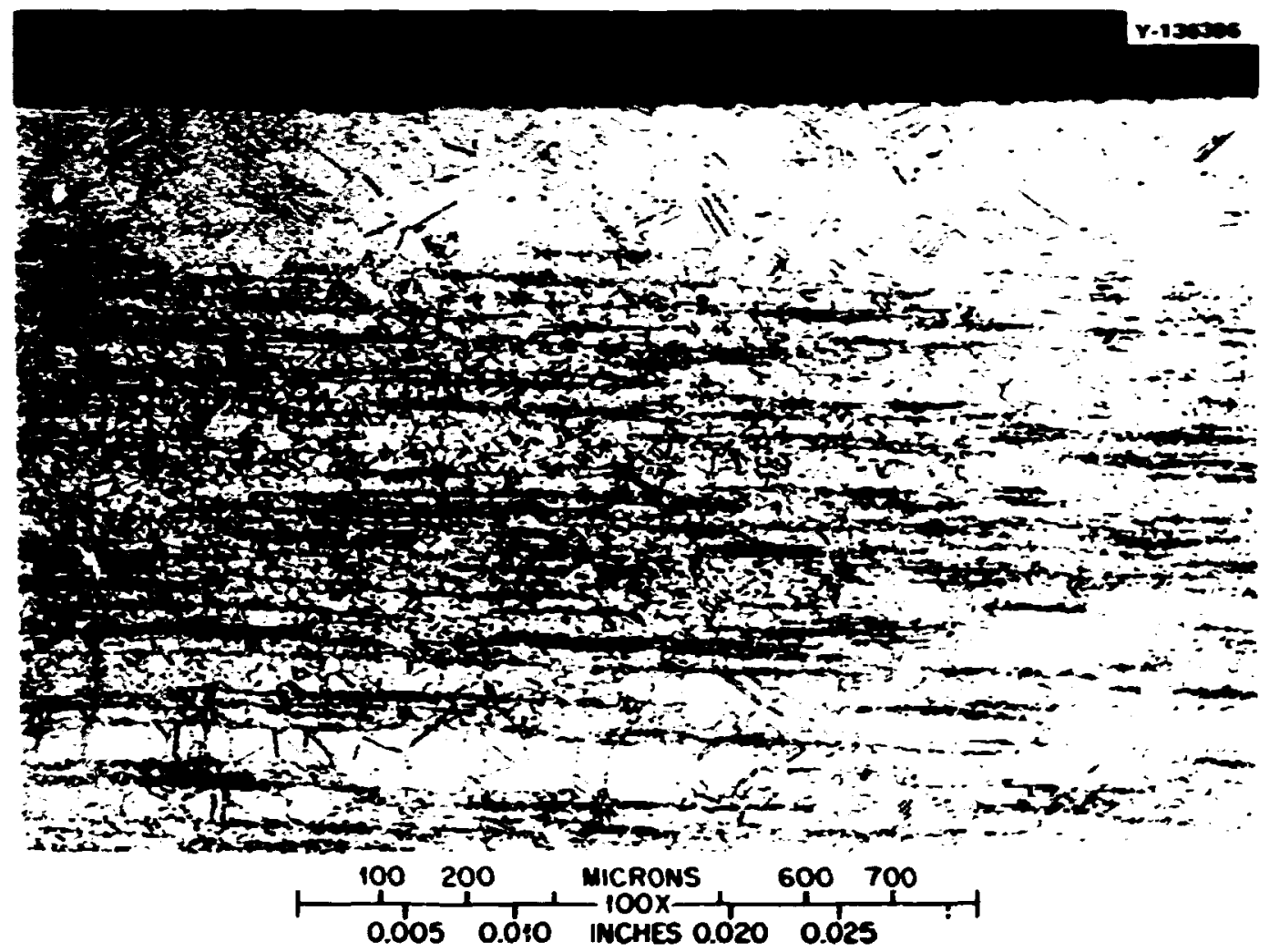

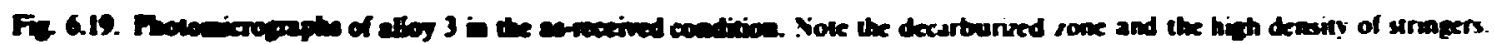
Eutwed with dyceria rejie.

an H:O-10\% $\mathrm{NaCl}$ solution. The quantity of precipitate would contain approximately 20 to $40 \mathrm{~K}$. of the arbon in the alloy. Thus. cooling in the cold zone is not fast enough for measurement of solubilities or the rate of solution of precipitates.

Our exploratory work on the solubility of carton does not appear to correlate with literature values. Results reported by Stover and Wuliff on the nickeltitanium-carbon system indicate that above $800 \mathrm{C}$. an alloy containing less than approximately 2.5 at. $\%$ titanium cannot precipitate $\mathrm{TiC}$ even in the presence of graphite. Alloy No. 3 contained only 2.3 at. \% titanium: yet TiC was identifred in a precipitate formed at $1170^{\circ} \mathrm{C}$. Unfortunately this alloy appeared to contain at all temperatures a pproximately $0.15 \mathrm{wt}$ T precipitate, which was amorphous (Table 6.12). This amorphous material, which is now being analyzed. has clouded interpretation of the present results. New albys are being prepared which should not contain this material.

Alloy No. 2 also appeared to contain $\sim 0.15$ w \% amorphous malerial (Table 6.12). X-ray diffraction of the precipitates yielded only weak TiC peaks. In one case, no detectable diffraction occurred. Assuming that the nondiffracting material in both alloys 2 and 3 was not TiC, the solubility of carbon in each alloy is greater than $0.10 \mathrm{wt} \mathrm{c}_{\mathrm{r}}$ at $1260^{\circ} \mathrm{C}$. At $760^{\circ} \mathrm{C}$ the solubility of carbon in alloy 2 was $\approx 0.05$ wt $\%$ and in 3 was $>0.1$ wt $\%$.

The precipitate from alloy No. ! gave brge. sharp diffraction peaks. even with very small amounts of material. If it is assumed that the material was stoichiom-tric TiC (Table 6.12). the solubility of carbon was $\sim 0.08$ wi co at $1260^{\circ} \mathrm{C}$. The precipitate formed at $760^{\circ} \mathrm{C}$ could not be stoichiometric TiC. since 0.73 wt $\%$ precipitate would require a bulk carbon concentration of $0.14 \mathrm{~m} \%$. and the alby contained 0.10 wt $\%$ carbon. Previous investigators estimated that in titanium- nodified Hastelloy $\mathbf{V}$ the precipitate was approximately $60 \mathrm{mt} 50$ molybdenum."

A limied amouni of work was also done on the effect of the alloying elements on the matrix lattice parameter (Table 6.13 and 6.14). It is hoped that changes in the buttice parasneter of the matrix can be correlated with precipitation. Unfortunately, the 
(a)

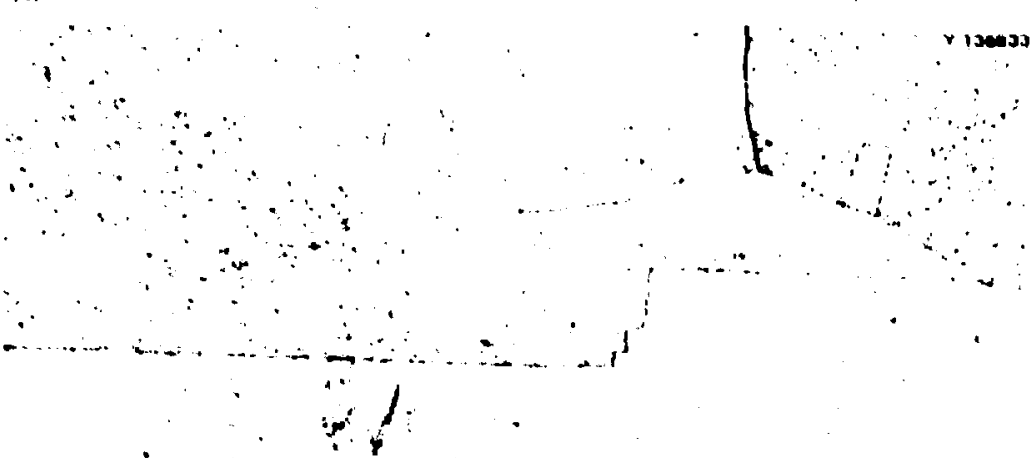

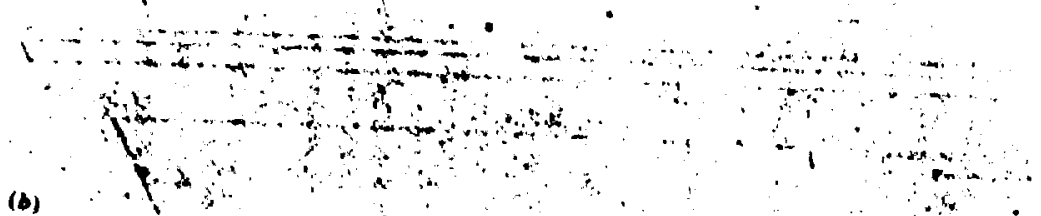

(i)

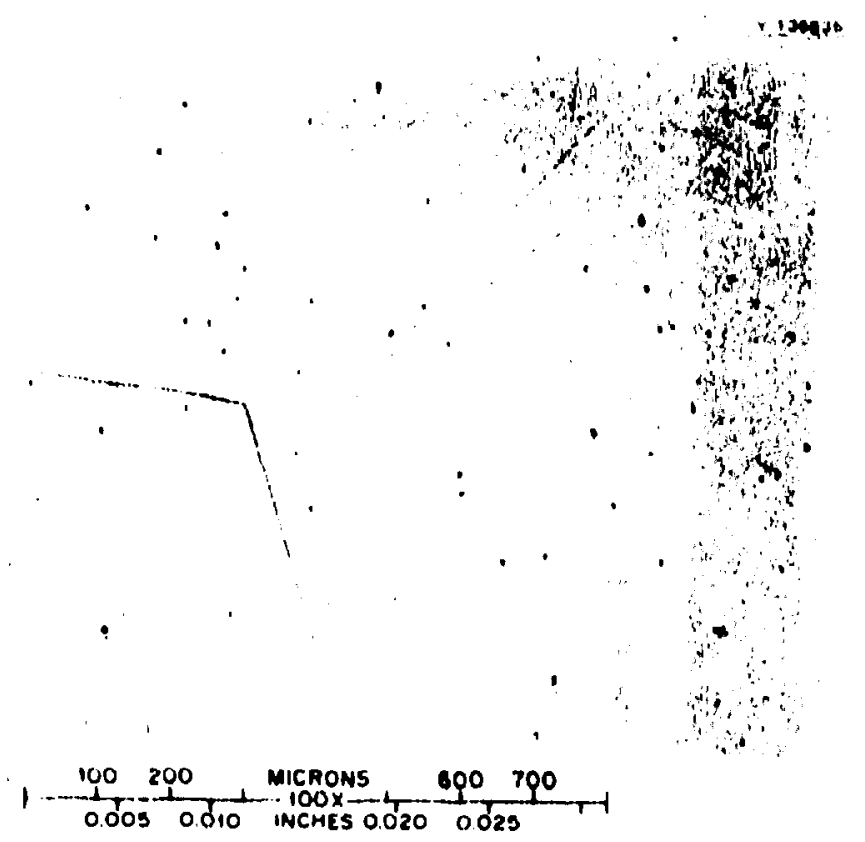

Fig. 6.20. Photomicrographs of the throe allo a annealed $16 \mathrm{hr}$ at $1260^{\circ} \mathrm{C}$ followed by aging at $760^{\circ} \mathrm{C}$ for $100 \mathrm{hr}$. 1 ) Alloy I (nelle the presence of alringers): (h) alloy 2; and (1) blloy .1. Fiched with slycerion renia. 


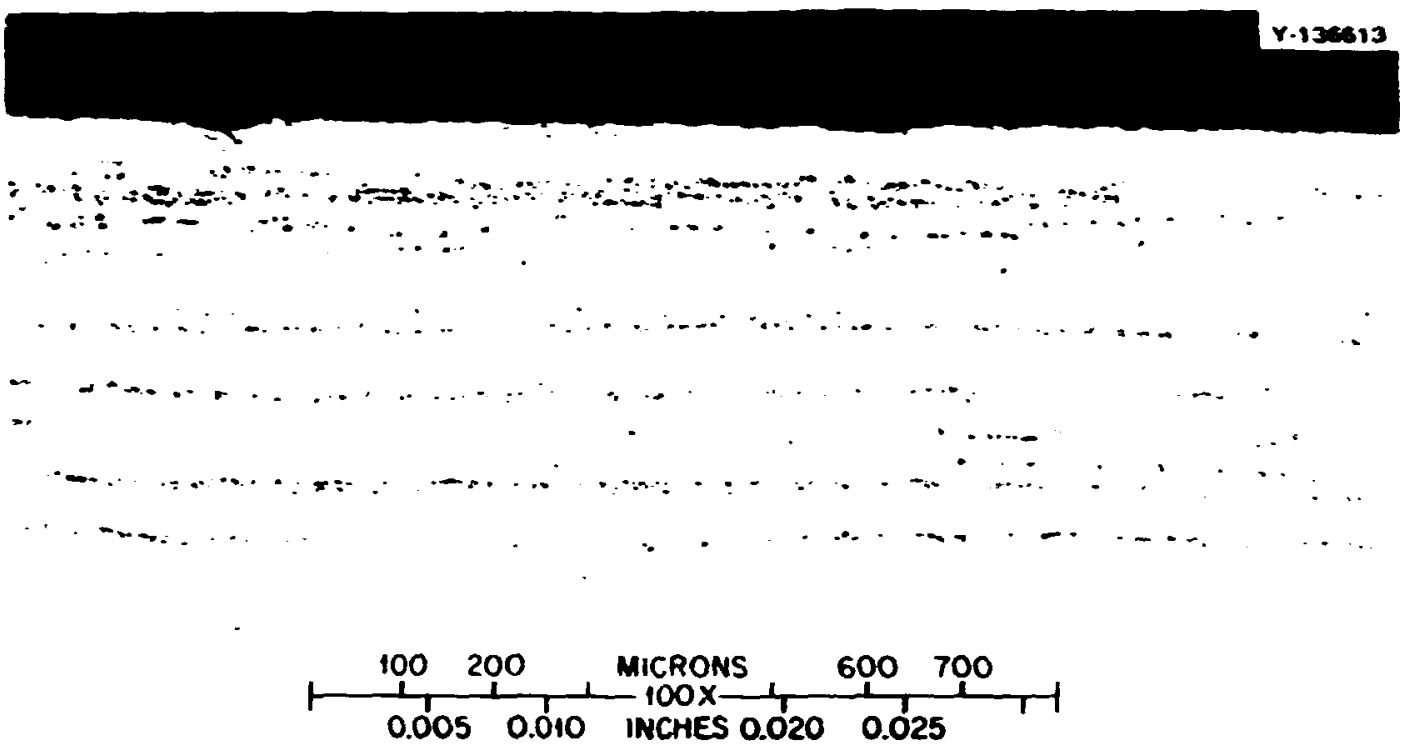

Fie 6.21. Photomicrographs of Hastelloy $N$, heat $452-503$, and $50 \mathrm{hr}$ at $1170 \mathrm{C}$. Nime the presence of stringers. As polished.

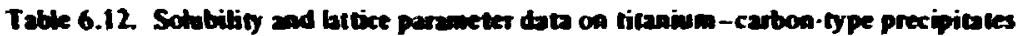

\begin{tabular}{|c|c|c|c|c|c|c|c|c|}
\hline \multicolumn{2}{|c|}{ Alloy } & \multirow{2}{*}{$\begin{array}{l}\text { Sample } \\
\text { number }\end{array}$} & \multicolumn{2}{|c|}{$\begin{array}{c}\text { Annealise } \\
\text { conditions" }\end{array}$} & \multirow{2}{*}{$\begin{array}{l}\text { Carbon } \\
\text { content } \\
\text { (we p) }\end{array}$} & \multirow{2}{*}{$\begin{array}{c}\text { Precipitale } \\
\text { exiracted } \\
(w t \pi)\end{array}$} & \multirow{2}{*}{$\begin{array}{l}\text { Minimum } \\
\text { carbos } \\
\text { solubility } \\
\text { (wt } \%)\end{array}$} & \multirow{2}{*}{$\begin{array}{l}\text { Latlice } \\
\text { parancier } \\
\text { (A) }\end{array}$} \\
\hline Number & Elemertis & & $\begin{array}{c}\text { Temperature } \\
\text { (C) }\end{array}$ & $\begin{array}{l}\text { Time } \\
\text { (hr) }\end{array}$ & & & & \\
\hline \multirow[t]{2}{*}{1} & Ni, Mo. Ti. C & $\begin{array}{l}A \& \\
A-10\end{array}$ & $\begin{array}{l}1260 \\
1260\end{array}$ & $\begin{array}{l}16 \\
16\end{array}$ & $\begin{array}{l}0.192 \\
0.092\end{array}$ & $\begin{array}{r}: 0930 \\
\mathbf{0 . 0 3 7 0}\end{array}$ & $\begin{array}{l}0.084^{e} \\
0.085^{e}\end{array}$ & $\begin{array}{l}4.288 \\
1.2991 \\
4.289\end{array}$ \\
\hline & & $A \& A$ & 760 & 100 & 0.096 & 0.7320 & ${ }_{1}$ & 4.313 \\
\hline 3 & Ni.Ti.C & $\begin{array}{l}\text { B13 } \\
\text { B15 } \\
\text { B15A }\end{array}$ & $\begin{array}{r}1260 \\
1260 \\
760\end{array}$ & $\begin{array}{r}16 \\
16 \\
100\end{array}$ & $\begin{array}{l}0.083 \\
0.080 \\
0.080\end{array}$ & $\begin{array}{l}0.1150 \\
0.1560 \\
0.1410\end{array}$ & $\begin{array}{l}>0.08^{\prime} \\
>0.0 w^{\prime} \\
>0.08^{\prime}\end{array}$ & \\
\hline 2 & Ni, Cr. Ti.C & $\begin{array}{l}\text { C7 } \\
\text { C6 } \\
\text { C6A }\end{array}$ & $\begin{array}{r}1260 \\
1260 \\
760\end{array}$ & $\begin{array}{r}16 \\
16 \\
100\end{array}$ & $\begin{array}{l}0.098 \\
0.103 \\
0.104\end{array}$ & $\begin{array}{l}0.1170 \\
0.1490 \\
0.3590\end{array}$ & $\begin{array}{c}>0.1 \alpha^{\prime} \\
-0.10^{\prime} \\
0.0 s^{\prime}\end{array}$ & 4.288 \\
\hline
\end{tabular}

The samples were annealed toxether and then cooled in the cold zone on the furance.

"Carbon concentration wai determined on a leco apparalus by analytical chemistry. Precision of the determination at this concentration is approximately 19.0030 wo $\%$.

'The weighe percent precipitate was oblained by electrolytic extraction of the semples in a $10 \mathrm{~h} \mathrm{HC1/methanol} \mathrm{solution} \mathrm{at} \mathrm{I.S} \mathrm{V.}$ The notmal extraction electrolyzed $1 \mathrm{~g}$ of metal. The precision of the weipht percent determination is approximateiy $\$ 0.015 \mathrm{wt} f$.

The betice parameter of the precipitate was determined by x ray difraction. The pectrometer normally covered a 20 ranpe of 20 to $120^{\circ}$. An internal standard of TaC was used to calibrate each run. The data were trated by means of a cose coth ertrapolation function.

e Based on the premise that the carbon content of the precipitate is $20 \mathrm{wt} \%$. This is the case for stoichiometric TiC.

Calculated ascuming that $0.15 \mathrm{mt}$ \% ppt was mot Tí. 


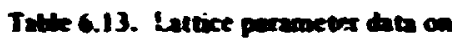

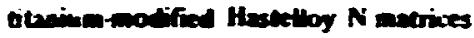

\begin{tabular}{|c|c|c|c|c|c|}
\hline \multirow[t]{2}{*}{ Alloy } & \multicolumn{4}{|c|}{$\begin{array}{c}\text { Compusition } \\
\text { (al. F) }\end{array}$} & \multirow{2}{*}{$\begin{array}{l}\text { Lative parametet } \\
\text { IAP }\end{array}$} \\
\hline & $\mathbf{N i}$ & $i \mathrm{i}$ & Mo & $\mathrm{Cr}$ & \\
\hline 1 & 88.55 & 2.50 & 8.95 & & $3.56739 \div 0.00041$ \\
\hline 3 & 97.7 & 2.30 & & & $353266: 0.00042$ \\
\hline 2 & 88.65 & 2.34 & & 9.01 & $3.54170 \div 0.00026$ \\
\hline
\end{tabular}

"The bitine porameter wos mearued with a DS. camera. The data were eitmpolated to $20=180^{\circ}$ with Netson-Ridey extrapolation function

Take 6.14. Effeces of aloying denuencs on the nicted bltice

\begin{tabular}{|c|c|c|c|c|}
\hline \multirow{2}{*}{ Alloy } & \multicolumn{2}{|c|}{$\Delta x_{n} /$ at. $F$} & \multicolumn{2}{|c|}{$\begin{array}{l}\text { Effective atomix } \\
\text { radib }\end{array}$} \\
\hline & This work & Literalure value" & Tnis work & Shater radice \\
\hline $\mathrm{Ti}$ & 0.00387 & 0.0034 & 1.398 & 1.40 \\
\hline Mo & 0.00398 & 0.0042 & 1.402 & 1.45 \\
\hline $\mathrm{Ct}$ & C.00100 & 0.0011 & 1.348 & 1.40 \\
\hline
\end{tabular}

"W. B. Pearsom. A Handbonk of Latlice Spacings and Struc tures of Metals and Allovs. Perpamon Prexs. Ovford. 19'17.

"Cakulated assuminf slose packing alone fcc disgon il and the value of $3.5238 \mathrm{~A}$ as the lattice parametcr of nickel (se ASTM card 4-0850).

ralues aken from J.C. Slaler. "Atomic Radii in Crystals," $J$. (hem. Phys. 41, 3199 (1964). previously mentioned probiems have not yet allowed this result. but the data on the decarburized specime "s do agree well with existing data on similar systems

\subsection{SALT CORROSION STUDIES}

\section{J. R. Keiser E. J. Lawrence}

Studies of the corrosion resistance of potential MSBR containment vessel materials (modifications of Hastelloy $\mathbf{N}$ ) have bees. carried out in both thermal convection and forced circubtion loops. Results indicater: a limited amount of mass transfer of chromium from the hot to the cold portions of the Hastelloy $\mathbf{I}$ systems. but the overall resistance of Hastelloy $\mathrm{N}$ to molten fluoride salt corrosion is very high. Unfortunately. Hastelloy $\mathbf{N}$ has been found to be susceptible to irradiation embrittement and to grain boundary atlack by fission products. ('nnsequently. investigations were begun with different commercial and experimen:sl alloys containing compositional modifications to Hastelloy $\mathrm{N}$ in order to find materials that provide sufticient resistance to the detrimental effects of irradiation and fission prodici's. Since it is necessary to ensure that these new or modified alloys are resistant to flunride salt corrosion. most of the loops now in operation are being used to evaluate the corrosion resistance of these various materials. The status of the operating thermal convection loops is given in Table 6.15. In

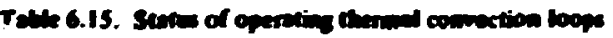

\begin{tabular}{|c|c|c|c|c|c|c|}
\hline $\begin{array}{l}\text { Joop } \\
\text { number }\end{array}$ & Loop & $\begin{array}{l}\text { Speciune: } \\
\text {-2aterial }\end{array}$ & Sale type & $\begin{array}{l}\text { Maximum } \\
\text { remperture } \\
\text { en }\end{array}$ & $\stackrel{\Delta T}{C}$ & Purpose \\
\hline \multirow[t]{3}{*}{214} & Sastefloy N & 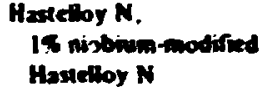 & MSten facd sali & 706 & 139 & $\begin{array}{l}\text { Dastine corrosion dats for } \\
\text { Hastaloy } N\end{array}$ \\
\hline & & & & & & 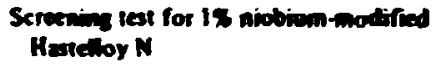 \\
\hline & & & & & & 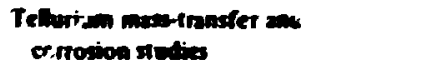 \\
\hline 23 & Inconel 60I & Graphine & MSDR fuel soli & 677 & 117 & 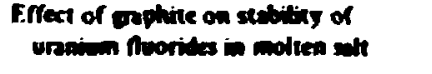 \\
\hline \multirow[t]{2}{*}{31} & $\begin{array}{l}316 \text { urialess } \\
\text { scel }\end{array}$ & $\begin{array}{l}316 \text { stainiss } \\
\text { Acel }\end{array}$ & interfs & 69 & 156 & Dasclime curssing dats \\
\hline & & & & & & $\begin{array}{l}\text { Effect of rofectant adinioas un } \\
\text { comosion }\end{array}$ \\
\hline 24 & Haselloy N & $\begin{array}{l}\text { Chrompun-modiried } \\
\text { Haselloy N }\end{array}$ & MSDR fuel solt & 704 & 1397 & Deterwine the effect on mrrosion \\
\hline ISC & Hasueloy $N$ & $\begin{array}{l}\text { Chrowanim-nodified } \\
\text { Hastelloy N }\end{array}$ & MBOR foct salt & $? 04$ & 139 & of Hatedby $N$ \\
\hline
\end{tabular}


addition to these five loops. three others have been built and are in varying stages of final preparation. Because of the anticipated termination of the program. these three loops will nut be put into operation.

\subsubsection{Thermal Convection Loup Results}

Thermal convection loops provide a very good experimental tool for measuring !ts corrusion rate of a material exposed to a corrosive medium under an imposed temperature gradient. Removable specimens permit periodic examination to determine weight changes. and electrochemical probes permit on-line measurement of the oxidation potential of the salt and the concentration of impurities in the salt.

Thermal convection loop 23 is constructed of Inconel 601. a material that has shown good resistance to grain boundany attack by tellurium. However. results have shown that Inconel 601 undergoes extensive corrosion in fuel salt, making it a material with little prospect for use in an MSBR. Because of the extensive corrosion which this alloy has undergone by reaction with fuel salt the $\mathrm{U}^{20} \mathrm{U}^{3 *}$ ratio of the salt has fallen to about 4. the most reducing level ever achieved in a loop. As reported previously ${ }^{\text {t' }}$ it was decided to use this very reducing salt to try to reproduce the results of Toth and Gilpatrick. "which predict tha: under the operating conditions of this loop and in the presence of graphite. $\mathrm{UC}$ : would be formed by the reaction

$$
4 L F:+2 C-3 \mathrm{LF}+U C_{:} \text {. }
$$

In the first altempt to produce this reaction. pyrolytic graphir: tha s exposed to the sal! for $500 \mathrm{hr}$. and no UC: was found. In the second attempt a kess dense graphite was used and a new phase was detected throuyh $x$-ray examination. This phase was tentatively identifi, $u$ as uranium oxide. A third set of graphite specimens which has been kept free of moisture is now undergoing a 2000-hr exposure and is scheduled to be examined in March 1976.

Hastelloy $\mathrm{N}$ thermal convection lonp 21A. which contains MSBR fuel salt, has beer. used to ohtain haseline corrosion data. Sixteen Hastelloy $\mathbf{X}$ specimens have been exposed a total of $10.009 \mathrm{hr}$. According to theory. the weight change of these specimens due to mass transter of chromium, $J . M$. per unit area during lime I should be given by

$$
د . K \propto C, \sqrt{D t} .
$$

where $C$, is the initial concentration of chromium in the alluy and $D$ is the diffusivity of chromium in the alloy. Figure 6.22 sheis a plot of experimeritally determined weizht change. $3 . M$, is the $I t$ for a specimen near the hottest point of koop 21A. The good fit of the data to a sraight line provides further evidence of a diffusion-controlked cotrosion mechanism. A new set of specimens fabricated from I"; niobium-modifred Hastelloy. $\mathrm{I}$ has been inserted intu ine loop and wili be used to obtisin corrosion dala for that alloy.

Thermal conitection bop 31 is cunstructed of type ? 16 stainless steel, has 316 staintess steel specimens. and cuntains Lif-BeF: (66-34 moke " $"$ ) salt. For the first $1000 \mathrm{~h}$ - of operation, this loop was used to gather baseline corrosion data with "as-received" salt. Sibsequently. reductant (beryllium) was added to the salt at the kvel of abciti $0.1 \mathrm{mg}$ He $\mathrm{cm}$ 'salt. Vew specimens were then inserted. and the corrosion rate has been measured for stainless steel in this redivcing salt. Addition of beryliitm made the salt quite reducing. but once the source of bervillium was removed. species in the salt were nc longer in equilibrium and the salt became progressic ely more oxidizing with increasing time. While the source of beryllium was in the salt. the corrosion rate was extremely low. However. after removal of the beryllium the specimen in the hottest position showed a pattern of increasing weight loss as a function of time. The increasing corrosion rate was

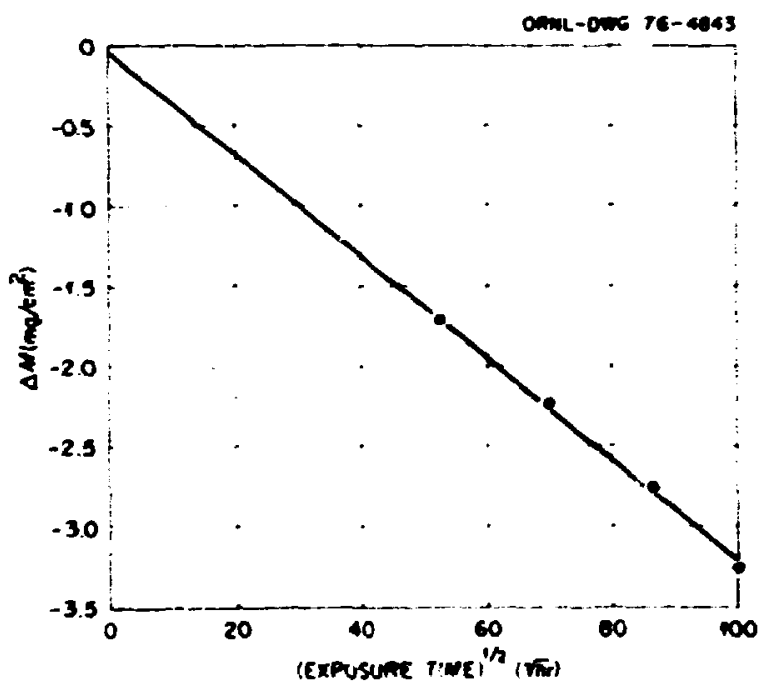

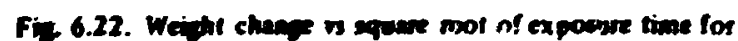

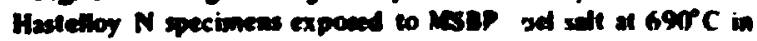
Herned ourestion loop 21 A. 
associated with the increasingly oxidizing state of the salt. Wight change results for specimens in both the "as-received" and "reducing" salt are shown in Fig. 6.23. Fresh salt and new specimens are to be added to this loop. and corrosion experiments will be continued.

Two Hastelloy $\mathrm{N}$ loops. $\mathrm{NCL} 24$ and $\mathrm{NCL}$ 18C. have been filled with MSBR fuel salt and put into operation recently. These two loops are being used to measure the effec: of chromium conventraion on the corrosion rate of Hastelley N. Increasing the chromium conitent of a nicke base alby generally increases the alloy resistance to grain boundary attack by tellurium. However, increasing the chromium content docreases the alby's resistance to mass transfer. From these tests and tellurium exposure tests. a possible optional chromium concentration may be determined. For these corrosion tests, four modified Hastelloy $\mathrm{N}$ alloys containing 7, 10, 12, and 15 $C_{\text {s }}$ chromium have been made. Specimens of the $7 \%$ chromium alloy have been exposed in NCL. 24 a total of $1060 \mathrm{hr}$. The maximum corrosion rate observed was $-1.9 \mathrm{mg} / \mathrm{cm}^{2}-$ year. The $100, \mathrm{c}$ chromium specimens have shown a maximum corrosion rate of -2.3

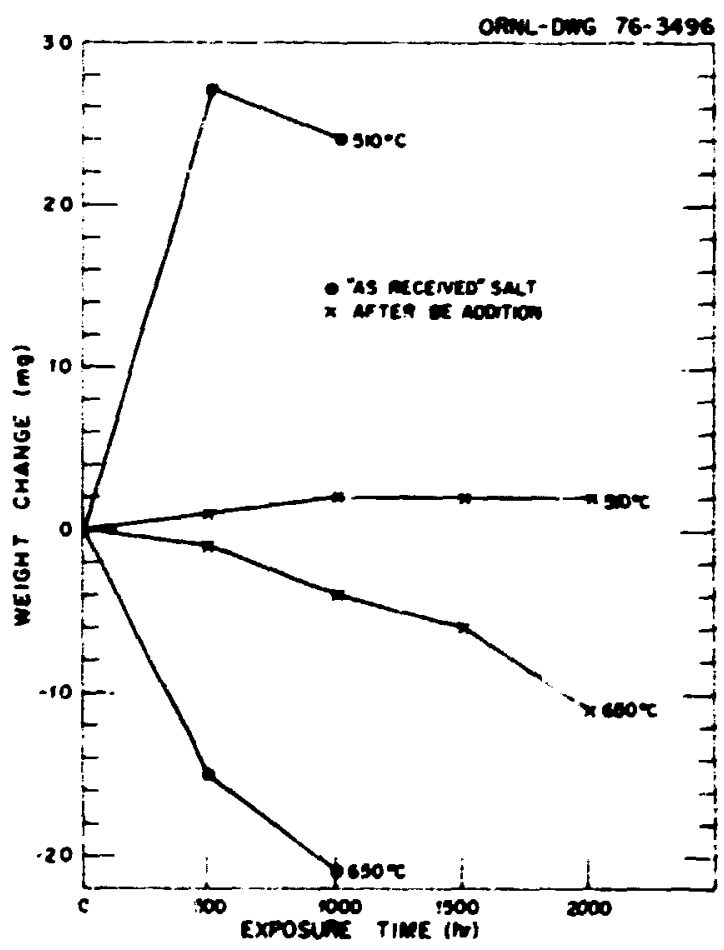

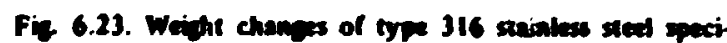

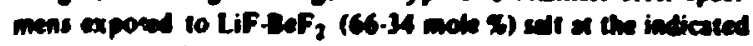
amperabure. Surfaces aseas of the specimens were approxi. mately $3.4 \mathrm{~cm}^{2}$ me $\mathrm{sm}$-year after $550 \mathrm{hr}$ in the salt of $\mathrm{NCL}$ ISC. Exposure will continue until each set of specimens has been exposed about 1000 ir.

\subsubsection{Forved Cirenhtion Loop Reralu}

Hastelloy N pump bop FCL-2b was used duriag the first six months of 1975 to obtain basetine corrosion data under conditions where the $U^{\text {en }} U^{\text {"- }}$ ratio was about 100. A maximum corrosioa rate of $-2.5 \mathrm{~ms}$ : cro"-year ( $-0.11 \mathrm{mil}$; year) was reported after a total of about 3200 hr of a phaned 4000 hr exposure to salt. Figure 6.24 shows the effece of material transfer or specimens from the hottest and coldest positions. There is svidence of materin removal and deposition. Heat iransfer meastiremeats were scheduled to follow the 3200-hr corrosion test but had to be delayed because a lak was discovered in the Hastelloy $\mathbf{N}$ tubing. Following repair of the tubing, the heat transfer measurements were made and then the corrosion specimens were inserted for ancther 1000-hr exposure. Weight change measurements made at the end of this period revealed that over the total $4309 \mathrm{hr}$ at specimen temperatures of 566, 635, and $704^{\circ} \mathrm{C}$ the corrosion rates were 0.0 . -0.2 . and $-2.3 \mathrm{mg} \mathrm{cm}^{2}$-year respectively. This rate of corrosion is weli within the limit that could be tolerated in an MSBR.

lt was planned to adjust the $\mathrm{U}^{\text {s+ }} \mathrm{U}^{\text {:- }}$ ratio of the sait upward to 1000 by mans of NiF: additions follower by a 4000 -hr corrosion test in the more oxidizing salt. Several vif: additions were made. and the $U^{40} U^{60}$ ratio did increase: but another leak occurred before the ratio reached 1000 . This lak was repaired, but shortly after operation was resumed. a third leak occurred. Because of plans to terminate the MSR Program, it was decided to forego funher testing of standard Hastelloy $\mathrm{N}$ and to use the loop to gather baseline corrosioi: data on $I F$ ninbiummodified Hasteiloy $N$. an alloy that shows improved resistance to teliurium srain 'soundary artack. Specimens were inserted at the end of February and will be removed periodically for examination.

After each of the three leaks, a section of tubing containing the failure was removed. and new tubing was welded into place. These lailed sections were examined metallographically. Figure 6.25 shows the appearance of the :-in. $-O D$ tuhing at the site of the first leak. This kak occurred at a $90^{\circ}$ hend on the nutermost poition of the tubing. Examination of a transverse section of the lube (Fig. 6.26) shoved extensive cracking in the vicinify of the lak. and the 

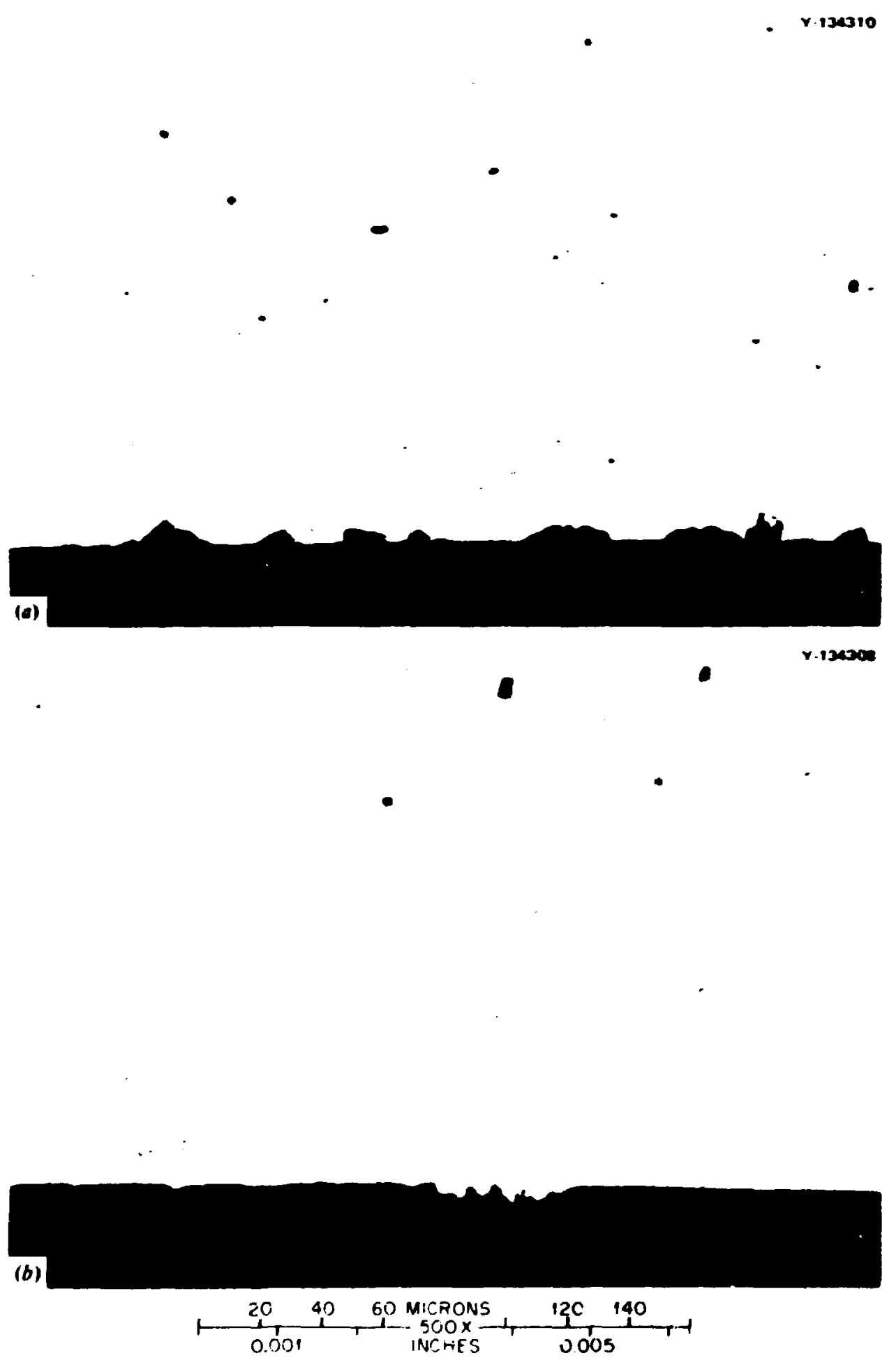

Fi. 6.24. Pholomicrographs of standard Hachelby N exposed to fuel sall in FCL.26 for $3200 \mathrm{hr}$. (a) $704^{\circ} \mathrm{C}$. (b) $566^{\circ} \mathrm{C}$. As polished. 


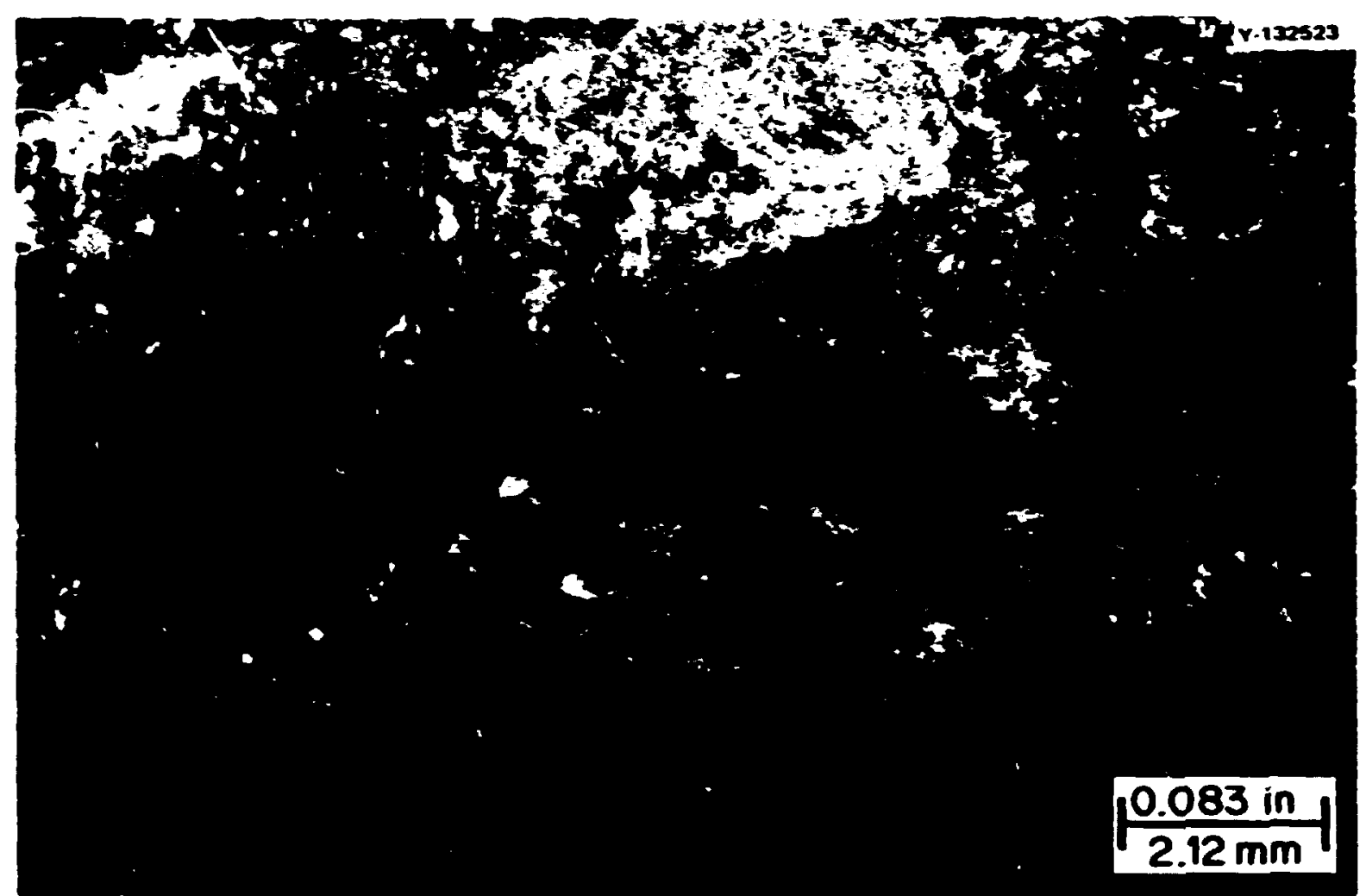

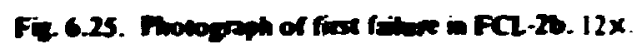

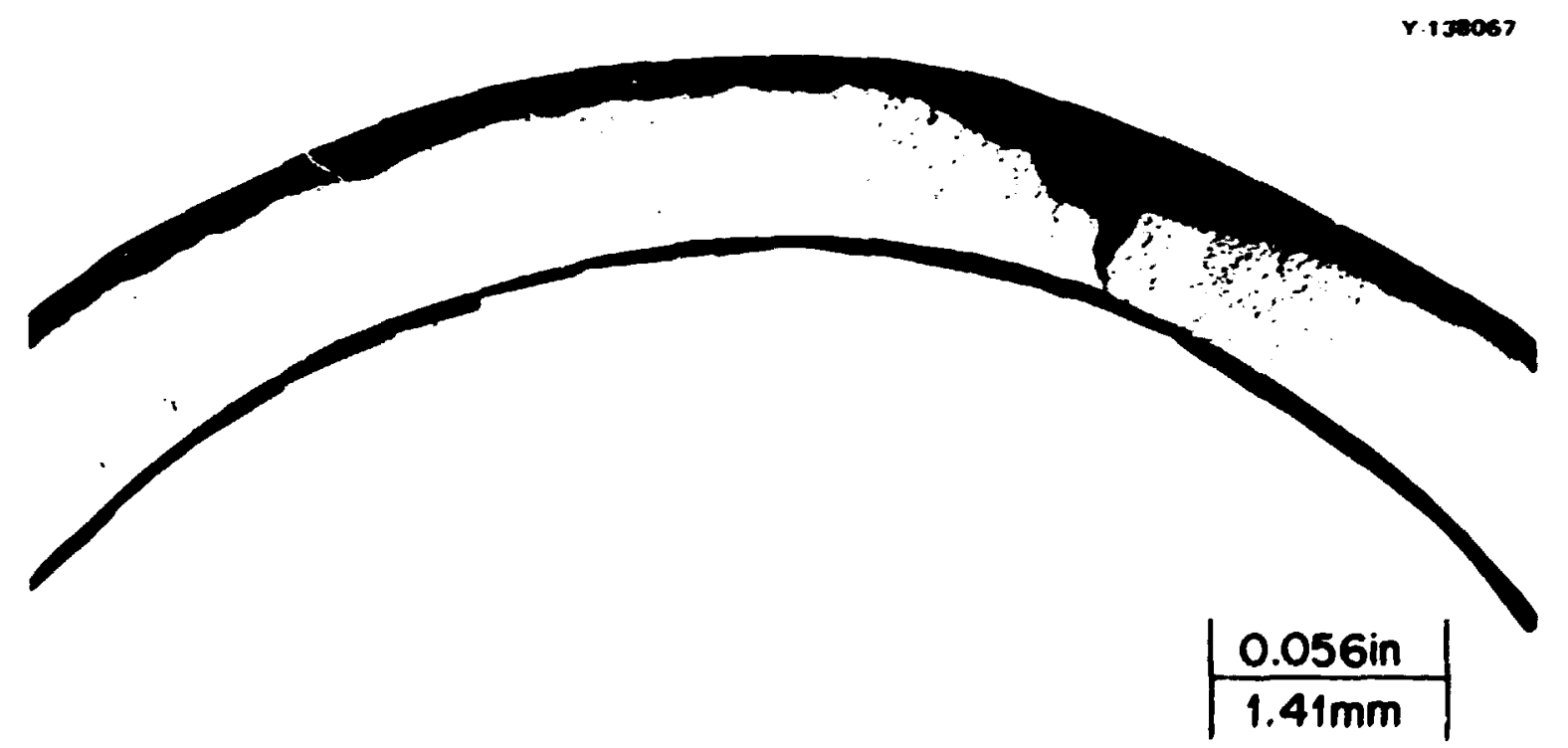

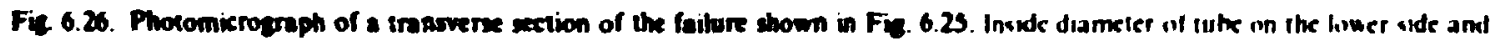
rulsude diameler in the upper sade 
longitudinal section (Fig. $6.2^{\top}$ ) sho -1 that these small cracts ran paralkel to the axis ot the tube. The presence of a shorted heater and a bumed-out thermocouple on the section of tubing where this failure occurred provides additional support for the conclusion that this failure resuhed from a combination of excessive temperature and bow stress for an extended time. This leak possibly could have been avoided if the tubing had been annealed afuer bending or if the temperature had been maintained in the desired range. This contention is further supported since sections of the failed tubing which had not been severety stressed during bending did not show cracking and since examination of a ncarby $0^{\circ}$ elbow that had been operated at the proper temperature showed no creking even in the most severety deformed regions. Howeter. the length of tubing involved would have made annealing difficuh. and changing the thermocouple would have required drainage and shutdown of the loop.

The second failure occurred in a straight section of resistance heated tubing: the appearance of the failed section is shown in Fig. 6.28. Transverse and bongtudiazal sections of the tailure (f tys. 6.29 and 6.30 respectively / show a single crack. The troasierse view show's evidence of necting or reduction of area indicatinc of a fairh brge siress. A high stress could have occurred during heating of this region if salt were trapped there between iwo tranen sath phes.

The third faibure occurred at a weld joint in one of the specimen access positions (fis. 6.31). Metallostaptic examination of the Gibare showed one creck. which probably occarred when a hiph stress again resuled from heating inpped sak (fis. 6.32). As reported by Huntley in Sect. 2.3.8. modifications have been made to the bop to prevent development of froxen sections.

\subsection{CORROSLON OF HASTELLOY $N$ AND OTHER ALLOYS IN STEAM}

\section{B. Mclibb H. E. Mecos}

The corrosion of Hastelloy $\mathbf{X}$ and ofher nictel. iron. and cobak-base allons is being crabuated in TVA's Bull Run Steam Plam at steam conditions of $538^{\circ} \mathrm{C}$ and 3500 psig. Unstresced sheet specinens 2

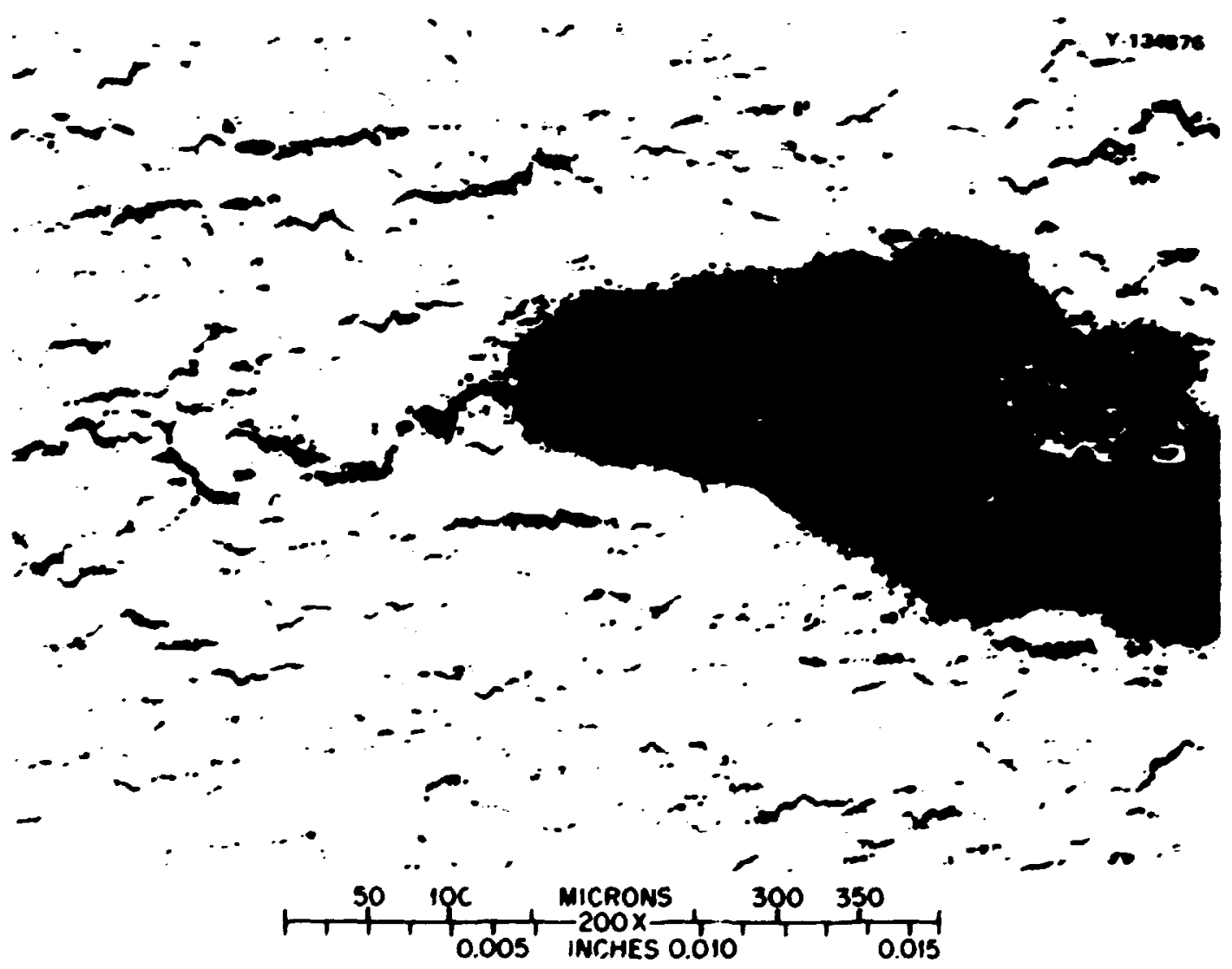

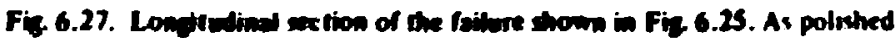




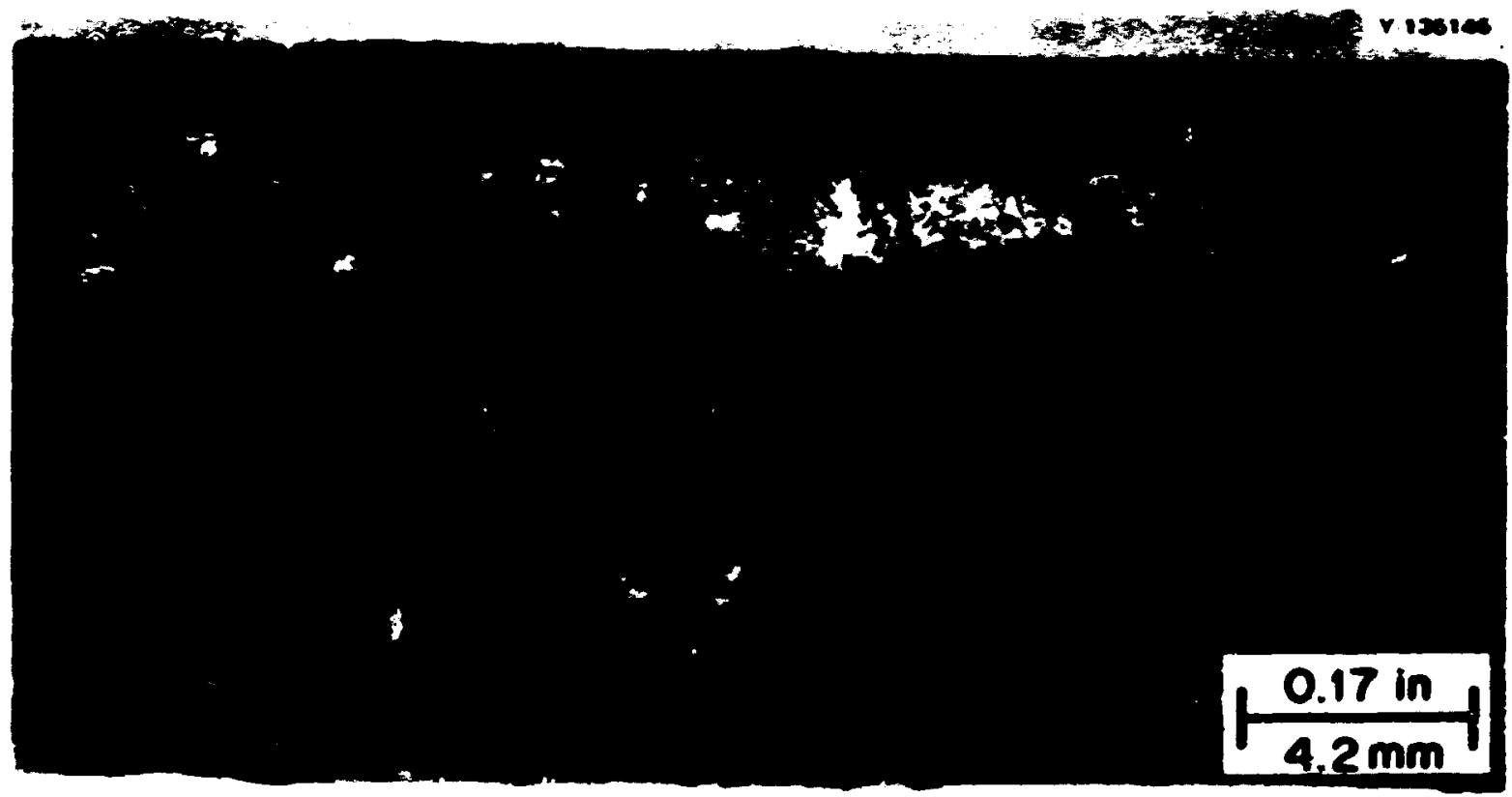

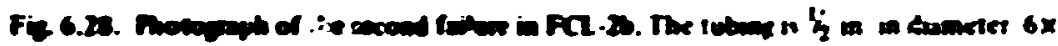

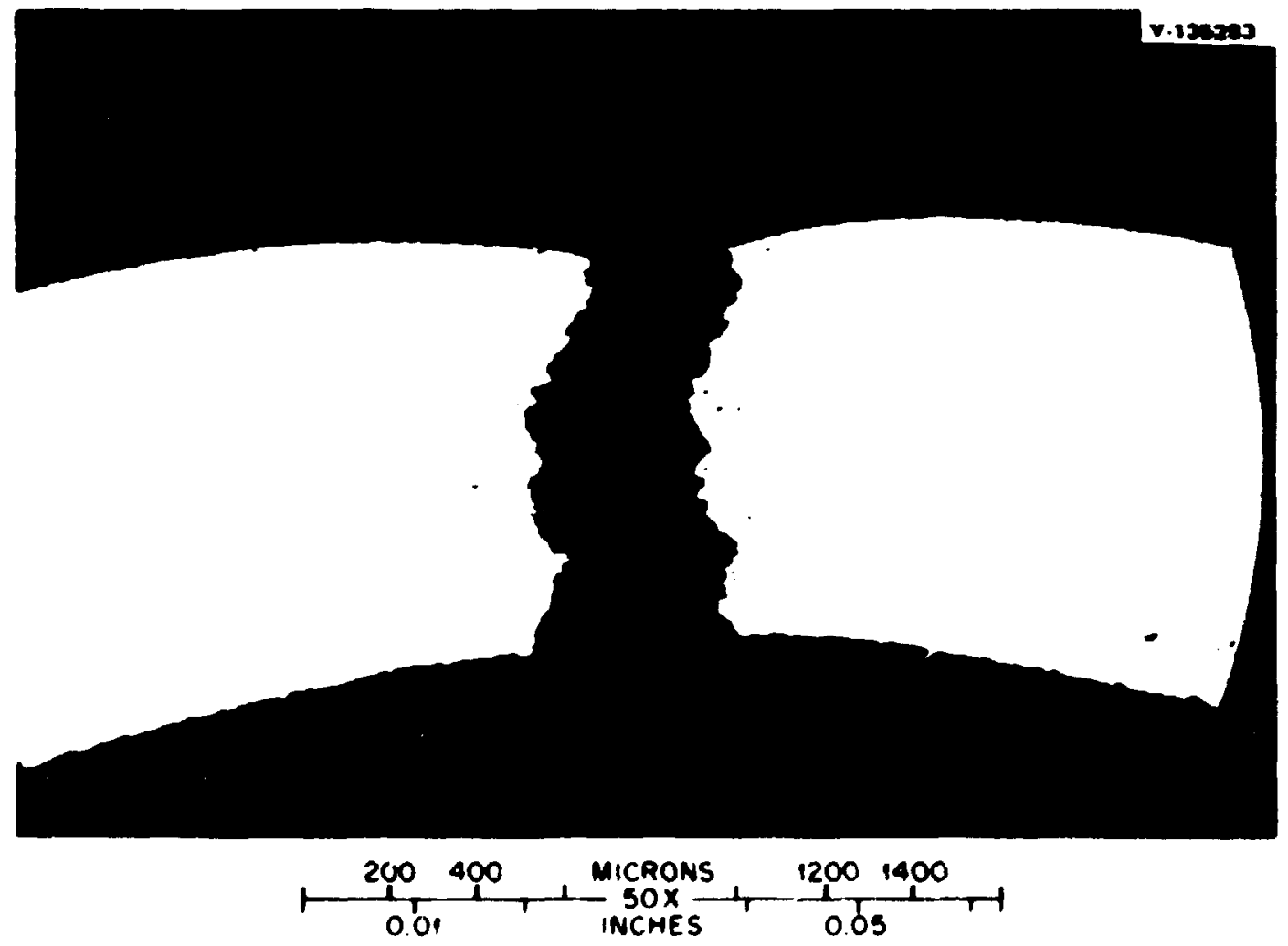

Fie 6.29. Tranowere section of the faibure shown ia Fie 6.22. As polvened 


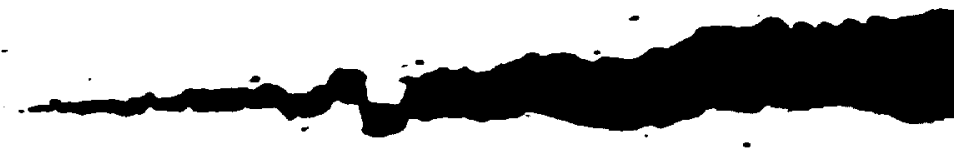

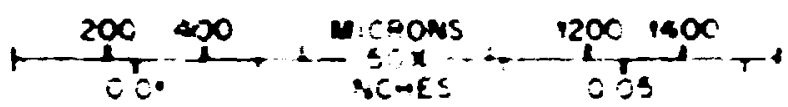

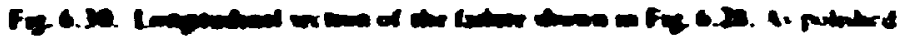

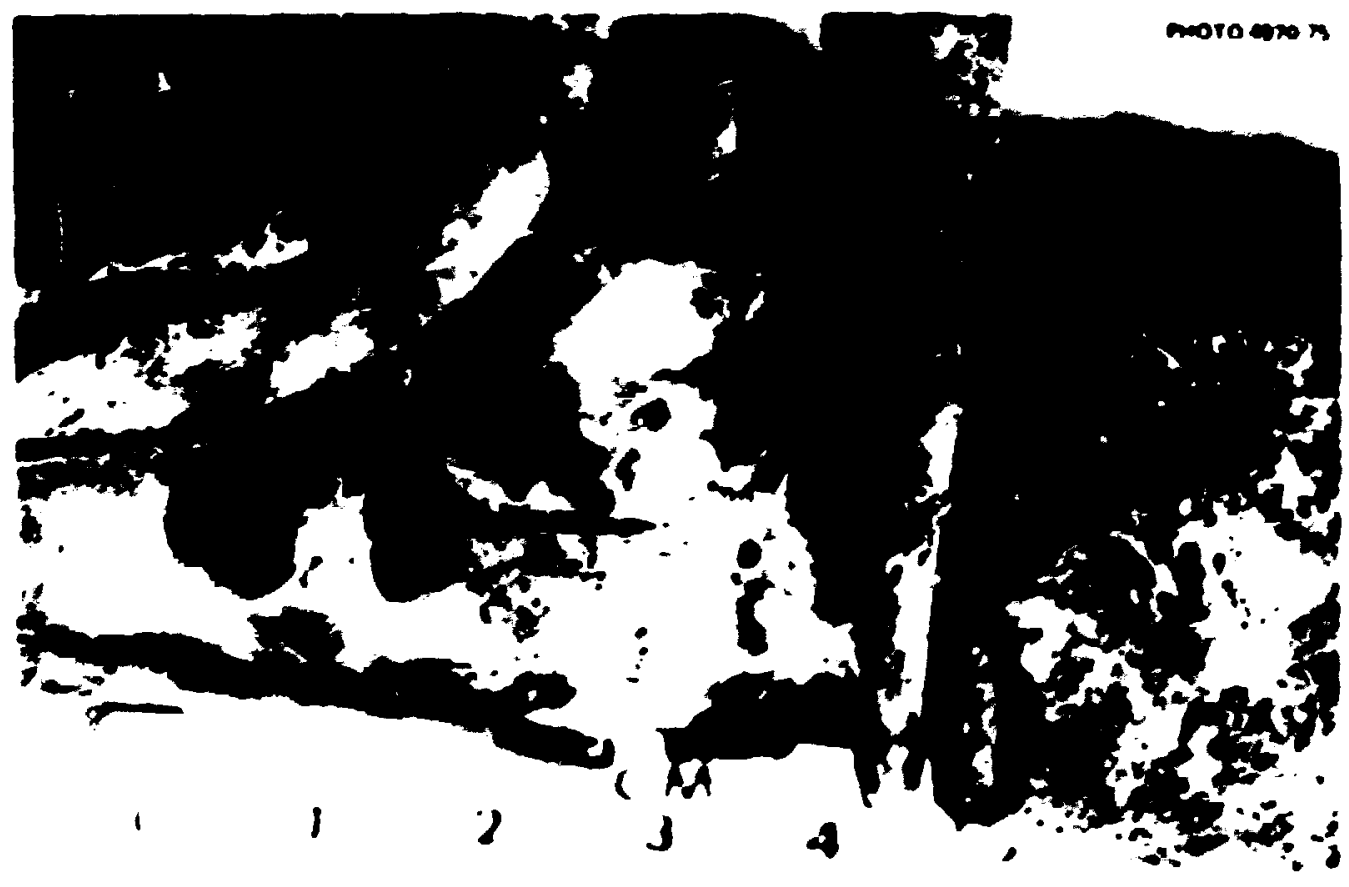

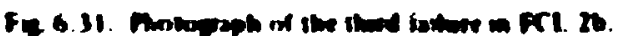




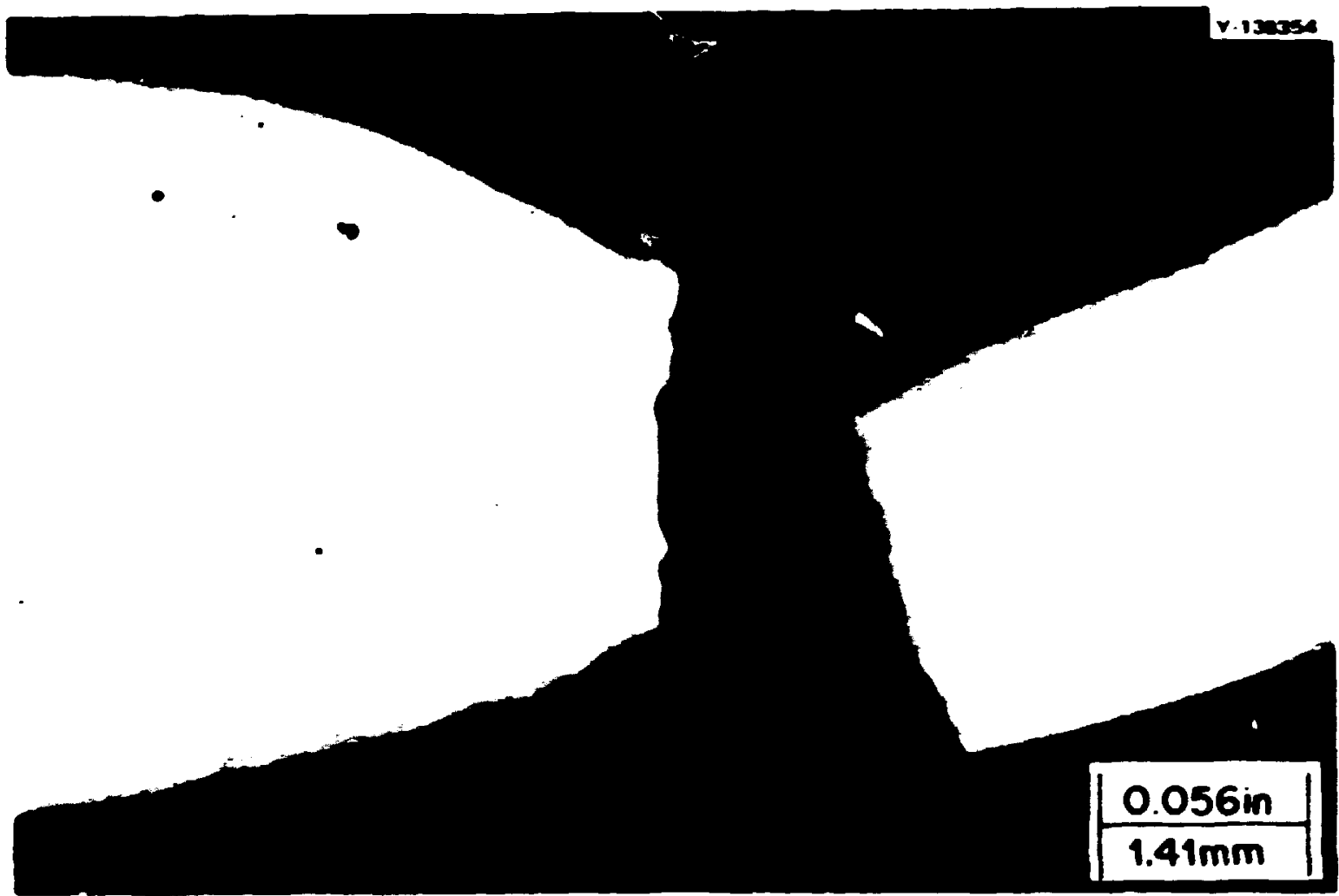

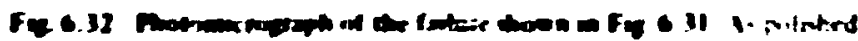

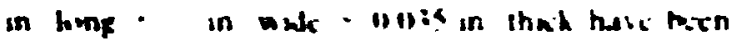

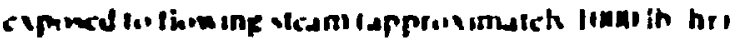

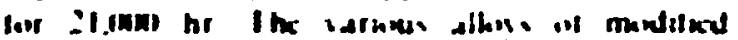

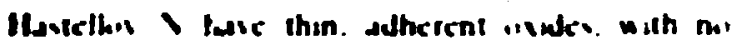

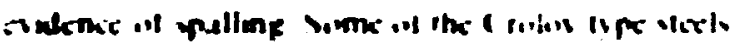

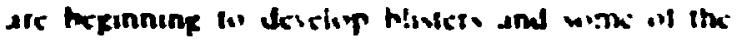

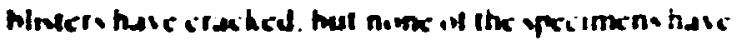

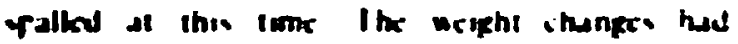

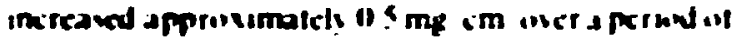

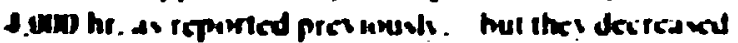

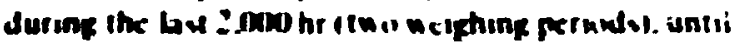

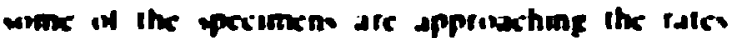

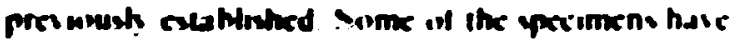

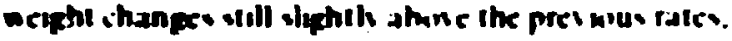

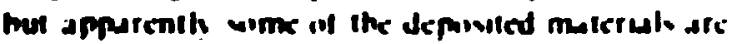
heang remaled

Ithe weipht thange hehulwe correlates well with Itre seam ywalits and with itwernatwons hyll Run engincerv Seicial kaking sondencer tuhes wers xaked inlt dureng the ien-nech Juedion in the bitter part of 19\%9, and i... veam yuilir! improncd comuderahly. Te coundenxer keak s had men experienced helore 197,1. hut wercal ixcurred during 14't

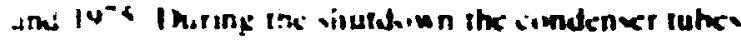
wers coistamenkalt, inopected. and ans rute whome

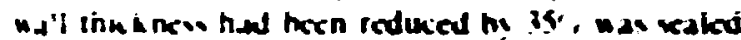

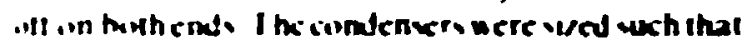

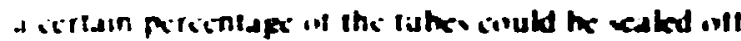
ind the condenuel vill perlorm winlactority I he condenut tuhe ate construited of edmiralts hraw. and corronnon incurs rear hultks in the reguon. where dropket. in firm and then capporate I his kat, t" an incriaxd comicntralum it impurtes

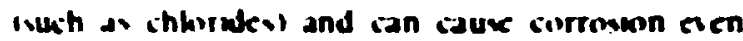
thiweh the mult concentratuns mas be in the hom parts per mulion or parts per hillom range the manulditurer of the condeners has made wonce reviommenduturn, to remed! the problem. such as nater injectuin fin wath the tubes in this area. Ihe iflect if plugging wime of the coundenser tubes is In

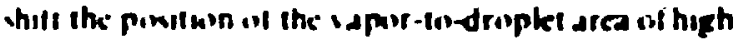

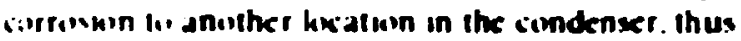
ceposing areas if the tuming that have lad kes currowinn and exposing the courroded areas in a kess curromise condiluin. Somx experimental condenser tuhes of (iv IOF, Di do nex exhibut as much 
uxeptibilin to this type of corroswn as the admirality brass. Thex hal: been piopined tor reptaceraent tubes and shoukd relicte the proshem.

I wo heats of sandard Hastelhy I r.twne $1 \mathrm{VI}$

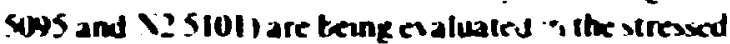

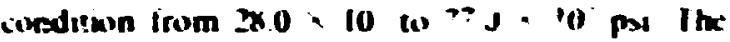
perimens of buth heats in the annshed condtingn of hr at $11^{-T}$ ( 1 have shorter rupur: come in seam than in argen. Specimens of heat MI S0O5 tosed in

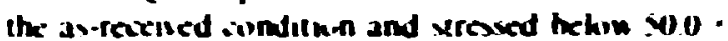
11) $m$ in sleam have rupture tumes cyual to thexe of perimens cested in argon. Fyeure 6.31 shows the veress-rupture propertics of heal 11 sUHS. As repurled earler. fluns in the spexemens may hale contributed (o) the seatter. hul at strenes - 5).(1) - 10 ms. where wall theh neweste heav wer. there appears

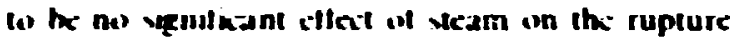

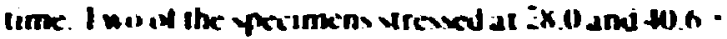

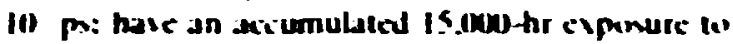
veam at $53 x$ ( 1 ithent ruplure. and three atter a al

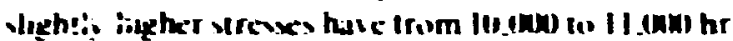

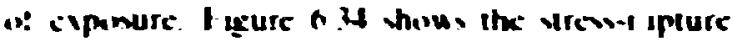

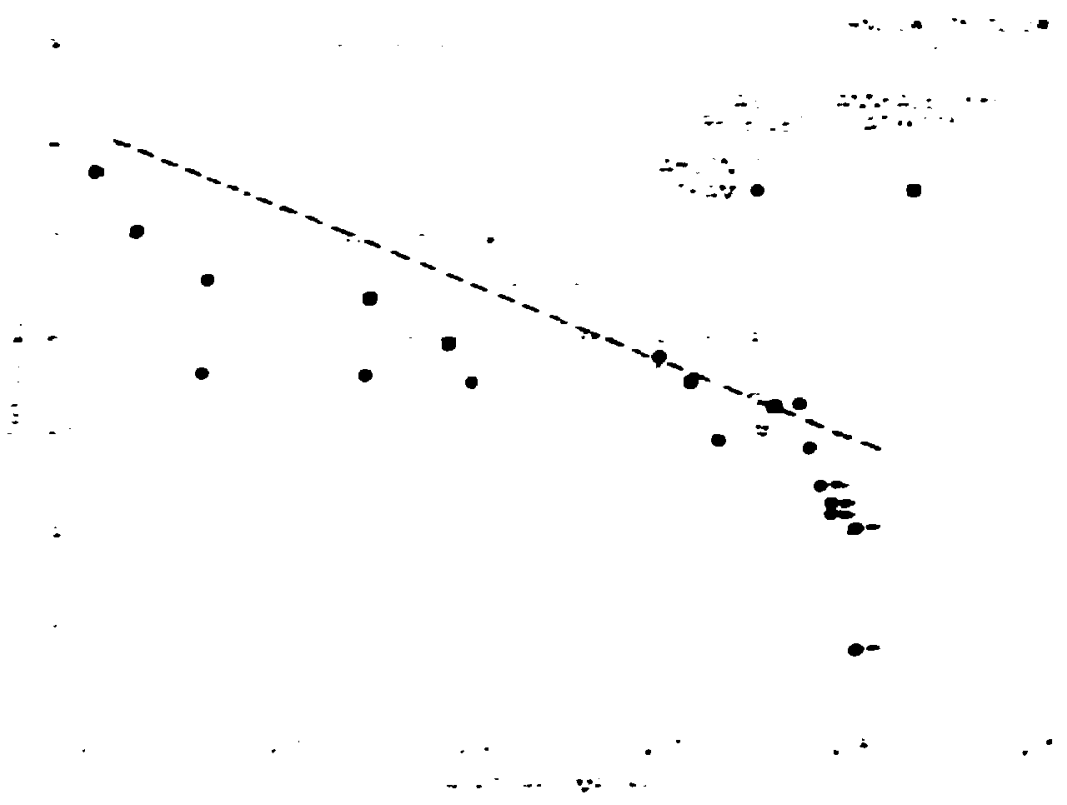

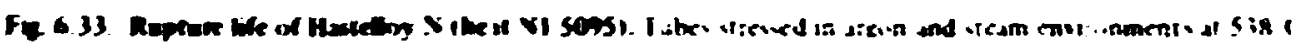

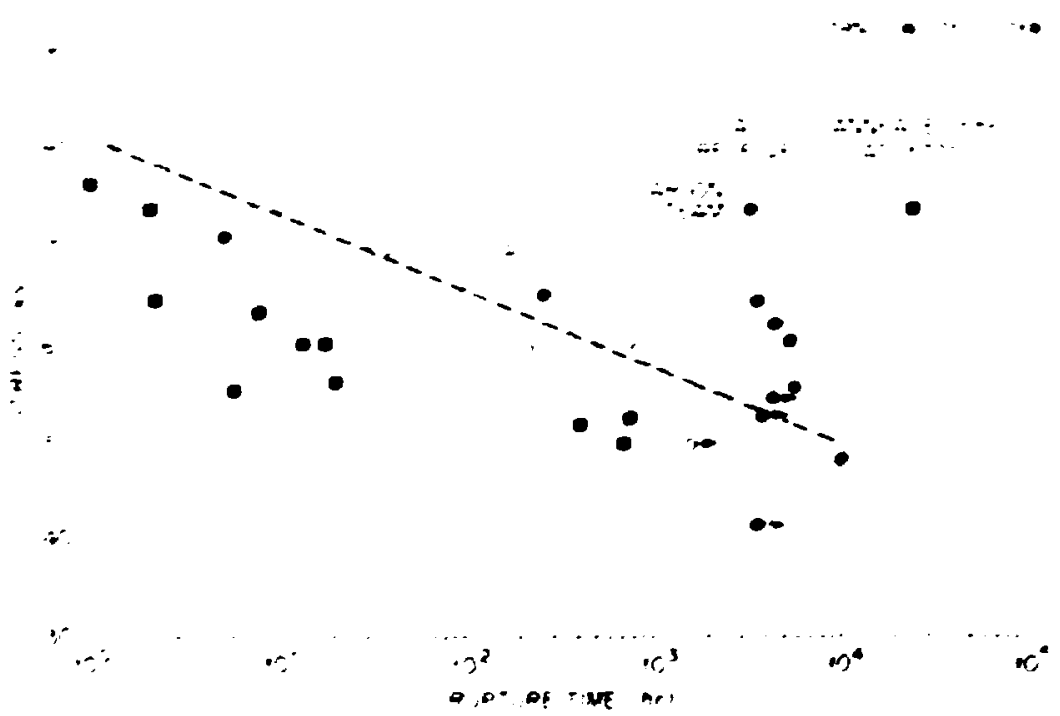

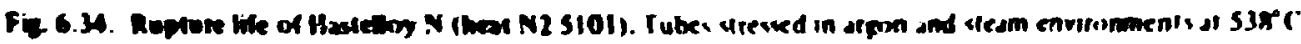




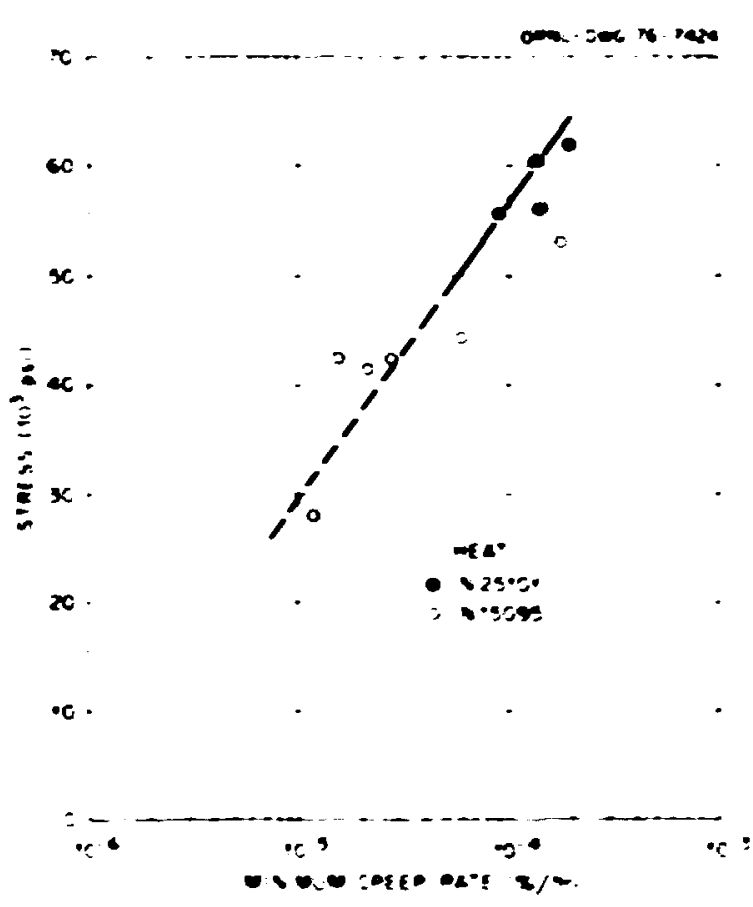

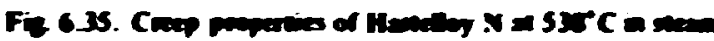
converme

properties of heat 12 5IOI Specumens in the ananealed condamn tested in steam have shorter raphure tmer than specimens tested in argon Specianens in the as-received condumon iested in stean have idpture tmues cyual to or greater than speciumens lesied a argan. The hapest nuphure ture of thus heat to date a as 12000 hr for a specunes seresced at $48.8 \times 10$ ps in steam at 5.38 . C.

The munumum creep rates of hrah heats of materal evere plotied as a functun of stress of te. 6.351. The creep rates are cakubied from phoss of drametral strain. $M D D$. is time. which are hased on measuremeats of the incernal dameter of the specinens at ICOD-hr intenals. There is consideraink scatter in the dat because of diffeculty in masuriog the mternal diameters at the point of maximum strim. hut the figure is uxeful as an indication of the strain rates expected in this stress range. Buidup of scak on the inside diameter exposed to steam abo contritules to the insccurecy of this method sunce the apparent strain is reduced as the sole thickens.

\subsection{VAPOR PRESSURE MEASUREMENTS OF METAL TEULURIDES}

\section{S. L. Benneti J. Brynestad}

Sereening lests were performed to establish whetiver standand and modiried Hastelloys are embrited by exposure to tellurium activities defined hy the sisiem M. Ie:(s) - Vits)at 00 C and 750-C:a knonledexe of the tellurnum actnit! li.e. Iapor pressure) under these conditions is important. Arrangements were made to attempt to oboin vapor presure measurements uter the two-piase system of nuckel plus Vi. Ie, at 700 ( by wass spectrometry at 1-12. However. the sensitn ity of the mstrument was far Irom satsbeton: a temperature of $\mathbf{8 5 0}$ ( was required in onder to begin to observe the sectes le and Ie. Ihe experment did coatirm. homever. that iellunum monomer and dimer are the ont pascous pecaes present in this sy stem. in accordance with the observatmens of Weaver and Redman.

Since measurabte weigh losses were observalte wh the Metilet Recordiag lizcuum Thermosenhret at about $800 \mathrm{C}$. Ad above. quantiatne vapor pressure measurements are bewe made on ths iechninues. The kinudsen etfuswon cywition.

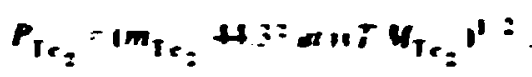

rebtes the partal prssure of the speckes to the mass ot that speckes of mokcubr werght $W$ which effuses in time $t$ through an witese of efkectne area a at seuperature $I$. A wibr expression can be nonticn in cerms of the It momomet. I he dissocation cyuthbnum

$$
\left|c, t_{\mathbf{p}}\right|=2|\mathrm{etg}| .
$$

Ior which the equitibrum conseant $A_{r}=P_{i}: P_{i r}$. must he sonutiancoush satisfied lettme $m=m_{p_{e}}$ mir. one can derne the retatioaship

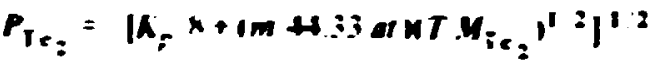

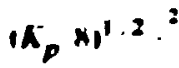

That is. the partial pressure of one species an be expressed in terms of the experimentally mensured tocal mass loss $m$ and the equilibriam constam. The equilibrium conseant as a function of cemperature is cakulated from Eq. (4):

$$
\begin{aligned}
& R \operatorname{Tin} x_{p}=D_{0}^{\circ}+T \cdot 2 \| K G_{T}^{\circ} H_{0}^{\bullet},\left.T\right|_{T,} \\
& \left\|\left(i_{T}^{\bullet} H_{0}^{\bullet}\right) T\right\|_{T_{2}}
\end{aligned}
$$

where the $\left(G_{i}{ }^{\prime \prime}-H_{n}{ }^{2}\right) T$ terms are the frece enery functions " and ${ }_{n}$ " is the emhalpy of disociation of Te: at or $\mathbf{K}$." $^{\text {in }}$ 


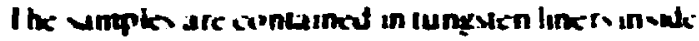

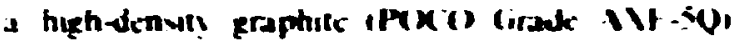

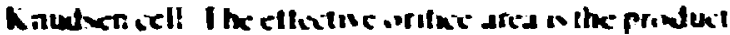

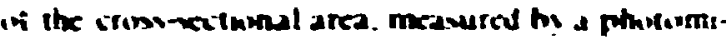

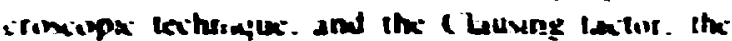

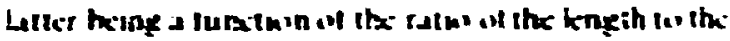
radius on the oriline

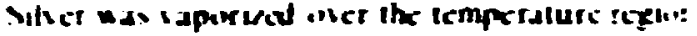

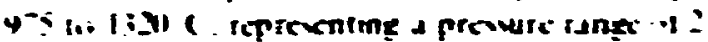

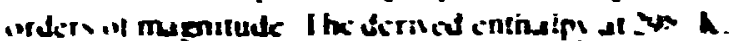

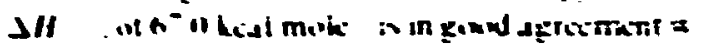

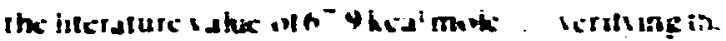

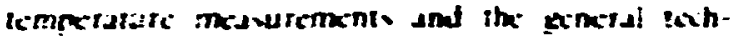
Inب̣ic

W. IAr. :hree ceperiment s hale heen dinc with th-

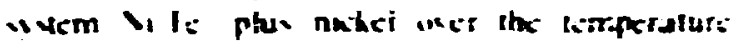

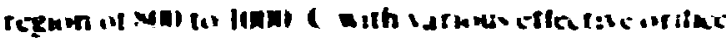

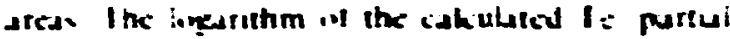

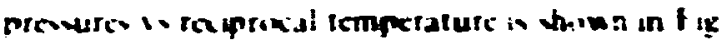

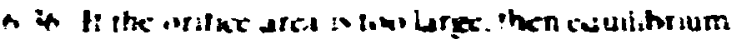
mis nen the athersod. and the akulatid presures

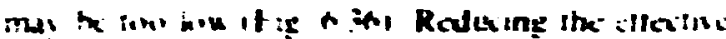

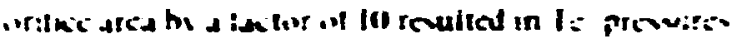

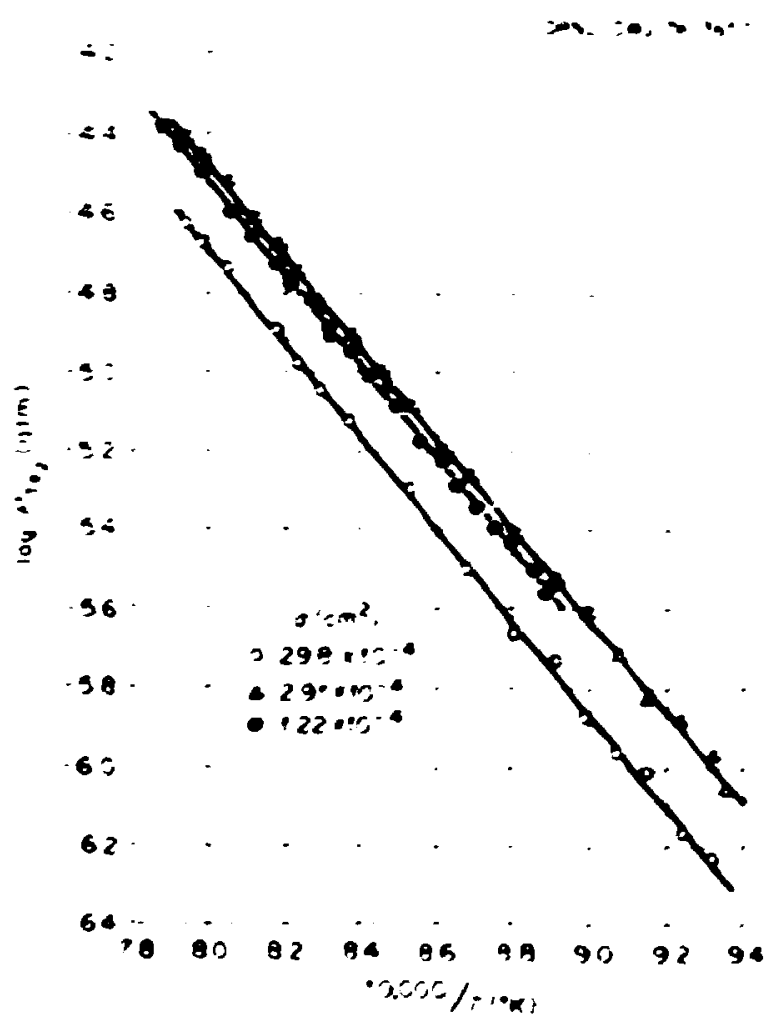

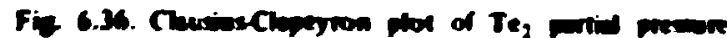

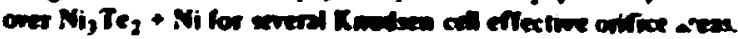

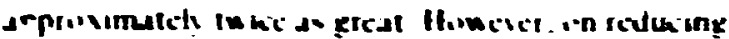

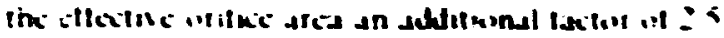

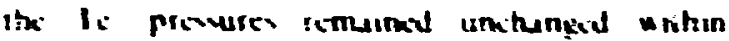

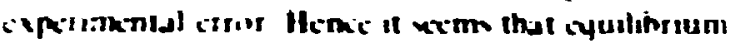

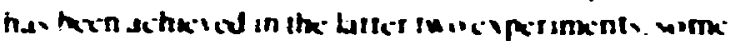

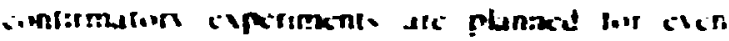

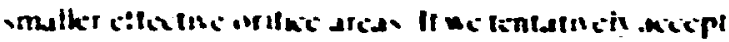

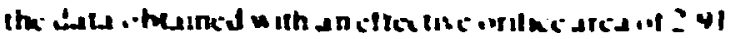

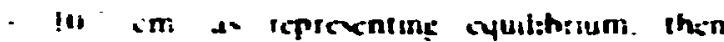

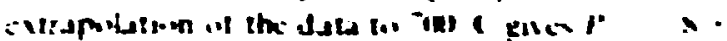

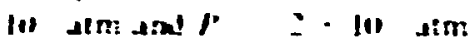

\subsection{OPERATION OF MEI AL-TELLLRILM-SALT SYSTEMS}

\section{K helus I I Anretic}

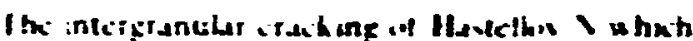

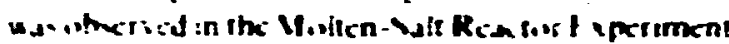

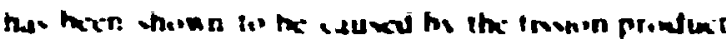

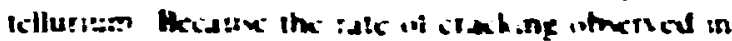

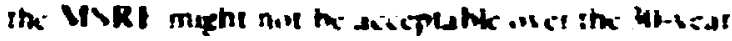

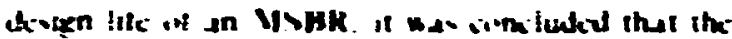

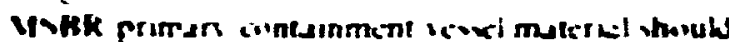

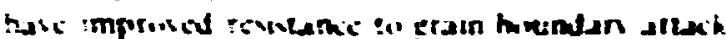

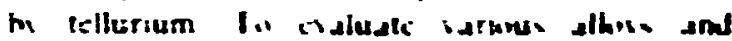

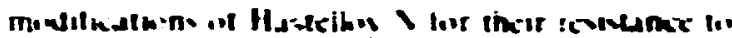

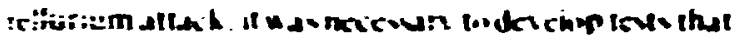

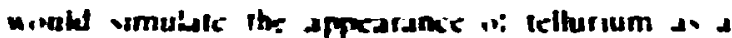

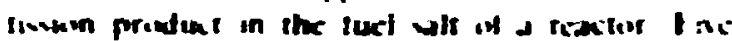

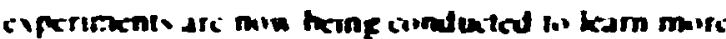

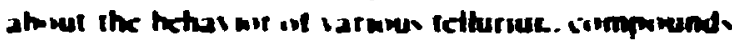
in vit and to cherminc ine ellect if the kelluratevit mivtureoun purental contsinment icuel materialv

\section{9.! Tellurian Expromenal Por No. I}

I hiv stem wa huit :o craluate the uxe ot lithium

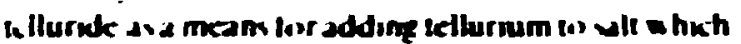
would simulate the production if cellurium in

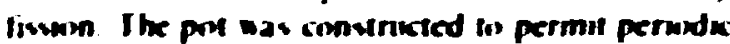
additsoms of alt pelkets comtaining small. medsured amounts of lothwom tellunde

for the first experument. I Ic wav uxed in the pelkets that were added in the I.1f-Ret - I ht, alt in the me. to cidence of a wiuhk tellurium pecimen was found by eather stuemual analy wo or ckectruxhemical examinatmn. A vecond esperiment was conducted using the reportedly move woluhk bithium tellurde. I ile Afier the pil had heen drained. cleaned. and trest oll added. three pelkets containing a iolal of ahoul B.I g of I ile: wers inverted Inurme the followng three weeks. ebetris- 


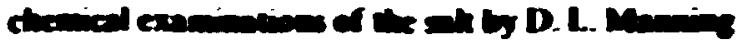

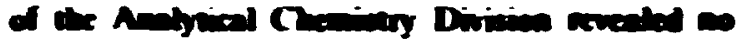

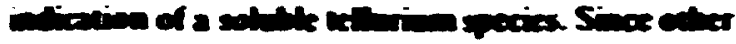

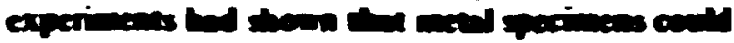

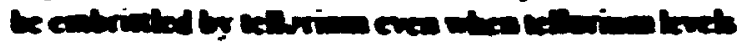

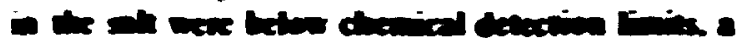

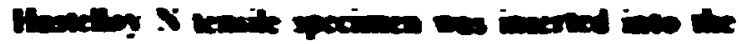

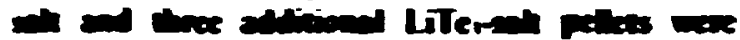

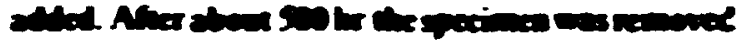

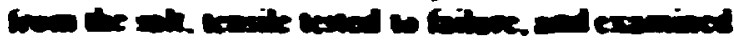

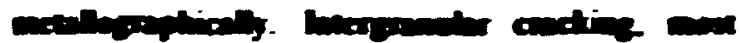

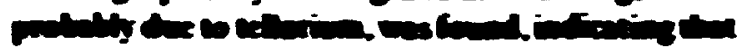

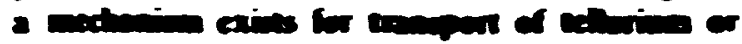
LiTer the

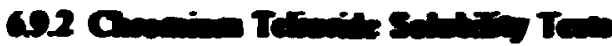

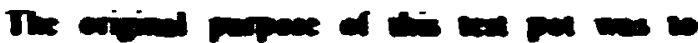

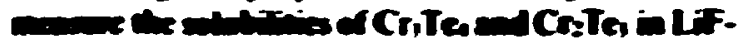

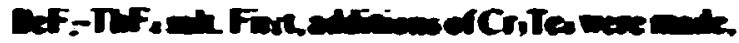

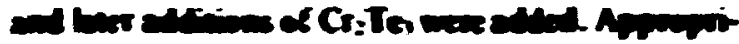

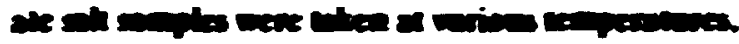

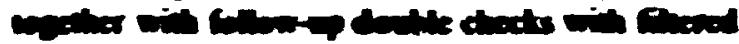

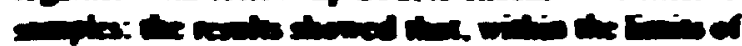

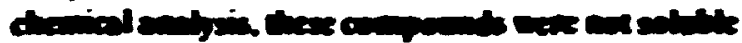

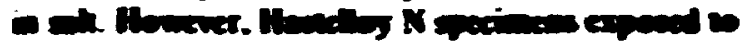

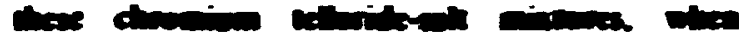

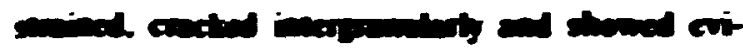

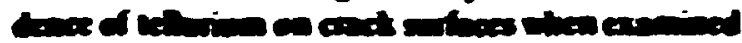

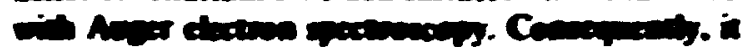

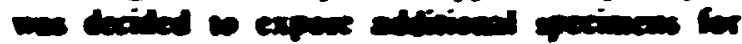

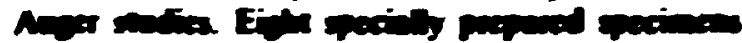

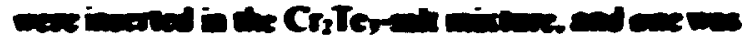

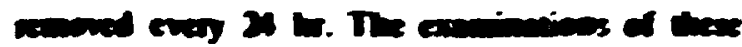

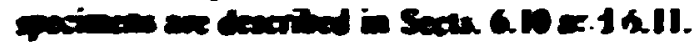

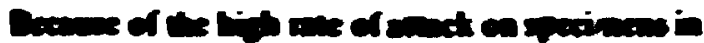

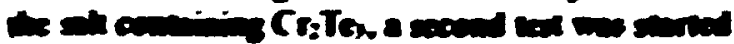

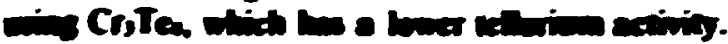

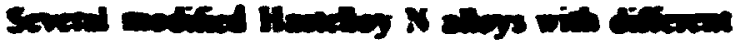

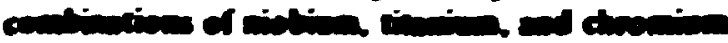

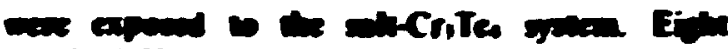

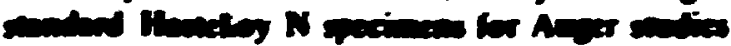

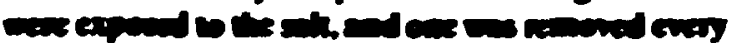

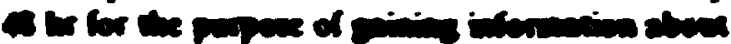

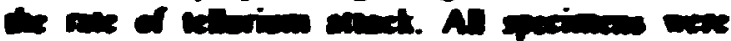

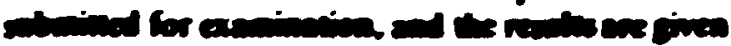
in sen a.10-12.12

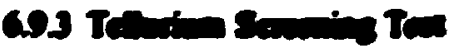

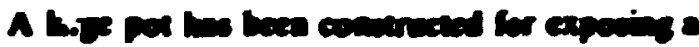

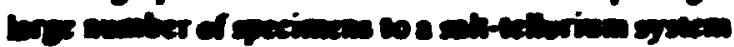

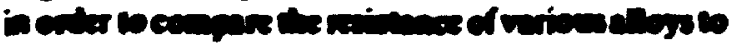

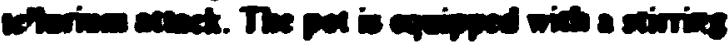

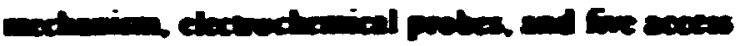

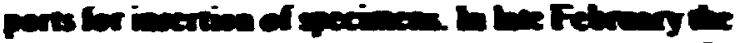

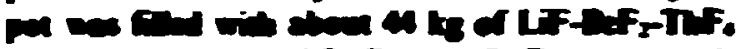

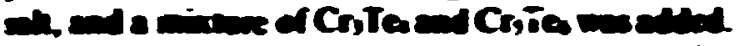

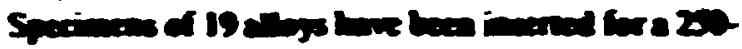

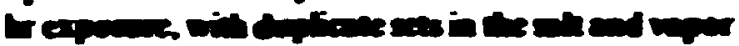

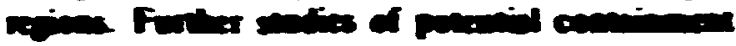

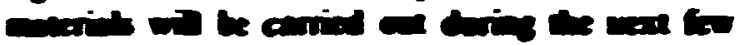
and

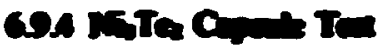

a

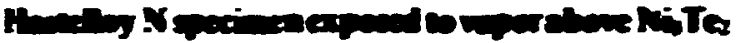

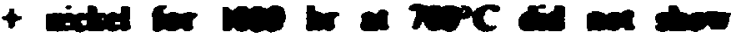

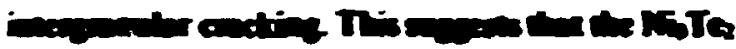
t

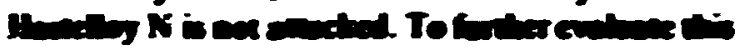

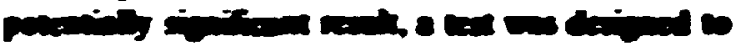

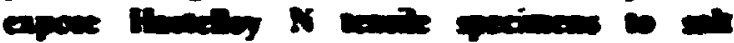

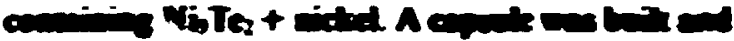

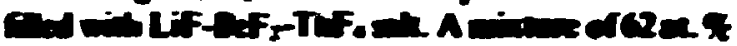

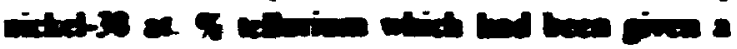

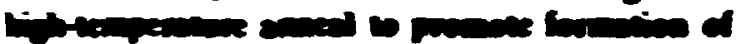

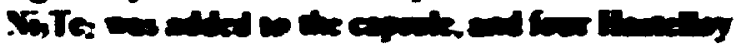

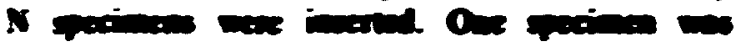

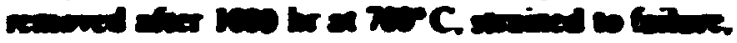

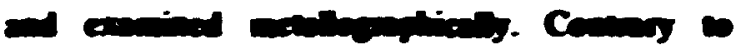

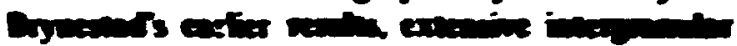

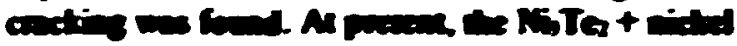

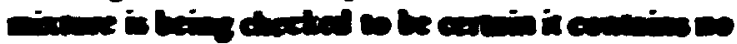

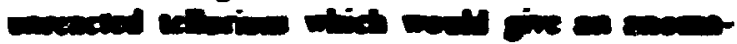

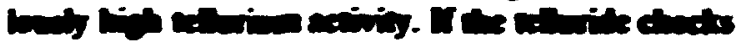

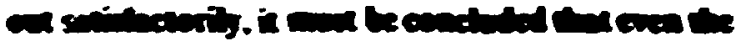

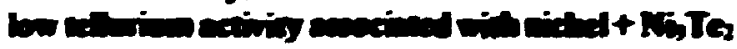

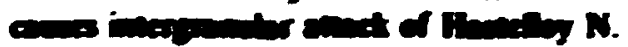

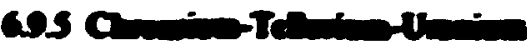

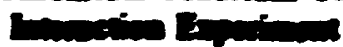

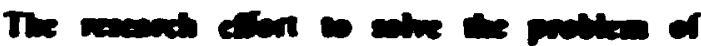

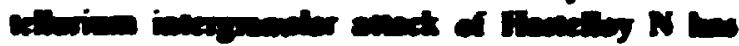

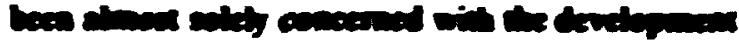

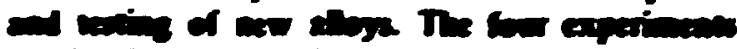

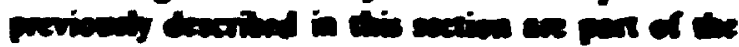

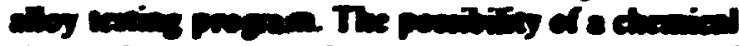

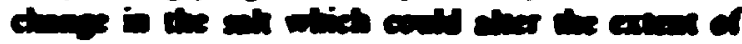

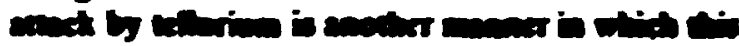

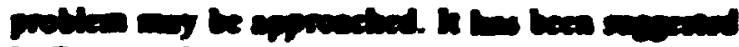

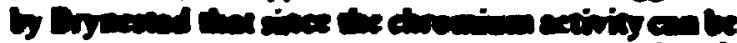

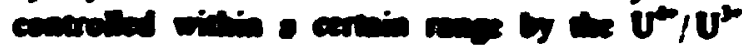

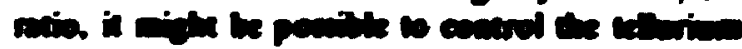
exiving is the nowions

$$
\mathrm{CrF}_{2}+2 \mathrm{UT}_{3}+\mathrm{Cr}_{3} \mathrm{Te}_{0}-\mathrm{FCrT}^{\circ}+2 \mathrm{UT}_{4}
$$




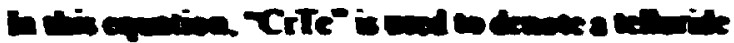

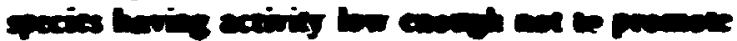

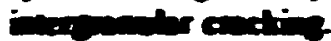

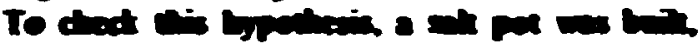

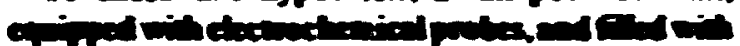

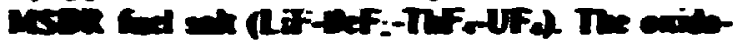

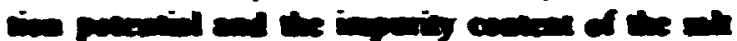

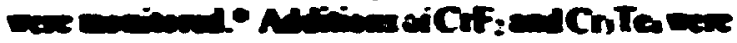

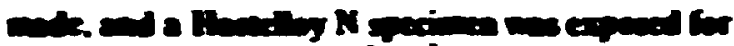

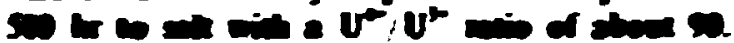

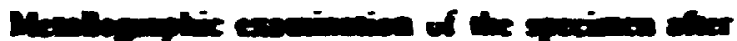

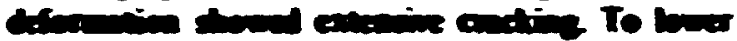

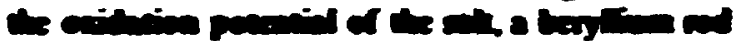

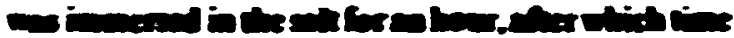

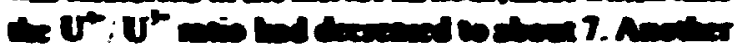

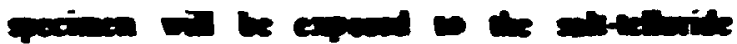

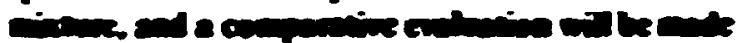

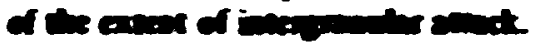

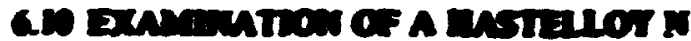

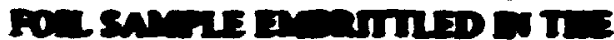

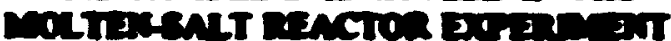

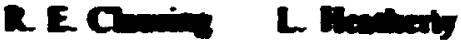

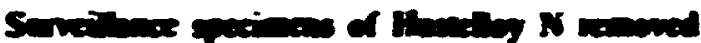

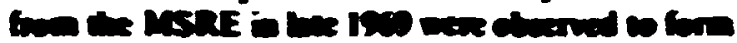

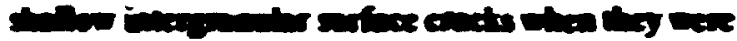

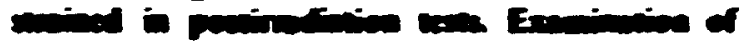

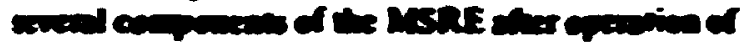

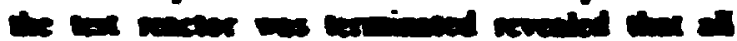

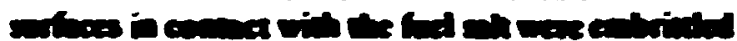

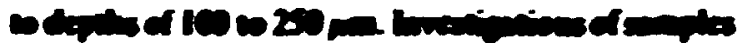

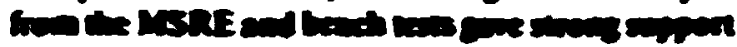

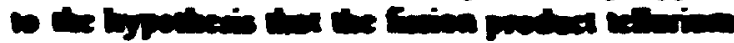

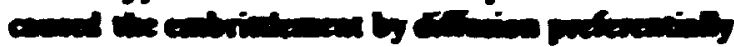

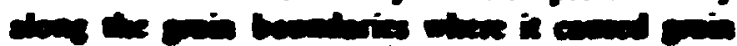

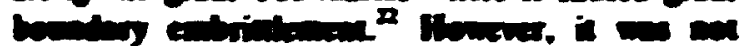

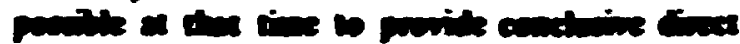

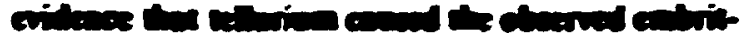
tring

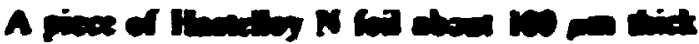

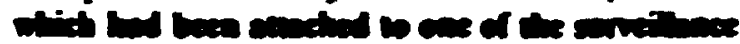

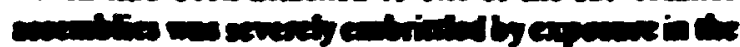

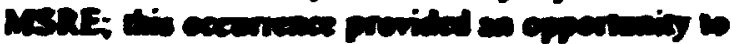

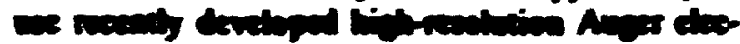

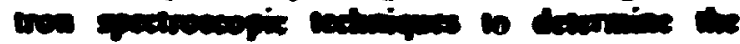

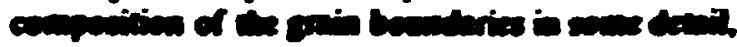
0 blimind nim.

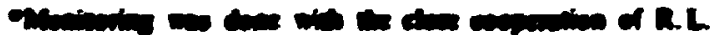

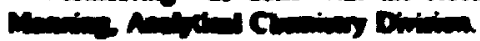

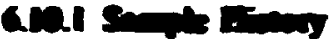

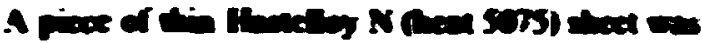

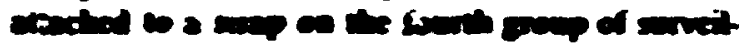

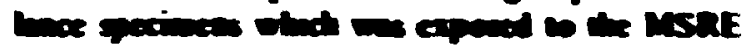

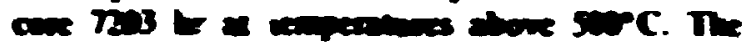

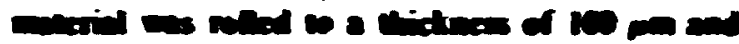

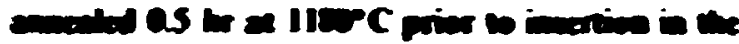

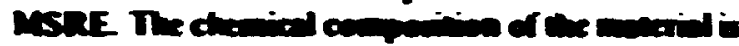

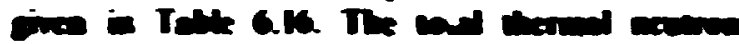

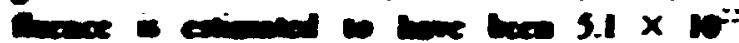

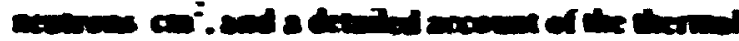

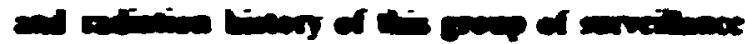

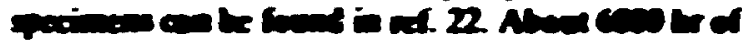

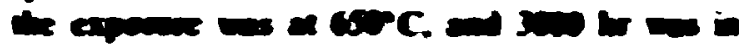

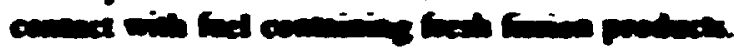

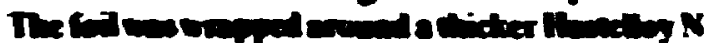

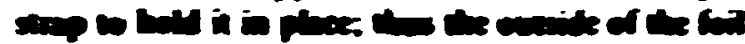

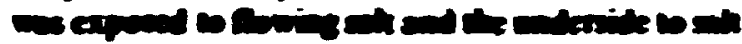

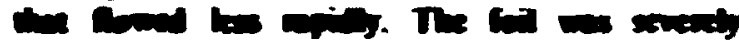

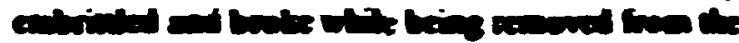

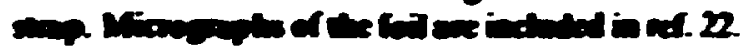

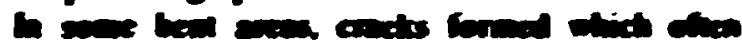

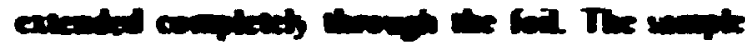
لف

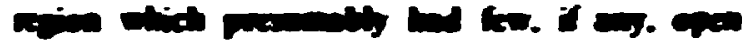

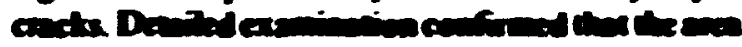

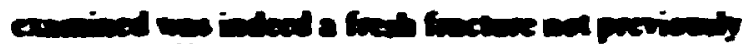

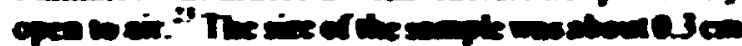

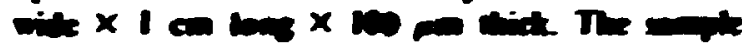

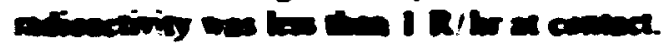

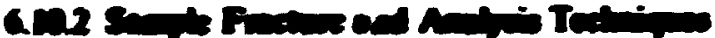

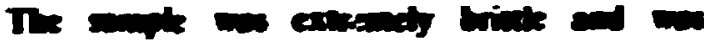

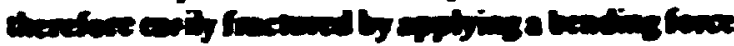

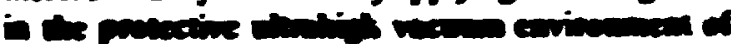

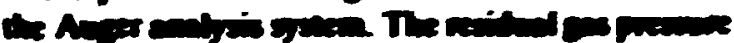

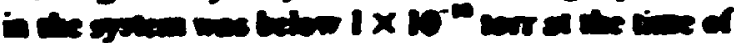

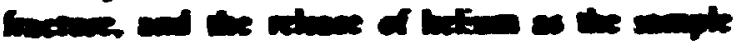

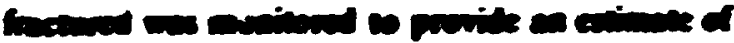

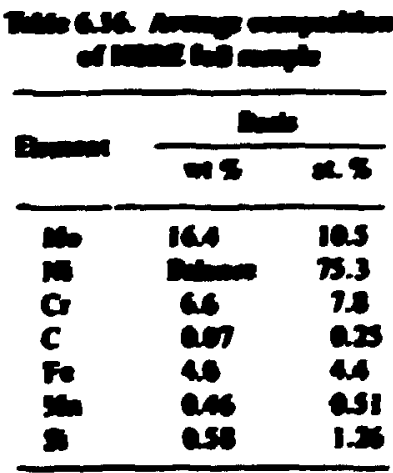




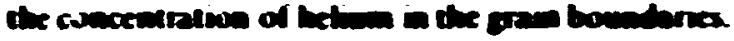

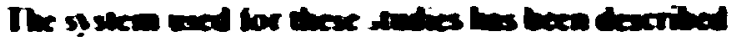
perevers. :-

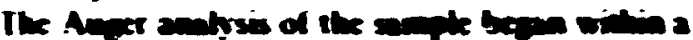

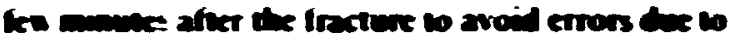

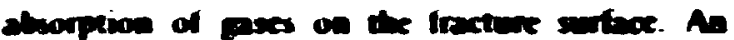

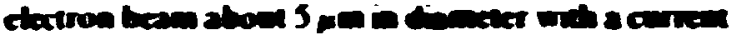

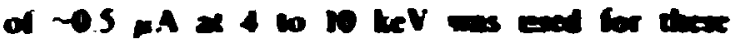
mounerneta.

\section{CDs Onamias}

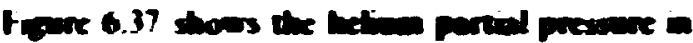

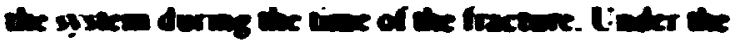

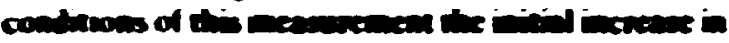

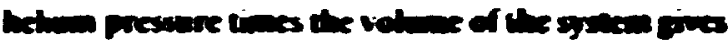

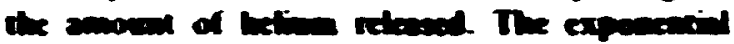

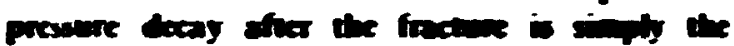

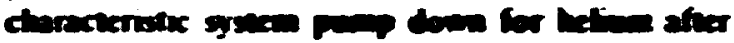

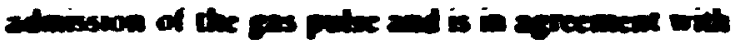

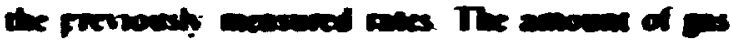

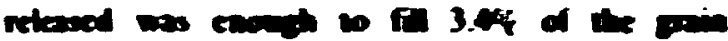

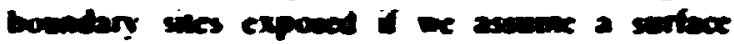
rouphas fecer of wo fice. the acturi anes of the

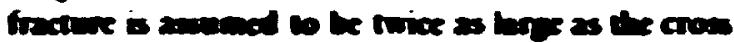

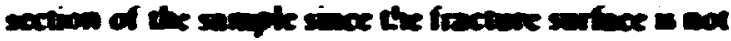

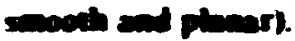

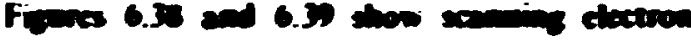

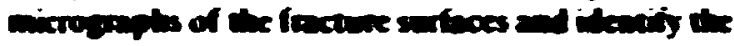

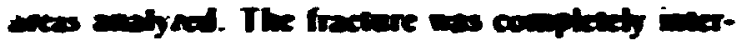
 carticte procipiente parides Thene is wo evilende of

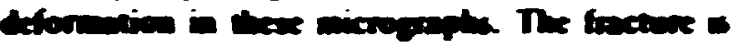

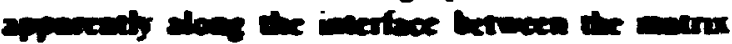

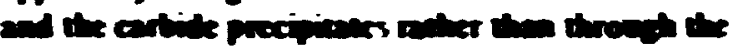

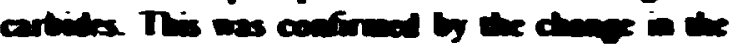

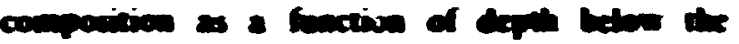

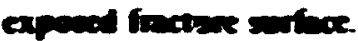

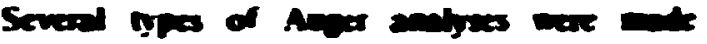

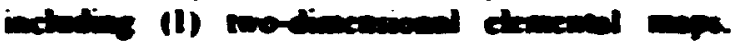

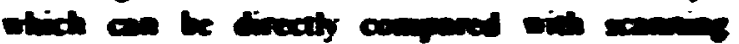

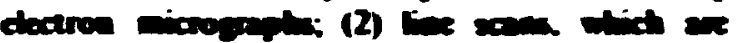

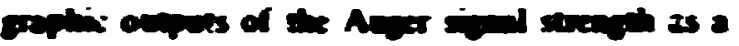

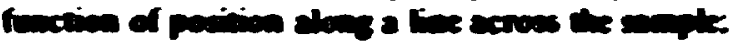

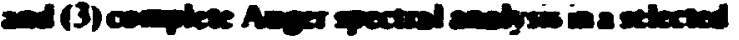

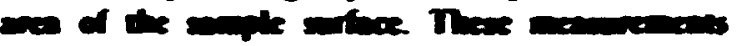

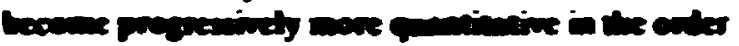

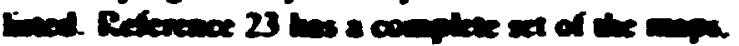

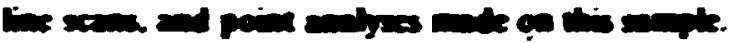

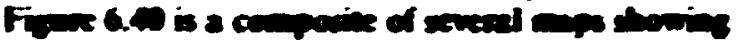

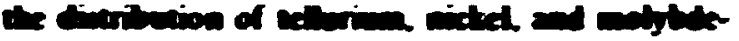

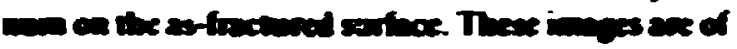

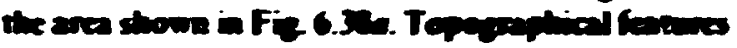

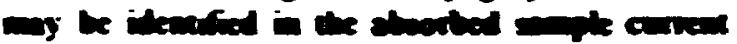

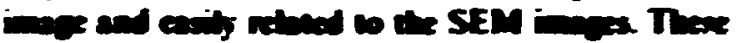

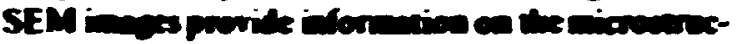

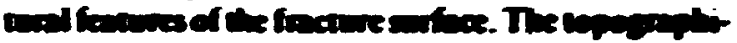

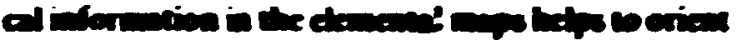

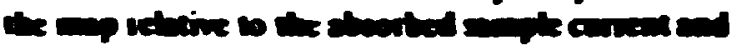

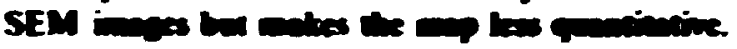

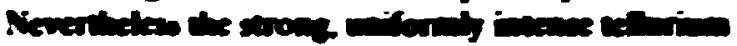

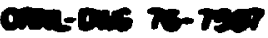

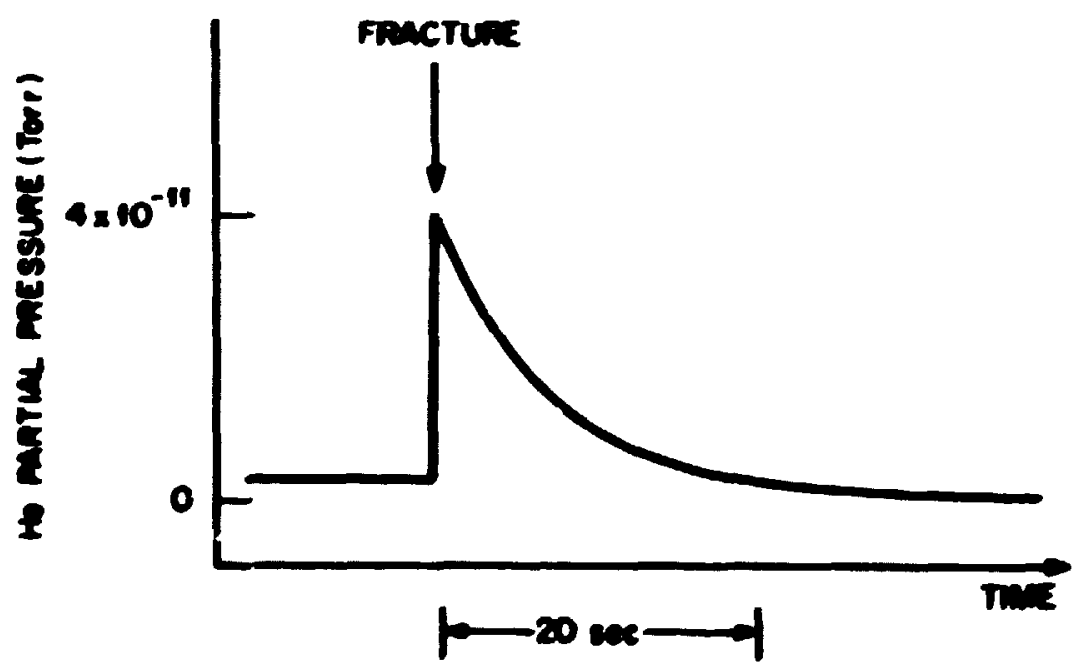

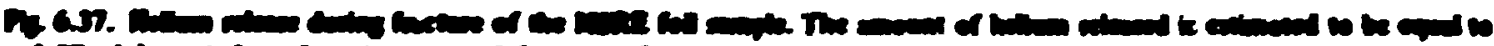

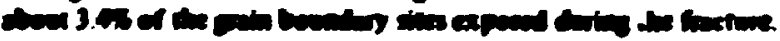



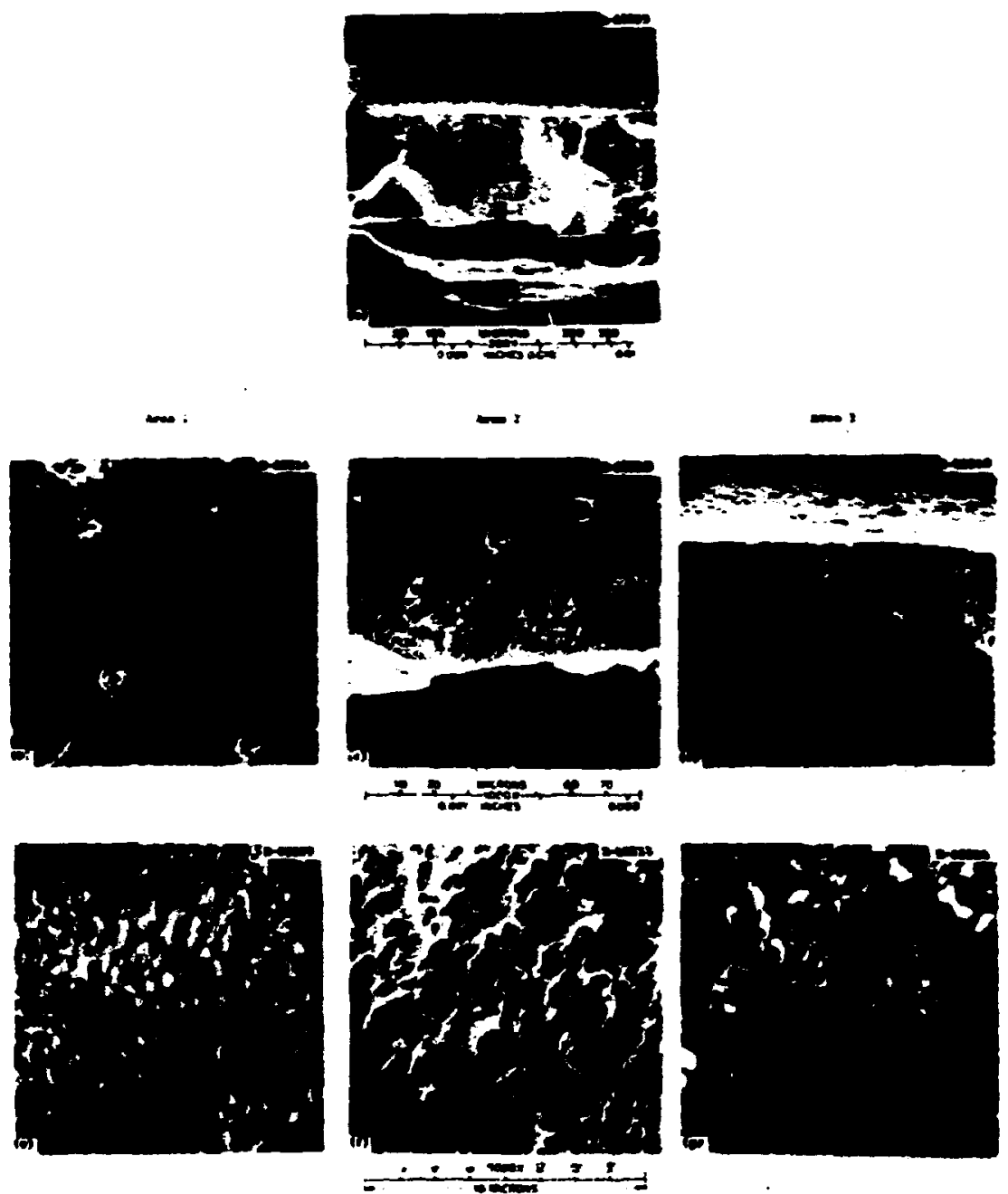

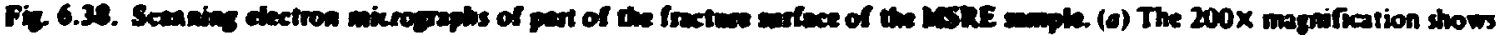
a particulorly interesting arca where one grain goes entirety through the thickness of the foil. and the exposed surface is nearly fat and perpendicular to the original foil surface. The numbers on the figure indieste aress brvestipted in detail and shown at highet magaifuation - at 1000X in parts (b). (c), and (d) and at $5000 x$ in parts (e). $(N)$. and (c). Note that these inages reveal that the grain boundary i: lined with small particles (likely carbides) a.d that they appeax to almost completely fill the grain boundary ares. Tlie fracture appears to be simply a separation of the particles from the matrix with litile or no durtile bethavior.

signal from the entire fracture surface of this sample is evident. The molybdenum and tellurium maps show similar distributiuns, while the nickel map shows a distribution somewhat complementary to that of molybdenum and tellurium. This is best seen in the central region slightly to the right and left of the area labeled $I$. The similarity of the tellurium and molybdenum c'istributions and the complementary nickel distributicn is easily seen in the line scans shown in Fig. 6.41. These scans are along the path indicated by the vertical white trace in Fig. 6.40. Similar relationships have been noted among other samples.
Complete Auger analyses of several selected spots were made immediately after the sample was fractured. Figure 6.42a shcws the Auger spectrum from tine center of the sample in area I shown in Fig. 6.38, and this was also typical of snectra taken in areas 2, 3, and 4. The strong tellurium Auger signals are evident. The compositions (in atomic percent) in areas 1 through 4 are listed in Table 6.17. Figure 6.42 compares the Auger spectra taken from area 1 immediately after fracturing the sample and the composition at the same area taken after sputter etching was used to determine the distribution of tellurium as a function of depth below the original 

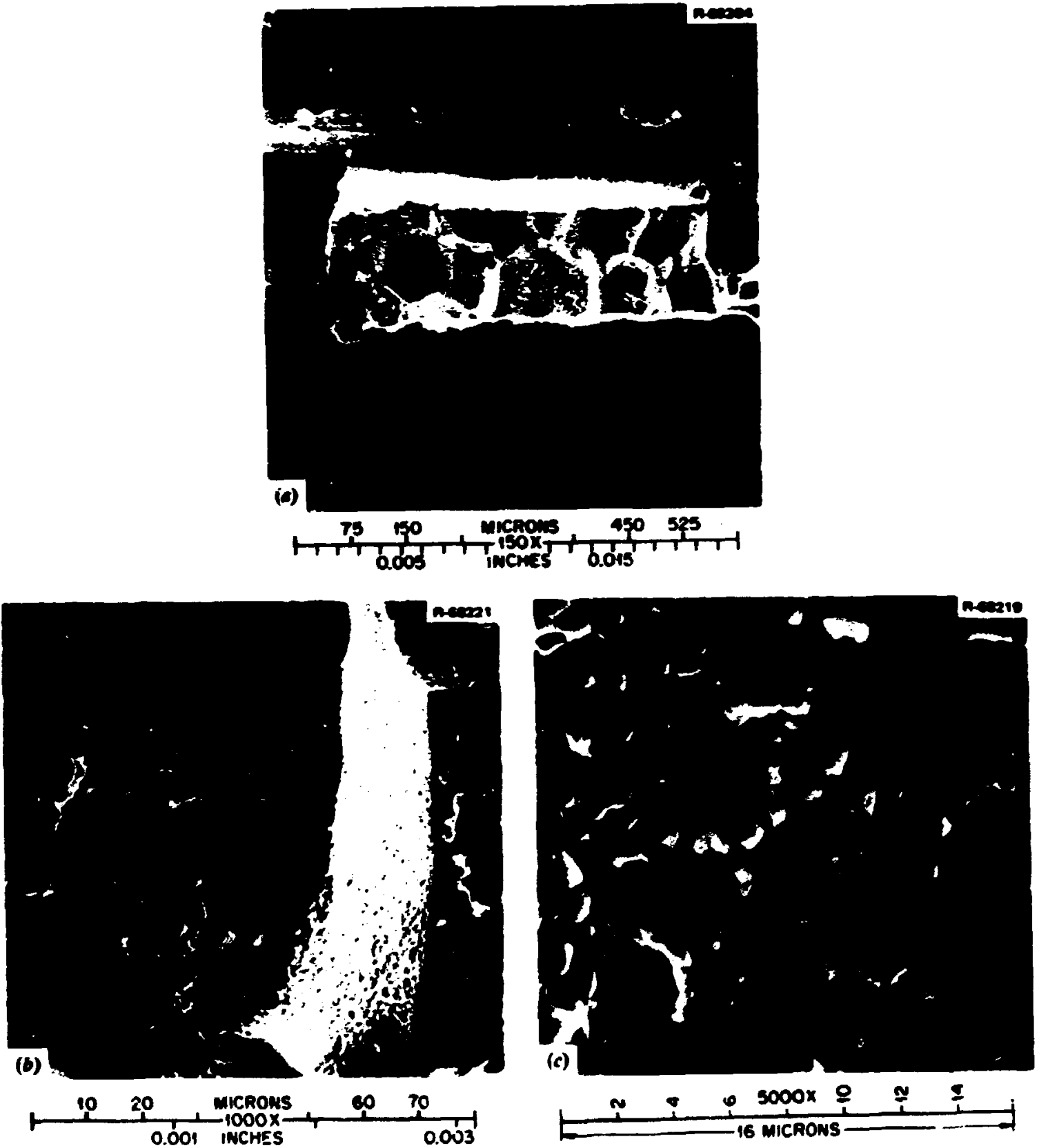

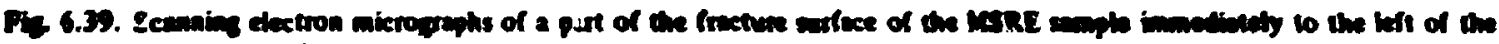

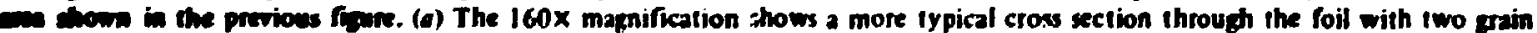
demeters acrose the foil thickness. Hipher magnification images of area 4 are shown in parts (b) and (c). at $1000 x$ and at $5000 x$ sappectivily. Thiy show a comewhat rougher fracture uurface than that shown in Fig. 6.2h. In this case. some of the particles appeat to remain on the observed surface wtile others are partially pulled out and still others appear to have adhered to the other half of the fracture interface. This would be expected when the adhesion of the prticlex is more of less equal between the grain on either side of the boundary. This adhesiun is quile likely a function of crystallopaphic mosphology. depending peshaps on the details of tellurium embrittlement as well as the mechanical properties of the embrittled interface. None of the particles appear to be fractured; instead. they have separated from the matrix. The particles in this region appear to be more or less equiaxed. while those shown in Fig. 6.38 are more platelike. Note especially the comparison betwe en Fig. 6.39c and Fig. 6.38g. In Fig. 6.38g. some of the flat particles have been palkd out. leaving shallow fat bottomed deptessions. 


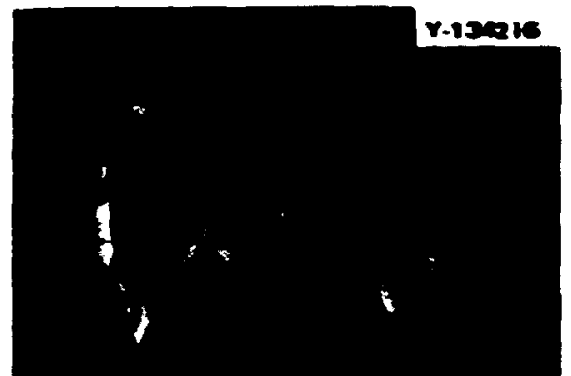

(a)
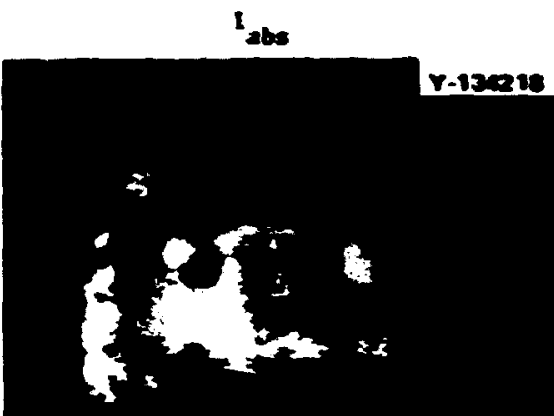

(c)

:ii (s+8 eV)

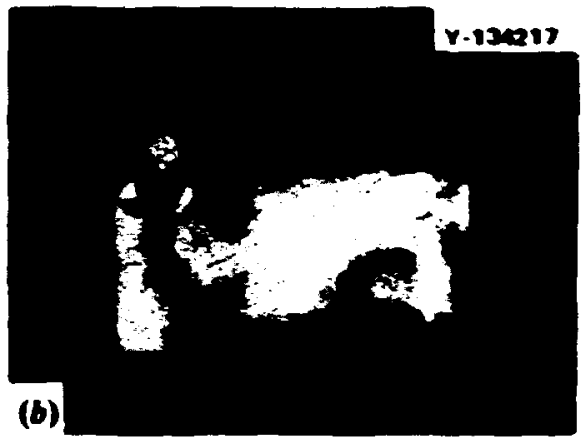

Te $(403 \mathrm{eV})$

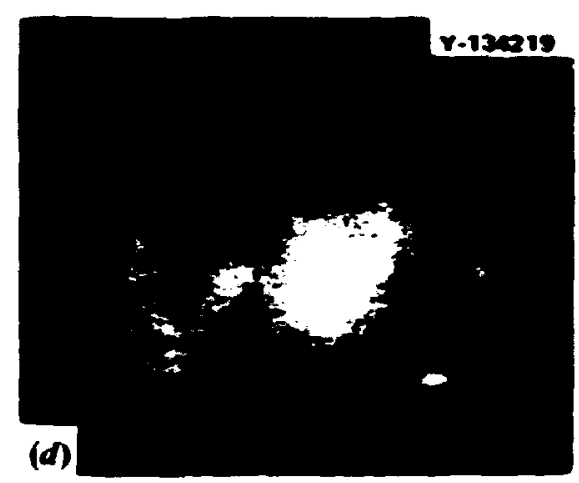

(to $(221 \mathrm{eV})$

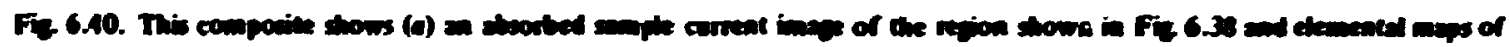

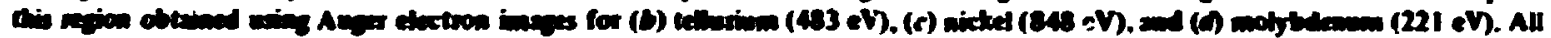
inages are at about 250x. Note the rather uniform tellurium composition oner the entire surface. the superposition of topoegraphical

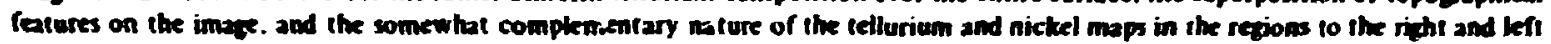
of point 1 .

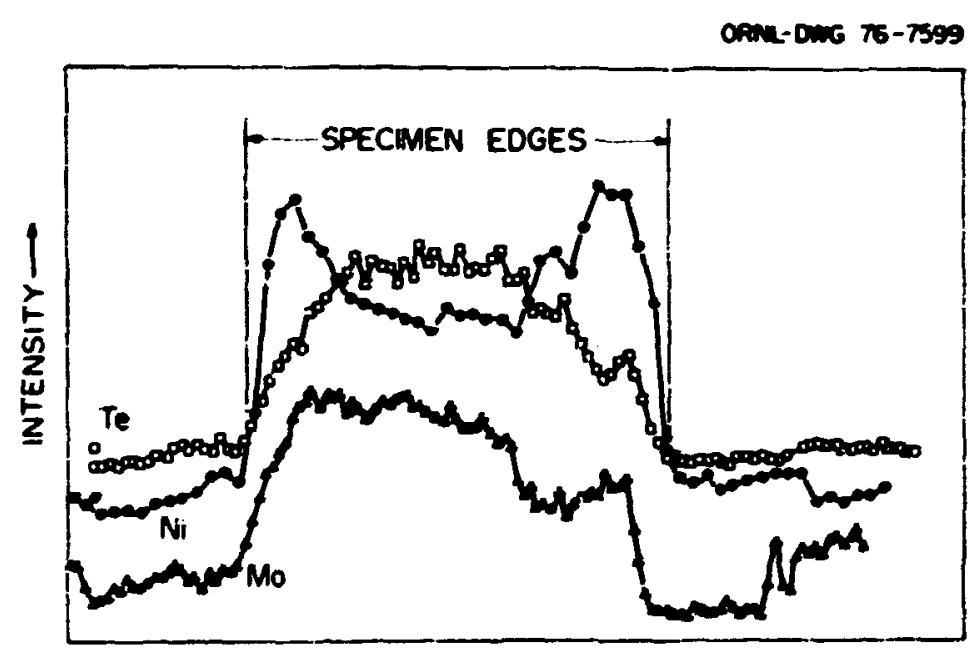

DISTANCE $\longrightarrow$

Fit 6.41. This compodite shows Acyer signal intsnsity along the tine strown in fit 6.40. The scan proceeds from top fe botfom of the inage and from left to right on the figure. Tive intensicy of the signals is moduluted by both topopaphy and composition so that both features appeat in these plots; however. it is quite appatent that the tellurium and molybdenum signals vary in the sume general way. while the nickel signal contains the ame topographical features but is somewhate complementary to the tellurium and molybdenum scans. 


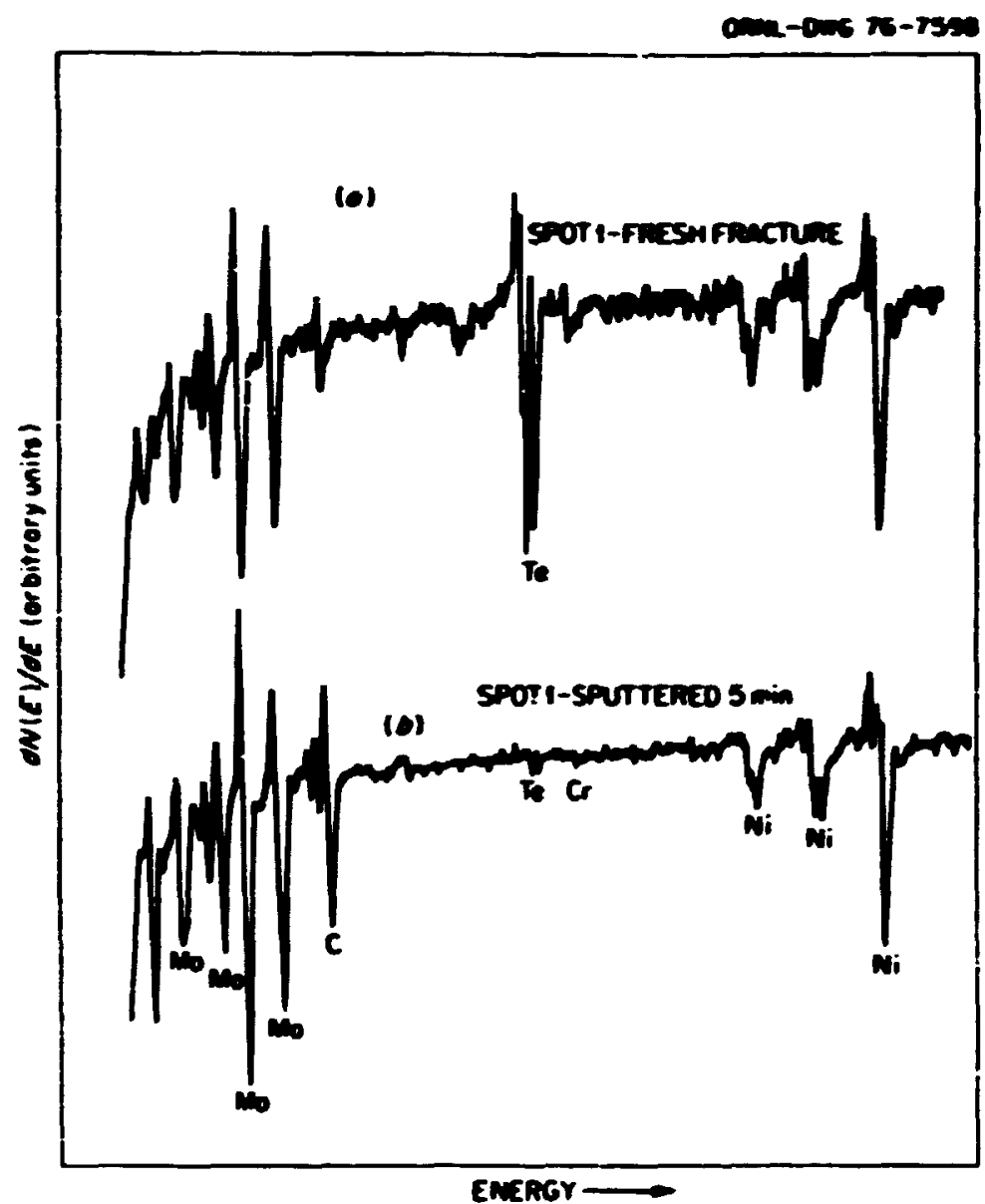

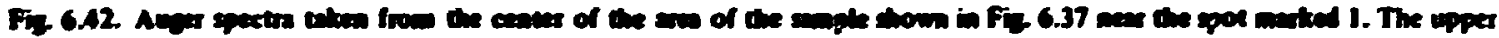
spectrum labeled (b) was oblained immediately after the sumple was fractured. while (b) was taten after sputtering about five atom byers from the exposed fracture sarface. The tellurivem peaks are quite prominent in spectrum (a) and represeat about If at. $\%$ tellurium on the surface. but tellurium is almose undetectable in spectrm (b). indicatias that the tellurien was nearly completely removed by the ine etching of only five atomic byeis irom the surfece. The other etemenis remain hidh. The molybdenum and earbon actually iacrease. as they should if bulk carbides were uncovered by removing the tellurium.

fracture surface. Table 6.18 is a tabulation of data taken from several spots during sputter ceching, and Fig. 6.43 is a graphical representation of the changes in composition near spot 4.

\subsubsection{Discusion of Observations}

The release of helium from this sample when it fractured was estimated to be sufficient to fill about $3.4 \%$ of the grain boundary sites exposed by the fracture. The most likely sources of this helium is the ${ }^{1 n} \mathrm{~B}(n, a)^{\prime} \mathrm{Li}$ reaction. Boron is present in the grain boundaries of the Hastelloy $N$ as the result of the melting practice and heat treatment of the alloy prior to irradiation and will also be concentrated in the carbides formed during irradiation. This amount of helium should not be enough to cause the observed intergranular embrittlement at room temperature. If it were. severe embrittement would have been found throughout the entire thickness of surveillance samples and other Hastelloy $N$ parts from the MSRE. This was not the case, and it can be concluded that this level of helium in the grain boundaries is not severely detrimental to the mechanical properties at room temperature.

The fracture surface was completely intergranular. There was no reduction of area at the fracture site, and no significant plastic deformation was apparent in the scanning electron micrographs. The appearance of the fracture surface sugesests that the grain boundaries were filled with precipitates and that the 


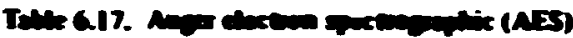

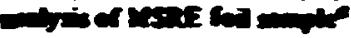

\begin{tabular}{|c|c|c|c|c|c|}
\hline \multirow{2}{*}{ "גats } & \multicolumn{5}{|c|}{ D=em (24. 35} \\
\hline & Te & $\mathbf{M o}$ & $\mathrm{Mi}$ & Cr & c \\
\hline 1 & 126 & 32.5 & 29.8 & 44 & 20.7 \\
\hline 2 & 9.0 & 17.5 & 4.8 & 5.9 & 20.7 \\
\hline 3 & 106 & 18.2 & 43.8 & 5.1 & 22 \\
\hline 4 & 12.3 & 6.8 & 54.6 & 5.8 & 20.5 \\
\hline
\end{tabular}

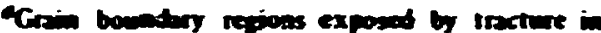
AES gsing

See Fic 632

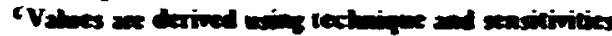

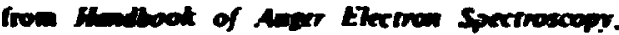

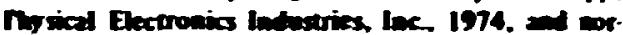
molined so that de reported rabes loved 100s dures andix

Carbon zhested to compensole for contanimation dries andis

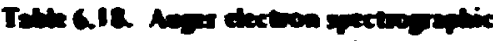

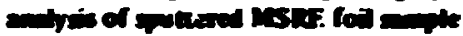

\begin{tabular}{|c|c|c|c|c|c|c|}
\hline \multirow{2}{*}{ Anea } & \multirow{2}{*}{$\begin{array}{l}\text { Spenter tine } \\
\text { (mia) }\end{array}$} & \multicolumn{5}{|c|}{ Flemeat (at. 7) } \\
\hline & & Te & Mo & N & $\mathbf{C r}$ & $\mathbf{c}$ \\
\hline $\mathbf{I}$ & & 126 & 32.5 & 29.8 & 4.4 & 20.7 \\
\hline I & 5 & 0.6 & 31.0 & 21.0 & 1.3 & 46.2 \\
\hline I & 20 & & 37.0 & 20.9 & 1.6 & 40.6 \\
\hline 1 & 60 & & 26.7 & 20.8 & & 48.1 \\
\hline 1 & 150 & & 26.9 & I9.1 & 2.1 & 51.3 \\
\hline 2 & & 9.0 & 175 & 46.9 & 5.9 & 20.7 \\
\hline 2 & 20 & & 22.2 & 35.6 & 3.3 & 38.9 \\
\hline 2 & 60 & & 19.3 & 27.8 & 2.6 & 49.1 \\
\hline 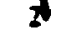 & 150 & & 16.1 & 34.1 & 3.4 & 4.6 \\
\hline 4 & & 12.3 & 6.8 & 54.6 & 3.8 & 20.5 \\
\hline 4 & 5 & 0.5 & 16.6 & 49.1 & 4.4 & 29.3 \\
\hline 4 & 20 & & 21.9 & 45.6 & 3.2 & 29.3 \\
\hline 4 & 60 & & 13.1 & 40.7 & 3.1 & 43.3 \\
\hline 4 & 150 & & 15.9 & 40.6 & 2.6 & 40.4 \\
\hline
\end{tabular}

fracture occured between the precipitates and the matrix. Figures 6.38e and 8 show areas where most of the particles were retained in the surface examined. These areas are rich in molybdenum and carbon (Table 6.17). In some areas, some particles have apparently been pulled from the surface examined (Figs. 6.38f and 6.39c). Areas such as these tend to have somewhat less molybdenum and carbon and to be richer in nickel: hence the complenentary nature of the elemental images and line scans reveals the presence of carbides and shows the surfaces to which they adhere. In no case have we seen fractured

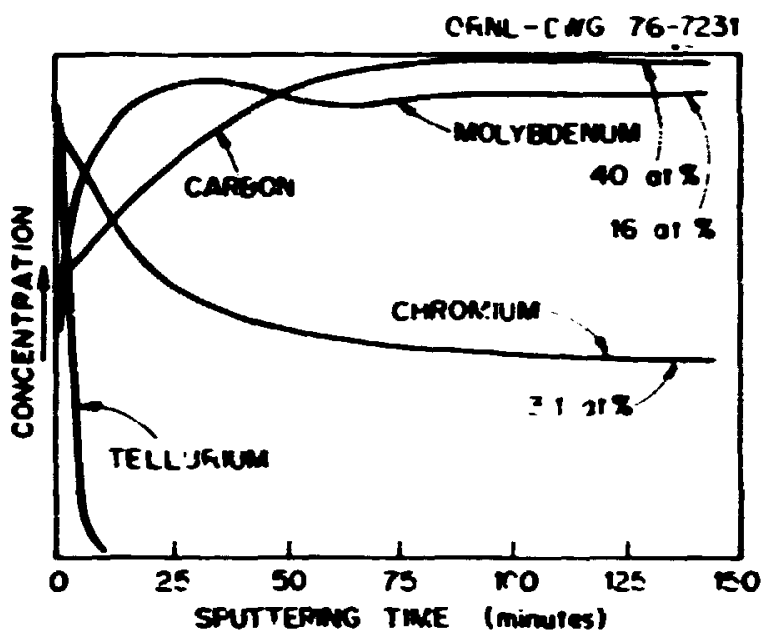

(APPROCGMTELY I ATOM LAYER REMONED/MMUTE)

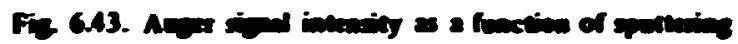

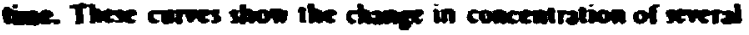
elements as a fusction of lepth betow ithe uripieal fractere

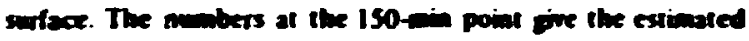

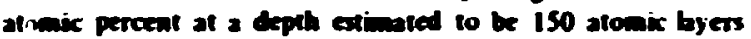
vow the original fracture surface. These data are from the arta wear point 4 on Fie 6.39

precipitate particks. There is no doubt that these precipitates are carbides since the fracture surfaces are rich in molybdenum and carbon and the concentrations of these elements remain high after sputter etching (Table 6.18 and Fiz. 6.43) which indicates an average bulk composition in the vicinity of the fracture surface consistent with the presence of large amounts of Gibide precipitates. The presence of the carbides in the boundaries reduces the ductility and tends to promote intergranuiar fracture, but not to the extent observed here. Many samples of standard Hastelloy N, including both irradiated and unirradiated control samples. have grain broundaries containing carbides and still retain elongations greater than $30 \%$ and reductions in area greater than $20 \%$ (ref. 22). Many of the samples exposed in the case of the MSRE show extensive intergranubr surface cracking while maintaining $800 d$ overall ductility. a fact which further supports the argument that the carbide precipitation in the grain boundaries is not the cause of the observed embrittlement. This last observation also argues that a combination of carbide precipitation and helium generation does not cause the observed embrittlement.

The Auger electron spectrum from the fracture surface. Fig. 6.42a. shows the presence of lare amounts of tellurium. The concentrations reported in Table 6.17 are based on the assumption of uniform 
componisn in the sebstrate. In the caxe of a monobvet er loss of contzminant on an intertace tha! in torn apan curing the sample fracture. the concentralings "beiced would be 100 small by more that: a iacior of 2 In this case the real concentration at the iatcraci: evold be substantially greater than 30 at. $6.1 \mathrm{i}$ compasition-depth profile in Fig. 6.43 show: Itwat the very brex tetlurium concentration on the as-iractuiec surface does not extend into the bulk: thas. telisirium is present in large amounts on the fracture strface but is concentrated very stronghy at the grain boundary interfaces and may indeed be present as a fractional monolayer at the grain boundart. It is known from previous experiments ${ }^{\text {it }}$ that grat. boundaries in Hastelloy $X$ can be embritiled by tellurium at bevels below those observed here. No other fission products or oher embritting apents were detected on the fracture surface, and one must conclude that tellurium does cause the obsened intergranular embrittement of ilastelloy $I: \rightarrow$ the MSRE.

\section{II HIGH-RESOLUTION FRACTOGRAPHY OF HASTELLOY $N$ ALLOYS EXPOSED TO TELLURIUM}

\section{X. Braski}

This investigation is aima at providing additional information conceming the mechanism of tellurium embrittlement of Hastelion $X$ alloys. Or particular interest were the fractographic details of samples exposed in several different ways to tellurium. These details were revealed by use of a modem transmisivon clectren microxcope with a high-resolution scanning attachonent. The results for two seandard Hastelloy 8 (theat 405065) samples are presemed fires. followed by the results for two modifind alloys. Although differem deliven systems were used. the same iellurium wurce. Cille, at 700 C. was used in all tests. After exposure to kellurium the samples were teasik lested to faiture at room kemperature. Iurme the rest a number of cracks onened up alone the pax lenglus of the samples. The number and depate of cracks wete mosured opically on metallogaphically prepared sections. Tabte 6.19 lials the alloy, heat ireatment. and tellermm exposure for each emple. Details of the expowire tests may be found in siects. 6.9 and 6.12 .

The forst ample. 79-43. was actualh a smaller Aucer spectromoopy pecimen that was exponed for

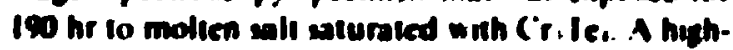
cemperature solution anoveal was prev wush done on this sample to grow baregrains for the Auger studies. After testing. the fracture mode was obsened at relatively low magnification to be intergranubr fl te. 6.44a). Tellu-im was detected in area $X$ by both Auper and energy-dispersive $x$-ray speciroscopy (FDS). Higher-magnification micrographs of area $X$ are shown in Fiss. 6.4h and $c$. The noduter features present on the surfece were similar to shose obsented in other materials that failed from stress corrosion or hydrowen embrittlement." These nodubr features were probably corrosion products that contained tellurium. Several facted areas were also obsenved at points $A$ and $B$ in Fiz 6.4kr. Faceting is characteristic of brittle failure and has previoushy been observed in iron-tellurium alloys." Figure 6.44d is a highermagnification fractograph taken of area $Y$. in which no tellurium was detacted. This area displayed some ductility during fracture. as evidenced by the dimpled surface caused by mictovoid coalescence. The mixcrovoids were initinted by the particles located at the bases of the dimples. These particles were probably the MaC-type carbides that are usually found in the grain boundaries of this alloy.

Standard Hastelloy $X$ was also exposed to the lapor above $\mathrm{Cr}$ : Ie+ at $700 \mathrm{C}^{\circ}$ in a closed system (see $\mathbf{S X} 13515$ in Table 6.19 for conditions). The (racture mode for this sample was complicated and difrecult to analyre. The central areas were dimpled (fiz. 6.45o). Areas near the edyx of the sample showed mixed modes of fracture (firs. 6.45h. I and al). Near the specimen od 2 in Fig. 6.45 h. the first area resembles a cleavape fracture with small steps. For the area further in. the mode shows charecteristics of ductile Iracture as evidenced by the dimples. At the base of these dimples is unusual microfeceting (fin. 6.45r.at $X$ and what appears to be a second-phase or corrosim product (fig. 6.45 and $d$. at $Y$. This btter ares abu shows an unusual peometric facting. Cher. more conventional bocking particles were found in the ame anca (Fig 6.4Sh at $Z$ ): these may he M.C'type cartides or posidbly corrosion product. Information on the composition and serecture of these phases has not yet been ohtained. Initial EIXS analy ses did not detect any cethrium in ang of blese ares. but that does not prectude the posisibiliny of small concentmino beine present.

faceting has nim heen otwerved in hoth standard llastellon I samples using two different cellurium detinen systems and therefore may he a characterisIx of cellurwom embritutement in this makerial. As meniconod prev kush. Rellich et al. "found eviensive facceline in an iron-iellurum allon which wasconled show from an auslenitwing temperature of 025 (". 


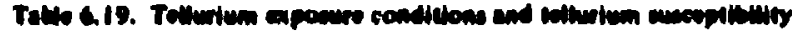

\begin{tabular}{|c|c|c|c|c|c|c|c|}
\hline Sprimon & $\begin{array}{l}\text { Hoat } \\
\text { andont }\end{array}$ & $\begin{array}{l}\text { Solution } \\
\text { enmel }\end{array}$ & Tellurium oxposwro & $\begin{array}{l}\text { Pixposwro } \\
\lim _{\text {(hi) }}\end{array}$ & $\begin{array}{c}\text { Sixposure } \\
\text { somporoluse } \\
\text { ('(') }\end{array}$ & $\begin{array}{l}\text { C'nacts } \\
\text { (numbon/cmi }\end{array}$ & $\begin{array}{l}\text { avernes } \\
\text { cencick } \\
\text { dopin } \\
\text { (w) }\end{array}$ \\
\hline $39-43$ & sasoss & $2 \mathrm{~W}+1250^{\circ} \mathrm{C}$ & 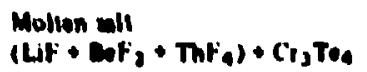 & 190 & 700 & \multicolumn{2}{|c|}{ 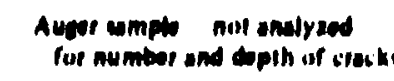 } \\
\hline SN I3S1S & sososs & I w a IIrec & Cr, Tou novi & 1000 & 900 & 94 & $\$ 4.9$ \\
\hline $3 \times 15720$ & ${ }^{413}(1 \times N D+\mid \times T)$ & I w a $117 \mathrm{rc}$ & Molken all * $\mathrm{C}_{3} \mathrm{~T}_{4}$ & 243 & 700 & 102 & 37.4 \\
\hline $3 \times 19725$ & $411(1 \% \mathrm{~ms})$ & I w a $1177 \mathrm{c}$ & Molion $=_{1}+C_{r} T_{0}$ & 243 & 200 & 17 & 30.5 \\
\hline
\end{tabular}



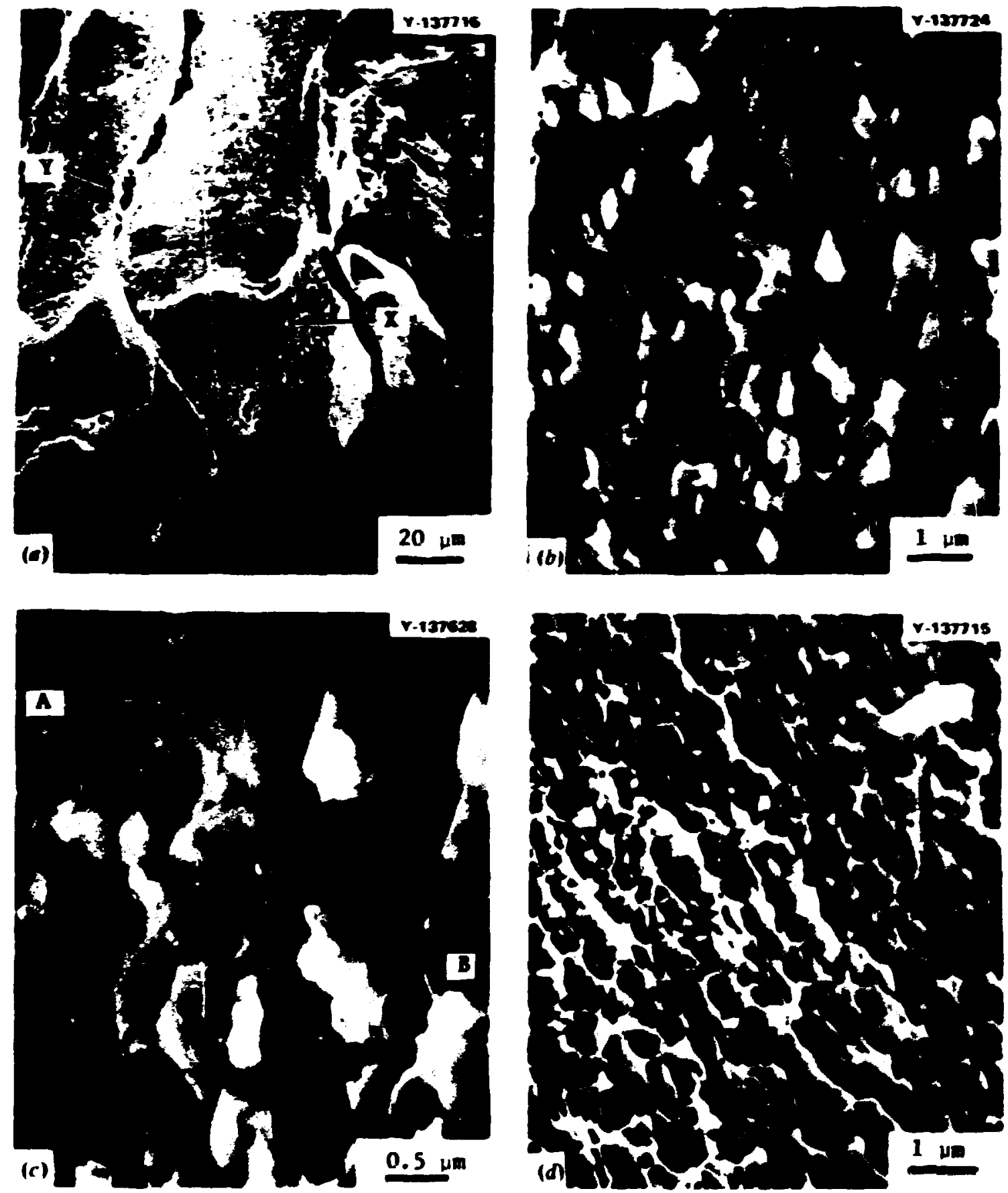

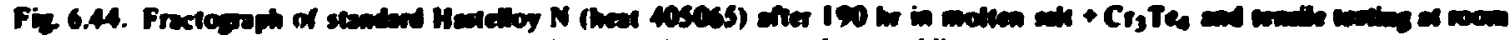
teimpersture. Parts o. b. and $r$ wete taken near the fracture edpe. and porn d in a midcke repion 

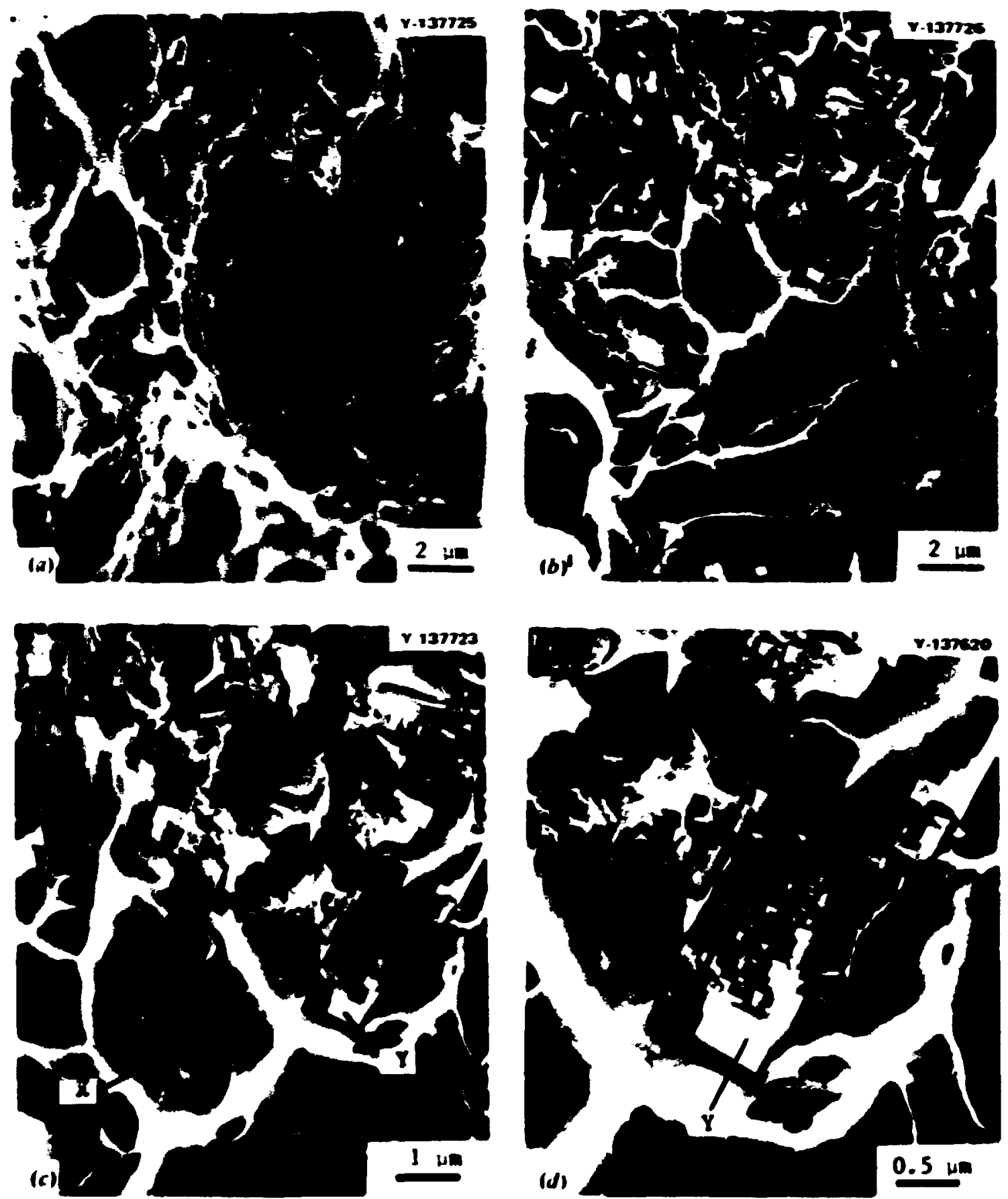

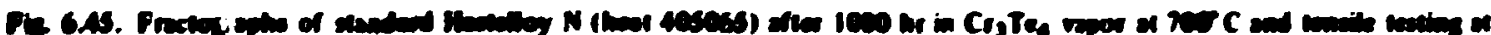

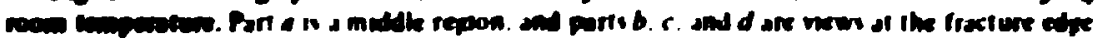


However. Hewy et al '- obsenved fuctions in aicted frecteres after thenial treatuents between 650 and

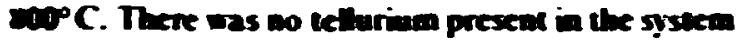
of these worters: bey attributed the facetion 10 the absorption of oxygen ia the grain bounder is Since decarborina byers have been obsenved in some of on Hastelloy $X$ samples if is possible that oxyera as

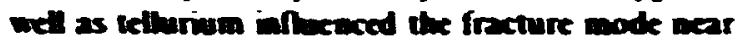
the surtece. Odber evidence in sepport of this idea is presenced in Fig 6.46. This micropraph uas nien from a trenserse section of pilpered (tabe-reduced)

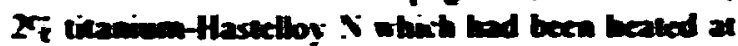
$533^{\circ} \mathrm{C}$ for 6 hr and air cooted. This particular treabent cased fire conction of ats malerial Noke thet the mode of crectiog throngle the decatbrived lyer was mined traspanter and imergramiler. wile it was catincty incrjandar beyoud te byet. The difference in frature in dis ase was probably caused as much by the absence of arbides in the prain boundary as by the presence of alsorbed oxyen. Thux decarburimtion an be a factor in the frecture mode of thermalk trealed Hasteiloy $\mathrm{N}$ and should be considered when interpreting the present investigation.

The fractures of in o modified Hasiellny $X$ alloy were compared. The first. alloy 411 . contained I wi $\%$ niobium and was considerabh more resistant to tellurium attack than the second. alloy 413 . which contained $I$ we $r_{r}$ niobium plus $I$ ne $r_{r}$ titanium

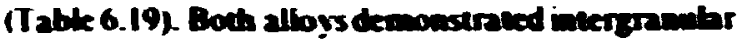
frecture modes in the ceratral portions of the moples (Fics. 6.47e and b). Ote normally associntes bow dectility with ineengrambr frecture. ben allogs 411 and 413 had lovl elomptions of 54.8; and 45.8. respectively. The frecture surfaces illsurate this ductile behavior by die dianpliag on safoces normal to the tensile bad and smiations on the surfeces parallet to the ceasile lood. The striations are ctaracteristic of an exlended stip process or fide. The ares an ure aftected by the cetherinan were at the

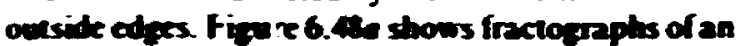
are war the olfe of the 411 sample. The fracture mode wos abo iner grenabr. bea the surface fotures reflect a more brifle behatior. Hidhet megrifotion of this are stowed the absoruce of dimples and the presence of corrosion prodects (Fige 6.4Bb). The ting holes in this surface (fig. 6.Ax) were crated by the pulloat of carbide particles or possibty a corrosion product. Tellurium was not detected on the surfaces in Fy. 6.48 using EDS. Exwmiantion of alloy 413 ner the ounside fracture ed ge revealed a tendency for this material to fail along the precipitate-matrix interface of the grain toundary (Fig. 6.49). This series shows an array of dendritic precipitates bing on the grain boundary which were aligned preferentialty in crystallographic dinections. The angles between tendrites were not measured accurately. but they would appear to correspond to the angles between

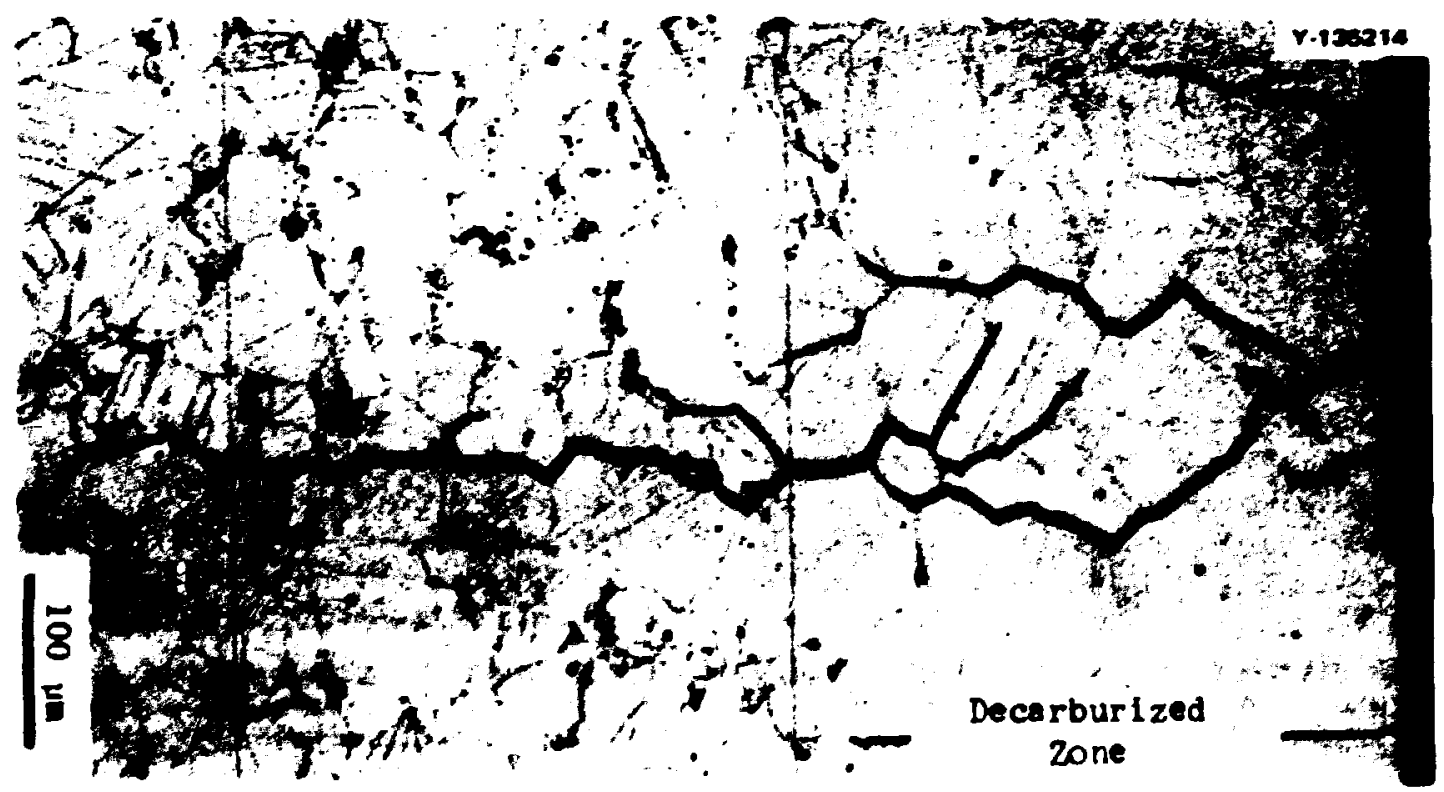

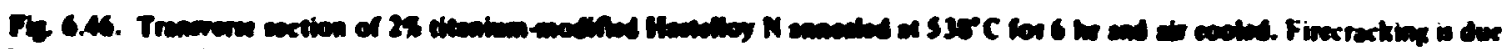
to thermomechenical ireatiments 

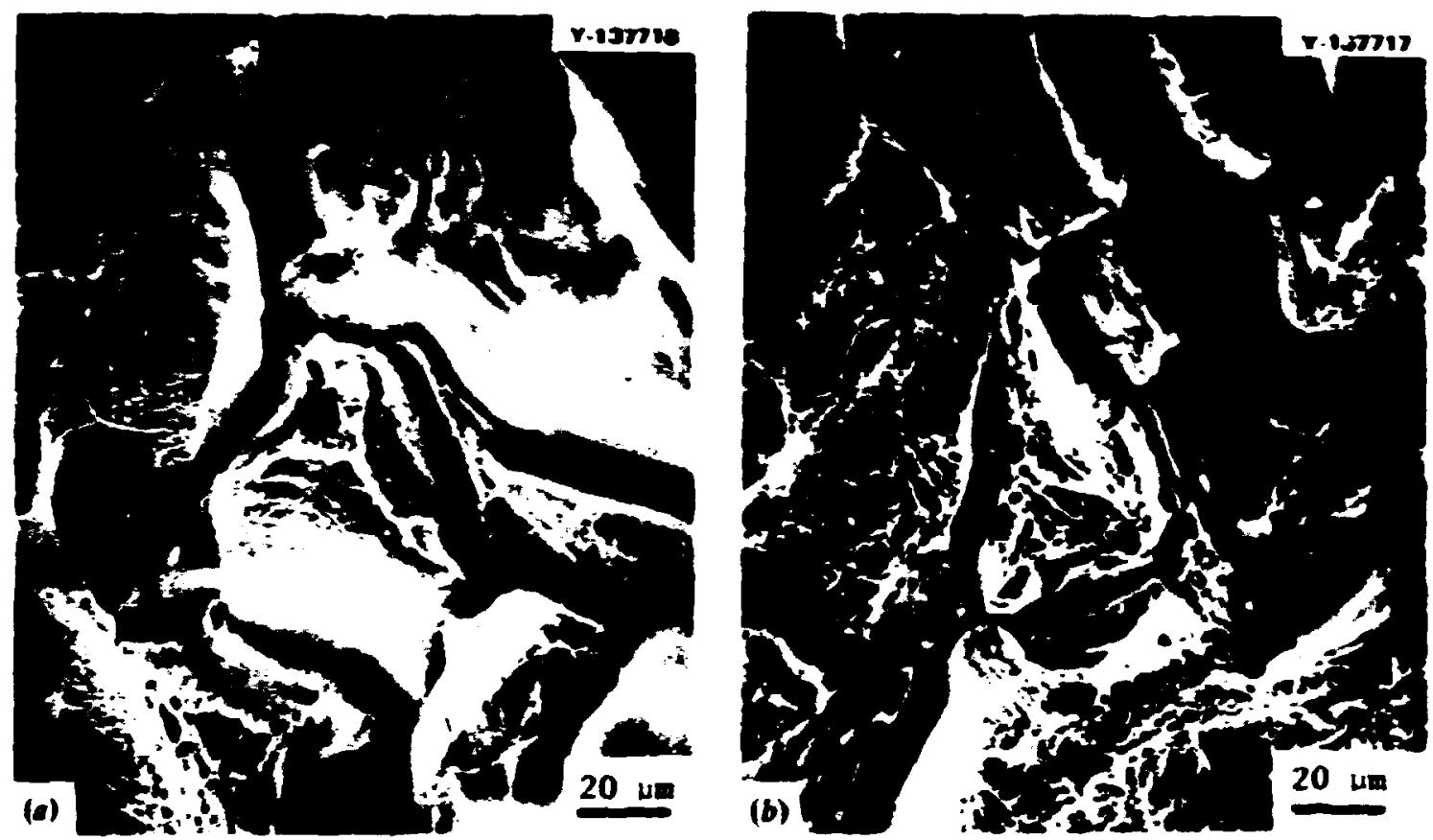

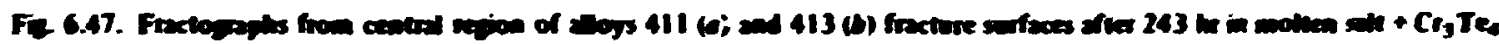

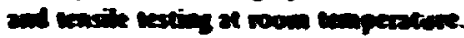

intersecting (III) planes. These are the habit planes for the MC-type carbides which are found in the alloy. where (III) MCI! (III) matrix. Evidence suggests an epitaxial relationship between the dendrite particles and the matrix (fig. 6.49a). The dendrite particles were found to end abrupty at the twin boundary. Close inspection of the twin band showed that simibr panicles were originally present but were retained in the mating fracture surface. The o ientation of the peaks of the dendrite pyramids in the twin band was opposite to those in the adjacent area (Fig. 6.496). Since no tellurium was detected by EDS in any of the areas in Fig. 6.49, one might presume thas only extremety small amounts of tellurium are needed to weaken the grain boundaries. This ccnclusion agrees with Augst spectroscopy studies:" that fund tellurium in small quanties $<10$ at. 7) and monolayer thickneses on tellurium-exposed Hastelloy $\mathbf{N}$ fractures.

In summary, high-resolution scamning electron microscopy has characterized the fracture auriaces of several Hastelby N samples which had been embrittled by exposure to tellurium at $700^{\circ} \mathrm{C}$. The central rejions. which were apparently not affected by the telturium. cenerally demonamied a highty ductile intergranular failure. Repions near the outer edge (the specimen suriace) were affected by the tellurium exposure and failed in a hrittle intergranulat mode. Minute features of the fracture surface in this latter region variad among alloys; these features included microfaceting. cleavage. and a number of unusual second-phase particles and corrosion products. The observation of faceting in Hastelloy $\mathbf{N}$ is particularly interesting hecause it has been seen by other investigators in iron-tellurium alloys. The effect of oxyzen. either absorbed in the grain boundary or involved in decarburimation. may also have infuenced the fracture mode at the outer ed ax. Tellurium was detected by EDS on the fracture surfaces of one 405065 sample exposed to molten zalt plus ( $r$, Tes, but was not found in the same alloy exposed to $\mathrm{Cr}_{3} \mathrm{Te}_{4}$ vapor or the tetanium-modified or titanium plus niobium-modified alloys.

\subsection{METALLOORAPHIC EXAMINATHON OF SAMPLES EXPOSED TO TELUURIUM- CONTANNDNO ENVIRONMENTS}
H. E. MeCoy
B. McNabb
J. C. Feliner

Samples of modified Hastelloy $N$ were exposed to rellurium-containing environments. These samples were deformed to failure at $25^{\circ} \mathrm{C}$. a procedure which forms surface cracks if the enin boundaries are 

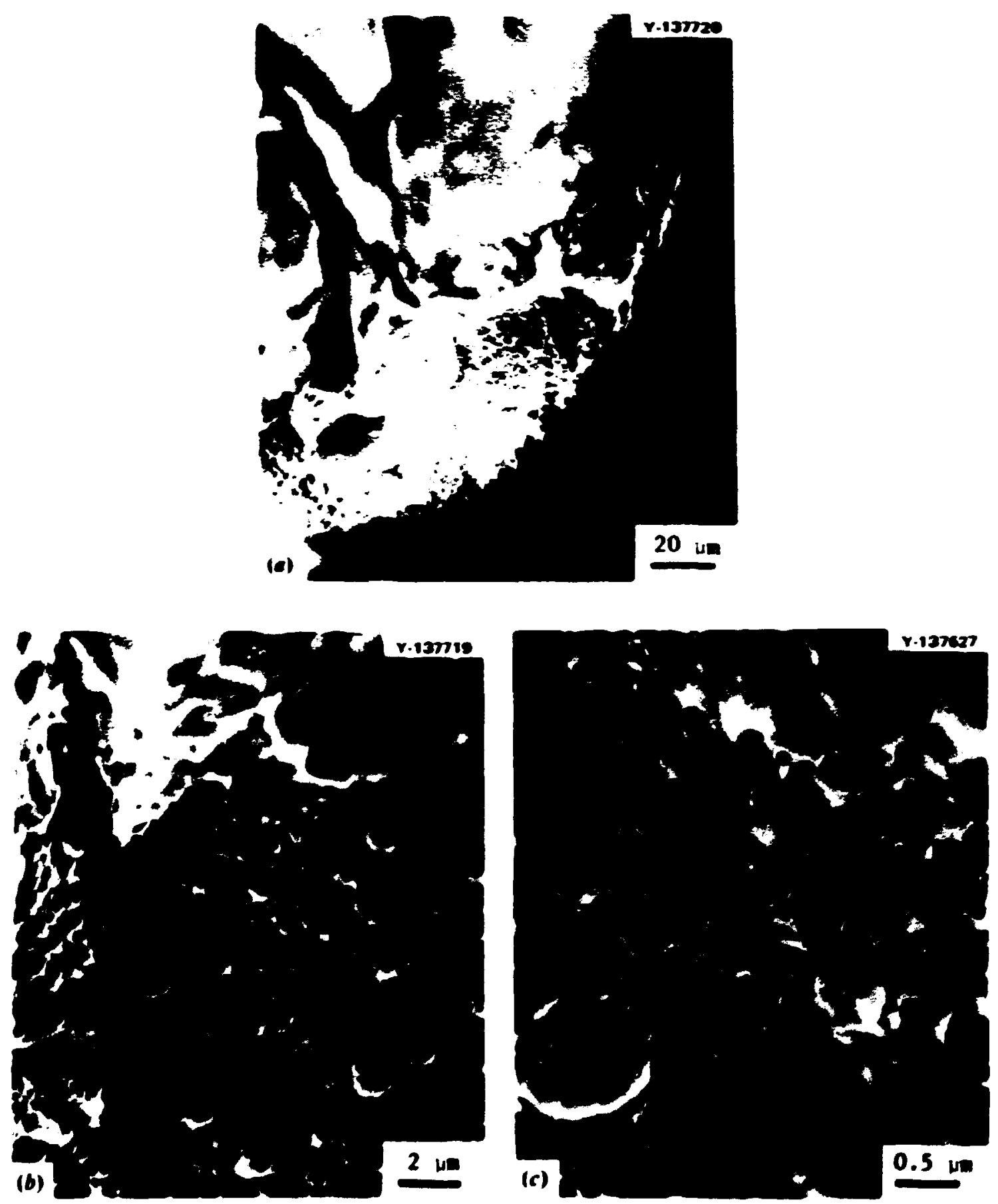

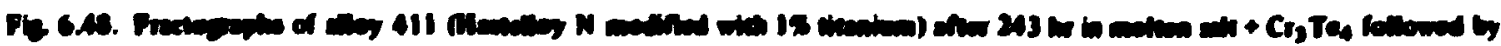

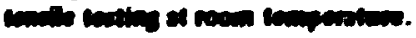



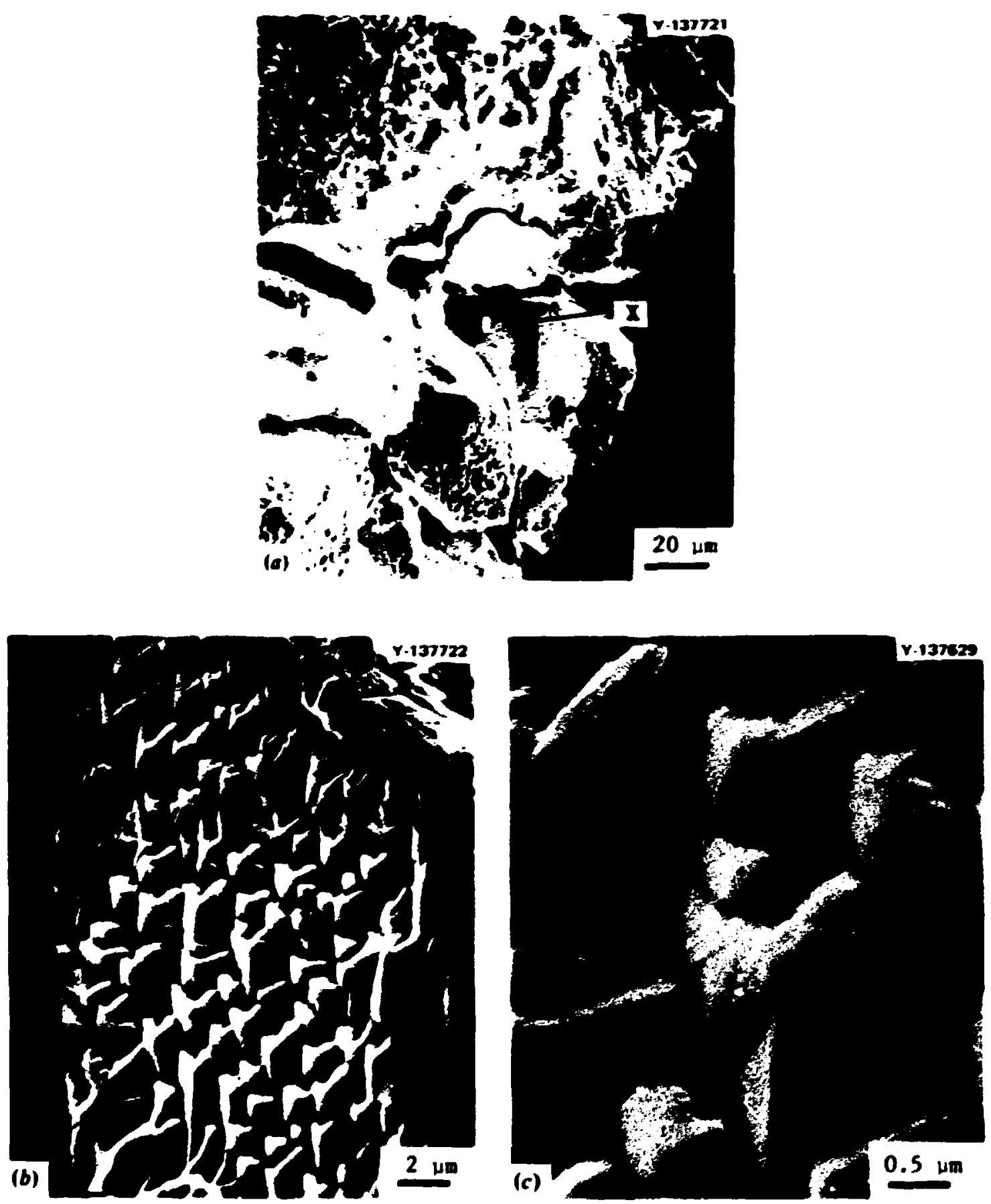

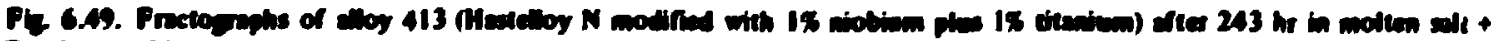

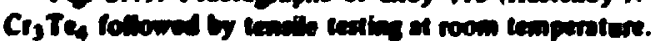


britk: a metallographe section of ech sample was prepared to permil determinatuon of the excent of crecting Dhese tests bave two objectives. Mue first is to develup a anthod for exposing samples to celturium to prodece a reaction ralc comparable to that anticipated for an MSER. This rave is thought to te a flux of tetharian of about $10^{\circ \prime}$ atoms cm "sec". The second objective is to compare the crection cendencies of various alloys of modified Hastelloy $\mathbf{N}$.

The method used for cratk comatiog and neasurias was described previously, and date were presented for several alloys." The experineatal conditions associated with the experiuseats to be dicusied in thas repert anc summaned an Iable 6.30. The chemical compositions of be alloss studied are given in Tabte 6.21. Lall cases the sample was a smoll censile specianen" "in. in dianeter by 1.38 in. long

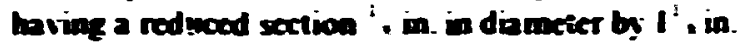
long. Lialess specified onterwise in Jable 6.21, the specimens mere sancaled I hr at $1177 \mathrm{C}$ in argon prior to exposure to uethurivm. The results of creck measurements and be resulting from tensile tests at 25. C which were used to open the embritlat grain boundaries are shown in Table 6.22.

Photumicrozraphs of the samples from experiment 75-1 I sow that the exteat of raction for these

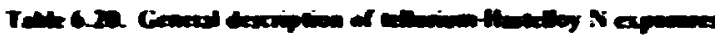

\begin{tabular}{|c|c|c|c|c|}
\hline Fyeriment & Evperimatalers & $\begin{array}{l}\text { Exposare } \\
\text { complomises }\end{array}$ & Allogs & Cramerat \\
\hline 75.11 & $\begin{array}{l}\text { nentobs } \\
\text { neroy }\end{array}$ & $\begin{array}{l}\text { IWo the at } 7000 \mathrm{C} \text { in mane } \\
\text { shove te at } 300^{\circ} \mathrm{C}\end{array}$ & $\begin{array}{l}405065.471-114.474-534.474-535 \\
\cos .00\end{array}$ & \\
\hline $75-12$ & $\begin{array}{l}\mathrm{MkNab} \\
\mathrm{MaCO}\end{array}$ & $\begin{array}{l}250 \text { he at 7006 in vaporr } \\
\text { thowe te at 300 C }\end{array}$ & tososs wih differemt prom anes & Specionens duscoloned \\
\hline $75-13$ & $\begin{array}{l}\text { MeNals } \\
\text { moroy }\end{array}$ & 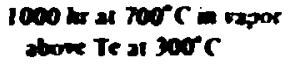 & $\begin{array}{l}\cos 045.421543 .295 .242 .345 .349 . \\
411.413 .421 .424 .425(2)\end{array}$ & \\
\hline 75.14 & Retset & 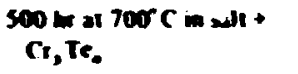 & $405064.470-135$ & Thim reaitun byers \\
\hline $75 \cdot 15$ & Kenet & $\begin{array}{l}243 \text { in at 7000 C in atil * } \\
\text { Cr, Te. }\end{array}$ & 411.413 & Thin rescomm layers \\
\hline $75-16$ & $\begin{array}{l}\text { Mekswb } \\
\text { Maroy }\end{array}$ & 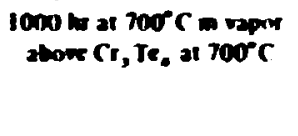 & $\begin{array}{l}\text { 405065. } 400600.471-114.474-533 \text {. } \\
474-534.474-535.237 .295 .291 . \\
303.345 .349 .417 .421 .422 . \\
424\end{array}$ & Rexrion byers, some spollente \\
\hline $75 \cdot 17$ & Keisot & $\begin{array}{l}\text { 6e9 in al } 650^{\circ} \mathrm{C} \text { in sellt } \\
\text { lite, }\end{array}$ & 4050ss & \\
\hline $75 \cdot 18$ & $\begin{array}{l}\text { MeNabu } \\
\text { Moroy }\end{array}$ & $\begin{array}{l}\text { I000 in as 700 } \mathrm{C} \text { in vapon } \\
\text { abone te at 300'5 }\end{array}$ & 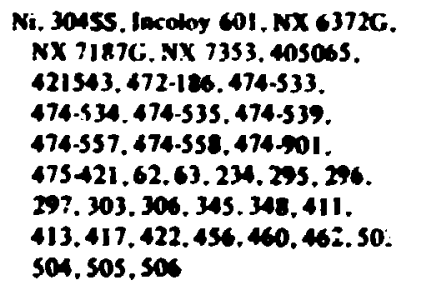 & Lurik evidence of rescriona \\
\hline 75.19 & Keiver & $\begin{array}{l}500 \mathrm{hr} \text { at } 700 \mathrm{C} \text { in selt + } \\
\mathrm{Cr}, \mathrm{Te}_{\text {. }}\end{array}$ & $503.504 .505,506$ & \\
\hline 75.21 & Keinet & $\begin{array}{l}1000 \mathrm{Mr} \text { at } 70 \mathrm{PC} \mathrm{C} \text { in selt }+ \\
\mathrm{Ni}, \mathrm{Te} \text {, }\end{array}$ & cososs & \\
\hline 75.21 & Krost & $\begin{array}{l}\text { soo ir at 700 C in soll + } \\
\text { Cr, Te, (half in wit. hall } \\
\text { in rapor) }\end{array}$ & cososs & \\
\hline $75-22$ & Erynestad & $\begin{array}{l}2500 \text { is at } 7000 \mathrm{C} \text { in repor } \\
\text { stowe } \mathrm{Ni}+\mathrm{Ni}_{3} \mathrm{Te} \text {, }\end{array}$ & cososs. 295. 424 & \\
\hline 75.23 & Dryocestad & $\begin{array}{l}2500 \text { hr at } 7500 \mathrm{C} \text { in rapor } \\
\text { soone } \mathrm{Ni}_{\mathrm{i}}+\mathrm{Mi}_{3} \mathrm{Te} \text {, }\end{array}$ & cososs. 295.424 & \\
\hline 75.24 & $\begin{array}{l}\text { MeNabs } \\
\text { MeCoy }\end{array}$ & $\begin{array}{l}207 \text { he st } 700 \mathrm{C} \text { in rapor } \\
\text { sbove Te al 300 C }\end{array}$ & $\begin{array}{l}450.513 .574 .515 .516,517 . \\
518,523.524\end{array}$ & \\
\hline
\end{tabular}

- Where no enmments are piren, there were mo vable reaction layers. 
104

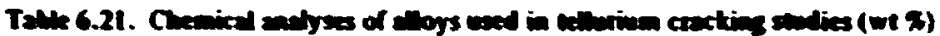

\begin{tabular}{|c|c|c|c|c|c|c|c|c|c|c|}
\hline Heat menter & Mo & $\sigma$ & Fe & $m$ & $\because$ & si & Ti & MS & $\boldsymbol{N}$ & Oding \\
\hline s2 & 11.34 & 7.52 & - & 0.50 & 0.042 & 0.01 & - & 1.9 & 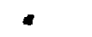 & \\
\hline 6 & 11.45 & 7.33 & - & 0.00 & 0.135 & 0.01 & - & 2.5 & - & \\
\hline $\ln$ & 11.2 & 7.0 & 0.040 & $0.1 ?$ & 0.046 & 0.01 & $<0.02$ & 184 & $=$ & \\
\hline IEI & ii.s & $6 \mathbf{n}$ & 0.004 & 0.23 & 0.045 & 0.01 & 0.50 & $\operatorname{tac}$ & - & $0.03=$ \\
\hline 230 & 16.0 & 72 & 4.0 & .0 .02 & $0.05^{\circ}$ & 0.13 & $\infty .02$ & .0 .05 & $\cos$ & $0.75 \mathrm{Ce}$ \\
\hline 37 & 12.0 & 6.7 & 4.3 & 0.7 & 0.032 & 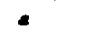 & 0.04 & 1.03 & 0.05 & \\
\hline 245 & 11.4 & $\cos$ & 402 & 0.28 & 0.057 & $\infty 02$ & $<0.02$ & 0.25 & - & $\cos \theta$ \\
\hline 36 & 115 & 8.6 & 3.4 & 0.24 & $0.05 s$ & .0 .02 & $\infty .02$ & 1.2 & $=$ & $0.2 \approx$ \\
\hline$m$ & $120^{\circ}$ & $7.0^{\circ}$ & $4.0^{\circ}$ & $0 . I^{*}$ & 0.05 & 0.02 & 0.24 & 0.57 & a & \\
\hline mex & $12.0^{\circ}$ & $70^{\circ}$ & 40 & $0.2^{\circ}$ & 0.0 & 0.02 & $\$ 01$ & 20 & - & \\
\hline 203 & $12.0^{\circ}$ & $7.0^{\circ}$ & $4.0^{\circ}$ & $0.2^{*}$ & 0.05 & 0.02 & 0.49 & 0.4 & 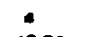 & \\
\hline 304 & 12.0 & 69 & 5.0 & 0.2 & $605^{\circ}$ & 0.05 & $\$ 01$ & $<0.05$ & $<0.01$ & $0.8 \mathrm{~W}$ \\
\hline 305 & 11.2 & 8.25 & 4.16 & 0.22 & 0.072 & $0 . \pi$ & ow & 1.3 & $\bullet$ & \\
\hline 30 & 10.6 & 8.04 & 3.11 & a.ts & $\approx x 5$ & 0.27 & e.di & 0.55 & 3 & \\
\hline 345 & 110 & 7.1 & 38 & 0.36 & $0.05^{\circ}$ & 0.22 & 0.02 & 0.45 & - & \\
\hline 346 & 11.0 & 6.7 & 3.7 & 0.18 & $0 \cos ^{\circ}$ & 0.4 & 0.02 & 0.49 & • & \\
\hline 347 & 12.0 & 7.6 & 4.3 & 0.25 & $0.05^{\circ}$ & 0.47 & $\infty .02$ & 0.83 & - & \\
\hline 340 & 12.0 & 72 & $0.0:$ & 0.19 & $0.05^{\circ}$ & 0.47 & $\$ 1.02$ & 0.62 & $*$ & \\
\hline 411 & 11.71 & 6.7 & 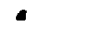 & 0.1 & 0.043 & - & 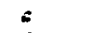 & 1.15 & * & \\
\hline 413 & 11.02 & 6.75 & $\bullet$ & 0.1 & 0.045 & - & 0.9 & 1.13 & - & \\
\hline 417 & 11.4 & 628 & 0.1 & 0.1 & 0.05 & $d$ & 0.01 & 229 & - & \\
\hline 421 & 11.43 & 6.75 & - & 0.1 & 0.048 & 4 & 1.9 & 1.04 & 0.07 & \\
\hline 422 & 11.27 & 678 & 0.0 & 0.15 & o.ns9 & 4 & 1.0 & 2.29 & 0.07 & \\
\hline 424 & 11.32 & 6.76 & 4 & 0.15 & ons 3 & 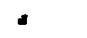 & 18 & 1.4 & 0.10 & \\
\hline 425 & 11.42 & 6.72 & - & 0.15 & 0.037 & - & 1.9 & 6,40 & 0.00 & \\
\hline$\$ 50$ & 13.6 & 8.1 & 0.3 & $<.1$ & 0.051 & 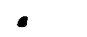 & 2.1 & $<0::$ & - & \\
\hline ess & $120^{\circ}$ & $70^{\circ}$ & - & $0 . x^{b}$ & $0.0000^{\circ}$ & $c$ & 2.1 & 1.03 & 0.18 & \\
\hline 40 & $12.0^{\circ}$ & $10.0^{*}$ & - & $0 . z^{*}$ & 0.000 & - & 2.36 & 1.21 & 0.17 & \\
\hline 462 & $12.0^{\circ}$ & $15.0^{\circ}$ & - & 0.7 & $0.010^{\circ}$ & 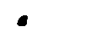 & 2.21 & 1.0 & 0.16 & \\
\hline 503 & 11.92 & 7.40 & - & 0.2 & 0.029 & $\bullet$ & $<0.01$ & $<n .02$ & -0.1 & \\
\hline 504 & 11.4 & 90.2 & $a$ & 0.17 & 0.03 & $\bullet$ & $<0.01$ & $<0.02$ & -0.1 & \\
\hline $\sin$ & 12.00 & 11.9 & - & 0.22 & 0.034 & • & $<0.01$ & $<0.02$ & -0.1 & \\
\hline 505 & 11.91 & 14.5 & $\bullet$ & 0.22 & 0.037 & $\bullet$ & 0.01 & $<0.02$ & $\rightarrow .1$ & \\
\hline 513 & 11.40 & 7.2 & $<0.95$ & 0.20 & 0.040 & $<0.02$ & $<0.02$ & 0.45 & o.ts & \\
\hline 514 & 11.50 & 7.05 & $<\cos$ & 0.20 & 0.035 & $<0.02$ & $<0.02$ & 0.69 & 0.05 & \\
\hline SIS & 11.53 & 7.10 & $<0.05$ & 0.20 & n.038 & $=0.02$ & $<0.02$ & 0.20 & 0.05 & \\
\hline 516 & 10.58 & 7.30 & $<0.03$ & 0.20 & 0.049 & $<0.02$ & .0 .02 & $<0.10$ & 0.05 & \\
\hline st? & 11.45 & 7.10 & $<0.05$ & $<0.01$ & 0.045 & $<0.02$ & $<0.02$ & 1.10 & 0.03 & \\
\hline s18 & 11.55 & 7.11 & $<0.05$ & 0.20 & 0.040 & o.ec & 0.95 & 0.5 & 0.10 & \\
\hline 523 & 11.40 & 10.40 & $<0.05$ & 0.23 & 0.037 & $<002$ & $<1.02$ & 0.47 & 0.10 & \\
\hline 524 & II.6s & 15.20 & $<0.05$ & 0.17 & 0.040 & $\infty, n 2$ & $<0.02$ & 0.4 & 0.10 & \\
\hline Nin.200 & 70 & 2 & 10 & 5 & & 15 & $<1$ & 3 & $<0.3$ & $100 \mathrm{Ta}$ \\
\hline 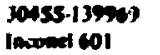 & & $\begin{array}{l}18.50 \\
21.91^{6}\end{array}$ & ${ }_{15.01^{r}}$ & $\begin{array}{l}1.51 \\
0.15^{5}\end{array}$ & $\begin{array}{l}0.027 \\
0.03^{r}\end{array}$ & $\begin{array}{l}0.45 \\
0.26^{6}\end{array}$ & & & & $\begin{array}{l}9.3 \mathrm{Nh} \\
0.03 \mathrm{Cu}^{\mathrm{r}}\end{array}$ \\
\hline $\begin{array}{l}\text { Inxonal } 1000 \\
000600\end{array}$ & & $15.3^{6}$ & $0.0^{\circ}$ & $0.5^{\circ}$ & $0.00^{\circ}$ & $0.25^{\circ}$ & & & & \\
\hline $\operatorname{Nx} 63726$ & & $15.13^{C}$ & $9.1 \%$ & $0.2 \pi$ & $0.10^{\circ}$ & $0.0 \%$ & & & & $0.316=$ \\
\hline$N \times 1187 G$ & & $15.82^{r}$ & $7.57^{r}$ & $0.11^{r}$ & $0.0 \%$ & 0.17 & & & & $0.28 \mathrm{cos}^{\mathrm{r}}$ \\
\hline NX 7353 & & $15.09^{r}$ & $9.44^{r}$ & D.3rer & $0.0 T^{5}$ & $0.14^{6}$ & & & & $0.31 \mathrm{cos}^{\circ}$ \\
\hline 421543 & 12.4 & 1.31 & 0.038 & 0.03 & o.cs & 0.014 & 0.001 & 0.70 & 0.02 & \\
\hline cososs & 16.0 & 7.1 & 4.0 & 0.55 & 0.06 & 0.57 & $<0.01$ & - & 80.03 & \\
\hline 459.344 & 13.0 & 1.4 & 4.0 & 0.56 & 0.11 & - & 0.17 & 1.7 & 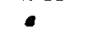 & $0.0192 r$ \\
\hline 4944 & 12.8 & 69 & 0.30 & 0.34 & 0.043 & - & 0.92 & 1.95 & $\bullet$ & \\
\hline 49.714 & 13.0 & 8.5 & 0.10 & 0.35 & 0.013 & - & 0.80 & 1.60 & - & \\
\hline $470-716$ & 12.2 & 1.6 & 0.41 & 0.43 & 0.044 & $\cdot$ & 0.22 & 0.62 & $\bullet$ & $0.024 \mathrm{Zr}$ \\
\hline$\$ 70-135$ & 12.5 & 7.9 & n.68 & $0.6 n$ & 0.052 & - & 0.71 & 2.60 & $\bullet$ & $0.031 \mathrm{Wr}$ \\
\hline $471 \cdot 114$ & 12.5 & 1.4 & $0 \cap 52$ & 0.02 & 0.058 & 0.026 & 1.75 & 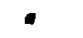 & 0.07 & \\
\hline $472-164$ & $\because .65^{\circ}$ & $15.4 \%$ & $0.6^{r}$ & $0.51^{\mathrm{r}}$ & $0.01^{\circ}$ & $0.27^{r}$ & & & $0.14^{x}$ & 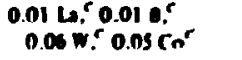 \\
\hline 472.503 & 12,9 & 6.79 & $0.0 \mathrm{nt}$ & $<0.01$ & 0.006 & 0.009 & 2.16 & 0.05 & 0.9 & \\
\hline 474.533 & 11.37 & 1.3 & $0.03^{r}$ & 0.04 & 0.0 .1 & 0.19 & 1.75 & 3 & 0.54 & $0.14 w^{r} 0.03 \mathrm{Cn}^{r}$ \\
\hline 474.534 & 11.7 & 7.1 & 0.06 & $<0.01$ & $0.0 \mathrm{n}$ & 9.03 & 2.09 & - & 0.53 & $0.14 w, 0.013 \mathrm{~L}$ \\
\hline 474.535 & 11.8 & 7.3 & 0.05 & -0.01 & 0.00 & 0.03 & 2.13 & $\bullet$ & 0.55 & $\begin{array}{l}0.10 \mathrm{w.0.010} \mathrm{L} \text {. } \\
00 \mathrm{Ce}\end{array}$ \\
\hline 474-539 & 11.38 & 7.4 & $0.0 \%$ & 0.03 & 0.0 .1 & 0.10 & 2.55 & - & 0.62 & $0.11 w, 0.04(n, 0.02 w$ \\
\hline 474.55? & 11.91 & 7.23 & 0.00 & $<0.01$ & 0.04 & 0.03 & 2.14 & $\bullet$ & 0.02 & \\
\hline 474-551 & 12.00 & 7.20 & 0.07 & $<0.91$ & 0.07 & 0.03 & 2.05 & 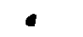 & 0.02 & $0.02 w, 0.021$ L \\
\hline $474-901$ & 12.5 & $6 . \%$ & $0.0 s^{r}$ & $0.02^{r}$ & 0.044 & 0.10 & 2.00 & - & - & \\
\hline $475-421$ & 11.93 & 7.10 & 0.05 & 0.12 & 0.07 & 0.04 & 1.90 & - & 0.12 & $0.02 \mathrm{Co}$ \\
\hline
\end{tabular}

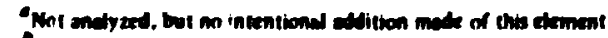

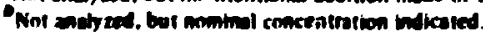

CVendor's andreter

Crmacentrations in pom 


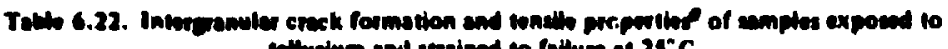

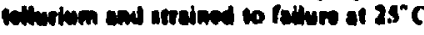

\begin{tabular}{|c|c|c|c|c|c|c|c|c|c|c|c|c|c|c|}
\hline \multirow{2}{*}{ Emp. No. } & \multirow{2}{*}{ Hout No. } & \multicolumn{2}{|c|}{$\begin{array}{l}\text { Crecks por } \\
\text { unil bovilh }\end{array}$} & \multicolumn{2}{|c|}{ Depeh (u) } & \multirow{2}{*}{$\begin{array}{l}\text { Siandayd } \\
\text { doriation } \\
\text { (w) }\end{array}$} & \multirow{2}{*}{$\begin{array}{l}\text { 997 confrdones } \\
\text { interval } \\
\text { (u) }\end{array}$} & \multirow{2}{*}{$\begin{array}{l}\text { Wolanto } \\
\text { changs } \\
(. n+1)\end{array}$} & \multirow{2}{*}{$\begin{array}{c}\text { Yrold } \\
\text { slpess } \\
\left(10^{3} \text { pai) }\right.\end{array}$} & \multirow{2}{*}{ 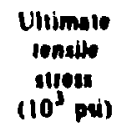 } & \multirow{2}{*}{$\begin{array}{l}\text { Preciure } \\
\text { slpess } \\
\left(10^{2} \text { pail }\right.\end{array}$} & \multirow{2}{*}{$\begin{array}{c}\text { Unifurm } \\
\text { elongalion } \\
\text { (x) }\end{array}$} & \multirow{2}{*}{$\begin{array}{c}\text { Iincture } \\
\text { Ilrain } \\
(x)\end{array}$} & \multirow{2}{*}{$\begin{array}{c}\text { Kedurion } \\
\text { in } \\
\text { ines } \\
\text { (4) }\end{array}$} \\
\hline & & Crnekulin. & Cracks/un & Av & $\operatorname{Miax}$ & & & & & & & & & \\
\hline \multirow[t]{5}{*}{$79-11$} & $\cos 0$ ss & 105 & 41 & 20.3 & 33.0 & 6.6 & 2.9 & 0.50 & 34.2 & 132.7 & 126.3 & 37.3 & 42.1 & 40.3 \\
\hline & 471.114 & 17 & 7 & 13.0 & 21.6 & 3.5 & $\$ .0$ & 0.29 & 51.5 & 118.9 & 113.4 & 54.1 & 36.6 & 47.6 \\
\hline & 474.534 & 363 & 143 & 22,5 & 41.2 & 6.3 & 1.2 & 0.31 & 58.1 & 129.9 & 117.5 & 41.7 & 44.6 & 48.8 \\
\hline & 474.535 & 0 & 0 & & & & & 1.39 & 52.8 & 124.9 & $: 19.4$ & 47.4 & 49.4 & 47.0 \\
\hline & 600600 & & 26 & 17.0 & 27.3 & 3.3 & 2.4 & +0.62 & 39.2 & 102.9 & 76.2 & 29.6 & 34.8 & 61.2 \\
\hline \multirow[t]{10}{*}{$75-12$} & $\cos r \mathrm{~s}$ & & & & & & & & & & & & & \\
\hline & $\begin{array}{l}\text { as swapd } \\
\text { aososs }\end{array}$ & 370 & 146 & 17.4 & 36.0 & 3.6 & 1.9 & $\bullet 0.91$ & 102.9 & 159.1 & 149.7 & 26.3 & 29.0 & 34.6 \\
\hline & 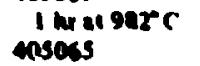 & 350 & 130 & 16.4 & 23.8 & 4.9 & 1.6 & +0.25 & 79.9 & 150.5 & 132.1 & 31.4 & 4.3 & 44.1 \\
\hline & $\begin{array}{l}\lim _{\text {of }} 1030 \mathrm{C} \\
\text { coscos }\end{array}$ & 330 & 130 & 13.2 & 27.1 & 3.2 & 1.8 & +0.43 & 62.8 & 141.3 & 123.7 & 24.8 & 37.2 & 44.11 \\
\hline & 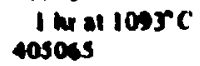 & 320 & 126 & 18.9 & 36.3 & 3.9 & 1.7 & $\bullet 0.26$ & 36.9 & 137.6 & 125.3 & 37.0 & 40.3 & 43.1 \\
\hline & $\operatorname{limet}_{\text {tososs }} 1150^{\circ} \mathrm{C}$ & 330 & 130 & 31.8 & 39.1 & 12.7 & 4.4 & +0.14 & $\$ 3.4$ & 130.4 & 122.6 & 39.3 & 41.8 & 41.1 \\
\hline & $\begin{array}{c}\text { I tur at } 117 r \mathrm{r} C \\
\text { sososs }\end{array}$ & 200 & 110 & 49.0 & 92.0 & 18.0 & 6.8 & $+c .29$ & 52.3 & 126.0 & 113.4 & 40.1 & 43.3 & 40.3 \\
\hline & $\begin{array}{l}1 \text { in al } 1204^{\circ} \mathrm{C} \\
\text { cososs }\end{array}$ & 300 & 79 & 69.6 & $: 07.4$ & 18.3 & 4.2 & +0.60 & so.n & 121.6 & 119.7 & 37.4 & 38.4 & 31.6 \\
\hline & $\begin{array}{l}\text { I hu at 123rC } \\
\text { cososs }\end{array}$ & 220 & 97 & 73.9 & 130.0 & 26.3 & 11.3 & +2.06 & so.4 & 111.3 & 109.6 & 33.3 & 33.6 & 26.6 \\
\hline & I hit at $1260^{\circ} \mathrm{C}$ & 110 & 43 & 87.3 & 179.4 & 36.4 & 14.7 & +1.96 & 49.3 & 104.2 & 100.9 & 31.2 & 31.5 & 27.6 \\
\hline \multirow[t]{11}{*}{75.13} & $\begin{array}{l}\text { cososs } \\
295\end{array}$ & $\begin{array}{r}213 \\
12\end{array}$ & is & $\begin{array}{l}22.9 \\
10.0\end{array}$ & $\begin{array}{l}54.1 \\
23.7\end{array}$ & $\begin{array}{l}9.9 \\
7.9\end{array}$ & $\begin{array}{l}3.0 \\
6.3\end{array}$ & $\begin{array}{r}-0.07 \\
+0.08\end{array}$ & $\begin{array}{l}33.6 \\
33.4\end{array}$ & $\begin{array}{l}132.4 \\
121.6\end{array}$ & $\begin{array}{l}120.3 \\
112.6\end{array}$ & $\begin{array}{r}39.5 \\
43.6\end{array}$ & $\begin{array}{l}41.7 \\
46.3\end{array}$ & $\begin{array}{l}37.7 \\
49.3\end{array}$ \\
\hline & 29 & 70 & 28 & 16.4 & 39.3 & 8.1 & 2.7 & +0.03 & 54.3 & 124.6 & 104.3 & 45.3 & 49.2 & 31.1 \\
\hline & 305 & 16 & 6 & 9.9 & 16.2 & 3.5 & 2.3 & +0.04 & 39.6 & $121 . \mathrm{m}$ & 111.1 & 39.6 & 42.7 & 47.1 \\
\hline & 348 & $\mathbf{2 4}$ & 29 & 8.5 & 73.8 & 13.0 & 4.3 & +0.11 & 32.7 & 121.9 & 105.3 & 43.5 & 46.1 & $\$ 1.3$ \\
\hline & 411 & 4 & 17 & 12.4 & 35.5 & 8.5 & 3.6 & +0.30 & 45.1 & 114.9 & 103.5 & 47.7 & 49.9 & 46.4 \\
\hline & 413 & 280 & $1: 0$ & 13.5 & 41.8 & 9.3 & 2.0 & -0.06 & 33.7 & 123.3 & 117.0 & 45.7 & 48.0 & 12.2 \\
\hline & 421 & 300 & 150 & 33.1 & 6.0 & 2v. 2 & 6.6 & 0.00 & 53.8 & 121.3 & 118.9 & 4.7 & 46.9 & +5.9 \\
\hline & 424 & 330 & 138 & 36.9 & 79.1 & 15.3 & 5.2 & 0.00 & 55.3 & i32.4 & 125.0 & 42.1 & 44.4 & 49.7 \\
\hline & 423 & 130 & 31 & 38.2 & 24.0 & 18.5 & 10.3 & +0.15 & 52.2 & 124.2 & 118.4 & 43.2 & 44.6 & 10.1 \\
\hline & 423 & 280 & 110 & 30.2 & 63.9 & 19.2 & 5.7 & 0.00 & 52.6 & 124.7 & 118.7 & 43.1 & 49.0 & 11.1 \\
\hline & 421543 & 22 & 9 & 17,9 & 41.1 & 11.9 & $\therefore 2$ & +0.14 & 51.9 & 117.0 & 106.7 & 45.0 & 47.7 & 50.5 \\
\hline \multirow{2}{*}{75.14} & cososs & 330 & 138 & 50.4 & 90.4 & 18.9 & 6.4 & $+n .44$ & 52.5 & 124.3 & 116.2 & 38,0 & 40.3 & 39.4 \\
\hline & $470-335$ & 247 & 97 & 24.2 & 94.7 & 20.3 & 4.7 & 0.90 & Sh. & 136.9 & 129.4 & 43.4 & $M .9$ & 39.3 \\
\hline \multirow{2}{*}{75.15} & ม1 & 43 & 17 & 30.5 & 66.6 & 17,3 & 9.5 & -4.13 & 41.5 & 112.7 & 97.9 & 31.7 & 54.8 & 33.4 \\
\hline & 413 & $\begin{array}{l}260 \\
195\end{array}$ & $\begin{array}{r}102 \\
77\end{array}$ & $\begin{array}{l}.17 .4 \\
29.1\end{array}$ & $\begin{array}{l}93.6 \\
62.9\end{array}$ & $\begin{array}{l}23.6 \\
13.9\end{array}$ & $\begin{array}{l}6.3 \\
4.5\end{array}$ & 4.18 & 49.3 & 120.4 & 111.3 & 43.5 & 45.8 & 42.7 \\
\hline
\end{tabular}


Table 6.22 (continued)

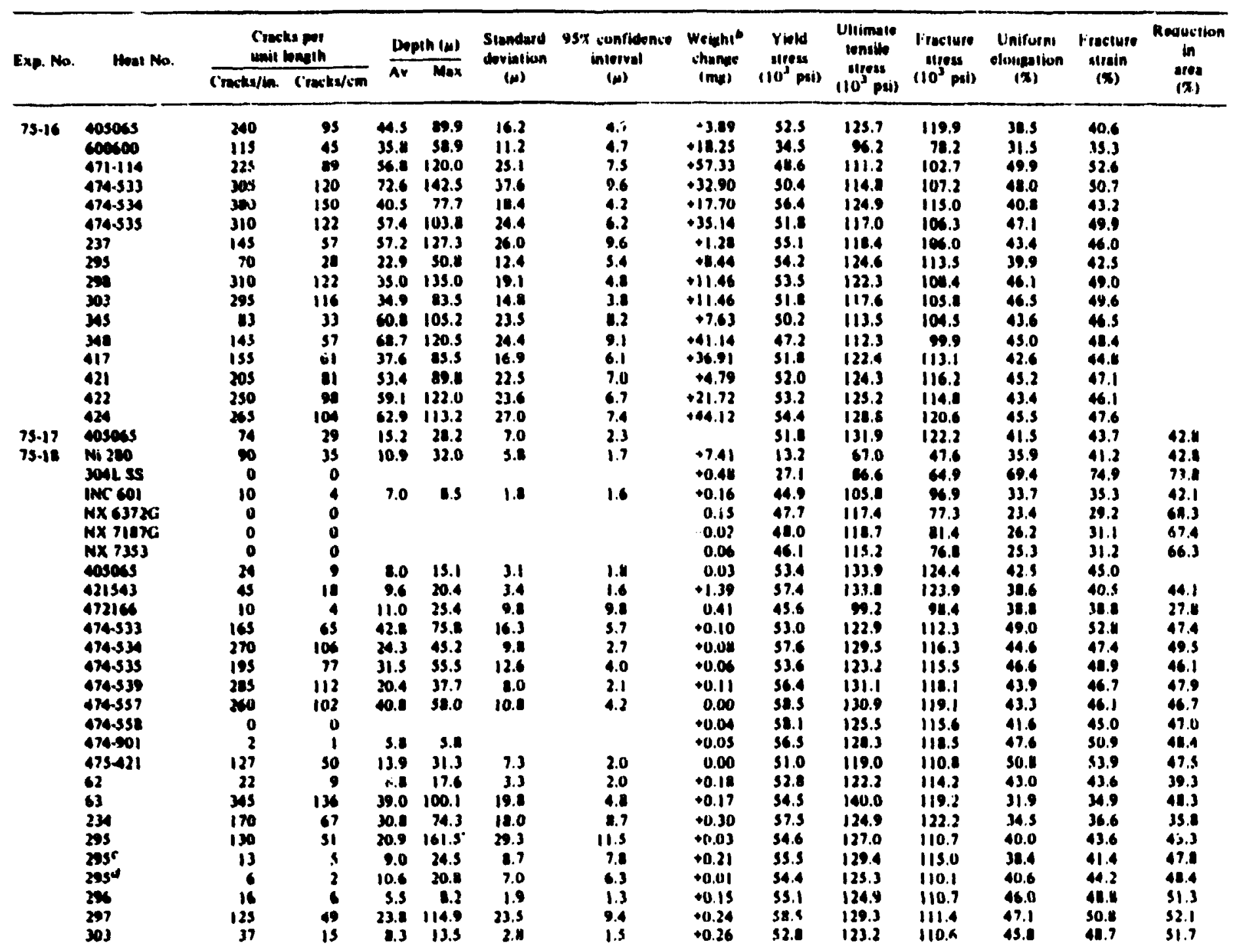


Tchis 6.22 (costinuad)

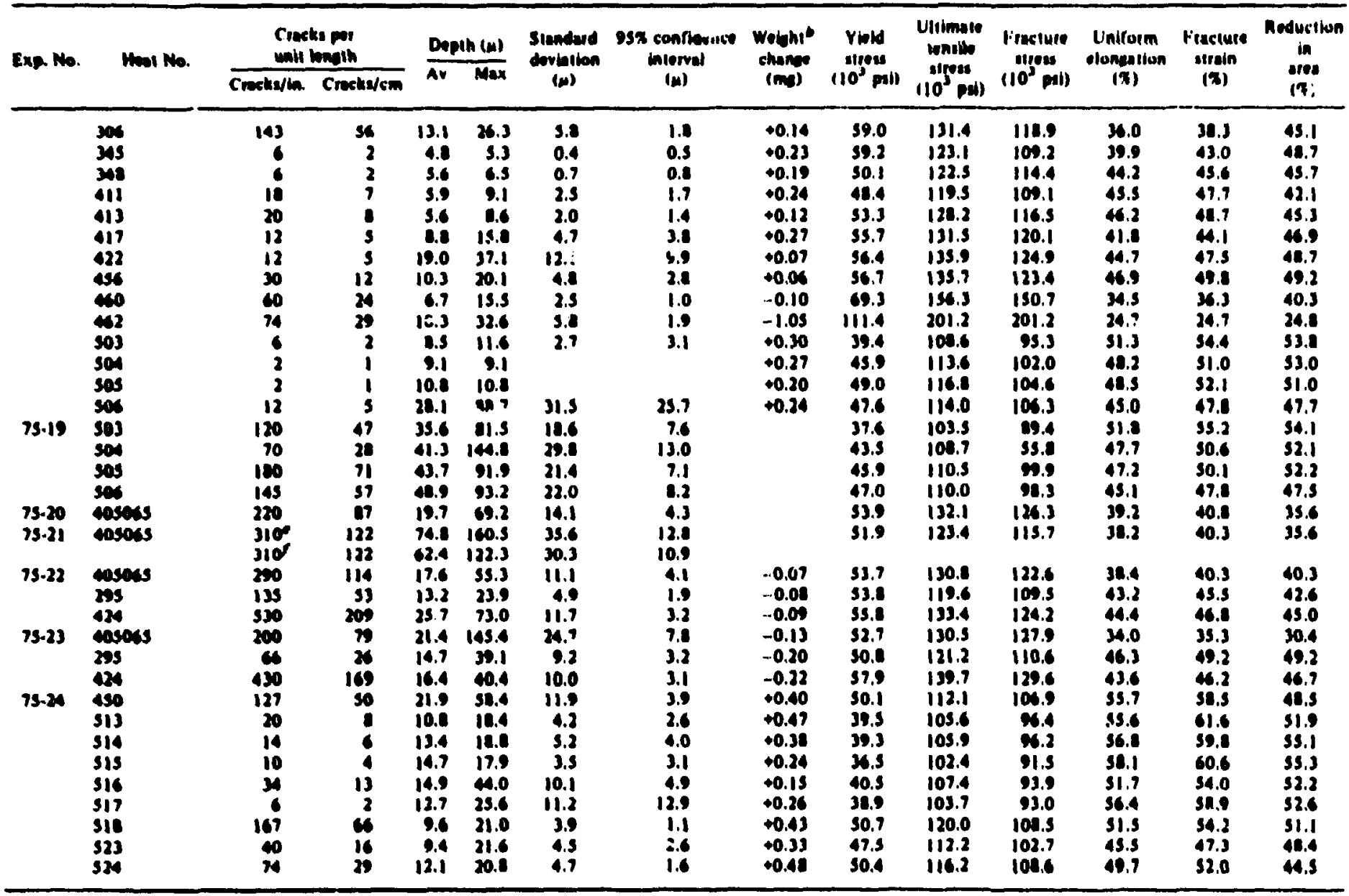

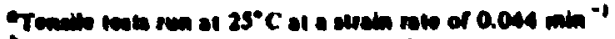

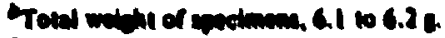

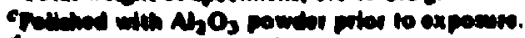

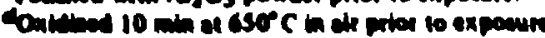

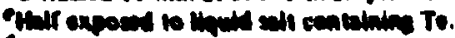

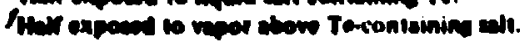


samples was within expected limits with no visible resction products on any specinens (Fis. 6.50). The crack severity varied anong the frue specineus, with the standard alloy (beat cos065) and one llianium-bathanm-anodified alloy (beat 474-534) showing extensive cracking and the of ter three alloys showing much less cracking. baconel 600 was obsen ved previoushy to be more resistant to intergranuhr crecting than standard Hastelloy $\mathbf{X}$. The variations amoas the three heats of modified Hastelloy $X$ are probably insigaifont.

Experiment is-12 was an evaluation of the infuence of grin sixe on the deph and frequency of interganubr cracking. Samples of standard Hastetby 1 (heat 405065) were nude from 's-in. diam sweged rod and were given various anacaline treatments prior to exposure for 250 hr at $700 \mathrm{C}$ to the apor above tellurium at $30 \% \mathrm{C}$. The speciuens were then strained to failure at $25^{\circ} \mathrm{C}$ and sectioned metallographically in determine the extent of cracking (Table 6.23). Photomictographs of the strained portions of the specimens (fiz- 6.51) ean be compared with elcted views of unstrined portions of the same specimens (Fig-6.52). Such comparisons show qualitatively that the frequency of cracling decreases and the depth of cracting increases with increasing amacaling temperature for increasing train sines).

These trends may be defred quaptnativeh if ie. 6.53). With smail grain sires the number of crects is proportional to $L "{ }^{\prime-}$. and at breet grain sines the number of cracks is proportional to $L^{\cdots \cdots}$. $t \bar{l}$. is the mean distanc between grain boundanss. I the deph of cracking goes through a shigh dec ease with the first few lowitedperature anacab bue then iacreases

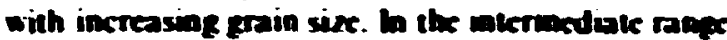
of prain sines the cract dephit laverax and man. mum) is proportival to $l . "$.

The speciancens in experimeal 75-13 werc exposed for 1000 be to the lapor above exturima metal at 300 C. This experionem is coopponed with a companion experiment (75-10) which operaled for unh 250 hr" (Table 6.24). The comparison is made con the basis of the prodect of the cract aumbet a ad averap depth. The rankine of the alloys on the busis of the paraneter is similar for the two expertunews. Alty 413 looks considerably worse in the bacer expenmeas. There is a very distinct break between the alloys anodifod with 27 ; or lews niobnem and thone

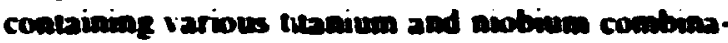

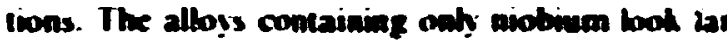
superior to those containiag siobuna and tuanum Photomicrographs of these speximens ctoert reilect

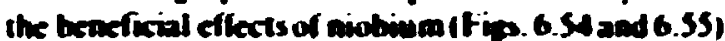

Experiments 75-14 and 75-15 exposed specranems

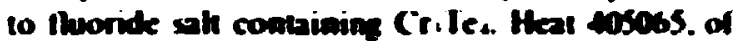
shandard Hastelby . . cracted mone sevencty in cxperinent 75-14 than did allon 470-835. of modifod Hastelloy $I$ (fire 6.56 and Table 6.22). Doth specinens showed sone evidence of very stallow surface reaction byers. In experieneat 75-15 two specimens were exposed. onc containiag acomialh IF niobium (alloy $4 I I$ ) and the other containian IF; niobium and Ir; titaning (alloy 113). The alloy

\begin{tabular}{|c|c|c|c|c|c|c|c|}
\hline \multirow{3}{*}{ Anond } & \multirow{2}{*}{\multicolumn{2}{|c|}{ Grim sine }} & \multirow{3}{*}{ 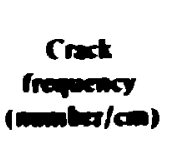 } & \multirow{3}{*}{ Anarax } & \multicolumn{2}{|c|}{ 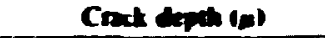 } & \multirow{3}{*}{ continger } \\
\hline & & & & & \multirow{2}{*}{ Maximem } & \multirow{2}{*}{ Sominged } & \\
\hline & G & I. & & & & & \\
\hline As sured & 9.9 & 10.5 & 146 & 17.8 & 368 & 56 & 1.9 \\
\hline I w at sezc & 8.9 & 12.8 & 130 & 16.4 & 258 & 4.9 & is \\
\hline I t a d & 7.9 & 20.0 & 130 & 13.2 & 27.1 & 5.2 & 18 \\
\hline I w at lostc & 1.6 & 22.5 & 126 & 18.9 & 363 & S.e & 1.7 \\
\hline I hr af IIS4C & 6.1 & 37.4 & 130 & 31. & S9.1 & 12.7 & 4.4 \\
\hline 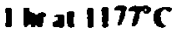 & 6.1 & 38.0 & 110 & 480 & 92.0 & 18.0 & 6.8 \\
\hline I W at $12 a 0^{\circ} \mathrm{C}$ & 3.1 & 53.0 & 7 & 696 & 107 & 18.3 & 8.2 \\
\hline I $\mathrm{kol} 1232 \mathrm{C}$ & 4.0 & 69.5 & 87 & 73.9 & 130 & 26.5 & 11.3 \\
\hline I th a $1260 \mathrm{C}$ & 1.9 & 160 & 43 & 87.3 & 17 & 34.4 & 14.7 \\
\hline
\end{tabular}

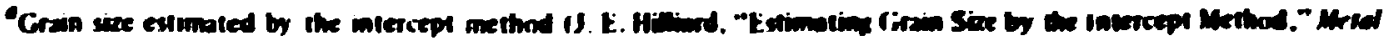

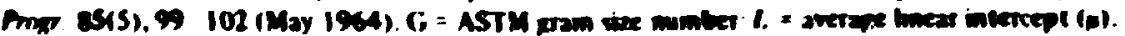



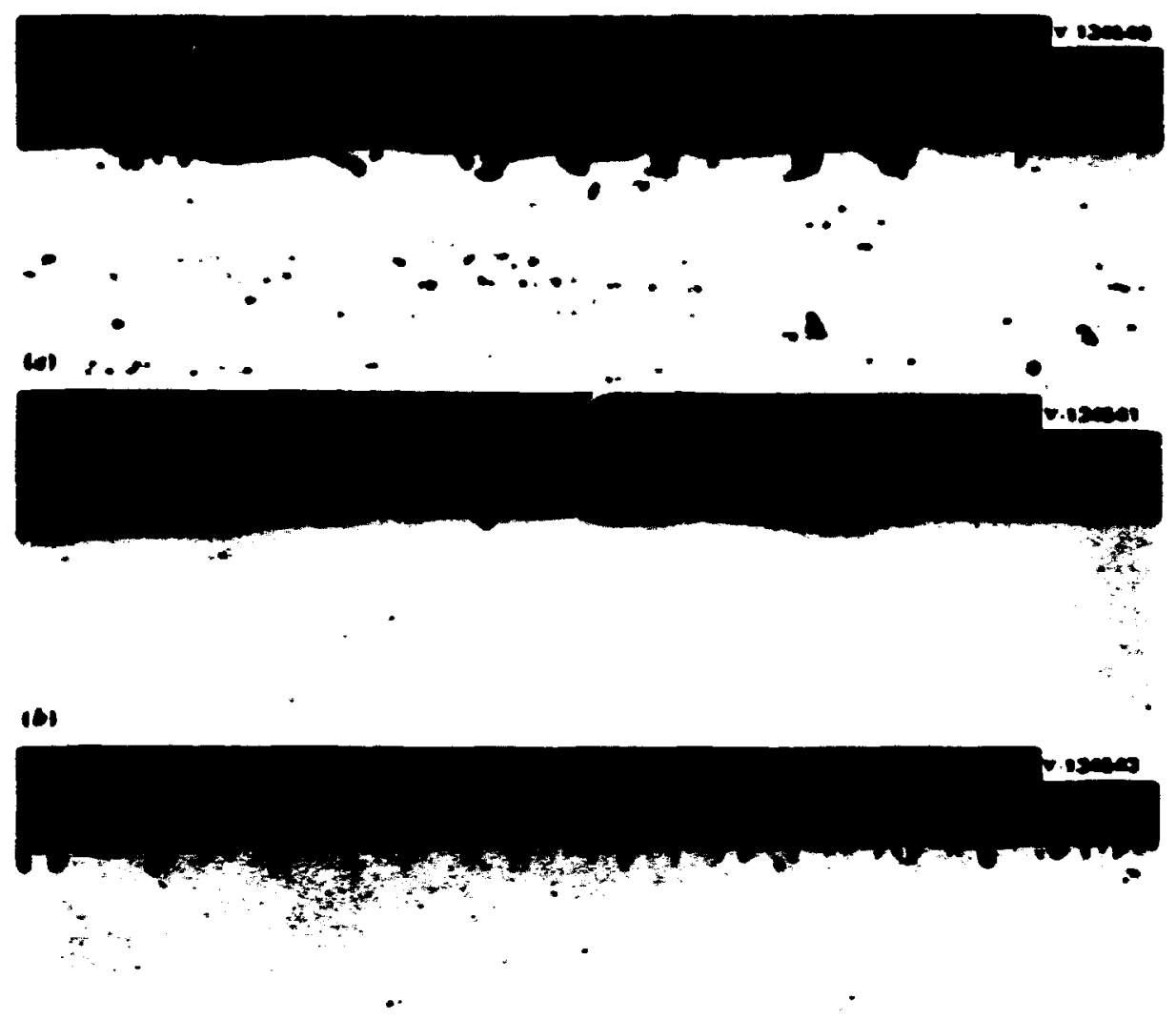

(r)

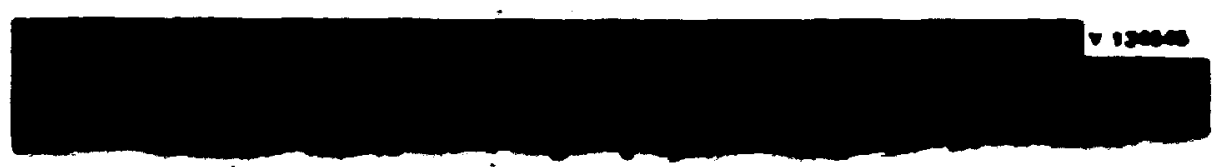

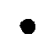

(1)

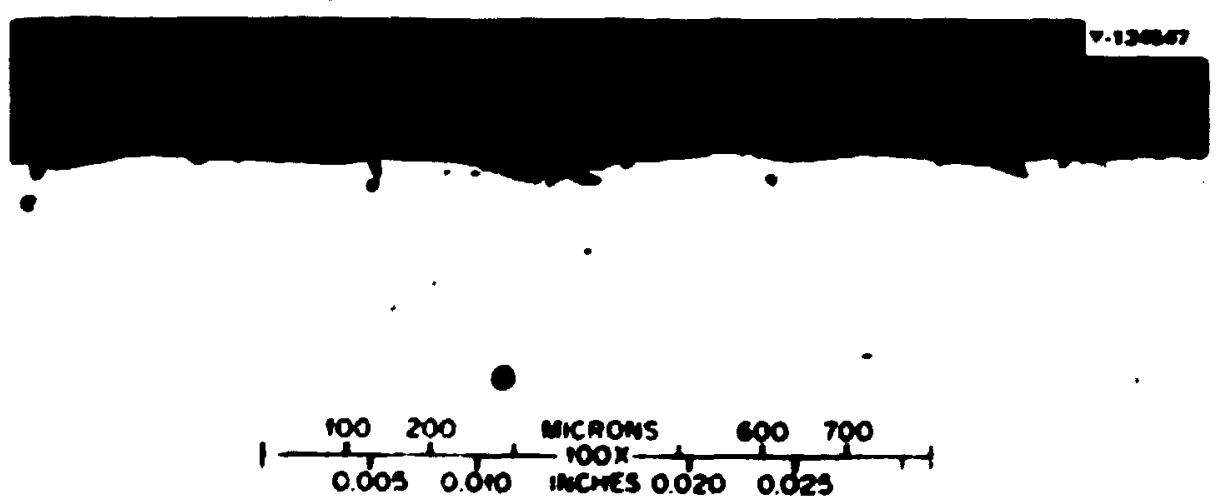

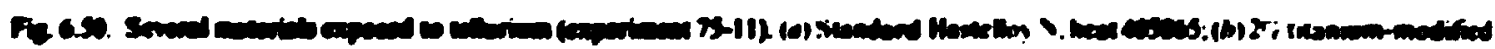

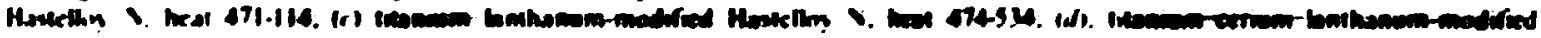

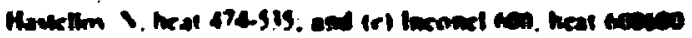




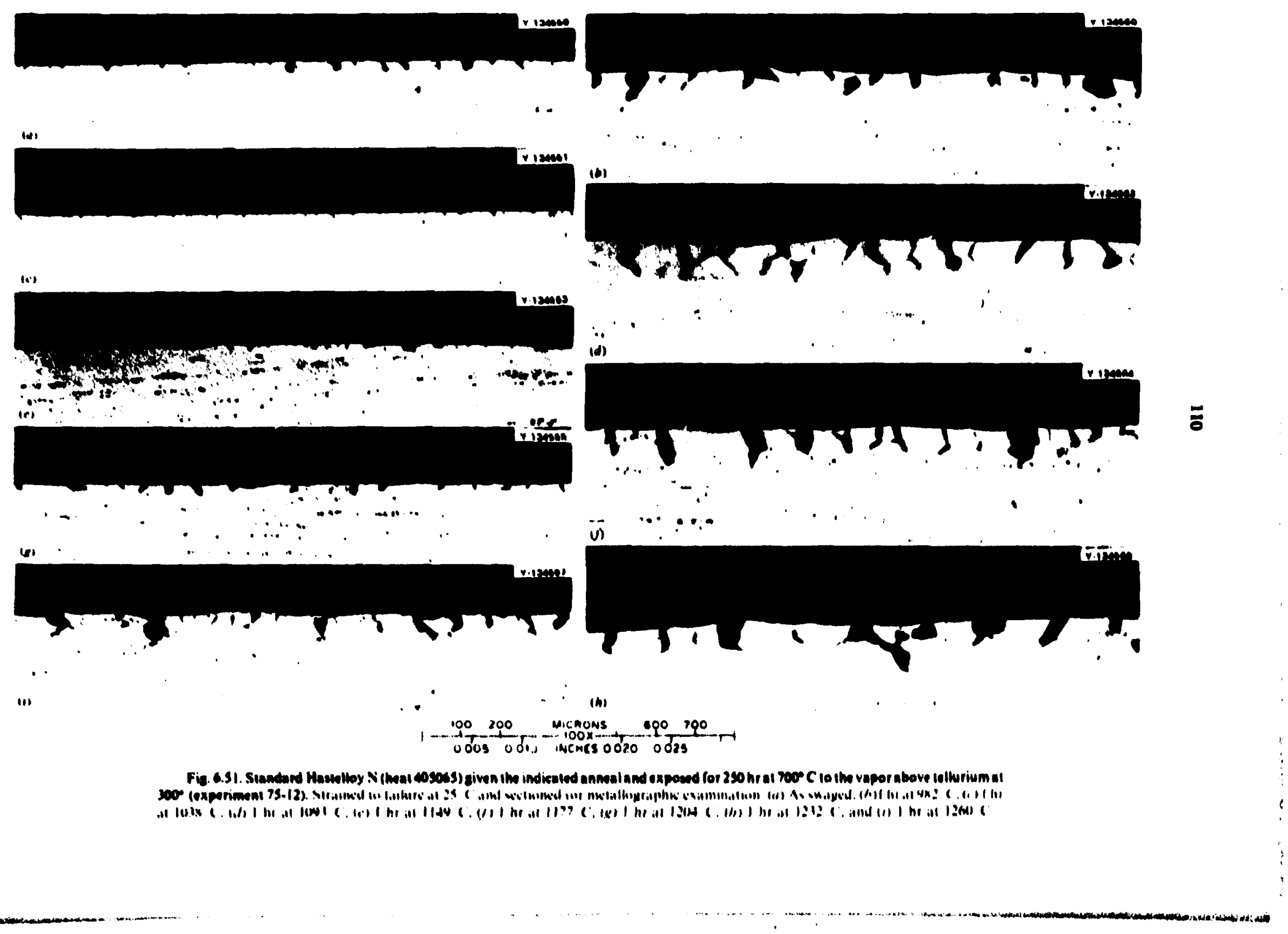




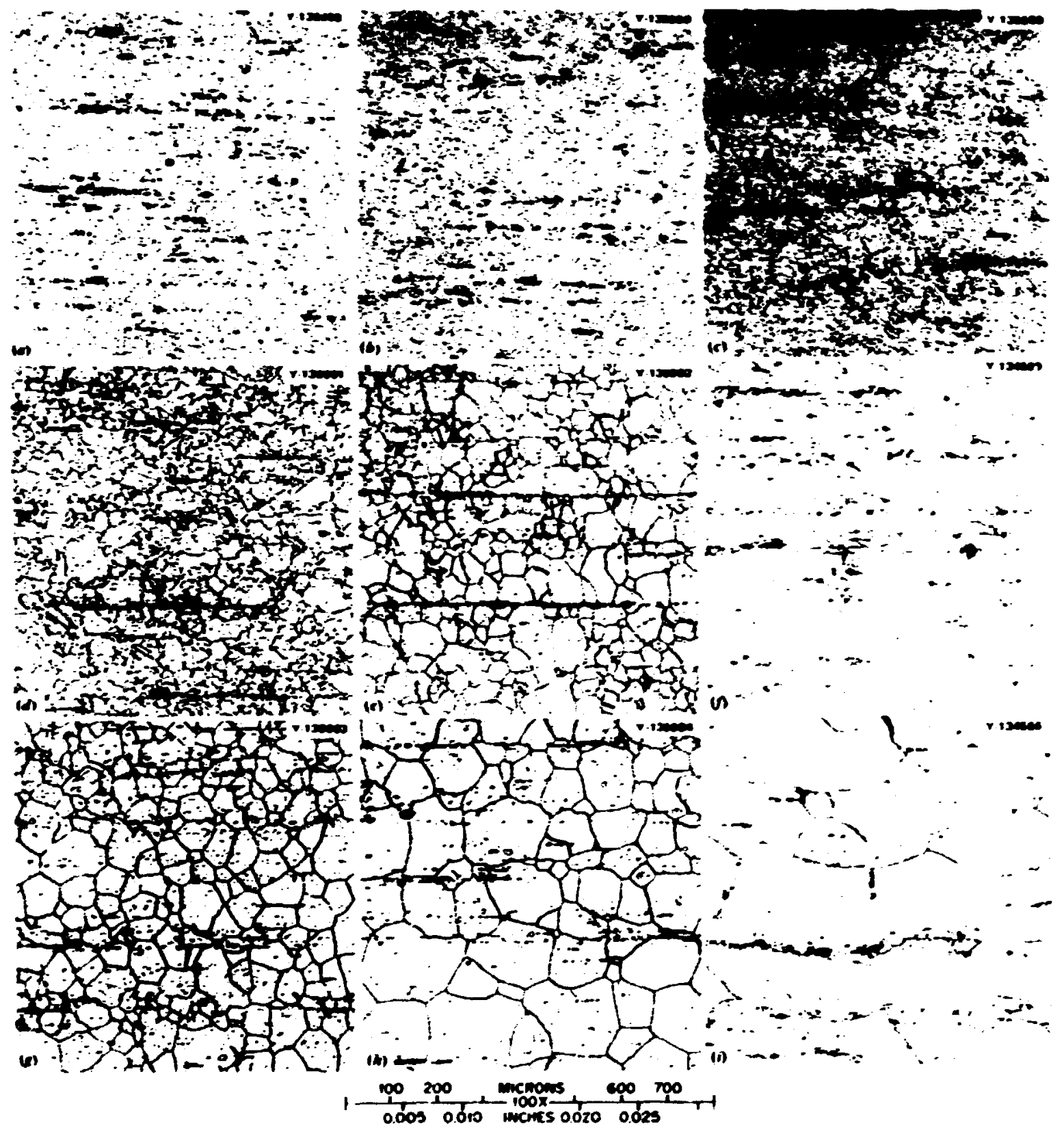

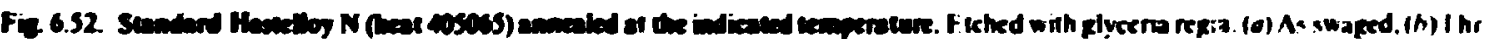

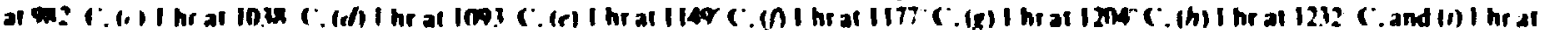
I? 


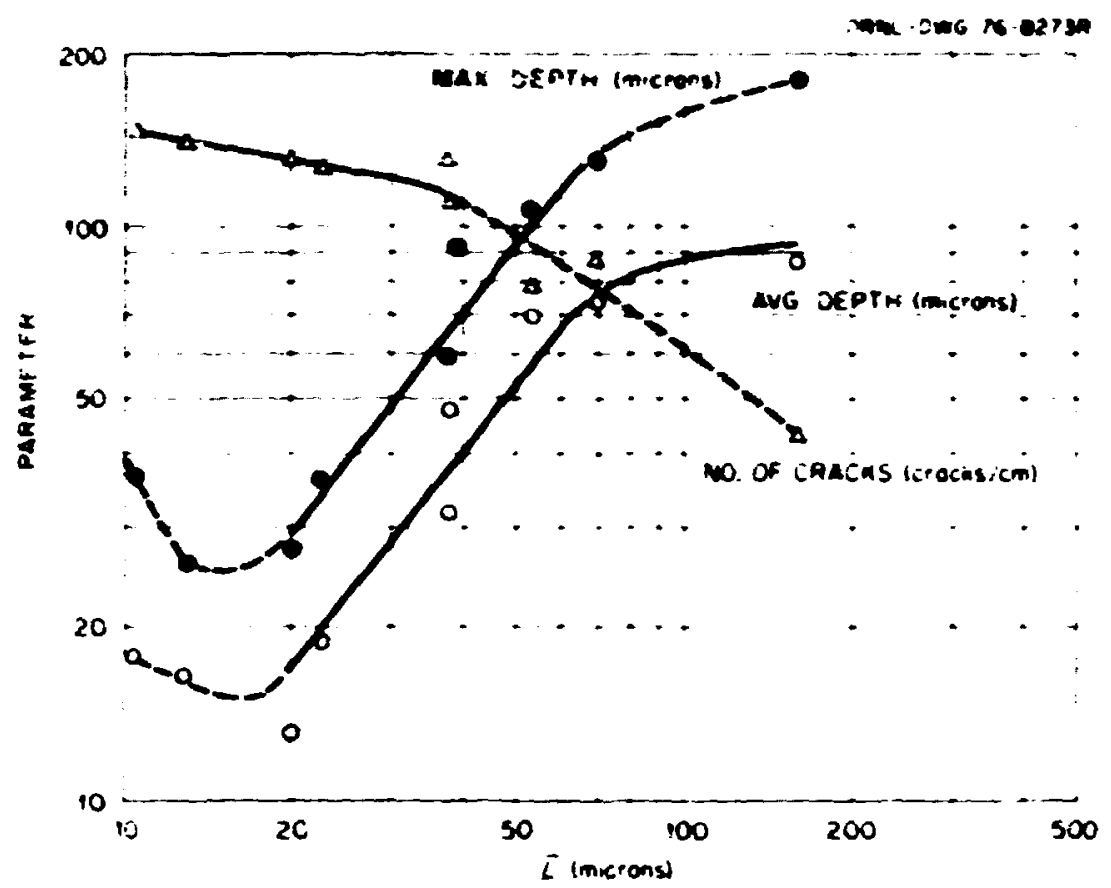

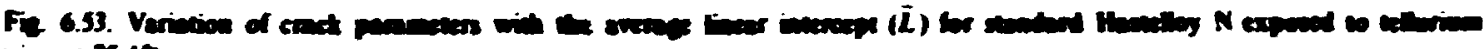
(experingen 75-12).

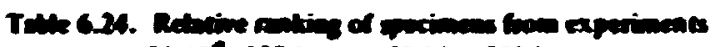

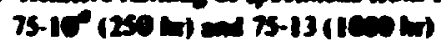

\begin{tabular}{|c|c|c|c|c|c|c|c|}
\hline \multirow{3}{*}{$\begin{array}{l}\text { Heat } \\
\text { number }\end{array}$} & \multirow{2}{*}{\multicolumn{3}{|c|}{ Comerentration ( $(x)$}} & \multicolumn{2}{|l|}{ Experiment 75-10 } & \multicolumn{2}{|l|}{ Experimess 75-13 } \\
\hline & & & & \multirow{2}{*}{$\begin{array}{l}\text { Product of musber of craxts } \\
\text { and averne depth } \\
\left(\frac{\text { crects }}{\mathrm{cm}} \times\right)\end{array}$} & \multirow{2}{*}{$\begin{array}{l}\text { Retative } \\
\text { sererity }\end{array}$} & \multirow{2}{*}{ 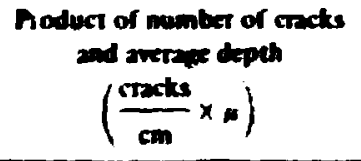 } & \multirow{2}{*}{$\begin{array}{l}\text { Retative } \\
\text { severity' }\end{array}$} \\
\hline & $\mathbf{T i}$ & No & Oaher & & & & \\
\hline 424 & 1.8 & 1.34 & & 4512 & 1 & soess & 2 \\
\hline 421 & 2.19 & I.04 & & 3245 & 2 & 5251 & $\mathbf{1}$ \\
\hline 425 & 1.90 & 0.48 & & 3196 & 3 & $\begin{array}{l}3322 \\
1938\end{array}$ & 3 \\
\hline 425 & 1.98 & 0.49 & & 2157 & 5 & 1955 & 4 \\
\hline 298 & & 2.0 & & 713 & 6 & 452 & 7 \\
\hline 413 & 1.0 & 1.13 & & 336 & 7 & 1488 & 6 \\
\hline 348 & & 0.62 & $0.47 \mathrm{Si}$ & 209 & 8 & 248 & 8 \\
\hline 411 & & 1.15 & & 133 & 9 & 215 & 9 \\
\hline 295 & & 0.85 & & 106 & 10 & 47 & 12 \\
\hline 421543 & & 0.7 & & 76 & 11 & iss & 10 \\
\hline 345 & & 0.45 & $0.22 \mathrm{Si}$ & 45 & 12 & 62 & 11 \\
\hline
\end{tabular}

asee pp. 108-122. ORNL.SOT8.

SSee Table 6.21 for detaiked chemical analyses.

Severity of crackine rances from a maximum of 1 to a minimum of 12. 


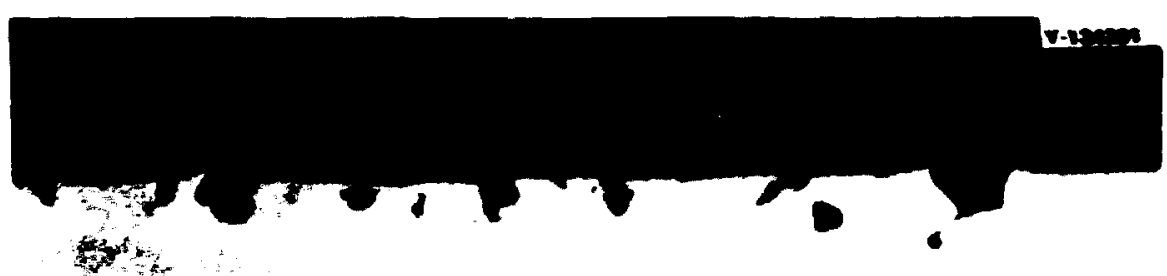

(a) $3 x^{2}+2,1 \ldots$

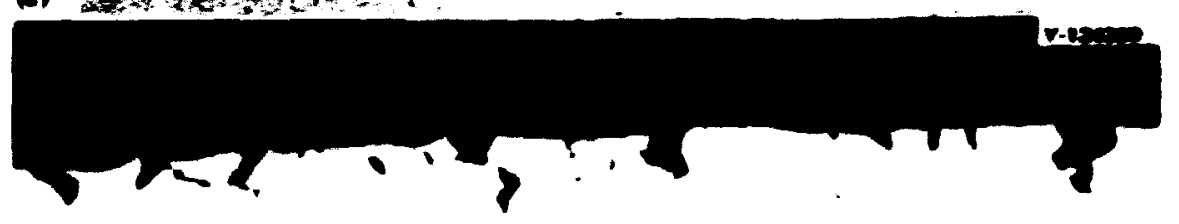

(b)

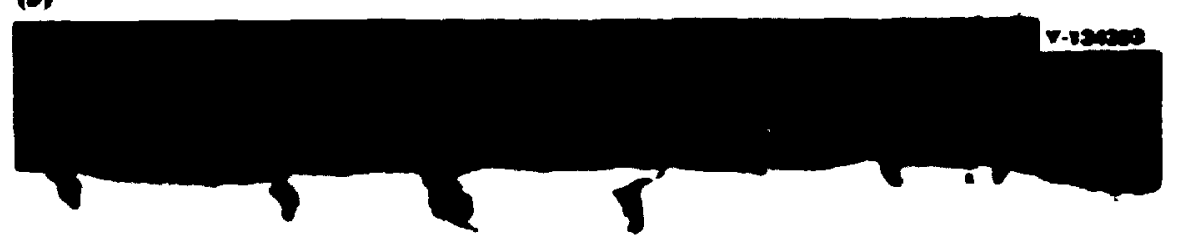

$|r|$

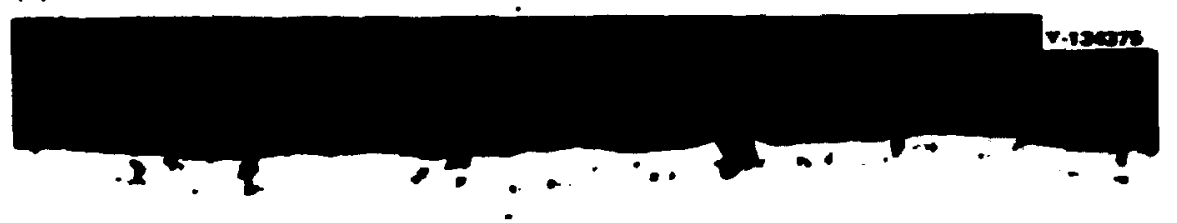

(d)

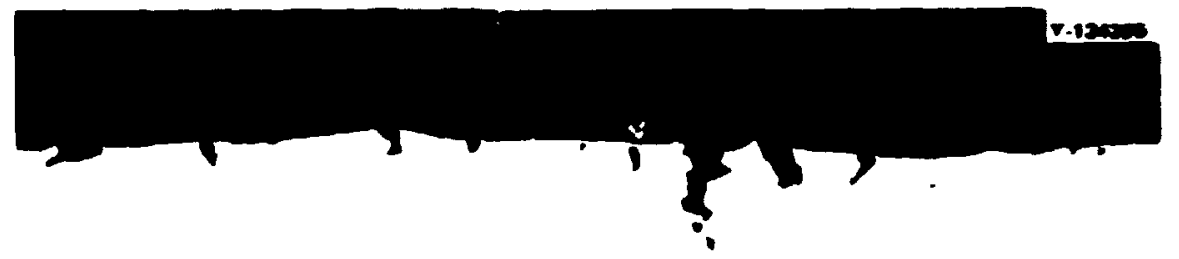

(e)

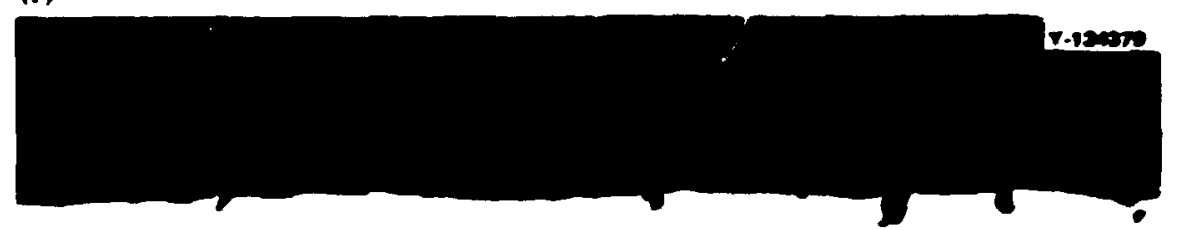

(n)

$$
\frac{100200 \quad \text { Microus } 600790}{0.0050 .010 \text { INCMES } 0.0200 .025}
$$

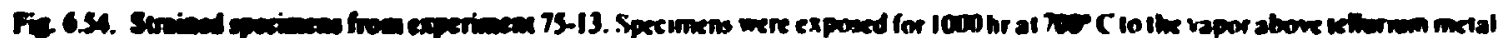

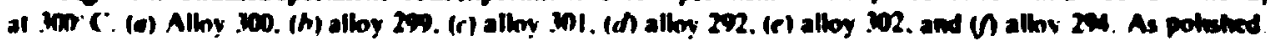




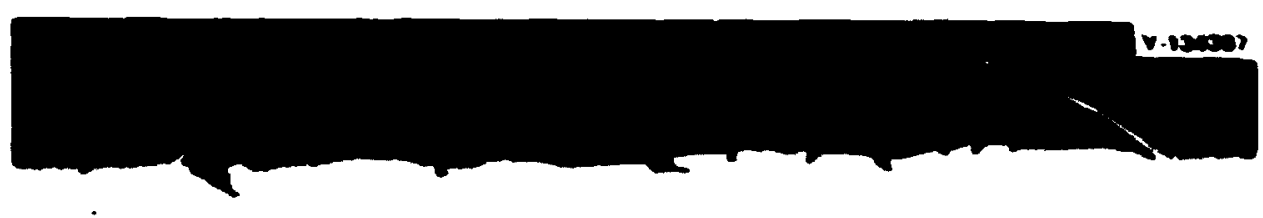

(a)

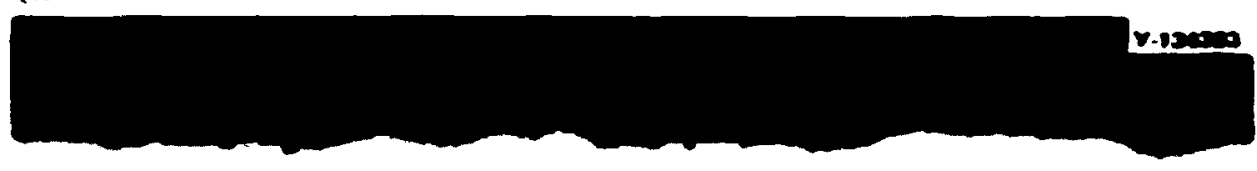

(6)

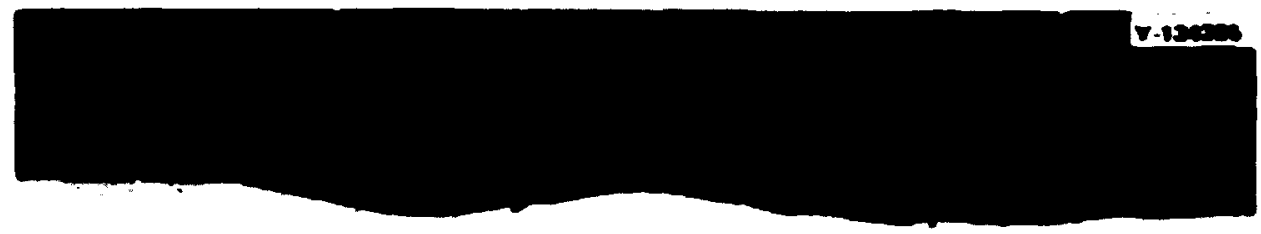

(c)

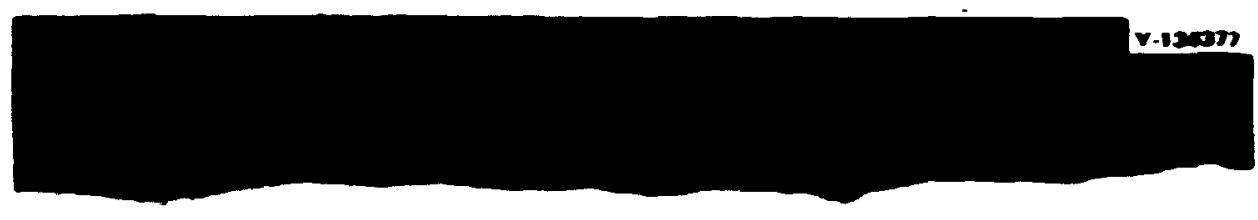

(d)

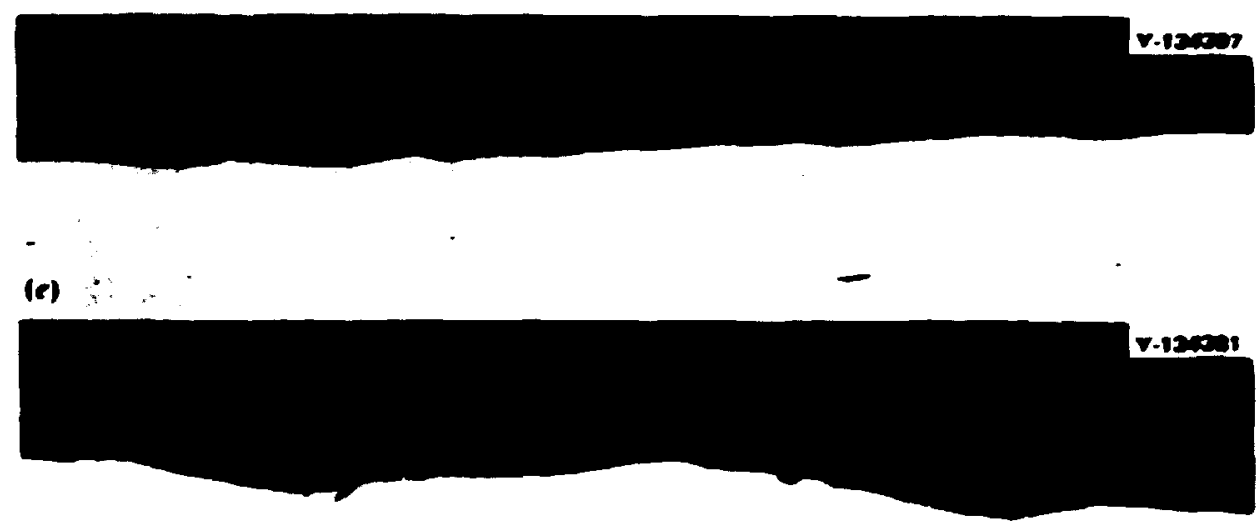

(1)

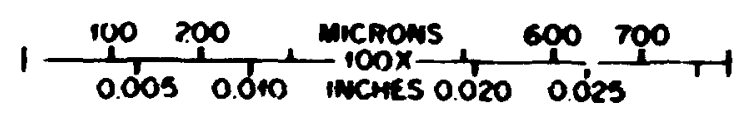

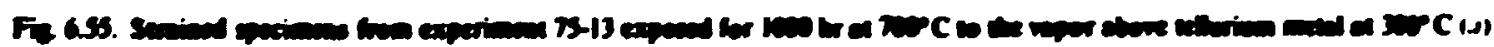

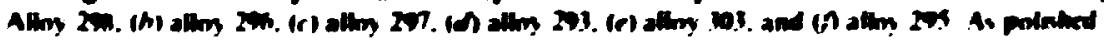



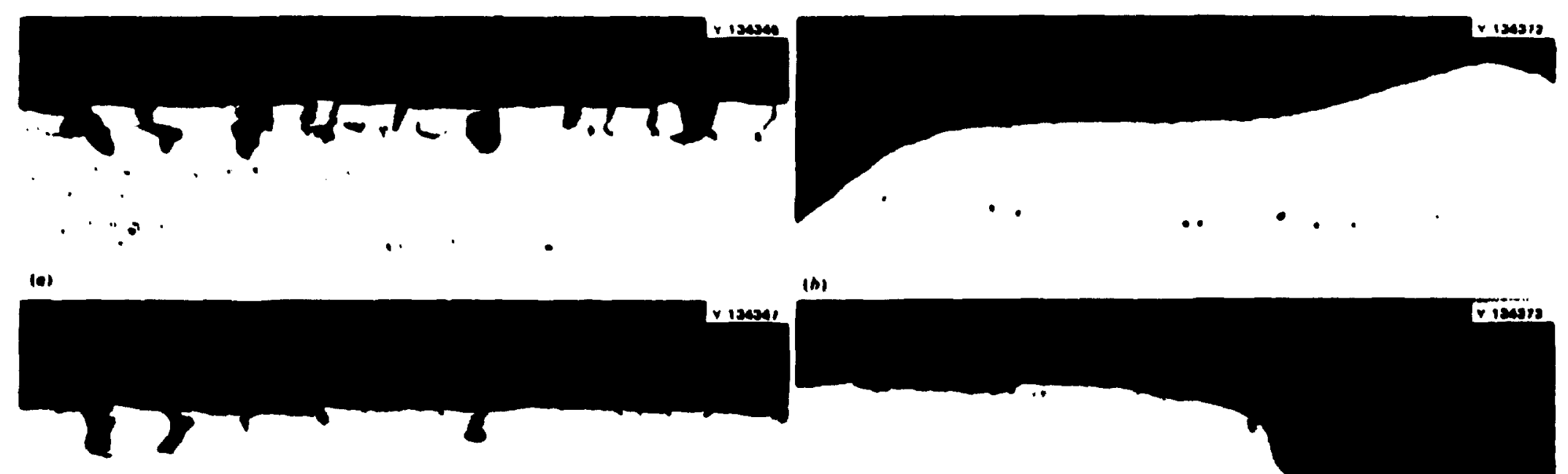

$\because$

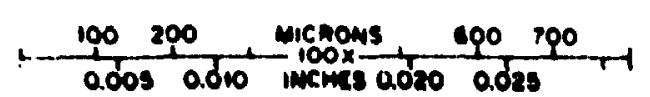

(a)

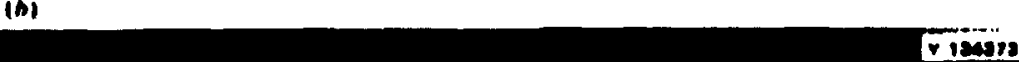

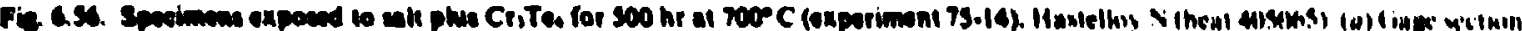

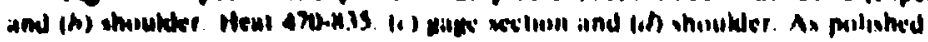

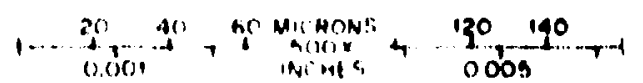


containing onh niobium was more resistant to intergranular cracking (Fig. 6.57). However, both allows formed surtace reaction products and did form cracks.

in experiment 75-16. specimens of several alloys were seaked in a capsule with $\mathrm{Cr}$ :Te, at $700^{\circ} \mathrm{C}$ and exposed to the vapor above the $\mathrm{Cr}$ :Te, for $1000 \mathrm{hr}$. The appearance of the specimens after removal from the capsule (Fig. 6.58) and the high weight gains (Table 6.22) are indicative of the relatively high reaction rate :urther investigation revealed tha: this lot of $\mathrm{Cr}$. Te, had not been sufficienth homogenized since suifixient tellurium was present to be detected by $x$-ray diffraction. Thus the activity of tellurium in this capsule would have been quite high. resulting in the observed high reaction rates. The extent of cracking was yuite severe in this experiment. however there were detectable differences ainong the various alloys. The alloys are ranked on the basis of the profuct of the number and depth of cracks (Table 6.25). The alboys containing additions of 0.45 to $2 r ;$ niobium showed kss extensive cracking. as did Inconel 600 (alloy 600600 ). Alloys containing titanium and various amounts of rare earth elements showed somewhat more cracking. Photomicrographs of the unstressed purions of the alkeys show reaction byers of varyeng thicknesses on all specimens (Fig- 6.59). Photomicrographs of the strained sections of seneral of the specimens are shown in fig. 6.60. The depth and ireyuency of cracking van markedly in the various alloys.

In experiment 75-17 a scandard Hasiclloy $x$ specimen was exposed for $649 \mathrm{hr}$ at 650 C $\mathrm{C}$ to alt containing lite:. Electroctemical probes in this melt failed to indicate the presence of a soluble tellurium species, but the Hastelby $X$ specimen was embrittled sufficiently to form intergranular cracks (Fig. 6.61).

Experiment 75-18 used tellurium metal as a source of tellurium. as was done in several othei expenments: but the tellurium activity was not reproducibie. probably because the emperature of the tellurium metal at $300^{\circ} \mathrm{C}$ could not be controlled. In experiment 75-18. there was little evidence of reaction of the tellurium with the specimens. The specimens atier exposure (fig. 6.62) had the simx colorations present betore inserion into the sapulk. and the weight changes were extremely small i lahk 6.22). The limited supply of telturium into the region of the capsuk where the specimens uste linated probably accounts for anomakous hehavior of this entire group of specimens.

Experiment 75-19 was run to ecamine the influence of chromium content on the extent of cracking ia the basic Haste?loy $N$ alky. four alloys containing Irom 7.4 to $14.5 F_{i}$ chromium were exposed to salt containing $\mathrm{Cr}_{1} \mathrm{Te}_{\mathrm{s}}$ for $500 \mathrm{hr}$ at

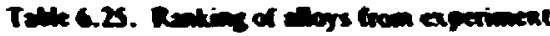

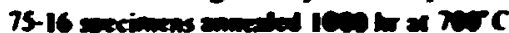

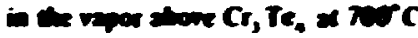

\begin{tabular}{|c|c|c|c|c|}
\hline \multirow{2}{*}{$\begin{array}{l}\text { Findace of momber of cracts } \\
\text { and Juerage epth } \\
\left(\frac{\text { cracks }}{\mathrm{cm}} \times\right)\end{array}$} & \multirow{2}{*}{$\begin{array}{c}\text { Anny } \\
\text { number }\end{array}$} & \multicolumn{3}{|c|}{ (excentration $(F)$} \\
\hline & & Ti & $\mathbf{M b}$ & Oxivet \\
\hline 8712 & 474.533 & 1.75 & & \\
\hline 2003 & $474-535$ & 2.13 & & 0.01 L. $0.030 \mathrm{Ce}$ \\
\hline 6542 & 124 & 1.8 & J.34 & \\
\hline co7s & $474-534$ & 2.07 & & $0.013 \mathrm{~L}$ \\
\hline 5792 & 422 & 1.0 & 2.27 & \\
\hline soss & $471 \cdot 114$ & 1.75 & & \\
\hline 4325 & 421 & 1.9 & 1.04 & \\
\hline $427 n$ & $2 \pi$ & & 2.0 & \\
\hline 4221 & ansous & & & \\
\hline ARAB & $\sin 3$ & 0.49 & $0 \Omega$ & \\
\hline 3916 & 348 & & 0.62 & \\
\hline 3200 & 237 & & 1.03 & \\
\hline 2294 & 417 & & 2.29 & \\
\hline ans & MS & & 0.45 & \\
\hline $\begin{array}{r}1611 \\
611\end{array}$ & $\begin{array}{l}\text { Ca,100 } \\
2,5\end{array}$ & & 0.35 & is Cr \\
\hline
\end{tabular}



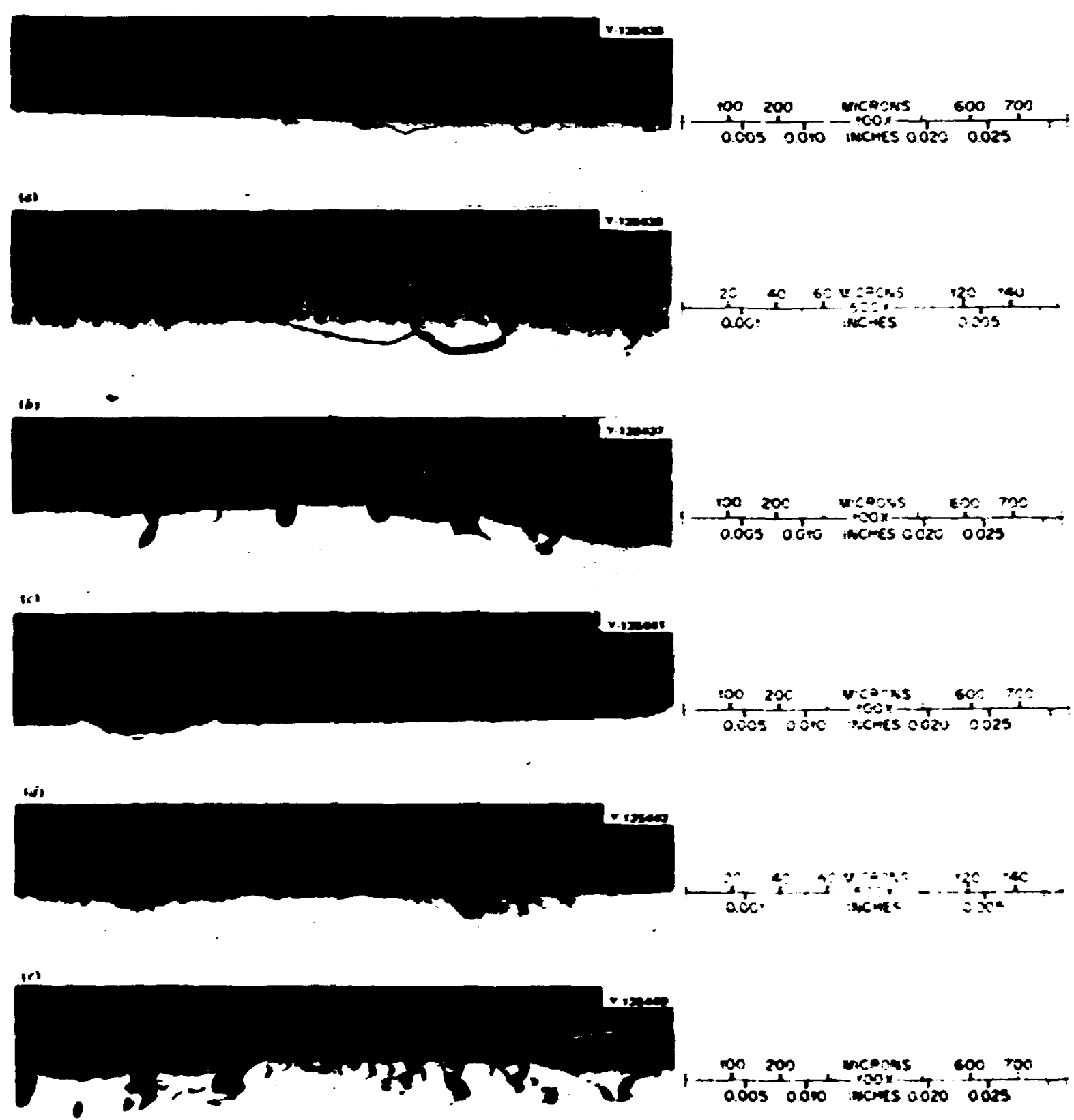

in

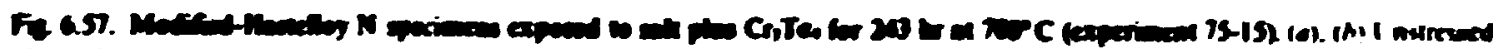

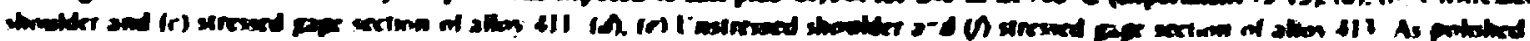




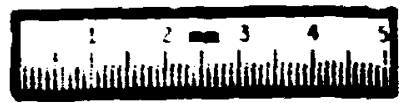

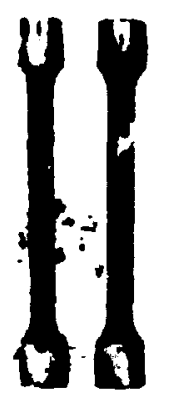

$23 ?$

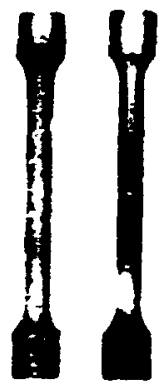

4065

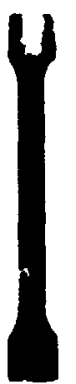

303
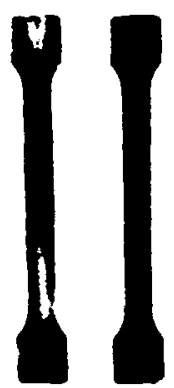

345

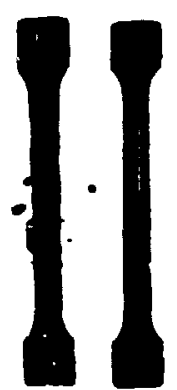

417

421

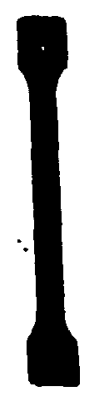

422
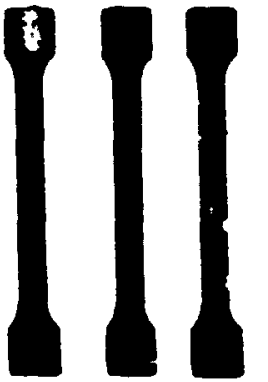

600 600
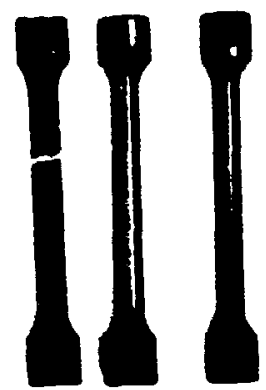

Y.134977

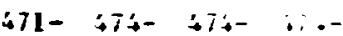

116 i3) ili i;

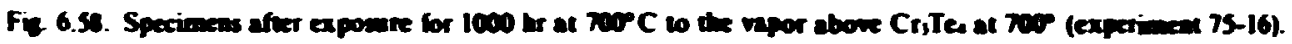

70) $C$. The crack sutistics (Table 6.22) and the photomicrographs ( Fig. 6.63) show that there was no detectable influence of there variations in chromium concentration on the seventy of cracking.

In experiment 75-20. standard Hastelloy $X$ was exposed to salt containing $\mathrm{Ni}$ :Te: at $700^{\circ} \mathrm{C}$. The crack statistics (Table 6.22) and the photomicrographs (Fig. 6.64) show that the material was embritted by the exposure.

In experiment 75-21, standard Hastelloy $N$ was exposed to salt containing $\mathrm{Cr}: \mathrm{Te}_{\mathrm{t}}$ ior $500 \mathrm{hr}$ at 700 C. The specimen was positioned partly in the salt and party in the vapor. The sample cracked extensively. with the cracking being much greater in the portion exposed to salt (Table 6.22 and Fig. 6.65).

In experiments 75-22 and 75-23. three alloys were exposed to the vapor above $\mathrm{Ni}+\mathrm{Ni}$, Te: for $2500 \mathrm{hr}$ at $7(0)$ and 750 - $C$ respectively (fig. 6.66). The cracking statistics ( Table 6.22) indicate several trends that may or may not be significant. The frey uney of cracking is slighty less for all three alloys when exposed at $750^{\circ} \mathrm{C}$ compared with $700^{\circ} \mathrm{C}$. The depth of cracking anpears greater at $750^{\circ} \mathrm{C}$ for two alloys and less for one alloy. A clear trend at both conditions is that alloy 295. which contains $0.85 \%$; niobium. formed fewer and shallower cracks than the other iwo alloys (Figs. 6.67 and 6.64).

In experiment 75-24, nine alloys were exposed for ?X7 hr at 700 C to the vapor ahove tellurium metal at woy (. These specimens all exhibited small weight gains and shaliow crack formation (Table 6.22). The alloys are ranked in Table 6.26 on the basis of the product of crack frequency and depth. Alloys 450 and $518 \mathrm{had}$ the poorest resistance to cracking. All the alloys with niobium additions but not titanium had good resistance to cracking. No systematic variation with nicbium content was detected. probably because of the very limited extent of cracking in this rather short expesure. Alloys 523 and 524. which contained more than the normal $7 C_{\text {; }}$; chromium. did not appear particularly good in this test. Typical appearances of the specimens from this experiment are shown in Fig. 6.69.

Although these experiments involved several techniques and methods $f_{\text {. }}$ - mosung specimens to tellurium-containing er. vironmet. 's. they lead to four important conclusions.

1. Hastelloy $\times$ modified with about 0.5 to $2 r$; niobium has good resistance to embrittkment by tellurium.

2. Hastelloy $\mathbf{N}$ modified with niobium and titanium has poor resistance to embrittkment. indicating that titanium courteracts the beneficial effects of niobium.

3. Although Inconel 600. which contains 16 $\%$ chromium. exhibited good resistance to tellurium cmbrittlement. Hastelloy $\mathbf{N}$ modified to contain i5\% chromium was not resistant to embrittlement by tcllurium.

4. A!though a soluble tellurium species was not detected by electrochemical techniques in any of the salt-telluride mixtures. standard Hastelloy $N$ was embrittled in all such systems. 

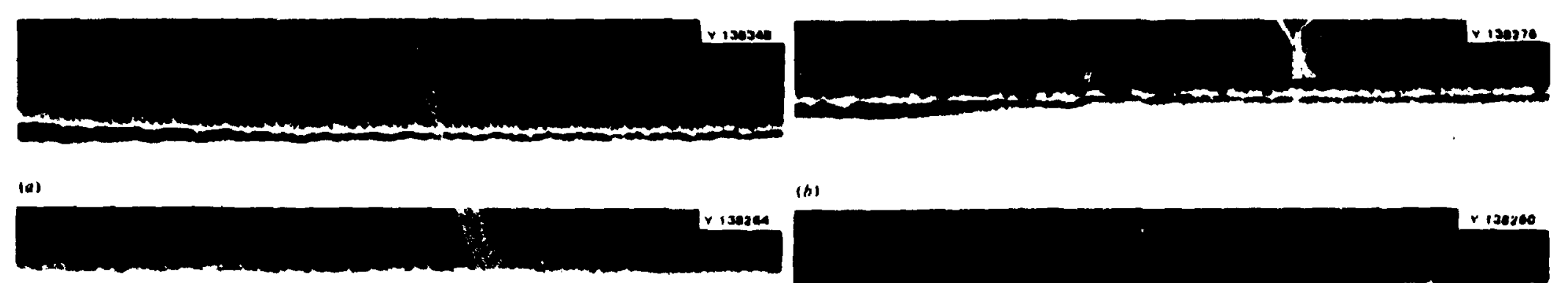

(b)

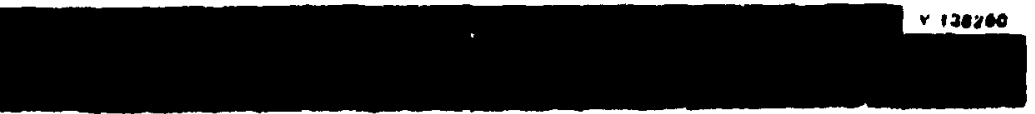

|c|

(d)
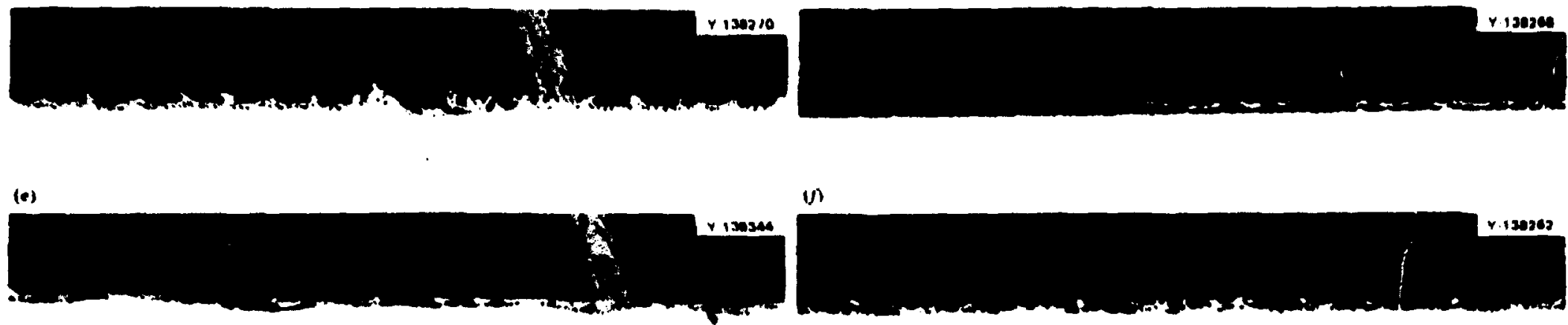

(a)

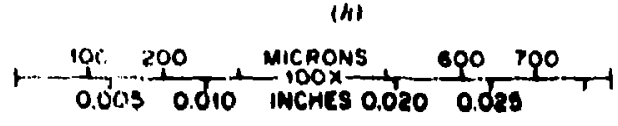

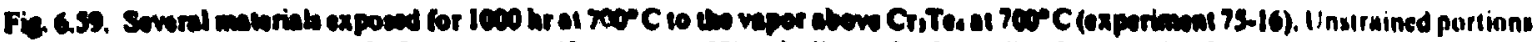

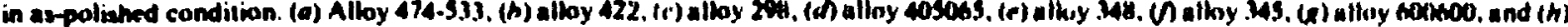
alluy 293. 


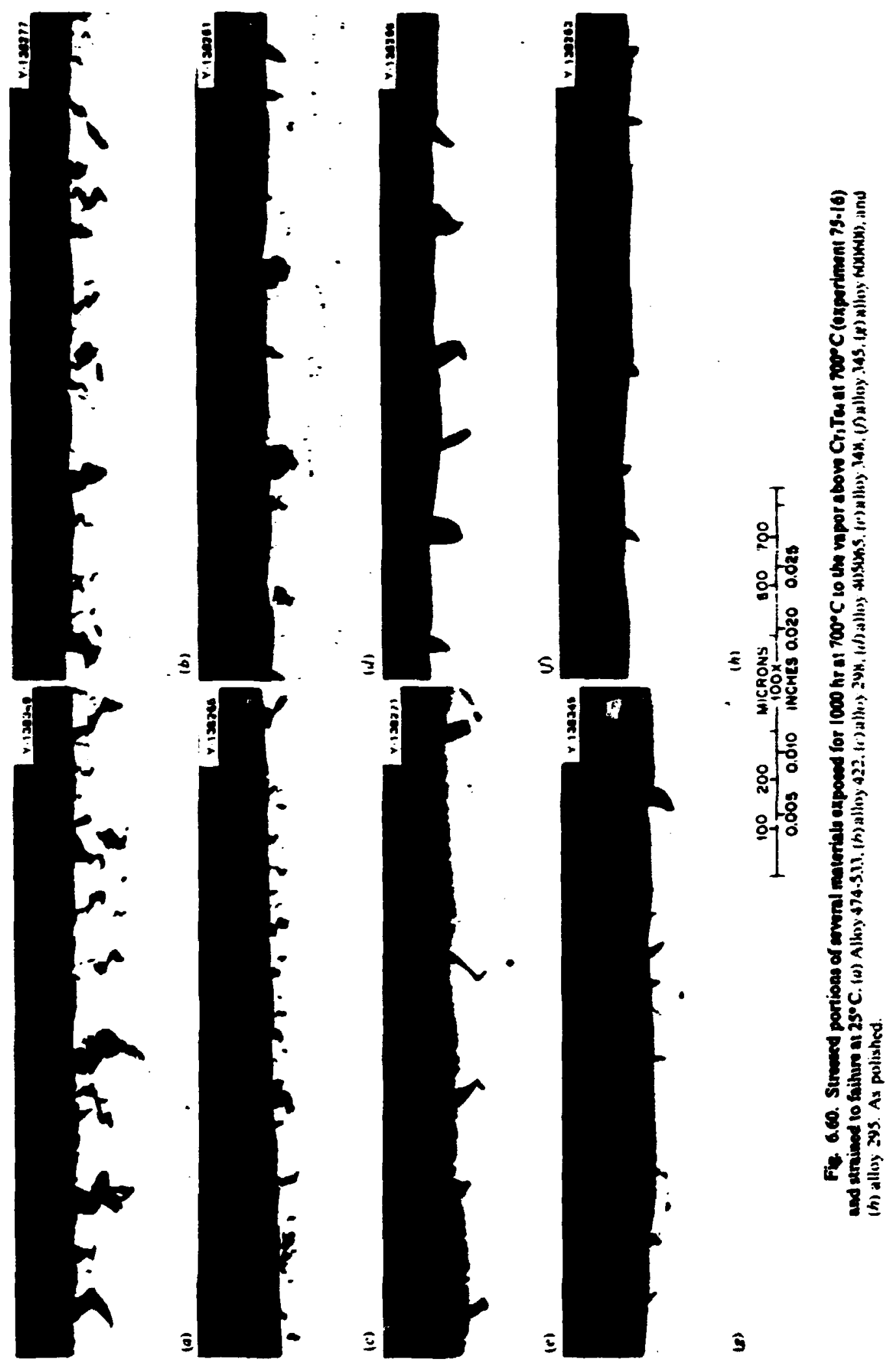




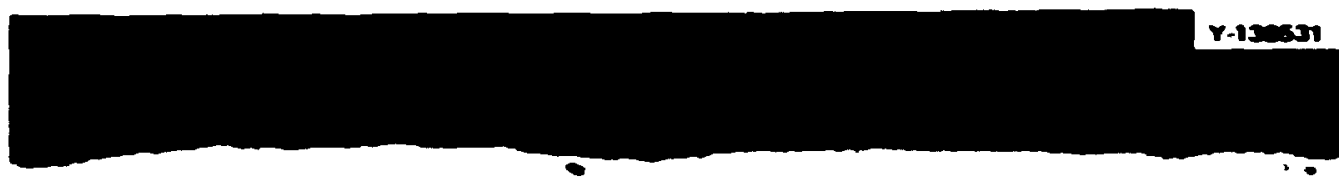

(a).

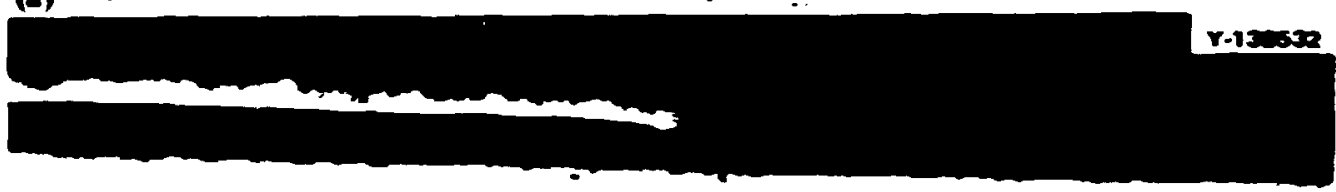

(b)
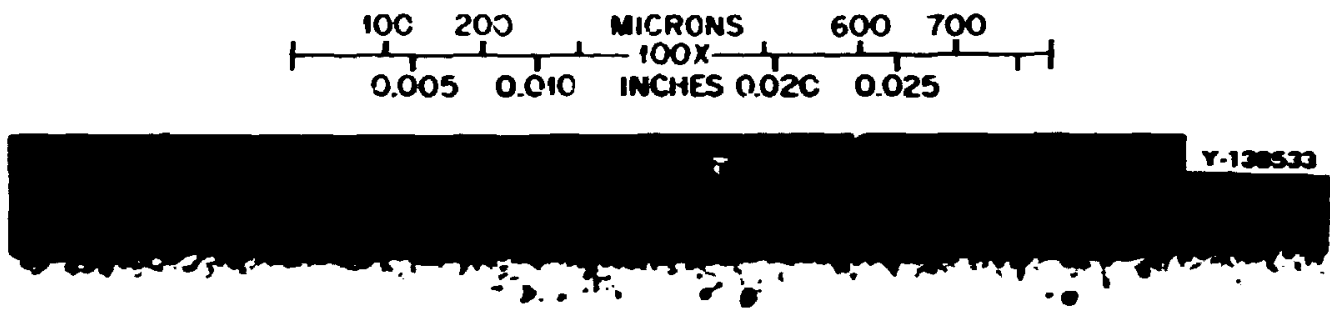

(c)

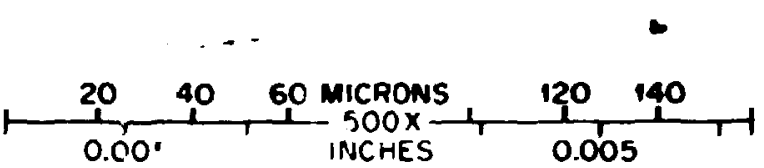

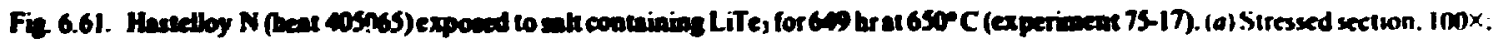
(h) unstressed section. 100X: (c) unstressed section, $500 \times$.

\subsection{SALT-TELLURIUM CREEP STUDIES}

\section{T. K. Roche}

B. McNabb

J. C. Feltner

The eight creep-rupture machines for testing in MSBR nuoride salt (LiF-BeF?:-ThF 4 -UF 4 , 72-16$11.7-0.3$ mole \%) are all now in operation. The test program has been set up to run duplicate tests on each alloy. one specimen being tested in clean salt and the other in tellurium-containing salt to obtain an indication of susceptibility to embrittlement while under stress in the presence of tellurium. Tellurium is supplied to the salt by additions of milligram quantities of $\mathrm{Cr}, \mathrm{Te}_{4}$ through valves in the top of each salt chamber. Provision has been made for salt sampling during the course of a test by drawing a small quantity into a copper tube that can be inserted into the chamber and pushed below the salt level. Also. these machines have been equipped with electroshemical probes for making voltammetric measurements to monitor $\mathrm{U}^{\text {s* }} ; \mathrm{U}^{\text {'" }}$ ratios of the salt (Sect. 5.1, this report). 


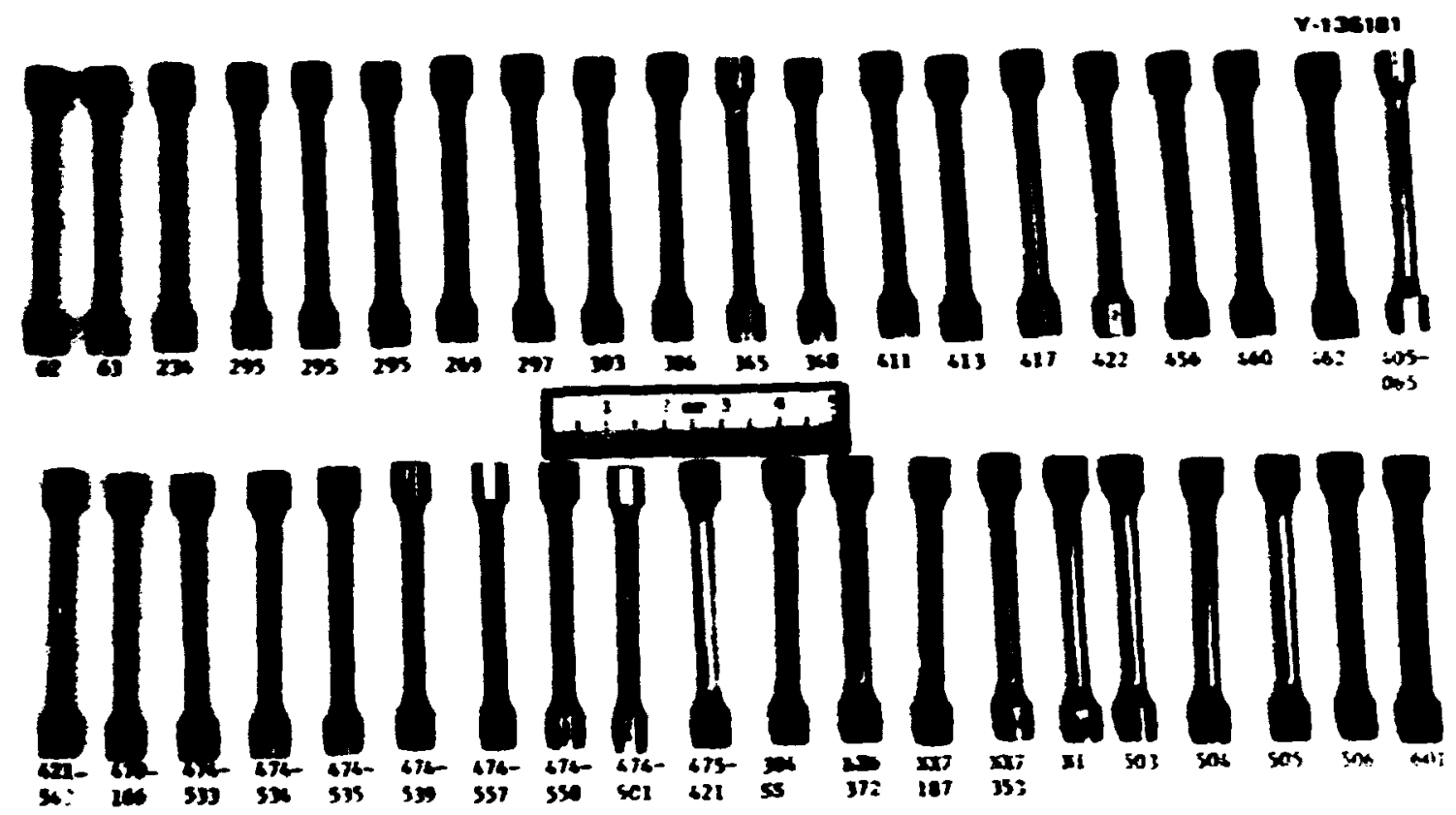

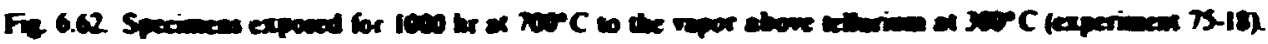

\begin{tabular}{|c|c|c|c|c|}
\hline \multirow{2}{*}{$\begin{array}{l}\text { Product of number of cracks } \\
\text { and arerapse depth } \\
\left(\frac{\text { cracts }}{\mathrm{cm}} x_{\mathrm{m}}\right)\end{array}$} & \multirow{2}{*}{$\begin{array}{l}\text { Alloy } \\
\text { number }\end{array}$} & \multicolumn{3}{|c|}{ Consentration $(\pi)$} \\
\hline & & $\mathbf{C r}$ & $\mathbf{T i}$ & $\mathbf{N b}$ \\
\hline 1095 & 450 & 8.1 & 2.1 & \\
\hline 634 & 518 & 7.18 & 0.95 & 0.96 \\
\hline 351 & 524 & 15.20 & $<0.02$ & 0.69 \\
\hline 194 & 516 & 7.30 & $<0.02$ & $<0.10$ \\
\hline 150 & 523 & 10.40 & $<0.02$ & 0.47 \\
\hline 86 & 513 & 7.20 & $<0.02$ & 0.45 \\
\hline 80 & 514 & 7.05 & $<0.02$ & 0.69 \\
\hline 59 & sis & 7.20 & $<0.02$ & 0.20 \\
\hline 25 & 517 & 7.10 & $<0.02$ & 1.10 \\
\hline
\end{tabular}

At present. all tests are being earried out at $650^{\circ} \mathrm{C}$ and $30.0 \times 10^{3} \mathrm{psi}$. The alloys include both titaniumand niobium-modilied Hastelloy $\mathbf{N}$. Two tests have been completed on specimens of $2 \%$ titaniummodified Hastelloy $\mathbf{N}$ (heat 74-533). A tesi in clean salt and its counterpart in tellurium-containing salt were discontinued after $4175 \mathrm{hr}$ and $2380 \mathrm{hr}$ respectively. Approximately $150 \mathrm{mg}$ of $\mathrm{Cr}_{1} \mathrm{Te}_{4}$ was added to the tellurium-containing salt test in a series of three additions. About this same quantity has also been added to other tests in progress. The salt from these tests has been sampled for analysis, but results are incomplete. Time-dependent strain measurements recorded for tests completed or still in progress in the salt environment are presented in Table 6.27. The differences observed for any one alloy eitier with or without tellurium being present are not considered significant. The most significant part of these tests will be the posttest metallographic examination to determine the crack severity. 


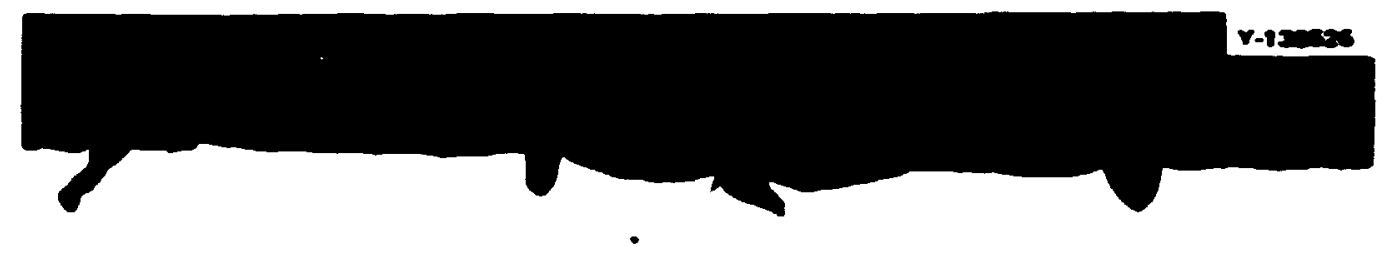

(a)

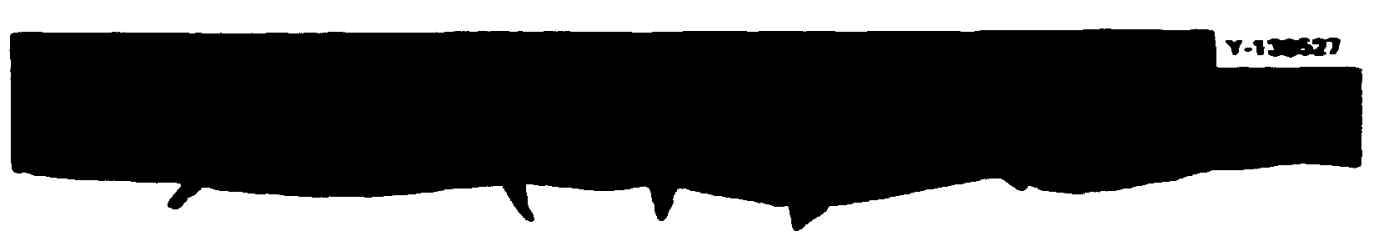

(b)

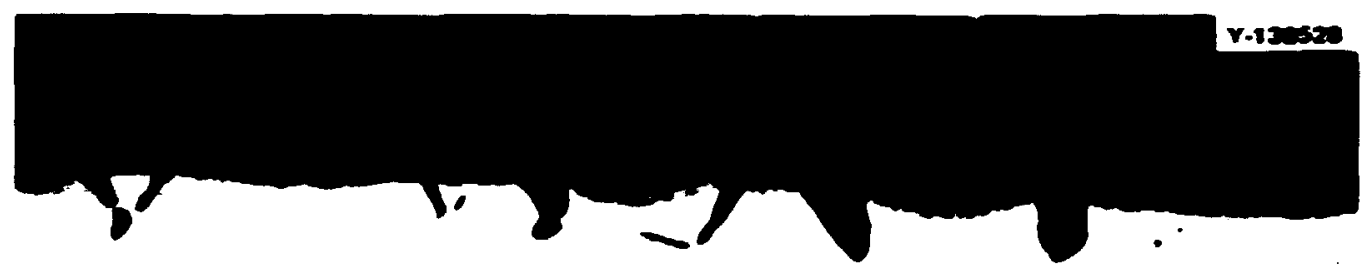

(c)

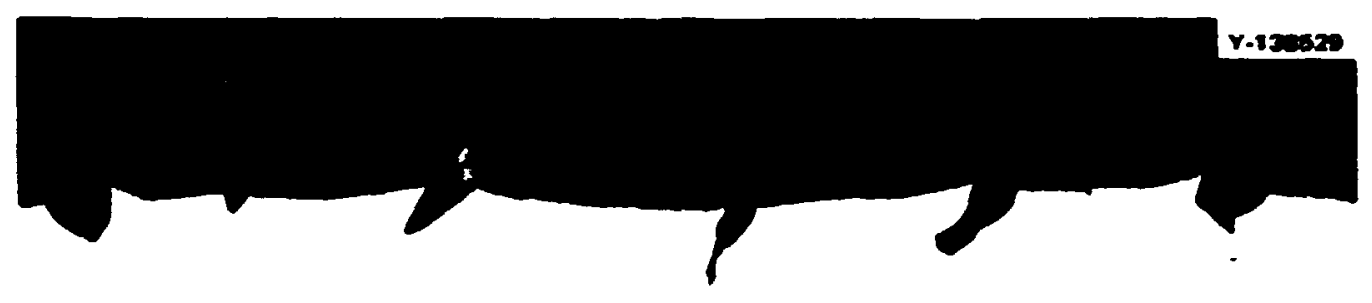

(d)

$$
\begin{array}{lllll}
100 & 200 & \text { MICRONS } & 600 & 700 \\
0.005 & 0.010 & \text { INCHES } 0.0200 .025
\end{array}
$$

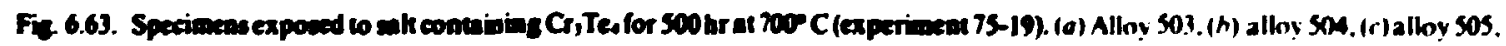
and in alloy SWh. 


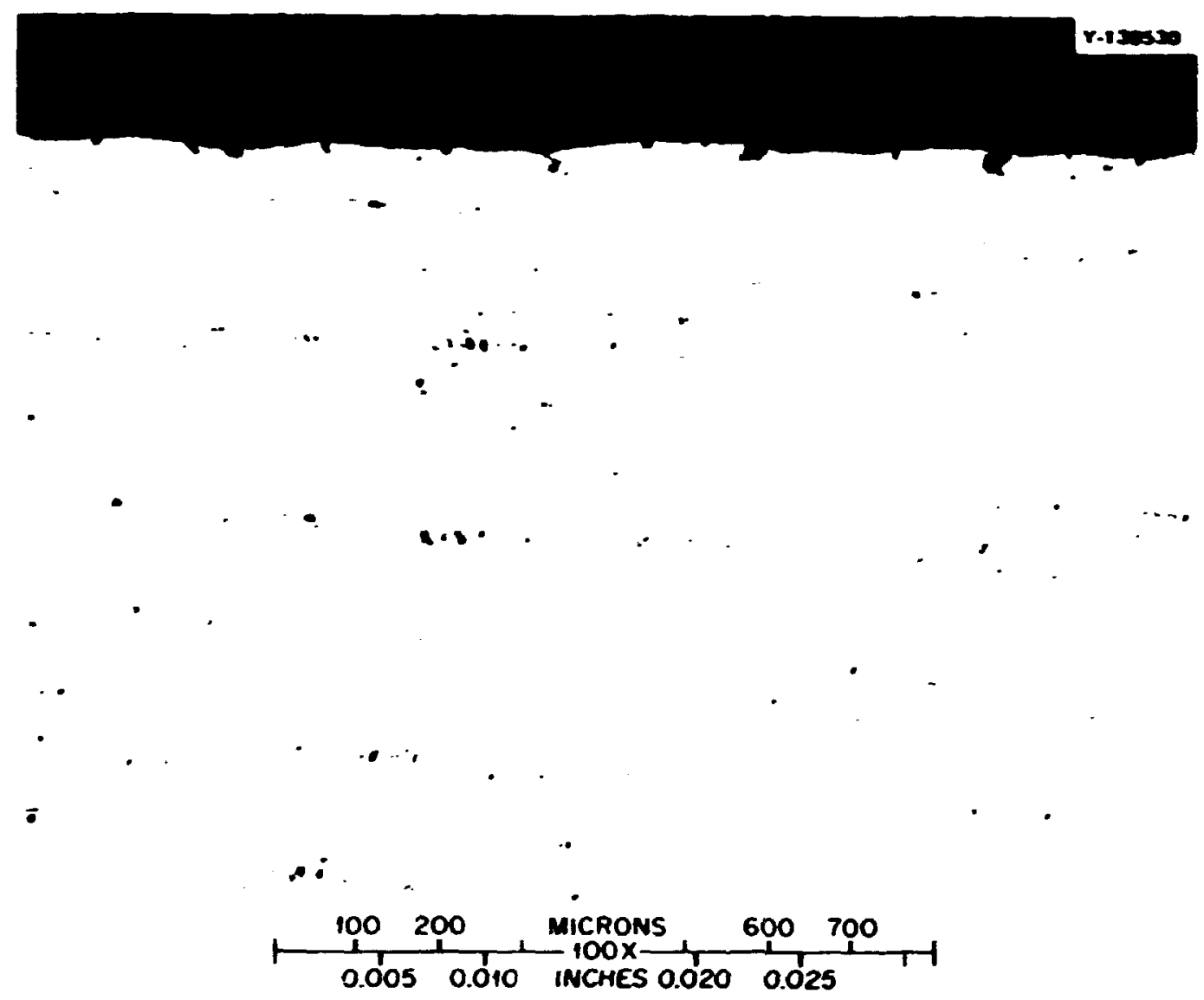

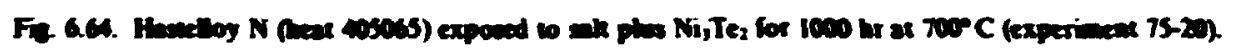

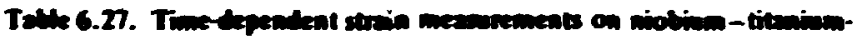

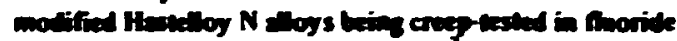
alt at 650 C. $30 \times 10^{3} \mathrm{mo}$

\begin{tabular}{|c|c|c|c|c|c|c|c|c|c|c|c|c|}
\hline \multirow{2}{*}{$\begin{array}{c}\text { Heal } \\
\text { number }\end{array}$} & \multicolumn{2}{|c|}{$\begin{array}{l}\text { Compasition" } \\
(\text { wI } ; n)\end{array}$} & \multicolumn{10}{|c|}{ Timedependent strain after indicated hours (7) } \\
\hline & Nb & $\mathbf{T i}$ & 100 & 250 & 500 & 1000 & ISOO & 2000 & 2500 & 3000 & 3500 & 4000 \\
\hline $\begin{array}{l}474-533 \\
474-533^{c}\end{array}$ & & 2.17 & 0.21 & 0.45 & 1.35 & 3.07 & 3.93 & 4.93 & 5.72 & 6.45 & 7.15 & $7.79^{b}$ \\
\hline $474-533^{2}$ & & 2.17 & & 0.33 & 1.55 & 3.26 & 4.36 & $5.43^{*}$ & & & & \\
\hline 421543 & 0.7 & & 0.23 & 0.27 & 0.45 & 0.89 & 1.46 & 2.04 & 2.76 & 3.49 & 4.23 & \\
\hline $421543^{c}$ & 0.7 & & 0.07 & 0.11 & 0.27 & 0.81 & 1.33 & 2.00 & 2.73 & 3.54 & 4.28 & \\
\hline 411 & 1.15 & & 0.30 & 0.38 & 0.60 & 1.16 & 1.76 & 2.49 & 3.33 & 4.17 & 5.05 & \\
\hline $411^{r}$ & 1.15 & & 0.46 & 0.57 & 0.66 & 1.15 & 1.63 & 2.22 & 2.88 & 3.62 & 4.40 & \\
\hline 413 & 1.13 & 0.9 & -0.09 & 0.01 & 0.36 & 1.46 & 2.28 & 3.14 & 3.96 & 4.70 & 5.59 & \\
\hline $413^{c}$ & 1.13 & 0.9 & 0.05 & 0.08 & 0.57 & 1.47 & 2.16 & 2.78 & 3.46 & 4.21 & 4.96 & \\
\hline 62 & 1.9 & & 0.26 & 0.42 & 0.89 & 1.87 & & & & & & \\
\hline $62^{5}$ & 1.9 & & 0.14 & 0.21 & 0.50 & 1.29 & & & & & & \\
\hline
\end{tabular}




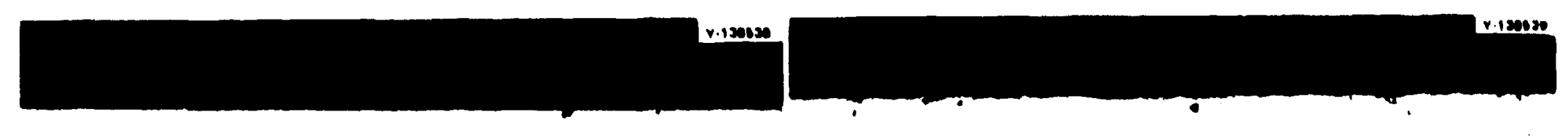

(e)

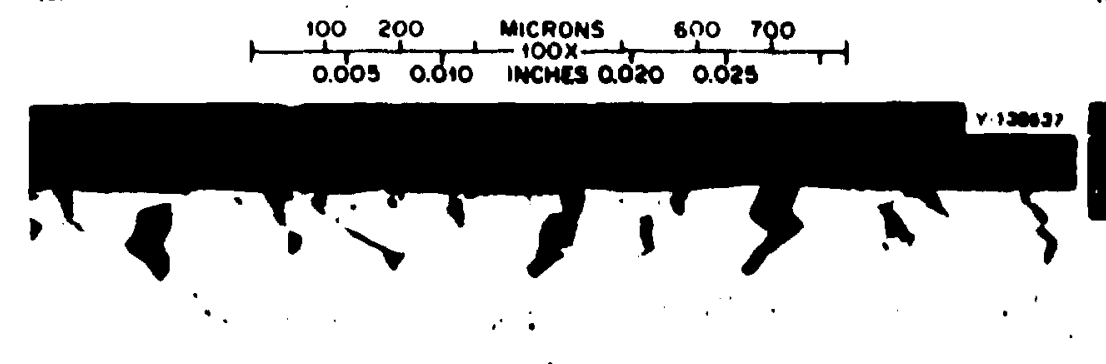

(s)

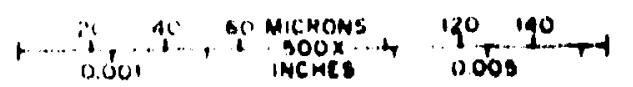

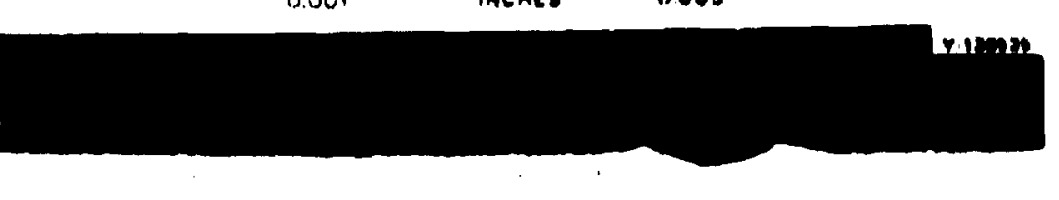

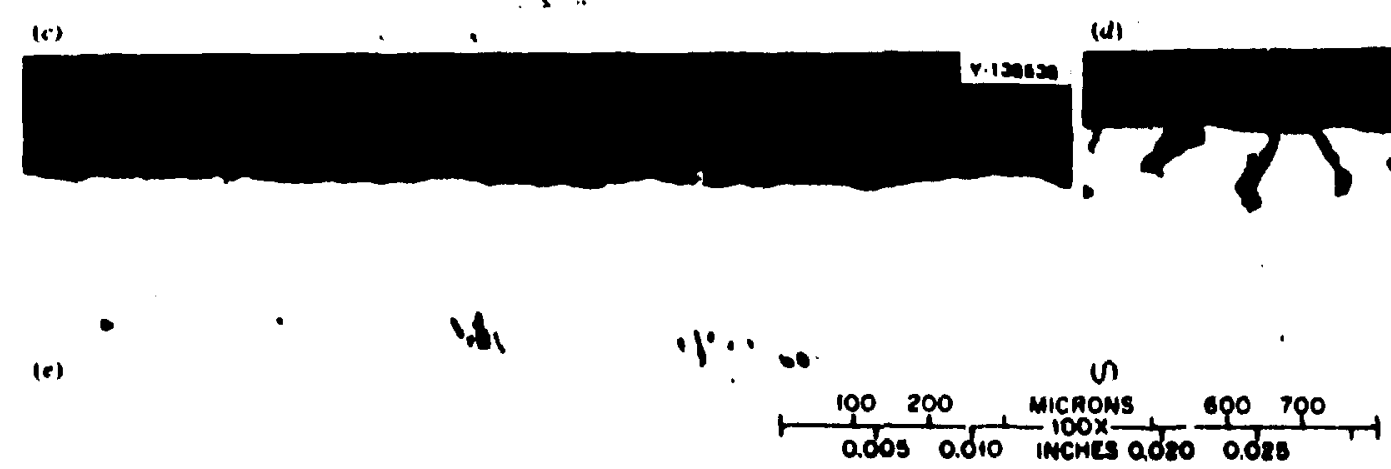

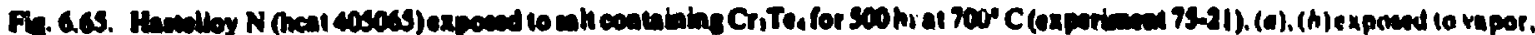

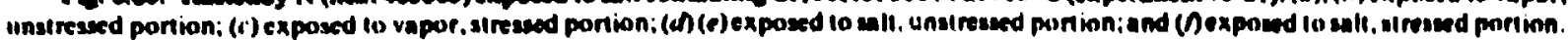



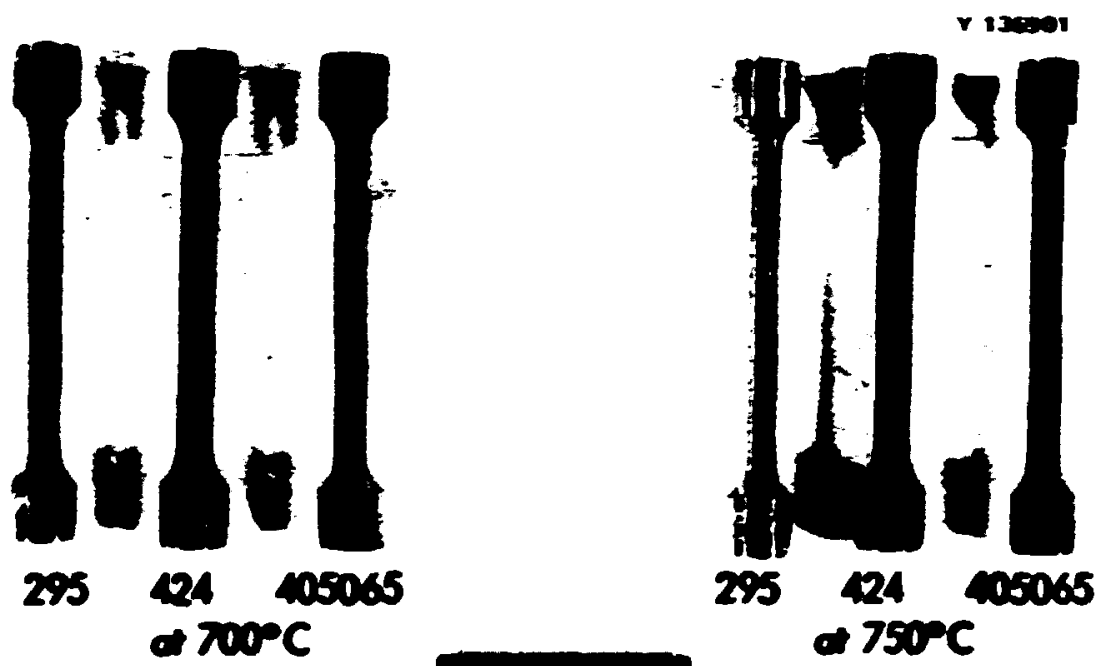

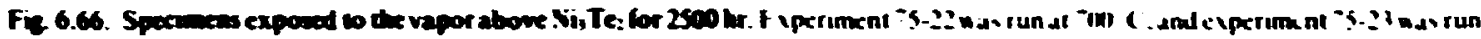
af ". 4
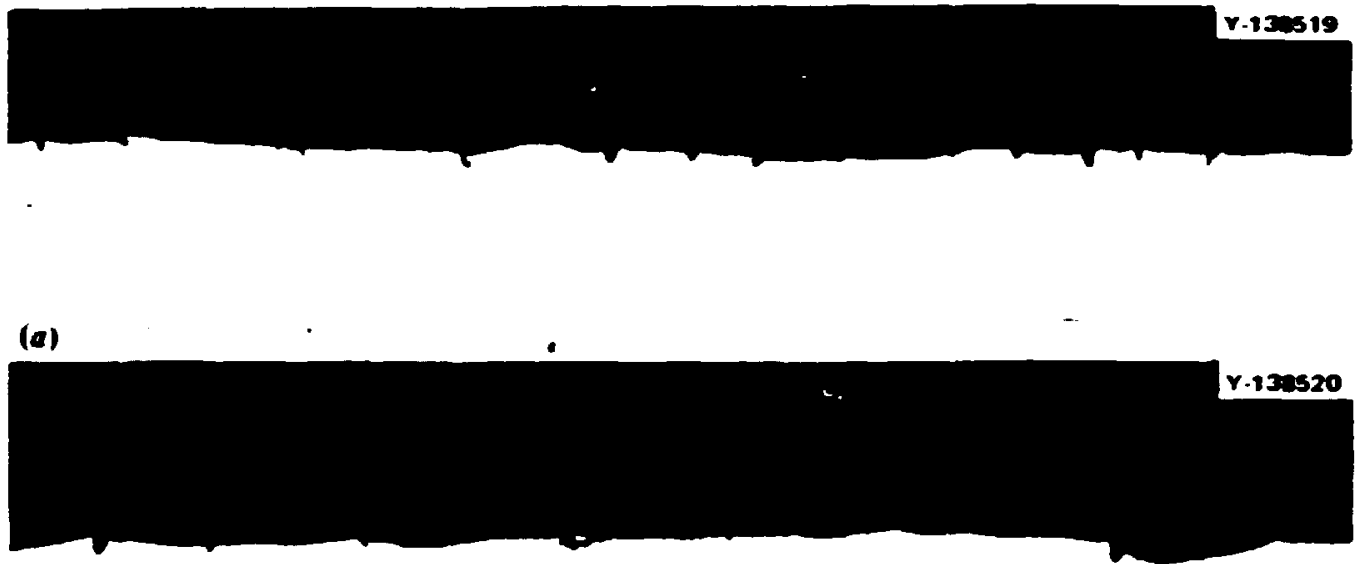

(b)

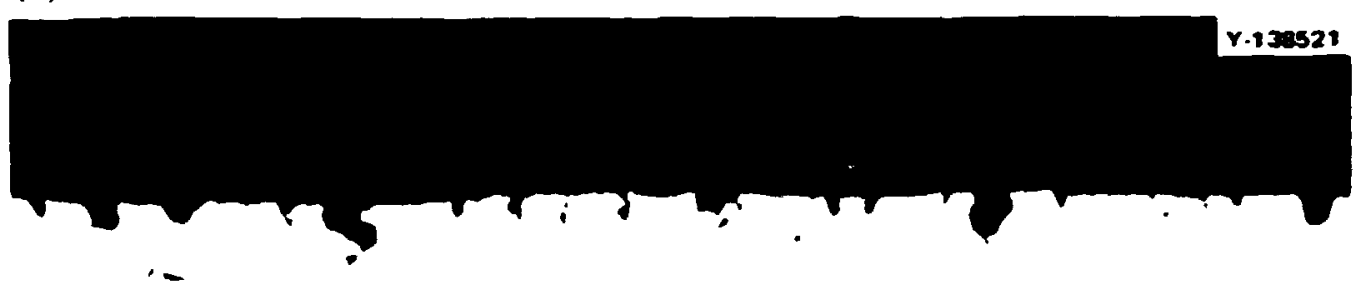

(c)

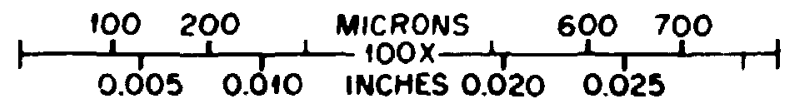

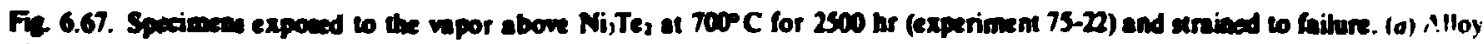
40Sins, (h) alloy 295. and (r) alky 424. As polished 


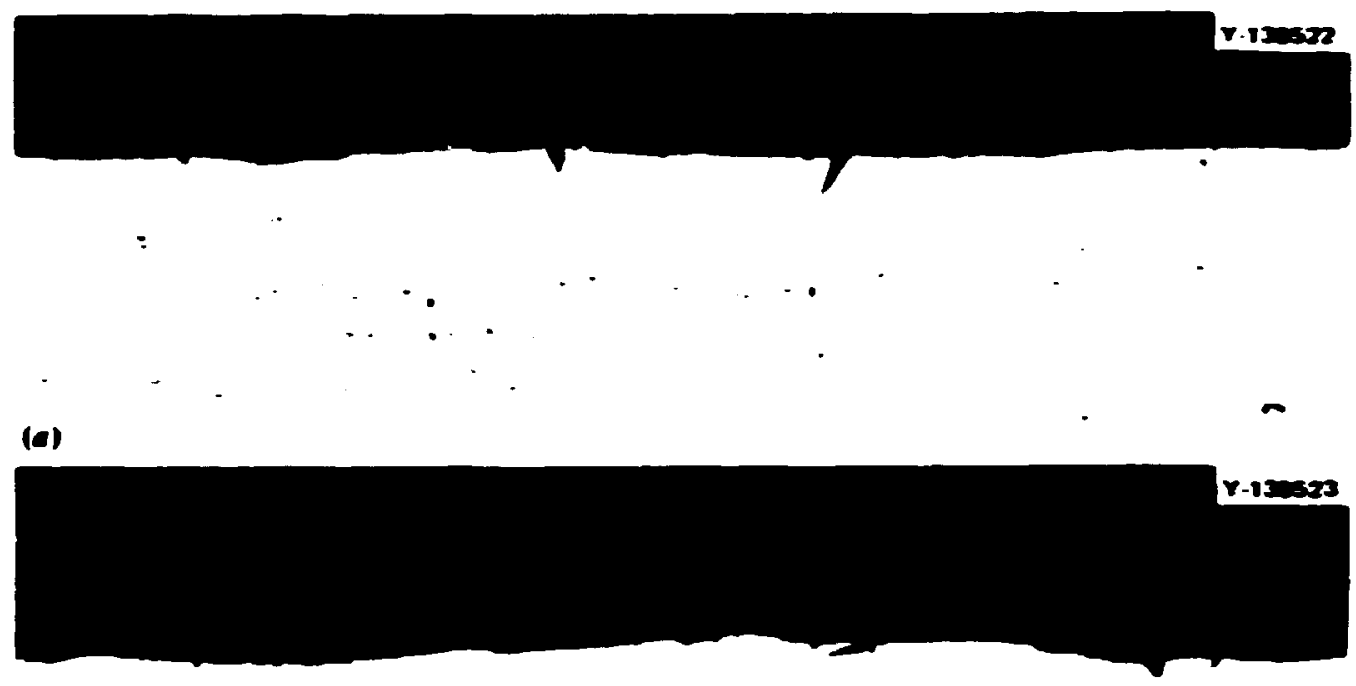

(b)

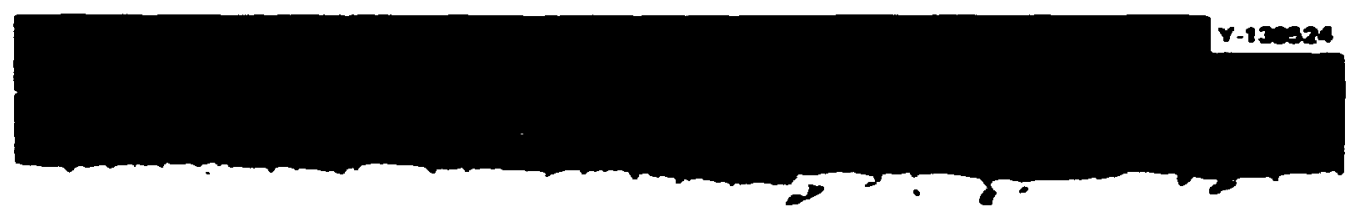

(c)

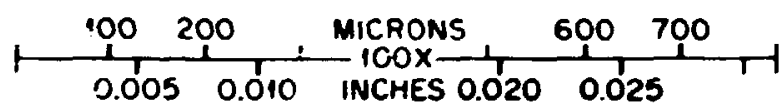

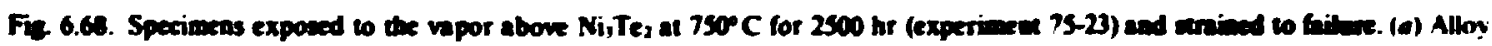
40SOh5. (h) alkn 295. and (c) allon 424. As poished

\subsection{SALT PREPARATION AND FUEL PN FILLING FOR MSR PROGRAM CAPSULE IRRADIATION EXPERIMENT TECen-2}

\section{R. Bennell A. D. Kelmers}

Fueled irradiation experiments were initiated in 1972 to investigate the behavior of fission products, particularly tellurium. on structural materials being considered for the Molten-Salt Breeder Reactor. The fuel pins were made of 4-in. lengths of '/:-in.-diam lubing of the varinus alloys under investigation and were filled with fuel salt containing " "U. Preparation of these fuel pins required that a suitable salt charge be prepared and transferred into the fuel pins and that the fuel pin be separated, seaked. and inspected for subsequent irradiation. Because of the use of ${ }^{23 \prime} U$, these pins were prepared in a glove box in the Plutonium Laboratory of the Metals and Ceramics Division.

The first fuel pins were prepared in 1972. bo' $i$ the MSR Program was discontinued before the pins were irradiated. The glove box was retained. but much of the equipment was disposed of. When the MSR Program was reinstated in 1974. the facility for 


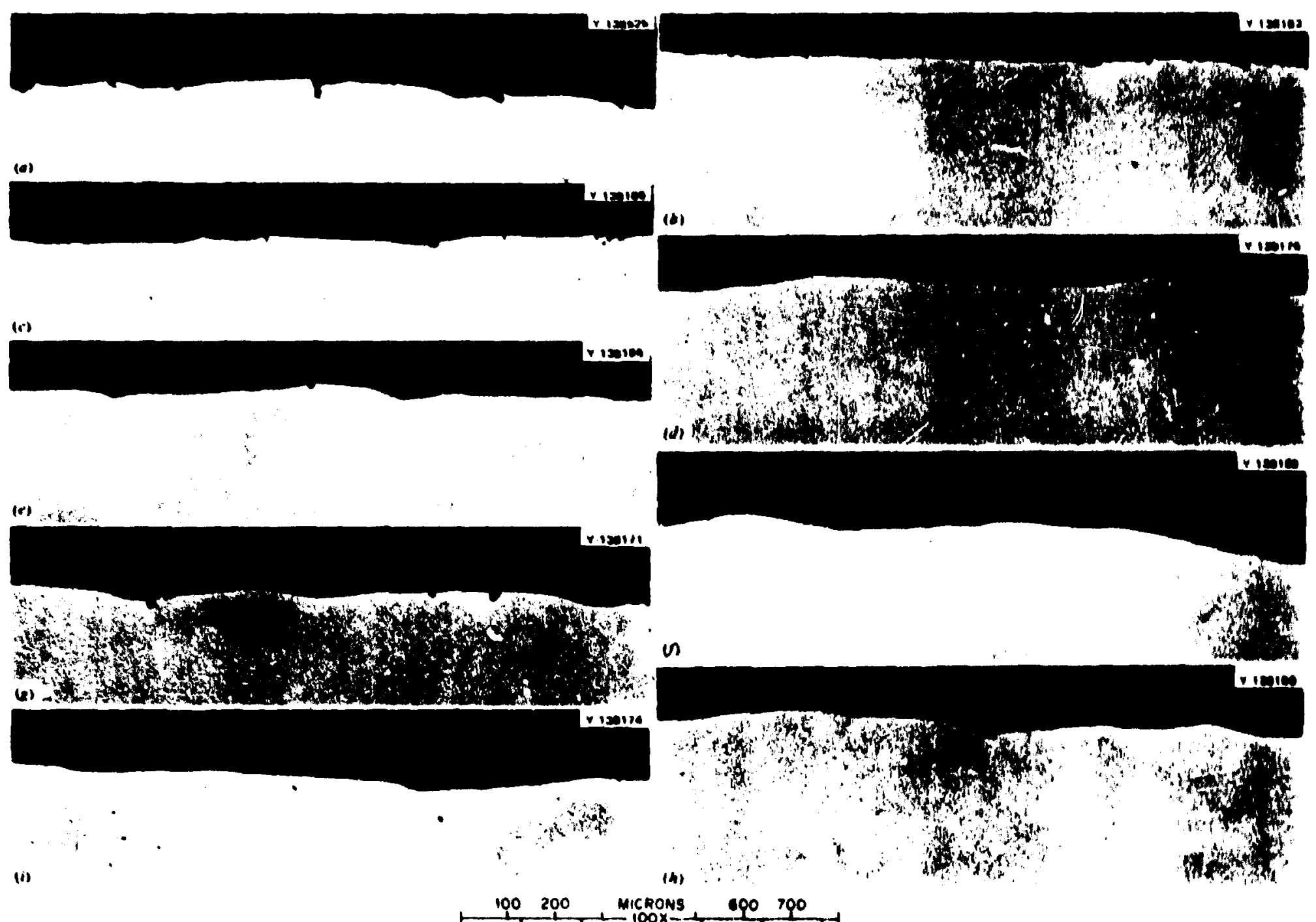

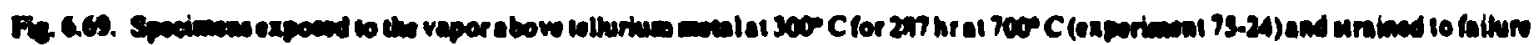

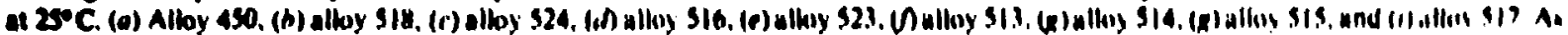
polisured. 


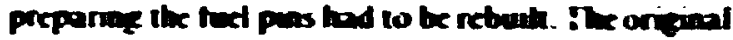

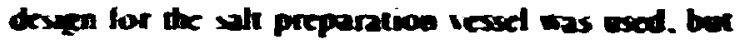

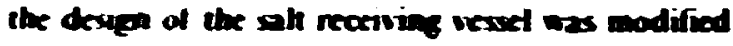
comsicraty.

Oac baich of ah was prepaned for follig severd pies. The indrideal sets of pins (six exh) were asserubled in the sale receiving resol by C. $C$. Dromes and J. N. Woods of the Meals and Ceramics Division. De operating wort associnted wh the sath preperation and filliag the pins wes done by W. B. Stives and W. H. Millet of the Metals and Ceramics Division. Various chemical analyses of the salt were performed by mezubers of the Analytial Chemistry Division. The filled fuel pins were made arailabte to C. R. Hymen of the Reactor Division for assembly into an irrediation capsule.

The following material will cover the preparation of the salt and the filling of the fucl pins for TeCen-2. There are several other experiments in this series. and some of the details conceming these experiments will be discussed in Sect. 6.15.

\subsubsection{Sah Prepantioa}

The Auoride fuel mixture for the TeGen-2 experiment was prepared in a nickel reaction vessel
Ebricated from a 10in. lemath of $2-7$. IPS. setwedele of pipe in acoondance with DwE M-1C6/3RM-0ME (Fis- 6.70). Following rocipt of the vessel. in was instined in the fowe box funace well if Feel

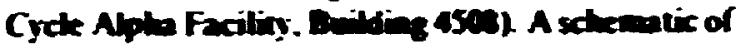
ine apperates is show in F \& 6.71. and a photograph of the pas detivery system is stown in Fy- 6.72 Prepantions were then ande for boding the foet mixterx. The conl feel mixture (714 g) coasised of 60 garriet alt. Lif-DeF-ZrF.165.4-29.6-5.6mole FX 73.0 8 :"LF and 41.18 " UO. The carriet salt convinad hafoinm-free $\left(20\right.$ ppon $Z_{r F}$ and isotopieally pure (S9.9+C) Li The "LO-contained less thas 7 ppon $:$ : $v$.

The following procedure wes ased to minimis contamination of the glovebox and component equipment duringaddition of the UF and $\mathrm{UO}$ :- Four 6 -in. knyth of ${ }^{t}-\mathrm{in}$. OD metal tubing were inserted into appropriate kngths of flexibit tygon tubing and taped together securely. These. in tum. were taped securely to polyethylene bottles. two containing ite carriet salt (half, or $300 \mathrm{~g}$. in each bottle) and the remaining two bottles containing the UF, and $\mathrm{UO}$. B) then adding the contents of each bottle through the large riser of the receiving vessel in the order (1)

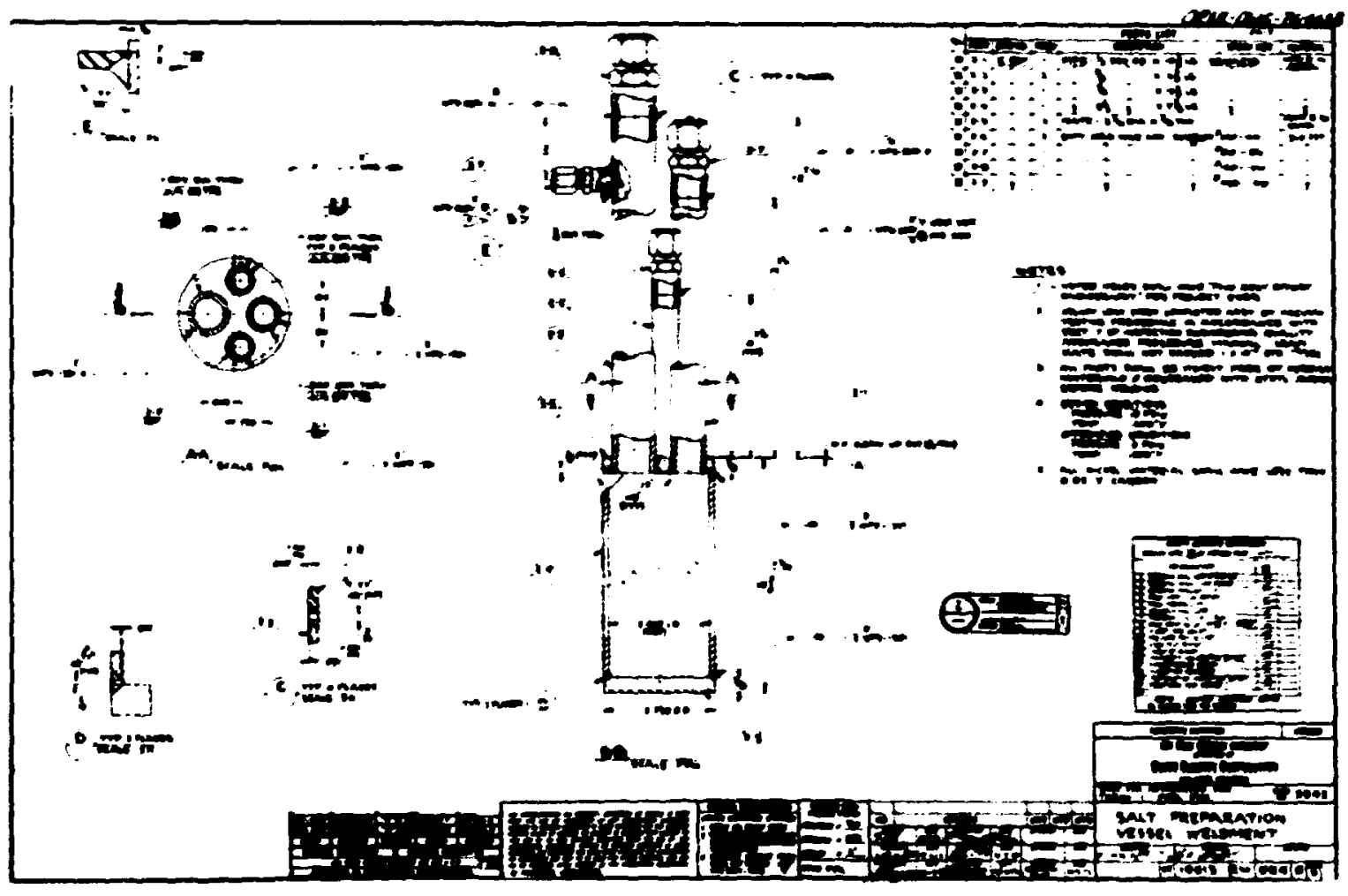

Fit 6.T. Sall prepantion 


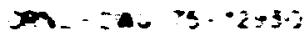

FLOW DUAGRAM FOR TEGEn-2

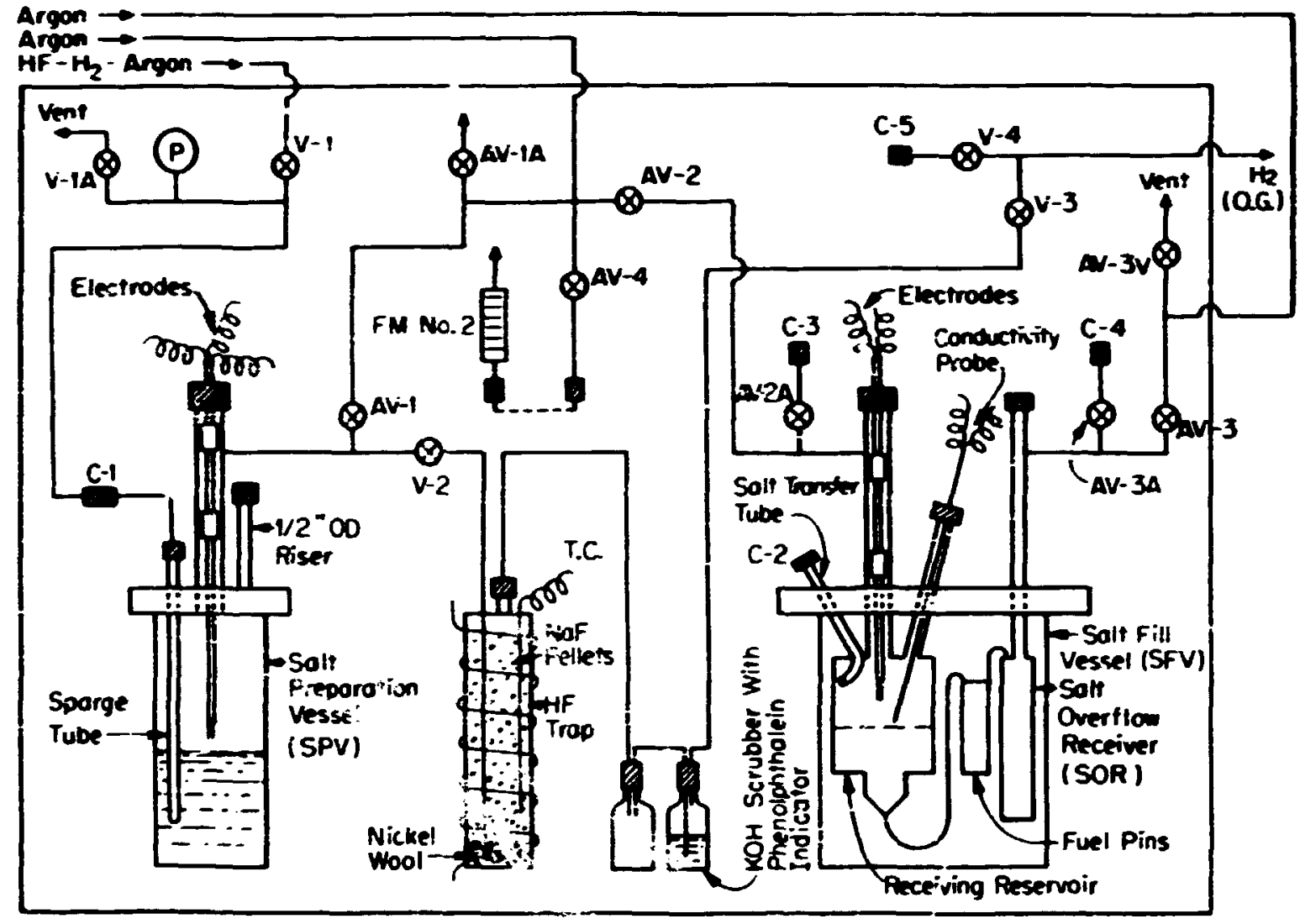

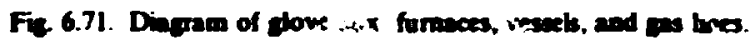

carrier salt. (2) $\mathrm{UO}$., (3) UF, and (4) carrier salt, the UF, and UO, were effectively "scrubbed" from the inside walls of the riser and covered with a layer of carrier salt.

After the riser-tube was recapped. the salt mixture was heated to $600^{\circ} \mathrm{C}$ (melting point of $450^{\circ} \mathrm{C}$ ) under $\sim 200$ sccm argon flow and sparged for $\mathrm{l} \mathrm{hr}$ in preparation for elect rochemical measurements of the oxide content of the salt by petionnel of the Analytical Chemistry Division. The oxide measurement was done by retractir.g the sparge tube and lowering a gold-iridium electrode to a depth of ${ }^{\prime}:$ in. into the molten salt. The volt-ammograms obtained from these measurements were for calibration of an experimental oxygen procedure and were not used in the TeGen-2 preparation.

\subsubsection{Hydrofluorination}

After the voltammetric measurements were made. the sparge tube was lowered into the salt mixture. and a $\because$-hr hydrofluorination was carried out at $600^{\circ} \mathrm{C}$ Uill: HF-H : (20-80 mole $;)$ mixture at a fow rate of $S(x) x$. The procedure stipulated a hydronuorination tim. of $48 \mathrm{hr}$ : however, time scheduling necessitated res'lcing this to $36 \mathrm{hr}$. At the end of this time. the HF and $H$. nows were cut off. and the salt was sparged with argun a' about 500 secm for 12 hi to remove dissolved HF. Iuv samples of the salt melt (one filtered and one unfiltcret) were then caken and submitted to the Analytical Chemistry Division for an isotopic uranium assay. Bäsurement of the $\therefore U$ :"U ratio, and determination or the concentrations of tntal U. Fe, $\mathrm{Ni} . \mathrm{Cr}$, and oxite.

The aralytical results for the uranisin inventory (Tables 6.28a.h. and, ) were in excellen: agreement with the theoretical values, showing less ian 10r; deviation. The discrepancies observed in the $1_{i}$, in and total oxide analyse are difficult in evalusic. It appears unquestionable. however, that oxidstion nccurred at some point during analysis of the $\mathrm{N}_{\mathrm{i}}$. I 


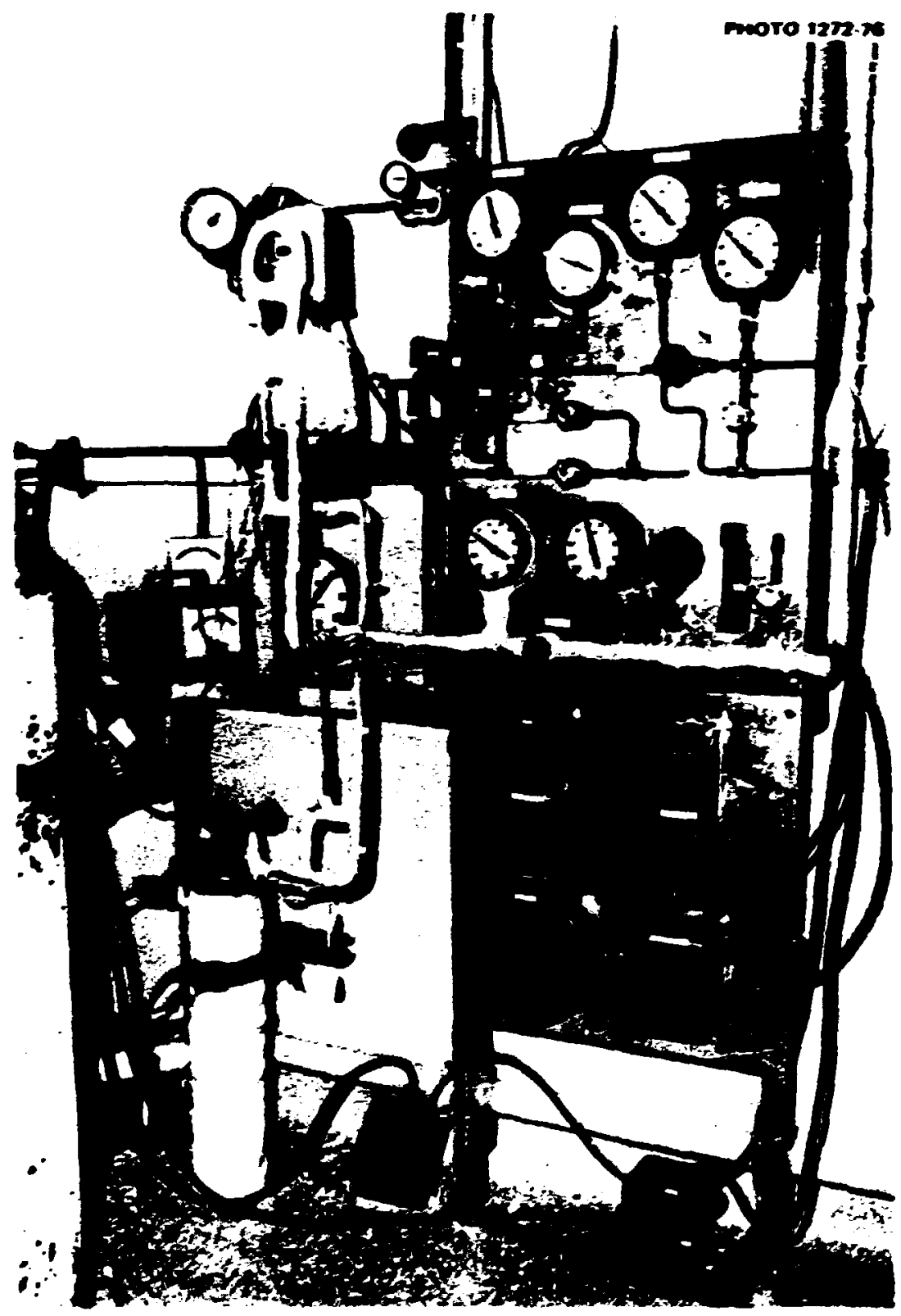

Fin. 6.72. Ges delivery gywem.

samples since the Vin. 2 samples with considerably lower oxide values were duplicates taker five days later.

In both cases the oxide conient was ton high to continue with the next sten in the operational procedure, and further hydrofluorination was required. The salt mixture was therefore reheated to $600^{\circ} \mathrm{C}$ under argon fow and hydrofluorinated with HF-H: for an additional $24 \mathrm{hr}$ using the conditions previously employed. Again. samples of the sait melt were laken before and after the hydrolluorination. As hefore. extreme care was taken during and after the sampling to preclude the possibility of contact with air: the results are shown in Table 6.29.

A comparison of the anaiytical data given in Table 6.2n with those obtained earlier (Table 6.28) gives further support to the speculation that the discrepancies in the data probably resulted from sample contamination. probahiy with moisture. during analytical procedures. The oxide content of both 


\begin{tabular}{|c|c|c|}
\hline Mass & Fithered & Uafitered \\
\hline 233 & 39.82 & 39.85 \\
\hline 234 & 0.511 & 0.512 \\
\hline 235 & 0.157 & 0.156 \\
\hline 236 & 0.007 & $0.00 ?$ \\
\hline 238 & 59.51 & 59.48 \\
\hline
\end{tabular}

after first hydrofhurination.

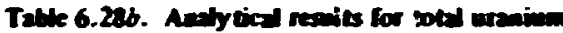
in the TeCen selt dher (24. X)

\begin{tabular}{|c|c|c|c|c|}
\hline \multirow{2}{*}{$\begin{array}{l}\text { Salt } \\
\text { sample }\end{array}$} & \multicolumn{2}{|c|}{ Uranium total (me/s) } & \multicolumn{2}{|c|}{${ }^{233} U /{ }^{238} U$} \\
\hline & Theoretion & Observed & Theoretical & Observed \\
\hline Filtered & 127.5 & 123.4 & 0.653 & 0.676 \\
\hline Unfiltered & 127.5 & 118.5 & 0.653 & C.677 \\
\hline
\end{tabular}

-After furst hydronuorination.

Table 6.28c. Andytical msedes for rotal methic

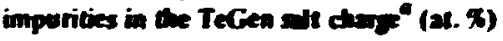

\begin{tabular}{|c|c|c|c|}
\hline \multirow[t]{2}{*}{ Impurity } & \multirow[t]{2}{*}{ Prehydrofluorination } & \multicolumn{2}{|c|}{$\begin{array}{c}\text { After } \\
\text { hydrofluorination }\end{array}$} \\
\hline & & Filterec & Unfiltered \\
\hline Fe & 129 & 255 & 213 \\
\hline $\mathrm{Ni}$ & 318 & $<25$ & $<2 s$ \\
\hline $\mathrm{Cr}$ & 56 & 34 & 33 \\
\hline Oxide & $1680 \pm 512$ & $\begin{array}{r}2100^{b} \\
678^{b}\end{array}$ & $\begin{array}{r}2000 \\
607\end{array}$ \\
\hline
\end{tabular}

"Sumple No. 1, Iaken Aug. 13. 1975.

'Sample No. 2, Laken Al:g. 18, 1975.

samples taken prior to additional hydrofluorination was lower by a factor of about 2 than that obtained from identical samples tuiken previously from the same salt. Also. the observation that the oxide content remained relatively constant after an additional $24 \mathrm{hr}$ of hydrofluorination is difficult to accept as valid. and it seems highly probable that the actual oxide content of the final salt mixture was kss than $300 \mathrm{ppm}$.

\subsection{3 $\mathrm{U}^{\text {st+ }} / \mathrm{U}^{3+}$ Ratio Adjustment}

The $U^{\text {t* }} U^{10}$ ratio was adjusted by heating the salt mixture to $700^{\circ} \mathrm{C}$ under argon flow and then introdtcing hyd rogen at $500 \mathrm{secm}$ for $6 \mathrm{hr}$. At the end of $:$ is time. the hydrogen now was cut off, and the salt was sparged for I hr with argon at about 200
Tall 6.29. Oxide concentrution (rm) after ecoed bydrofooriantion

\begin{tabular}{lcc}
\hline Salt somple & \multicolumn{2}{c}{ Concentration } \\
\cline { 2 - 3 } & After $36 \mathrm{ht}$ & After $60 \mathrm{hr}$ \\
Filtered & 420 & 357 \\
Unfintered & 332 & 603
\end{tabular}

sccm. Preparations were then made for evaluation of the $U^{\text {s* }} U^{\text {it }}$ ratio by retracting the sparge tube above the sait level and lowering the gold-iridium electrodes into the melt to a depth of ${ }^{\prime}+$ in. Analytical Chemistry Division personnel then made vult-ammogram recordings. A final $\mathbf{U}^{\mathrm{s*}}: \mathrm{U}^{\mathrm{i}-}$ value of $58\left(1.72{ }^{\circ}\right.$; of the total $U$ as $U^{3 *}$ ) was obtained. which was within the desired range of 1.0 to $1.8 \%$ of the total $U$ as $U^{\text {:- }}$. After retraction of the electrodes from the melt. the salt mixture was cooled to room temperature under argon and maintained in storage status for subsequent transfer to fuel pins.

\subsubsection{Preparation of Salt Fill Veasel}

A drawing of the assembled salt fill vessel is shown in Fig. 6.73. The ressel is shown in two different stages of assembly in Figs. 6.74 and 6.75. The salt is first transferred to the short vessel in the center and then pushed by gas pressure into the individual fuel pins, with the overflow going into the long vessel. The top $1 / 2$ in. of the salt from the fuel pins is then blown back to the initial vessel where the salt can te analyzed. The outer flanged vessel remains in place. but a new inner assembly is made for each filling.

In preparation for receiving the sall transfer from the salt preparation vessel, the salt fill vessel was pretreated with hydrogen. The salt fill vessel was heated to a temperature of $665^{\circ} \mathrm{C}$ under an argon flow of about $200 \mathrm{sicm}$. The operational procedure stipulated a pretreatment temperature of $700^{\circ} \mathrm{C}$ : however, because of failure of one of the Calrod heating units. the maximum temperature obtainable was $665^{\circ} \mathrm{C}$. The a rgon flow was cut off, and hydrogen was allowed to now through the vessel and pins at about $500 \mathrm{scem}$ for $4 \mathrm{hr}$. At this time the hydrogen was cut off, and the vessel was cnoled to room semperature under argon. All valves and connections were then closed off.

\subsubsection{Salt Transfer}

With both the salt preparation vessel and the salt fill vessel at room temperature, a preshaped 's-in.OD nickel salt-transfer line was connected between 


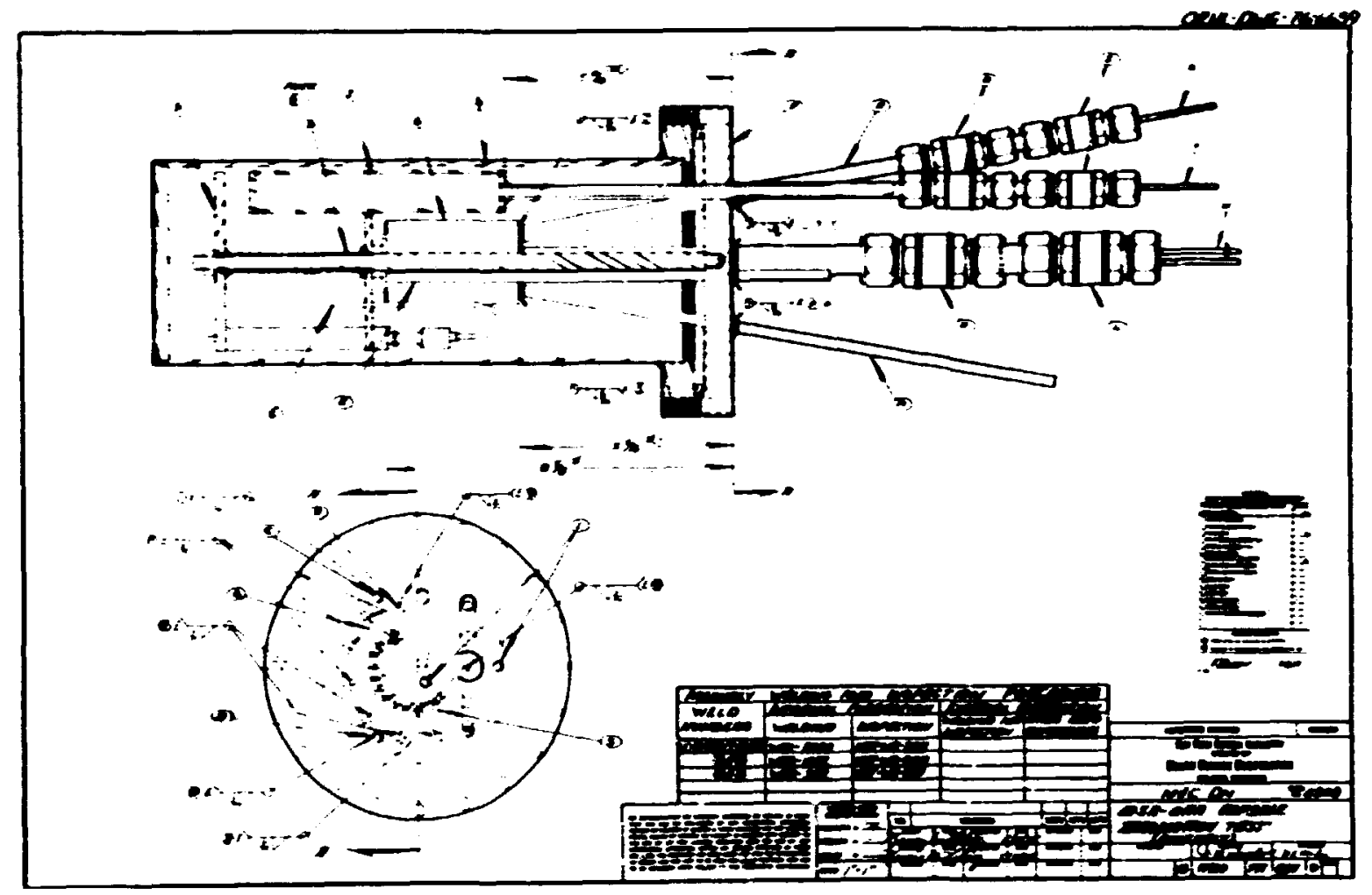

Fie. 6.73. Sah fill vemet.

the sparge tube exit of the salt preparation vessel and the salt transfer inlet line to the salt fill vessel (fig. 6.76). A 750-W Calrod heating unit was fastened securely to the salt-transfer line, and the entire assembly was then heavily insulated. With argon flowing through. both vessels and the salt-transfer line were heated to $650^{\circ} \mathrm{C}$ in preparation for the salt transfer. The objective in this part of the procedure was to transfer about $85 \mathrm{~cm}^{\prime}(203 \mathrm{~g})$ of the salt mixture from the salt preparation vessel into the receiving reservoir of the salt fill vessel. A conductivity probe was positioned at a predetermined level in the receiving reservoir to monitor the salt level. Contact of the rising sait with the probe was indicated by a red lignt on the instrumert panel. At this point. argon was allowed to flow through the bypass line leading to the salt preparation vessel at a rate of about $100 \mathrm{sccm}$ (under 5 psig pressure). After the vent valves of the salt fill vessel were opened. the bypass valve to the salt preparation vessel was closed. Salt was then observed to transfer as evidenced by "smoking" of the insulation. Within about I min. the red light went on, indicating completion of the transfer. The argon now was cut off, and the appropriate valves were closed. A determination of the salt level in the receiving reservoir was then made by raising the probe and measuring the point at which the red light went off. This was shown to be 's in. above the specified level. or the equivalent of a 7.6 $\mathrm{cm}^{3}$ exress of salt. The total transfer was thus about $92.5 \mathrm{~cm}^{3}$. Which was less than $10 \%$ deviation from the stipulated transfer iolume of $85 \mathrm{~cm}$ '.

In preparation for sall transfer from the receiving reservoir into the fuel pins. the temperature of the salt fill vessel was reduced to $600^{\circ} \mathrm{C}$, and argon was Howed at a rate of about $25 \mathrm{sccm}$ through the bypass line leading to the receiving resen oir. The by pass line valve was then ciosed. at which time the pressure slowly increased to 5 psig. After a few minutes. the pressure decreased slowly to zero. indicating completion of the transfer. This was confirmed by lowerin? the conductivity probe into the receiving reservoir (1) a position about', in. from the bottom of the vesse' and observing that the red light failed to go on. Al. valves on the salt fill vessel were then closed. and th: salt was allowed to equilibrate in the fuel pins for 24 hr at a temperature of $600^{\circ} \mathrm{C}$.

After $24 \mathrm{hr}$ of equilibration. preparations wert made for iransfer of excess salt in the upper regions of the fuel pins into the electrode cup of the ieceiving 


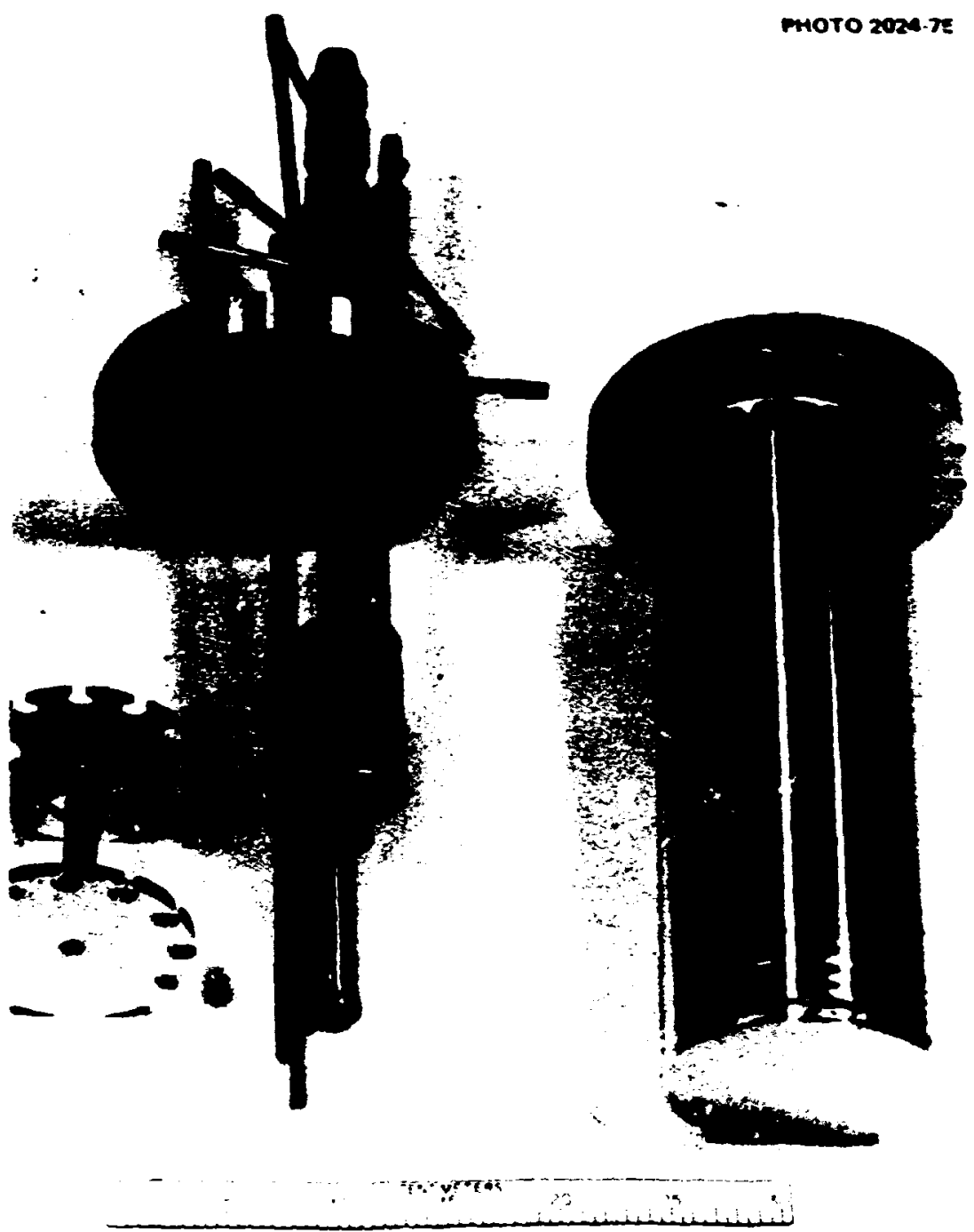

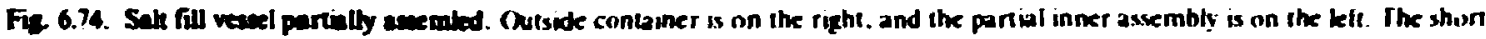
vessel initially recerses the salt. Ithe knger vessel is the sall overflow rece iver. which catches any solt in excess of that reyuired to fitl the fucl pins.

reservoir for final evaluation of the $U^{3 \cdot} U^{\text {i. }}$ ratio. At a temperature of $600^{\circ} \mathrm{C}$. argon was flowed at a rate of about $25 \mathrm{sccm}$ through the bypass line leading to the fuel pin overflow reservoir. The bypass line valve was then closed. pressurizing the overilow reservoir to about 5 psig. In less than I min. the pressure dropped to about 0.1 psig. indicating that the salt had transferred and that argon was bubbling up through the salt in the receiving reservoir. The argon flow was then cut off. and all valves to the salt fill vessel were closed. After lowering the iridium electrode ' $;$ in. into the salt in the receiving reservoir cup. final determination of the $U^{\text {". }} U^{\text {". }}$ ratio was made by Analyticas
Chemistry Division personnel. Interpretation of the volt-ammograms obtained gave a $U^{\text {s* }} U^{\text {"* }}$ ratio of $200\left(0.5 \%\right.$ of the total $U$ as $\left.U^{i *}\right)$. It seems possible that hydrogen pretreatment of the salt fill vessel and fuel pins at the lower temperature $\left(665^{\circ} \mathrm{C}\right)$ than the $700^{\circ} \mathrm{C}$ stipulated in the operating procedure may have contributed somewhat to the reoxidation of some of the $U^{\prime \prime}$.

It was decided to make a second measurement of the $\mathrm{U}^{\mathrm{s}}, \mathrm{U}^{\text {t" }}$ ratio since there was some uncertainty as to the proper functioning of the instrumentation during the volt-ammogram rerordings. This was done under the same conditions as the previous 


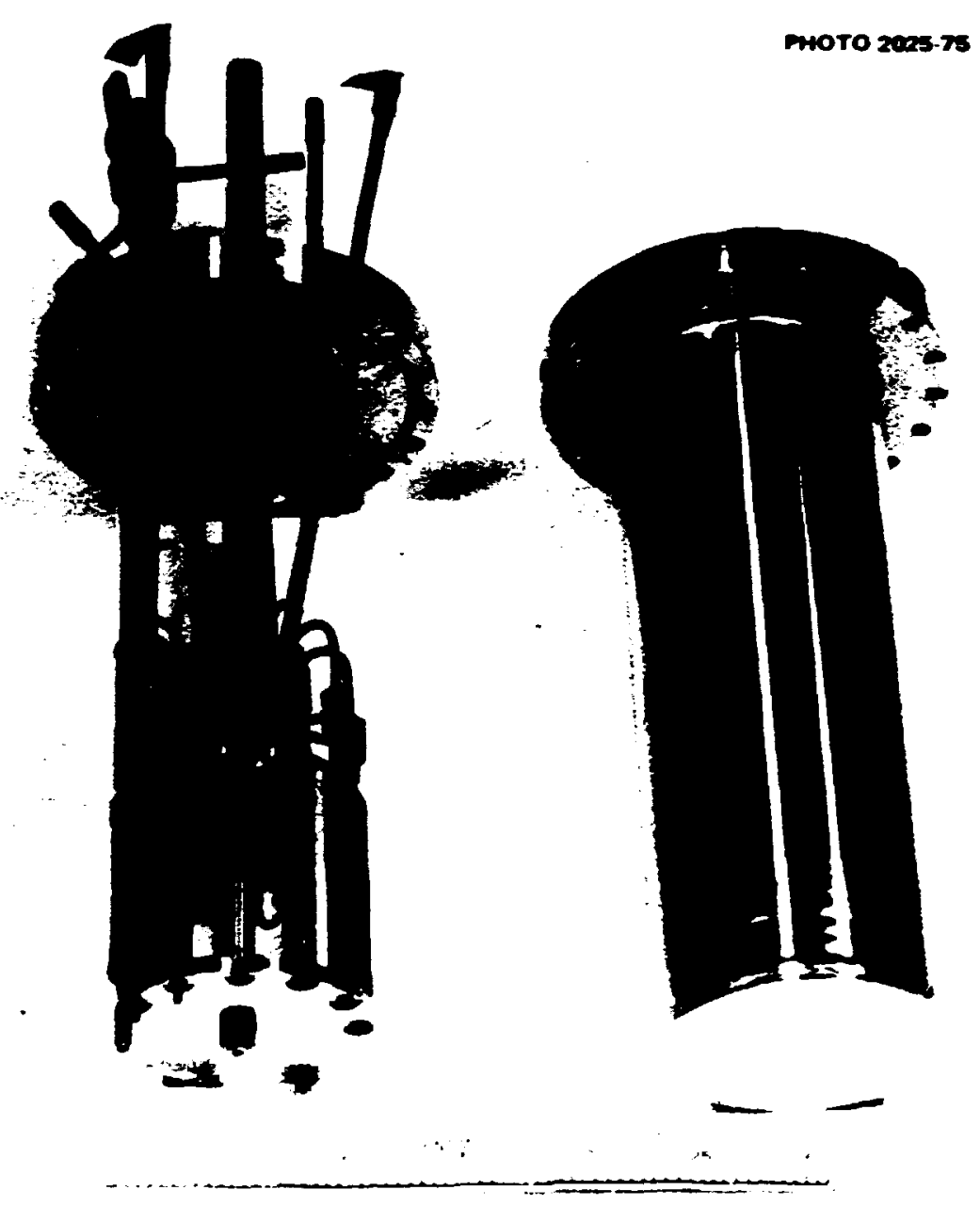

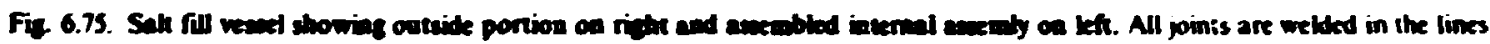
connecting the small sexuels and the fuel pins.

determination. A $U^{\text {t* }} U^{\text {t" }}$ ratio of $20510.499^{\circ}$ of the total $U$ as U:"? was ohtained, which is in excellent agreement with the initial value of $0.50 r_{i}$. Since this value was considered acceptable. the salt fill vessel was cooled to room temperature under argon for subsequent disassembly. All valves and connections were closed. and the glove box was then decontaminated.

\subsection{SALT PREPARATION AND FILLING OF TeGen-3 AND 4}
H. E. Mcloy
W. H. Milkr
B. Mciabb
W. B. Stines

The same salt prepared for the filling of TeGen-2 was used to fill the fuel pins for TeGen-3 and 4 . The same hasic procedure was also used for transferring the salt from the preparation vessel into the fuel pins. but some changes were made which shortened the time required.

During the interval between the filling of the pins for TeGen-2 and for TeGen-3. the salt in the preparation vessel was under a positive pressure of argon. Before the pins for TeGen-3 were fillad. the transfer line and the salt fill vesuel (including the fuel pins) were purged with hydrozen for $4 \mathrm{hr} a \mathrm{t} 300 \mathrm{C}$. The salt preparation vessel was then heated. and approximately $100 \mathrm{~cm}$ ' of salt was transferred inio the receiving reservnir. At this time the $\mathrm{U}^{\text {** }} \mathrm{U}^{4 *}$ ratin was determined to be 0.001 . The salt was transferred into the pirs and allowed to remain at $600^{\circ} \mathrm{C}$ for $8 \mathrm{hr}$. The sample blown hack for analysis did not indicate a detectable change in the $\mathrm{U}^{\prime \prime}$. $\mathrm{U}^{4 \cdot}$ mitio. Although the salt was more oxidizing than desired. it was judged to be suitable for these experiments. The salt fill vessel was disassembled, the pins separated. cinsure welds 


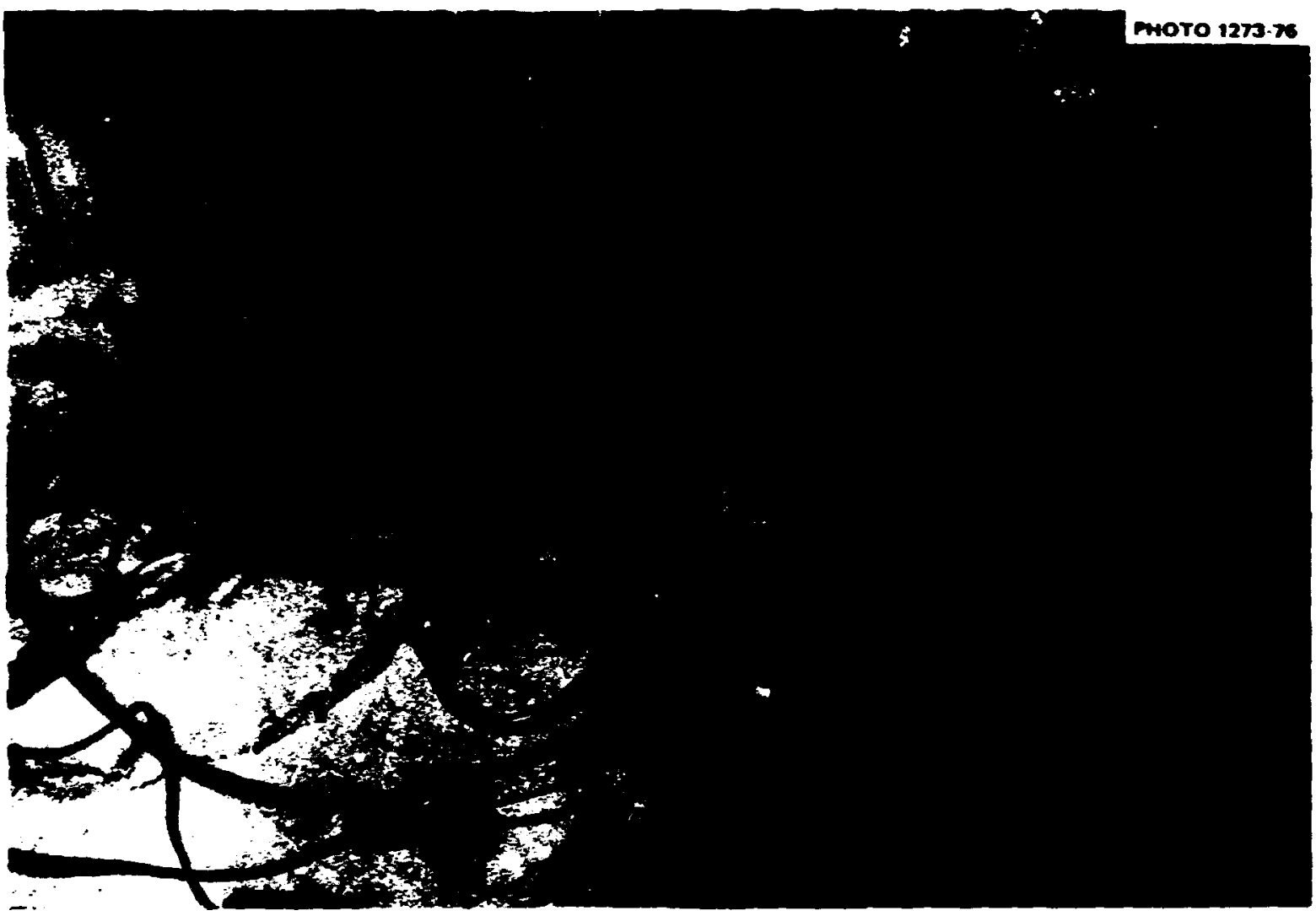

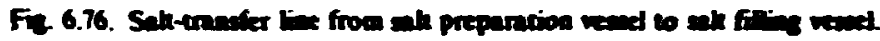

made. pins radiographed and leak checked. and the pins given to the Reactor Division for assembly into the irradiation capsule.

It was decided that prior to filling the pins for TeGen-4 the salt remaining in the preparation vessel would be retreated with hydrogen to increase the $\mathrm{C}^{-1} \mathrm{C}^{\mathrm{A}-}$ ratio. Since the new salt fill vessel and the transfer line were to be pretreated with hydrogen also. the entire sy stem was heated and pretreated with hydrugen for $4 \mathrm{hr}$ at $750^{\circ} \mathrm{C}$. The $\mathrm{U}^{\circ /} \mathrm{It}^{\text {st }}$ ratio in the wit preparation vessel could not be determined. prohably hecause a conductive film had formed on the surface of the salt. Approximately $100 \mathrm{~cm}$ ' of salt was iransferred to the sait fill vessel where the

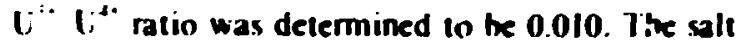
was then transferred into the individual pins. heit at $600 \mathrm{C}$ for $\mathrm{d}$ hr. and partially transferred back to tine receiving reservoir. The $\mathrm{U}^{\prime \prime} \mathrm{U}^{*}$ ratio was determined to the in the range of 0.013 to 0.010 . The salt fill ressel was disassembled. the pins separated. closur: welds made. pins radiogranhed and leak checked. and pins given to the Reactor Division for assembly into the irradiation capsule.

\subsection{OPERATION OF TeGen-2 AND -3}

\section{R. Hyman}

TeGien-2 and -3 are the second and third ORR poolside experiments designed to irradiate prospective MSBR vessel materials. The experiments were designed to produce a fission product inventory of at

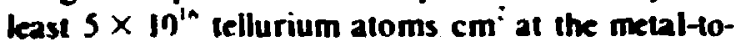
salt interface, together with a representative mix of other fission products. The test device is an irradiation capsule containing three ' $:$-in.-OD $x$ 0.035-in.-wail. 4-in.-lung tubular fuel pins, partially filled with fuel salt. The three fuel pins in TeGen-2 were 2r; titanium-modified Hastelloy. Inconel-600. and tiranium-lanthanum-modified Hastelloy for the top. middk. and bollom fuel pins respectively. In TeGien-3 the three fuel pins were $2 r_{i}$ titanium ${ }^{\prime}, F_{7}$ niohium-modifed Hastelloy. $2 r_{i}$ tizanium $I_{r}$ niobium-modified Hastelloy, and Ir; titanium IF; niobium-modifned Hastelloy for the top. middk, and bottom pins respectively. The fuel pins were filked with approximately $7.14 \mathrm{~cm}$ ' of fuel salt, leaving a ', in. void at the top of the fuel pin. which was back filled 
with helium after salt filling. The fuel salt was a

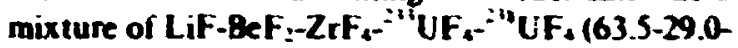
5.0-1.0-1.5 mobe cic).

The fuel pins were arranged vertically inside a double-walked iype 304 stainless steel vessel. The void between the fuel pins and the inner wall of the vessel was filled with NaK for improving heat transfer. A schematic of the experiment is shown in Fig. 6.77. Small design changes were made in TeGen-2 and -3 . which should be noted. Small hubs were attached to the end plugs inside each fuel pin. and four foils 0.005 $\times 0.125 \times 0.375$ ir. were attached to each huo. The bottom hub was solid and was 0.265 in. in diameter $X$
0.125 in. thick. The top hub was 0.267 in. in OD $x$ 0.135 in in ID $\times 0.125$ in. thich. The foils and hubs for each fuel pin were made of the same material as their respective fuel pin. The foils were inchuded to provide samples that could possibly have sufficiently Icw activity for Auger analysis.

The capsules were instrumented with four Chromel-Alumel thermocouples per fuel pin. One electrical resistance heater was wrapped around each fuel pin, with the heaters positioned to minimize axial temperature gradients. The heaters also maintained the fuel pins abouse $150^{\circ} \mathrm{C}$ during periods when the reactor was shut down and while the capsule was

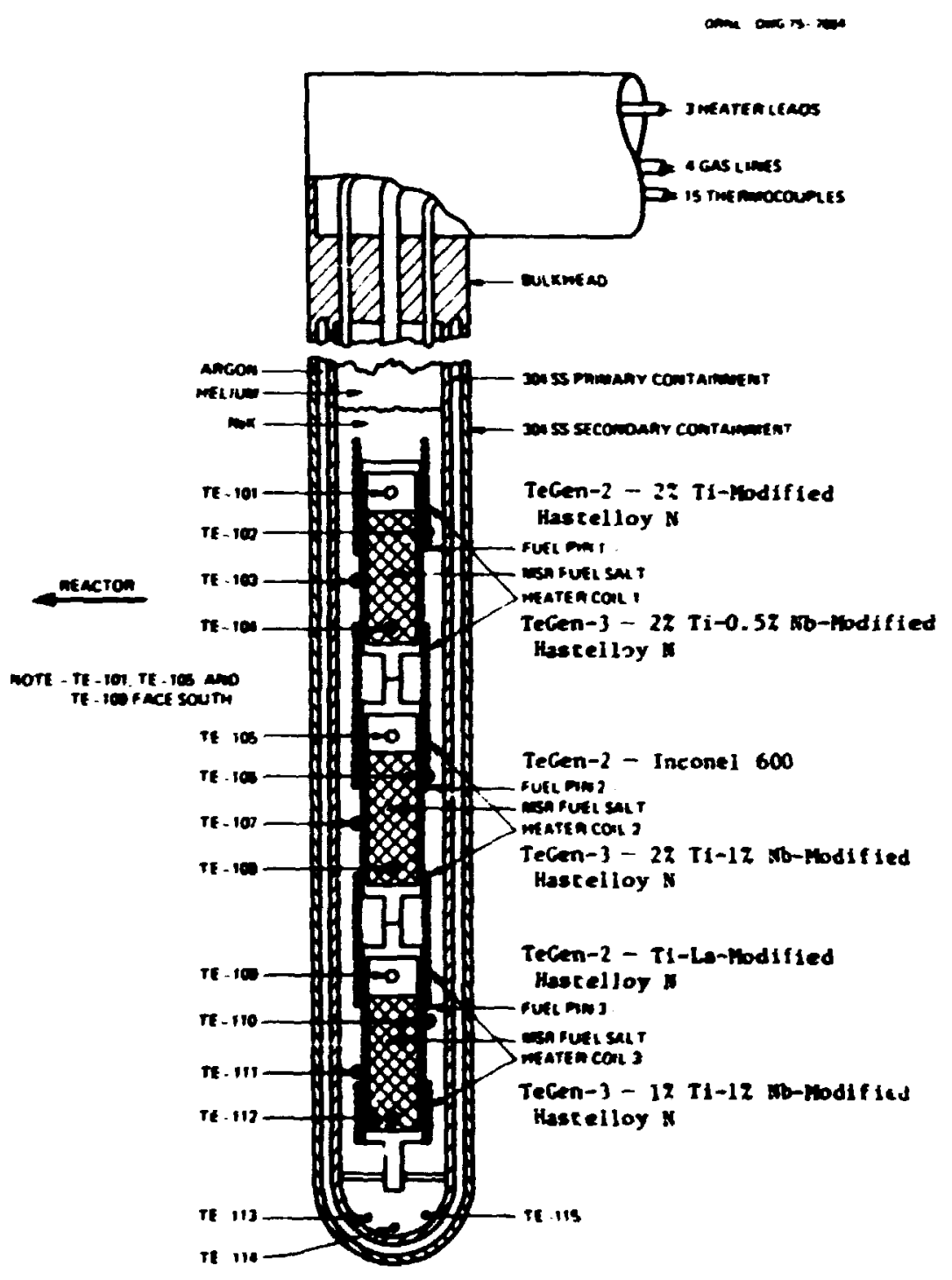

Fin 6.77. Dravies of TeGon-2 and -3 aponles. 
removed from the reactor after completion of the irradiation but prior to hot cell disassembly. Fission pinduct decay radiation in frozen sah $(<150 \mathrm{C}$ ) causes dissociation of the fuel salt components at a faster rate than recombination at that temperature. At temperatures hugher than this. recombination exceeds evolution. and no net huorine is generated.

The design operating temperature for the specimens was $700 \mathrm{C}$ at the salt-to-metal interface. and this temperature was maintained as uniform as possible over the length of the capsule throughout the irradiation. Bulk temperature control was maintained by adjusting the experiment position with respect to the reactor by means of the movable track on which the experiment was placed in the ORR poobide facility. This movement changed the neutron fux at the experiment and thus baried the fusion heat pruduced. Fine temperature control and uniform axial temperatures were attainad by heater power adjustment. A more comficte description of the experiment design may be found in an earlier repon." Figures 6.78 and 6.79 are piciures of TeGen-

PMOTO 4735-75

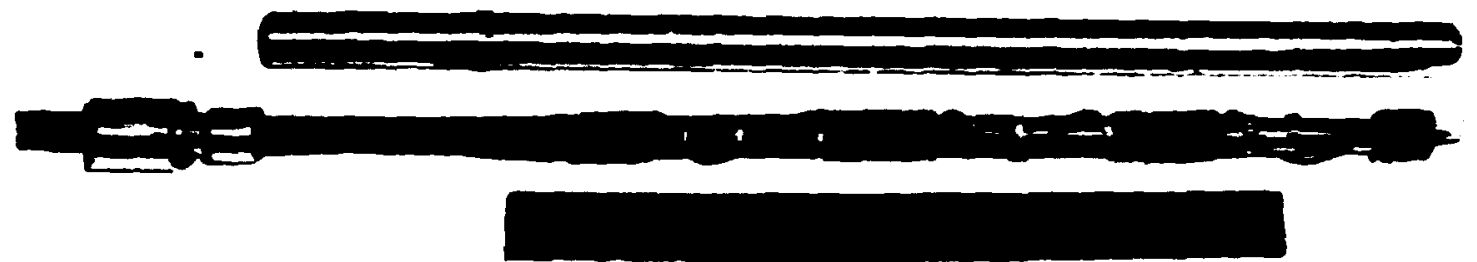

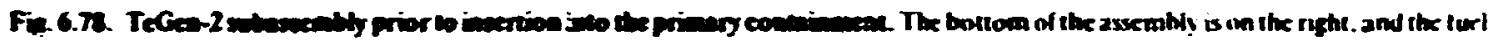
puas from keft to right are numbered 1.2 . and 3 respectivety.

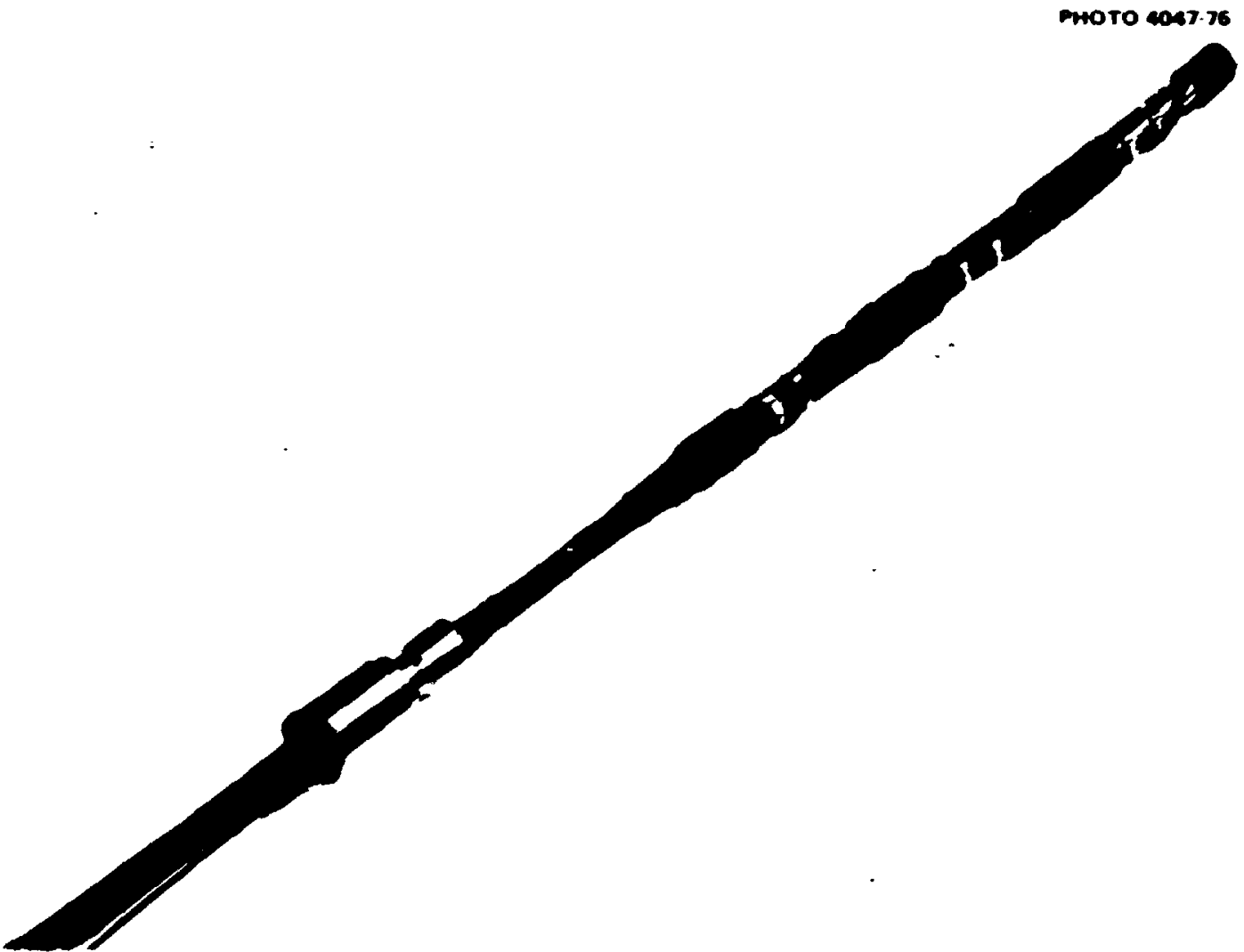

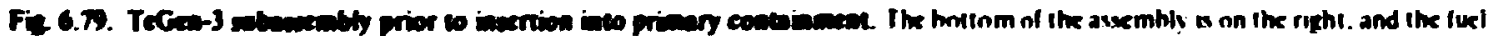
pans from ie't in nghi are numbered 1. 2. and t respecinety 
2 and -3 subassemblies before insertion: into the primary containment.

\subsubsection{Openting Histors of TeGeon-2 and -3}

TeCen-2 was instalked into the ORR poolside irradiation facility position P-4A or Novenber 3 . 1975. and full-power irradiation began on November 4. 1975. The experimental assembly was irradiated for a tolal of $1492 \mathrm{hr}$ but was retracted away from the reactor several times during this period. Irradiation was ended on January 21. 1976. at which time the experimental assembly was retracted to 16 in. away from the face of the reactor. Since TeGen-3 was r.ady for insertion at the same time TeCen-2 was being removed. the gas lines of the TeGen-2 capsule were cut one day before tmasterring it to the hot cell. However, during this time the heater and thermocouple instrumentation remained intact, and the heater power kept the capsule at $>150^{\circ} \mathrm{C}$. On January 28. 1976. TeCen-2 was transferred to the ORR hot cell and disassembled. Flux monitors and fuel pins were retained.

One unexpected problem developed after irradiation of the capsule had been completed. While removing the capsule and transferring it to the hot cell. it was necessary to depressurize the gas systems in the capsule. The secondary (argon) gas system was depressurized with no problems. but the primary (helium) system could not be depressurized. The lines keading to and away from the capsule were depressurired so that if only one plug existed. the capsule would depressurize. Forward purging and back purging were attempted. but the plug was not cleared. Finally the gas lines were severed and welded. The nexi day the capsule was transferred to the hot cell. where dissassembly bezan. No unusual events or physical characteristics were observed when the experimental assembly was dismantled. The pins appeared to be intact.

The most likely cause of the plug in the primary gas line was impurities in the NaK system. The carrier used to transfer the $\mathrm{NaK}$ from the source ank to the capsuke filling apparatus was not filled with the required amount of NaK and thus had to be refilled two more times. In addition. the procedure for filling the experimental assembly with NaK from the carrier had to be done twice before the NaK fill was completed. It is possible that during the filling of the carrier from the source tank. air may have been introduced into the NaK. This would have formed metallic oxides, which could have plugged the lines during or after transfer of the Nak to the experimental assembly. To prevent this problem in the future. a brger laK carrier witi be used and a better procedure followed in filling the carrier from the source ank.

TeGen-3 was inserted un January 28. 1976. and began full-power operation at design temperature on January 30. 1976. Since that time. TeGen-3 has been operating at design temperature. There have been periods when the temperatures indicated by the safety thermocouples Te-1 13. -114. -1 15(Fig. 6.77) at the bottom of the primary containment have oscillated rather severeh. The amplitudes of the oscillations have been as high as $100^{\circ} \mathrm{C}$. which is much higher than was recorded for the previous two capsules. Smaller oscilbtions occurred at the middle and upper regions of the apsule as well.

At one time there was a 200 C drop in the readings of the safety thermocouples of TeCen-3. The reactor and experiment were operating under unusual conditions when the drop occurred. The previous two TeCen capsules ex perienced temperature oscillations that were probably due to NaK currents inside the primary containment. These currents were undesirable because they cooled the bottom of the capsule by convection. The bottom fuel pin hit an axial temperature difference of approximately $70^{\circ} \mathrm{C}$, and the safety thermocouples were $50^{\circ} \mathrm{C}$ cooler than the lowest thermocoufl- on the lower fuel pin. To alkviate this problem. Teli-n-i was constructed with a baffle positioned on the bottom of the lowest fuel pin. However. the temperature distrisurtion was worse, with an axial gradient of $200^{\circ} \mathrm{C}$ on the bottom fucl pin and the safety thermocouples about $100^{\circ} \mathrm{C}$ cooker. These data. in addition to the oscilbting pattern observed. suggest that Nak currents may still exist in the capsule. In any event. the temperature abberations noticed have not posed any threat to the experiment or to the reactor.

\subsubsection{Dan Ambyis for TeGen-2 and -3}

Tables 6.30 and 6.31 give typical operating data for TeGren-2 and -3. The average temperature of TeGen2 over the kngth of the capsule was $693.7^{\circ} \mathrm{C}$. Which corresponds to a fuel-salt to fuel-pin interface temperature of about $700 \mathrm{C}$. In $\mathrm{TeCen}-3$ the average temperature is $677.3^{\circ} \mathrm{C}$. and the corresponding interface temperature is approximately $684^{\circ} \mathrm{C}$. The maximum temperature variation occurs in the bottom fuel pin in each capsule. This variance occurs because of MaK currents existing in the primary containment. Even though TeGen-3 had a baflle to 


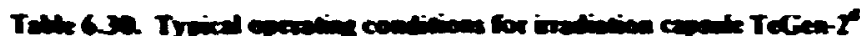

\begin{tabular}{|c|c|c|c|c|c|}
\hline \multicolumn{2}{|c|}{ Find pin } & \multirow{3}{*}{$\therefore$-asocouple } & \multirow{2}{*}{\multicolumn{2}{|c|}{ 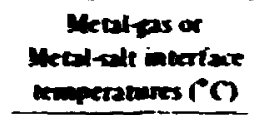 }} & \multirow{3}{*}{$\begin{array}{c}\text { Heater power } \\
\text { in }\end{array}$} \\
\hline \multirow[t]{2}{*}{ Locativa } & \multirow{2}{*}{ Menctial } & & & & \\
\hline & & & Obecture & Anerere & \\
\hline Top & 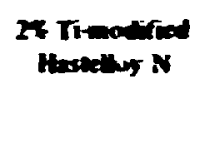 & $\begin{array}{l}101 \\
102 \\
103 \\
104\end{array}$ & $\left.\begin{array}{l}21 \% \\
205 \\
200 \\
697\end{array}\right\}$ & 701 & 228 \\
\hline 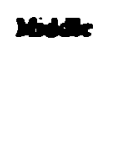 & Inowad 000 & $\begin{array}{l}105 \\
105 \\
107 \\
100\end{array}$ & $\left.\begin{array}{l}708 \\
718 \\
710 \\
657\end{array}\right\}$ & 69 & 57.1 \\
\hline Eortum & 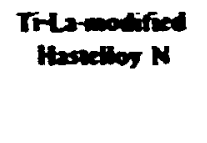 & $\begin{array}{l}199 \\
110 \\
111 \\
112\end{array}$ & $\left.\begin{array}{l}722 \\
711 \\
653 \\
653\end{array}\right\}$ & 62 & 183.1 \\
\hline
\end{tabular}

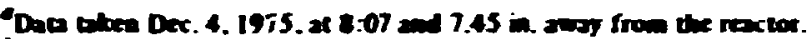

see Fis. 6.77 for borions.

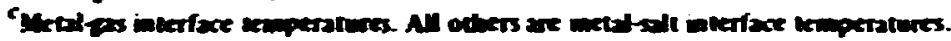

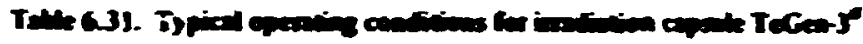

\begin{tabular}{|c|c|c|c|c|c|}
\hline \multicolumn{2}{|r|}{ Find pin } & \multirow{2}{*}{ nosimocogite } & \multicolumn{2}{|c|}{ 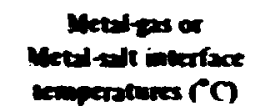 } & \multirow{2}{*}{$\begin{array}{l}\text { heover womer } \\
\text { (n) }\end{array}$} \\
\hline Locationa & Mererel & & Osurnal & Ancere & \\
\hline Top & 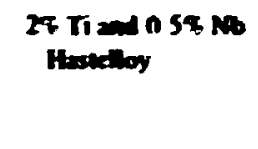 & $\begin{array}{l}101 \\
102 \\
103 \\
104\end{array}$ & $\left.\begin{array}{l}594^{6} \\
692 \\
714 \\
720\end{array}\right\}$ & 309 & 230.3 \\
\hline vise & 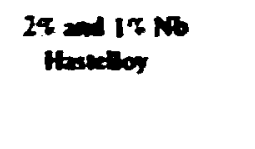 & $\begin{array}{l}105 \\
105 \\
107 \\
105\end{array}$ & 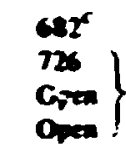 & 726 & 86 \\
\hline Dotrom & 17 Tiand 1780 & $\begin{array}{l}109 \\
110 \\
111 \\
112\end{array}$ & $\left.\begin{array}{l}700 \\
65 \\
655 \\
530\end{array}\right\}$ & 630 & 1738 \\
\hline
\end{tabular}

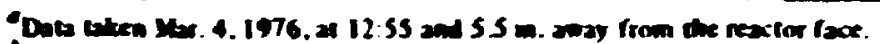

bet fo 6.77 for locotions.

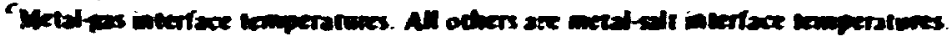

obstruct the currents, a Gvorable peometry still existed for the occurrence of very boal vioknt viak currents. which were evidenced by the acillating cemperalures recorded during operation of the capale. Fizure 6.80 gives the relative beations of the thermocouples. both rerticaly and circumferentially. as well as iheir orientation rebive to the face of the reactor.
Several sets of temperature dala are plotied in Fis. 6.81 and 6.82 for TeGen-2 and -3 respectively. The top set of cunves repesents the normal operating conditions with the heater power as noted in Tables 6.30 and 6.31. the modle curves denote the temperplures at the same capsule position but without the heater power. and the hotiom curves denole temperalures at the retracied position with 
OANL - OWG r5-7865A

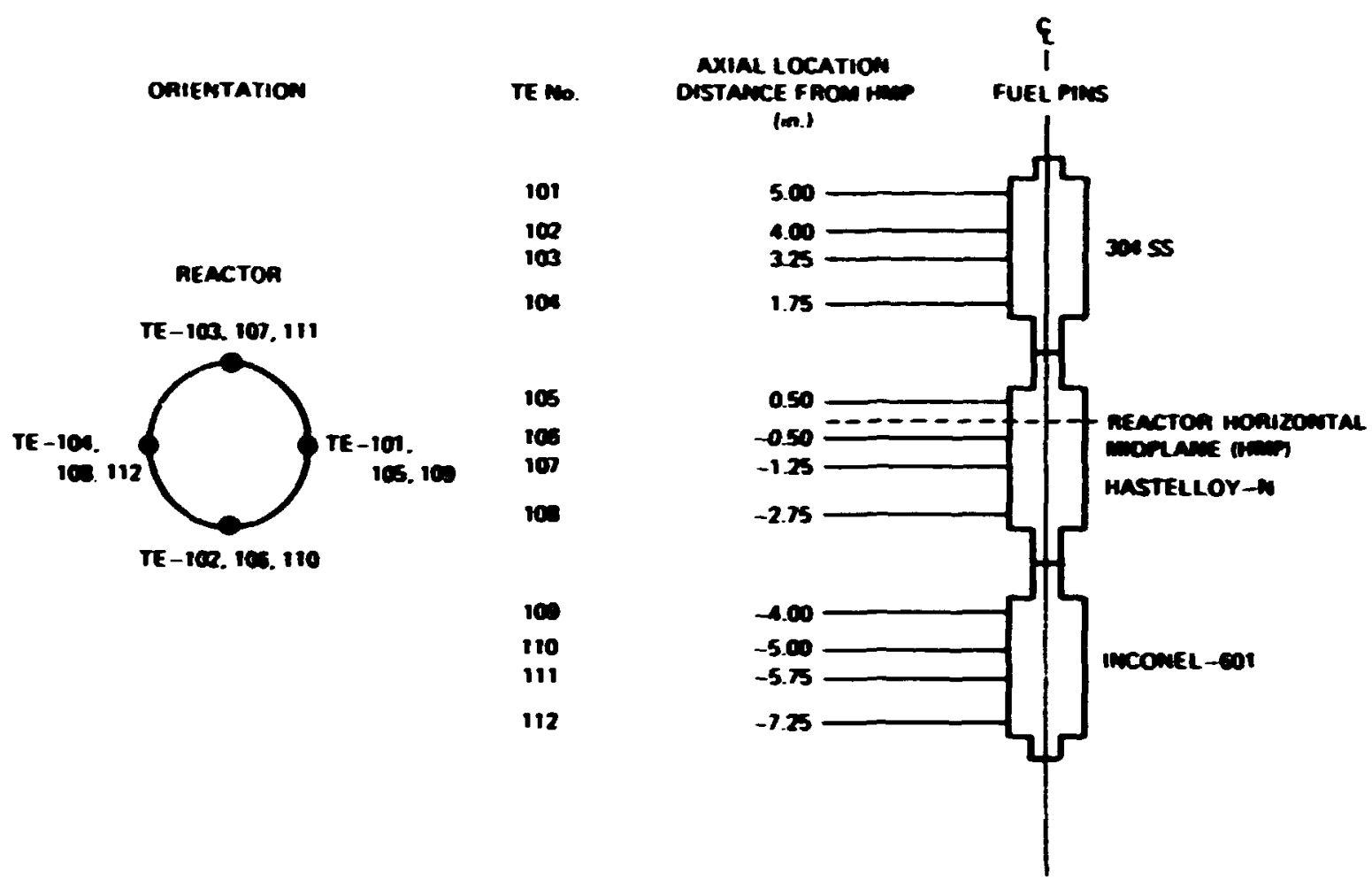

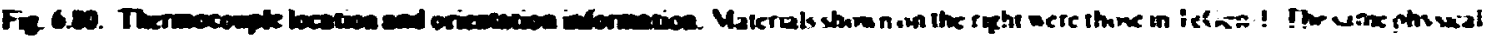

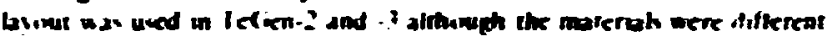

the heater poner as noted in Tables 6.30 and 6.31 This bst condition represents neplizible gamma and Tession heat.

Figure 6.83 oresents the desizn terroperature distribution in the fuel region of the pins where the fission heal production is considered the major source of heat flux. Figure 6.84 presents the temperature dsuribution in the hester region of the pin and assumes no fission heat and an averay heat raiz of $26.5 \mathrm{~W} g$ in the region of the heaters. thermocouples. and laK. The maximum amount of power that a heater must produce was esimated from the $26.5 \mathrm{~W}$ ementioned above to be approximalety $300 \mathrm{~W}$ heaier. The actual heaker power used during operation was much less hecause of the conduction of fraion heat from the ends of the fuel pins.

Figure 6.85 gives an estimate of the retativic ratol iemperaiure profile for tix top. middle. and mitom fucl pins respectively. Although exact temperature distributions are aol known. the differences in the respective fussion reaction rales in the fuel pins cause the centerline temperatures of the middle and hotiom fucl pins to be higher than for the top fuel pin. As a result. the temperature eradienes in the fuet pins differ substantially. radialy as well as axialb. and therefore may unfuence the cornesponding fission product deposition ratex on the surfaces of the fuel pins. This occurs in spite of having the same temperature along the outsule of the fuel pins. Nols that the temperatures at the surtaces of the fuel pins are the respective averapes of the lower three thermocouple readings on each fuet pin in Tabke 6.30.

These thermocouple readings represent actual fusl region temperatures and not those of the void region above the salt. Atw note that the henter power provides heat in the ends of the fuel pins where litile or no fission heat is produced. This has the effect of leveling out the ie.pperalures over the kength of the experiment.

\subsubsection{Pretinivary Remites of TeCen-2}

I sing a crude heat habancing technrque. the steady-state fission heal peneration pisers were 


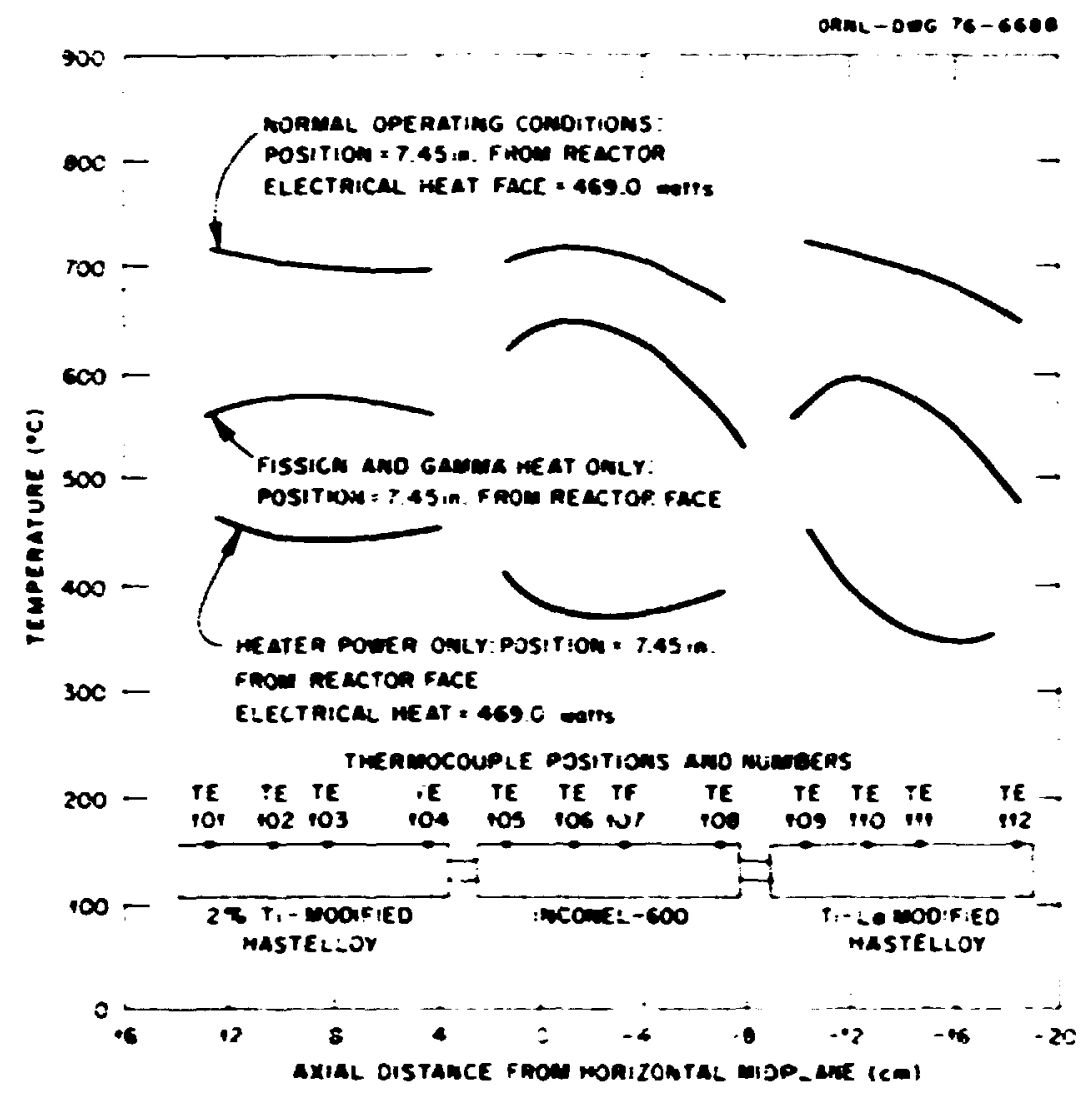

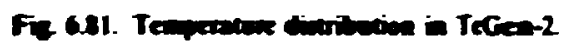

cakculated as 163. 258. and 173 it for the top. middk. and bottom fuel pins respectivety. These were cakulated knowing haver powers. gamma hats. thermal conductivities. cemperatures. and several othet parameters and iterating the GENGiTC fossion heat values to cakubte the obsence temperatures. Values produced by this method of evaluating fission rates will be compared with those produced from neutronics support of TeCien-2.

The tellurium production w as cakulated from the above estimates of fission heat rates. Assuming a yield of 0.04 stable tellurium atnms per fission. tellurium inventories of $1.21 \times 10^{\circ} .1 .92 \times 10^{\circ}$. and $1.29 \times 10^{\circ}$ cellurium atoms were produced in the top. middle. and bottom fuel pins respectiveh. Assuming a surface area of $29.7 \mathrm{~cm}^{2}$ in contact with the wit and an even deposition rate on all surlaces. The tellurium deposition should the approximalely $4.07 \times 10^{\prime \prime}$.6.46 $\times 10^{\text {is }}$. and $4.34 \times 10^{\text {; }}$ cellurium atoms $\mathrm{cm}^{2}$ for the top. middle, and bottom fuel pins respectively. These 1alues compare favorably with the design kevel of $5 x$ 10 atoms $\mathrm{cm}^{\circ}$. More-detailed tellurium production esi:mates will be made when the fhux monitors from the experiment are amalyred.

\subsection{Fore Indintions}

Future irradiation of capsules wilt he ven simitar to that of capsules run previoush in this series. However. the ballk sincture placed in the bottom of the primany containment will be eleminated because of the temperature profik and thectuations seen in Tecien-3. In future experiments. fre yuaru wool will be placed between the primany and secondary containment to reduce heat radiation from the hotion of the capsule. This insubtion should reduce the heat loss and thus raise the temperatures in the bwet end of the capule. I he heater coils will be arranged as they were in Ietien-?. 


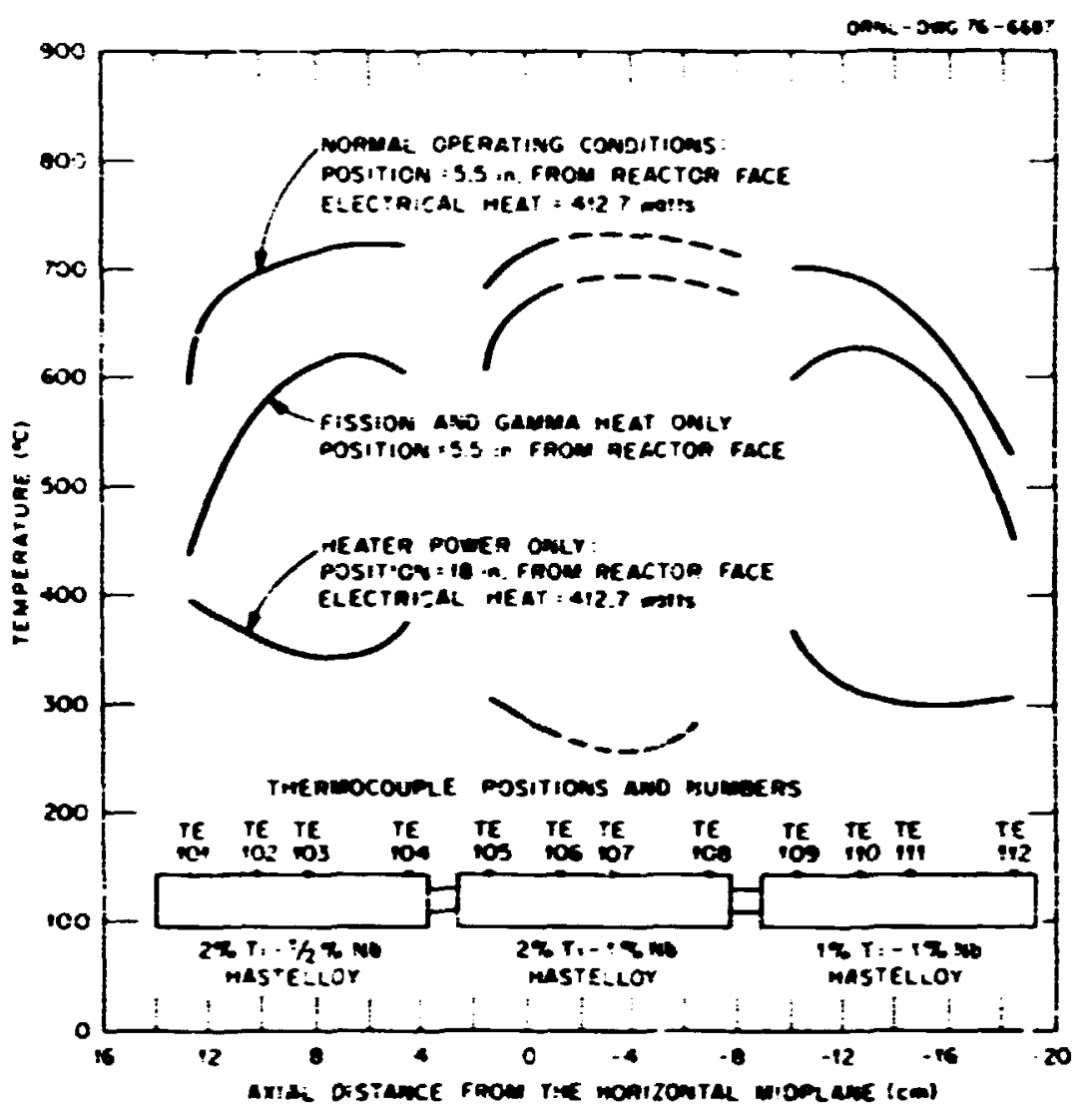

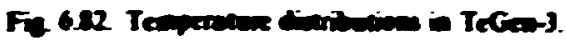

\subsection{EXAMINATHON OF TEGen-2}

\section{B. Mcliabo H. E. Mecoy}

The TeCen experiments were designed to evaluate the resistance to cracting of several materiats of interest to MSBR when they are exposed in molien salt containing fission products. The :-in. OD fuel pin is made of the material being evaluated. TeGen-I containment materials consisted of type-304 stainless steel. standard Hastelloy $X$. and Inconet 601 As reponed previoushy." Inconel 601 was the most resistant to cractinge-

TeGen-2 is almost identical in design to TeGen-1. but the fuel pin materials were 2 r tiznium-modifed Hastelloy . Theal 74533 (lop fuel pin). Incerel 600 (middk fuel pin). and $2 r_{r}$ titanium-modified Hastelloy $\mathrm{X}$ plus 0.013 lanthanum (bottom fuet pin). The chemical compositions are given in Tahte 6.32. The irradiation of Te(ien-2 rapproximatety $157 \mathrm{~h} \mathrm{hr}$ at 700 () was concluded on Jamuary 26. 1976. and disassembly in the ORR hor cells was dme on
Janwary 28. The operating conditions of TeGen-2 are reporked in detail in Sect. 6.16.

Visual inspaction of the disasse.nbled equipment showed the parts to be unchanged in their appearance after the irradiation. The top and boitom fuel pins of modified Hastelloy ? 1 (pin 2. heat 74533. and pin 6. heal 74534. respectivety) had a sligin roold tint, and the anidde pin (pin A. Inconel $\mathbf{5 0 0}$ ) had a silver tint zfter annealing but before assembly in the experimental equipment. The top fuel pin had a small scratch alone ins kength. probably from a stheathed thermocouple pulked across it during disassembly. The small scratch did not affect the tensite oropertics of rings cul from the pin and tensik tested. and it was undetected in subsequent metalbyophic examinaimn. Affer disassembly. the fuel pins were hated in a small furnace iso C or highter to prevent evolution of fuprine from the fuel salt. The pins were maintained at this temperature except during transfer to the High Radiation l.eeel Examination laboratory :HRI.EL.). during gamma sanning and measuring. 


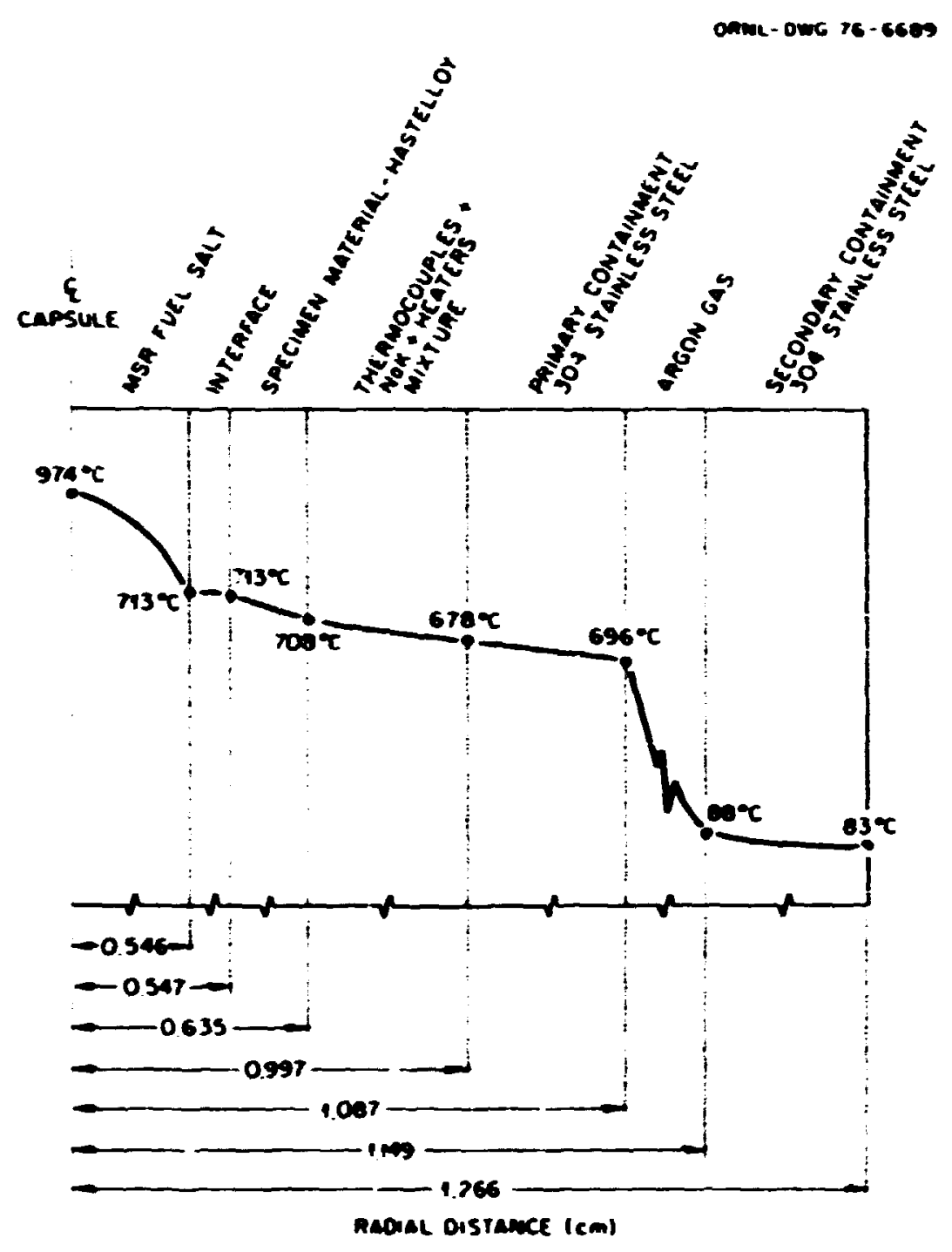

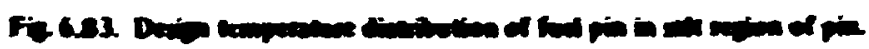




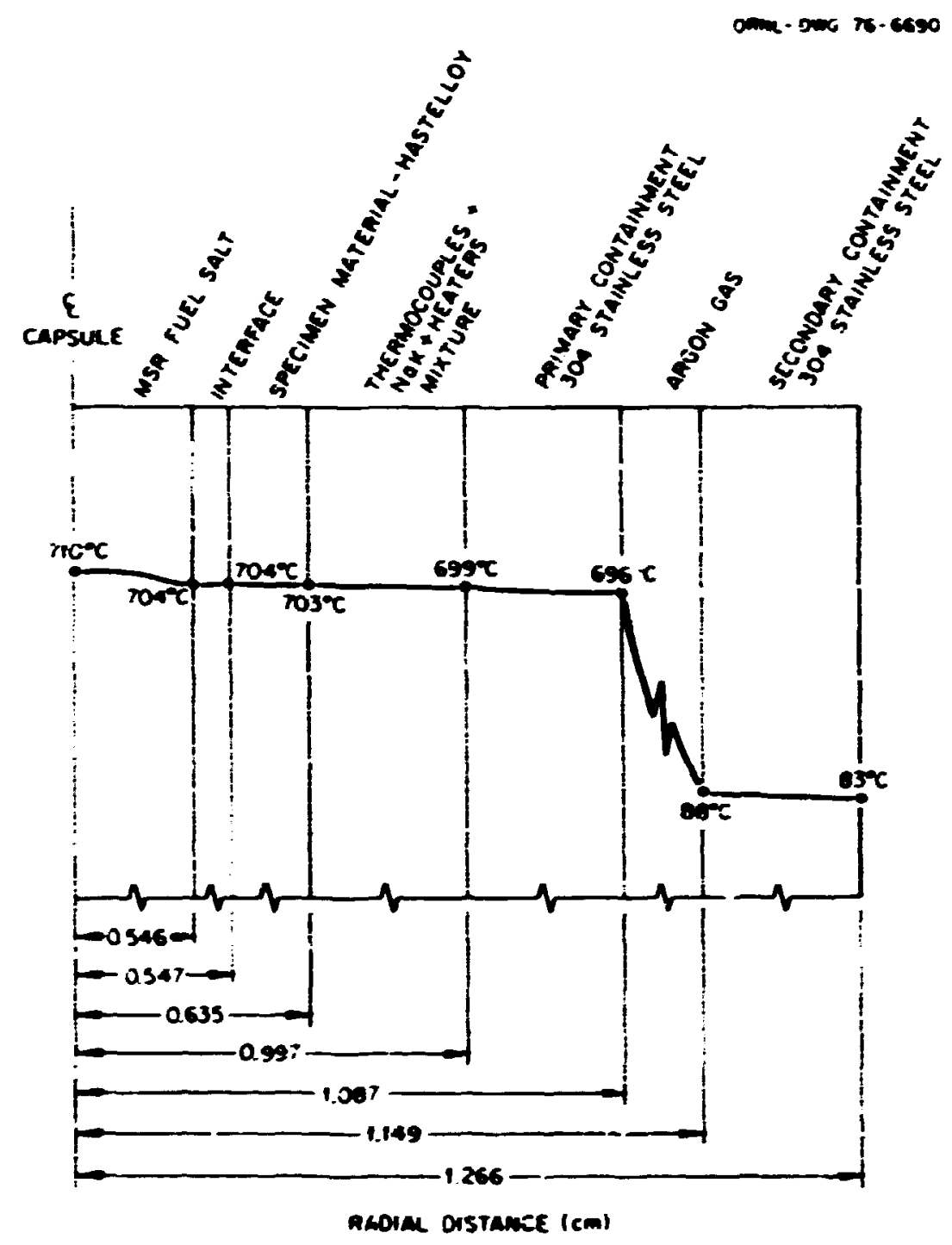

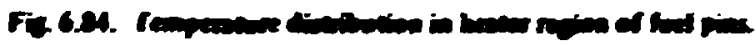




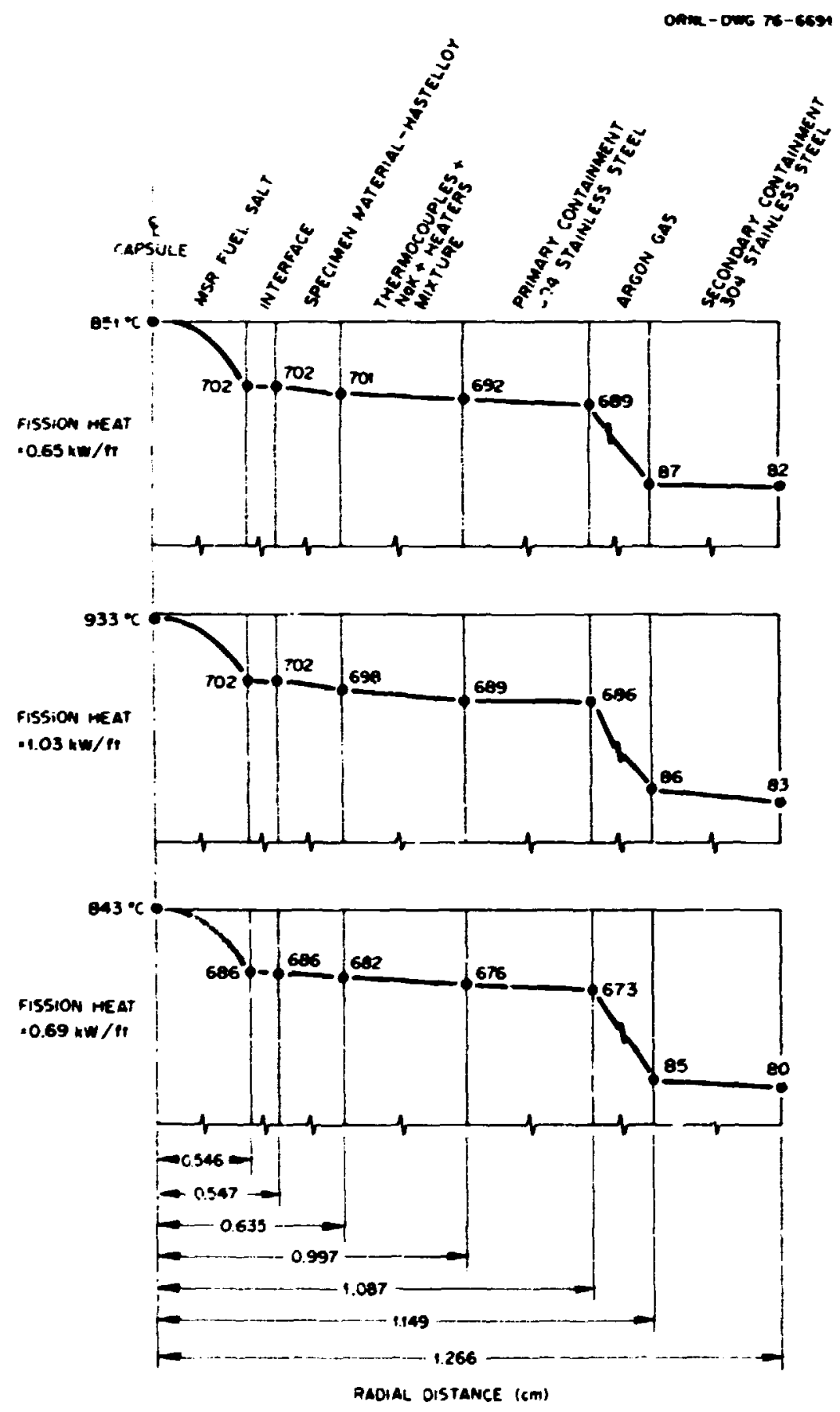

Fin 6.85. Relative meial temperature profiles. 
Tablo 6.32. Compoditions of alloys und in Telon.2 (in wi 5$)$

\begin{tabular}{|c|c|c|c|c|c|c|c|c|c|c|c|c|c|c|c|c|c|c|c|c|c|}
\hline Alloy & $\begin{array}{c}\text { Hoat } \\
\text { number }\end{array}$ & Sowrod" & $\mathrm{Ni}$ & Mo & $c$ & Fo & Mn & si & c & $\mathbf{T i}$ & $\mathbf{A} \mathbf{I}$ & $\mathbf{w}$ & $\mathbf{v}$ & Co & $\mathrm{Cu}$ & $\mathbf{s}$ & B & $\mathbf{N}$ & La & H & 0 \\
\hline Mocined Hantalty N & $545: 3$ & $\hat{\mathbf{v}}$ & Balence & $\begin{array}{l}11.67 \\
11.37\end{array}$ & $\begin{array}{l}7.02 \\
7.30\end{array}$ & 0.03 & $\begin{array}{r}<0.01 \\
0.01\end{array}$ & $\begin{array}{l}0.03 \\
0.15\end{array}$ & $\begin{array}{l}0.05 \\
0.09\end{array}$ & $\begin{array}{l}2.17 \\
1.75\end{array}$ & $\begin{array}{l}0.48 \\
0.54\end{array}$ & 0.14 & 0.02 & $\begin{array}{l}0.01 \\
0.1\end{array}$ & $<.0 .01$ & $<0.002$ & 0.002 & $\begin{array}{l}0.005 \\
0.0015\end{array}$ & & 0.0001 & 0.18 \\
\hline Inconal 600 & $\mathrm{NX} 3732$ & $A$ & 75.58 & & 15.03 & 8.62 & 0.27 & 0.16 & 0.03 & & & & & & 0.28 & 0.007 & & & & & \\
\hline Modined thaswloy N & 24534 & $\hat{b}$ & Balance & $\begin{array}{l}11.66 \\
11.38\end{array}$ & $\begin{array}{l}7.12 \\
7.67\end{array}$ & 0.06 & $\begin{array}{r}<0.01 \\
0.02\end{array}$ & $\begin{array}{l}0.03 \\
0.1\end{array}$ & $\begin{array}{l}0.08 \\
0.09\end{array}$ & $\begin{array}{l}2.09 \\
1.77\end{array}$ & $\begin{array}{l}0.53 \\
0.34\end{array}$ & 0.14 & 0.02 & $\begin{array}{l}0.03 \\
\text { C.03 }\end{array}$ & 0.02 & $<0.002$ & $<0.002$ & $\begin{array}{l}0.007 \\
0.0012\end{array}$ & $\begin{array}{l}0.013 \\
0.010\end{array}$ & 0.0002 & 0.0020 \\
\hline
\end{tabular}

A - wombors: - ORNL. 
and until their final sectioning for tensik and analytical specimens.

The three fuel pins were gamma-scanned in the HRLEL with a sodium-iodide detector using a 17 in. thick lead collimator with a 0.010 -in. $\times 1$-in.-wide slit (Fig. 6.86). The pins were first scanned using a single-channel analyzer and the differential from 0.55 MeV to $0.75 \mathrm{MeV}$ with 5000 counts sec full scale and $2 C_{i}$ standard deviation. An aluminum spacer ': in. long was placed between each pin. Each fuel pin recording has a spite which indicates sudden increased activity at the top surface of the fuel salt: the top pin (No. 2. heat 74533) has three spikes for this region but did net have a spike for the bottom of the fuet. as did the other two pins. None of the pins in TeGen-I had a spike for the bottom of the luel. The only difference in TeGen-I and TeGen-2 construxtion was that TeCen-2 had a hub with four small foils $' s$ in. wide $X$ ", in. long $\times 0.005$ in. thick welded to it at the top (gas plenum) and bottom (immersed in salt). The top pin (No. 2. heat 74533) had a void at the bottom of the pin, with no solt around the bottom hub and foils.

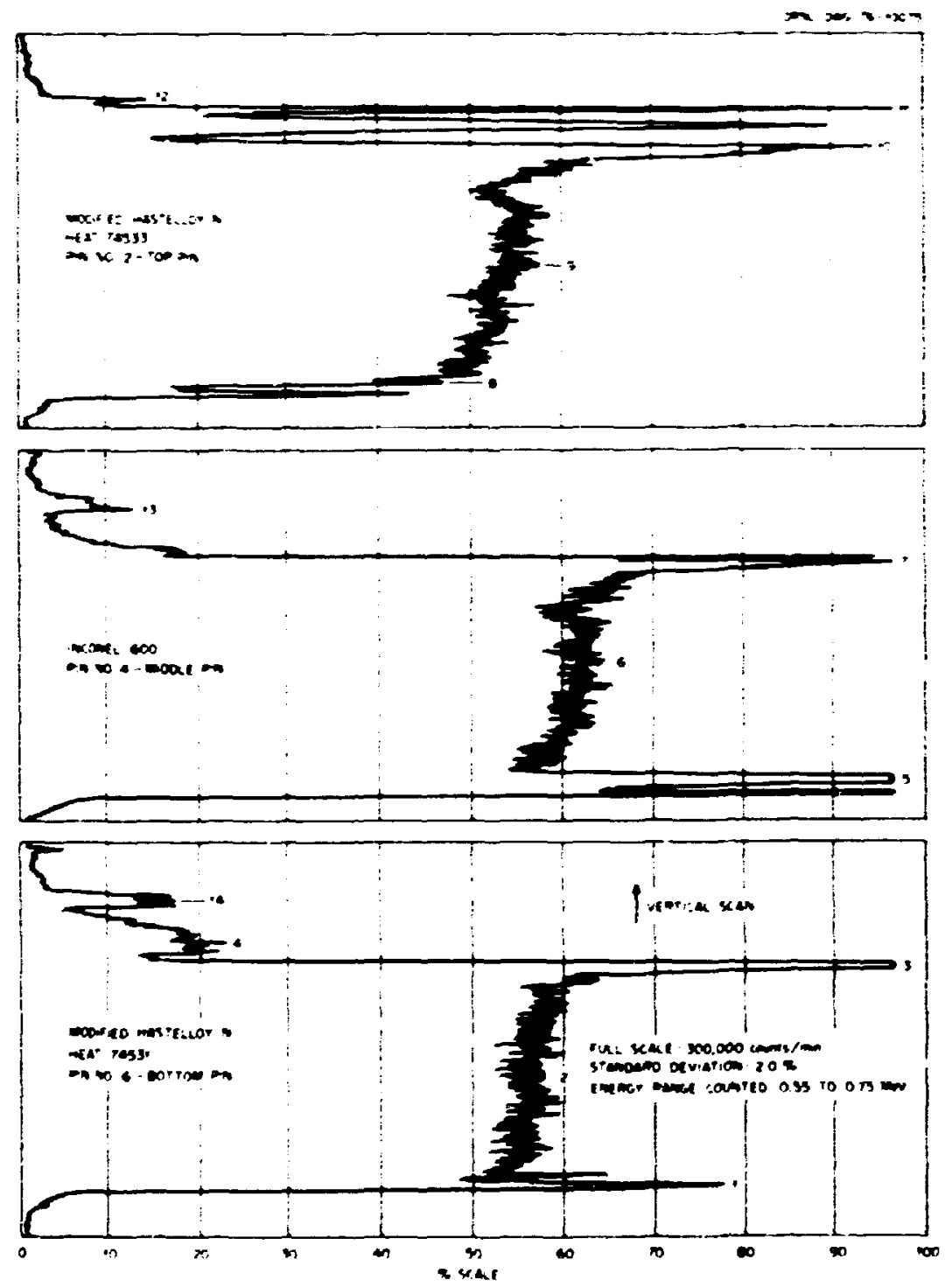

Fie 6.86. Gamme scans of fuel pins from the TeGon-2 experineat. Scans made vetically from botiom in inp of ecech pin. Numbers denote positions for activity we energy scans. 
Each of the fuet pins was scannod for etements present at the bottom. middk. and top of the salt and in the gas plenum. using the 512 chanoel anatyzer with a sodium-diode detector in HRLEL. A counting time of 15 sec was used for all sans except for those of the gas plenum and the background scans. which lasted $10 \mathrm{~min}$ because of the reduced activity. Figure 6.87 is a plot of energy or activity counts per minute per channet for ech of the three fuel pins at the bottom of the fuet. The scans were on the spite of increased activity on the bottom of pins 6 (bottom) and 4 (middk) and at an equivakent position at the bottom of the fuet in pin 2 (top). The activity was highes for the middle pin. as expected. slintly lower for the ivotiom pin. and considenbly lower for the cop pin. There were differences in the imeasities in the 0.6- to I. O-MeV range where the peaks are contribured to by "Zr. "Mb. "Co. and "I. These differences are nue presently understood but my be rethed wo the void spece at the bontom of pin 2. These scans were made four days after removal from the reactor fhex. and some of the stort half-tife frscion products are in evidence. wherens TeGen-1 had a longer (about (wo months) cooling period and no evidence of stort talf-life fission products.

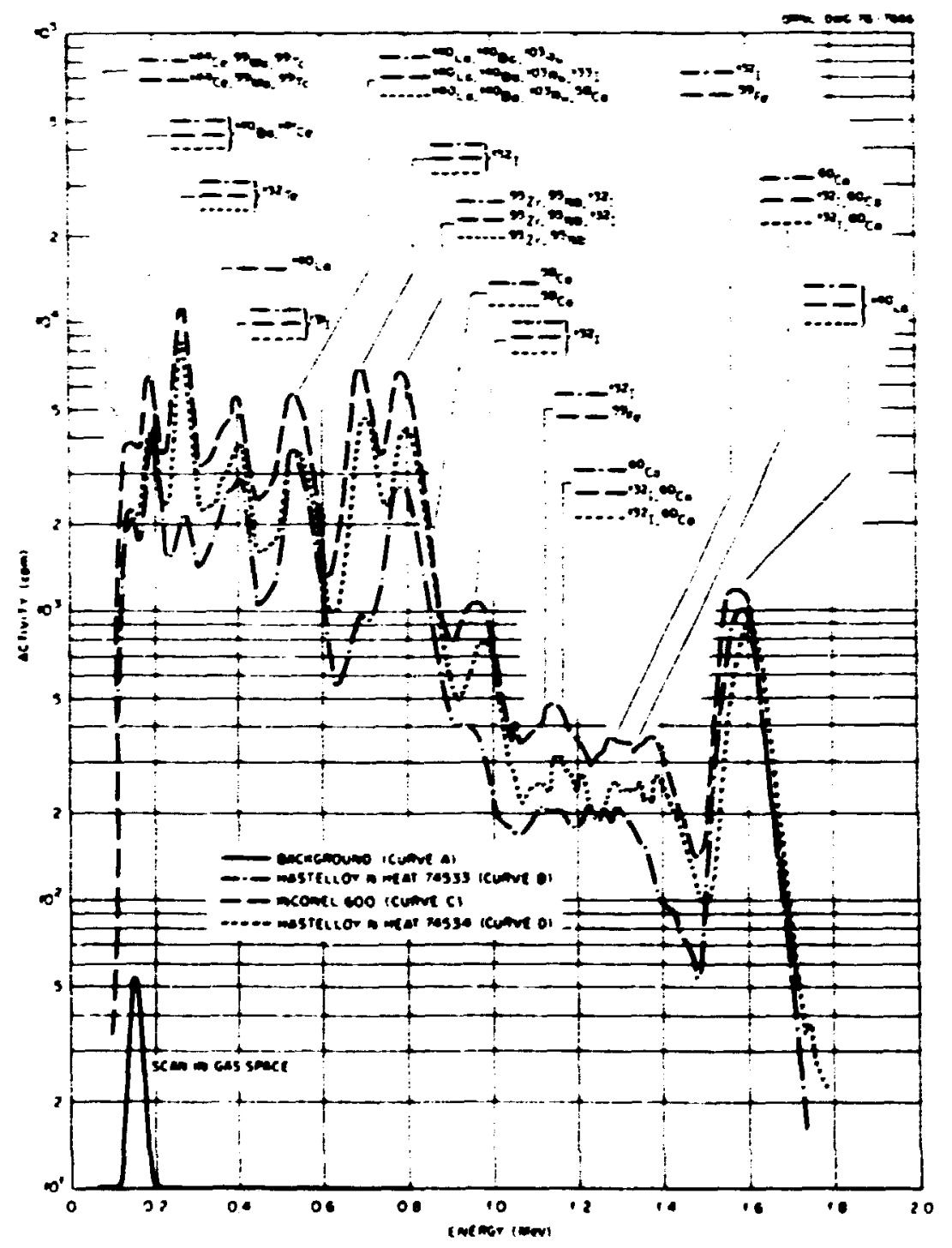

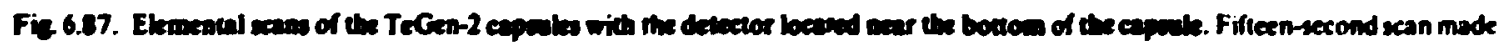
inrough a $0.010 \times 1 \times 17$-in. deep slit. 
Each of the fuet pins had a spite of activity al the top of che fuel salt: Fig. 6.8 show s a flot of activing is encrgy at the peat of the spite. Some of the fuet salt is present in each of the scans at the top of the salt. as shown by the high "La peak at 1.596 Mel in the first three scans. These scans are simibr to those at the middle of the salt. except that the activing is slightly higher at the peak. The fourth scan in Fig. 6.88 ons made on the third spike above the salt in the gas phenum on pin No. 2. shown as point 11 in Fig-6.86.
Note the beret peak for ${ }^{10} 1 \mathrm{a}$ at $1.546 \mathrm{MeV}$. indicating littk. if am. fucl glt. and the higher peaks for icdine and tellurium which should migrate to the ens space. This curve is simiter to the ones at the bottom of the salt of the middle and bottom pins. except for the bihanum peak. shown in Fiz 6.87 . The differences in these scans and the renson for deposition in layers. leading to spikes of activity in the gas space in the top pin. are not undersood at this time. Anatytical Chemising samples were taken from

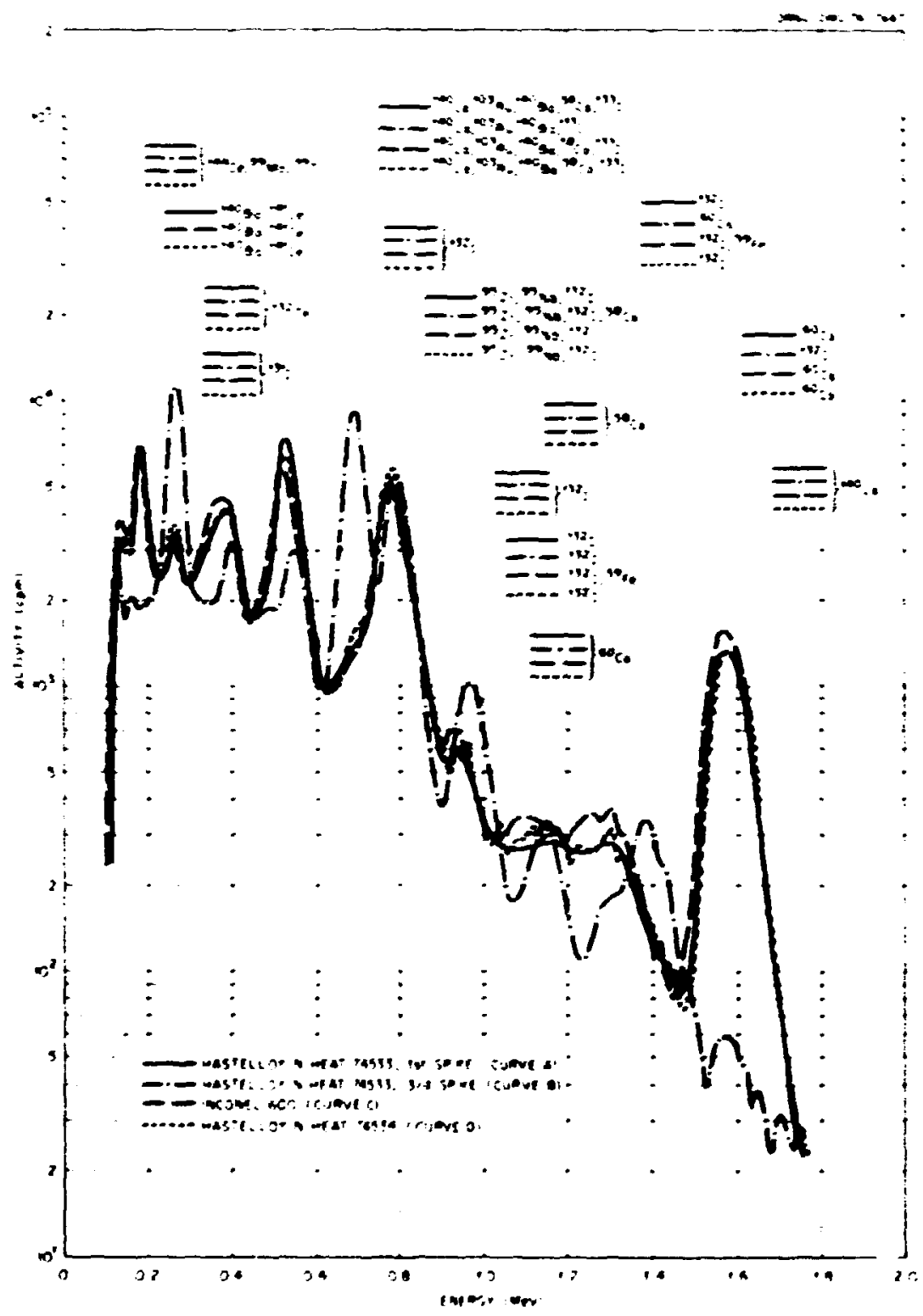

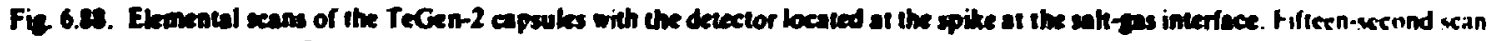
made through a $0.010 \times 1 \times 17$-in. deep slis. 
these varivus areas, and the roults ma! help to explain the counting data.

Scans were buen in the pas space of each of the fucl pins. but the peaks are similar to the one shown in Fig- 6.xy. scan 11 . except that the activity was much bower in areas not on actn ity spites. Scans mere also made at the middle of the fuel of each pin hut the? were iery similas to san 8 at the bottom of the No. 2 fuel pin shown in Fig- 6.87. Anahitical Chemistry has a multichannel analyzer with a germanium detector that can better separate the peaks of the different fission products. and these anahses will better define which elements are present.

The fucl pins were masured in HRLEL. for diametral change by using a V-block and dial gape arrangement. Table 6.33 shows the changes in dimensions to be very small. with a maximum of 0.3\% inctease in the diameter in the pos space of pin? at the sop. Prior to measuring. the pins had been maintained at $150 \mathrm{C}$ in a fumace. removed. and then allowed to cool. It is possible that they were still slight!y warm when measured. An unirradiated control pin measured in the same way showed a slight negative change. 0.10; and it had not heen healed previously. These changes are very small and are probably not significant. The pins were sectioned in the same manner as TeCien-1 by gripping the pin in a rotating chuck and using an abrasive cut-off saw. The sections cut and their respective eppositions are shown in fig. 6.x9. The salt surfaces. or menisci, were photographed during sectioning (fic 6.90). The sall level varied in pin?. Since the salt level was higher in pin 2 due to the loid at the bottom. pin 2 was pholographed aiter cut A-2. and pins 4 and 6 werc phutegraphed aiter cut $A-4$. The surfaces look different for each of the pins. as did TeCen-1. but the reason for these differences is not known. It could possibly be related to slizhtly different cooling rates for each fuel pin during solidification as they were remoled from the irradiation nux. Cbemistr. samples of the salt were taten from the surface of each of the fuel pins. and the results of these anatyses may help explain these differences.

The pins were sectioned through cut A-7 from the top of the pin. then reversed. and section C-I placed in the rotating chuck and the boitum end cap cut of with ang A-16 still attached wo that the foils could $h$ remuved without damage: then tuts $A-16$ through $A$ $x$ were madc. I he top pin ( Bo. 2. heat 74533 ) had a wid at the buttom of the pin. and no salt was around the foils welded to the hub. Figure 6. Hla shous a photograph of the hottom hub and foils surrounded by the tube (scgment A- $(6)$. There is no salt around the foils or in the bottom of the pin on top of the end

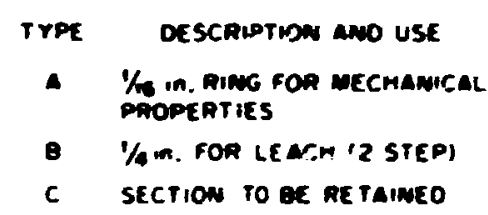

ont:- ons $75-\operatorname{sos} 2 \theta$

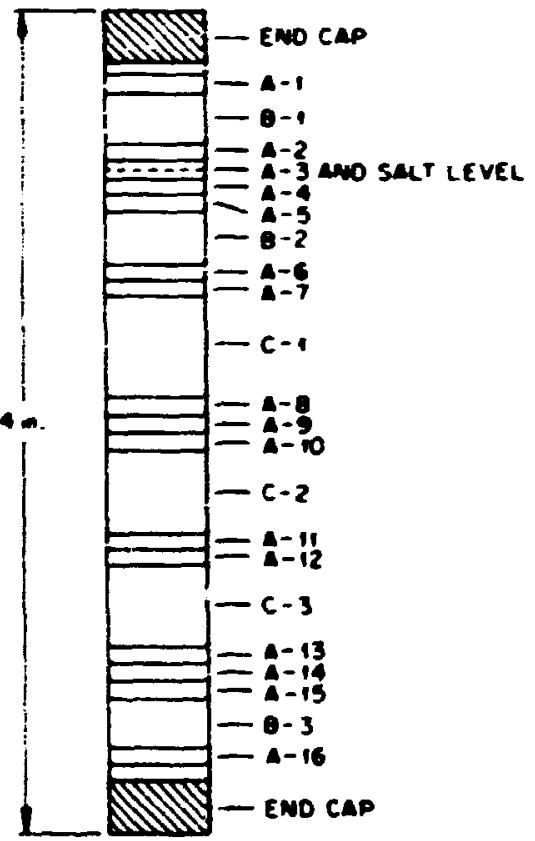

F4. 6.09. Schematic diegnam of individeal frel pia showion the locations of texp specinens. 
cap. Fige 6 6.91h is a photograph of the bottom of the salt e:at resed on wp of the hub in fiz 6.91 . Note the paricles hing on the hub (fig-6.9la) and the matching impressions ia the salt (fic-6.91h). The salt receded from the botion area in a meniscus, and the saw accidentally cut into it part of the way around. It is not understood how this void could have cecurred. removing the salt so ctanly from the a.ea of the foils and raising the entire volume of sate greater than , in. higher in the tube. X-ra! phutosraphs were bken of ihe fucl pin before it was instalked in the experiment. and there was not a vond in the bottom of the pin at that tirac. The luel puns uste maintained at 700 C approximately $1600 \mathrm{hr}$.

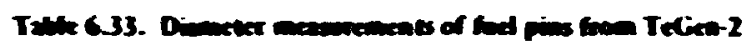

\begin{tabular}{|c|c|c|c|c|c|}
\hline Trum & Posisiva & $\begin{array}{c}\text { Postirratiotion } \\
\text { inencest } \\
\text { inj) }\end{array}$ & $\begin{array}{l}\text { Averse } \\
\text { dineneter } \\
\text { In. }\end{array}$ & 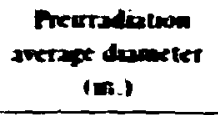 & $\begin{array}{c}\text { Domeles } \\
\text { cthoupe } \\
1 \% 1\end{array}$ \\
\hline \multirow[t]{4}{*}{2} & $\begin{array}{l}\text { Top } \\
\text { Top }\end{array}$ & $\begin{array}{l}0.5000 \\
0.5004\end{array}$ & 0 socs & 0.5001 & 0.10 \\
\hline & voulik & $\begin{array}{l}0.5006 \\
0.5 n 0 ?\end{array}$ & 0.5007 & $0.5 \mathrm{rres}$ & ons \\
\hline & $\begin{array}{l}\text { Dortom } \\
\text { Dotiom }\end{array}$ & $\begin{array}{l}0.5003 \\
0.4997\end{array}$ & 0.5000 & 0.4991 & 0.15 \\
\hline & $\cos$ & $\begin{array}{l}0.5017 \\
0.5003\end{array}$ & 0.5010 & 0.4995 & 0.30 \\
\hline \multicolumn{2}{|c|}{ AnTs: } & n.500s & & 0.4998 & 0.16 \\
\hline \multirow[t]{4}{*}{+} & $\begin{array}{l}\text { Top } \\
\text { Top }\end{array}$ & $\begin{array}{l}0.50033 \\
0.5007\end{array}$ & 0.5005 & $0 \sin 3$ & 0.04 \\
\hline & $\begin{array}{l}\text { Yoddle } \\
\text { Middle }\end{array}$ & $\begin{array}{l}0.5012 \\
0.5012\end{array}$ & 0.5012 & $0 \sin 3$ & 0.18 \\
\hline & $\begin{array}{l}\text { Entionn } \\
\text { Bntionn }\end{array}$ & $\begin{array}{l}0.5 n i s \\
n .5 n 11\end{array}$ & 0.5013 & Dsm? & 0.22 \\
\hline & $\begin{array}{l}\text { Caxs } \\
\text { Cass }\end{array}$ & $\begin{array}{l}0.4999 \\
0.4999 \\
\end{array}$ & 0.7999 & $0 . \sin 2$ & 0.16 \\
\hline \multicolumn{2}{|c|}{ Avetage } & $0.5 \mathrm{m7} 7$ & & $1+5 n 03$ & n.0s \\
\hline \multirow[t]{4}{*}{$t$} & $\begin{array}{l}\text { Ton } \\
\text { Top }\end{array}$ & $\begin{array}{l}0.5 \mathrm{~mm} 7 \\
0.501 ?\end{array}$ & 0.5010 & 0.SOOS & 0.10 \\
\hline & $\begin{array}{l}\text { Muddke } \\
\text { Moddke }\end{array}$ & $\begin{array}{l}0 . \sin 8 \\
0.5 m 07\end{array}$ & $0.500 x$ & $n \sin \theta$ & n.0? \\
\hline & $\begin{array}{l}\text { Pintionm } \\
\text { Rostinm }\end{array}$ & $\begin{array}{l}0.5 m 2 \\
\text { n.smons }\end{array}$ & 0.5004 & 0.5109 & n.1n \\
\hline & Giss & $\begin{array}{l}0 . \sin \theta \\
0 . \sin \theta \\
\end{array}$ & $0.5 \mathrm{~m}) ?$ & $\begin{array}{l}0.5004 \\
-\end{array}$ & $\begin{array}{l}\text { n.ms } \\
-.\end{array}$ \\
\hline \multicolumn{2}{|c|}{ Averapt } & 0.5097 & & $0.5 \mathrm{mon} 7$ & $n . M n$ \\
\hline \multirow[t]{4}{*}{$3^{\circ}$} & $\begin{array}{l}\text { Trpp } \\
\text { Trp }\end{array}$ & $\begin{array}{l}0.4994 \\
0.4994\end{array}$ & 0.4995 & n.sonl & 0.12 \\
\hline & $\begin{array}{l}\text { Muddle } \\
\text { Middk }\end{array}$ & $\begin{array}{l}0.4995 \\
0.4994\end{array}$ & 0.4995 & 0.5002 & 0.14 \\
\hline & $\begin{array}{l}\text { Anlinm } \\
\text { Bntlonm }\end{array}$ & $\begin{array}{l}0.4994 \\
0.4996\end{array}$ & 0.4995 & $0.5 \mathrm{mI}$ & 0.12 \\
\hline & $\begin{array}{l}\text { iass } \\
\text { (;ass }\end{array}$ & $\begin{array}{l}0.4994 \\
0.5001\end{array}$ & 0.4998 & n.s001 & 0.76 \\
\hline \multicolumn{2}{|c|}{ Average } & 0.4996 & & 0.5001 & f.10 \\
\hline
\end{tabular}



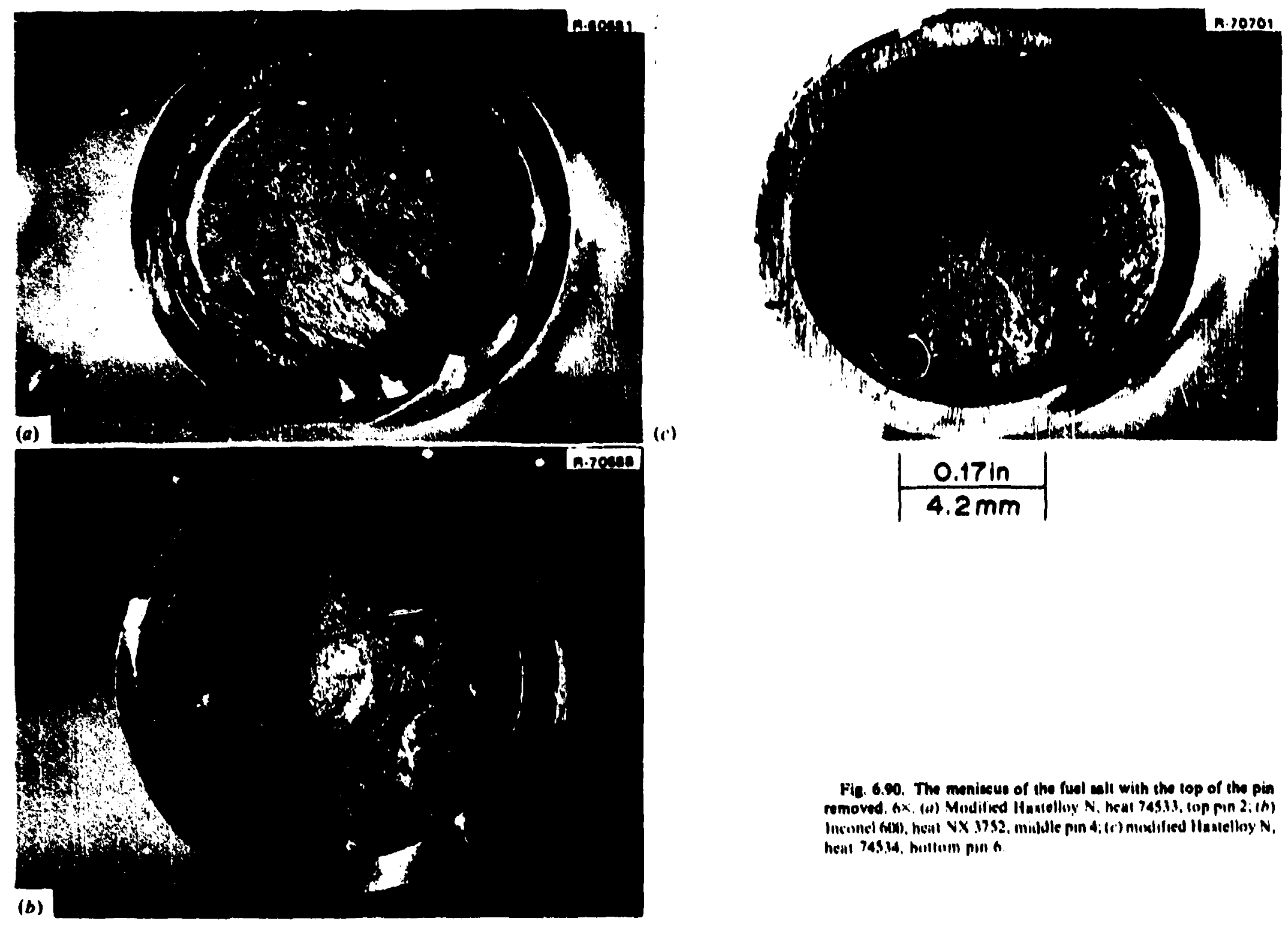

Fig. 6.90. The moniceus of the fual all with ithe top of the pin romoved. hx. (te) Mindilied Hancelloy N, hewl 745.13, lop pin 2:(h)

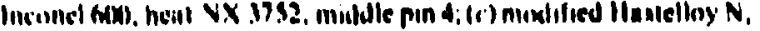
heill 74s, 14. helltilln pin a 


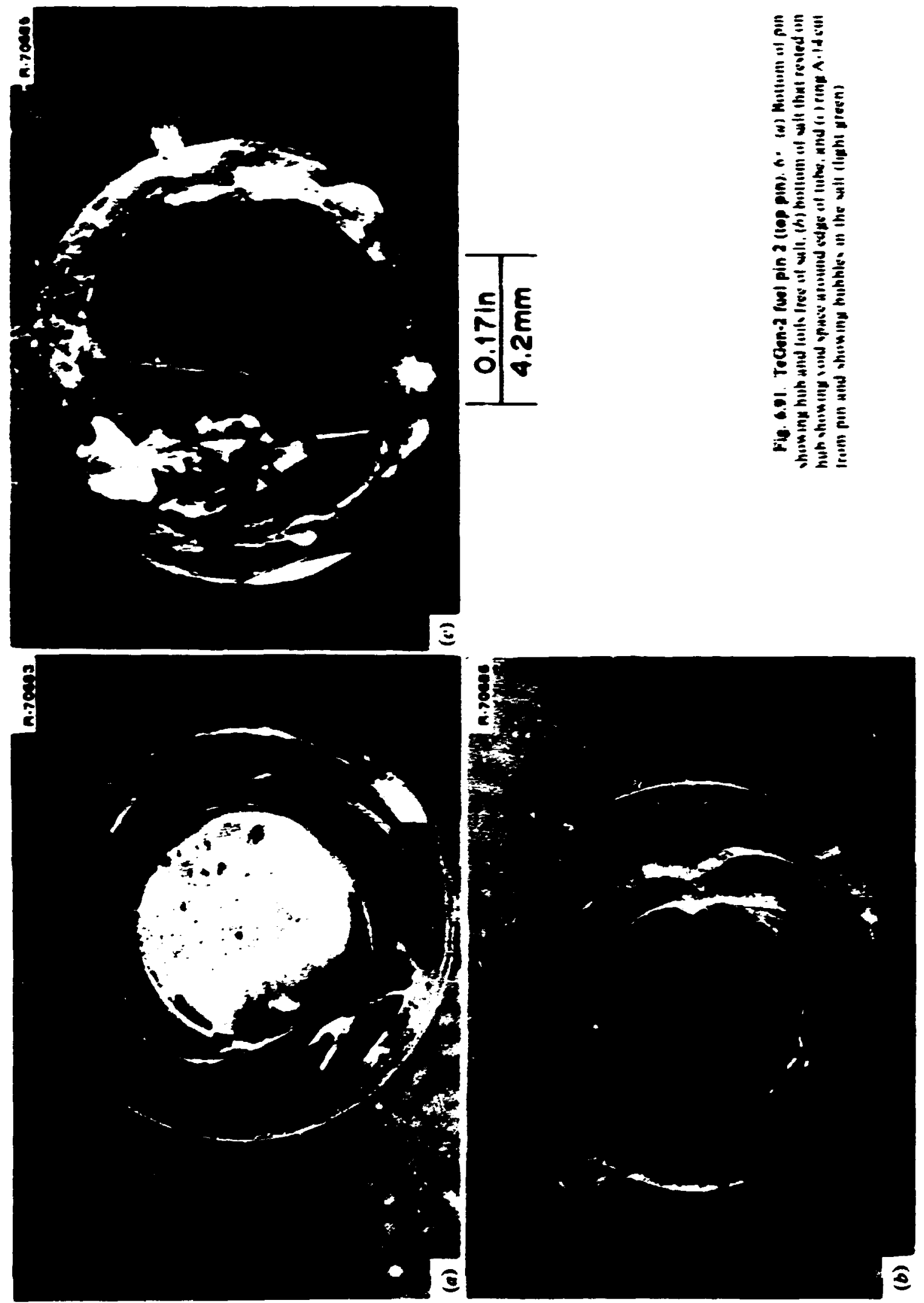


and the ofl would musi certainh have been mohen during that tounc. Fyure 6.91. shoms the next nag

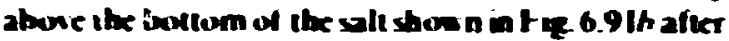

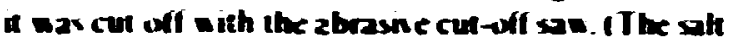
with son martines in $n$ and nubbles around it is still in the rive, The hubbles were very lethe green. contraled with the dart green of the resi of the foel all. Evidkat. sone of the glt was methed by the beat gencrated by the uncooled cul-ofl whed! : in. away) while cuting the bact side of the rine Some bubiles were noted ia the cutting of each ring nar the bottom bet not as many formed nar the lop of pin 2. and ven few were noted a cuting the ofler ino inel pies rivel pia 2 (lop) and foel ping (botena) are almos dentical in composition. and the same bekcin of satt was used to fill all the fuet pins; so this variable behavior is not understood. Pin o (that 7453) contained 0.01\%; bathanum. bet this should oot change the thermal conductivity appreciably, and the salt was well mixed by spargine with bydrown and argos before the foet pins were filled.

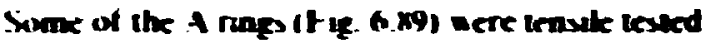
on an Insirua tenste mochns in the Buldune 3026) hot cells. I he rine fiviure as modified so that the rine could he bed in plece. Fquure 6.92 is a Fhotugraph of the future $\mathrm{sith}$ a 0.5-in-dian $\times 0.35$ in.-all $x$. -in-bog ring in plece and the top ctant partially rotated to bold bhe riagto pretear its shdats cut. During icsing as the mo hahes of the fixture were pulled apant. buth ctamps were rotated to the closed position I his modification worked well and allevinted the problems encouptered in testing of Tetien-l riag. Teasile dan for be lop. middle. and botom irrediated fuel pias are given in Tables 6.34. 6.35. and 6.36 respectinet. An arbitraty aswoned gage length of $0.5 \mathrm{in}$. azs used in the calcubtion of the yield strength and the uniform and loul ebonations. The values ginen in the tables are not absolute alues bet are useful for comparisons within the series. The !ield strengths appear te be slutht! increased and the elongations and reductions in are sligheț decreased by the irradiation and exposure to

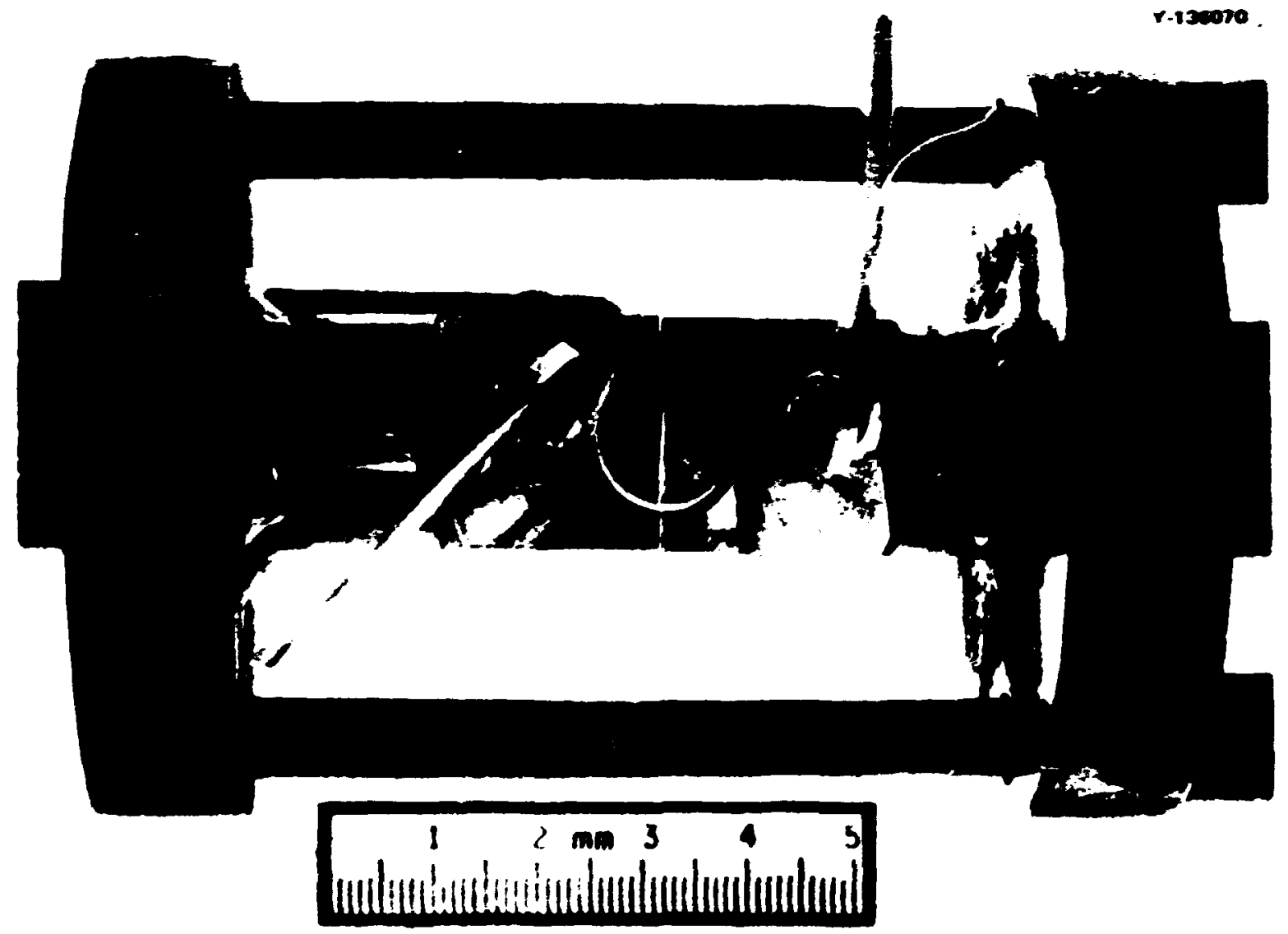

Fit 6.92. The fixtore for ceating ring in cencion, showing ring in position for teaine. 


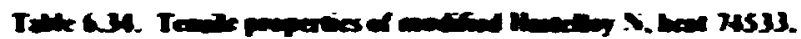

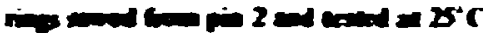

\begin{tabular}{|c|c|c|c|c|c|c|c|c|}
\hline \multirow{2}{*}{ Specienes } & \multirow{2}{*}{$110^{-3}=$} & \multirow[b]{2}{*}{ mopertional } & \multicolumn{2}{|c|}{$\sec 110^{3} \mathrm{mal}$} & \multirow[b]{2}{*}{ Firsiture } & \multicolumn{2}{|c|}{ 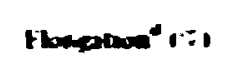 } & \multirow{2}{*}{ 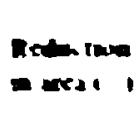 } \\
\hline & & & ricur & Clomatic & & ledent & Tut & \\
\hline $2 A-1$ & $4.2 !$ & 65.6 & 710 & 1346 & 121.3 & $9 . ?$ & 25 & 279 \\
\hline $24-2$ & 5.20 & 55.2 & 61.6 & 10.4 & Iet & 195 & $\mathbf{2 0 .}$ & 19.7 \\
\hline 2A-3 & 2.07 & 47.4 & 53.3 & 1106 & ice? & 19.9 & 214 & 27.2 \\
\hline $2 A 4$ & 5.33 & 619 & 675 & 123.4 & 10.7 & 24.3 & 36 & $12: 2$ \\
\hline $2 A-5$ & 5.03 & 6.7 & $\omega .7$ & litis & 1100 & 232 & 249 & 168 \\
\hline $2 A 6$ & 650 & $5-7$ & $\infty:$ & $11: 0$ & 1112 & 198 & 214 & $2 \div 0$ \\
\hline $24 . ?$ & 5.16 & $\omega .9$ & 70.8 & 1229 & 118.2 & 19.3 & 20.t & 18: \\
\hline $2 A+4$ & 5.19 & 53.0 & 57.4 & 836 & 4.4 & 7.0 & $10 ?$ & 197 \\
\hline $2 A-11$ & 5.07 & 622 & 67.1 & 120.2 & 1154 & 258 & 27.2 & 267 \\
\hline $2 A-13$ & 350 & 62.3 & $\omega .0$ & 114.9 & 109.4 & 218 & 22.7 & 31.1 \\
\hline $2 A-16^{6}$ & 3.41 & 85.1 & 93.3 & 126.7 & 121.7 & 7.9 & 88 & 26.3 \\
\hline Cromorod & & & 57.9 & IIs.; & 116.9 & 498 & $5 ! 3$ & 36.7 \\
\hline Control & & & 57.1 & ist & 113.5 & Hot & $\$ 9.2$ & ens \\
\hline
\end{tabular}

Courd on pape kenth of $0.5 \mathrm{~m}$.

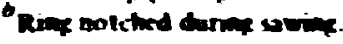

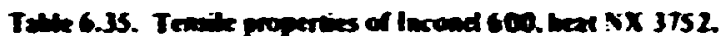

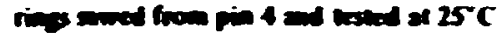

\begin{tabular}{|c|c|c|c|c|c|c|c|c|}
\hline \multirow{2}{*}{$\begin{array}{l}\text { Specimen } \\
\text { aumber }\end{array}$} & \multirow{2}{*}{$\begin{array}{c}\text { Cross } \\
\text { sectional } \\
\text { anea } \\
\left(10^{-3} \text { in. }^{2}\right)\end{array}$} & \multicolumn{4}{|c|}{ Siress $\left(10^{3}\right.$ par $)$} & \multicolumn{2}{|c|}{ Shapariono" $(r)$} & \multirow{2}{*}{$\begin{array}{l}\text { Reductions } \\
\text { in area (7) }\end{array}$} \\
\hline & & $\begin{array}{c}\text { Proportional } \\
\text { lumit }\end{array}$ & vieter & $\begin{array}{l}\text { Eilimale } \\
\text { rensile }\end{array}$ & Fracture & Vinitiorm & Total & \\
\hline $4 A-1$ & 5.11 & 45.0 & 50.9 & 93.0 & 85.5 & 22.0 & 23.7 & 28.6 \\
\hline AA-2 & 6.13 & 37.5 & 42.1 & 24.5 & 73.4 & 24.9 & 27.9 & 27.1 \\
\hline 4A-3 & 3.52 & 34.1 & 38.9 & 4.i & 57.7 & 21.0 & 26.6 & 42.9 \\
\hline and & 3.96 & 36.9 & 38.9 & 76.5 & 04.4 & 19.0 & 22.7 & 28.1 \\
\hline $4 n \cdot 5$ & 3.97 & 40.3 & 4.3 & 85.4 & 69.8 & 20.4 & 24.9 & $1+.6$ \\
\hline $4 A-6$ & 5.72 & 34.1 & 39.3 & 86.4 & 59.5 & $2 n+$ & 25.4 & 4.3 \\
\hline $4 A \cdot 7$ & 4.76 & 36.4 & 40.5 & 86.6 & 79.8 & 21.0 & 23.4 & 334 \\
\hline $4 A 8$ & 4.06 & 40.6 & 44.8 & 84.0 & 77.6 & 18.9 & 21.8 & 32.7 \\
\hline $4 A-11$ & 5.88 & 43.4 & 46.8 & 86.6 & 77.2 & 22.6 & $2 C .4$ & 36.4 \\
\hline $4 A \cdot 13$ & 5.34 & 35.6 & 39.1 & 86.7 & 76.2 & 25.5 & 29.6 & 20.6 \\
\hline $4 A-16$ & 4.13 & 45.3 & 48.9 & 94.2 & 84.3 & 18.9 & 22.6 & 22.9 \\
\hline $3 A-1^{b}$ & 4.86 & 35.4 & 38.4 & 83.0 & 77.1 & 30.6 & 3.3 .0 & 31.0 \\
\hline $3 A-2^{b}$ & 4.65 & 36.6 & 39.8 & 83.7 & 78.5 & 22.6 & 25.0 & 22.9 \\
\hline $3 A-3^{D}$ & 4.94 & 39.5 & 47.5 & 89.0 & 77.9 & 24.3 & 27.6 & 16.0 \\
\hline $3 A 4^{b}$ & 5.11 & 45.0 & 47.9 & 87.7 & 79.3 & 20.2 & 23.4 & 18.8 \\
\hline ;A-S" & 4.33 & 37.9 & $\$ 2.7$ & 88.2 & 79.6 & 24.5 & 27.3 & 21.1 \\
\hline Conirni & & & 35.8 & 82.5 & 69.3 & $4 n .6$ & 44.5 & 44.1 \\
\hline Contsol & & & 36.2 & 82.3 & 68.4 & 39.7 & 437 & 44.1 \\
\hline
\end{tabular}

Gased un ke knglh of 0.5 in.

${ }^{b}$ Contrnl pin falled with walt at sume time but not irradiated or tested in hot cell. 


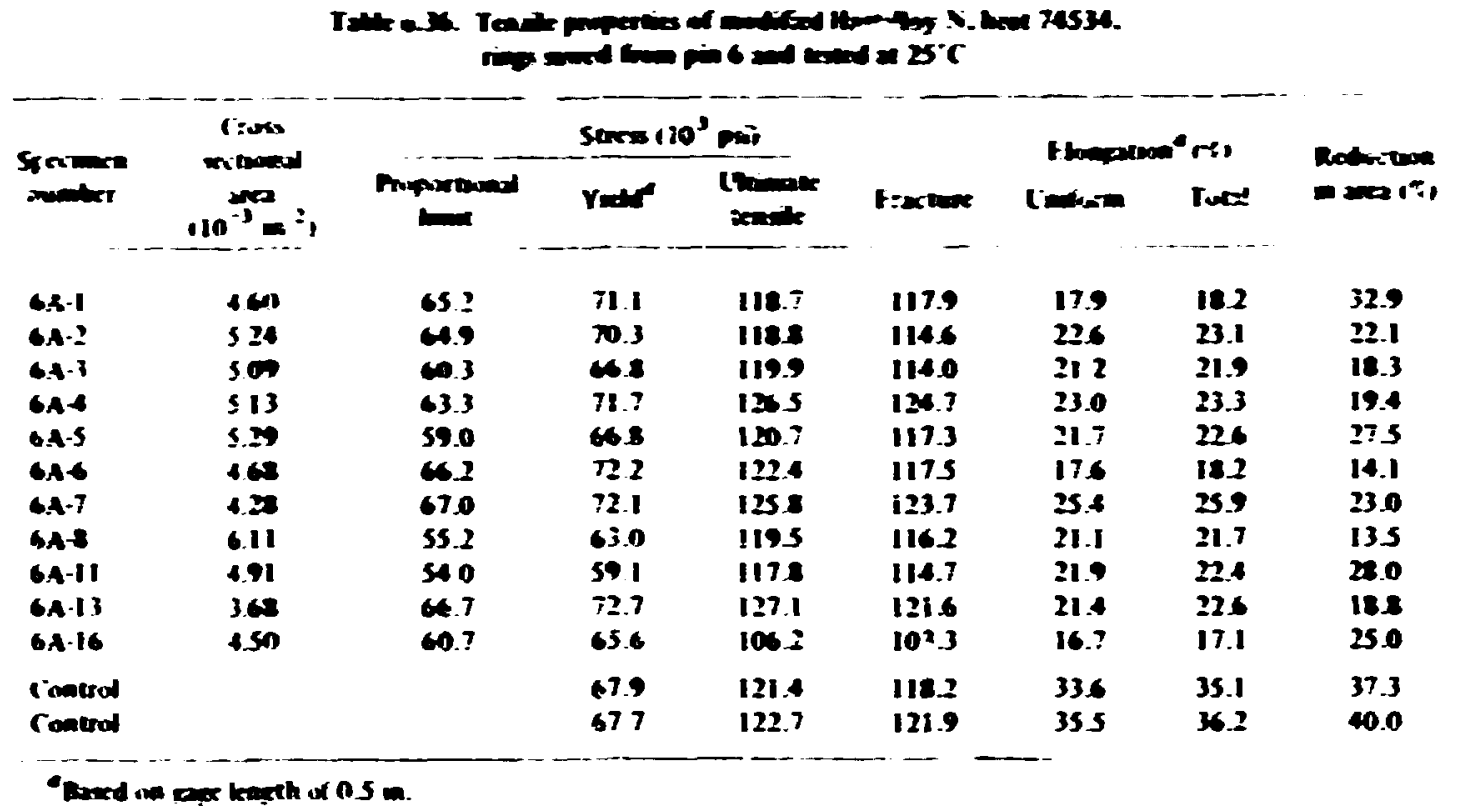

fission products. The elongations are still approximately 20; lexcept for some rings that had small notchss accidentally sured in them). which is acceptable. These changes are due to the combined effects of being at $700^{\circ} \mathrm{C}$ for approximatety $160 \mathrm{~h} \mathrm{hr}$ of exposure to the thermal neutrons and of the shallow cacking caused hy the fission products.

The rings were numbered consecutively from the top of each facl pin (fig. 6.89). The fucl salt kvel was higher in the top pin (approximately at ring A3) than the middle and bottom pins (approximately at ring A6) duc in the void at the bottom of the top pin elevating the salt. As discussed previously. ":." the most severe cracking in the MSRE occurred near the salt-tongas interface in the pump bowl. In the standard Hastelloy $X$ pin in TeGen-I, the rings at the top of the gas plenum (A-I and A-2) cracked almost as severely as at any other location (approximately 2.0 mil deep). Figure 6.93 shows photomicrographs of the top pin (modifsed Hastelloy $N$, heat 145.3. rings after irnsile testing at $25^{\circ} \mathrm{C}$. Rings $\mathrm{A}-\mathrm{I}$ (top) and A-16 (boitom) did not develop cracks. Both rings were shielded to some extent by the foils welded to the hub in the center (Fig. 6.9la). ( $R$ ing N.-16 was later cut from the area surrounding the foils.) $R$ ing $A$ I was surrounded by similit foils at the top or gas space of the same furl pin. As previously noted. the void at the bottom of the pin would indicate that both rings $(A-I$ and $\Lambda-I h)$ were in a gas space not exposed to the fuel walt. Ring A-2 (Fig. 6.91h) was just ahove the salt level, ring A-? (Fig. 6.91,; was at the surface of the salt. ring A-8 (fig. 6.91/) was at the middle of the salk. Ring A-2. just above the salt surface. appears to have deepe: cracks than the other rings.

Rings of the middle pin (Inconel 600 . heat $\mathrm{NX}$ 3752). after tensik testug at $25^{\circ} \mathrm{C}$. are shown in Fis. 6.94. Ring $A-1$ was at the top of the gas plenum, ring $A-5$ was just above the salt. ring $A-b$ was at the surface of the salt. ring A-8 was at ihe middle of the salt. and ring $A-16$ was at the bottom of the salt. Ring A-I (Fig-6.94a) at the top of the gas plenun did not crack on the inside lexposed to gaseous fission products) or on the outside exposed to VaK. Rings A-15 (Fig. 6.94h). A-t (Fig. 6.94). and A-8 (Fig. $6.94 d$ cracked on both the inside. ex rused to salt and fission products. and on the outside. which was exposed to Vak. Ring A-16 (Fig. 6.946) did not crack as severely on the inside as the rings near the top and middle of the salt and did not crack on the outside. exposed to NaK. Unkss there was a severe temperature gradient aiong tive kngth of the fuel pin. no explanation for this varied behavior can be given at this time.

Rings of the bot1om pin imodified Hastelloy $\mathbf{X}$. heat 745.34) tested at $25^{\circ} \mathrm{C}$ are shown in Fig. 6.95 . Ring A-I (Fig. 6.95a) was located at the top of the gas plenum. A-5 (Fig. 6.95h) was just above the salt surface. At (Fig. 6.95r) was just below the salt surface. A-8 (Fig. 6.95 $/$ ) was at the middle of he salt. and A-16 (fig. 6.95e) was at the hottom of the sa!'. Again. note that ring $A-1$ at the top of the gas plenum did not crack. as it was probably masked to some 


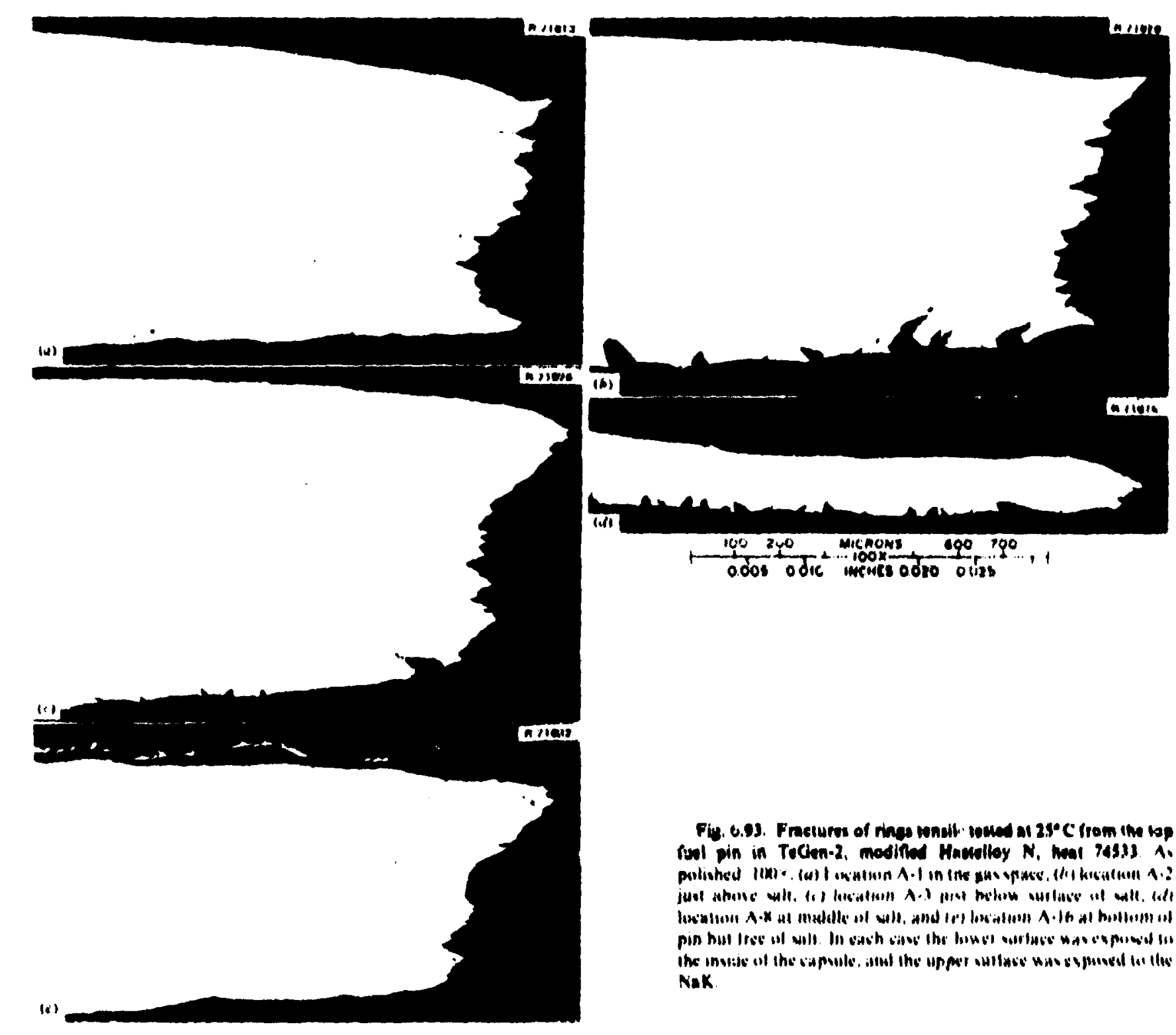

Cirom ing lap A

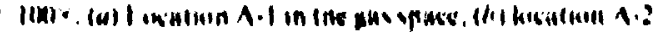

the whe

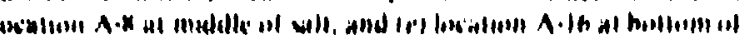

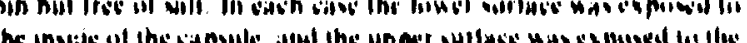
Nin 

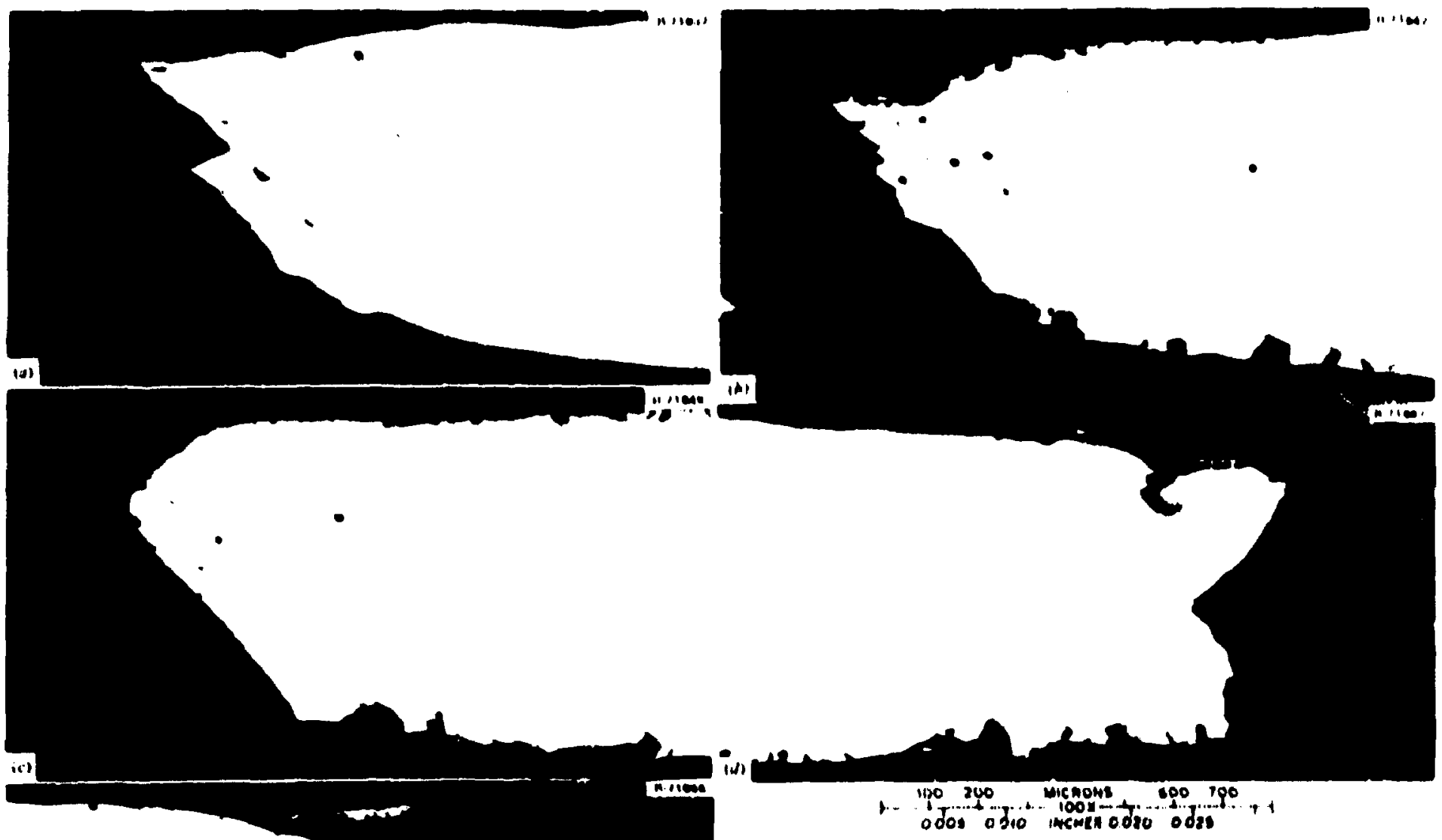

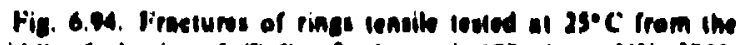

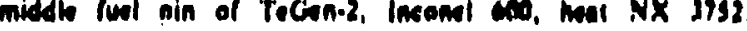

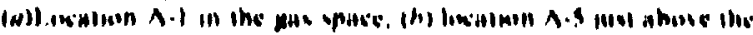

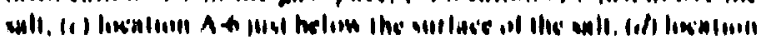

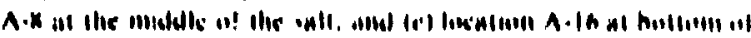

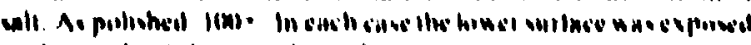

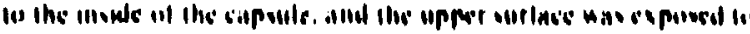
ine Nak 

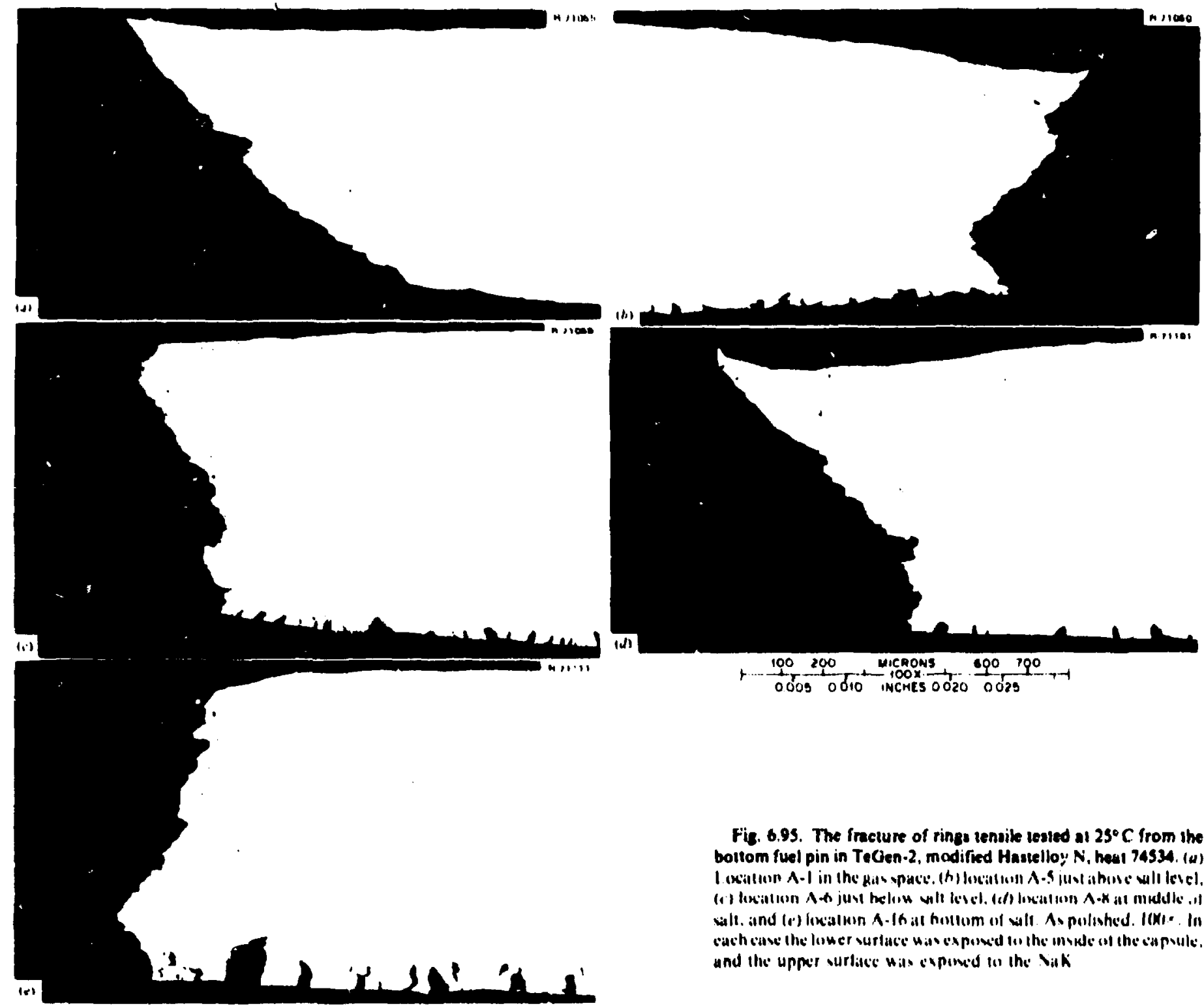

Fig. 6.95. The frecture of rings lensile lested a $25^{\circ} \mathrm{C}$ from the bollom fuel pin in TeClen-2, madified Hasielloy N, heul 74534. (4)

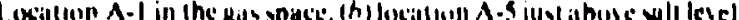

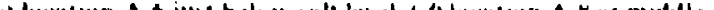

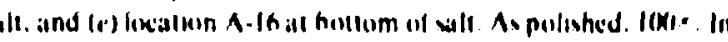

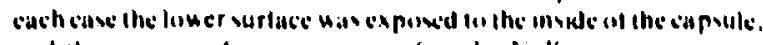
and the upper surlatec Hits cenpuese to the Silk 
extent by the foils. Ring A-16 at the hollom of the salt appears to have the most severe cracking of any of the rings. which is opposite to the trends noted in the middle and top pins.

The cracking in the Inconel 600 pin has slightly different charactiristics than the cracting in either of the modified Hastellox $\boldsymbol{X}$ pins. In our experiments with Inconel 600 expused to tellurium-containing environments. some heats of Inconel 600 were observed to crack. and other heats in the same capsuk did not. All the heats had almost identical chemical compositions. and it appears that 15\%; chromium is bordertine for crack resistance in this alloy. Inconel 601 with $2 y_{\text {; }}$ chromium resisted cracking much better in Tefien-I than Incon: 600 did in TeCien-2.

Analytical chemistry samples were taken from each fuel pin in the B sections (Fig. 6.89: designations are from top to hottom!. Specimen $B-1$ was from the gas plenum. B-? was fro $n$ near the salt surface and B-3 was from near the bottom of the salt. Fuel salt from the A rings containing the surface of the salt in each fuel pin was mecianically pressed from the rings and sent for analysis. This surfare satt probably contained the elements causing the spike of activity in this region. These chemisiry samples should help in understanding the distribution of the fission products along the length of the fuel pins and the reason for the different cracking behavior in different areas of the fuel pins.

Also being investigated in the Telien series of experiments are other alloys which are more resistant to Iellurium attack in our experiments and which should he more rasistant to Iission products. Some of these alloys were included in TeGen-3. scheduled for completion of the irradiation period in mid-March. and in TeCien-4. scheduled for insertion in the ORR in mid-April.

\section{REFERENCES}

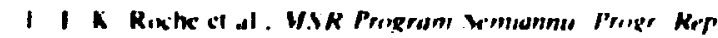

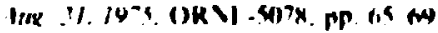

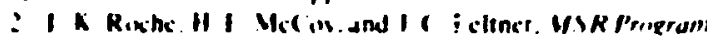

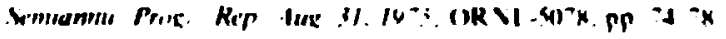

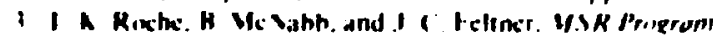

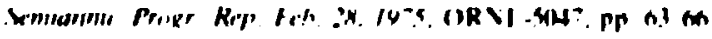

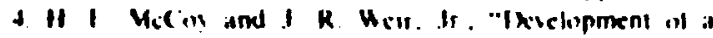

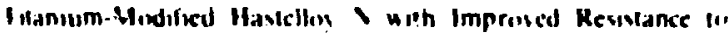

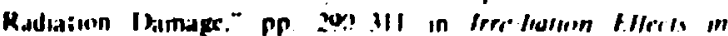

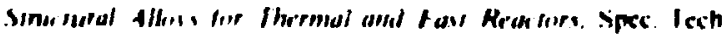
Puhl. 45?, Amerkian Sixiels lier Iesting and Waicrials. Philadel. phis. Iowe

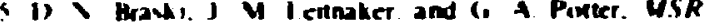

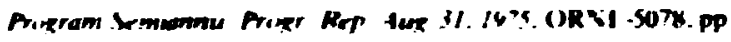
$4+41$

$h$ J $U$ sikixh and $u$; Irnstalf. Partal Inshcatum.

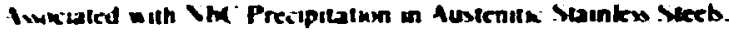

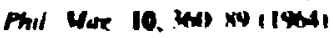

- I) I Mavd, I $Y$ I ennaker and G, A Poter. USA

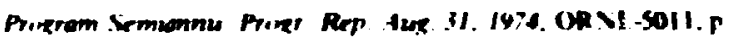
$+4$

M I R Whet and J Wull. Irans Met be t/Wf. 215, 127 (14.4)

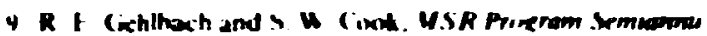

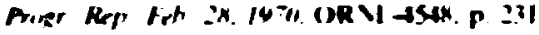

11) J R. Kencr. J R. Intectanco, and I J I an rence. USR

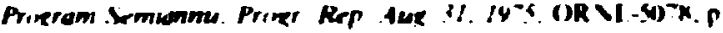
4

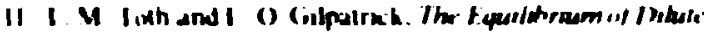

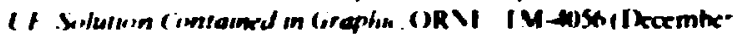
14:3,

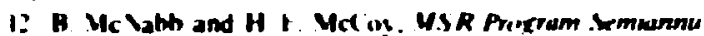

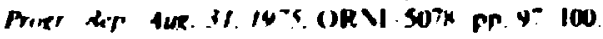

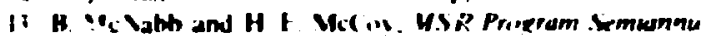

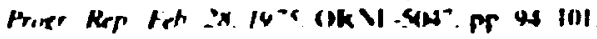

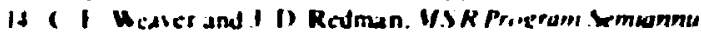

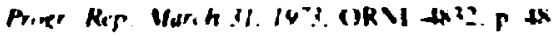

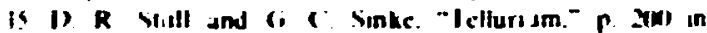

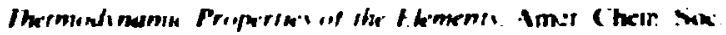
Ushingtion. I) ( . 145h

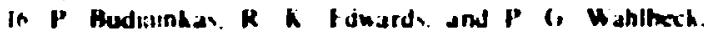

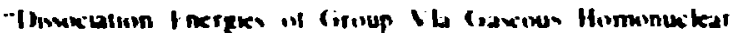
I bulumk Makcule, III Icllurium.- J ( hrm Phis. 49. 2x?I) || $4, \mathrm{k} \mid$

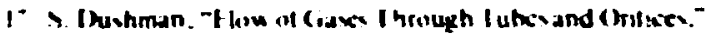

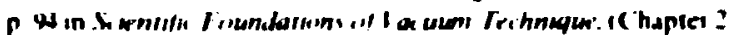

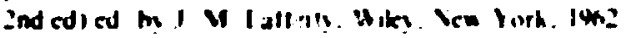

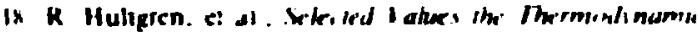

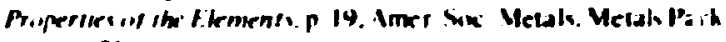
(Thiv. 19:?

14 Ithe lithwom tolluredes uxd in thes comeriments werc

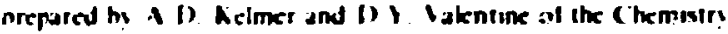
innsers

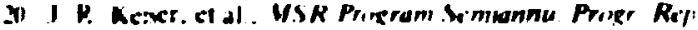

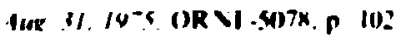

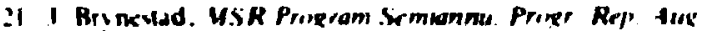

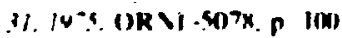

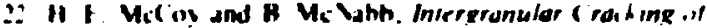

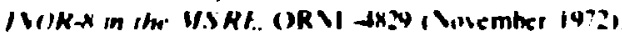

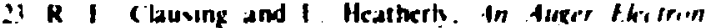

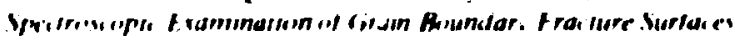

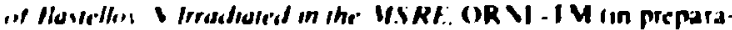
[uin)

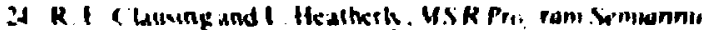

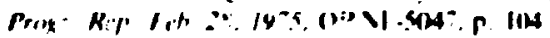

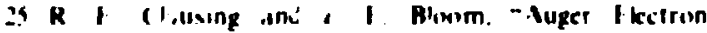

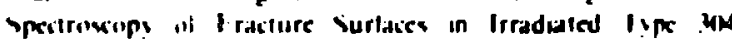

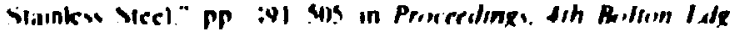

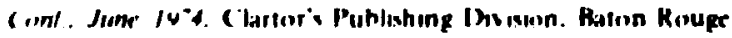
I a. 1474

2h. "Fractographs and Allas of traclographs. pp. $71,72,454$ Mrel, Mondhorh. Wol 4. ISM Metals Park. (Ohw. 147t 


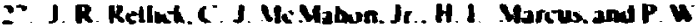

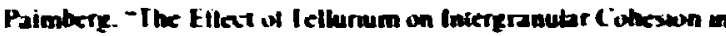

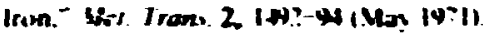

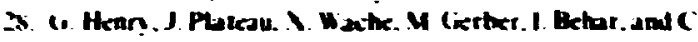

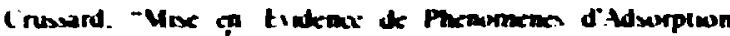

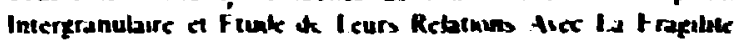

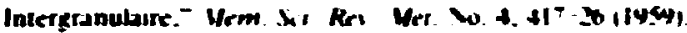

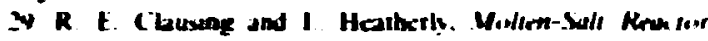

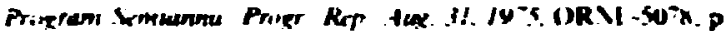
106 w H. F. Mocior, B Mclabb. and J. C. Fether. MSR

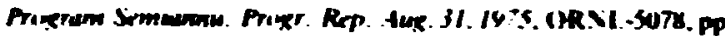
10* 122

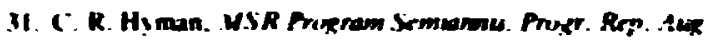
31. 19\%. ORNI 501:. PP. KI- 55 .

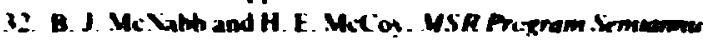

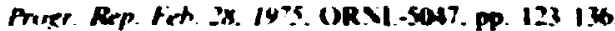

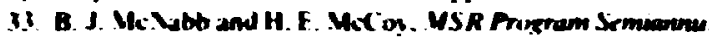

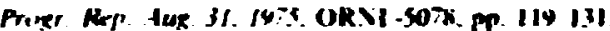




\section{Fuel Processing Materials Development}

\section{J. R. DiStefano}

The processes that are being developed for isolation of protactinium and removal of fission products from molten-salt breeder reactors require materials that are corrosion resistant to bismuthlithium and molten Muoride solutions. Past experience has indicated that although the solubilities of iron-base alloys in bismuth are low. they mass transfer rapidly in bismuth at sc0-700 C. The most promising materials for salt reprocessing are molybdenum. Ta-10\%: $W$. and graphite.

Molybdenum has been tested in a wide range of bismuth-lithium solutions jor up to $10,000 \mathrm{hr}$ and has shown excelknt compatibility. Thermodynamic data and literature reports indicate that moly bdenum will also be compatible with molten fuoride mixtures.

Tantalum-10\%, tungsten also has excellent compatibility with bismuth-lithium solutions. but tests are reyuired to demonstrake its compatibility with molten fuo:ide salts. A thermal convection loop was constructed of Ta-10\%; $W$. and a 3000-hr test at 600-700' $C$ with L.iF-BeF,-ThF_-UF_172-16-11.7-0.3 mole $\left.r_{i}\right)$ was initiated.

Graphite has shown excelknt compatibility with hoth bismuth-lithium solutions and molten salts. Although no chemival interaction between bisnuthlithium solutions and graphite has been found. the liquid-metal solution tends to penetrate the open porosity of graphite. Graphite exposed to Bi-2.4 wit $r_{r}\left(42\right.$ at. $\left.{ }^{\prime}\right)$ li in a molybdenum thermal convection lonp for $3000 \mathrm{hr}$ at $600-700^{\circ} \mathrm{C}$ picked up large quantities of bismuth and smali quantities of molybdenum. Recent tests have focused on evaluating the extent of dissimilar material interaction in Mo-(Bi-Li)-C and (Ta-10;i W)-Bi-li)-C systems.

\subsection{SUMMARY OF COMPATIBILITY STUDIES}

\section{J. R. DiStefano}

\subsubsection{Te-10\% W Thermal Convection Loop Tex}

Tantalum-10\% tungsten tubing of 0.875 -in. $O D X$ 0.050-in. wall was fabricated from 3.5-in.-diam rod using extrusior: and tube drawing techniques. This material was then used to fabricate a thermal convection loop (fig. 7.1). The loop contains Ta-10\% $W$ tubular and tensile specimens in the vertical hot and cold leg sections. The loop surge tank located above the hot leg is also constructed of

\section{H. E. McCoy}

Ta-:0\%, $W$, and the fluoride salt fill tank conrected to it is made of nickel. Tantalum resistance heaters are used to heat the vertical hot leg. portions of the two horizontal crossover lines. and the surge tank. Calrod resistance heaters were used in other areas. The entire loop system was heated to $700^{\circ} \mathrm{C}$ before salt was transferred into the loop. After fow was established. the Calrod heaters were tumed off: however. ttey will subseyuently be used when the loop is drained. The loop is circulating the salt mixture LiF-BeF:-ThF \&-LF (72-16-11.7-0.3 mole $F_{\text {) }}$ and has the temperature distributions shown in Table 7.I. The test is being conducted in a vacuum

\begin{tabular}{|c|c|}
\hline Location & $\begin{array}{c}\text { Temperature } \\
{ }^{2} \mathrm{Cl}\end{array}$ \\
\hline Bottom of hot keg & 510 \\
\hline Top of hot ke & 690 \\
\hline Top of coid lep & 680 \\
\hline Middle of cold lep & gan \\
\hline Botiom of coid itz & 585 \\
\hline Surge tank & 690 \\
\hline
\end{tabular}

bell jar at a pressure of $1 \times 10$ torr. and has operated for $\mathbf{4 0 0}$ of a scheduled $3000 \mathrm{hr}$.

\subsubsection{Discimibr Meterial Tests}

It was previously found that mass transfer of molybdenum to graphite occurred in a thermal convection loop test' after $3000 \mathrm{hr}$ at $600-700^{\circ} \mathrm{C}$. Since various components of a chemical processing system might well be constructed of graphite and a refractory metal, tests were begun to evaluate the extent of interaction of such dissimilar materials when they are both in contact with the same solution. Four test variables were investigated (Table 7.2). Molybdenum or Ta-10\% $\mathrm{W}$ specimens were heated for 1000 hr in a graphite crucible containing hismuth. lithium at 600 or $700^{\circ} \mathrm{C}$. A summary of the results obtained are shown in Tables 7.3 and 7.4. and typical metallographic results are shown in Fig. 7.2.

The conclusions that can be drawn from these results are that (1) the extent of intera:tion was slight 


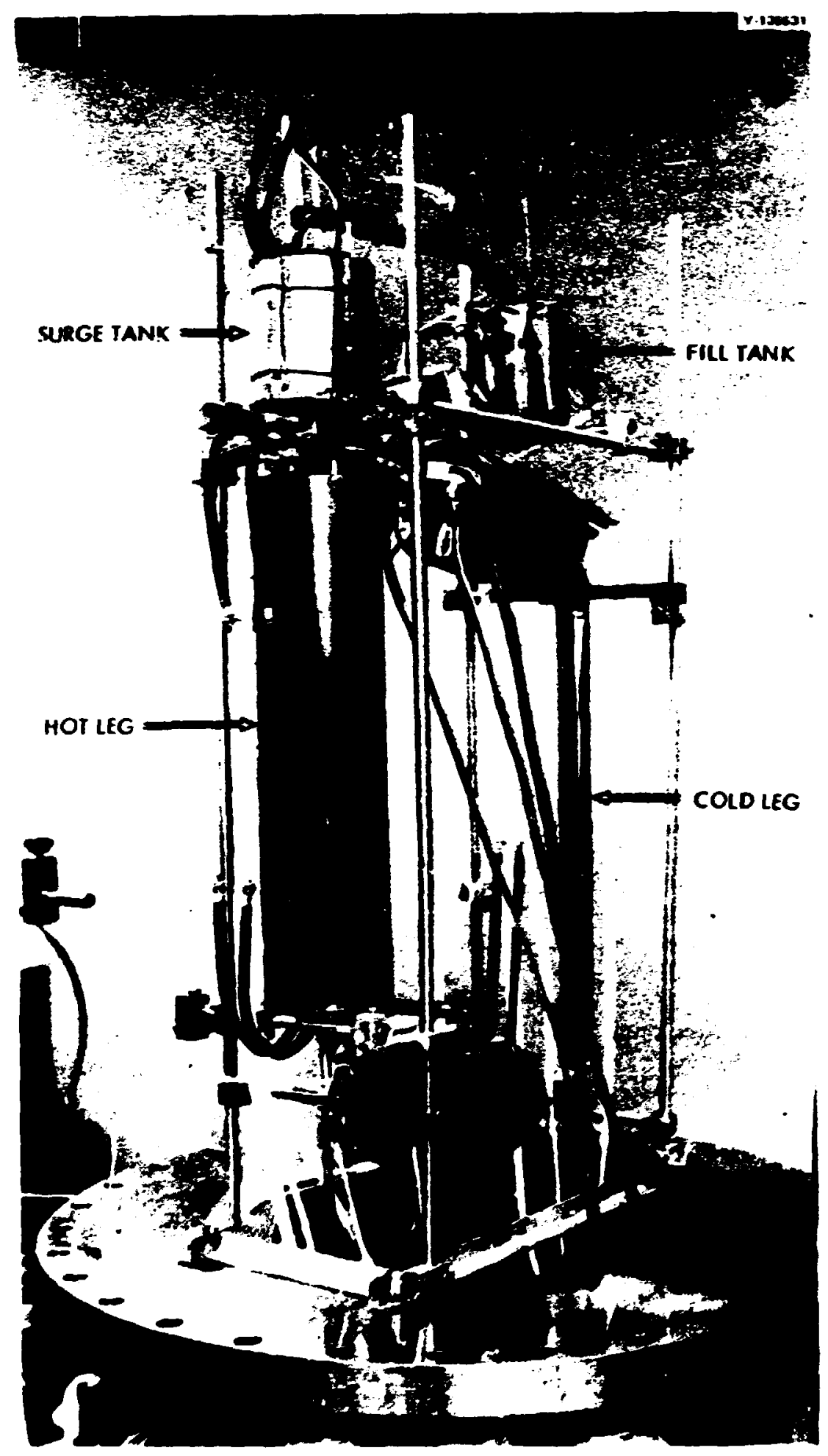

Fit 7.1. Tr-10\% W therwal competion bep. 


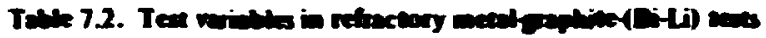

\begin{tabular}{|c|c|}
\hline Varuble & Desciption \\
\hline Refractory metal & Mo. Ia $10 \% \mathrm{w}$ \\
\hline Graphite & ATI. pyrolytically custed gesphize \\
\hline Temperature & $600.700 \mathrm{C}$ \\
\hline Lithium concentration of wlutum & B1. Bi 00F Li. Bi-2.5F Li \\
\hline
\end{tabular}

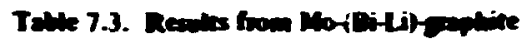

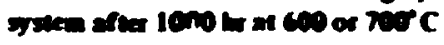

\begin{tabular}{|c|c|c|c|c|c|c|}
\hline \multirow{2}{*}{ Solution } & \multirow{2}{*}{$\begin{array}{l}\text { Mo } \sigma \\
\text { change } \\
\text { (mg) }\end{array}$} & \multicolumn{2}{|c|}{$\begin{array}{c}\text { Carbua cuncentratusn } \\
\text { (ppm) }\end{array}$} & \multicolumn{3}{|c|}{$\begin{array}{l}\text { Concentrathen } \\
\text { in graphite (ppon) }\end{array}$} \\
\hline & & Solutixn & Mo sample & $M 0$ & $\mathrm{Bi}$ & $\mathbf{L}$ \\
\hline \multicolumn{7}{|c|}{$\cos C$} \\
\hline \multirow[t]{2}{*}{ Bi } & ) & 34 & 5s & 20 & $=20$ & $<2$ \\
\hline & ) 3 & 28 & 47 & $<10$ & $<20^{\circ}$ & $<2^{4}$ \\
\hline Bi $0.01 \approx L_{i}$ & 2.3 & 5I & 58 & 30 & 30 & 50 \\
\hline \multirow{2}{*}{ B. $2.57 \mathrm{Li}$} & 0.8 & $15^{\circ}$ & 85 & $<10$ & 1000 & 250 \\
\hline & 06 & 66 & 71 & $<10$ & 30 & $25 \pi^{\circ}$ \\
\hline
\end{tabular}

\begin{tabular}{|c|c|c|c|c|c|c|}
\hline \multirow[t]{2}{*}{ Bi } & 118 & 42 & so & $<10$ & 90 & $<2$ \\
\hline & 112 & 21 & 43 & Sll1 & "هo & $\div 2^{\circ}$ \\
\hline $\mathrm{B}_{1} 01017 \mathrm{Li}$ & 22 & 8: & 55 & 50 & 20 & (1) \\
\hline \multirow[t]{2}{*}{ B. $25=21$} & 0 & 49 & $2(n)$ & -10 & IOS & 200 \\
\hline & n & 4h & 2411 & $\angle 10$ & 47 & $2(m)^{2}$ \\
\hline
\end{tabular}

Pyrocarbon-inated graphite umple

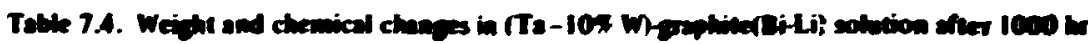

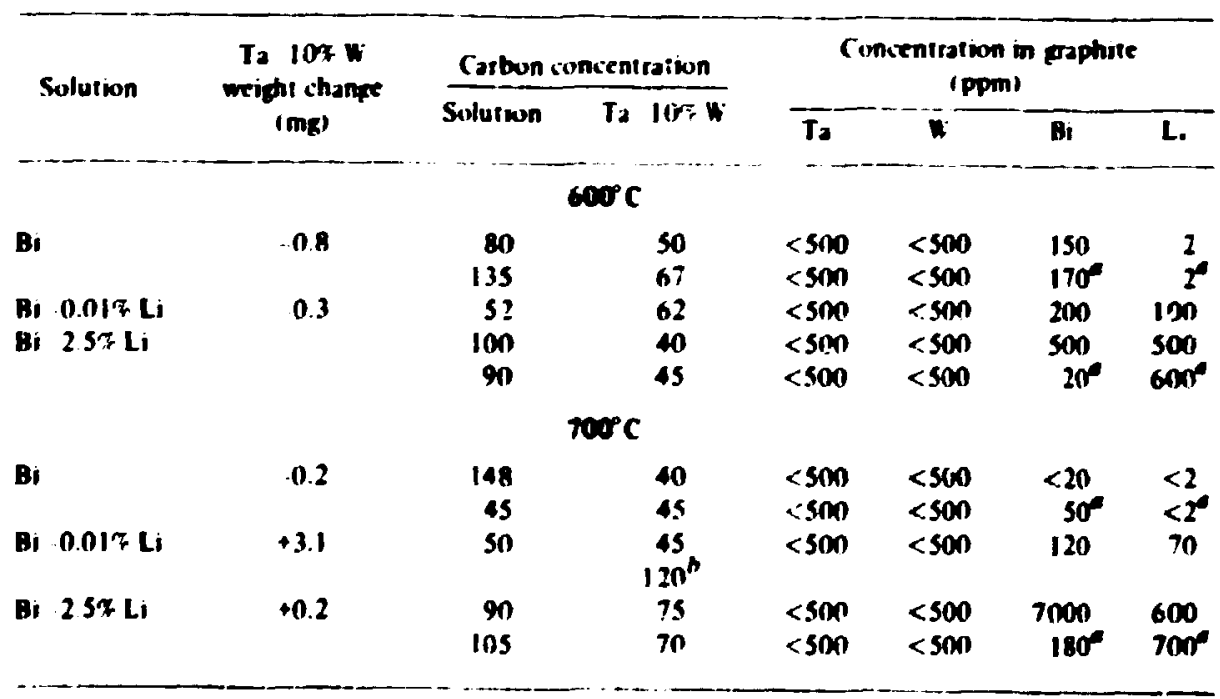

Pyrocarbon-coated gaphite sample.

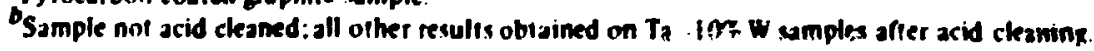



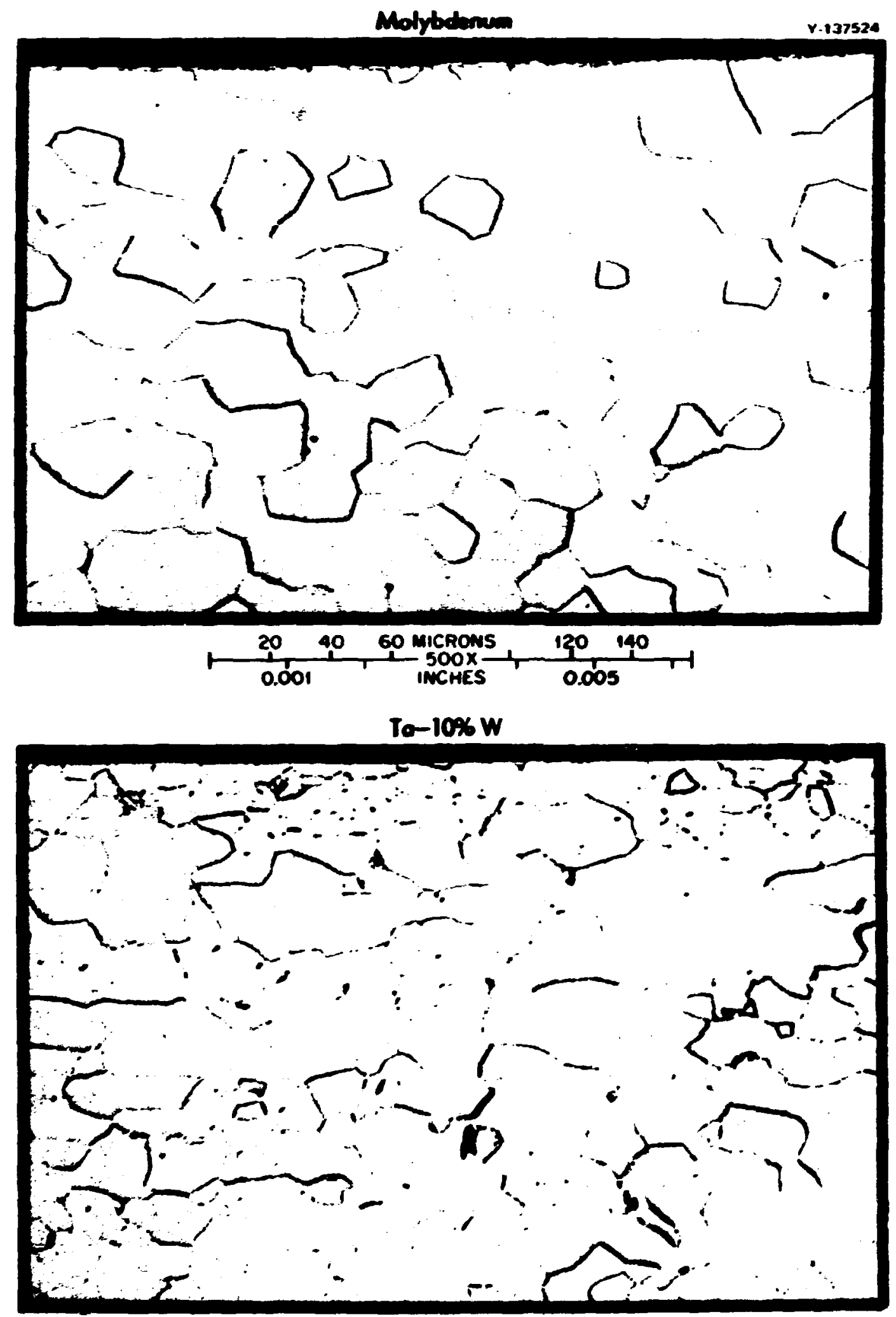

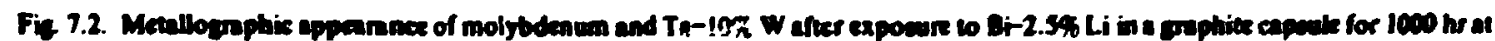
noc. 
bisinuth are being done to determine how to extrapolate results of mass-transter measurements in a small salt-bismuth contactor to the brge sines that would be used in a fuel processing plant. During this report period. mass-transfer-coefficient measurements were completed for three stirred. nondispersing water-mercury contactors. covering a wide range of agitator diameters and speeds.

A nonradioactive demonstration of froxen-salt corrosion protection in a continuous fluorinator requires an internal heat source not subject to atlack by fluorine. To provide such a heat source for future fluorinator experiments, studies have continued of autoresistance heating of molten salt in a fluorinator mock-up. These tests have shown that a major problem with the present design is plugeing that occurs in the unheated end of the salt inkt tube. which also senes as an electrude for autoresistance heating. Preliminany testing of the effectiveness of frozen-salt films for protecting against nuorine corrosion has continued.

The uranium removed from the fuel salt by Auorination would be returned to the processed sah in the fuel reconstitution step. The equipment is being installed for an engineering experiment to demonstrate the fuel reconstitution step. During this repon period the salt metering system was tested by flowing sall at the design flow rate $\left[100 \mathrm{~cm}^{i} \min \left(1.67 \times 10^{-2}\right.\right.$ $m^{\prime}$ s)] through the process vessels. Also. the UFa supply system was tested and calibrated. and the two gas density cells for off -eas anabysis were calibrated. The squipment now works sufficiently well that guldlined equipment can be instalke and the fuel reconstituiton siep demonsirated. 


\section{Chemistry of Fluorination and Fuel Reconstitution}

\section{R. Beanett}

An initial investization' of the reaction

$$
2 U F \text { (d) }+H_{.}(s)-2 U F(d)+2 H F(s)
$$

indicated that the reaction rate was bow. Subsequeatby, it was shown:" that the reaction follows zeroonder kinetics with a rate constant of 1.35 willimoles hr and that the rection can be calalyeed by platinum. A series of experiments at 5500 C (823 K) has been bezun to teas the canbric activity of platinum in forms that could be used in the foel Reconstitution Engineering Experiment (FREE) reduction colum and to investigate the onder of reaction of the catalyzed reaction. In the previous tests the catabzed reaction was so rapid that only one sample could be aken before completion of the reaction.

Daring this report period the experimental facility in Building 45r.I was reactivated. After the first tests. problems were encountered with plugeed lines in the UF, generator system. The phuged lines were repheed. and additional heating ta pes and insulation were used to prevent the oceurrence of cold spots in the generator system.

To evaluate the catalytic activity of smooth platiuum. a 1.25 -in. $(3 ! .8-\pi, m)$ diam disk of ' $1 \mathrm{w}$ in.(1.6-mm - Hhick platinum sheet was pressed into a 1.75-in.(44.5-mm)-diam by ":-in.(24-mm)-thick gold dist so that only the surface of the phtinum (are. $8.6 \mathrm{~cm}$ ) would be exposed to the mohen fuel salt. This disk was placed in the bottom of the gots reaction vessel: $0.200 \mathrm{~kg}$ of fuel salt. LiF-BeF-Tt.F. (72-16-12 mole $\%$ ). ciuntaining about I wt T uranium as UF, was added; and the s) siem was hydrolhuorinated for 24 hr at $600^{\circ} \mathrm{C}(873 \mathrm{~K}) 10$ remove any ox ides present. Gaseous $\mathbf{C F}$ a was then introduced to yield a finaj UF, concentration of about $2 \mathrm{mt} \%$. The temperature was reduced to $550^{\circ} \mathrm{C}(823 \mathrm{~K})$, and hydrogen was bubbled into the salt at $10 \mathrm{~cm}^{2} \mathrm{~min}$ $\left(1.67 \times 10^{-} \mathrm{m}^{\prime}\right.$ s) through a ', atin. $(64-\mathrm{mm})$-diam dip tube. The melt was periodially sampled. At the end of $2 \mathrm{hr}$. all the uranium was reduced to UF. Apparently even smooth platinum of limited surfece area affords appreciable catalytic activity: thus platinum sheet that could readily be incorporated in the FREE experiment should provide adequale catalytic activity in an MSBR processing system.

To determine the reaction order of the cathalyred reaction. two teats were carried out (test 16 UR with 2.04 wi $\% U^{* 0}$ and lest 17 UR with 3.54 wt $\%$ U").

\section{A. D. Ketuners}

Hydrogen was introduced at $20 \mathrm{~cm}^{\prime} \min 13.3 \times 10$ $\mathrm{m}^{\prime}$ ' s) and samples were caten at 10 or $15-\mathrm{min}$ intervak. The resuling dat (Fig. 8.I). when normalined and plotied as in (U." $)\left(V_{*}, "\right)$ vs time. gave a straight line, sugessing first-onder kinetics for the catalyaed reaction with a half-life of $65 \mathrm{~min}$. Additional tests are phnoned to evaluate the effect of hydrogen partil pressure and UF، concentration on the reaction kinetics to try to determine if the reaction exhibits true first-order kineties or if it is pseudo firstonder because of an ercess of one of the reactants in these first experiments. First-onder tinetics might be expected of a reaction that is diffusion limined. This could be diffusion of a reactant to the catabtic site or diffusion of an active speciess or product from the catabric site.

In addition to uranium. fissin'n products that remain in the MS8R fuel salt and have fluorides thel are vobatike at $500-600^{\circ} \mathrm{C}(773-873 \mathrm{~K})$ will be removed from the fuel salt by fluorination and will appear in the fuel reconstitution sep. Therefore. it is of interese to establich the chemistry of typical fission product fluorides; in particular, it would the desirable to know if the rero-order kinetics and concomitant bw hydrozen utilization obsened for $\mathrm{CF}$, is unique

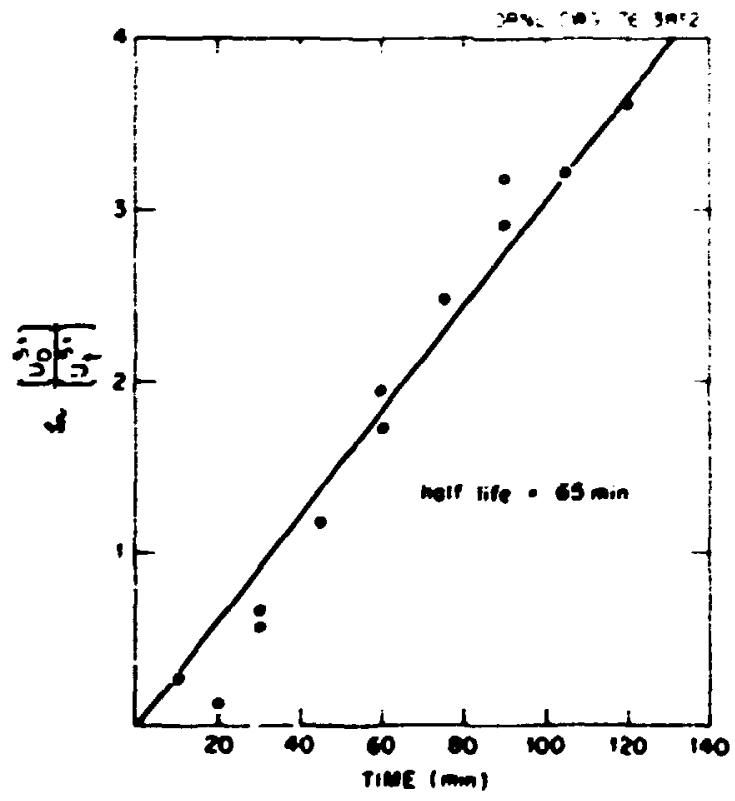

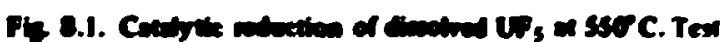
I6 UR, c: tent 11 UR. 
or represents a general case. Niobium, one of the major fosion prodices, should be volatilized as NbFa from the fuorination step and would then react with the UF, in the fuel reconstitution step for formsoluble NbF, Previous wosk has shown that the reaction

$$
\mathrm{NbF}(d)+2 H_{z}=4 H F+\mathrm{Nb}^{0}
$$

proceeded very slowly at $700 \mathrm{C}(973 \mathrm{~K})$ in Li, D.:F. According to Beses, under these coaditions. No (d) should be in equilibrium with $\mathrm{Nb}^{\mathrm{N}}$; that is. no intermediate oxidation states should exist.

A series of tesas was carried out using the gold reactor and apparatus previoushy used for the upcatalyzed UF, reduction experiments. In these ceses. $200 \mathrm{~g}$ of fucl sali and about $\mathrm{g}_{\mathrm{g}}$ of niobium metal chips were placed in the reactur and hydrofluorianated at $600^{\circ} \mathrm{C}(873 \mathrm{~K})$ with anhydrous $\mathrm{HF}$ both to remove oxides from the salt and to form discolved NbF 4 . It had been previously shown" that reaction of HF and Nb" proceed. slowly. In four experiments, meits containing 0.33 to 1.1 wt 5 NbF \& were prepared. The temperature was adjusted to $550 \mathrm{C}(823 \mathrm{~K})$, and hydrogen was bubbled into the sah at $40 \mathrm{~cm}^{3}: \min$ $\left(6.6 \times 10^{\circ} \mathrm{m}^{\prime}\right.$ s) through $a^{\prime}-\mathrm{in} .(6.4-\mathrm{mm})$-diam dip tube. The melts wer: periodically sampled, and the off-tas was scrubbed to Irap HF. which was subsequently determined as fucoride ion by a specificion elcetrode. The reduction reaction proceeded very slowly. Scatter in the molten-salt solution anabyses prevented use of those data; however. the measure of the HF evolution was useful. After normalization to correct for an initial surge of HF renerated when hydrogen was imitially admitied to the reactor, the data from all four tests gave a single line of slope of 0.203 millimok niobium reduced per hour when plotled in the fo:m for zeto-onder kinctics (Fiz. 8.2). Thus it appears that the reduction of NbF, is simitar to that of UF:

A fifth test was then carried out with granubs platinum. The generation rate of HF was increased for the first 2 hr and then fell to a value similar to that recorded for the uncatalyzed condition. The quantity of HF evolved during the first 2 hr was equivalent to that for the reaction

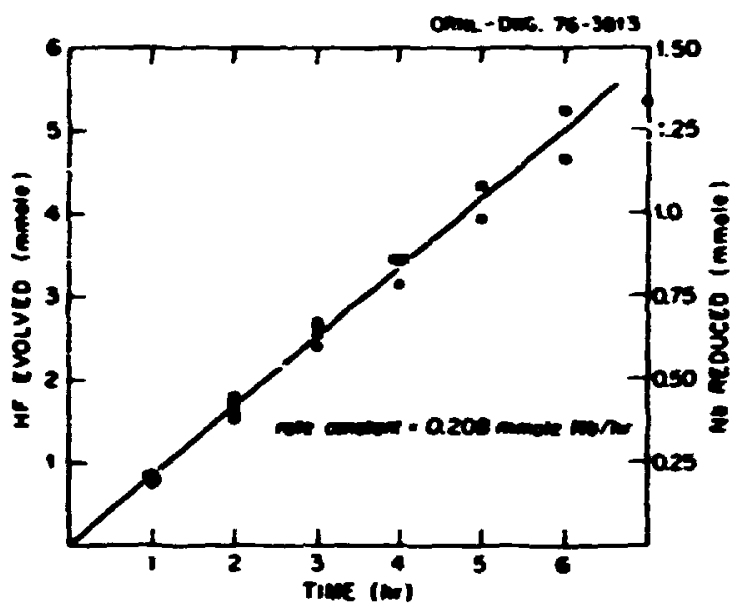

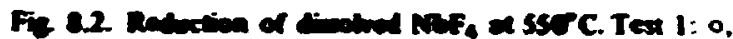

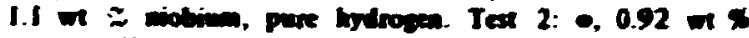

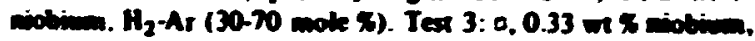

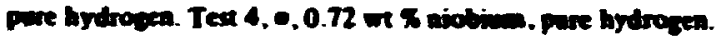

$$
N b F_{d}(d)+: H_{2}(s)=N b F_{3}(d)+H F
$$

Possibly an intermediate oxidation state, such as NbF, may be metastable and may offer a kinctic barrier to the complete reduction to Nb". Conversely. the platinum calalyst may be poisoned by the reaction products: so the apparent generation of HF equivalem to the reduction to NhF, may be coincidental. If the platinum catalyst is poisoned by fission products, this could have significant implications for its practical use.

\section{REFERENCES}

I. M. R. Benneti and L. M. Ferris. J. Mork. Vurl (Mom. 36, 1215 (1974).

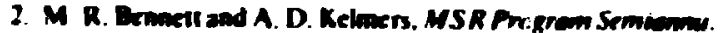

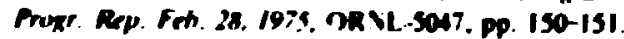

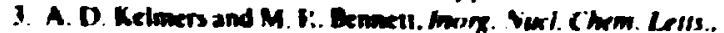
in press.

4. C F. Weaver and J. S. Cill. MSR Proknem Simiduman. Prog.

Arp. Fot. 28. 1971, OnNe 4676. p. ns.

S. C. F. Des. Jr.. J. Inil Mavr. S1, I99 (1974)

h. C F. Weaker and J. D. Redman. MSR Prokreon Sommanm. Prog. Aep. Alar. J1. 1970. ORVI.4622. p. 73. 


\title{
9. Engineering Development of Processing Operations
}

\author{
J. R. Hightower. Jr.
}

\subsection{METAL TRANSFER PROCESS DEVELOPMENT}

\section{H. C. Savage}

The metal transfer process for the removal of rareearth-eiement fussion products from Moiten-Sait Breeder Reactur (MSBR) fucl salt is being studied in engineering scale experimental equipment designated MTE-3B.' The experiments carried out in MTE$3 B$ are to determine the rate of removal of representative rare-earth elements trom molten-salt breeder reactor fucl salt (LiF-BeF:-ThF , 72-16-12 mole $\varphi_{t}$ ) and to measure the overall mass-transfer coefficients between the salt and bismuth phases in the mechanically agitated process vessels.

Results obtoined from the furst two experiments using the rare-arth element neodymium (:id-I and Vd-2) have been reported.' During these experiments. fluoride fuel salt was unexpectedly entrained into the lithium chloride in the mechanically agitated contactor. Agitator speeds of 5 rps were maintained throughout both "ns Nd-I and Nd-?. duplicating conditions that were preiousty used successfully in similar equipment:

During this report period, it was determired that entrainment occurred when the agitators were operated at a speed of $5 \mathrm{rps}$ but would not occur at lower speeds (up to 4.6 ps). The lithium chloride. contaminated with fluoride salt, was removed from the process vessels along with the lithium-bismuth in the stripper vessel. Purified lithium chloride and lithium-bismulh were added to the system, and two additional experiments were completed. ihese experiments were to determine the effect of agitator speed on the removal rate and overall mass-transfer coefficients across the three salt-bismuth interfaces for the rare-earth element neodymium. In one run (Nid-3) the agitator speed was maintained at 4.17 ps. In the second run (Nd-4) the agitator was maintained at $1.67 \mathrm{rps}$.

Results oblained in these two experiments (Nd-3 and -4) are given in the following sections.

\subsubsection{Entringent Sudies in Experiment MTE-3B}

Based on previous studies in a water-mercury system.' it was concluded that entrainment of fluoride salt into the bismuth and LiCl phases in the mechanically agitated contactor would occur if the agitators were operated at speeds of 5.0 rps or higher. However. in the first metal transfer experiment. MTE-3. entrainment was not observed at 5.0 rps but was seen at 6.7 rps."

Since fluoride salt entrainment occurred at an agitator speed of 5 ps in experiment MTE-3B. tests were made to determine the maximum allowable agitutor speed that could be used in experiment MTE-3B without entminment. These tests were conducted by operatirig the agitators in the contracte. al several different speeds (3.3. 4.2. and 5.0 ps) for times periods ranging from $\sim 50$ to $\sim 140 \mathrm{hr}$. During each test at constant agitator speed, samples of the $\mathrm{LiCl}$ were removed from the contactor and analyzed for fluoride content since an increase in fuoride ion concentration would indicate entrainment of fluoride salt into the $\mathrm{LiCl}$. Resultz are shown in Fig. 9.I, in which the fluoride ion concentration as a function of time is plotted for each agitator speed. The initial concentration of fuoride ion of $\sim 4 \mathrm{wt} \%$

onim towe 7e-34s

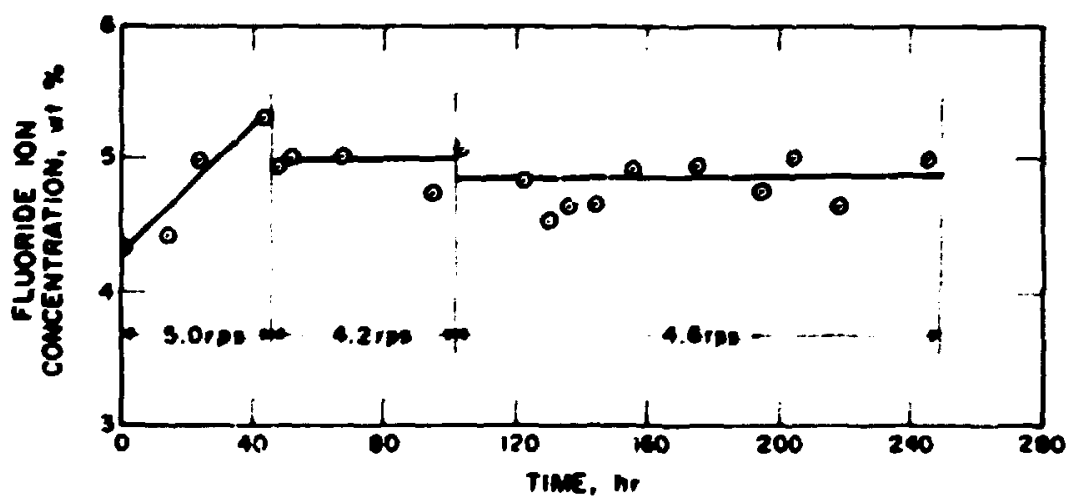

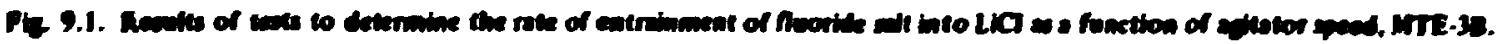


represents the amount of entrainment that occurred over a period of $\sim 250$ hr during runs $\mathrm{Nd}-1$ and $\mathrm{Nd}-2$. The seyuence of agilator speeds shown in Fig. 9.1 represents the order in which the tests were run. Entrainment is clearly indicated in the $\sim 50$ hr test at 5.0 rps. At agitator specds of 3.3 and 4.2 ps. no entrainment (within experimental limits) appears to have occurred over the $\sim 200$-hr combined test periuds.

It was concluded that future experiments could be carricd out at agitator speeds up to about 4.6 rps without en:rainment. It was also concluded that periodic determination of fuoride ion cuncentration in the LiCl to verify that no entrainment was occurring could be done rapidly and would be cesirable in future experiments. For this purpose an Orion Model 80IA jH mV meter* equipped with specific-ion (fluorix.e) electrodes was oblained for these experiments. This very accurate meter can also be used : o continuously measureand record ite EMF ( $250 \mathrm{mV}$ ) between the two bismuth phases in the contactor and stripper vessels containing different concentrations of lithium reductant $\sim-0.0015$ and $\sim 0.050$ atom (rastion lithium). Changes in EMF would indicise a change in the relative lithium concentrations in these phases. with a resultant change in the equilibrium-distribution coefficient for neodymium between the salt and bismuth phases. Determination of the overall mass-transfer coefficients is dependent on the equilibrium distribution coefficients.

\subsubsection{Removal of $\mathrm{LiCl}$ and Bi- $\mathrm{Li}$ Phases and Addition of Purified Sohutions}

The lithium chloride (contaminated with nuoride salt) in the contactor and stripper vessels and the bismuth (depleted in lithium reductant) in the stripper were removed without dificulty. The lithium chloride and bismuth were removed by transfer into an external receiver tank through a heated transfer line and dip tube extending into the process vessels. A new charging vessel was fabricated for subseyuent use in purification and addition of the lithium chloride and bismuth-5 at. Fithium solution to the process vessels.

Chemical analyses of the purified lithsum chloride in the contactor and stripper indicated that the

- Mrion Kexarch Inc. Cambridg. Mas.
Muoride ion content had been reduced from $\sim 5$ wil $r_{i}$ to $\sim 0.15$ wi $c_{i}$. The 0.15 wi $c_{\text {; }}$ theoride content of the purified lithium chloride indicated that a heel of

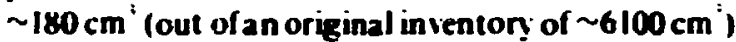
of the contaminated lithium chloride was not removed from the process vessels. This amount of nooride 10.15 wt $c$ ) would not be expected to affeet the equilibrium-distribution coefficients for neodymium or thorium at the LiCl bismuth interface in the contactor." Analysis of the purified bismuth-lithium in the stripper indicated a lithium reductant content of 0.048 atom fraction L.i-- near the desired 0.050 atom fraction. However. the bismuth-lithium solution contained $\sim 3000$ ppm (wt) thorium--presumably from a precipitated thorium compound (ThBi:) remaining in the stripper after removal of the bismuth. which was saturated with thorium as a result of the fluoride salt (LiF-BeF:-ThF 4 . 72-16-12 mole $(i)$ entrainment during runs $\mathrm{Nd}-\mathrm{l}$ and $\mathrm{Nd}-2$. No adverse effeat on the transfer of neodymium would be expected by the presence of thorium in the bismuth in the stripper.

Following the addition of purified $\mathrm{LiCl}$ and $\mathrm{Bi}-5$ at. ${ }^{*} \mathrm{C}$ Li to the process vessels of Metal Transfer Experiment MTE-3B. two experiments were conducted as described below. The quantities of salt and bismuth solutions in MTE-3B are shown in Table 9.1.

\subsubsection{Experiments $\mathrm{Nd-3}$ and $\mathrm{Nd}-4$}

Two experiments. Nd-3 and Nd-4, werecompleted in Metal Transfer Experiment MTE-3B. The experiments were to measure the overall mass-transfer coefficient for reodymium across the three saltbismuth interfaces in the metal transfer process and to determine the effect of agitator speed on these coefficients. For experiment Nid-3. an agitator speed of $4.17 \mathrm{rps}$ was maintained in the contactor and stripper vesseis. and for cxperiment Nd-4.an agitator speed of 1.67 rps was maintained. The experiments were made over a period of two weeks in January 1976. during which the process equipment was operated continuously.

Experiment Nd-3. Prior to the start of experiment $\mathrm{Nd}-3.2030 \mathrm{mg}$ of $\mathrm{NdF}$ ( $1450 \mathrm{mg} \mathrm{Nd})$ containing 149 $\mathrm{mCi}$ of "Nd iracer (II-day half-life) were added to fuel salt in the reservoir tank. This addition increased the neodymium concentration in the fuel salt from 21 ppm (wt). remaining after run Nd-2. to 34 ppm (wt).

Run Nd-3 was started at the following conditions: agilator speeds (contactor and stripper) $=4.17 \mathrm{rps}$. fuoride sait circulation rate $=\sim 35 \mathrm{~cm}^{2} \min (5.8 \times$ 


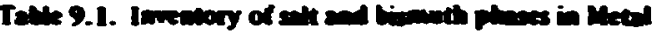

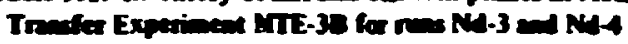

\begin{tabular}{|c|c|c|c|c|}
\hline Material & Vend & $\begin{array}{l}\text { Volous: } \\
\text { af } 923 \mathrm{x} \\
\left(\mathrm{m}^{3}\right)\end{array}$ & $\begin{array}{c}\text { Wright } \\
\text { (kg) }\end{array}$ & $\begin{array}{l}\text { Salt or } \\
\text { bismulh } \\
\text { sobution } \\
\text { (lkg-moles) }\end{array}$ \\
\hline $\begin{array}{l}\text { Fhoride foet and } \\
\left(72-16-12 \text { molk } \& \text { Lif-BeF } 2-\mathrm{THF}_{4}\right)\end{array}$ & Reservair & 0.0294 & 97.0 & 1.535 \\
\hline Fivorice fuet alk & Contecter & 6.0031 & 10.2 & 1.61 \\
\hline Bedentb-thuriom & Fleorite silt side of contactor & 0.0028 & 27.0 & 1.29 \\
\hline Disenuth-thorienm & LCT side of contactor & 0.0034 & 32.8 & 1.56 \\
\hline LCI & Contactour & 0.0029 & 4.3 & 1.01 \\
\hline LCI & Stripper & 0.0032 & 47 & 1.10 \\
\hline Bi-S at. \& Li & Stripper & 0.0043 & 418 & 2.00 \\
\hline
\end{tabular}

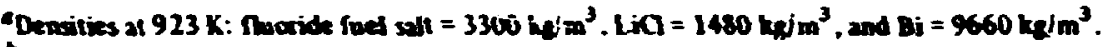

Mole wetigt $=0.0632 \mathrm{kt}$.

$10^{--} \mathrm{m}^{3}$ s). $\mathrm{LiCl}$ citculation rate $=\sim 1200 \mathrm{~cm}^{3}: \min$ $\left(2.0 \times 10^{\circ} \mathrm{m}^{\prime} \mathrm{s}\right)$. temperature $=923 \mathrm{~K}$. After $19 \mathrm{hr}$ of operation the fluoride salt circulation was stopped. and the run was continued for a total of $108 \mathrm{hr}$, at which time the $\mathrm{LiCl}$ salt circulation was stopped while agitation at 4.17 ps was continued for an additional $57 \mathrm{hr}$. The salt and bismuth phases were sampled throughout the run at 4-to 8-hr intervals for "Wd counting and total neodymium analyses to determine the rate of trensfet of neodymium across the three sa!t-bismuth interfaces.

The purpose of the initial period of nuoride salt circulation (19 hr) was to transfer neodymium containing "Nd tracer into the nuoride salt in the contactor. When this was accomplished. the fluoride salt circulation was stopped. This procedure resulted in an increased rate of change of vid content in the relatively small volume of $3.1 \times 10^{\circ} \mathrm{m} \times 3.5 \times 10^{\prime}$ : $\mathrm{m}^{3}$ in the contactor and fricl salt reservoir and improved the measurements of overall mass-transfer coefficients. When the $\mathrm{LiCl}$ circulation was stopped (after $108 \mathrm{hr}$ ), nendymium transfer into the stripper was stopped, and the equilibrium distribution of neodymium between the salt and bismuth phases was established. Th.is procedure was required to determine the equilibrium-distribution coefficients for neodymium for calculation of the oyerall masstransfer coefficients."

Experimeat Nd4. At the start of run Nd4. the agitator speeds were reduced from 4.17 ips to 1.67 rps. nuoride salt and $\mathrm{LiCl}$ salt circulation were at $\sim 35$ $\mathrm{cm}^{\prime} ; \min \left(5.8 \times 10^{\circ} \mathrm{m}^{\prime}:\right.$ s) and $\sim 1200 \mathrm{~cm}^{\prime} \min (2.0 \times$ 10 ' $\mathrm{m}$ 's) respectively. and the emperature of all phases was $\sim 650^{\circ} \mathrm{C}(923 \mathrm{~K})$. The iluoride salt circulation was continued for $21 \mathrm{hr}$ to replace the neodymium and ${ }^{14}$. Nd tracer in the fluoride salt in the contactor which was extracted during run Nd-3. The concentration of neodymium in the fluoride salt in the contactor had been reduced by about $50 \%$ during run Nd-3. The experiment was continued with $\mathrm{LiCl}$ circulation for $110 \mathrm{hr}$. Agitation of all phases at 1.67 rps (without salt circulation) was continued for an additional $55 \mathrm{hr}$, again to determine the cquilibriumdistribution coefícients for neodymium between the salt and bismu:h phases. Samples of all phases were taken at about 4- to 8 hr intervals during the experiment for ${ }^{14}$ id counting and intal neodymium analyses.

\subsubsection{Rewita}

The neodymium concentrations in the fuoride salt in the contactor and the bismuth-S at. $\%$ lithium in the stripper during runs Nd 3 and Nd-4, based on counting of the ${ }^{14}$. Nd tracer, are shown in Figs. $9.2 \mathrm{iv}$ 9.5. Neodynium concentrations in the hismuththorium and $\mathrm{LiCl}$ phases in the concactor and stripper are not included since the ${ }^{14} \mathrm{Nd}$ counting data do not accurately reflect live very low neodymiin concentrations $(<1 \mathrm{ppm})$ in these phases. Concentrations in all phases. based on total neodymium analyses using an isotopic dilution mass spectrometry technique. will be used for the final determination of overall mass-transfer and equilibrium-distribution coefficients and will be included in a final summary rapor. 
onim ons rose n

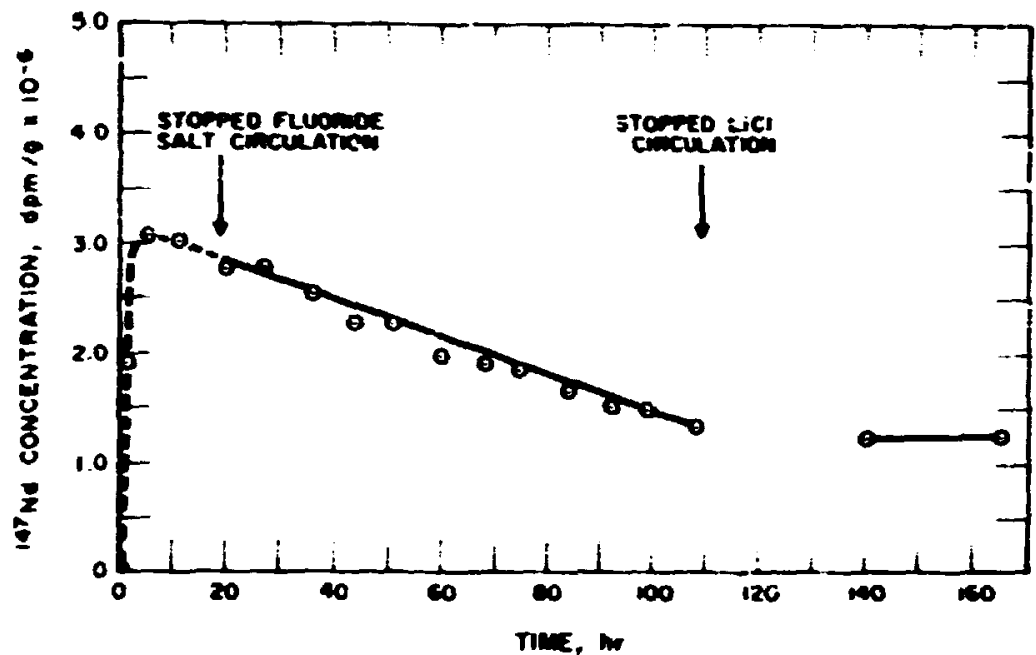

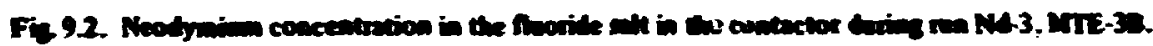

one one x-sed

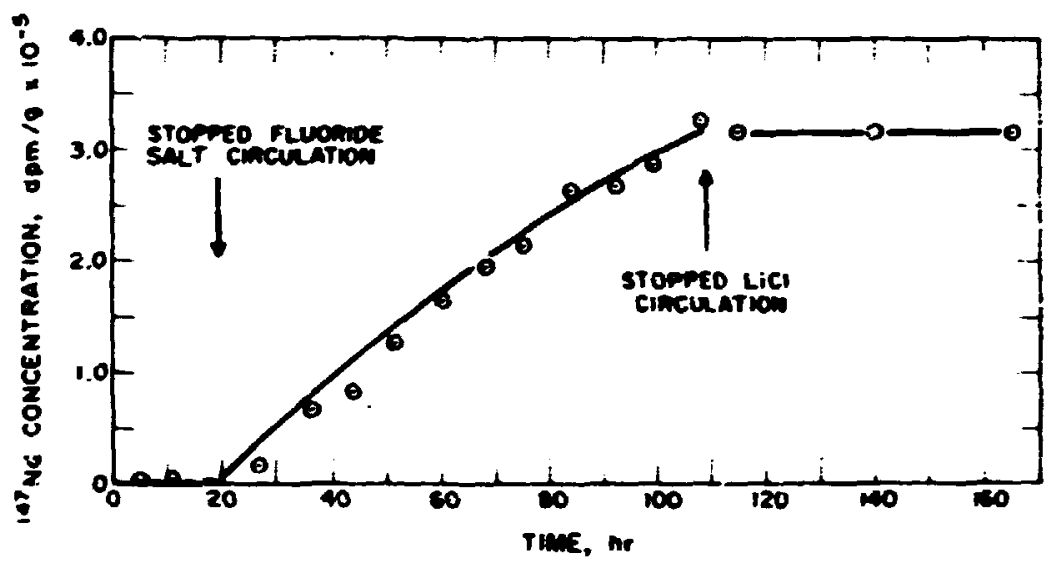

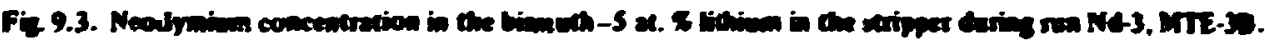

Onin one $78-352$

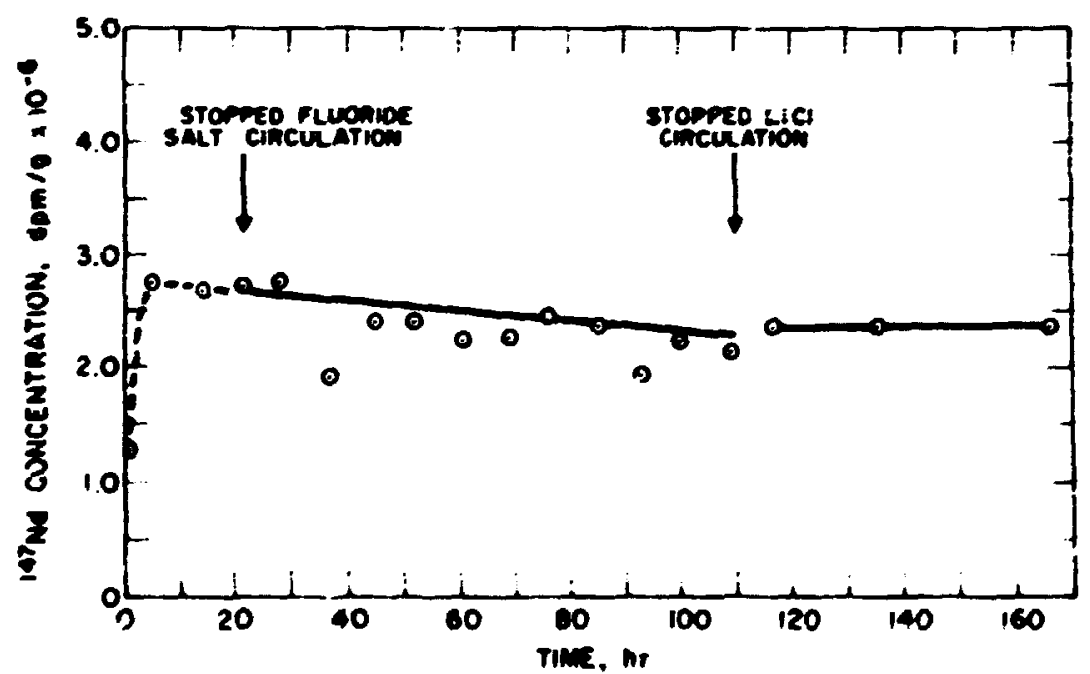

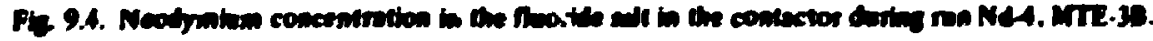


and ons 753

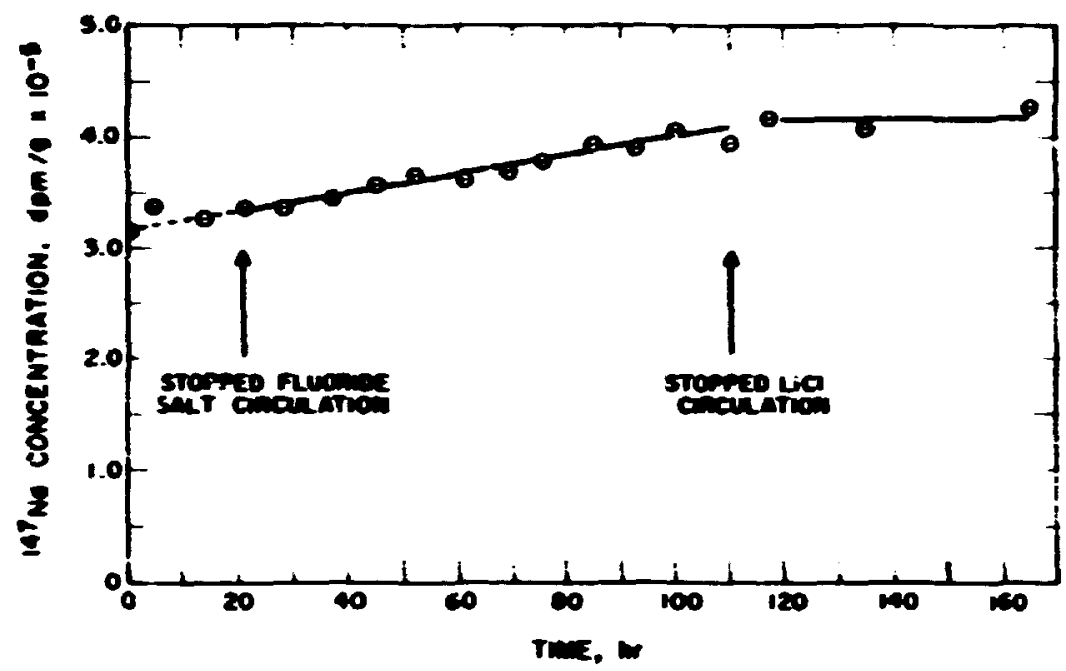

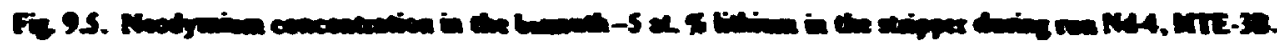

The lines drawn through the data points in Fiss. 9.2 to 9.5 represent the test-fin" values for the overall mass-transfer coefficients at the three salt-bismuth interfaces in the experimem.

Based oa anabyses for total ncodymium. about 100 me of neodymium was extracted from the fluoride salt during run Nd-3. and a bout $40 \mathrm{~ms}$ of neodymium was extracted from the flusride salt during run Nd-4. The operating time for both runs was essentialty the same (110 hr). Thus the rate of removal of neodymium was reduced by about 300 to $400 \%$ when the aeitator speed was reduced from 4.17 to $1.67 \mathrm{mps}$.

Results of five metal transfer process experiments in which neodymium was used as the representative rare-earth element fission product are shown in Tables 9.2 and 9.3. One nun, Nd-2, is not shown since complete consumption of lithium from the stripper alloy caused by entrainment of thooride salt into the lithium chloride precluded measurement of the overall mass-transfer coefficients. Two of the runs (EU-6 and EU-7) were conducted in experimen. MTE-3 during 1972. and three runs (Nd-1, Nd-3, and Nd4) were conducted in experiment MTE-3B during 1975-1976.

As seen in Tabk 9.2. the overall mass-transfer coefficients increase with increasing agitator speed. as predicted, with one exception - $K_{1}$ did not increase in run EU-7 when the agitator speed was increased from 3.33 to 5.0 rps. There is also good agreement between runs EU-7 (MTE-3) and Nd-1 (MTE-3B) at agitator speeds of 5.0 rps. In runs Nd-3 and Nd-4
(MTE-3B) the overall mass-transfer coefficients were decreased by aboul 300 to $400 \%$ when $t x$ agitalor speeds in the contactor and stripper were reduced from 4.17 to 1.67 pps. Also. the overall mass-transfer coefficient values at the fluoride sil bismuththorium interface $\left(K_{1}\right)$ for all experiments in MTE3B are in the range of 50 to $100 \%$ co the values predicted by the Lewis correbation. compared to the 15\% of predicted value observed in the two experiments in MTE-3. The overall mass-transfer coefficients at the $\mathrm{LiCl}$; biemuth-thorium and $\mathrm{LiCl}$ bismuth-5 at. \% lithium interfaces $\left(K_{2}, K_{3}\right)$. however, are sienificantly bwer than in run Nd-3 at 4.17 rps than would be expected from the values at S.0 Tps seen in runs EU-h, EU-i, and Nd-1.

Because of the limited number of experiments and the rather lare variation in the experimentalty determined overall mass-transfer coefficients, a meaningful correbtion of the data for use in design of a metal transfer process system for an MSBR has not been possible. An increase in the mass-transfer rates would be nceded for reasonably sized process equipment to remove the rare-earthelement fission products from a $1000 \mathrm{MW}(\mathrm{e}) \mathrm{MSBR}$. in the case of neodymium at a rate of about 1.28 -moles/day. For run Nd-3 in MTE-3B, an increase of abuut $500 \%$ in the removal rate of neodymium could be achieved if the mass-transfer coefficients at the two $\mathrm{LiCl} /$ bismuth interfaces. $K_{2}$ and $K_{3}$, could be increased (without increasing the transfer coefficient at the fuoride salt; bismuth interiact) to about $20 \%$ and 


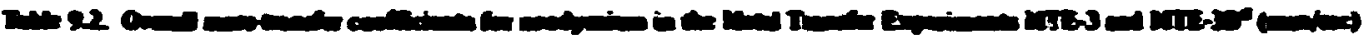

\begin{tabular}{|c|c|c|c|c|c|c|c|c|c|}
\hline & & De & & $x_{1}$ & & $x_{2}$ & & $E_{3}$ & Amen \\
\hline 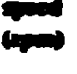 & in & 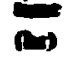 & nem & Dromed Lew & & 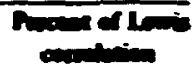 & $m$ & Romed ef lais & $\tan$ \\
\hline 20 & Exto & 45 & $\operatorname{cen}$ & is & aess & 10 & 02 & 7 & \\
\hline 30 & EUP & s5 & $2 \cos 2$ & 15 & a.1 & 19 & 02 & 4 & \\
\hline 300 & Mers & $x$ & ents & $50-10$ & ens & 10 & $\underbrace{13}_{13}$ & 25 & 210 \\
\hline 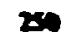 & $\mathbf{M} \boldsymbol{T}$ & 110 & e.16 & 14 & (now) & 19 & (1) & $\mathbf{I}$ & 14 \\
\hline 10 & mer & 110 & edens & 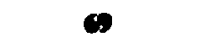 & & (n) & & מגו & 41 \\
\hline
\end{tabular}

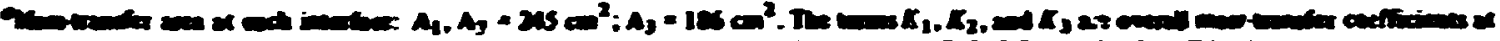

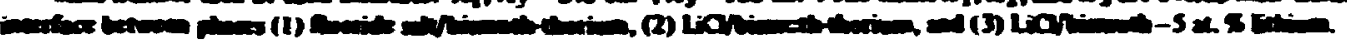

Expinime-3.

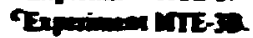

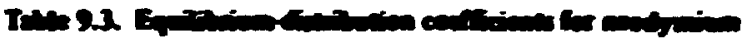

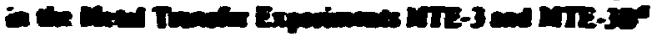

\begin{tabular}{|c|c|c|c|c|c|c|}
\hline \multirow{2}{*}{$20 \times 5}$. & \multicolumn{2}{|c|}{$D_{1}$} & \multicolumn{2}{|c|}{$D_{E}$} & \multicolumn{2}{|c|}{$D_{c}$} \\
\hline & Calcalnat & 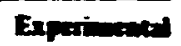 & Colctend & Expinated & 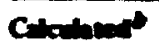 & Exparinated \\
\hline $\mathbf{M}-\mathbf{1}$ & a.os & 0.03 & 1.67 & 1.01 & $35 \times 10^{6}$ & $>1 \times 10^{3}$ \\
\hline M-3 & a.017 & 0.022 & ast & oss & $35 \times 10^{4}$ & $>1 \times 10^{3}$ \\
\hline Not & a.01r & $(0,022)$ & aspe & & $35 \times 10^{4}$ & \\
\hline EU6.7 & & 0.012 & & 030 & $35 \times 10^{4}$ & $2 \times 10^{3}$ \\
\hline
\end{tabular}

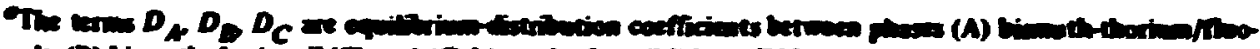

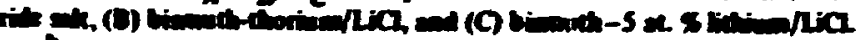

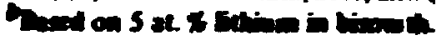

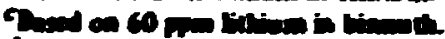

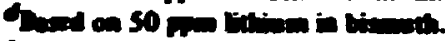

Expatimant iTtE-33.

S\%, respectively, of the value predicted by the Lewis correbtion, which is near the values observed in rums EU-6 and EU-7. Large increases in these two coefficients might be accomplished by increased apitation, even to the point of dispersing the LiCl into the biasmuth phase.

\subsection{MASS-TRANSFER STUDIES USING WATER-MERCURY CONTACTORS}

\section{H. Brown, Jr. J. R. Hidhlower, Jr.}

Mechanically acitated nondiepersing salt-bismuth contuctors are being considered for the protactinium removal step and the mre-earth-element removal step in the reference MSBR procesains phan flowsheet. These contactors have severl advantages over packed-column mit-bismuth coneactors:

1. They can minimize entninment of bismuth into the fuel salt retuming to the reactor.
2. They can be fabrisated more economically from maphite and molybulenom. and

3. They can be opereted more easily with brefe flow mite retios of molten salt and bismuth.

Experimental development of these stirred contactors has been carried out in two different systems, a facility in which molten fluoride sah is contacted with bismuth containing a diseolved reductant and a system in which mercury and an aqueous electrobre phase are used to simulate bismuth and molten salt. In the first facility, mass transfer of uranium and zirconium was studied in a singte atirred contector using actual process thids. ${ }^{\text {hy }}$ The studies with water and mereury will allow many physical parameters (such as size and configuration of the contactor vescels and agitators) to be examined at relatively small expense over a wide nage; then results measured in the salt-bismuth facility can be extrapolated to the larger contactor sizes that will be present in the procesuing plant. 
An electroctrewical tectivine has been deweboped to meassure wener-side mas - isster coefificients a walet-mercary comectors. Dering this report period an extensine set of experinenes esing this rectaine hus been done by a grome from the MIT Sebool of Cremical Engineering Prectice to devermive the effect of apientor dinmeter and speed and of cell sine on the weler-side mass-tunoufer coefficiem in square water-mercary comectors.

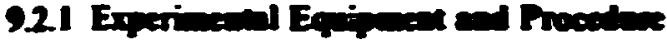

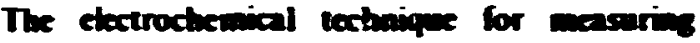
water-side mons-trander coeficieiets is based upon the diffesion-inied redection of quinome to

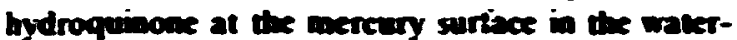
netcury cosenctor.

$0=\Longrightarrow=0+2 H^{+}+22^{-}=H O-\longrightarrow-0 n$.

As has been discussed previously. "o reaction (I) can be driven electrochemically in the forward disection at the mercury sorface (which acts as a cathode in an electrothemial cell) and in the reverse direction at anotber electrode (the anode of an etectroctremical ceili id contact with the aqueous phase of the wavermercury contector. The concestration of hydroquinone can be made much higher than the concentration of quinose, and the area of the anode can be made much greater than the area of the mercury surface. When this is done and an electric current is passed between the two electrodes. the mercury sarface is pobrized. The mapaitude of the electric current is then limited by the rate at which quinone is transferred to the mereuny surface, and the waler-side mass-transfer coefficient is rehted to the c=ll current. the bulk concentration of quinone in the aqueous phase, and the area of the mercury surface by the rebtion

$$
k=\frac{I}{2 A F C_{\Omega}}
$$

where

$$
\begin{aligned}
& k=\text { mass transfer coefficient, } \mathrm{mm} / \mathrm{sec} \\
& I=\text { diffusion-limited cell current, } A \\
& A=\text { area of mercury surface, } \mathrm{mm}^{2}
\end{aligned}
$$

\footnotetext{
-J. Hermmz. S. R. Eloxom, J. B. Keekr. and S. R. Roth
}

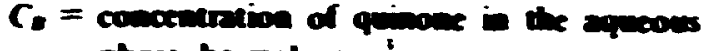

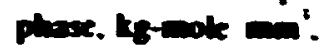

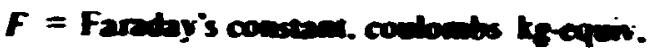

$$
\begin{aligned}
& z=\text { mopes of etectrons dischaped. If } \\
& \text { exisir termok. }
\end{aligned}
$$

The definimg oquation for the mass trander coefitcien is

$$
J=f\left(C_{0}-C_{i}\right)
$$

otwere

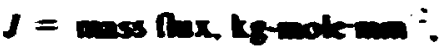

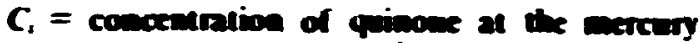

When the cell is operating ander conditions sach that the anereury sartace is polarized.

$$
C_{t}=0 \text {. }
$$

A diagrem of the experienceal apparatus is stown in Fie 9.6. The comoxior vesucts were Plexidas boxes of square cross-section twioc as deep as illey were wide: the agiasions were latebuled turtines having four blades. with one turbine cesolered in each phase. The anode for earb cell was ande from 1.6mm-hict berses sheet. which was formed to fil the inner periaseler of the cell and was supended in the aquecess phase. The anodes were plaved with pold of silver to resiat chemical artuck by the equeows solution.

The potential of the mercury surface was comtrolled versous a saturated calomet electrode (SCE). which was suspended in the equeous phare whike current was pased between the anode and the Cathode. A potentiostat was used which was capable of automaticaliy varying the impressed volane between limits of $+2 \mathrm{~V}$ (SCE) and $-2 \mathrm{~V}$ (SCE) at rutes up to $1 V_{/} \min$. The current throogh the cell was plotied vs the mercury surface potential on a ifewlett-Pactand X-Y plotter.

The composition of the aqueous phase for all rums was $001-0.05 M$ hydroquinone. $0.0002-0001 M$ quinose, in a $0.2 M$ phosphate buffer sotutior. avins a pH of 7.0.

The cell was filled with an appropriate volume of each phase, and a turtine was positioned at the midpoint $e^{*}$ :ach phace. The apitator drive was then started and adjusted to the desired apeed. The variable voluse was increased from 0 to $+1.0 \mathrm{~V}$ vs SCE at a rate of $0.5 \mathrm{~V} / \mathrm{min}$, and the cell current and 


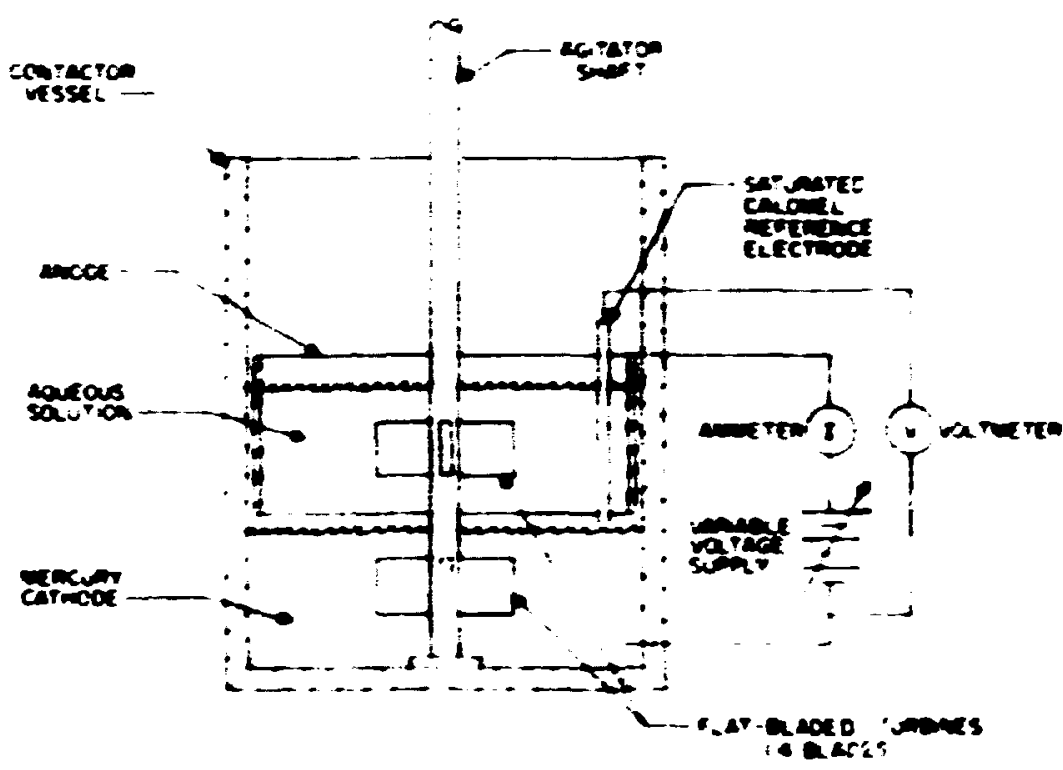

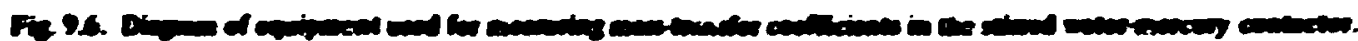

voluage were reconded achomatreally on a. X.Y reconder. The ajiator speed was then adjusied to another valice. and the procedere was nepented unill a stiofiectory rance of agiator speeds had been investioned.

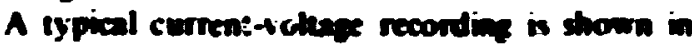
Fiz 9.7. In this foure. the aell cument is reconded

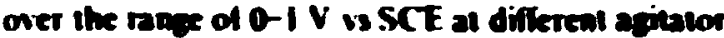
preds. For ench apistor sped. the xell curnem rives at low volkaces with increasing voluars and reaches a conetant value at hidhet volnges. This constam current is the desired diffusiontiniad corrent. The daffucion curreat actually oscillates about an averace

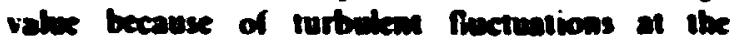
inerfince. An avernce vatue of the diffesion curnent is determinied from the recondians, and this averne value is reconded and und for the deternimination of

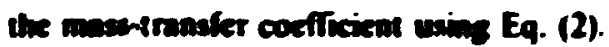

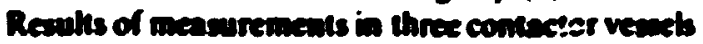
are poresaned in the followies rection.

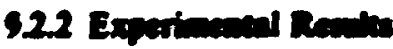

Wateraide mentrander coeficients were moneured in three different Piexichs ath, $102 \mathrm{~cm} x$ $106 \mathrm{~mm} .203 \times 203 \mathrm{~mm}$, and $303 \times 305 \mathrm{~mm}$. In each cell, two or three phase volumes were examined. the volume of exch phase being equal. For ench phase volume. severnl agitators with differemt diameters

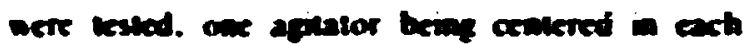

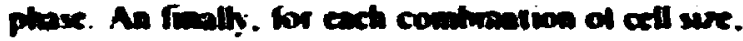

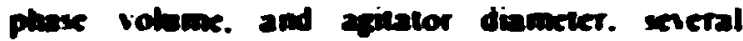
determinations of liniting diffesion curreat were unde oner a rons of agitat xs speds. Apitator spects wene teph betos that peed at whict dispersal of the

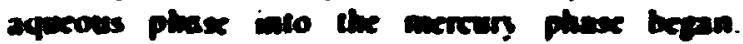
Diperisal was detected by sendil droplets of water leavines the mercury phase neare the ale of the cell. A sumbon of the experionestal parancters is given in Table 9.4 .

All the movermaket deta dermined in these experimeats are repored etwewhene." Repond bere are representatine revals which indiente the efiect of

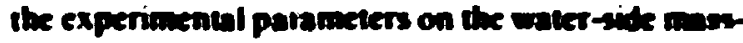
troaket coefficicm.

Figunes 9.8 w 9.10 show the mantonales

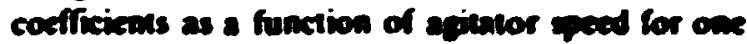
value of phase voluane in exch of the three cetis. The plat for ench eqintor dianeter prians to the compriad of two rejions. At low spintor speds the

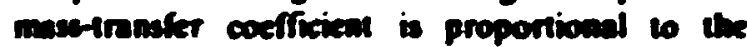
apintor speed to the 0.7 pomet. and at himp ecintor

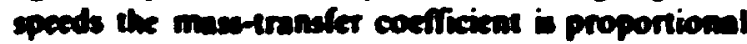
10 apieter speed 10 a powet near 2. The chanes between the two rejows is Girly abropt for small

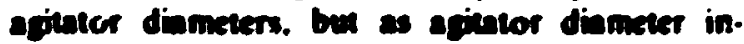

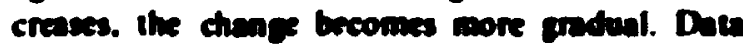
from the waler-mercury contactor are compares wis. 


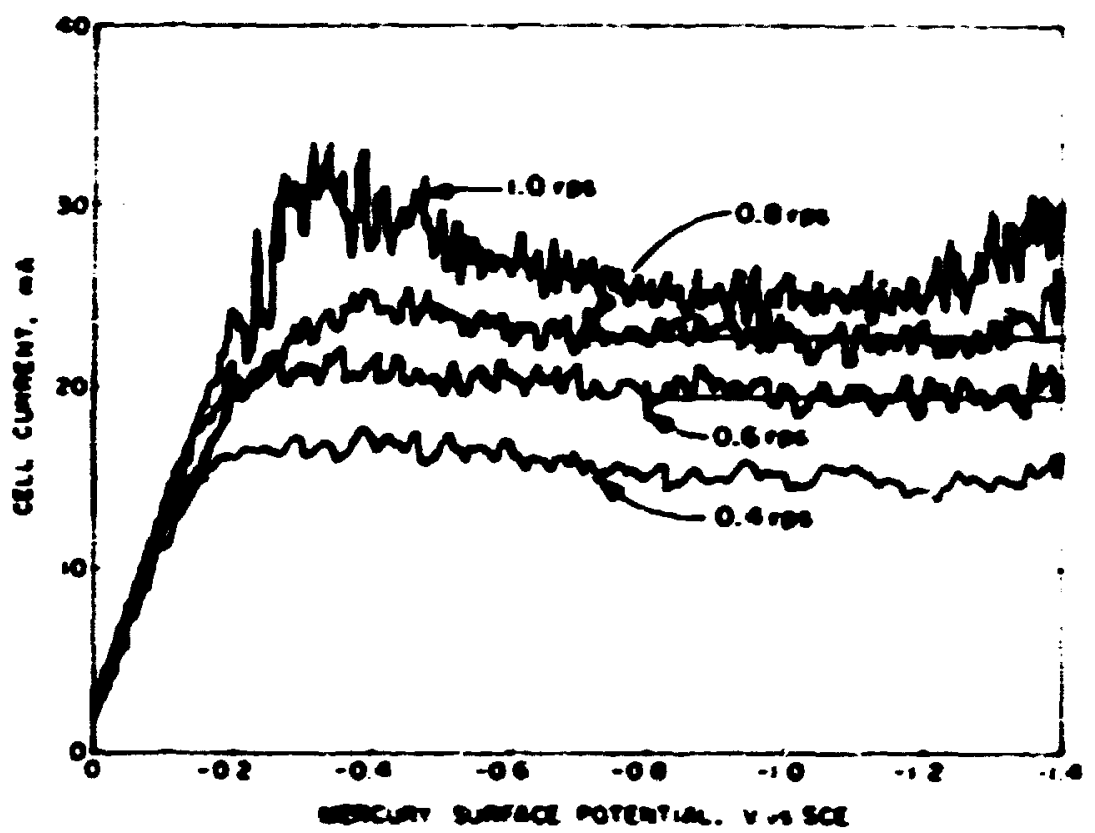

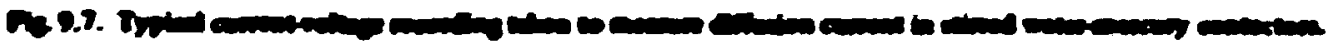

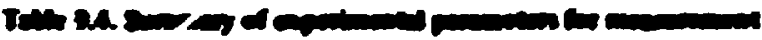

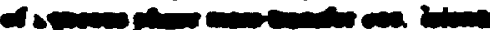

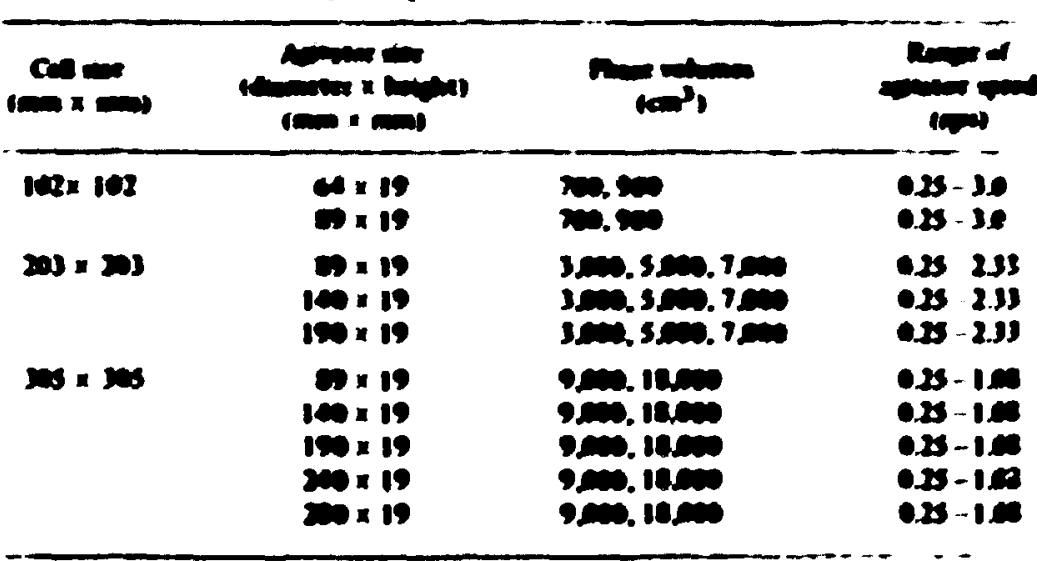


Come Dus 76-359

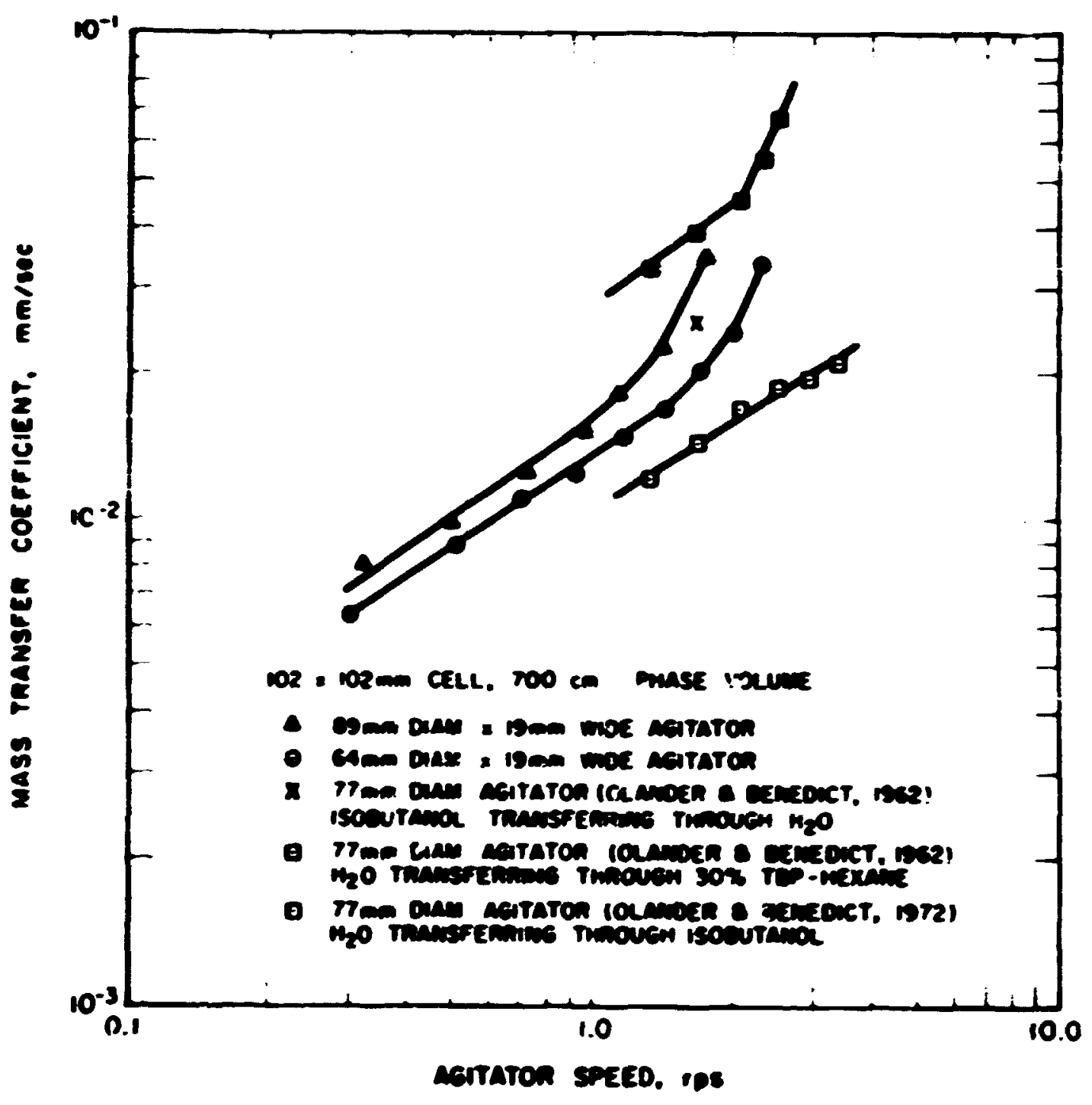

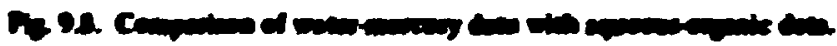

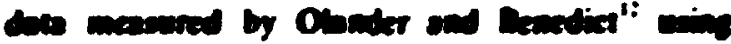

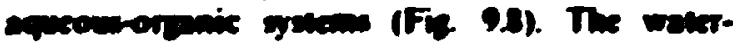

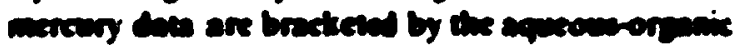

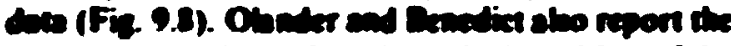

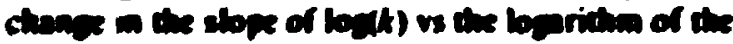
acieter rad.

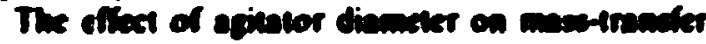

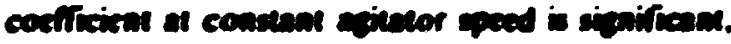

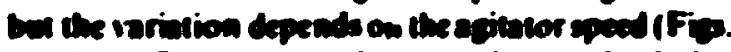

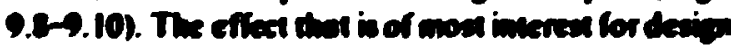

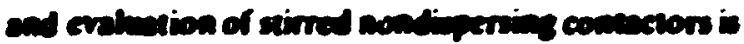

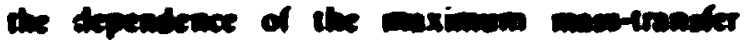

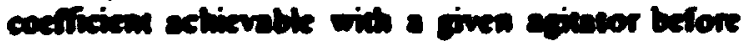

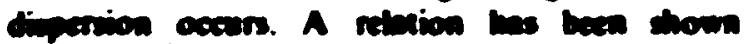

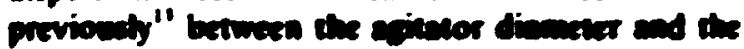

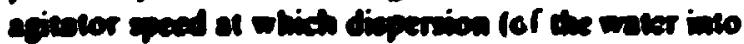

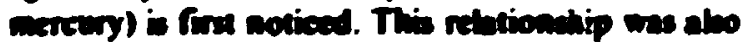

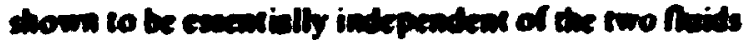

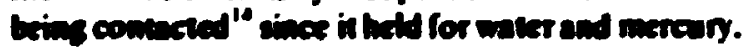
water and earton retndilorite. and water and 


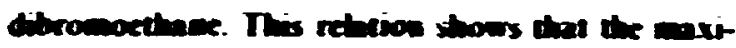
bin ajotor sped decresses with increxing.

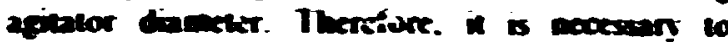

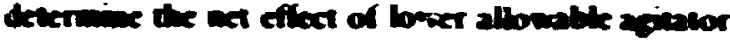

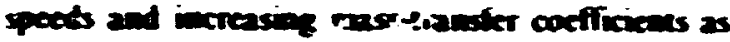
a.jeor dinocut inctere

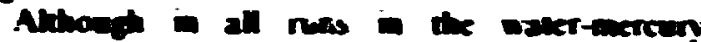

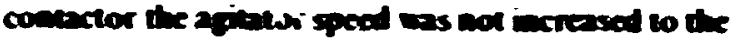

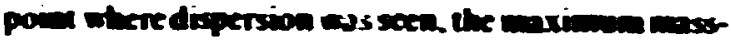

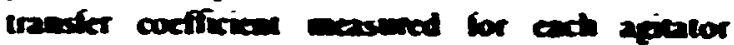

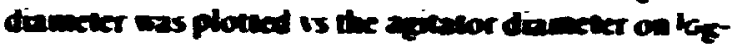

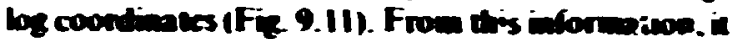

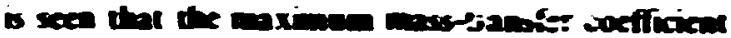

pencrily increases with incresing aysolor diancter.

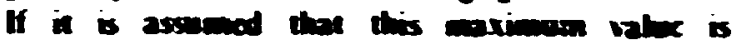
proportional to the agjector dinencter raised lo some

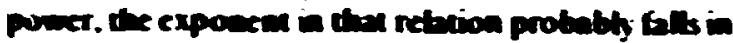
the rane 0.t-1.6 witio the range of agiator diancers sivestigned $14-200 \mathrm{~cm})$

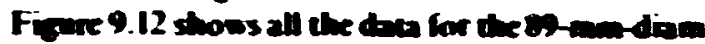

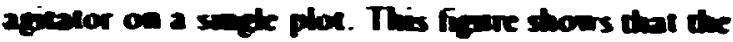

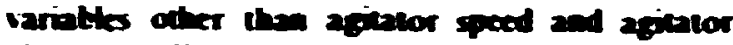
diancter eflect the value of the mastiraster

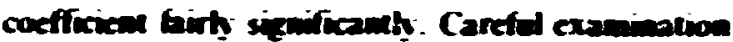
of Fie 9.12 shows bial for a given cell sine the masstranske coefificien varies inversely with the pheses

Oxing Dow $75-360$

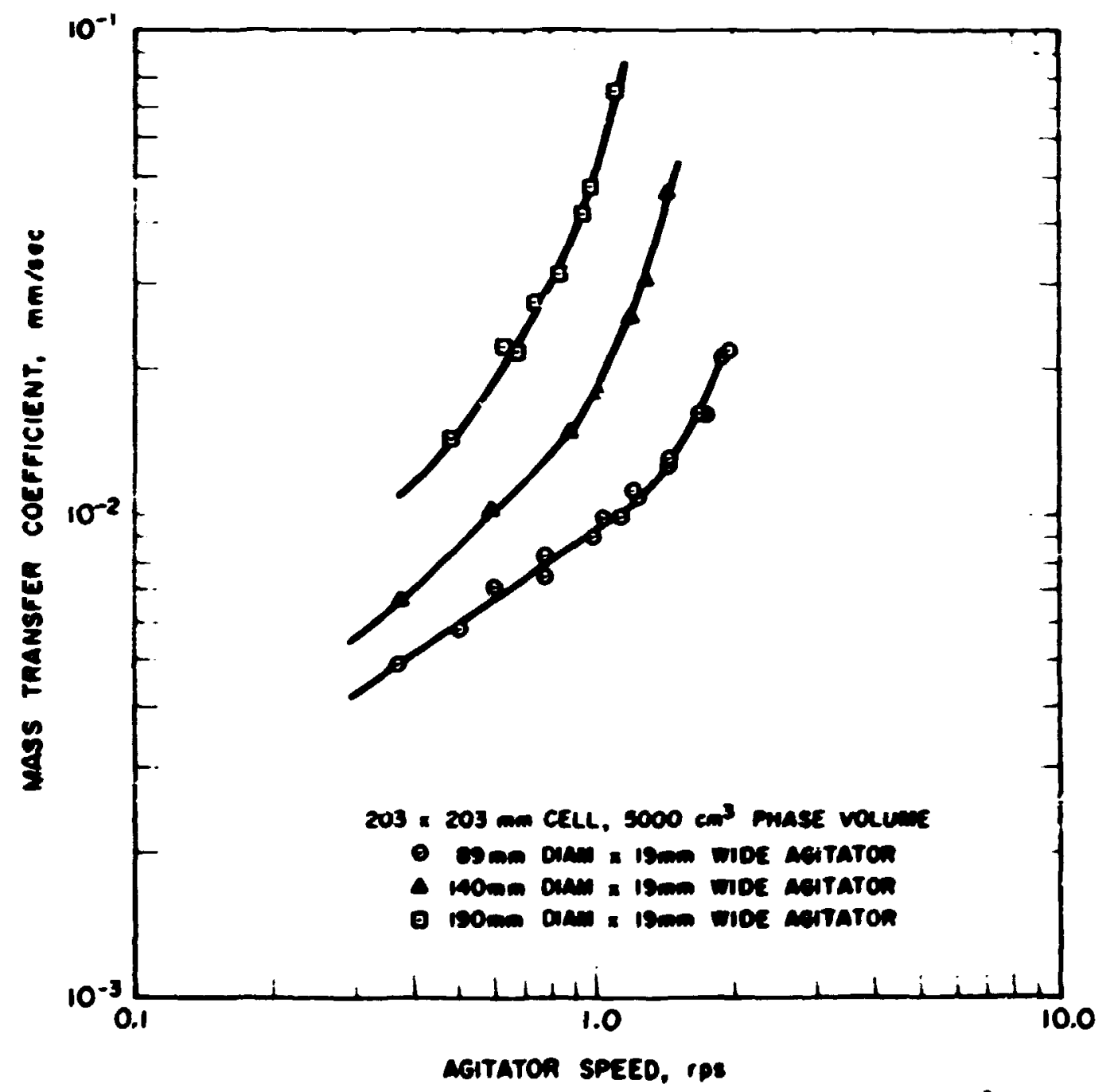

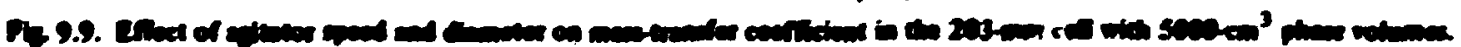




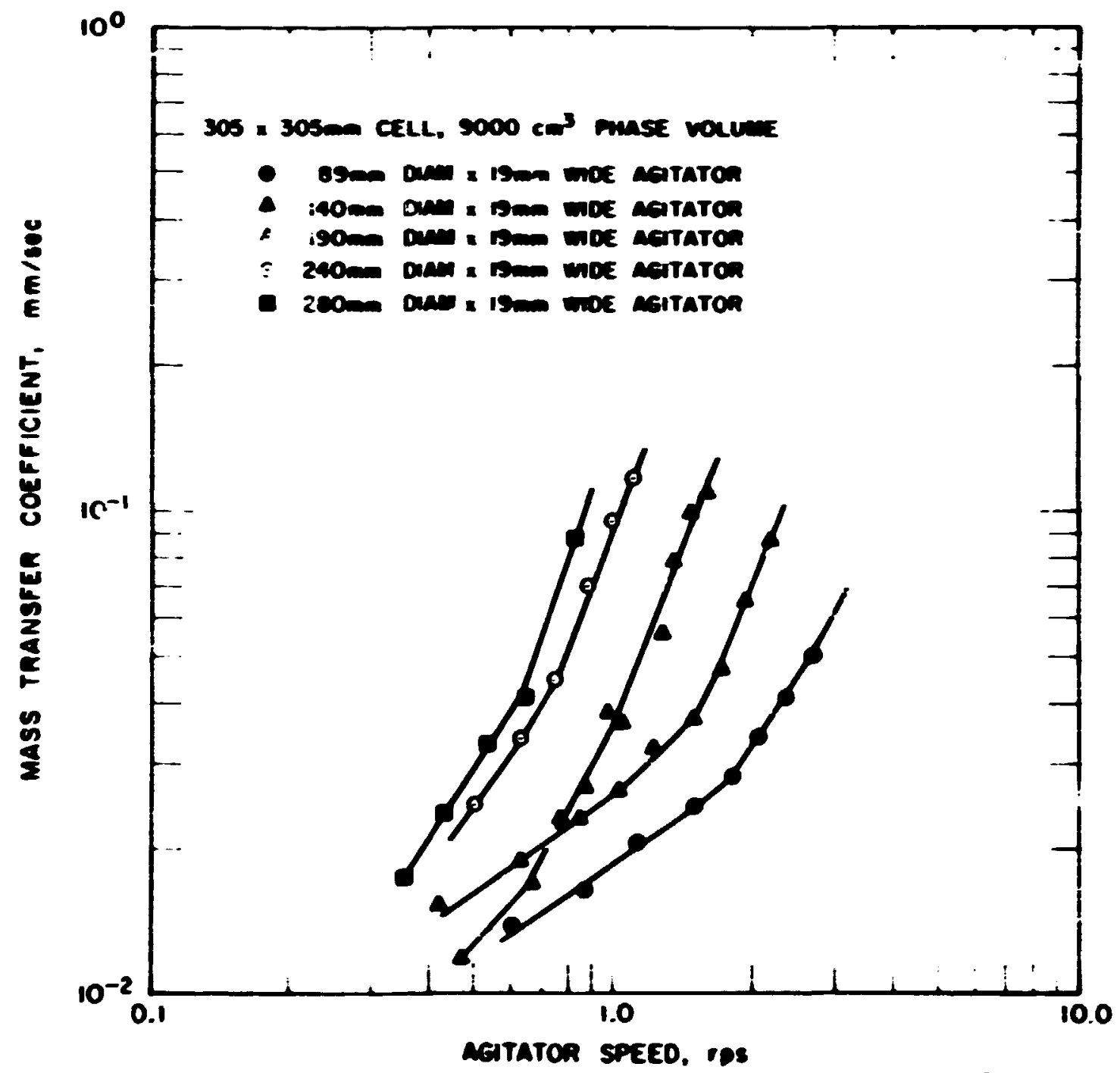

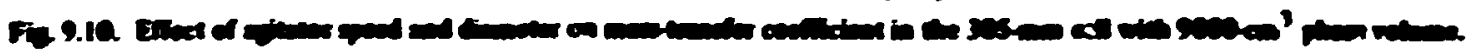

voluane uned. This may reflect the effect of dianace between the agiotor and the interfice since in all coses the apiotors were positioned at the nidpoim of each phase. Systernatic variations bave not yet been extracted from the date. ben these date serve wo show stast details in the cell devipan cen aftat the value of the maso-trander coefificiem by $200 \%$ in the case of thase experimeats.

The rebtive effect on the water-side nan-iranales coefficiem of stirring in exch phase is shown in Fis. 9.13. One cext was performed in the 305-min cell. with phase voluones of $18.000 \mathrm{~cm}^{2}$ and one spitureor dianocter of 190 ming. Fing the man-traseder coefficiem was meanurod as a function of acioner speed. with en apitelor in each plase. The teat whes then repeated twice. first with an apitsior in the merenery phase only and then with the apiancor in the water phase only. The reselts indicate that at bow apieator speeds. apitation in the woket affects the water-side mav-irasefer prodominambly: whereas, as apientor speed increases, apitation in the mercury affects the water-side mase-ironder coefficient more strondy than agiention in the water phase. Moreover. the mase-iransfet coefficient resulting from apiention 


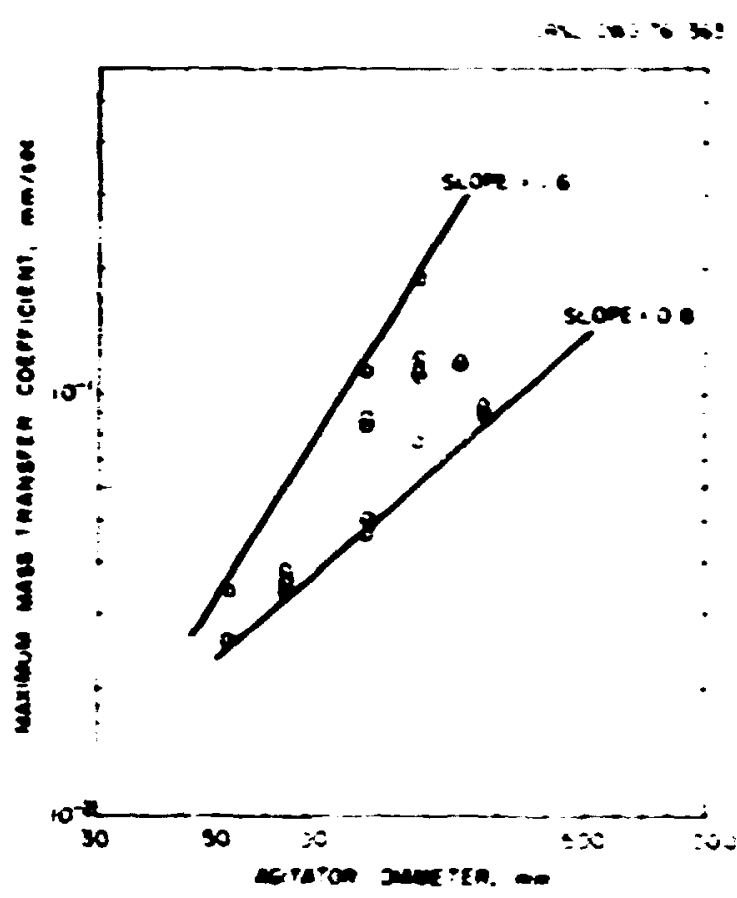

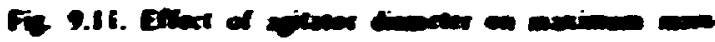

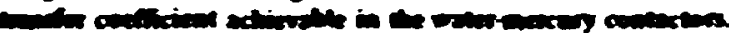

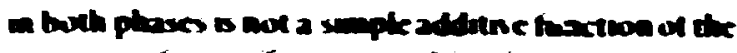

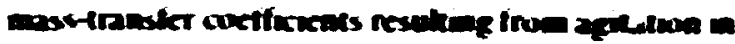
cure phase and.

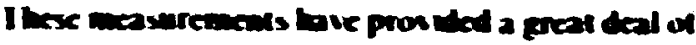

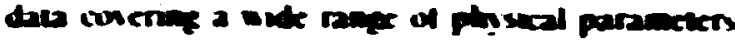

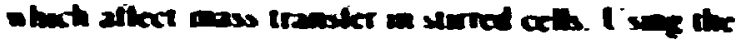

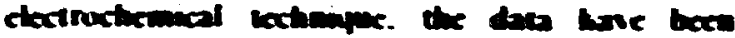

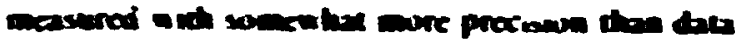

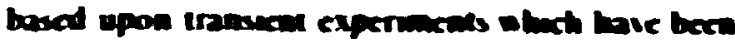

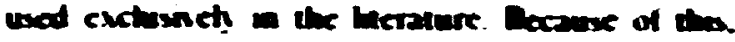

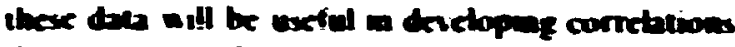

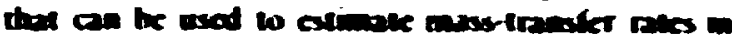

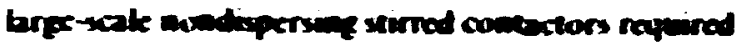
in the MSDR redectice extratum procesces.

\section{3 contmuous Fuondwaton DEVELOMIENT}

\section{R. B. Indaner}

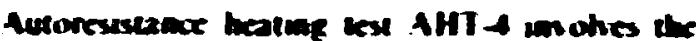

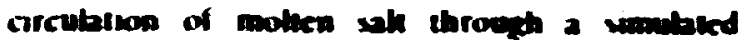

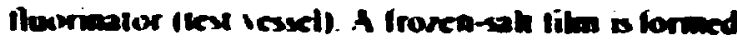
by cooling the lest veseel wall. and the salt is lept

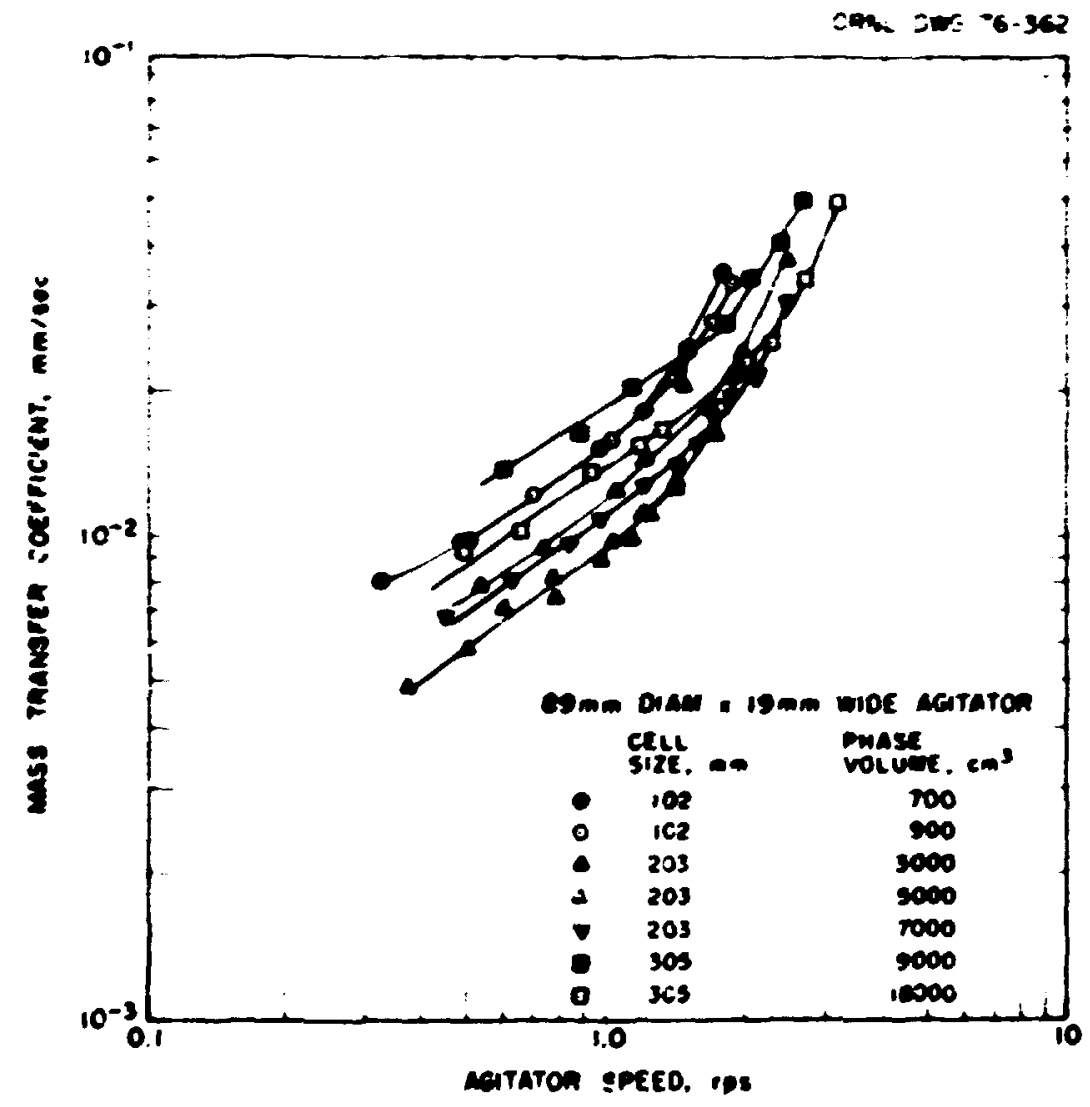

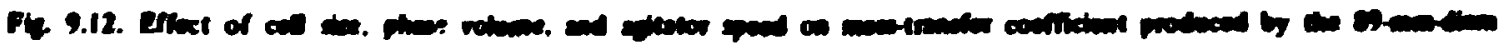
20. 


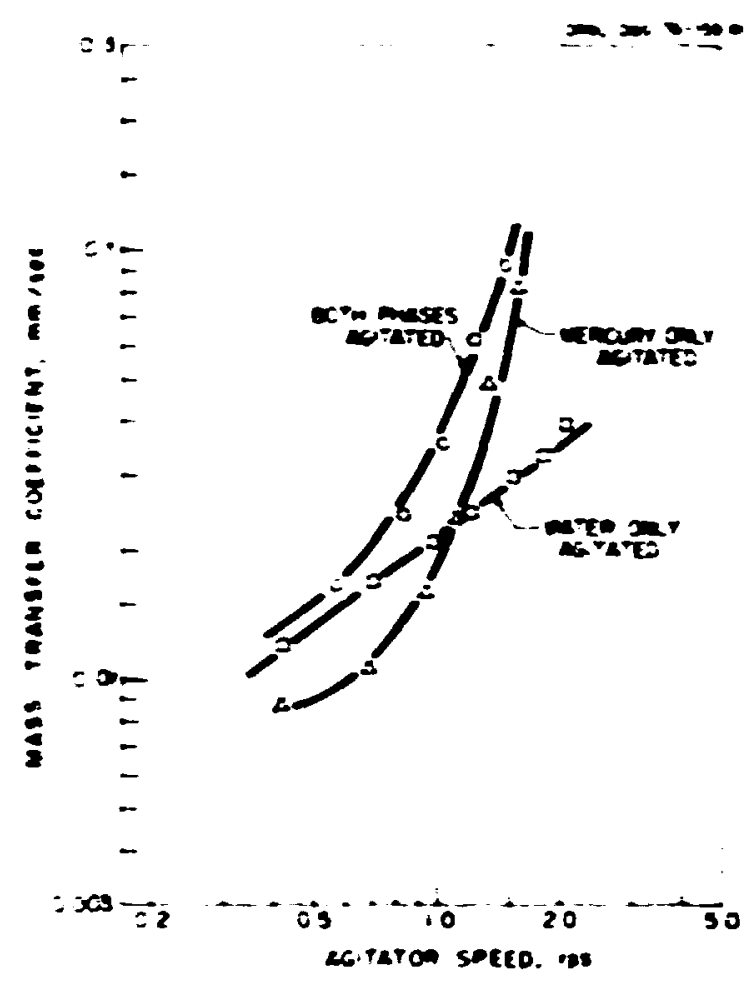

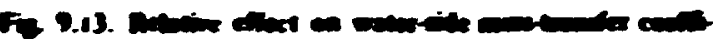

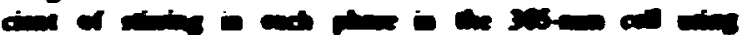
17.

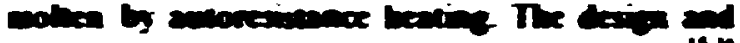

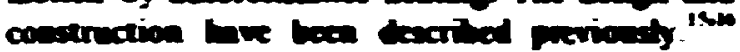

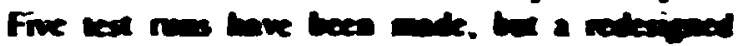

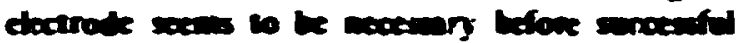
operation cos be adirwal.

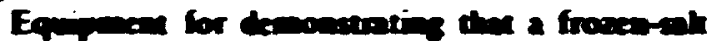

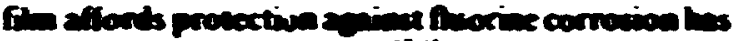

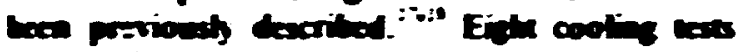

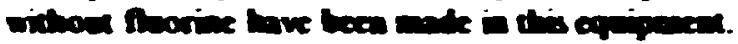

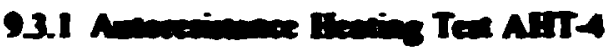

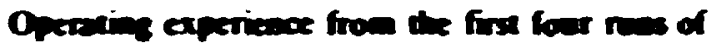

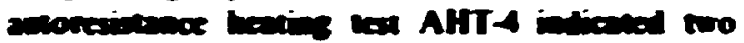

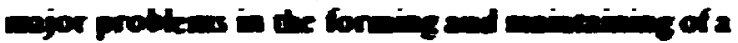

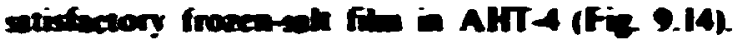

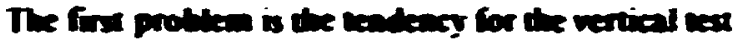

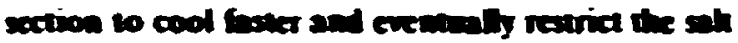

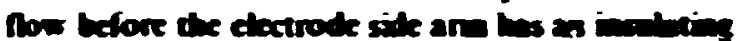

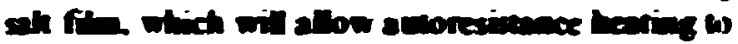

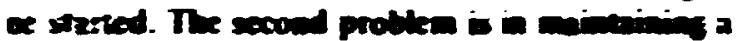

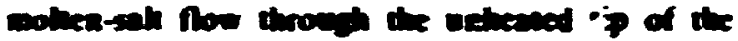
etectrode. Before modifying the dectrote. a no

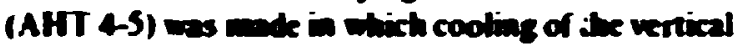

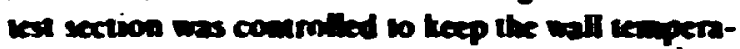
ture above that of the etactrode sidean. Afet 8 : ar

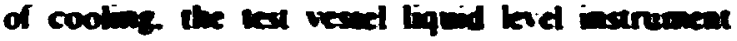

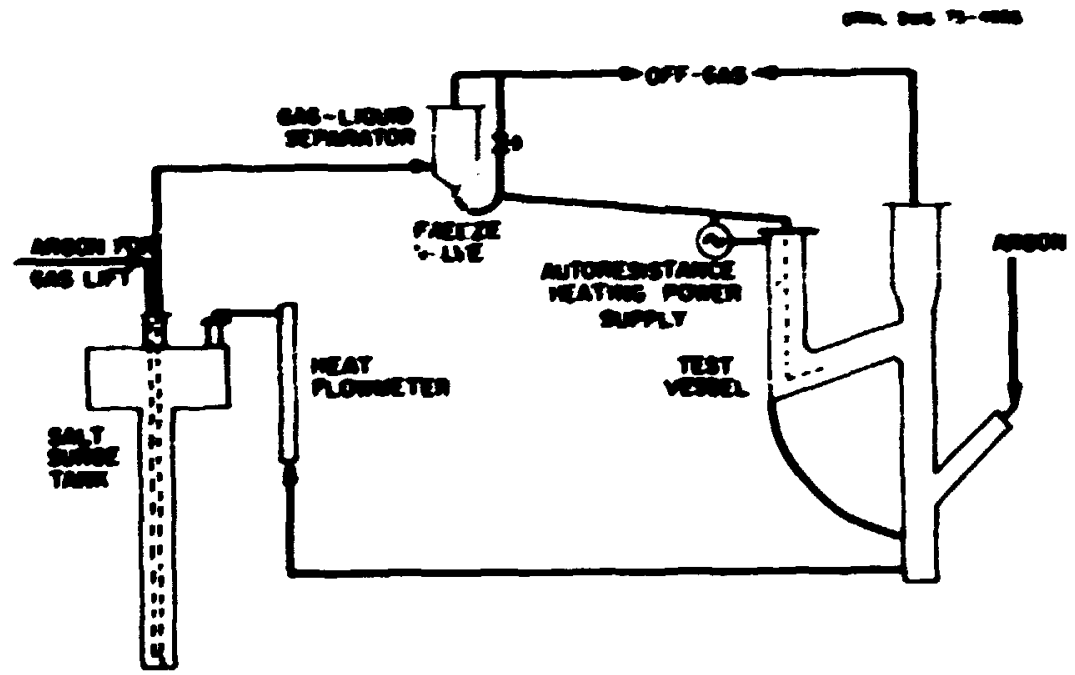

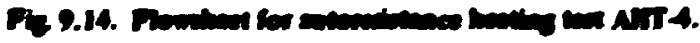




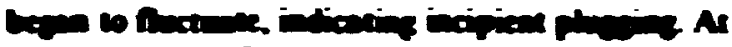

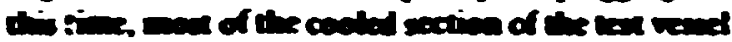

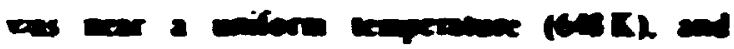

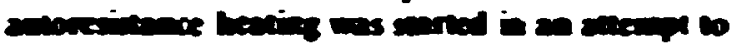

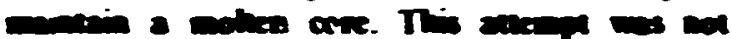

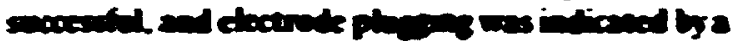

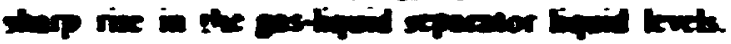

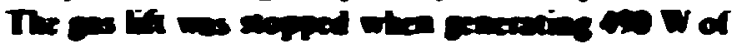

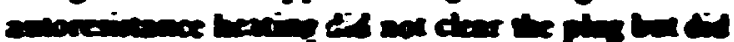

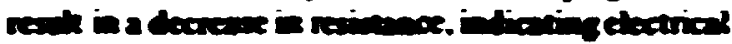

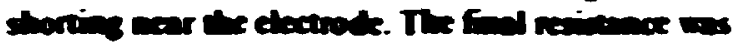

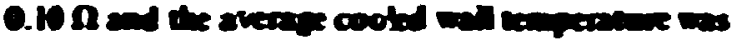
G2R

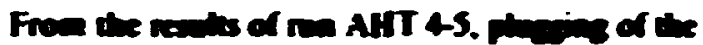

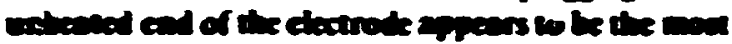

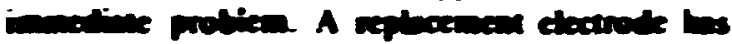

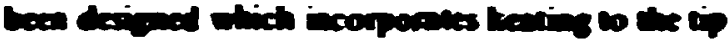

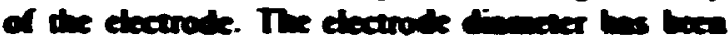

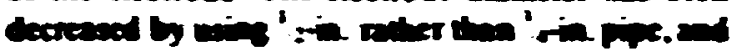

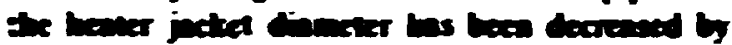

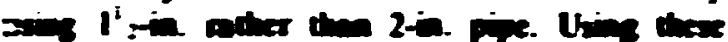

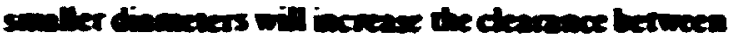

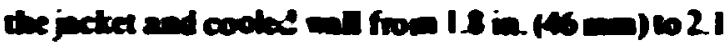

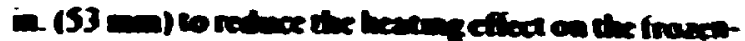

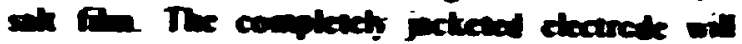

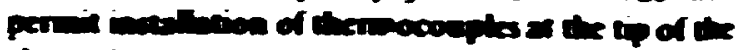

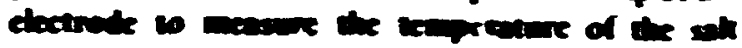
encing the went

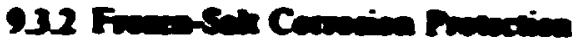

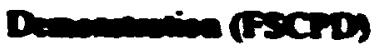

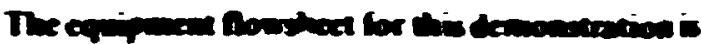

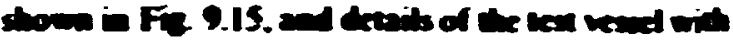

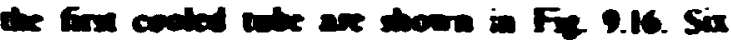

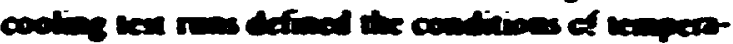

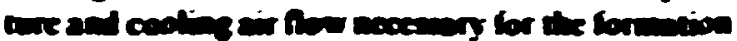

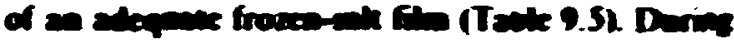

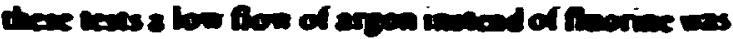

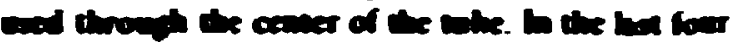
noc a s.

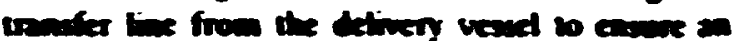

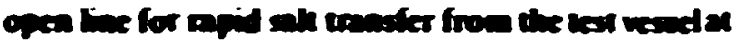

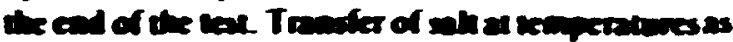

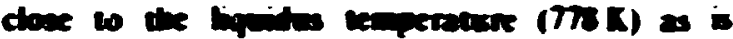

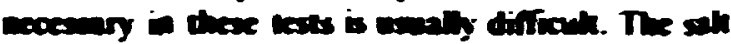

ounc ons is-cien

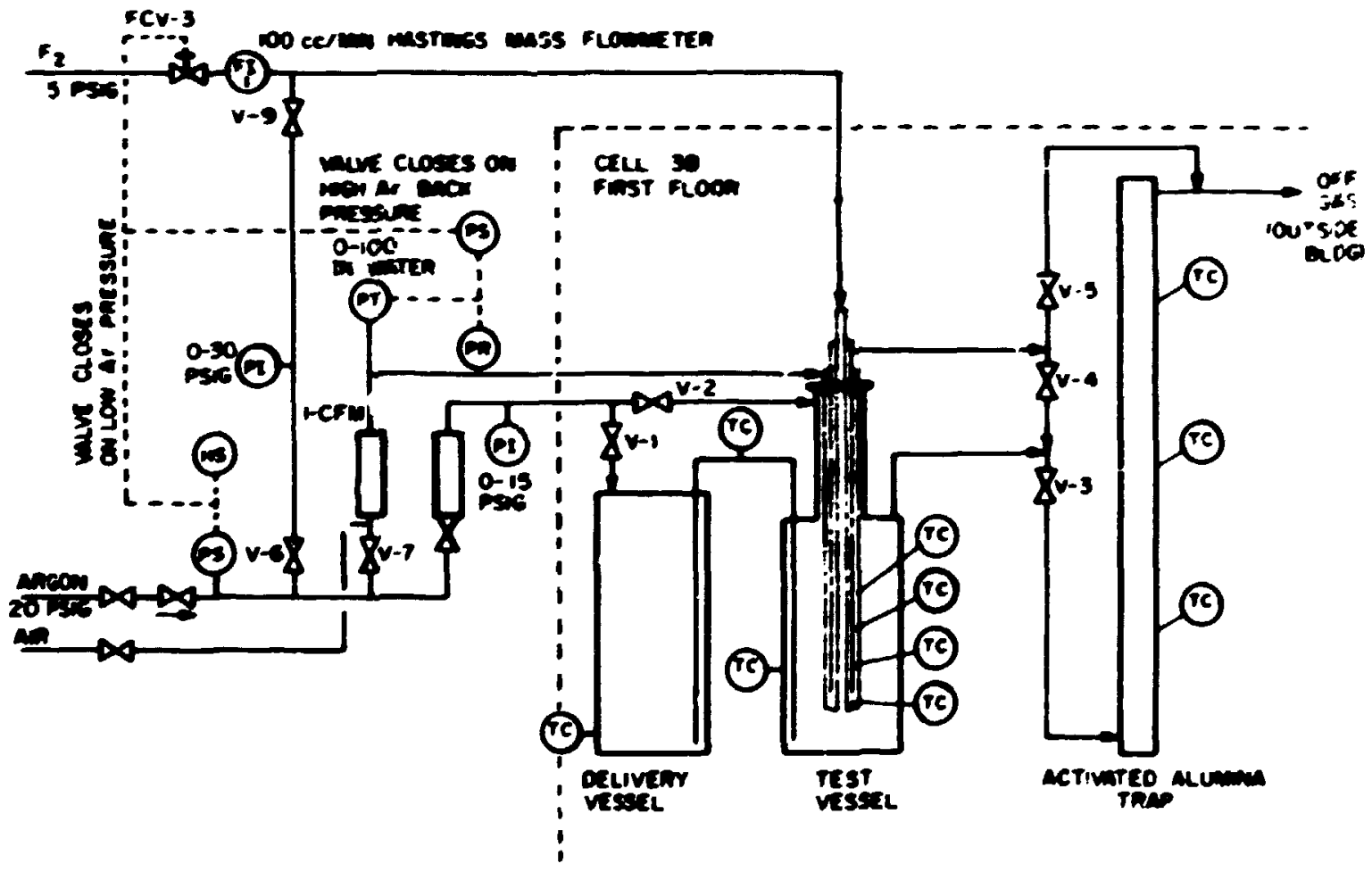

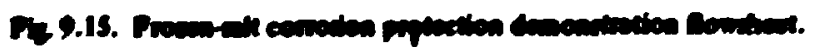


18

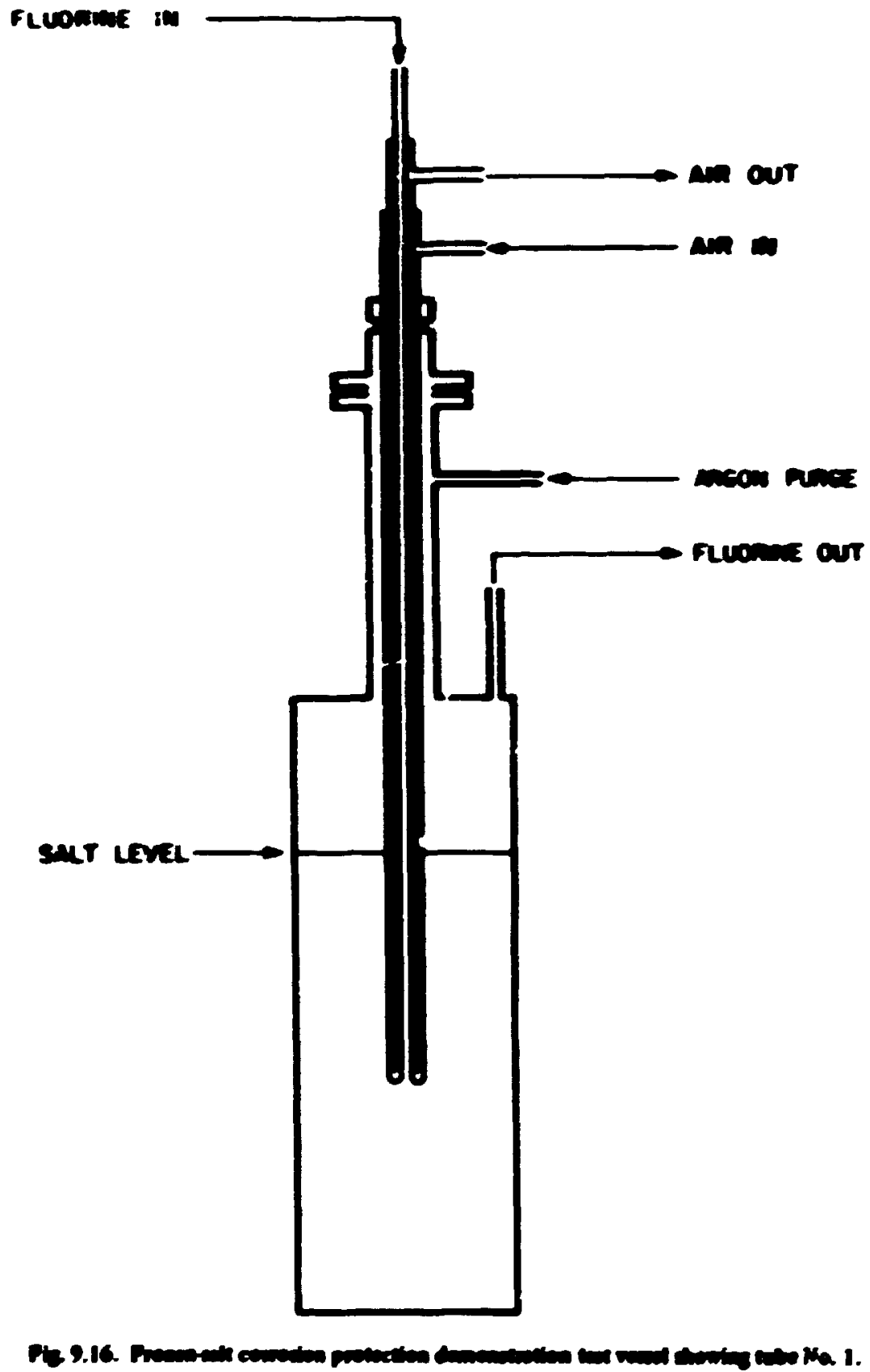




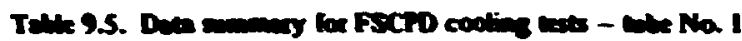

\begin{tabular}{|c|c|c|c|c|c|c|c|c|c|}
\hline \multirow{3}{*}{$\begin{array}{l}\text { Test } \\
\text { No. }\end{array}$} & \multicolumn{2}{|c|}{ Cootine ais } & \multirow{2}{*}{\multicolumn{2}{|c|}{$\begin{array}{l}\text { Arow sparge } \\
\left(\mathrm{con}^{3} / \mathrm{min}\right)\end{array}$}} & \multicolumn{3}{|c|}{ Temperatures $(\mathrm{C})$} & \multirow{3}{*}{$\begin{array}{l}\text { Yesid } \\
\text { wall } \\
\text { cootion } \\
\text { rale } \\
\text { (\%/mia) }\end{array}$} & \multirow{3}{*}{ Rewarts } \\
\hline & \multirow{2}{*}{$\begin{array}{l}\text { Bact } \\
\text { puacese } \\
\text { (pis) }\end{array}$} & \multirow[b]{2}{*}{$\begin{array}{l}\text { Flowrete } \\
\text { Ciners/ming) }\end{array}$} & & & \multirow{2}{*}{$\begin{array}{l}\text { Coolad } \\
\text { tule } \\
\text { minimen }\end{array}$} & \multirow{2}{*}{$\underset{\substack{T e x \\
\text { well }}}{ }$} & \multirow[b]{2}{*}{$\Delta T$} & & \\
\hline & & & Trumfer & $\begin{array}{c}\text { Fluoriax } \\
\text { inlet }\end{array}$ & & & & & \\
\hline 1 & 2.5 & $\boldsymbol{\omega}$ & & 17 & 432 & 556 & 124 & 0.23 & $\begin{array}{l}\text { Selt tucuferred out - } \\
\text { vary thia fine }\end{array}$ \\
\hline 2 & 3.4 & $n$ & & e & 420 & $\$ 52$ & 132 & 0.40 & $\begin{array}{l}\text { Sell noc trasterred - } \\
\text { bine phesped }\end{array}$ \\
\hline 3 & $>4$ & $>00$ & 160 & - & 410 & 575 & 165 & 1.00 & $\begin{array}{l}\text { Salt transferred oet - } \\
\text { ver thin fln }\end{array}$ \\
\hline 4 & 8 & 129 & 80 & $\infty 0$ & 400 & 540 & 140 & 0.60 & Ialet piryod \\
\hline 5 & $\begin{array}{l}7.0 \\
5.2 \\
4.4\end{array}$ & $\begin{array}{r}126 \\
101 \\
94\end{array}$ & $\begin{array}{r}100 \\
20 \\
150\end{array}$ & $\begin{array}{r}84 \\
90\end{array}$ & $\begin{array}{l}431 \\
417 \\
405\end{array}$ & $\begin{array}{l}543 \\
528 \\
512\end{array}$ & $\begin{array}{l}122 \\
111 \\
107\end{array}$ & $\begin{array}{l}0.53 \\
0.27 \\
0.12\end{array}$ & 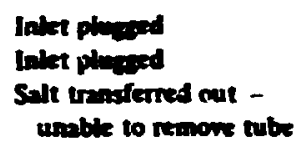 \\
\hline 6 & $\begin{array}{l}6.8 \\
4.0 \\
4.4 \\
4.0\end{array}$ & $\begin{array}{r}118 \\
89 \\
94 \\
89\end{array}$ & $\begin{array}{l}100 \\
100 \\
100 \\
120\end{array}$ & $\begin{array}{l}30 \\
41 \\
30 \\
75\end{array}$ & $\begin{array}{l}420 \\
446 \\
439 \\
443\end{array}$ & $\begin{array}{l}529 \\
522 \\
523 \\
521\end{array}$ & $\begin{array}{r}109 \\
76 \\
75 \\
78\end{array}$ & $\begin{array}{l}0.27 \\
0 \\
0.13 \\
0\end{array}$ & $\begin{array}{l}\text { Ialet pluged } \\
\text { lolet plocied } \\
\text { Inlet ploged } \\
\text { inlet pluged }\end{array}$ \\
\hline
\end{tabular}

Alvorine iniet plueved.

was transferred from the test vessel after three of the runs. In one of these cases, the tube could not the removed for examination, probably because of an unusually large sait ring formed above the salt level from 100 high a sparge rate. The annular clearance around the outer tube is $0.3 \mathrm{in} .(76 \mathrm{~mm})$. In the other two cases the salt film was too thin to measure and did not cover the metal at several points. The main problem with this tube design was plugging of the fluorine inlet tube at temperatures as high as $719 \mathrm{~K}$. Since this temperature is well above the solidus remperature $(623 \mathrm{~K})$ of the salt, formation of a suitable film was not possible.

Tests using the No. I cooled tube were ended when a leak deveiopeu in the air conling annulus of the tube. The tube was cut off $5 \mathrm{in}$. (127 $\mathrm{mm}$ ) from the bottom, and this section was examined in the Metallography Laboratory. Figure 9.17 shows the area where the failure occurred, the grain boundary attack, and the nickel oxide that was formed. A horizontal crack developed in the $1 / 3$-in. $(0.8-\mathrm{mm}$ thick nicket inner [ $3 / \mathrm{n} \cdot \mathrm{in}$. (9.5 mm) OD] tube. The crack was aboui $1 / 4$ in. $(6 \mathrm{~mm})$ long ( $20 \%$ of the circumference). The crack was not near a weld but occurred in inetal that had been machined from a 1 in. nickel rod. Figure 9.17 also shows that the thickness of the tube was reduced to less than onehalf of the original thickness.
The second cooled tube was designed to be sufficiently smai! to permit the use of argon instead of air coolant to avoid nickel oxidation. Also, since introduction of fluorine through the center of the cooled tube is not required for this demonstration. the tes: vessel dip tubes were modified as shown in Fig. 9.18. Ail three tubes are of $3 / \mathrm{n}$-in. $(9.5-\mathrm{mm})$-OD nickel tubing, with the argon coolant inlet tube of $1 / 15$ in. $(4.8-\mathrm{mm})-0 D$ nickel. This cooled tube has only $13 \%$ of the cooled area of the first tube and will require considerably less cnolant fiow. Air cnolant flow with the first tube had to be restricted to 90 liters $/ \min \left(1.5 \times 10^{-3} \mathrm{~m}^{3} / \mathrm{s}\right)$ to maintain the bulk of the molten salt above $793 \mathrm{~K}$ using the maximum power on the vessel heaters. With the second tube an argon flow of 35 liters/min $\left(5.8 \times 10^{-4} \mathrm{~m}^{3} / \mathrm{s}\right)$ (proportionally three times greater) could be used while maintaining a steady bulk salt temperature.

Two test runs were made with the second cooled tube. In the first teat the tube was cooled by an argon flow of 35 liters $/ \mathrm{min}\left(3.8 \times 10^{-4} \mathrm{~m}^{3} / \mathrm{s}\right)$ for $3.8 \mathrm{hr}$. Salt was then transferred from the test vessel, with the bulk of the salt at $803 \mathrm{~K}$. Cooling air was maintained on the tube until the test vessel wall temperature was reduced to $623 \mathrm{~K}$. In the second test a higher argon flow, 54 liters $/ \mathrm{min}\left(9.0 \times 10^{-4} \mathrm{~m}^{3} / \mathrm{s}\right)$, was used for 5 $\mathrm{hr}$, and the salt was transferred. with the bulk salt temperature at $823 \mathrm{~K}$ and falling. In neither case was 


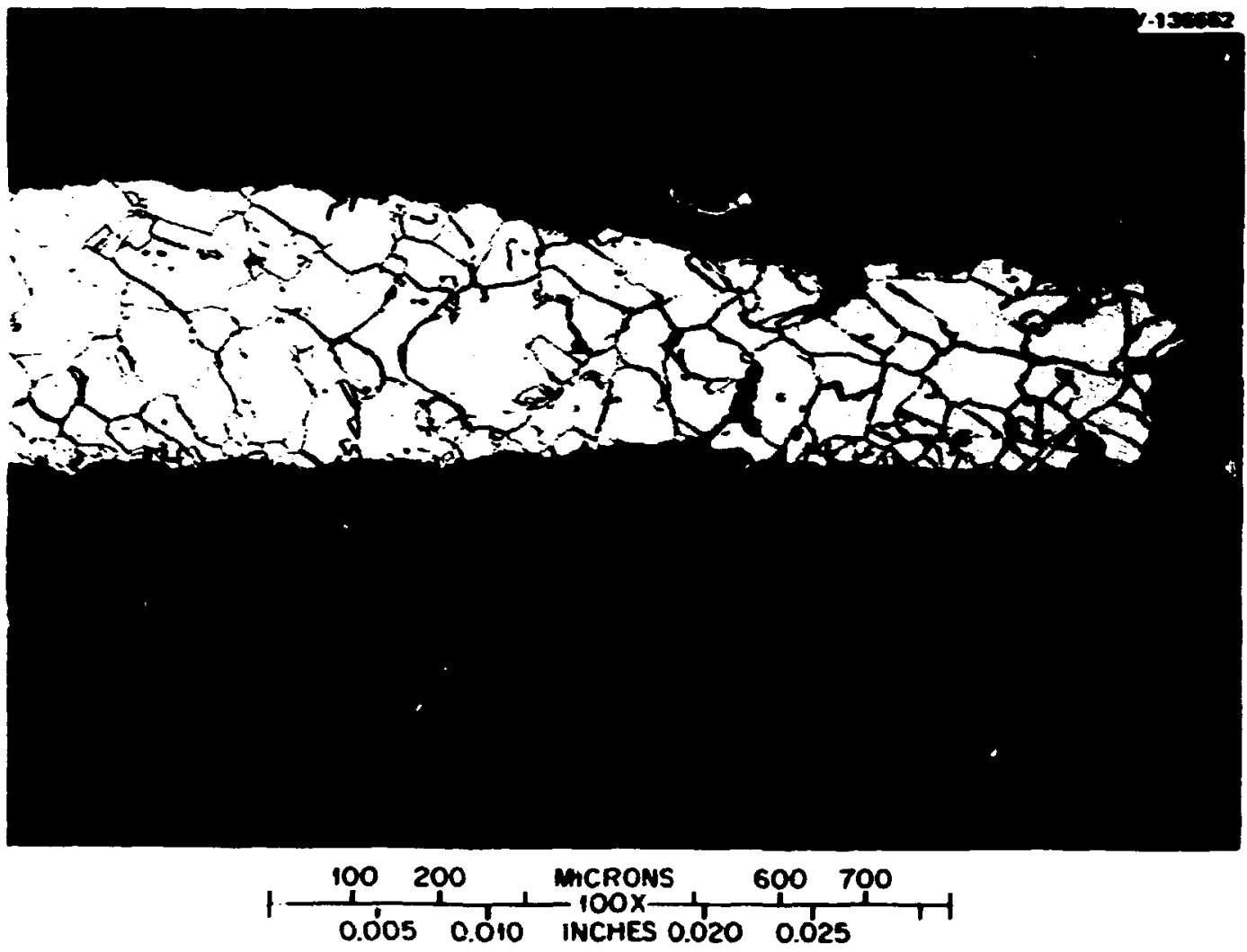

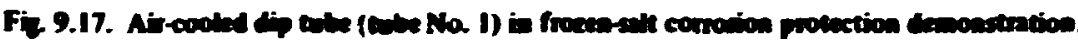

a sacisfactory salt film formed. In the first test, $a^{\prime} / y^{-}$ in. $(0.8-\mathrm{mm}$ ) -thick film covered the bottom '1: in. (13 $\mathrm{mm}$ ) of the tute. In the second test. only the tip of the tube was covered with a salt film. The bulk salt temperature was probubly too high in the second test.

\subsection{FUEL RECONSTITUTION ENGINEERING DEVELOPMENT}

\section{R. M. Counce}

The reference flowsheet for processing the fuel salt from a moiten-salt breeder reactor (MSBR) is based upon removal of uranium by fluorination to UFn as the first processing step. ${ }^{10}$ The uranium removed in this step must subsequently be recombined with the fuel-carrier salt before its retum to the reactor. The method for recombining the uranium with the fuelcarrier salt (reconstituting the fuel salt) consists of absorbing pseous UF, into a recycled fuel salt stream containing dissolved UF, according to the reaction

$$
U F_{M(1)}+U F_{\text {(d) }}=2 U F_{\text {(d) }} \text {. }
$$

The resultant UF, would be reduced to UF, with hydrogen in a separate vessel according to the reaction:

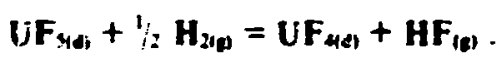

Engineering studies of the fuel reconstitution step are being started to provide the technology necessary for the design of larger equipment for recombining UF a gener. ted in fluorinators in the processing plant. with the processed fuel-carrier salt retuming to the reactor.

During this report period a preliminary hydrodynamics test of the experimental equipment. in which salt flow through the sysiem was maintained under simulated experimental conditions. was successfully completed. A calibration of the UF, metering system was completed: a gas density cell used for measuring concentrations of $U_{F}$ in argon was calibrated: and apparatus for producing known concentrations of HF in hydrogen was developed and was used to calibrate the gas density cell used for measurisg concentrations of $\mathrm{HF}$ in hydrogen. These operations are discussed in the remainder of the report. 
ORNL DWG 76-364

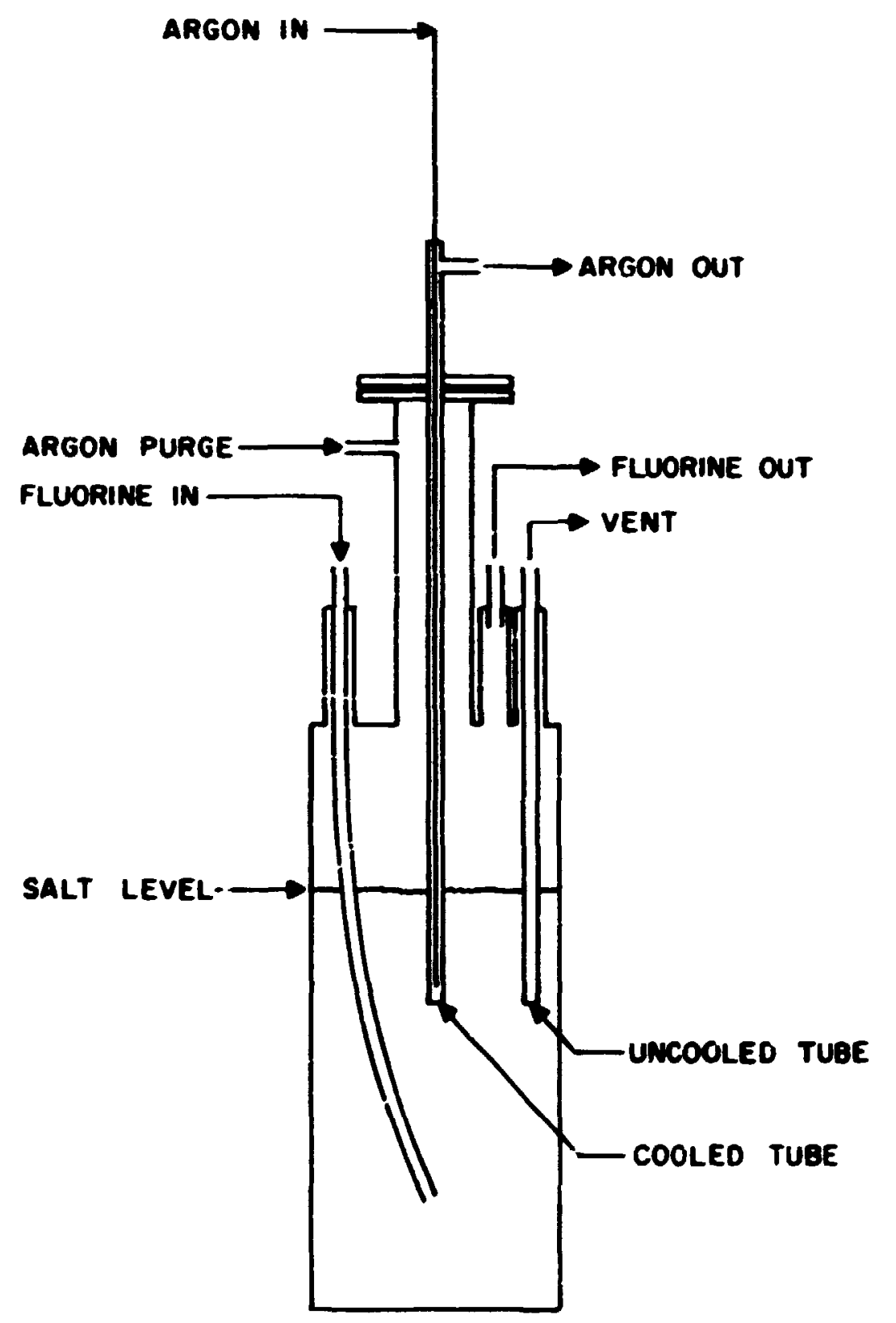

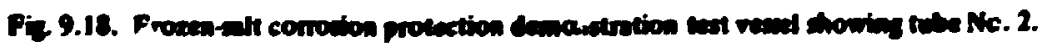




\subsubsection{Hydrodymamic Operation}

The hydrodynamic operational procodure for the experiment has been discussed prevnousty. ${ }^{-0}$ During this report period, five hydrodynamic experiments were conducted: HR-1, HR-2, HR-3, HR-4, and HR5. The fourth and fifth experiments, HR-4 and HR-5, resulied in salt being metered from the foed tank through the UF, absorption vesul and tydrogen reduction colum to the receiver (Fig. 9.19) at a constant flow rate of approximately $100 \mathrm{~cm}^{3} / \mathrm{min}$ $\left(1.67 \times 10^{-6} \mathrm{~m}^{3} / \mathrm{s}\right)$.

In HR-1, the UF, absorption vessel and the hydrogen reduction columa were fil ed. The siphon was primed in HR-2, and alt flow was stared from the feed tank. Run HR-2 ended abruptly when plugeing occurred in the effhrent salt transfer line from the hydrogen reduction colvens. A thind run. HR-3, did not get under way because of a plug in the transfer line from the feed ant to the absorption vesseet.

In nun HR-4, the UF, absorption vessel and the hydrogen reduction columen were filled in preparation for run HR-S. In run HR-S, a salt flow of 100 $\mathrm{cm}^{3} ; \min \left(1.67 \times 10^{-6} \mathrm{~m}^{3} ; \mathrm{s}\right)$ was started and was maintained for 1 hr. The gas streams of UF, and hydrogen were simulated by two argon flows. The two argon flow rates of $180 \mathrm{sed} \mathrm{cm}^{3} / \mathrm{min}\left(3 \times 10^{-6}\right.$ $\mathrm{m}^{3} / \mathrm{s}$ ) simulate the stoichiometric gas flow rates of UF, and hydrogen mecesseary to increase the UF. concentration in the salt from 0.15 mole $\%$ in the feed stream of the UF, absorption vessed to 0.3 mole $\%$ in the effluent stream from the hydrogen reduction column.

conel bus ra-ncocen

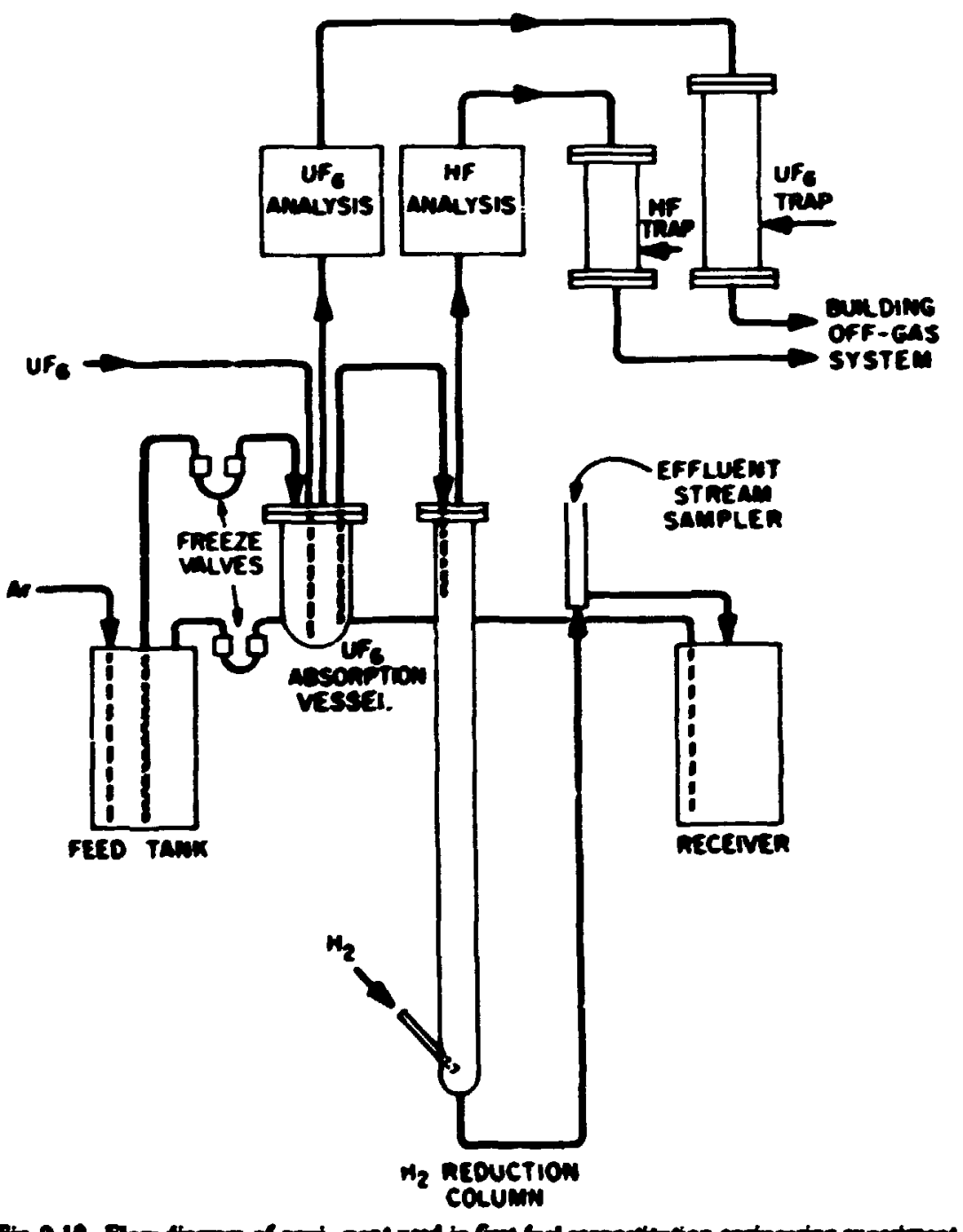

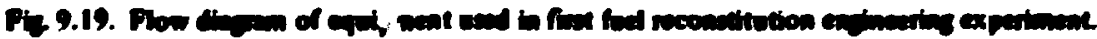




\subsection{Calibation of the UF. Metaries Sywa}

The UFo supply system ${ }^{21}$ (Fig. 9.20) provides UF。 at known flow rates to the UF, absorption vesset during the operation of the experiment and to the UF,-Ar gas density cell for calibration parposes. The supply system contains a model ALF-S00W Hzstings mass flowmeter which indicates and controls the UF. Ilow rate. Because the UF, flow rate is an important experimental parameter, this flowmeter must be calibrated before the experiment begins.

The flowmeter was calibrated as follows. A steady flow of UF, was established to the main off-gas trap. The UF, stream was then diverted through the calibration trap. a pacted bed of NaF pellets maintained at $373 \mathrm{~K}$. The Now of UF, through the alibration trap was maintaired long enough to produce a loading of $0.2 \mathrm{~kg}$ UFo/ kg NaF. The UF。 stream was then diverted back to the main UF, trap. and the flow of UF, stopped. The system was then completely purged with argon. The calibration trap was then removed and weighed again. The weight of IIF. baded into the trap was determined by suberacting the original weight from the frnal weight. The flow rate of $U F$, was determined then by dividing the weight of UF, by the length of time UF, nowed into the calibration trap. This process was repeated for several flow rates of UF, up to 560 sed $\mathrm{cm}^{\prime}$ ! min

Cnin owe r6-365

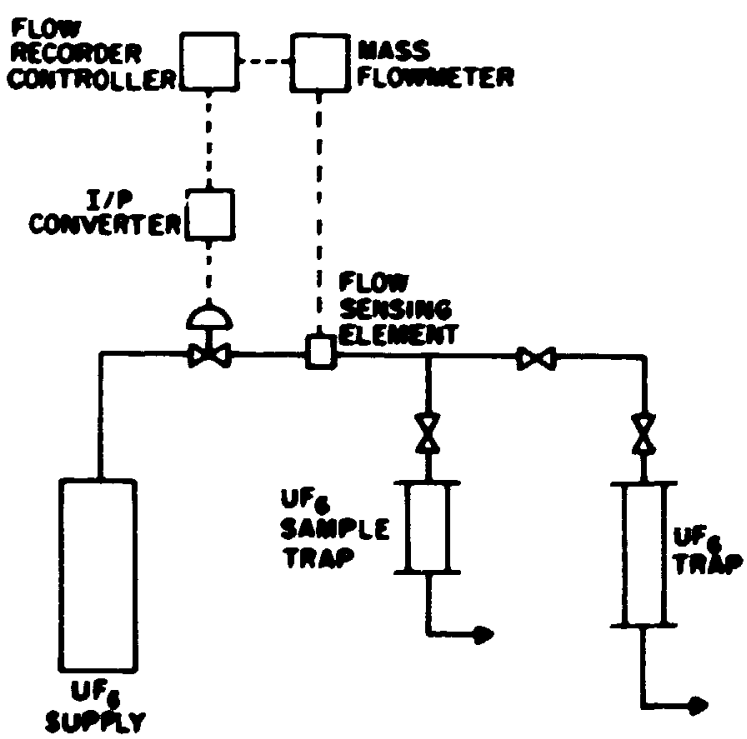

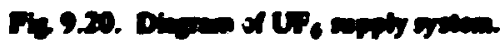

$\left(9.33 \times 10^{-6} \mathrm{~m}^{3} ; \mathrm{s}\right)$. The results agreed very closely with the published alibration curves provided by the manufacturer.

\subsubsection{Caliontion of Ar-UF. Cas Deasis Devector}

Calibration of the gas density cell that is used in eterminiog the concentration of UF, in the argon stram laving the UF, absorption vessel requires UF,-Ar mixtures of known concentrations. These mixtures were provided by mixing separate UF, and argon streams of known flow rates and feeding the mixture to the gas density cell used for UF,oAr amalysis. This gas density cell ${ }^{22}$ was calibrated for concentrations of 0-50 mole $\%$ UF, in argon (Fig. 9.21).

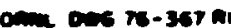

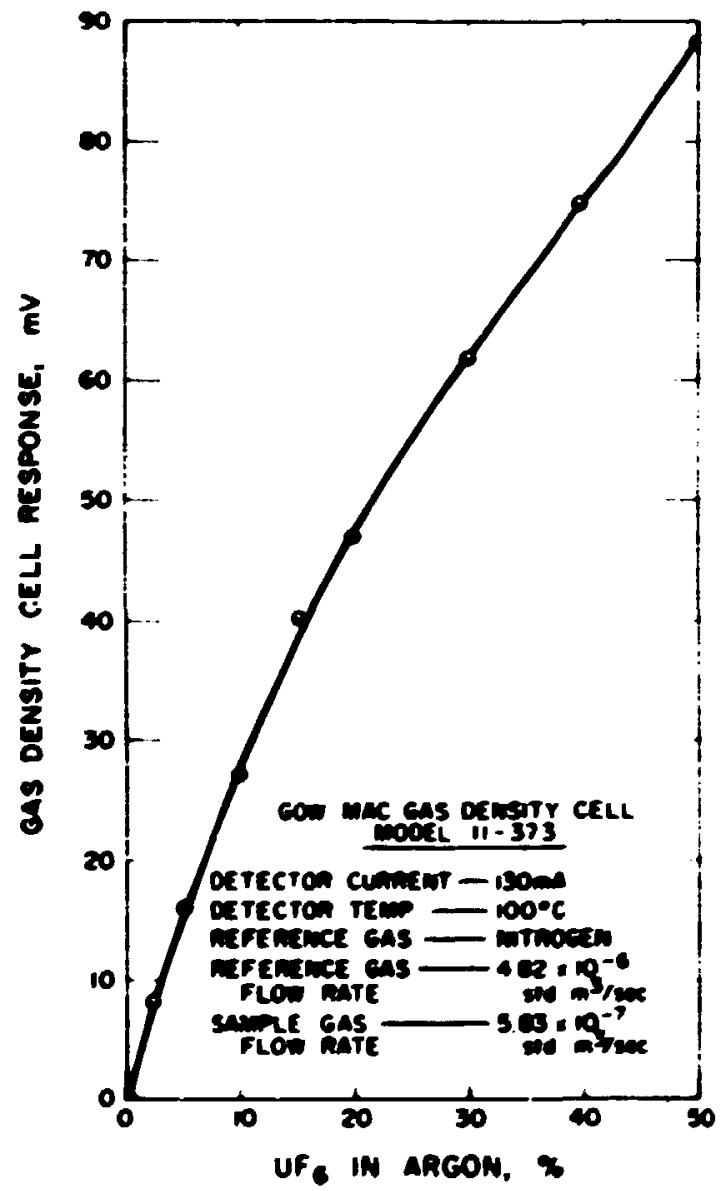

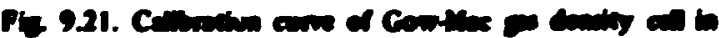

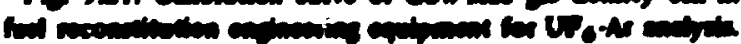




\subsubsection{Calibration of the HF $\mathrm{H}_{2}$ Cas Deamits Cell}

Calibration of the gas density cell that is used in determining HF concentration in hydrogen from the hydrogen reduction column requires a supply of HFH: mixtures of known concentrations. Since HF is not otberwise required in the experiment, a means is used for producing HF-H mixtures which does not require an HF supply and metering system. Fired concentrations of HF in bydrogen can be generated by passing hydrogen gas over NaF.HF in a manaer such that the HF partinl pressure is increased to the dissociation pressure of the complex by using the equilibrium

$$
\mathrm{NaF}-\mathrm{HF}-\mathrm{NaF}+\mathrm{HF} \text {. }
$$

In this system the HF partial pressure is a unique function of temperature as long as both $\mathrm{NaF}$. HF and via are present. Consequently the concentration of HF in the gas stream in equilibrium with the NaF-HF-NaF mixture can be set by controlling the temperature of the system.

The vesuel for producing hydrogen saturated with

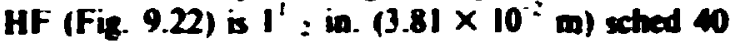
Monet pipe $0.97 \mathrm{~m}$ long. mounted verizally with standand 150-1b Monet flanges at either ead. This veswel was filled with a commercial grede of NaF.HF in the form of ${ }^{\prime},-i n .{ }^{\prime} 3 \mathrm{~mm}$ ) rielu cincular cyliadrieal pellets.

Hydrogen was passed over the NaF.HF bed in this vesset at various lemperatures at a total preseare of $1 \mathrm{~atm}$. and the concemtration of HF in the resulhing mixtures was compared with values calculated from pubtished values of the LifF-HF disecciation pressure.

The equilibriven conceatrations of panecus HF in hydrosen over NaF.HF obenined from thexe experiwests were compared to those of Duvie" and

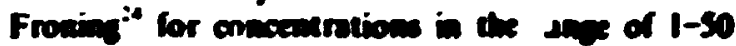

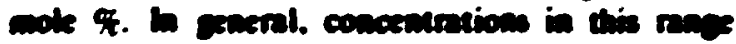
cocerred at kemperatures approximancty sor C lower
Orime Bus ro-3as

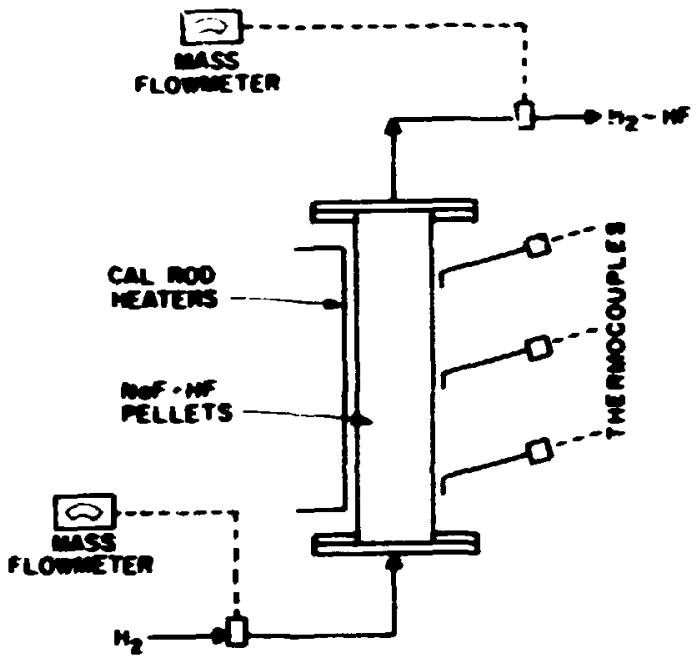

P4 922. Dimes of of oin bylowem.

than temperatures predicted from the work of Froning and epproximately $75^{\circ} \mathrm{C}$ bower than lemple ratures predicued from the work of Davis." In Fie 9.23. the experimental results are defrincly closer to the lineniture values of HF over NaF.HF than HF over ofther known Naf.HF complexes." The results of the HF saturelor experianemt have thown reproducibility. ahbough the error is such that the flow rales in and out of the mtunkes are used as the busis in alcubtion gas composition levines the satumber.

Using the HF attarnlor to generale HF concentrotions in lydrosen. the analytical syatem for H.-HF andysis was calibrated for concentintioses of O-SOt HF in bydropen. This pess anabyis gystem bes been cexcribed previonaly." This colibretion cane ad perimeal opernting conditions are shown in Fit. 9.24. Neo stown for compariese in Fie 9.24 is a

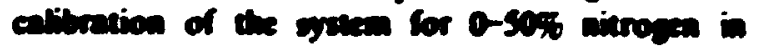

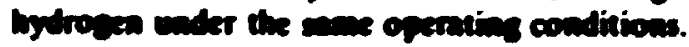




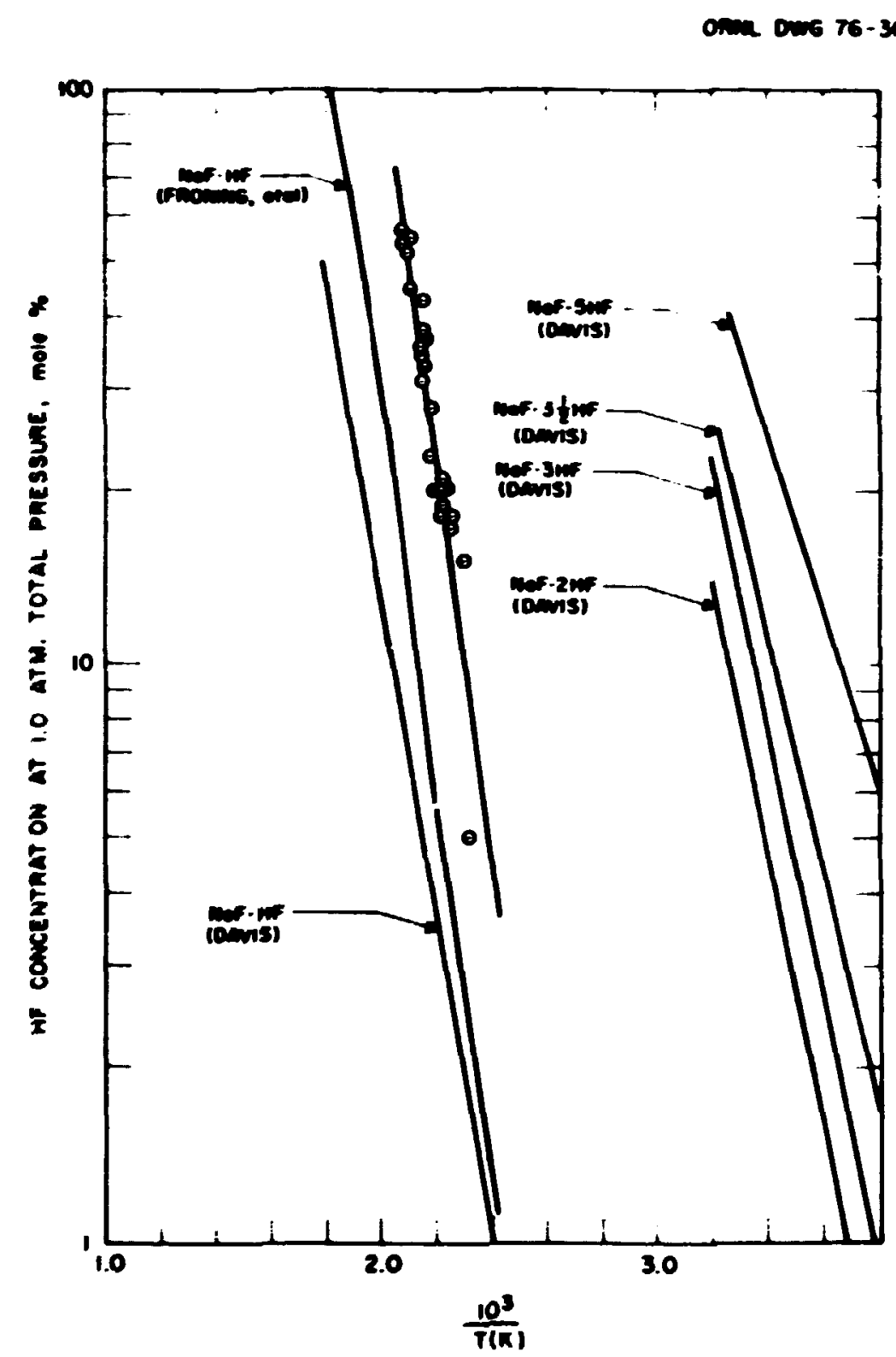

P.t. 923. n. 
Oame Dow 76-369m

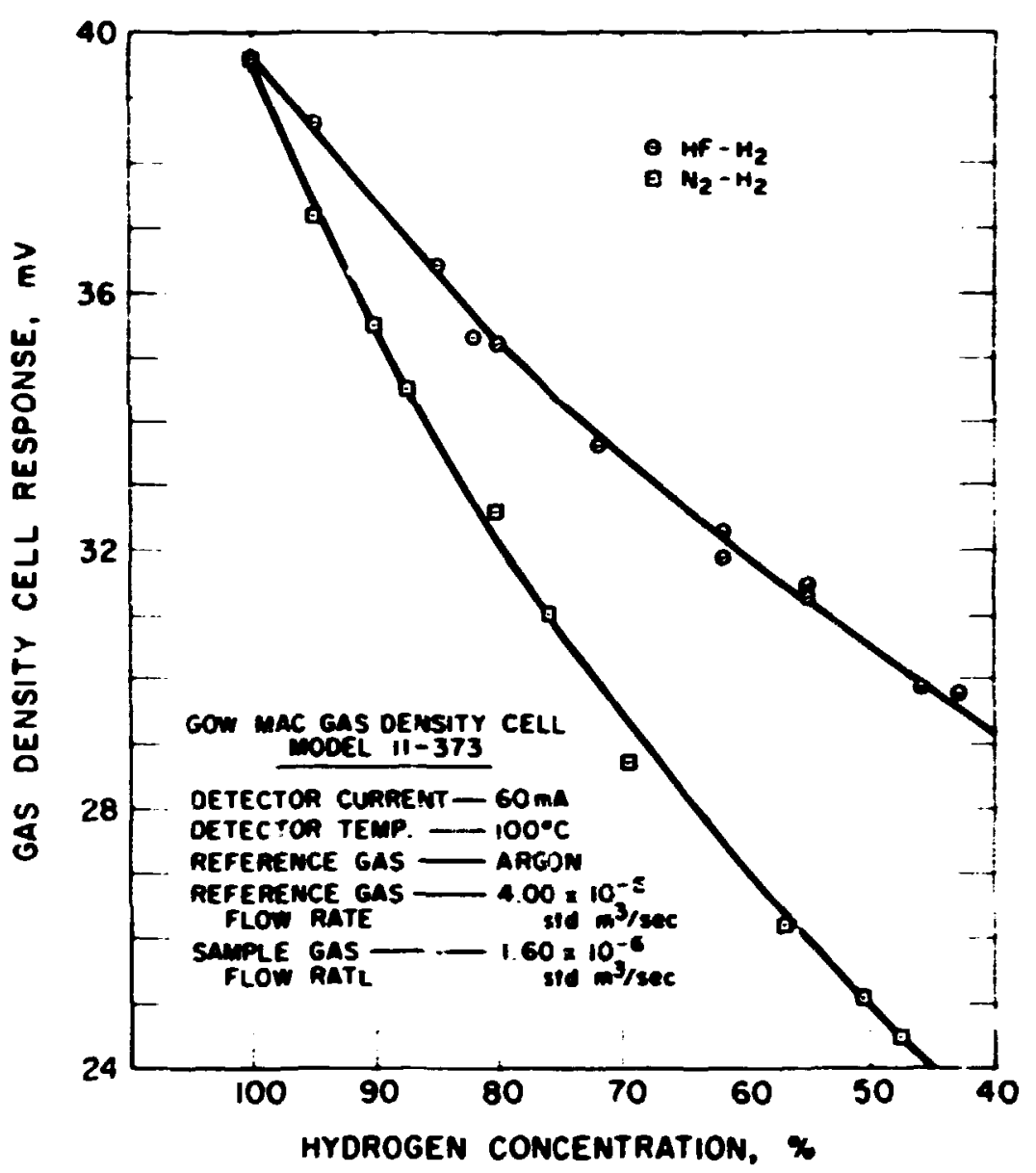

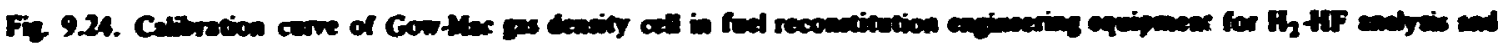
$H_{2} N_{2}=$ andis

\section{REFERENCES}

1. Chem. Techiol. Div. Anviu. Progr. Rep. Aug. 31. 1975. ORNL-SOT. Pp. 142-47.

2. Chem. Tectionol. Div. Anmu. Progr. Rep. Mer. 31. 1973. ORNL-4683, pp. 23-25.

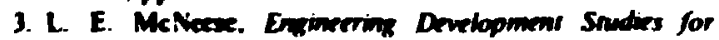
Molven-Solt Sureder Reareor proressing No. 10. ORNL TM3352. pp. 33-57 (December 1972).

4. Chem. Tectingol. Drv. Anne. Progr. Arp. Mer. 31. 1973. ORNL 4083, p. 25.

3. L. M. Ferris et al.. "Diatribution of Lanthenide and Actinide Elements Detween Liquid Bismuth and Motuen LiCHiF and LiDr-Lif Solutions." J. Mong. Nurl. Chrom. 34, 313-20 (1972).

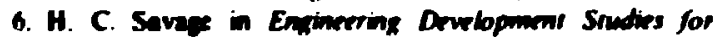
Molim-Salt Burder Rrecior Proressing No. 23. ONNL TM. 5252 (in preparation).

7. J. A. Klein a al.. MSR frogrom Semienour. Pmer. Rep. Aes 3I. 1974. ORNL-SOII. pP. !14-18.

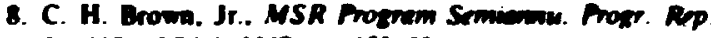
Feb. 28. 1975. ORNL-S047. pp. 152-57.

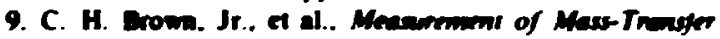

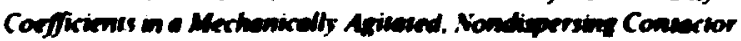
Openeting with a Molven Mixnme of Lif-ESF-THF. and Moten Dienu/h. ORNL-3143 (a preporation).

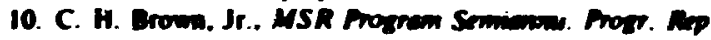
Feb. 28. 1975. ORNL-S047. pp. 157-62.

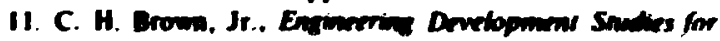

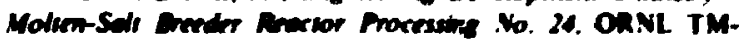
5339 (in preparation).

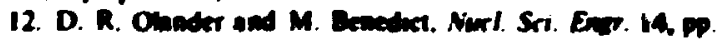
237-4 (1962).

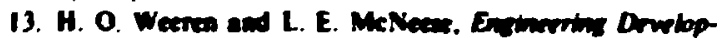

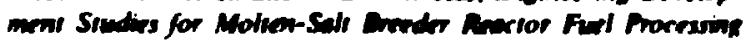
No. IO. ORNL TM-3352. p. 55 (Desenter i972).

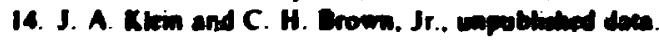

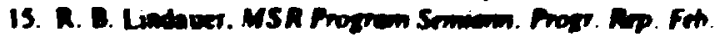
28. 1975. ONNL-S0A7. po. 163-6s. 


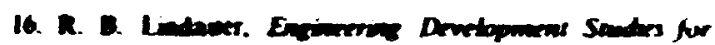

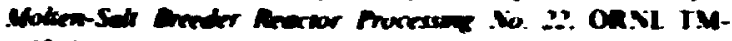
403 in preparation).

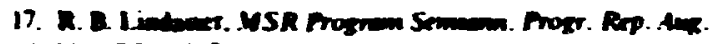
31. 1979. ORNL-507. pp. 152-55.

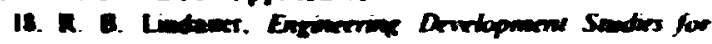

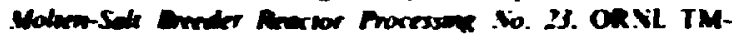
5252 (i) preperation).

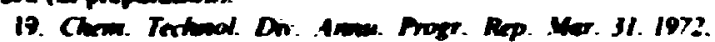
ORNL-4TA. p. I.

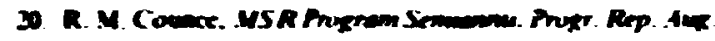
JI. 1974. ORNL-soll. p. I3.

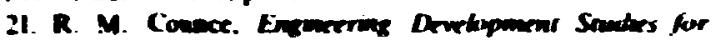

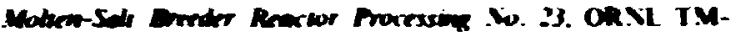
5252 (in preparation).

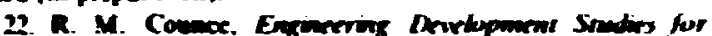

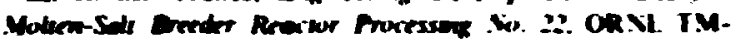
403 (in preparation).

23. Wallece Devis. Jr., XLI-2552 p. 3 (Sepr. 21. 1953).

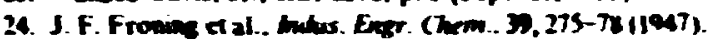




\section{Part 5. Salt Production}

\section{PRODUCTION OF FLUORIDE SALT MIXTURES FOR RESEARCH AND DEVELOPMENT}

\author{
F. L. Daley R. W. Honton*
}

At the beginning of this report period. the repaired meltdown vessel was returned to service for production of MSBR fuel-carrier salt. A total of $450 \mathrm{~kg}$ of fuet-carrier salt was produced in three $150-\mathrm{kg}_{\mathrm{g}}$ batches in the new copper-fined treatment vessel. which also has a protective copper sheet on the inside of the vcssel head. Completed analyses on salt sampies from the first two production batches (FS-108 and FS-109) show that impurities were present at kevels much lower than normal. The oxygen content of the salt was below 100 ppm. These results point out the strong effect of purification vessel corrosion products on the quality of salt that is produced.

- Consultant.
During this report feriod. the decision to terminate work on the MSR Program by the end of FY 1976 was reached. The need for salt during the babnce of the fiscal year was deterrined. and this need was supplied while preparations to place the sak production facility in a safe standby condition were proceeding. At the end of the production period. a tctal of $1975 \mathrm{~kg}$ of salt (of various compositions) had been produced since activation of the facility in earty 1974. Shipments to the program totaled $865 \mathrm{~kg}$. and $678 \mathrm{~kg}$ have been stored for possible use.

All production areas were decommissioned and cleaned to remove potential health hazards. Unused materials and equipment were either set aside for burial or were stored: some major property items were transferred to the Reactor Division. A report on the final production and decommissioning activities piovides a reference for stored material and records final comments on the performance of the salt purification system. 


\section{MOLten-SAlt ReACtOR program} FEeruary $19 x$

L. E. MaveEse, mocham oInEcTon

\begin{tabular}{l} 
WOA DESAEW \\
J. R. ENGEL' \\
\hline SVSTEMS ANO \\
J. R. ENGEL \\
E. J. ALLEN' \\
H. T. KERA' \\
G. T. MAYS \\
D. L. REED' \\
G. T. YAHA'
\end{tabular}

SYSTERS ANO COMMONEQUTS DEVELONIEETT

ค. H. GuYmon

W. A. MUNTLEY'

M. D. SILVERMAN"

A. N. Sanith

ค. F. Bensow'

E. L. BIDOLE

D. J. Fravsien

h. E. ROEERTSON

R
ค
ค
A
ค

AC Amal rTICAL COEMISTAY DIVISION

C CHEMistar oivisirn

CT CHEMCAL teCHMolugr division

mec metals ano Ceramics oIvision

a nencton oivision

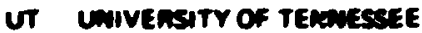

ipant.TIme on nesp

2 DuAl Capacity

scCUN STUDENT PARTICIPANT

ioecenaseo

sonau stuocent

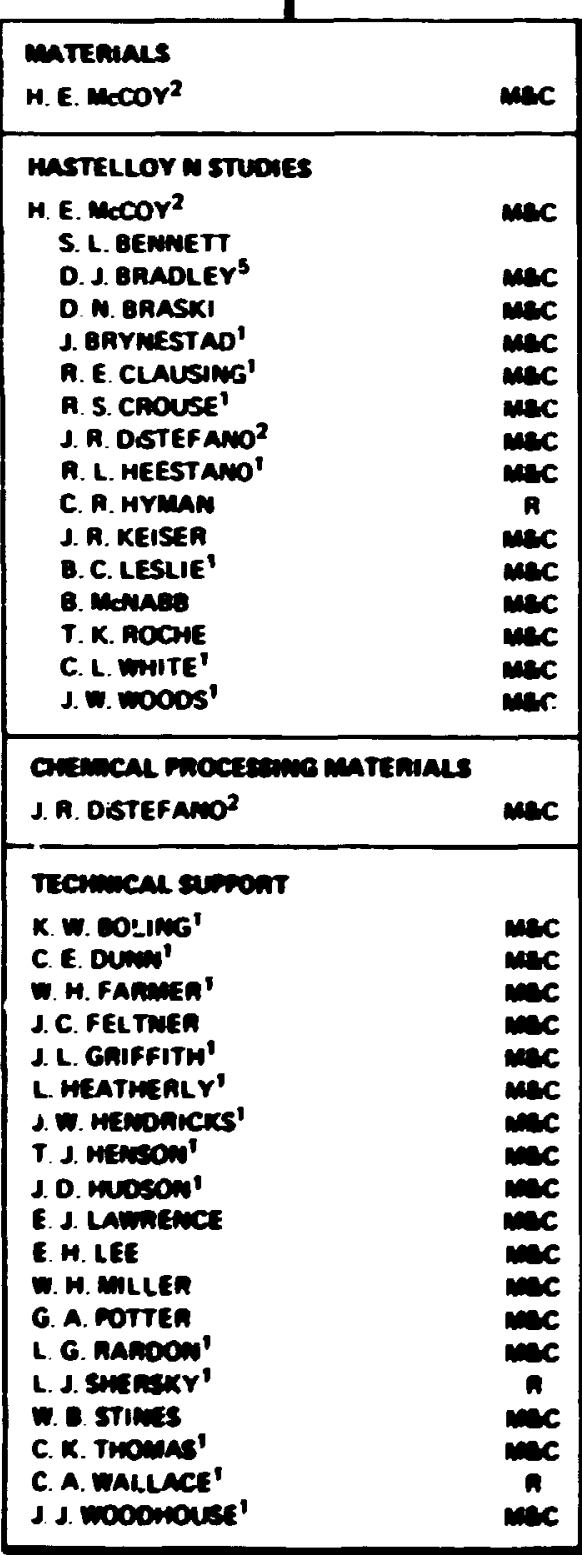

\begin{tabular}{|c|c|}
\hline 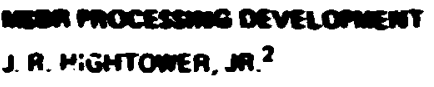 & CT \\
\hline 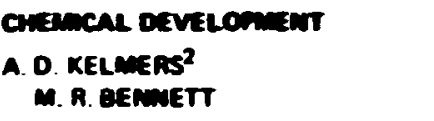 & $\begin{array}{l}c \\
c\end{array}$ \\
\hline 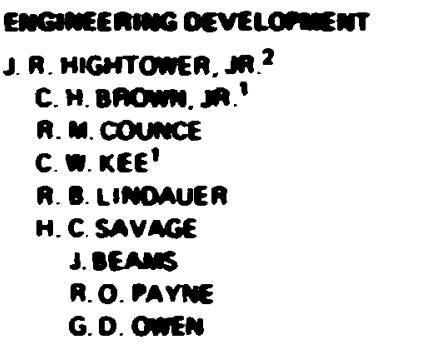 & $\begin{array}{l}C T \\
C T \\
C T \\
C T \\
C T \\
C T \\
C T \\
C T \\
C T\end{array}$ \\
\hline
\end{tabular}




\section{BLANK PAGE}




\section{BALT REACTOR PROGRAM}

FEDRUARY 197

\section{F MeneESE, PROGRAM DAAECTOR}

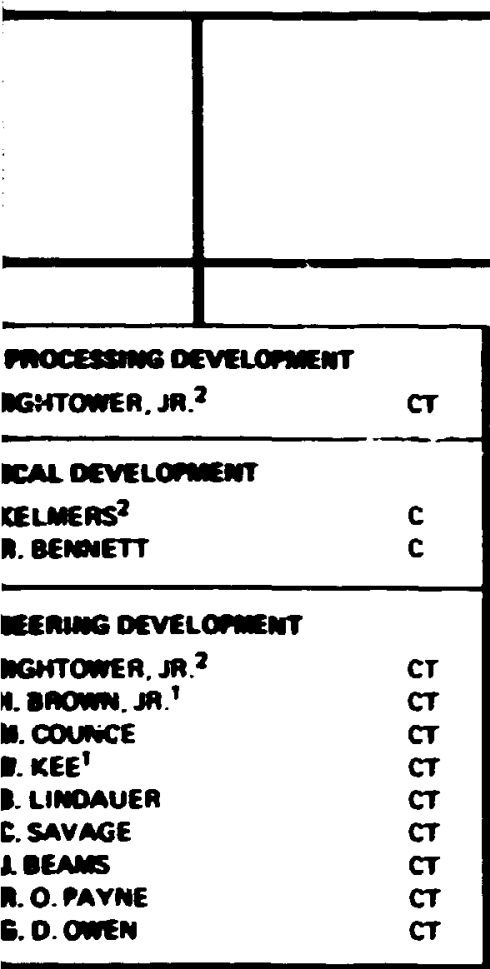

\section{min cricanstar}

L. M. FERRIS'

A. D. Kelmers

L. mara

B. F. HITCH'

L. M. TOTH'

L. O. GILPATAKX'

F. A. POSEY'

H. R. BRonstein

D. E. MEATHERL Y'

S. N. RUSSELL?

D. Y. VALENTINE

amal rTical CuEansthr

neseanch anp otvelorment

A. S. MEVER"

P. F. APre'

J. M. OALE'

D. L. manmung

$A C$

AC

$A C$

\section{amalvess}

L. T. conen'

J. H. COONEA'

w. R. LAING'

J. A. CARTER'

AC

AC

AC

$M$

comentrant

G. mamantov

\section{salt moouction}

F. L. DaleY

w. J.eRYaM

A. L. conison

conirutant

A. W. moRTON 